UNIVERSIDAD POLITÉCNICA DE MADRID ESCUELA TÉCNICA SUPERIOR DE INGENIERÍA AGRONÓMICA, AGROALIMENTARIA Y DE BIOSISTEMAS

Caracterización de las poblaciones de Ulmus glabra Hudson en el Sistema Central. Elaboración de propuestas para su Gestión y Conservación

\author{
Tesis Doctoral
}

María Martín del Puerto

Licenciada en Biología 

DEPARTAMENTO DE BIOTECNOLOGÍABIOLOGÍA VEGETAL

ESCUELA TÉCNICA SUPERIOR DE

INGENIERÍA AGRONÓMICA, AGROALIMENTARIA Y DE BIOSISTEMAS

Caracterización de las poblaciones de Ulmus glabra Hudson en el Sistema Central. Elaboración de propuestas para su Gestión y Conservación

\author{
María Martín del Puerto \\ Licenciada en Biología
}

Directores:

Dr. Juan Pedro Martín Clemente

Dr. Felipe Martínez García 



\section{UNIVERSIDAD POLITÉCNICA DE MADRID}

Tribunal nombrado por el Magfco. y Excmo. Sr Rector de la Universidad Politécnica de Madrid el día de de 2017.

Presidente:

Vocal:

Vocal:

Vocal:

Secretario:

Suplente:

Suplente:

Realizado el acto de lectura y defensa de la tesis el día de

de 2017 en la ETS de Ingeniería Agronómica, Alimentaria y de Biosistemas.

EL PRESIDENTE

LOS VOCALES 

D. Juan Pedro Martín Clemente, Profesor Titular del Departamento de Biotecnología-Biología Vegetal de la Escuela Técnica Superior de Ingeniería Agronómica, Agroalimentaria y de Biosistemas de la Universidad Politécnica de Madrid y D. Felipe Martínez García Profesor Contratado Doctor del Departamento Sistemas y Recursos Naturales de la Escuela Técnica Superior de Ingeniería de Montes, Forestal y del Medio Natural de la Universidad Politécnica de Madrid

Certifican:

Que la tesis doctoral titulada "Caracterización de las Poblaciones de Ulmus glabra Hudson en el Sistema Central. Elaboración de Propuestas para su Gestión y Conservación", presentada por Dña. María Martín del Puerto para optar al Grado de Doctor en "Biotecnología y Recursos Genéticos de Plantas y Microorganismos Asociados" ha sido realizada bajo nuestra dirección y reúne los requisitos suficientes para su lectura y defensa.

Y para que así conste, firmamos el presente certificado en Madrid, a de junio de 2017. 

"Parecía que habíamos llegado al final del camino y resulta que era sólo una curva abierta a otro paisaje y a nuevas curiosidades"

José Saramago El año de la muerte de Ricardo Reis 



\section{AGRADECIMIENTOS}

En primer lugar, hay dos responsables fundamentales de que esté hoy aquí: Juan Pedro y Felipe. Juan Pedro, no sé cómo, pero me fuiste liando con unas cosas y con otras; desde 2008 que crucé la puerta del departamento, hasta ahora. He aprendido un montón, de verdad, gracias. Y Felipe, qué decir, me has ayudado muchísimo, especialmente con la parte de conservación, donde andaba algo más perdida. Siendo más de laboratorio, has conseguido que esa parte me encante. Estos últimos meses he estado un "pelín superada" por tanto acontecimiento junto, así que gracias de verdad a los dos

A la unidad entera de Biología Vegetal, especialmente a Esperanza y a Consuelo, que me habéis ayudado mucho. A todos los que han sido en algún momento mis jefes en el Banco: Itziar, Jesús, César... Especialmente a Elena, que te escribía desde la otra punta del mundo con mis preocupaciones y rollos diversos. Aprendí mucho de ti en mis múltiples idas y venidas al banco. También debo de agradecer a la unidad de Genética, llegué hace apenas un año y habéis acogido muy bien. También quiero agradecer a Diego, por su ayuda en la parte más ecológica de la tesis, que sin su ayuda no hubiese sido posible.

Todo el sacrificio, los malos momentos, el "que no llego, que no llego", han merecido la pena. Gracias a esto me ha permitido conocer a gente de aquí y de allá. Me permitió conocer un país increíble y una gente estupenda. De forma especial debo de agradecer a mis "ecuatorianos favoritos"; yo fui vuestra "española maja" y vosotros fuisteis una familia para mí el tiempo que pasé allí: Pablo, Myriam e Inés, Hernán y Juanito, compañeros de bielas... ¡que decir! ¡Nos volveremos a ver!

Dicen que la memoria es frágil, que es fácil olvidar, sobre todo olvidar lo obvio. No soy de olvidar. Por ello, debo de dar las gracias a mis padres, porque ellos son los responsables de mi vocación, porque este trabajo son muchas cosas, pero sobre todo es fruto de la vocación. A mi padre, porque aún recuerdo aquel día hace más de 20 años que, tras años de insistencia, conseguí convencerte para subir a la Sierra del Cuervo. Hay muchas cosas que me han marcado, pero probablemente, el responsable de mi vocación eres tú. A mi madre, qué decir, pronto terminé con su paciencia. El motivo, mis primeros pasos en la ciencia, con 10 años, se focalizaron en sus geranios. Pocos afortunados sobrevivieron. El otro $50 \%$ de mi vocación eres tú. A Jesús, que has sido mi compañero de piso muchos años, aguantaste mis correos en momentos difíciles y me ayudaste con todo lo geológico. A Isma, por esas tardes animadas de riego y por recordarme que debo de mantenerme firme en mis principios (cabezonería lo llaman). 
He de decir que seguir mi vocación me ha traído muchos momentos de amargura, de tristeza, de rabia, e incluso, en los últimos meses ira; pero me trajo lo más bonito que tengo, tú. Pablo muchas gracias por todo, por aguantarme tantos años ya. Solo por conocerte mereció la pena estudiar Biología. Mi ser humano favorito.

Mención aparte merecen mis amigos. En algunos casos desde la incubadora, en otros, más recientes. A todos, mil gracias. Solo quiero hacer una pequeña mención, Luisa muchas gracias y perdón por todo el tormento; Pablo y Ana, siempre listos para unas cañas; Eli, por la gestión de ese grupo tan variopinto y complicado. 




\section{RESUMEN}

El olmo de montaña (Ulmus glabra Hudson) es una especie que se localiza fundamentalmente en el centro y norte de Europa, siendo la península ibérica el límite suroccidental de su distribución. En el Sistema Central ibérico presenta una distribución fragmentada, con 27 núcleos poblacionales de carácter relicto. En el presente trabajo se ha llevado a cabo un estudio de caracterización molecular y ambiental de esas poblaciones; de manera que, con la información obtenida se han elaborado propuestas adecuadas para su gestión y conservación, con objeto de asegurar la supervivencia de la especie en este territorio.

La caracterización molecular se ha realizado a nivel del ADN nuclear y del genoma de cloroplastos, para lo cual se han estudiado 427 individuos de U. glabra en 22 poblaciones. Por un lado, se ha analizado el polimorfismo existente en 11 loci de microsatélites del genoma nuclear, con objeto de conocer la diversidad genética tanto individual como poblacional, e identificar posibles eventos demográficos 0 procesos de introgresión que han podido influir en la diversidad y estructura genética de las poblaciones.

Se han identificado un total de 360 genotipos diferentes en los 427 individuos analizados. En las poblaciones, se ha detectado un nivel moderado de diversidad genética, además de un elevado y significativo grado de diferenciación entre ellas (24\%; $P=0,0001)$. Rozas de Puerto Real ha mostrado los valores más elevados de diversidad. Asimismo, ésta junto con la población de Mombeltrán han presentado una considerable heterocigosidad observada $(>70 \%)$, coincidiendo con unos elevados valores negativos del índice de Fijación. Por último, en ellas también se ha detectado un elevado número de híbridos putativos (50 de los 55 posibles híbridos encontrados), lo cual podría explicar los elevados valores de diversidad y heterocigosidad observados en dichas poblaciones.

Los valores estimados del tamaño efectivo de las poblaciones han sido, en general, muy bajos $(<20)$, lo cual aumenta la probabilidad de desaparición de estas poblaciones. Asimismo, el estudio demográfico también ha evidenciado signos de cuellos de botella ancestrales en 15 poblaciones analizadas, y más recientes en cuatro de ellas (Navafría, El Tiemblo, Rozas de Puerto Real y Mombeltrán).

El análisis espacial de la diversidad genética ha detectado la existencia de una autocorrelación positiva y significativa $(P<0,01)$ en seis de las poblaciones analizadas (Riaza-Becerril, Rozas de Puerto Real, El Tiemblo, El Barraco, Casavieja y Benfeita). Este análisis ha revelado qué aspectos parecen afectar a la estructura genética espacial de las poblaciones: su entorno, la localización de sus individuos o incluso la existencia de introgresión.

En el genoma de cloroplastos, se han analizado 38 fragmentos que abarcan toda la región larga de copia única o LSC (Large Single-Copy region) utilizando la técnica de PCR-RFLP, así como 18 loci de microsatélites. Se han detectado polimorfismos en siete de los fragmentos y cinco de los microsatélites, que han permitido diferenciar ocho haplotipos diferentes. El haplotipo $\mathrm{H} 1$ se ha encontrado en 325 individuos y en 19 de las 22 poblaciones estudiadas. Este haplotipo también parece ser el mayoritario en 
el suroeste de Europa. Por otro lado, el haplotipo H2, propio de poblaciones del norte de Europa, ha sido exclusivo de los individuos de Cercedilla. Finalmente, el haplotipo $\mathrm{H} 7$ sólo se ha observado en las poblaciones más occidentales del Sistema Central (Villamiel, San Martín de Trevejo y Benfeita).

En general, la diversidad detectada en el genoma de cloroplastos ha sido escasa. La mayoría de las poblaciones fueron monomórficas, tan solo cinco de ellas (Valle de Iruelas, Casavieja, Cuevas del Valle, San Martín de Trevejo y Benfeita) presentaron variabilidad intrapoblacional. Aun así, el análisis llevado a cabo ha detectado la existencia de estructura filogeográfica significativa.

La caracterización ambiental de la especie en el Sistema Central se ha realizado utilizando diez variables climáticas, además de la altitud y la litología. Se han identificado las variables ecológicas más relevantes en este territorio y se han comparado con las que presenta la especie a escala de la península Ibérica. Respecto a las poblaciones peninsulares, los núcleos del Sistema Central reciben significativamente mayores precipitaciones en invierno y durante la temporada lluviosa (primavera, otoño e invierno), presentan mayor temperatura anual media, temperatura media de las máximas diarias de verano, temperatura media de las mínimas diarias de invierno y mayor oscilación térmica anual. Por contra, la precipitación recibida durante los meses de verano fue significativamente inferior. En el Sistema Central, esta especie se localiza en zonas con una precipitación anual cercana a los $1020 \mathrm{~mm}$. La mayor parte de las lluvias se concentran en la temporada lluviosa ( 930 mm), especialmente en invierno ( 385 mm); mientras que en verano sufren sequía estival más o menos pronunciada $(\sim 85 \mathrm{~mm})$, que ha de ser compensada mediante su localización en ambientes favorecidos hídricamente. El modelo predictivo de distribución potencial de $U$. glabra para la península ibérica, ha detectado importantes áreas con condiciones adecuadas para la presencia de la especie. En el Sistema Central ha mostrado un área potencial de unos $5000 \mathrm{~km}^{2}$.

Además, se ha evaluado el grado de amenaza de la especie a escala regional del Sistema Central, mediante los criterios y categorías de la UICN. Los datos del área de Extensión de presencia $(<20000$ km²), del área de Ocupación $\left(<20 \mathrm{~km}^{2}\right)$, la elevada fragmentación, el bajo porcentaje de individuos maduros estimados (32\%) y el reducido número de poblaciones por encima de la Población Mínima Viable, catalogan a U. glabra en el Sistema Central como EN: B2 a, b (i, ii, iii, v). Atendiendo a este elevado grado de amenaza, se sugieren algunas medidas generales de gestión y conservación para asegurar la persistencia de esta especie, p.e. su catalogación por las administraciones competentes donde aún no está protegida legalmente (Portugal, Extremadura y Castilla y León). En este sentido, se propone la utilización de herramientas legales ya establecidas, como la creación de microrreservas en Castilla y León y Castilla La Mancha, y proteger bajo esta figura las poblaciones más relevantes en sus ámbitos territoriales. Y en general, para todas, la elaboración de planes de gestión que contemplen medidas de actuación in situ, como llevar a cabo reintroducciones y reforzamientos, y ex situ, mediante la colecta y almacenamiento de material biológico de reproducción. 


\section{SUMMARY}

Wych elm (Ulmus glabra Hudson) is a species located mainly in the centre and north of Europe, being the Iberian Peninsula the southwestern limit of its distribution. In the Iberian Central System, it presents a fragmented distribution with 27 relict populations. In the present work, a study of molecular and environmental characterization of these populations has been carried out. Therefore, with the information obtained, adequate proposals have been developed for its management and conservation in order to ensure the survival of the species in this territory.

Molecular characterization has been performed both at the level of nuclear DNA and the chloroplast genome; for that, 427 individuals from 22 populations of $U$. glabra have been studied. On one hand, the polymorphism of 11 microsatellite loci from nuclear genome has been analyzed in order to know both individual and population genetic diversity, as well as identifying possible demographic events or introgression processes that may have influenced in diversity and genetic structure of populations.

A total of 360 different genotypes were identified in the 427 individuals analyzed. A moderate level of genetic diversity has been detected in the populations, in addition to a high and significant degree of differentiation between them $(24 \%, P=0,0001)$. Rozas de Puerto Real showed the highest values of diversity. Likewise, this population together with Mombeltrán showed a considerable observed heterozygosity $(>70 \%)$, coinciding with high negative values of the fixation index. Finally, a high number of putative hybrids ( 50 out of the 55 possible hybrids found) has also been detected in them, which could explain the high values of diversity and heterozygosity observed in these populations.

In general, estimated values of effective population size have been very low $(<20)$, which increases the probability of disappareance of these populations. Likewise, the demographic study has also shown signs of ancestral bottlenecks in 15 analyzed populations, and more recent in four of them (Navafría, El Tiemblo, Rozas de Puerto Real and Mombeltrán).

Spatial analysis of genetic diversity has detected a positive and significant $(P<0.01)$ autocorrelation in six of the analyzed populations (Riaza-Becerril, Rozas de Puerto Real, El Tiemblo, El Barraco, Casavieja and Benfeita). This analysis has revealed which aspects seem to affect the spatial genetic structure of populations: their environment, the location of their individuals or even the existence of introgression.

In the chloroplast genome, 38 fragments covering the entire Large Single-Copy (LSC) region using the PCR-RFLP technique as well as 18 microsatellite loci have been analyzed. Polymorphisms have been detected in seven of the fragments and five of the microsatellites, which allowed to distinguish eight different haplotypes. The $\mathrm{H} 1$ haplotype has been found in 325 individuals and in 19 out of the 22 populations studied. This haplotype also seems to be the majority in southwestern Europe. On the other hand, the $\mathrm{H} 2$ haplotype, typical of northern European populations, has been exclusive of Cercedilla individuals. Finally, the $\mathrm{H} 7$ haplotype has only been observed in the most western populations of the Central System (Villamiel, San Martín de Trevejo and Benfeita). 
In general, the diversity detected in the chloroplast genome has been low. The majority of the populations were monomorphic; only five of them (Valle de Iruelas, Casavieja, Cuevas del Valle, San Martín de Trevejo and Benfeita) presented intrapopulation variability. Even so, the analysis carried out has detected the existence of a significant phylogeographic structure.

Environmental characterization of the species in the Central System has been carried out using ten climatic variables, besides the altitude and the lithology. The most relevant ecological variables have been identified in this territory and have been compared with those presented by the species in the Iberian Peninsula. With respect to peninsular populations, Central System populations receive significantly higher rainfall in winter and during the rainy season; they present higher mean annual temperature, average temperature of daily maximum of summer, average temperature of daily minimum of winter and greater annual thermal oscillation. Conversely, precipitation received during the summer months was significantly lower. In the Central System, this species is located in areas with an annual precipitation near 1,020 mm. Most of the rains are concentrated in the rainy season ( $\sim 930 \mathrm{~mm})$, especially in winter ( $\sim 385 \mathrm{~mm})$; while, in summer they suffer more or less pronounced estival drought $(\sim 85 \mathrm{~mm})$, which has to be compensated by their location in environments favoured by water. The predictive model of potential distribution of $U$. glabra for the Iberian Peninsula detected important areas with adequate conditions for the presence of the species. In the Central System, it has shown a potential area of about $5,000 \mathrm{~km}^{2}$.

In addition, the degree of threat of the species at the regional scale of the Central System has been assessed using IUCN criteria and categories. The data of the Extension of presence area ( $<20,000 \mathrm{~km} 2)$, the Occupation area (<20 km2), the high fragmentation, the low percentage of estimated mature individuals $(32 \%)$ and the small number of populations above the Population Minimum Viable, catalogue U. glabra in the Central System as EN: B2 a, b (i, ii, iii, v). Taking into account this high degree of threat, some general management and conservation measures are suggested to ensure the persistence of this species, i.e. its cataloguing by the competent authority where it is not legally protected yet (Portugal, Extremadura and Castilla y León). In this sense, it is proposed to use already established legal tools, such as the creation of micro-reserves in Castilla y León and Castilla La Mancha, and to protect the most relevant populations in their territorial areas under this figure. In general, for all, it is suggested the development of management plans that include measures of action in situ, such as reintroduction and reinforcement, and ex situ through the collection and storage of biological reproduction material. 




\section{ÍNDICE}

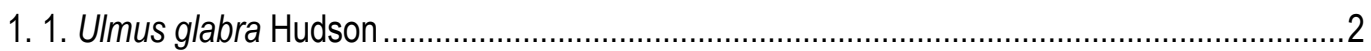

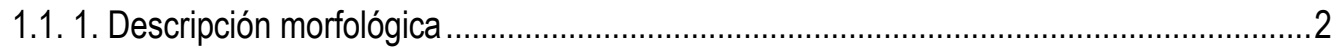

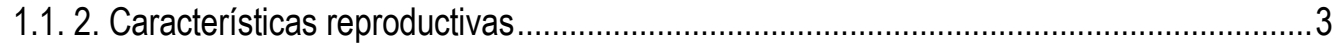

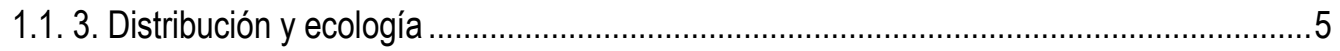

1.1. 4. El olmo de montaña en el Sistema Central .............................................................. 7

1.1.4. 1. Características litológicas y climáticas del Sistema Central ..................................7

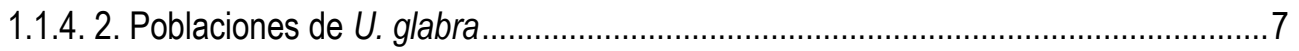

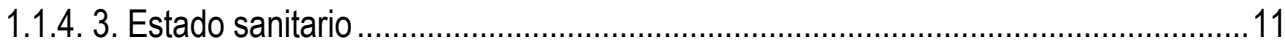

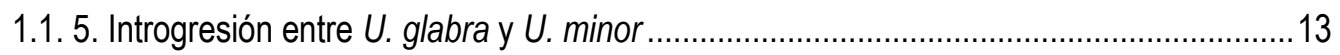

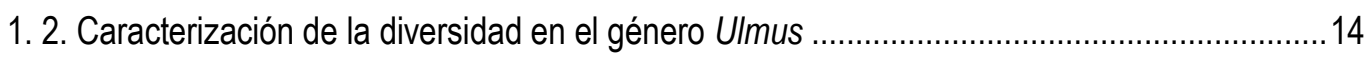

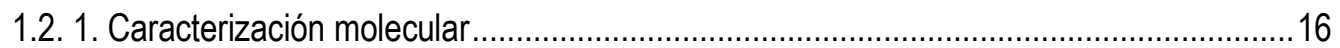

1.2.1. 1. Caracterización a nivel del ADN nuclear ......................................................... 16

1.2.1. 2. Caracterización a nivel del ADN de cloroplastos .................................................19

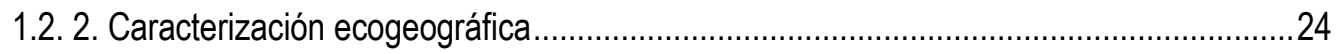

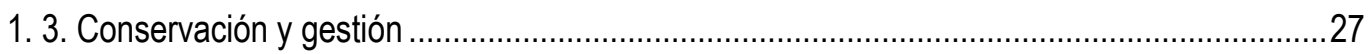

1.3. 1. Situación legal y de amenaza de Ulmus glabra en el Sistema Central .........................28

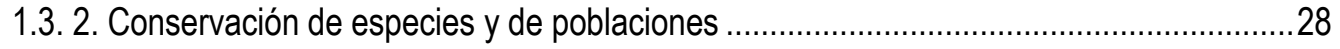

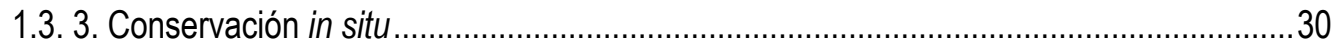

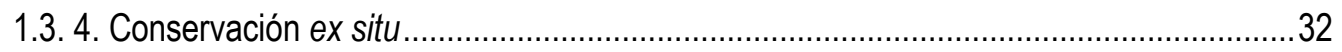

2. OBJETIVOS

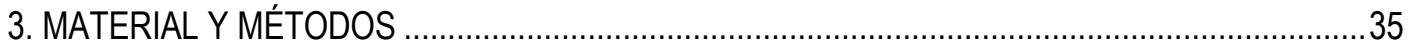

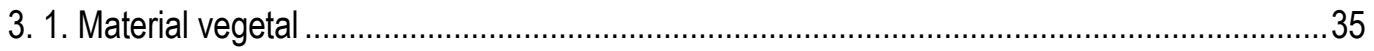

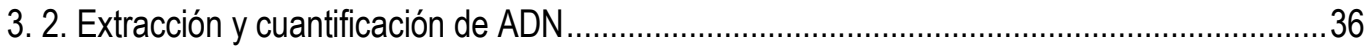

3. 3. Caracterización molecular a nivel del ADN nuclear ............................................................... 37

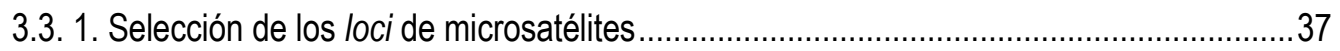

3.3. 2. Amplificación mediante PCR y detección de polimorfismos..........................................39 


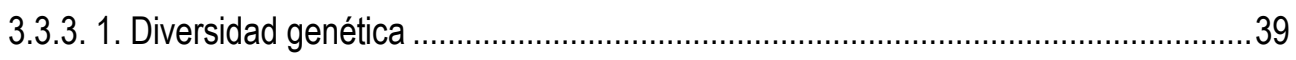

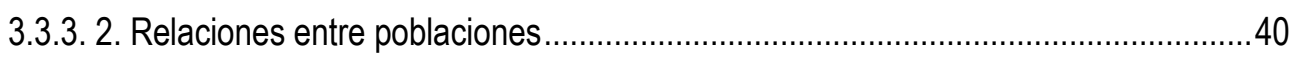

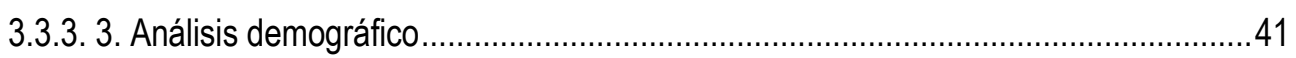

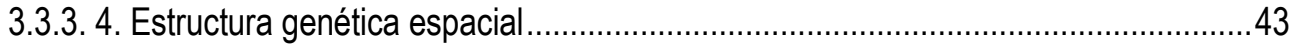

3.3.3. 5. Introgresión entre U. glabra y U. minor ...............................................................4

3. 4. Caracterización molecular a nivel del ADN de cloroplastos .................................................46

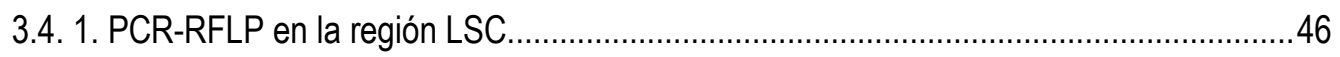

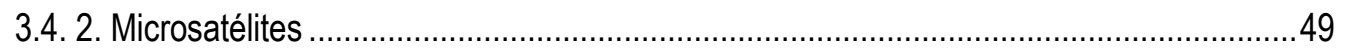

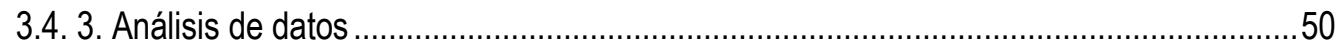

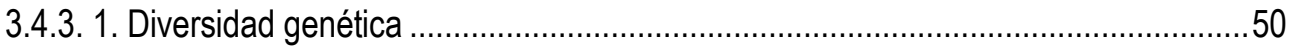

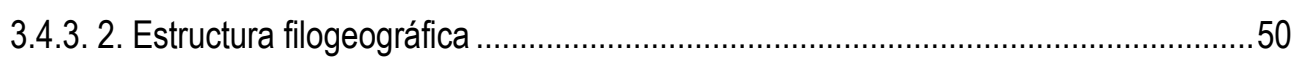

3. 5. Datos de presencia de U. glabra en la península ibérica ..................................................52

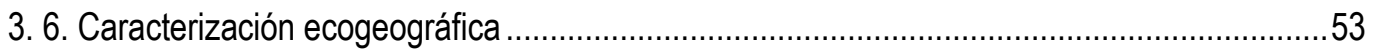

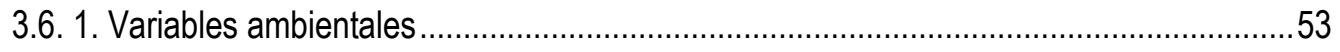

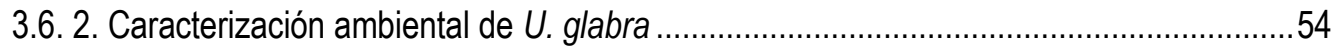

3.6. 3. Elaboración del modelo de distribución de U. glabra ...................................................55

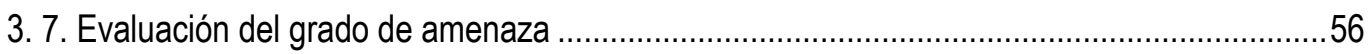

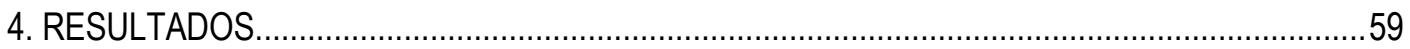

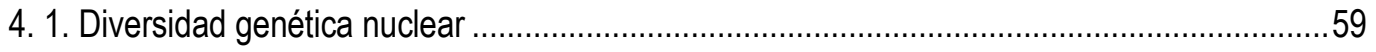

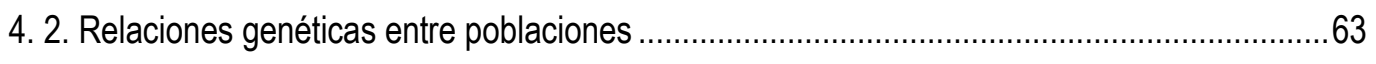

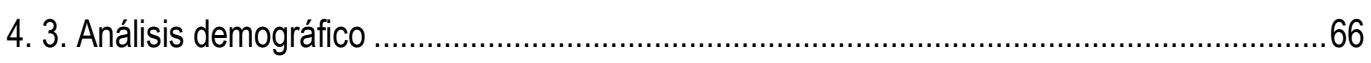

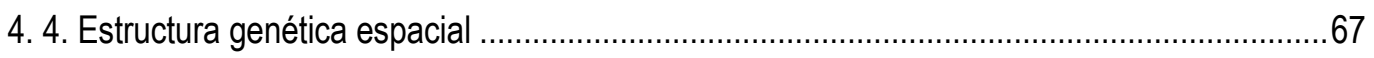

4.4. 1. Estructura espacial global en el Sistema Central ...................................................... 67

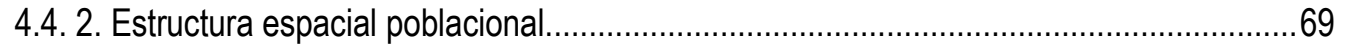

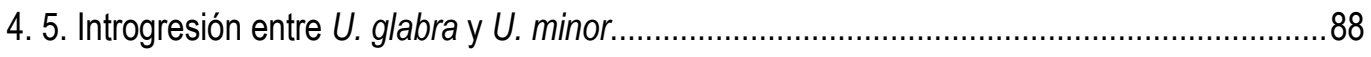

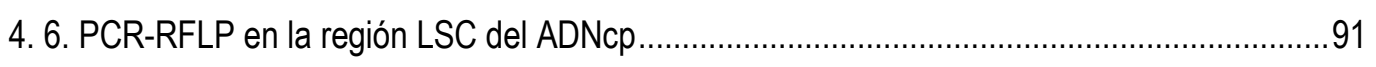

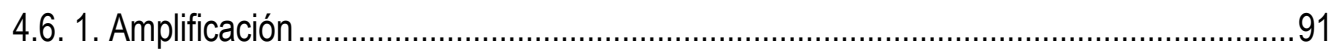


4.6. 2. Digestión con enzimas de restricción.

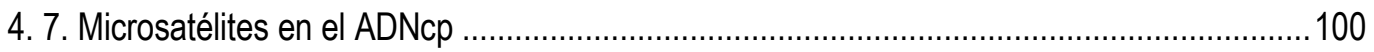

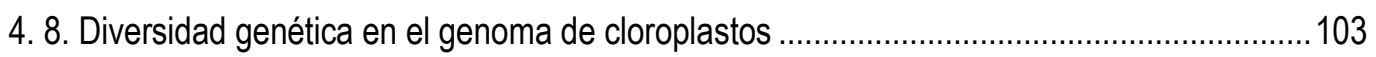

4. 9. Distribución de los haplotipos y estructura filogeográfica ................................................. 105

4. 10. Caracterización ambiental de U. glabra...................................................................110

4. 11. Modelo de distribución potencial de U. glabra en la península ibérica ..............................116

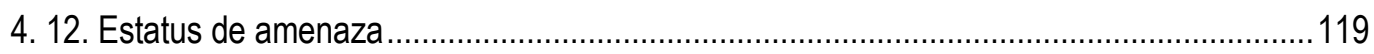

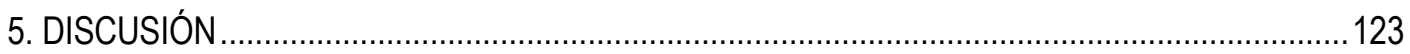

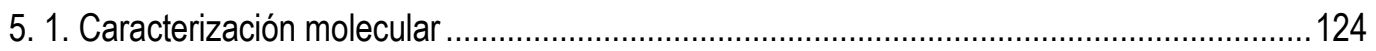

5.1. 1. Diversidad en el genoma nuclear................................................................... 124

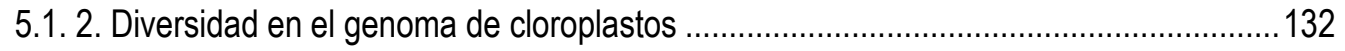

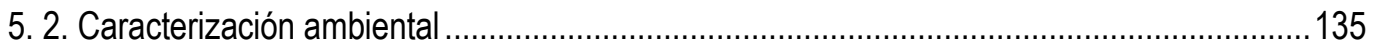

5. 3. Análisis demográfico y estructura filogeográfica ........................................................139

5. 4. Evaluación del grado de amenaza en el Sistema Central ...............................................142

5. 5. Propuestas de gestión y conservación ...................................................................... 146

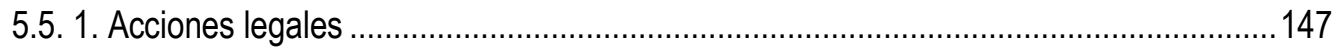

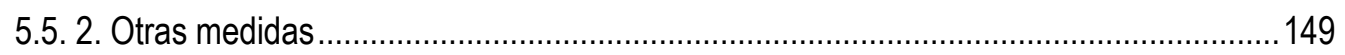

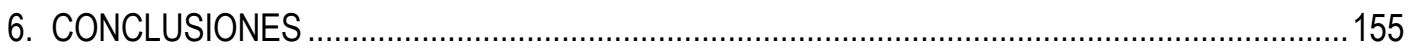

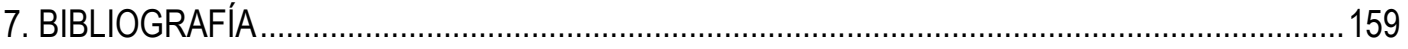

ANEXOS

Anexo I

Anexo II

Anexo III 


\section{ÍNDICE DE FIGURAS}

Figura 1.1. Características de Ulmus glabra: rama con hojas (a), ramilla con yemas y flores (b), Detalle de una de las flores (c), Detalle de una bráctea de la inflorescencia (d) y fruto en sámara (e). Fuente: Illustrations of the British Flora (1924)

Figura 1.2. Distribución de U. glabra en el continente europeo. Fuente: Global Biodiversity Information Facility (www.gbif.org; fecha de consulta 31/05/2017).

Figura 1.3. Distribución del olmo de montaña en la península ibérica, con un detalle de la localización de las poblaciones en el Sistema Central. Elaborado con ArcGis 10.3 (ESRI, 2014)...6

Figura 1.4. Imágenes de algunos individuos de olmo de montaña en poblaciones de Sistema Central: RZA (a), NAV (b), RAS (c), PAU (d), CER (e), ROZ (f), TIE (g) y STR (h). Ver Tabla 1.1 para los códigos de población. Fuente: Felipe Martínez García.

Figura 1.5. Scolytus scolytus (izquierda arriba), Scolytus multistriatus. (izquierda abajo) y galería característica de la grafiosis (derecha). Fuente: Cornell Plant Pathology Herbarium.

Figura 1.6. Primeros signos de afección por la grafiosis en individuos de la población de RascafríaMorcuera. Ramillas secas (izquierda) y ramillas muertas y combadas (derecha).

Figura 1.7. Estructura del ADN de cloroplastos en U. macrocarpa, especie filogenéticamente más próxima a U. glabra cuyo genoma de cloroplastos ha sido secuenciado. Fuente: elaboración propia a partir de Zuo et al. (2017).

Figura 1.8. Localización de las 38 parejas de cebadores sobre la región larga de copia única (LSC) del ADN de cloroplastos de tabaco. Fuente: modificado de Grivet et al. (2001).

Figura 1.9. Modelos de distribución potencial actual (a) y durante el último máximo glacial (b), para U. glabra, U. laevis y U. minor. Fuente: modificado de Svenning et al. (2008). .26

Figura 1.10. Regiones de procedencia de U. glabra (arriba) y de U. minor (abajo). Aparecen sombreadas las regiones que no aplican para la especie correspondiente. Fuente: Alía Miranda et al. (2009).

Figura 4.1. Dendrograma generado con el método UPGMA, en el que se muestran las relaciones entre las 19 poblaciones de $U$. glabra del Sistema Central con al menos seis individuos muestreados, basadas en los datos de 11 loci SSR y usando la distancia genética de Nei. Los números en los nodos muestran el soporte del agrupamiento (>50\%) obtenido mediante análisis de bootstrap (10000 réplicas). Ver Tabla 1.1 para los códigos de población. 
Figura 4.2. Correlograma obtenido del análisis espacial de la estructura genética para los 427 individuos de U. glabra del Sistema Central analizados con los datos de 11 loci de microsatélites. La línea continua representa los valores del coeficiente de autocorrelación $(r)$ calculado para cada una de las 12 clases de distancia definidas (de 0-1 km a 320-640 km). Las líneas discontinuas indican los límites superior $(U)$ e inferior $(L)$ del intervalo de confianza al 95\% bajo la hipótesis nula de no existencia de estructura espacial $(r=0)$, obtenidos mediante 10000 permutaciones. Las barras verticales hacen referencia a las barras de error para cada estima de $r$, calculadas para un intervalo de confianza del 95\% mediante 10000 remuestreos (bootstrap)

Figura 4.3. Correlograma obtenido del análisis espacial de la estructura genética para los 22 individuos de U. glabra de la población de Riaza-Becerril (RZA) analizados con los datos de 11 loci de microsatélites. La línea continua representa los valores del coeficiente de autocorrelación ( $r$ ) calculado para cada una de las seis clases de distancia definidas (de 0-52 m a 211-232 m). Las líneas discontinuas indican los límites superior $(U)$ e inferior $(L)$ del intervalo de confianza al 95\% bajo la hipótesis nula de no existencia de estructura espacial $(r=0)$, obtenidos mediante 10000 permutaciones. Las barras verticales hacen referencia a las barras de error para cada estima de $r$, calculadas para un intervalo de confianza del 95\% mediante 10000 remuestreos (bootstrap) .70

Figura 4.4. Localización de los 22 individuos pertenecientes a la población de Riaza-Becerril (RZA). En amarillo se muestran los siete individuos con correlación positiva significativa $(P<0,05)$ con sus $\mathrm{N}=6$ vecinos más próximos. Ver Anexo I para los códigos de cada individuo.

Figura 4.5. Correlograma obtenido del análisis espacial de la estructura genética para los 46 individuos de U. glabra de la población de Rozas de Puerto Real (ROZ) analizados con los datos de 11 loci de microsatélites. La línea continua representa los valores del coeficiente de autocorrelación (r) calculado para cada una de las 14 clases de distancia definidas (de 0-5 m a 143-199 m). Las líneas discontinuas indican los límites superior $(U)$ e inferior $(L)$ del intervalo de confianza al $95 \%$ bajo la hipótesis nula de no existencia de estructura espacial $(r=0)$, obtenidos mediante 10000 permutaciones. Las barras verticales hacen referencia a las barras de error para cada estima de $r$, calculadas para un intervalo de confianza del 95\% mediante 10000 remuestreos (bootstrap)

Figura 4.6. Localización de los 46 individuos pertenecientes a la población de Rozas de Puerto Real (ROZ). En amarillo se muestran los 42 individuos con correlación positiva significativa 
$(P<0,05)$ con sus $\mathrm{N}=20$ vecinos más próximos. Ver Anexo I para los códigos de cada individuo.

Figura 4.7. Correlograma obtenido del análisis espacial de la estructura genética para los 42 individuos de U. glabra de la población de EI Tiemblo (TIE) analizados con los datos de 11 loci de microsatélites. La línea continua representa los valores del coeficiente de autocorrelación $(r)$ calculado para cada una de las 25 clases de distancia definidas (de 0-13 m a 1074-1112 m). Las líneas discontinuas indican los límites superior $(U)$ e inferior $(L)$ del intervalo de confianza al 95\% bajo la hipótesis nula de no existencia de estructura espacial $(r=0)$, obtenidos mediante 10000 permutaciones. Las barras verticales hacen referencia a las barras de error para cada estima de $r$, calculadas para un intervalo de confianza del 95\% mediante 10000 remuestreos (bootstrap) .76

Figura 4.8. Localización de los 42 individuos pertenecientes a la población de El Tiemblo (TIE). En amarillo se muestran los 35 individuos con correlación positiva significativa $(P<0,05)$ con sus $\mathrm{N}=18$ vecinos más próximos. Ver Anexo I para los códigos de cada individuo.

Figura 4.9. Correlograma obtenido del análisis espacial de la estructura genética para los 57 individuos de U. glabra de la población de El Barraco-Valle de Iruelas (IRU) analizados con los datos de 11 loci de microsatélites. La línea continua representa los valores del coeficiente de autocorrelación $(r)$ calculado para cada una de las 29 clases de distancia definidas (de 0-46 m a 3309-3933 m). Las líneas discontinuas indican los límites superior $(U)$ e inferior $(L)$ del intervalo de confianza al $95 \%$ bajo la hipótesis nula de no existencia de estructura espacial $(r=0)$, obtenidos mediante 10000 permutaciones. Las barras verticales hacen referencia a las barras de error para cada estima de $r$, calculadas para un intervalo de confianza del 95\% mediante 10000 remuestreos (bootstrap) .80

Figura 4.10. Localización de los 57 individuos pertenecientes a la población de El Barraco-Valle de Iruelas (IRU). En amarillo se muestran los 26 individuos con correlación positiva significativa $(P<0,05)$ con sus $N=7$ vecinos más próximos. Ver Anexo I para los códigos de cada individuo......82

Figura 4.11. Correlograma obtenido del análisis espacial de la estructura genética para los 20 individuos de U. glabra de la población de Casavieja (CVJ) analizados con los datos de 11 loci de microsatélites. La línea continua representa los valores del coeficiente de autocorrelación $(r)$ calculado para cada una de las cinco clases de distancia definidas (de 0-22 m a 114-173 m). Las líneas discontinuas indican los límites superior (U) e inferior $(L)$ del intervalo de confianza al 95\% bajo la hipótesis nula de no existencia de estructura espacial $(r=0)$, obtenidos mediante 10000 
permutaciones. Las barras verticales hacen referencia a las barras de error para cada estima de $r$, calculadas para un intervalo de confianza del 95\% mediante 10000 remuestreos (bootstrap) .83

Figura 4.12. Localización de los 20 individuos pertenecientes a la población de Casavieja (CVJ). En amarillo se muestran los dos individuos con correlación positiva significativa $(P<0,001)$ con sus $\mathrm{N}=8$ vecinos más próximos. Ver Anexo I para los códigos de cada individuo

Figura 4.13. Correlograma obtenido del análisis espacial de la estructura genética para los 25 individuos de U. glabra de la población de Benfeita (BEN) analizados con los datos de 11 loci de microsatélites. La línea continua representa los valores del coeficiente de autocorrelación $(r)$ calculado para cada una de las ocho clases de distancia definidas (de 0-35 m a 246-289 m). Las líneas discontinuas indican los límites superior $(U)$ e inferior $(L)$ del intervalo de confianza al 95\% bajo la hipótesis nula de no existencia de estructura espacial $(r=0)$, obtenidos mediante 10000 permutaciones. Las barras verticales hacen referencia a las barras de error para cada estima de $r$, calculadas para un intervalo de confianza del 95\% mediante 10000 remuestreos (bootstrap) .86

Figura 4.14. Localización de los 25 individuos pertenecientes a la población de Benfeita (BEN). En amarillo se muestran los 7 individuos con correlación positiva significativa $(P<0,05)$ con sus $\mathrm{N}=8$ vecinos más próximos. Ver Anexo I para los códigos de cada individuo.

Figura 4.15. Estimación del número óptimo de grupos genéticos $(K)$ basados en la tasa de cambio en el estadístico $\Delta K$ entre los sucesivos valores de $K$ (Evanno et al. 2005) para (a) $K=1-25$ (usando los datos de los 11 loci SSR analizados en las 427 muestras de U. glabra) y (b) $K=1-10$ (usando los datos de los 9 loci SSR que amplificaron en los 427 individuos de $U$. glabra y en los 15 de $U$. minor) .89

Figura 4.16. Amplificaciones obtenidas en 35 muestras de Ulmus para seis (CP2, CP8, C13, CP25, CP29 y CP38; ver Tabla 3.4 para los códigos) de los 38 fragmentos analizados de la región larga de copia única del ADN de cloroplastos. Marcador: escalera de 1-KiloBase (Pharmacia), las flechas indican la banda de 1000 pares de bases. En todos los casos, el orden de las muestras se corresponde con el siguiente: CNT01, CNJ03, CNJ07 BOC01, RZA04, RZA05, NAV04, MON02, RAS07, RAS08, PAU01, CER01, ROZ11, ROZ40, TIE11, TIE12, IRU19, IRU20, CAS20, CAS21, PIE04, CVJ06, CVJ07, CVA02, MOM02, CAN05, ALD10, VIL10, STR22, STR23, BEN02 y BEN03 de U. glabra; PAUm01, VILm03 y BENm05 de U. minor. Ver Tablas 1.1 y 3.2 para el código de las poblaciones. 
Figura 4.17. Patrones de restricción obtenidos al digerir los fragmentos $\mathrm{CP} 2(\mathrm{HK}), \mathrm{CP} 3\left(\mathrm{~K}_{1} \mathrm{~K}_{2}\right)$, CP16 (DT), CP19 (SfM), CP28 (OA) y CP33 ( $\left.\mathrm{B}_{1} \mathrm{~B}_{2}\right)$ con la enzima de restricción Hinfl. En todos los casos, cada muestra se corresponde consecutivamente con RZA04, NAV04, CER01, MON02, RAS07, ROZ11, TIE11, IRU19, CAS21, PIE04, CVA02, MOM02, CAN05, ALD10 y STR22. Ver Tabla 1.1 para el código de las poblaciones. Marcador: escalera de 100 pares de bases (100 BasePair Ladder; Pharmacia), las flechas indican la banda de 800 pares de bases. Algunos de los polimorfismos detectados se han señalado con puntas de flecha. .93

Figura 4.18. Patrones de restricción obtenidos para la región $\mathrm{CP} 2$ con la enzima Hinfl. $\mathrm{M}$, Marcador: escalera de 100 pares de bases (100 Base-Pair Ladder; Pharmacia); la flecha indica la banda de 800 pb y el asterisco señala la zona de fragmentos polimórficos. Pocillos 1 a 20 , individuos de Casavieja (CVJ); pocillos 21 a 25, individuos de U. minor de Villamiel (VILm); pocillos 26 a 28, de individuos de U. glabra (CNJ03, TIE12 y BEN02); pocillos 29 a 31, individuos de $U$. minor (PAUm01, PAUm03 y ESBm02). Ver Tablas 1.1 y 3.2 para el código de las poblaciones....95

Figura 4.19. Patrones de restricción obtenidos para la región CP16. Combinación CP16-Hinfl (a). M, Marcador: escalera de 100 pares de bases (100 Base-Pair Ladder; Pharmacia); la flecha indica la banda de 800 pb y el asterisco señala la zona de fragmentos polimórficos. pocillos 1 a 3 , individuos de U. glabra (CNJ03, TIE12 y BEN02); pocillos 29 a 31, individuos de U. minor (PAUm01, PAUm03 y ESBm02); pocillos 4 a 9, individuos de Cercedilla (CER). Combinación CP16-Taql (b). M, Marcador: escalera de 100 pares de bases (100 Base-Pair Ladder; Pharmacia); la flecha indica la banda de 800 pb y el asterisco señala la zona de fragmentos polimórficos. Pocillos 1 a 3 y 10 a 12, individuos de U. glabra (CNJ03, RZA04, ROZ40, TIE12, ALD10 y BEN02); pocillos 29 a 31, individuos de U. minor (PAUm01, PAUm03 y ESBm02); pocillos 4 a 9, individuos de CER. Ver Tabla 1.1 para el código de las poblaciones. 97

Figura 4.20. Patrones de restricción obtenidos para la región CP19. Combinación CP19-Hinfl (a). M, Marcador: escalera de 100 pares de bases (100 Base-Pair Ladder; Pharmacia); la flecha indica la banda de $500 \mathrm{pb}$ y el asterisco señala la zona de fragmentos polimórficos. Pocillos 1 a 2 y 9 a 16, individuos de U. glabra (CNJ03, BOC01, RZA04, MON02, ROZ40, CVA02, TIE12, ALD10, STR22 y BEN02); pocillos 3 a 8, individuos de Cercedilla (CER). Combinación CP19-Mval (b). M, Marcador: escalera de 100 pares de bases (100 Base-Pair Ladder; Pharmacia); la flecha indica la banda de $500 \mathrm{pb}$ y el asterisco señala la zona de fragmentos polimórficos. Pocillos 1 a 4 y 11 a 18, individuos de U. glabra (CNJ03, BOC01, RZA04, MON02, RAS07, ROZ40, MOM02, CVA02, TIE12, ALD10, STR22 y BEN02); pocillos 5 a 10, individuos de CER. Ver Tabla 1.1. para el código de las poblaciones 98 
Figura 4.21. Patrones de restricción obtenidos para la región CP28. Combinación CP28-Hinfl (a). M, Marcador: escalera de 100 pares de bases (100 Base-Pair Ladder; Pharmacia); la flecha indica la banda de $500 \mathrm{pb}$ y el asterisco señala la zona de fragmentos polimórficos. Pocillos 1 a 3 y 10 a 15, individuos de U. glabra (CNJ03, BOC01, RZA04, MON02, ROZ40, CVA02, TIE12, ALD10 y BEN02); Pocillos 4 a 9, individuos de Cercedilla (CER). Combinación CP28-Taql (b). M, Marcador: escalera de 100 pares de bases (100 Base-Pair Ladder; Pharmacia); la flecha indica la banda de $500 \mathrm{pb}$ y el asterisco señala la zona de fragmentos polimórficos. Pocillos 1 a 6 y 13 a 15 , individuos de U. glabra (CNJ03, BOC01, RZA04, MON02, ROZ40, CVA02, TIE12, ALD10 y BEN02); pocillos 7 a 12, individuos de CER. Ver Tabla 1.1. para el código de las poblaciones. 99

Figura 4.22. Red haplotípica de máxima parsimonia (maximum parsimony haplotype network) obtenida con el programa NETWORK 5.0 para los ocho haplotipos $(\mathrm{H} 1$ a H8) detectados en las poblaciones de U. glabra del Sistema Central. Los tamaños de los círculos son proporcionales a la frecuencia del haplotipo (ver Tabla 4.24 para las frecuencias haplotípicas). 106

Figura 4.23. Estructura filogeográfica detectada en el análisis espacial de la varianza molecular realizado con el programa SAMOVA 2.0 con los datos del ADNcp en las 19 poblaciones del Sistema Central con $\mathrm{N}_{\mathrm{m}}>5$. Grupos o clústeres detectados para $\mathrm{K}=4$ (a); grupos o clústeres obtenidos para $\mathrm{K}=2$ (b). El relleno de los círculos de las poblaciones es proporcional a la frecuencia de los haplotipos detectados en ellas (ver Tabla 4.25). * Poblaciones que no fueron incluidas en este análisis, al contar con menos de cinco individuos muestreados. Ver Tabla 1.1 para los códigos de las poblaciones y Figura 4.22 para identificar los símbolos de cada haplotipo. 108

Figura 4.24. Poblaciones con mayor (en azul) y menor (rojo) precipitación acumulada durante los meses de verano. Ver Tabla 1.1 para los códigos de poblaciones 113

Figura 4.25. Poblaciones con mayor (en azul) y menor (rojo) precipitación acumulada durante la temporada lluviosa (primavera, otoño e invierno) anual. Ver Tabla 1.1 para los códigos de población. 113

Figura 4.26. Poblaciones con mayor (en azul) y menor (rojo) temperatura media diaria mínimas invierno. Ver Tabla 1.1 para los códigos de población. 115

Figura 4.27. Mapa de probabilidades de presencia de U. glabra en la península ibérica obtenido para un tamaño de malla de $500 \mathrm{~m}$. ArcGis 10.3 (ESRI, 2014).

Figura 4.28. Modelo de distribución de $U$. glabra en la península ibérica obtenido para un tamaño de malla de 500 m para el valor máximo de TSS. ArcGis 10.3 (ESRI, 2014)..... 118 
Figura 4.29. Modelo de distribución potencial para U. glabra en el Sistema Central obtenido para una malla de 500m, obtenida para el valor máximo de TSS. ArcGis 10.3 (ESRI, 2014). 118 Figura 4.30. Extensión de Presencia de U. glabra en el Sistema Central. ArcGIS 10.3 (ESRI, 2014). 119 


\section{ÍNDICE DE TABLAS}

Tabla 1.1. Localización de las poblaciones de U. glabra en el Sistema Central. Se indica el número de individuos censados o estimados (Nt), así como los valores medios del diámetro y la altura de las mismas.

Tabla 3.1. Número de individuos muestreados ( $\mathrm{Nm}$ ) y censados o estimados ( $\mathrm{Nt}$; entre paréntesis) en cada en cada una de las 22 poblaciones de U. glabra del Sistema Central analizadas (ver Tabla 1.1 para los códigos de población).

Tabla 3.2. Localización y número de individuos muestreados $(\mathrm{Nm})$ de $U$. minor en cada una de las tres localidades ubicadas en el Sistema Central.

Tabla 3.3. Secuencias de los pares de cebadores ( $F$, forward; $R$, reverse) utilizados para amplificar los 22 loci SSR probados inicialmente en el presente estudio. Se indica el motivo repetido de cada microsatélite.

Tabla 3.4. Denominación y secuencias de los 38 pares de cebadores universales empleados para amplificar los correspondientes fragmentos (CP1 a CP38) de la región larga de copia única del ADNcp. Se indica la temperatura de annealing o unión (TA) y el tiempo de elongación o extensión (TE) utilizados para la amplificación de cada fragmento.

Tabla 3.5. Factores abióticos empleados en los análisis. Los factores climáticos y geológicos fueron modelados mediante CHAID para obtener el modelo de ausencia/presencia de U. glabra. Stepwise multivariate regression fue empleada en los factores geográficos para obtener mapas climáticos.

Tabla 3.6. Matriz de confusión empleada para el cálculo de los principales estadísticos que valoran la bondad de los modelos de predicción de presencia-ausencia. En ella, a y d representan el número de veces que el resultado esperado coincide con el observado; mientras que b y $\mathrm{c}$ se corresponden con el número de veces en las que no coinciden. A partir de la suma de estos, se calculan los valores $n_{1}(a+c), n_{0}(b+d), m_{1}(a+b), m_{0}(c+d)$ y $n(a+b+c+d)$.

Tabla 4.1. Tamaño de los alelos (en pares de bases, pb) y sus frecuencias detectados para cada uno de los 11 loci de microsatélites analizados en 427 muestras de U. glabra y 15 de U. minor del Sistema Central.

Tabla 4.2. Parámetros de diversidad genética para los 11 loci SSR analizados en 427 individuos de U. glabra del Sistema Central 
Tabla 4.3. Parámetros de diversidad genética calculados para las 22 poblaciones de U. glabra muestreadas en el Sistema Central usando datos de los 11 loci de microsatélites. Ver Tabla 1.1 para los códigos de población.

Tabla 4.4. Valores de diferenciación genética ( $F_{S T}$; debajo de la diagonal) y su significación ( $P$; sobre la diagonal), obtenidos entre las 19 poblaciones de U. glabra analizadas (poblaciones con Nm<5 -CNT, BOC y PAU- no se incluyeron en este análisis) con los datos de 11 loci SSR y usando el método AMOVA. La significación se obtuvo con 10000 permutaciones. El mayor valor de $F_{S T}$ Se muestra en negrita y los dos valores más bajos subrayados. Ver Tabla 1.1 para los códigos de población.

Tabla 4.5. Detección de cuellos de botella en las 15 poblaciones de U. glabra con al menos diez individuos muestreados, empleando el estadístico $\mathrm{T}_{2}$ y los valores de $P$ obtenidos al aplicar el test de Wilcoxon bajo el modelo TPM (two-phase model) implementado en BOTTLENECK 1.2, así como los valores medios para el conjunto de todos los loci obtenidos para el M-valor calculado con Arlequin 3.5. Ver Tabla 1.1 para los códigos de población. .66

Tabla 4.6: Tamaño efectivo poblacional $\left(N_{e}\right)$ estimado en las 10 poblaciones de $U$. glabra con al menos 20 individuos muestreados, usando una aproximación computacional bayesiana (ONeSAMP 1.1) y un método de desequilibrio de ligamiento (LDNe 1.31). Entre paréntesis se muestran los valores del intervalo de confianza (IC) al 95\%. Ver Tabla 1.1 para los códigos de población.

Tabla 4.7: Análisis de autocorrelación espacial global para las 427 muestras de U. glabra del Sistema Central analizados con los datos de 11 loci de microsatélites. $\mathrm{N}$ : número de pares de comparaciones para cada una de las 12 clases de distancia definidas (de 0-1 km a 320-640 km); $r$ : coeficiente de autocorrelación; $U$ y $L$ : límites superior e inferior del intervalo de confianza al 95\% para aceptar la hipótesis nula de no existencia de estructura espacial $(r=0)$, obtenidos a partir de 10000 permutaciones; $P$ : probabilidad de existencia de autocorrelación positiva, $r_{\mathrm{e}}$ ( $r$ estimada) $\geq r_{0}$ ( $r$ observada), o de autocorrelación negativa, $r_{\mathrm{e}} \leq r_{0} ; r_{\mathrm{B}}$ : valor medio de $r$ estimado por remuestreo (bootstrap); Ur y $L r$ : límites superior e inferior del intervalo de confianza al 95\%, determinados mediante 10000 remuestreos. En negrita se señalan los valores de $r$ que resultaron ser significativos $(P<0,05)$, así como su nivel de significación $(P)$. También se indica el punto de intercepción en $\mathrm{km}$.

Tabla 4.8. Análisis de autocorrelación espacial para los 22 individuos de U. glabra pertenecientes a la población de Riaza-Becerril (RZA) analizados con los datos de 11 loci de microsatélites. $\mathrm{N}$ : 
número de pares de comparaciones para cada una de las seis clases de distancia definidas (de 052 m a 211-232 m); r : coeficiente de autocorrelación; U y L : límites superior e inferior del intervalo de confianza al 95\% para aceptar la hipótesis nula de no existencia de estructura espacial $(r=0)$, obtenidos a partir de 10000 permutaciones; $P$ : probabilidad de existencia de autocorrelación positiva, $r_{\mathrm{e}}\left(r\right.$ estimada) $\geq r_{0}$ ( $r$ observada), o de autocorrelación negativa, $r_{\mathrm{e}} \leq r_{0}{ }^{\prime}, r_{\mathrm{B}}$ : valor medio de $r$ estimado por remuestreo (bootstrap); Ur y $L r$ : límites superior e inferior del intervalo de confianza al 95\%, determinados mediante 10000 remuestreos. En negrita se señalan los valores de $r$ que resultaron ser significativos $(P<0,05)$, así como su nivel de significación $(P)$. También se indica el punto de intercepción en $\mathrm{m}$. .71

Tabla 4.9. Individuos de la población de Riaza-Becerril (RZA) que presentaron correlación ( $r$ ) significativa $(P<0,05)$ con sus $\mathrm{N}=6$ vecinos más próximos. Ver Anexo I para los códigos de cada individuo.

Tabla 4.10: Análisis de autocorrelación espacial para los 46 individuos de U. glabra pertenecientes a la población de Rozas de Puerto Real (ROZ) analizados con los datos de 11 loci de microsatélites. $\mathrm{N}$ : número de pares de comparaciones para cada una de las 14 clases de distancia definidas (de 0-5 m a 143-199 m); $r$ : coeficiente de autocorrelación; U y L : límites superior e inferior del intervalo de confianza al 95\% para aceptar la hipótesis nula de no existencia de estructura espacial $(r=0)$, obtenidos a partir de 10000 permutaciones; $P$ : probabilidad de existencia de autocorrelación positiva, $r_{\mathrm{e}}\left(r\right.$ estimada) $\geq r_{\mathrm{o}}\left(\mathrm{r}\right.$ observada), o de autocorrelación negativa, $r_{\mathrm{e}} \leq$ $r_{0} ;, r_{\mathrm{B}}$ : valor medio de restimado por remuestreo (bootstrap); Ur y $L r$ : límites superior e inferior del intervalo de confianza al 95\%, determinados mediante 10000 remuestreos. En negrita se señalan los valores de $r$ que resultaron ser significativos $(P<0,05)$, así como su nivel de significación $(P)$. También se indica el punto de intercepción en $\mathrm{m}$.

Tabla 4.11. Individuos de la población de Rozas de Puerto Real (ROZ) que presentaron correlación (r) significativa $(P<0,05)$ con sus $\mathrm{N}=20$ vecinos más próximos. Ver Anexo I para los códigos de cada individuo. .75

Tabla 4.12. Análisis de autocorrelación espacial para los 42 individuos de U. glabra pertenecientes a la población de EI Tiemblo (TIE) analizados con los datos de 11 loci de microsatélites. $\mathrm{N}$ : número de pares de comparaciones para cada una de las 25 clases de distancia definidas (de 0-13 m a 920-989 m); $r$ : coeficiente de autocorrelación; U y L : límites superior e inferior del intervalo de confianza al 95\% para aceptar la hipótesis nula de no existencia de estructura espacial $(r=0)$, obtenidos a partir de 10000 permutaciones; $P$ : probabilidad de existencia de autocorrelación 
positiva, $r_{\mathrm{e}}$ ( $r$ estimada) $\geq r_{\mathrm{o}}$ ( $r$ observada), o de autocorrelación negativa, $r_{\mathrm{e}} \leq r_{0} ;, r_{\mathrm{B}}$ : valor medio de $r$ estimado por remuestreo (bootstrap); Ur y $L r$ : límites superior e inferior del intervalo de confianza al 95\%, determinados mediante 10000 remuestreos. En negrita se señalan los valores de $r$ que resultaron ser significativos $(P<0,05)$, así como su nivel de significación $(P)$. También se indica el punto de intercepción en $\mathrm{m}$.

Tabla 4.13. Individuos de la población de El Tiemblo (TIE) que presentaron correlación ( $r$ ) significativa $(P<0,05)$ con sus $\mathrm{N}=18$ vecinos más próximos. Ver Anexo I para los códigos de cada individuo. .78

Tabla 4.14. Análisis de autocorrelación espacial para los 57 individuos de U. glabra pertenecientes a la población de El Barraco-Valle de Iruelas (IRU) analizados con los datos de 11 loci de microsatélites. $\mathrm{N}$ : número de pares de comparaciones para cada una de las 29 clases de distancia definidas (de 0-46 m a 3506-3933 m); $r$ : coeficiente de autocorrelación; U y L : límites superior e inferior del intervalo de confianza al 95\% para aceptar la hipótesis nula de no existencia de estructura espacial ( $r=0)$, obtenidos a partir de 10000 permutaciones; $P$ : probabilidad de existencia de autocorrelación positiva, $r_{\mathrm{e}}(r$ estimada $) \geq r_{\mathrm{o}}$ ( $r$ observada), $\mathrm{o}$ de autocorrelación negativa, $r_{\mathrm{e}} \leq$ $r_{0} ;, r_{B}:$ valor medio de r estimado por remuestreo (bootstrap); Ur y $L r$ : límites superior e inferior del intervalo de confianza al 95\%, determinados mediante 10000 remuestreos. En negrita se señalan los valores de $r$ que resultaron ser significativos $(P<0,05)$, así como su nivel de significación $(P)$. También se indica el punto de intercepción en $\mathrm{m}$.

Tabla 4.15. Individuos de la población de El Barraco-Valle de Iruelas (IRU) que presentaron correlación $(r)$ significativa $(P<0,05)$ con sus $\mathrm{N}=7$ vecinos más próximos. Ver Anexo I para los códigos de cada individuo

Tabla 4.16. Análisis de autocorrelación espacial para los 20 individuos de U. glabra pertenecientes a la población de Casavieja (CVJ) analizados con los datos de 11 loci de microsatélites. $\mathrm{N}$ : número de pares de comparaciones para cada una de las cinco clases de distancia definidas (de 0-2 $\mathrm{m}$ a 114-173 m); $r$ : coeficiente de autocorrelación; U y L : límites superior e inferior del intervalo de confianza al 95\% para aceptar la hipótesis nula de no existencia de estructura espacial $(r=0)$, obtenidos a partir de 10000 permutaciones; $P$ : probabilidad de existencia de autocorrelación positiva, $r_{\mathrm{e}}$ ( $r$ estimada) $\geq r_{\mathrm{o}}$ ( $r$ observada), o de autocorrelación negativa, $r_{\mathrm{e}} \leq r_{0} ;, r_{\mathrm{B}}$ : valor medio de $r$ estimado por remuestreo (bootstrap); Ur y $L r$ : límites superior e inferior del intervalo de confianza al 95\%, determinados mediante 10000 remuestreos. En negrita se señalan los valores 
de $r$ que resultaron ser significativos $(P<0,05)$, así como su nivel de significación $(P)$. También se indica el punto de intercepción en $\mathrm{m}$.

Tabla 4.17. Análisis de autocorrelación espacial para los 25 individuos de U. glabra pertenecientes a la población de Benfeita (BEN) analizados con los datos de 11 loci de microsatélites. $\mathrm{N}$ : número de pares de comparaciones para cada una de las cinco clases de distancia definidas (de 0-35 m a 246-289 m); $r$ : coeficiente de autocorrelación; U y L : límites superior e inferior del intervalo de confianza al 95\% para aceptar la hipótesis nula de no existencia de estructura espacial $(r=0)$, obtenidos a partir de 10000 permutaciones; $P$ : probabilidad de existencia de autocorrelación positiva, $r_{\mathrm{e}}(r$ estimada $) \geq r_{\mathrm{o}}$ ( $r$ observada), o de autocorrelación negativa, $r_{\mathrm{e}} \leq r_{\mathrm{o}} ;, r_{\mathrm{B}}$ : valor medio de $r$ estimado por remuestreo (bootstrap); Ur y $L r$ : límites superior e inferior del intervalo de confianza al 95\%, determinados mediante 10000 remuestreos. En negrita se señalan los valores de $r$ que resultaron ser significativos $(P<0,05)$, así como su nivel de significación $(P)$. También se indica el punto de intercepción en $\mathrm{m}$.

Tabla 4.18. Individuos de la población de Benfeita (BEN) que presentaron correlación $(r)$ significativa $(P<0,05)$ con sus $\mathrm{N}=8$ vecinos más próximos. Ver Anexo I para los códigos de cada individuo.

Tabla 4.19. Número y porcentaje de individuos asignados a los clústeres $A$ y B, o considerados individuos mezcla, para cada una de las poblaciones analizadas, en función de los resultados obtenidos mediante el análisis de STRUCTURE. Ver Tabla 1.1 para los códigos de población. .90

Tabla 4.20. Grado de amplificación (NA, no amplifica; +, débil; ++, buena; +++, muy buena) y tamaño estimado en pares de bases $(\mathrm{pb})$ para los 38 fragmentos de la región LSC amplificados en las 35 muestras de Ulmus (32 de U. glabra y 3 de U. minor) para el análisis preliminar

Tabla 4.21. Tamaños de los fragmentos de restricción (en pares de bases) y haplotipos detectados mediante la técnica de PCR-RFLP con las 18 combinaciones región de ADNcp-enzima de restricción que resultaron ser polimórficas en las dos especies de Ulmus (I a III = haplotipos de U. glabra; $i$ a $i i$ = haplotipos de U. minor). Se indica el número de individuos (entre paréntesis), y en casos específicos las poblaciones, en donde fueron detectados los distintos haplotipos para ambas especies. Ver Tablas 1.1 y 3.2 para el código de las poblaciones.

Tabla 4.22. Tamaño de los alelos (en pares de bases) de los nueve loci SSRcp que fueron monomórficos en el estudio preliminar llevado a cabo en 35 muestras (32 U. glabra y $3 \mathrm{U}$. minor) 
Tabla 4.23. Tamaños de los alelos (en pares de bases) y haplotipos detectados para el conjunto de los nueve loci SSRcp polimórficos en UImus ( $A$ - $G$ = haplotipos en $U$. glabra; a - $c$ = haplotipos en $U$. minor). Se indica el número de individuos que presentaron cada haplotipo $\left(N_{h}\right)$ y su distribución en las poblaciones estudiadas. Ver Tablas 1.1 y 3.2 para el código de las poblaciones. 102

Tabla 4.24. Distribución de los ocho haplotipos $(\mathrm{H} 1$ a H8) obtenidos con los datos combinados de PCR-RFLP (clorotipos I, II y III) y SSRcp (clorotipos $A$ a G) en las 19 poblaciones analizadas (con $\mathrm{Nm}>5$ ). Se indica el número de individuos por haplotipo, así como las frecuencias globales de cada haplotipo, calculadas con el programa Haplodiv. Nm, número de individuos muestreados; Hd, diversidad haplotípica y error estándar (e. s.) entre paréntesis; Hr, riqueza haplotípica, obtenida tras aplicar la rarefacción para $\mathrm{Nm}=6$. Ver Tabla 1.1 para los códigos de las poblaciones 104

Tabla 4.25. Parámetros de diversidad y diferenciación genética en el ADNcp calculados con el programa Permut 2.0 para las 19 poblaciones de U. glabra analizadas. Los errores estándar se muestran entre paréntesis. 105

Tabla 4.26. Índices de fijación ( $F_{S C}$, diferenciación entre poblaciones dentro de los grupos 0 clústeres; $F_{S T}$, diferenciación entre poblaciones respecto al total; $F_{\mathrm{CT}}$, diferenciación entre clústeres de poblaciones) y composición poblacional de los clústeres obtenidos para valores de $\mathrm{K}$ de 2 a 10 con el programa SAMOVA 2.0, utilizando 10000 iteraciones MCMC (Markov chain Monte Carlo) y 500 repeticiones, sobre las 19 poblaciones de $U$. glabra con un tamaño muestral $>5$. En todos los casos, los tres índices de fijación fueron altamente significativos $(P<0,00000)$. Los clústeres que van apareciendo desde $\mathrm{K}=3$ a $\mathrm{K}=10$ por primera vez en el análisis se muestran en negrita. En negrita aparece el máximo valor de $\mathrm{F}_{\mathrm{CT}}$ obtenido.

Tabla 4.27. Análisis de la varianza molecular (AMOVA) con los datos de los haplotipos detectados en el ADNcp para las poblaciones de U. glabra sin el establecimiento de grupos de poblaciones, 0 bien considerando los clústeres detectados en el análisis con SAMOVA para K=4 y K=2 (ver Tabla 4.26). 110

Tabla 4.28. Media, rango y desviación estándar (D.E.) de las variables ecológicas empleadas en la modelización de U. glabra en la península ibérica y para las 27 poblaciones del Sistema Central. $\mathrm{P}$, precipitación $(\mathrm{mm}) ; \mathrm{T}$, temperatura $\left({ }^{\circ} \mathrm{C}\right)$.

Tabla 4.29. Sectorización y características climáticas según Ruiz-Labourdette et al. (2011) para las poblaciones del Sistema Central (ver Tabla 1.1 para los códigos de población). Entre 
paréntesis, aparece el número de individuos para las poblaciones que se localizan en más de un sector climático. STR, VIL y BEN, sin datos.

Tabla 4.30. Media y rango de las 12 variables ecológicas empleadas en la modelización de las poblaciones de U. glabra en en el Sistema Central (ver Tabla 1.1 para los códigos de población). P: precipitación $(\mathrm{mm}), \mathrm{T}$ : temperatura $\left({ }^{\circ} \mathrm{C}\right)$. Sombreado oscuro: valores máximos; sombreado claro, valores mínimos.

Tabla 4.31. Matriz de confusión con la clasificación de las cuadrículas de presencia de U. glabra en la península ibérica observadas-esperadas y principales estimadores de la calidad del modelo. 116

Tabla 4.32. Código, Área de Ocupación, número de subpoblaciones (Subpob), número estimado de individuos (Nt), número de individuos maduros estimados (diámetro $\geq 10 \mathrm{~cm}$ ); poblaciones con número de individuos maduros mayor o menor al MVP (Población Mínima Viable). Ver Tabla 1.1 para los códigos de población.

Tabla 4.33. Número de subpoblaciones y de individuos maduros (diámetro $\geq 10 \mathrm{~cm}$ ), número de subpoblaciones con número de individuos maduros mayor o menor que la MVP (Población Mínima Viable) suponiendo que es una especie Muy longeva (>100 años; MVP 50 individuos maduros) 0 Medianamente longeva (25-100 años; MVP 100 individuos maduros). 121 




\section{INTRODUCCIÓN}

La familia Ulmaceae, a la que pertenece el género Ulmus, se encuadra en el Orden Urticales en el grupo Eurósidas I, muy relacionada con otras familias como Celtidaceae, Cannabaceae 0 Moraceae, según datos derivados de los análisis filogenéticos (APG 1998). Esta familia engloba 16 géneros y cerca de 2000 especies de árboles o arbustos distribuidos en zonas tropicales, subtropicales y templadas del hemisferio norte (Navarro \& Castroviejo 1993b). Uno de sus rasgos morfológicos característicos son sus hojas, de borde fuertemente serrado y asimétricas en la base (Navarro \& Castroviejo 1993a).

El género Ulmus L. agrupa unas 40 especies de árboles caducifolios presentes en todo el hemisferio norte, principalmente en zonas templadas y, en menor medida, en los trópicos (Buchel 2000). El mayor número de especies del género se encuentra en Asia, lo que parece indicar que es este continente el centro de origen del género. En Europa, existen tres especies de olmo que se encuentran presentes en la práctica totalidad del continente, desde las islas británicas hasta Escandinavia, pasando por las penínsulas ibérica, itálica y llegando hasta el centro de Rusia (Richens 1983).

Las especies de este género presentan una gran variabilidad morfológica en los caracteres vegetativos (Richens 1983; Navarro \& Castroviejo 1993b). Los rasgos distintivos del género hacen referencia a la morfología foliar, de manera que presentan hojas simples, alternas, glabras en el haz, pero pelosas en el envés, con nervadura pinnada, margen foliar dentado o serrado y con la base asimétrica en el limbo (Navarro \& Castroviejo 1993b). Las flores son anemófilas, hermafroditas, aunque puntualmente pueden ser unisexuales, agrupadas en inflorescencias que se desarrollan en las ramas del año. Su fruto es seco e indehiscente en forma de sámara emarginada en el ápice, con un ala que rodea a toda la semilla (Buchel 2000; Navarro \& Castroviejo 1993b).

El género Ulmus presenta una gran complejidad taxonómica, que se ve reflejada en la propia organización del mismo, motivo por el que ha sufrido varias reestructuraciones (Cheng et al. 1963; Schneider 1910). Un nuevo planteamiento, basado en datos moleculares (Wiegrefe et al. 1994), divide al género Ulmus en dos subgéneros: Oroptelea (Spach) Planchon y Ulmus L. Dentro del primer subgénero se localizan tres secciones: Blepharocarpus Dum., Chaetoptelea (Leibm.) C. Schn y Trichoptelea C. Schn. Por su parte, el subgénero Ulmus se divide en las secciones Microptelea (Spach.), Lanceifolia (C. Schm.) Grudzinskaya, y Ulmus L. 
En el continente europeo, el género olmo estaría representado por U. glabra Hudson (olmo de montaña), U. minor Mill. (olmo común) y U. laevis Pallas (olmo blanco o pedunculado). En la península ibérica se ha discutido mucho sobre el carácter autóctono de alguna de estas especies (Richens, 1983; Ipinza, 1989, 1990), especialmente sobre la espontaneidad de U. laevis (Richens \& Jeffers 1986; Navarro \& Castroviejo 1993b; González 2006). Las dudas que existen a este respecto se deben principalmente a que, ya desde antaño, los olmos se emplearon con fines madereros, ornamentales y en viticultura (Heybroek 2000; Gil et al. 2000), por lo que pudieron ser introducidos. A este respecto, los últimos estudios llevados a cabo mediante marcadores moleculares avalan la presencia natural de $U$. laevis en la península ibérica (Fuentes-Utrilla et al. 2014b). Por ello, actualmente se asume que las tres especies europeas del género Ulmus (U. glabra, U. minor y U. laevis) se encuentran de manera natural en la península.

\section{1. Ulmus glabra Hudson}

\subsection{Descripción morfológica}

Ulmus glabra Hudson $(2 n=28)$, es conocido vulgarmente como olmo de montaña, olmo montano, servellano o llamera, entre otros nombres. Se trata de un árbol caducifolio que puede llegar hasta los $40 \mathrm{~m}$ de altura. Sus hojas son muy características, pueden alcanzar hasta $18 \times 13,5$ $\mathrm{cm}$, de elípticas a obovadas, muy asimétricas en su base, con la parte distal terminada en un ápice muy delgado, que a menudo presenta una o dos puntas más a modo de lóbulos incipientes laterales; glabras por el haz y con pelos rígidos en el envés que le dan una textura áspera, aunque no tanto como las de U. minor. El margen foliar está irregularmente serrado. Presenta nervadura pinnada, de 12-20 pares de nervios paralelos muy prominentes en el envés (Navarro \& Castroviejo 1993b) (ver Figura 1.1). Las inflorescencias se presentan en cimas congestas sobre las ramillas de un año. Flores con 4-5 segmentos en el perianto cubierto de pelos rojizos y 4-5 estambres. El fruto es una sámara de hasta $25 \times 18 \mathrm{~mm}$ de diámetro, con un ala que rodea a la semilla, mayor que la del olmo común. La semilla se sitúa en el centro del fruto y alejada de la escotadura que, a su vez, está poco marcada; siendo esta una de los principales caracteres en su diferenciación de U. minor (Navarro \& Castroviejo 1993b; Ruiz de la Torre 2006) (ver Figura 1.1). 


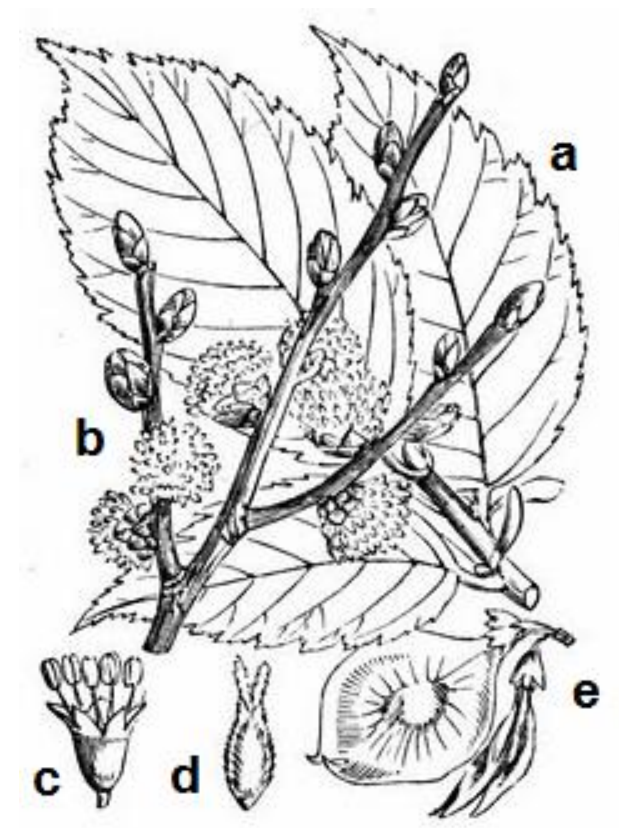

Figura 1.1. Características de Ulmus glabra: rama con hojas (a), ramilla con yemas y flores (b), Detalle de una de las flores (c), Detalle de una bráctea de la inflorescencia (d) y fruto en sámara (e). Fuente: Illustrations of the British Flora (1924).

\subsection{Características reproductivas}

La reproducción es principalmente sexual, aunque también se ha descrito en algunos casos multiplicación vegetativa, especialmente en individuos jóvenes. En todo caso, y a diferencia del olmo común, el olmo de montaña no brota de raíz, sino que presenta rebrote de cepa (Cox et al. 2014).

Centrándonos en la reproducción sexual, al igual que otras especies del género, U. glabra es anemógama y autoincompatible (Townsend 1975; Nielsen \& Kjær 2010b). Las flores que presenta son generalmente hermafroditas y de desarrollo muy temprano. La floración se da entre los meses de marzo-abril (Rossignoli 1999; Navarro \& Castroviejo 1993b). La edad de floración es bastante variable, pudiendo llegar a ser muy temprana (3-4 años) o alcanzar los diez años o más, aunque como norma general, la primera floración se suele producir entorno a los siete años (López Almansa \& Gil 2003). En cuanto a la producción de semillas, la edad de inicio de alta producción de semilla viable ronda los 30-40 años (Alía Miranda et al. 2009). A pesar de ello, la presión selectiva de patógenos, como la grafiosis, está produciendo la selección de individuos que entran en edad reproductiva antes en algunas poblaciones, llegando a florecer cuando alcanzan los $4 \mathrm{~cm}$ de diámetro de cepa (Nielsen \& Kjær 2010b). Por otro lado, al igual que la edad la floración, la densidad de flores varía de unos individuos a otros, pudiendo verse incrementada con la edad (López Almansa \& Gil 2003). 
Por otro lado, la capacidad dispersiva del polen de los olmos, al contrario de lo que se pueda creer, es limitada. Por ejemplo, en $U$. laevis se ha estimado una distancia próxima a los $100 \mathrm{~m}$ en individuos dentro de masas forestales, mientras que, en individuos localizados en campo abierto, esa distancia puede superar el kilómetro (Nielsen \& Kjær 2010a). La distancia de dispersión génica estimada para esa misma especie, se ve reducida hasta los 19-41 m en climas mediterrános (Venturas et al. 2013b). En U. glabra, se han registrado distancias de más de $100 \mathrm{~m}$ bajo cubierta forestal (Nielsen \& Kjær 2010b). Estos resultados bajo cubierta forestal son similares a los descritos en otras especies de árboles anemófilos como por ejemplo Fraxinus excelsior L. (Bacles et al. 2005) y Quercus lobata Née (Dutech et al. 2005).

La dispersión del fruto de U. glabra es fundamentalmente anemócora. En poblaciones relictas, en las que los individuos se suelen situar en zonas húmedas como barrancos 0 arroyos (Rossignoli \& Génova 2003), la dispersión por hidrocoría se ve facilitada, posibilitando el desplazamiento de los frutos a mayores distancias (Venturas 2013). A pesar de ello, la capacidad dispersiva de estos frutos es, en general, limitada. En un estudio en U. laevis (Venturas 2013), se encontró que el $95 \%$ de las semillas no se dispersaban más allá de los $30 \mathrm{~m}$, con una distancia media de $13 \mathrm{~m}$.

Un hecho relevante, detectado en varias especies y poblaciones de olmos, es la abundancia de sámaras vanas (Venturas 2013; Arche 2010), con porcentajes que varían anualmente y que p.e. puede llegar a suponer más del $87 \%$ en U. laevis (Venturas 2013). En U. glabra también se ha descrito la existencia de un elevado porcentaje de sámaras vanas, así como una rápida pérdida de viabilidad en la semilla (Crocker 1938; Gosling 2007). En este sentido, en algunas de las poblaciones de olmo de montaña del Sistema Central, se ha observado un bajo porcentaje de fructificación, llegándose a encontrar poblaciones con ausencia total de frutos (Arche 2010). El porcentaje de semillas vanas en muchas de estas poblaciones rozó algunos años incluso el 100\% de la producción; además, dentro del escaso porcentaje de semillas morfológicamente completas, la germinación fue muy baja (Arche 2010; Bascuñana 2010). Este fenómeno varió en años sucesivos (Felipe Martínez, comunicación personal).

En U. glabra se ha observado que, por partenocarpia, se pueden formar frutos en ausencia de fertilización (López Almansa et al. 2004); siendo por tanto las semillas inviables y una de las causas de la formación de semillas vanas. Otra de las posibles causas de dicho fenómeno es la predación de las semillas por aves, que puede llegar a suponer cerca del 30\% de la producción en U. laevis (Venturas 2013), y que también se ha observado en U. glabra, especialmente en la población del Valle de Iruelas (Arche 2010). 


\subsection{Distribución y ecología}

El olmo de montaña se distribuye por todo el continente europeo y parte de Asia, desde Escandinavia y los Urales hasta el Mediterráneo, siendo la península ibérica el límite suroccidental de su distribución (Richens 1983; Collin et al. 2000; Caudullo \& de Rigo 2016). Esta especie claramente eurosiberiana, no tolera muchos días secos al año, por lo que necesita abundantes precipitaciones anuales $(800-1000 \mathrm{~mm}$ ) y cerca de $200 \mathrm{~mm}$ en época estival (Ceballos \& Fernández 2001). Por ello, aunque tiene una distribución amplia por el viejo continente, es más frecuente en la zona norte de Europa, donde aparece desde los 0-100 m hasta los 1700-2000 m (Ruiz de la Torre 2001) (ver Figura 1.2). Los ejemplares de esta especie se localizan en diferentes tipos de bosques mixtos con presencia de tilos, arces y fresnos, en hayedos y abetales (Collin et al. 2000; Tutin \& Walters 1993) y en pinares. Además, el olmo de montaña requiere veranos frescos, suelos ligeramente ácidos, ricos y húmedos, también crece a lo largo de arroyos, pero muy raramente tolera suelos encharcados (Caudullo \& de Rigo 2016).

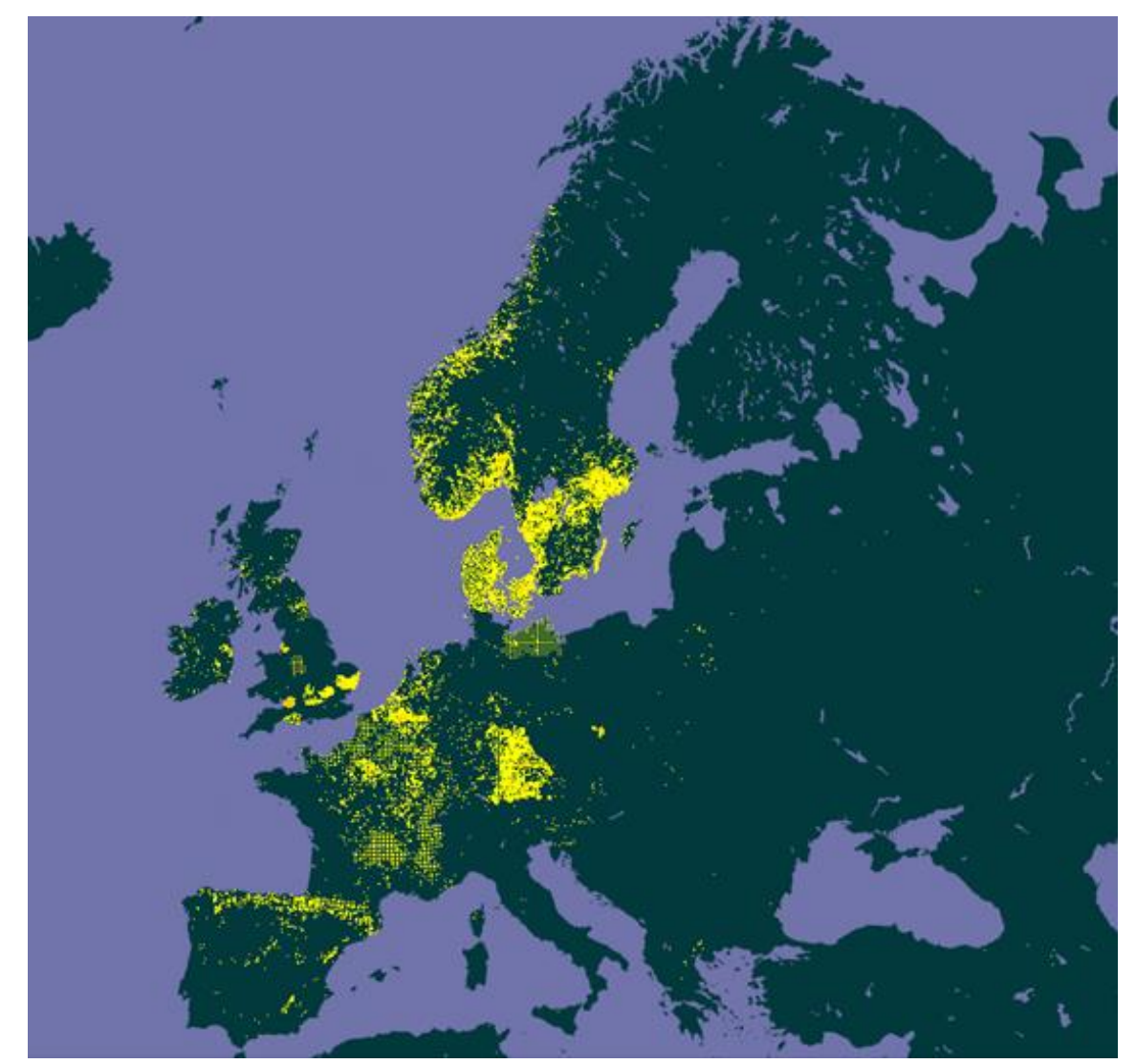

Figura 1.2. Distribución de U. glabra en el continente europeo. Fuente: Global Biodiversity Information Facility (www.gbif.org; fecha de consulta 31/05/2017). 
Centrándonos en la península ibérica, U. glabra siempre se ha considerado nativo en España; mientras que en Portugal han existido dudas acerca de su espontaneidad, de manera que para algunos autores es una especie naturalizada (Navarro \& Castroviejo 1993b), otros la consideran nativa (Monteiro-Henriques et al. 2010). En general, es menos común que U. minor y se localiza principalmente en el tercio norte, siendo muy habitual en los Pirineos y en el macizo cantábrico, y menos en Galicia, donde aparece muy raramente. En el centro y sur peninsular es mucho más escaso, quedando restringida su presencia a zonas de montaña en bosques de galería (Collin et al. 2000; Ruiz de la Torre 2006; Tutin \& Walters 1993) (ver Figura 1.3). Tal es el caso de los núcleos poblacionales localizados en los sistemas montañosos Ibérico, Central y del Maestrazgo, constituyendo el límite suroccidental de esta especie en Europa la Sierra de Cazorla (García Nieto et al. 2000) (ver Figura 1.3).

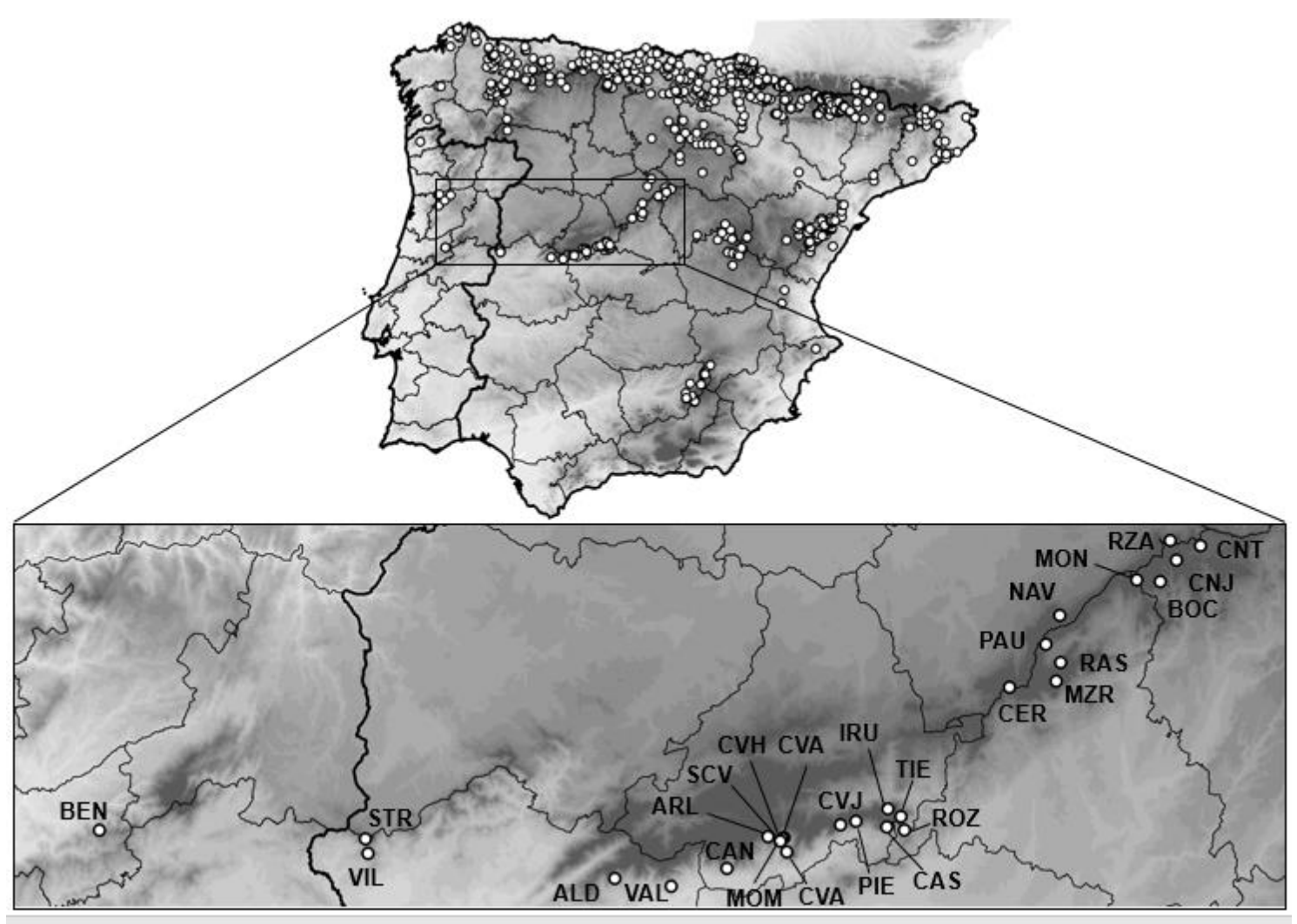

Figura 1.3. Distribución del olmo de montaña en la península ibérica, con un detalle de la localización de las poblaciones en el Sistema Central. Elaborado con ArcGis 10.3 (ESRI, 2014).

En la península, el olmo de montaña se encuentra en bosques templados y húmedos, en suelos frescos y pedregosos muy desarrollados (Navarro \& Castroviejo 1993b), aunque puede aparecer en afloramientos rocosos (García Nieto et al. 2000). Suele localizarse en zonas con una humedad media-alta o en las proximidades de ríos, entre los 0 y los $1800 \mathrm{~m}$ (Navarro \& Castroviejo 
1993b), aunque en algunos puntos del Sistema Ibérico puede alcanzar los 2300 m (Ruiz de la Torre 2006). Los ambientes peninsulares donde aparecen individuos de olmo montano se caracterizan por ser bosques principalmente de pino silvestre, aunque también aparecen en castañares y, de forma excepcional, en hayedos. Es una especie no muy abundante, que aparece como individuos dispersos o formando pequeños rodales acompañando a otras formaciones vegetales, como bosques mixtos de caducifolios, castañares, hayedos, pinares de pino silvestre y pino resinero.

\subsection{El olmo de montaña en el Sistema Central}

\subsubsection{Características litológicas y climáticas del Sistema Central}

El Sistema Central es una cadena montañosa que se localiza en el centro peninsular y que recorre unos 600 km en orientación oeste a este, desde Portugal hasta la provincia de Guadalajara. En dirección noreste-suroeste, se compone por las siguientes sierras: macizo de Ayllón, Somosierra, Guadarrama, Malagón, Gredos, Sierra de Francia y Béjar, Sierra de Gata y Serra da Estrela. Los picos de mayor altitud se encuentran en la Sierra de Gredos (Almanzor, $2592 \mathrm{~m}$ ) y Guadarrama (Peñalara, $2430 \mathrm{~m}$ ).

El clima en este amplio territorio, que es claramente mediterráneo, se ve interrumpido por el Sistema Central (Allue 1990). El Sistema Central presenta algunos sectores que, en términos generales, se puede decir que tienen un matiz mediterráneo, con un período de estrés hídrico en verano y precipitaciones concentradas en otoño y primavera; mientras que otras zonas presentan características climáticas próximas al clima eurosiberiano (Ruiz-Labourdette et al. 2011). Las mayores precipitaciones se registran en los extremos oriental y occidental, este último de influencia atlántica, lo que se traduce en un incremento en las precipitaciones, aunque mayor estrés hídrico en verano (Ruiz-Labourdette et al. 2011). Térmicamente, el clima del noreste del Sistema Central tiende a ser más continental y a perder el carácter mediterráneo, presentando una gran oscilación térmica y un verano más húmedo (Ruiz-Labourdette et al. 2011).

\subsubsection{Poblaciones de U. glabra}

Las sierras que componen el Sistema Central, con altitudes considerables, la existencia de una red hidrográfica permanente y una multitud de barrancos sombríos, ha generado enclaves adecuados para la persistencia de especies no mediterráneas. Estos enclaves tienen un microclima particular, con elevada y/o permanente humedad edáfica que permite paliar la sequía estival característica del clima mediterráneo. Estos lugares especialmente favorecidos son los que 
han permitido la persistencia de poblaciones de carácter relicto en el Sistema Central. Son muchas las especies que, presentando su principal área de distribución en ambientes atlánticos 0 eurosiberianos, cuentan con poblaciones relictas en el Sistema Central (Abel Schaad et al. 2014). Quizás entre las más llamativas podemos destacar las de Pinus sylvestris, Fagus sylvatica, Betula sp., Populus tremula, Fraxinus excelsior y un largo etc; entre las que figuran Ulmus glabra (García Nieto et al. 2000).

Precisamente, la influencia del clima mediterráneo en el Sistema Central ha provocado que la presencia de $U$. glabra se limite a lugares con elevada humedad edáfica, tales como barrancos, surgencias de agua, bosques en galería y valles encajados (Rossignoli \& Génova 2003).

El número de poblaciones conocidas hasta hace unos años en el Sistema Central no alcanzaban la veintena (Rossignoli 1999; Arche 2010). Estos núcleos fueron localizados entre las Sierras de Ayllón y de Gata, en las provincias españolas de Segovia, Madrid, Ávila y Cáceres (Arche 2010; Rossignoli 1999) (Tabla 1.1). Tras llevar a cabo nuevas prospecciones, el Grupo de Investigación "Historia y dinámica del paisaje vegetal" de la Universidad Politécnica de Madrid, ha localizado diez nuevos núcleos, incrementando el número de poblaciones del Sistema Central conocidas a 27 (ver Tabla 1.1, Figura 1.3), de las cuales dos se presentaron un único individuo Cantalojas (CNT) y El Paular (PAU). En la Figura 1.4 se muestran imágenes de individuos de algunas poblaciones del Sistema Central.

Las poblaciones españolas en el Sistema Central se distribuyen a lo largo de cinco provincias diferentes. En la provincia de Guadalajara, localizadas sobre el macizo de Ayllón, se encuentran tres núcleos poblacionales: CNT, CNJ (Cantalojas-arroyo de la Zarza) y BOC (El Cardoso de la Sierra-El Bocígano) (ver Tabla 1.1 y Figura 1.3). En las vertientes segovianas de la Sierra de Guadarrama, se localizan dos poblaciones de olmo de montaña NAV (Navafría) y RZA (RiazaBecerril) (ver Tabla 1.1, Figura 1.3 y Figura 1.4 a, b). Madrid cuenta con seis poblaciones situadas en la Sierra de Guadarrama y en Ayllón: MON (Montejo de la Sierra-El Cardoso de la Sierra), RAS (Rascafría-Morcuera), MZR (Manzanares El Real), PAU, CER (Cercedilla) y ROZ (Rozas de Puerto Real) (ver Tabla 1.1, Figura 1.3 y Figura 1.4 c, d, e, f).

La provincia con mayor número de poblaciones es Ávila, con un total de 11 núcleos localizados sobre la Sierra de Gredos: TIE (EI Tiemblo), IRU (EI Barraco-Valle de Iruelas), CAS (Casillas), PIE (Piedralaves), CVJ (Casavieja), SCV (Santa Cruz del Valle), CVA (Cuevas del ValleRío Pasaderas), CVH (Cuevas del Valle-Río del Herradero), ARL (El Arenal), MOM (Mombeltrán) y CAN (Candeleda) (ver Tabla 1.1, Figura 1.3 y Figura 1.4 g). Por último, en Cáceres se localizan cuatro poblaciones diferentes en la Sierra de Gata: VAL (Valverde de la Vera), ALD (Aldeanueva 
de la Vera), VIL (Villamiel), STR (San Martín de Trevejo-Eljas) (ver Tabla 1.1, Figura 1.3 y Figura 1.4 h). Finalmente, en Portugal, únicamente se ha descrito una población, BEN (Benfeita), situada en la Serra da Estrela, en concreto en el Paisagem Protegida da Serra do Açor. Se trata de la población más suroccidental de todo el Sistema Central (ver Tabla 1.1 y Figura 1.3).

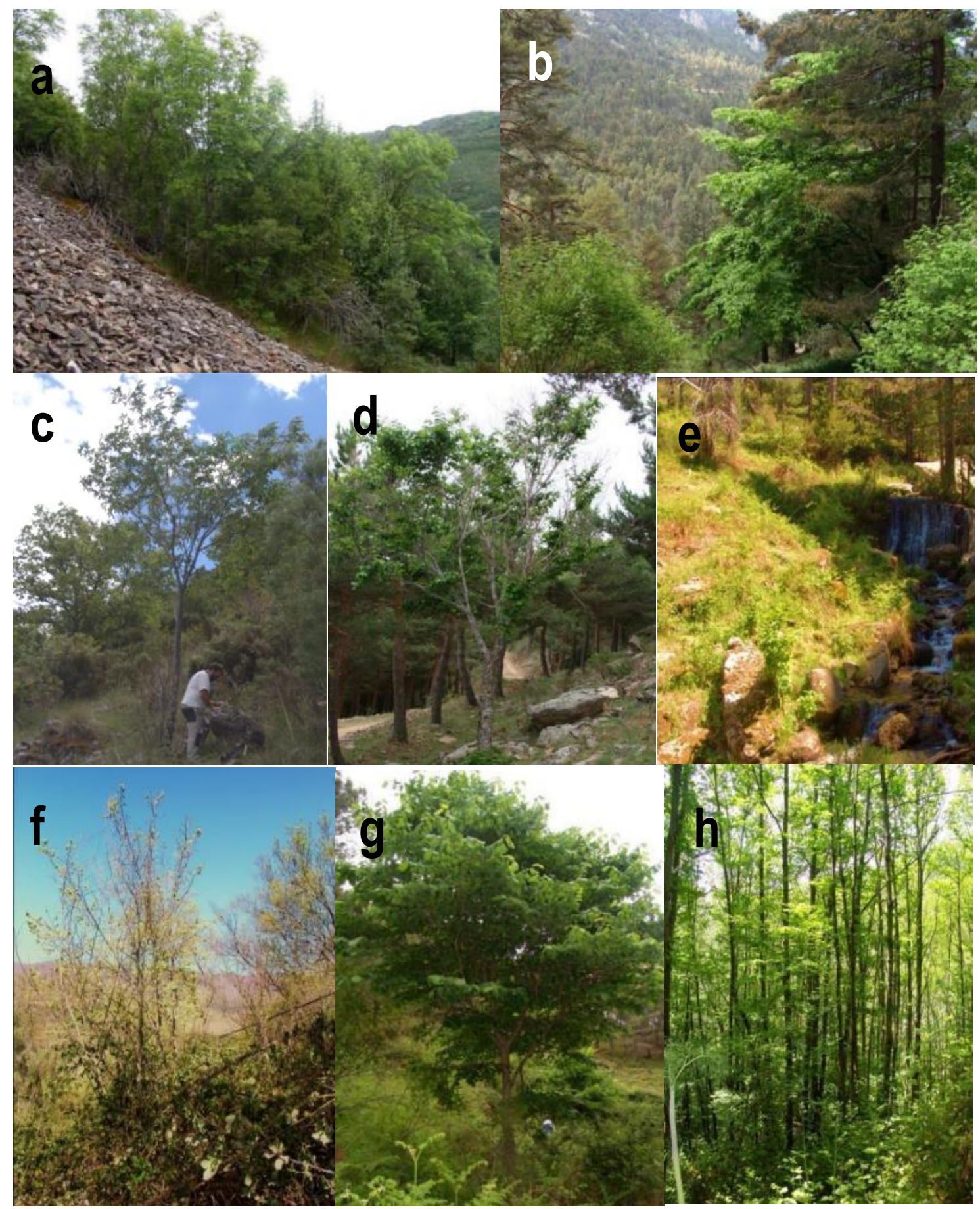

Figura 1.4. Imágenes de algunos individuos de olmo de montaña en poblaciones de Sistema Central: RZA (a), NAV (b), RAS (c), PAU (d), CER (e), ROZ (f), TIE (g) y STR (h). Ver Tabla 1.1 para los códigos de población. Fuente: Felipe Martínez García. 
Tabla 1.1. Localización de las poblaciones de U. glabra en el Sistema Central. Se indica el número de individuos censados o estimados (Nt), así como los valores medios del diámetro y la altura de las mismas.

\begin{tabular}{|c|c|c|c|c|c|c|c|c|c|c|}
\hline $\mathbf{N}^{\mathbf{O}}$ & Códige & Localidad ${ }^{1}$ & Provincia & Sector & Latitud & Longitud & Altitud $(\mathrm{m})^{2}$ & ${ }^{2}$ Diámetro $(\mathrm{cm})^{2}$ & Altura $(\mathrm{m})$ & $\mathrm{Nt}$ \\
\hline 1 & CNT & Cantalojas & Guadalajara & Ayllón & 41,24913 & $-3,23853$ & 1393 & 1,81 & 3,38 & 1 \\
\hline 2 & CNJ & Cantalojas (Arroyo de la Zarza) & Guadalajara & Ayllón & 41,20193 & $-3,34225$ & 1557 & 6,94 & 4,66 & 194 \\
\hline 3 & $\mathrm{BOC}$ & El Cardoso de la Sierra - Bocígano & Guadalajara & Ayllón & 41,13182 & $-3,41177$ & 1314 & 5,43 & 5,54 & 8 \\
\hline 4 & RZA & Riaza-Becerril b,c & Segovia & Ayllón & 41,26585 & $-3,36955$ & 1556 & 6,04 & 2,96 & 27 \\
\hline 5 & NAV & Navafría $b, c$ & Segovia & Guadarrama & 41,01932 & $-3,84353$ & 1512 & 11,25 & 4,42 & 14 \\
\hline 6 & MON & Montejo de la Sierra - El Cardoso de la Sierra $b, c$ & Madrid & Ayllón & 41,13687 & $-3,51304$ & 1463 & 11,51 & 6,89 & 9 \\
\hline 7 & RAS & Rascafría-Morcuera c & Madrid & Guadarrama & 40,86605 & $-3,83780$ & 1451 & 10,58 & 4,59 & 37 \\
\hline 8 & MZR & Manzanares el Real & Madrid & Guadarrama & 40,80514 & $-3,85625$ & 1598 & 21,25 & 2,63 & 4 \\
\hline 9 & PAU & El Paular (Pista de las Poyatas) c & Madrid & Guadarrama & 40,92471 & $-3,90225$ & 1670 & 10 & 7 & 1 \\
\hline 10 & CER & Cercedilla ${ }^{b, c}$ & Madrid & Guadarrama & 40,78363 & $-4,05626$ & 1260 & $<5$ & 1,57 & 6 \\
\hline 11 & $\mathrm{ROZ}$ & Rozas de Puerto Real $b, c$ & Madrid & Gredos & 40,31348 & $-4,49671$ & 801 & 9,95 & 4,68 & 46 \\
\hline 12 & TIE & El Tiemblo b,c & Ávila & Gredos & 40,35743 & $-4,51245$ & 1163 & 15,38 & 9,46 & 91 \\
\hline 13 & IRU & El Barraco (Valle de Iruelas) a, b, c & Ávila & Gredos & 40,38169 & $-4,56854$ & 1260 & 10,67 & 6,01 & $>6500$ \\
\hline 14 & CAS & Casillas $b, c$ & Ávila & Gredos & 40,32280 & $-4,57195$ & 955 & 9,01 & 4,58 & 78 \\
\hline 15 & PIE & Piedralaves $b, c$ & Ávila & Gredos & 40,33955 & $-4,70401$ & 1042 & 12,91 & 6,5 & 14 \\
\hline 16 & CVJ & Casavieja & Ávila & Gredos & 40,32676 & $-4,76926$ & 1170 & 10,28 & 5,16 & 60 \\
\hline 17 & SCV & Santa Cruz del Valle & Ávila & Gredos & 40,23495 & $-4,99575$ & 948 & 33,8 & 5 & 6 \\
\hline 18 & CVA & Cuevas del Valle-Río Pasaderas ${ }^{b, c}$ & Ávila & Gredos & 40,28133 & $-5,00840$ & 797 & 21,4 & 7,3 & 17 \\
\hline 19 & $\mathrm{CVH}$ & Cuevas del Valle-Río del Herradero & Ávila & Gredos & 40,27778 & $-5,01679$ & 797 & 16,22 & 7,5 & 17 \\
\hline 20 & ARL & El Arenal & Ávila & Gredos & 40,28312 & $-5,07689$ & 1014 & 27,67 & 7,5 & 5 \\
\hline 21 & MOM & Mombeltrán $\mathrm{b}, \mathrm{c}$ & Ávila & Gredos & 40,26935 & $-5,02413$ & 757 & 14,91 & 9,22 & 18 \\
\hline 22 & CAN & Candeleda $b, c$ & Ávila & Gredos & 40,17660 & $-5,24816$ & 654 & 43,25 & 11,95 & 11 \\
\hline 23 & VAL & Valverde de la Vera & Cáceres & Gredos & 40,11356 & $-5,482940$ & 414 & S.D. & S.D. & 2 \\
\hline 24 & ALD & Aldeanueva de la Vera ${ }^{c}$ & Cáceres & Gredos & 40,13357 & $-5,72310$ & 696 & 16,35 & 5,79 & 11 \\
\hline 25 & VIL & Villamiel b & Cáceres & Sierra de Gata & 40,18574 & $-6,77448$ & 680 & 9,29 & 6,79 & 22 \\
\hline 26 & STR & San Martín de Trevejo-Eljas $\mathrm{b}, \mathrm{c}$ & Cáceres & Sierra de Gata & 40,23256 & $-6,78812$ & 820 & 4,99 & 4,26 & $>3000$ \\
\hline 27 & BEN & Benfeita & Arganil (Portugal) & Serra da Estrela & 40,21813 & $-7,91848$ & 546 & 5,42 & 4,72 & 195 \\
\hline
\end{tabular}

${ }^{1}$ Poblaciones descritas en: a Maqueda, 2006; ' ${ }^{2}$ Rossignoli, 1999; c Arche, 2010. S.D: sin datos. 
El rango altitudinal en el que se localizan estas poblaciones varía de los apenas $400 \mathrm{~m}$ de VAL, hasta los casi 1700 m en PAU (ver Tabla 1.1). Además, cabe destacar que únicamente para las poblaciones de IRU y STR se ha censado y/o estimado un número elevado de individuos, mientras que en la gran mayoría no se alcanza la centena de efectivos (Arche 2010) (Tabla 1.1). Si atendemos a las regiones bioclimáticas definidas por Ruiz-Labourdette et al. (2011), las poblaciones españolas se localizan en siete de las 13 las regiones bioclimáticas descritas en el Sistema Central: oceánicomediterráneo cálido de piedemonte, oceánico-mediterráneo de baja montaña, mediterráneo interior cálido de piedemonte, sub-mediterráneo interior de media montaña, eurosiberiano interior de media altura, eurosiberiano interior templado de media montaña y eurosiberiano interior frío de media montaña.

Otra de las características principales es la elevada proporción de individuos jóvenes, tal y como se puede observar por la altura media y, especialmente, por el diámetro medio de los efectivos que componen cada población, con la única excepción de CAN (Tabla 1.1). De hecho, los trabajos previos indican que más del $75 \%$ de los individuos no superan los $15 \mathrm{~cm}$ de diámetro, siendo la clase más común los individuos de diámetro inferior a $4 \mathrm{~cm}$, ejemplares que en muchos casos son rebrotes (Rossignoli 1999; Arche 2010). El escaso número de individuos maduros tiene consecuencias reproductivas importantes. Así, en estas poblaciones se ha descrito una baja capacidad reproductiva, que puede estar relacionada con la elevada proporción de individuos sexualmente no maduros (Arche 2010). Uno de los problemas derivados del bajo número de poblaciones y el escaso número de individuos, junto con su aislamiento geográfico, es la fragmentación de las poblaciones (ver Figura 1.3).

\subsubsection{Estado sanitario}

El estado sanitario de estas poblaciones no es bueno, estando afectadas, en general, por diferentes plagas y patógenos. Por una parte, podemos destacar el crisomélido Xanthogaleruca luteola Müller (galeruca), que produce defoliación y minaduras, cuya presencia ha sido detectada en el $80 \%$ de los individuos del Sistema Central (Rossignoli 1999). Aunque este patógeno no causa mortandad, sí debilita y predispone a otras infecciones a los pies afectados, especialmente a los escolítidos (Rossignoli 1999; Génova \& Rossignoli 2001). Además, otras afecciones de preocupación menor para el olmo de montaña han sido detectados en estas poblaciones, como la presencia de agallas de Tetraneura ulmi y de oidio (p.e. Uncinula spp., Erysiphe spp., Sphaerotheca spp.), aunque esta última en menor medida (Rossignoli 1999).

El mayor problema sanitario para los olmos en general, y para el olmo de montaña del Sistema Central en particular, es sin lugar a dudas la grafiosis. La grafiosis es una afección en la que cuatro 
componentes diferentes interactúan entre sí: el olmo (Ulmus sp.), el hongo Ophiostoma ulmi (Buism.) Nannf. y más recientemente 0. novo-ulmi Brasier, el vector escolítido Scolytus sp. (principalmente Scolytus scolytus, S. kirchi y S. multistriatus; ver Figura 1.5; Pajares 1987) y el ambiente (Ipinza Carmona \& Gil 1987). Estos cuatro componentes interaccionan, de tal forma que el vector y el hongo causan la enfermedad en individuos susceptibles, y las condiciones ambientales locales y adversas al olmo producen la aceleración de la epidemia (Ipinza Carmona \& Gil 1987). Algunos de los signos más característicos de esta enfermedad son el desarrollo de galerías producidas por los escolítidos (ver Figura 1.5) y la posterior aparición de ramas secas y combadas en la copa (Figura 1.6).
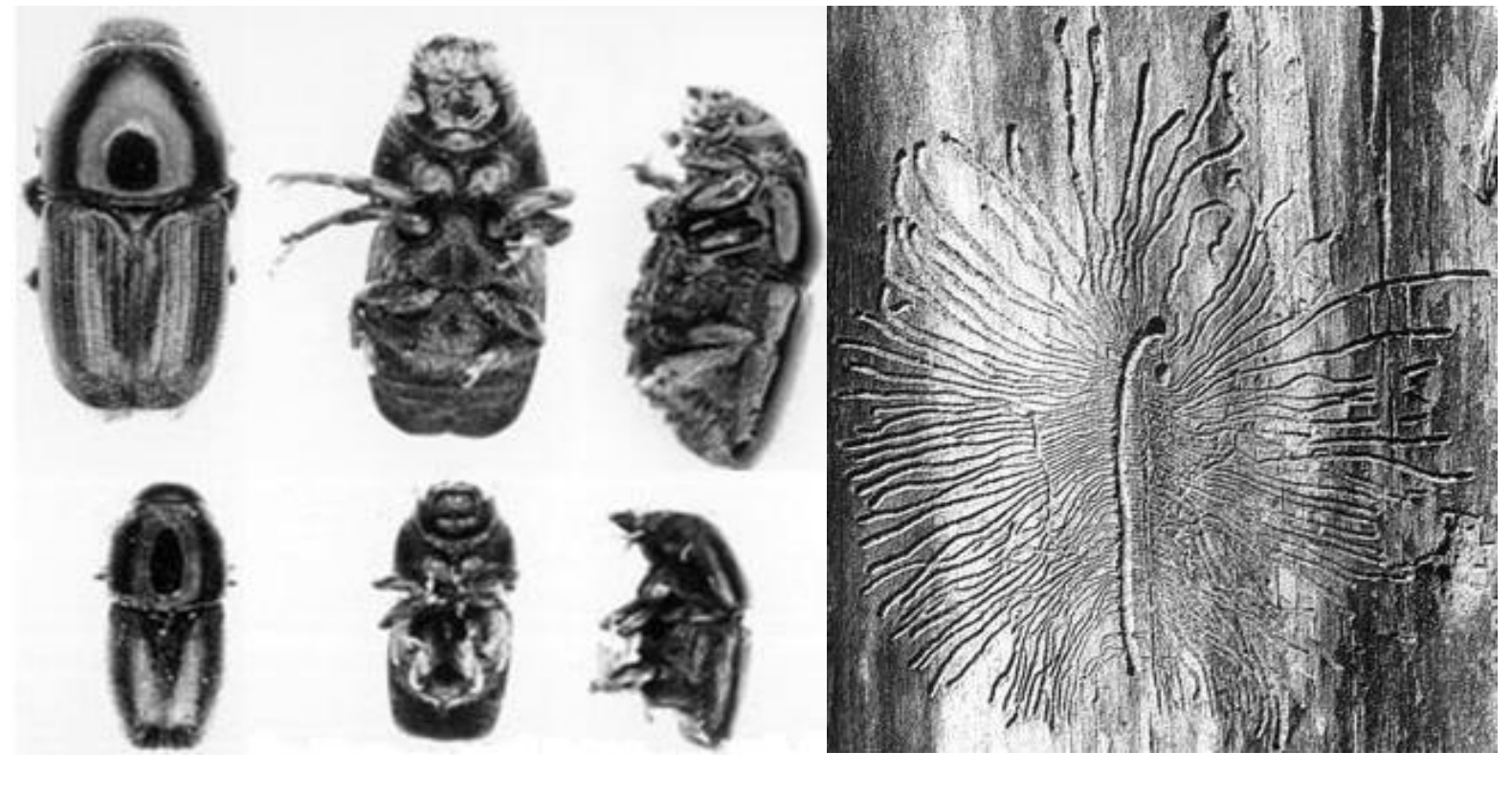

Figura 1.5. Scolytus scolytus (izquierda arriba), Scolytus multistriatus. (izquierda abajo) y galería característica de la grafiosis (derecha). Fuente: Cornell Plant Pathology Herbarium.
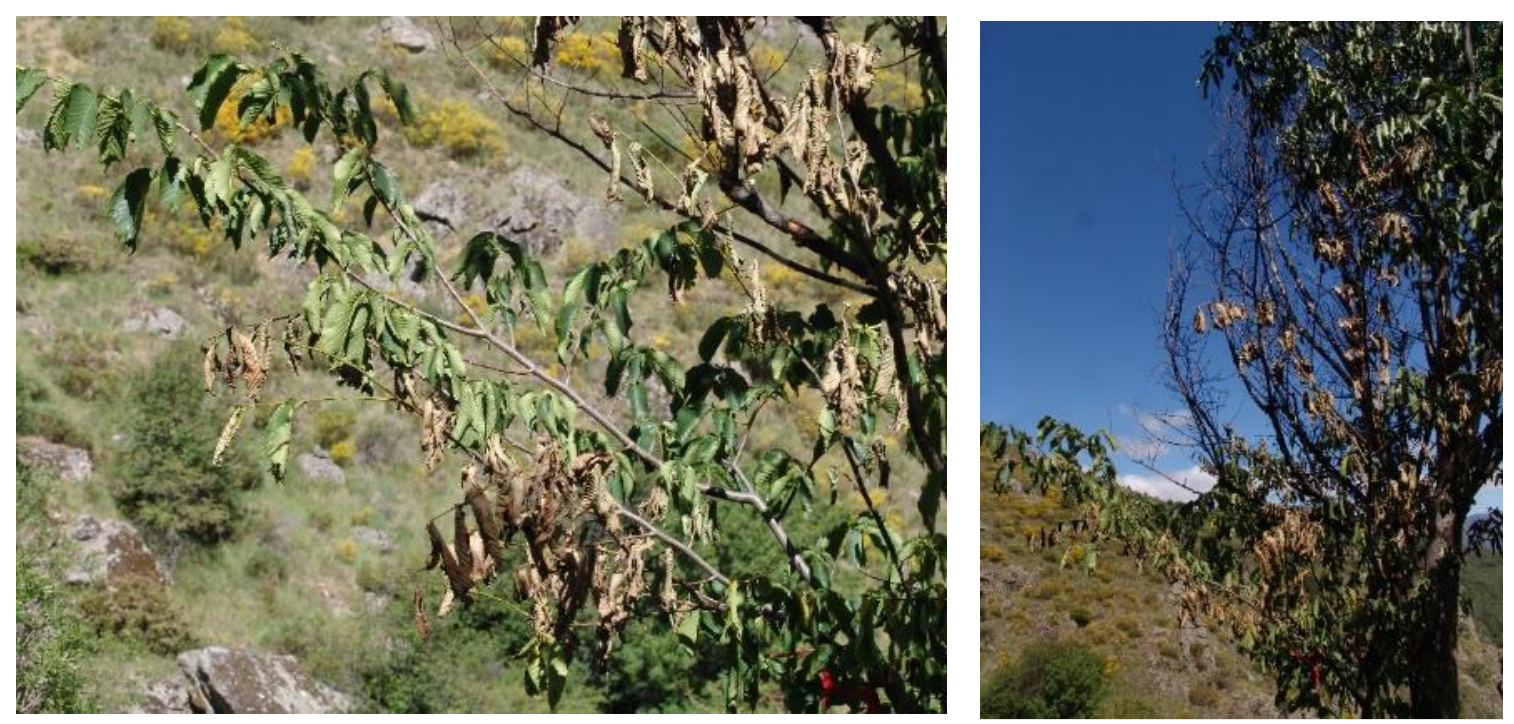

Figura 1.6. Primeros signos de afección por la grafiosis en individuos de la población de Rascafría-Morcuera. Ramillas secas (izquierda) y ramillas muertas y combadas (derecha). 
La primera noticia que se tiene de la presencia de la grafiosis en la península ibérica es a principios de los años 30 , que provocó la desaparición o reducción de numerosas olmedas. En los años 80 , el proceso se ve acelerado con la llegada de la cepa agresiva O. novo-ulmi Brasier, causando la muerte masiva de olmos (Solla et al. 2000). La afección de esta enfermedad en las poblaciones del Sistema Central parece haberse incrementado. Así, Rossignoli (1999) encontró signos de esta enfermedad en 7 de las 14 poblaciones que estudió; mientras que Arche (2010) detectó individuos afectados en las 16 poblaciones que analizó. Generalmente, el vector escolítido prefiere individuos adultos (Webber 2004), con diámetros en troncos y ramas mayores de 10 y $5 \mathrm{~cm}$, respectivamente (Pajares 1987). Este hecho puede ser la causa de la abundancia de individuos juveniles en muchas de las poblaciones del Sistema Central, al igual que ha sido reportado para otras poblaciones naturales de $U$. glabra en Dinamarca (Nielsen \& Kjær 2010b).

\subsection{Introgresión entre U. glabra y U. minor}

La existencia de hibridaciones e introgresiones entre las distintas especies del género Ulmus está bien documentada y ha sido descrita en numerosas ocasiones (Brunet et al. 2013; Zalapa et al. 2009; Zalapa et al. 2010; Cox et al. 2014; Richens \& Jeffers 1986). Esto es debido a la debilidad de las barreras reproductivas que existen entre la mayoría de ellas (Mittempergher \& La Porta 1991). En estos casos, la determinación puede ser compleja, siendo la morfología de sus hojas y frutos, junto con la corteza, los aspectos más útiles para la identificación (Ruiz de la Torre 2006).

Centrándonos en las especies de olmo ibéricas, frecuentemente se localizan individuos que presentan caracteres morfológicos intermedios entre U. glabra y U. minor, fruto de la hibridación entre ambas especies (Richens \& Jeffers 1986); tal es el caso de los individuos de U.x hollandica Miller. La mayor proximidad filogenética entre estas dos especies con respecto a U. laevis (Wiegrefe et al. 1994), puede explicar este fenómeno. Además, la introgresión entre el olmo de montaña y el olmo común puede verse favorecida por el hecho de que pueden presentar zonas de contacto, pudiendo llegar a coexistir, dado que U. minor llega a alcanzar los 1650 m (Navarro \& Castroviejo 1993b).

Otro de los factores que puede favorecer la introgresión entre especies próximas es la alteración del medio por parte del hombre, favoreciendo la aparición de nichos que pueden ser ocupados por los individuos híbridos (Ellstrand \& Schierenbeck 2000; Rhymer \& Simberloff 1996). Esta circunstancia, junto con el uso tradicional del olmo común en viticultura y su uso ornamental (Fuentes-Utrilla et al. 2004; Fuentes-Utrilla et al. 2014b), ha favorecido aún más la coexistencia de ambas especies. Además, 
las especies que son autoincompatibles, como U. glabra (Nielsen \& Kjær 2010b; Townsend 1975), pueden ser más sensibles a la hibridación con especies próximas (Ludwig et al. 2013).

Morfológicamente, los individuos híbridos de olmo común y olmo de montaña ( $U . \times$ hollandica) presentan las hojas como característica distintiva principal. Éstas se caracterizan por tener una forma elíptica u ovalado-elípticas, con un ápice acuminado o abovado, de dimensiones 9-12 cm × 4-7 cm, con 16 a 22 pares de nervios, siendo muy asimétricas en la base y presentan un lado de la lámina foliar convexo mientras que el lado contrario es cóncavo o recto (Scialabba et al. 1997). Debido a que los caracteres morfológicos son muy variables y pueden dar lugar a una incorrecta identificación (GoodallCopestake et al. 2005), en los últimos años se han empleado marcadores moleculares para una mejor diferenciación, los cuales han permitido detectar introgresión entre diferentes especies de olmo (Zalapa et al. 2009; Zalapa et al. 2010; Brunet et al. 2013; Bertolasi et al. 2015), incluyendo la hibridación entre U. glabra y U. minor (Cox et al. 2014).

En cuanto a la capacidad reproductiva, los híbridos suelen presentar problemas de fertilidad, tales como la producción de semillas vanas debido la ausencia de fertilización en los híbridos $F_{1}$ (Leliveld 1935). Este hecho ha sido sugerido como causa de la ausencia de individuos $F_{2}$ en trabajos previos de introgresión entre U. glabra y U. minor (Cox et al. 2014) y entre U. pumila L. (olmo siberiano) y U. minor (Brunet et al. 2013). Otra de las consecuencias derivadas de la introgresión con el olmo común es el incremento de la capacidad de rebrote, no solo de cepa, sino también de raíz (Cox et al. 2014); capacidad derivada del parental U. minor.

\section{2. Caracterización de la diversidad en el género Ulmus}

Son numerosos los trabajos del género Ulmus en los que se han empleado caracteres tanto morfológicos como bioquímicos y moleculares con objeto de obtener un mayor conocimiento de la diversidad a nivel específico o bien poblacional. También se ha empleado la caracterización ecogeográfica gracias a las posibilidades que ofrece el desarrollo de los Sistemas de Información Geográfica (SIG o GIS, de sus siglas en inglés).

Tradicionalmente, la caracterización en plantas se ha basado en el estudio de numerosos caracteres morfológicos. Éstos presentan una gran variación fenotípica en las poblaciones debido a que suelen estar influenciados por el ambiente (Cogolludo et al. 2000). Aunque se han empleado multitud de caracteres de la madera, la flor o las semillas (Zavada \& Kim 1996; Elowsky et al. 2013; López Almansa et al. 2003), los de mayor utilidad en la caracterización morfológica de los olmos, según Richens (1980) e Ipinza Carmona (1990), son los aportados por la hoja: longitud del peciolo, ancho, profundidad y longitud del diente primario; número total de dientes; asimetría basa; longitud y anchura 
máxima de la lámina foliar, etc. Algunos de ellos fueron los primeros en emplearse en el estudio y caracterización de las distintas especies de olmos, tanto a nivel interespecífico como a nivel intraespecífico (Jeffers \& Richens 1970; Petrokas \& Baliuckas 2012; Scialabba et al. 1997; Melville 1939; Richens 1955; Richens \& Jeffers 1978; Jeffers 1999). Dentro de las especies ibéricas, cabe destacar los trabajos de Richens \& Jeffers (1986), de Ipinza Carmona (1989) y Cogolludo et al. (2000), y dentro de U. glabra, el estudio de Myking \& Yakovlev (2006) en poblaciones noruegas. Aunque los caracteres morfológicos son útiles, están muy influidos por las características ambientales, tales como el estrés hídrico (Black-Samuelsson et al. 2003), el ataque de insectos (Møller 1995) o la grafiosis (Møller 1999). Por ello, los estudios más recientes combinan los caracteres morfológicos y moleculares, detectando discrepancias en la identificación de los individuos (Zalapa et al. 2009; Zalapa et al. 2010; Brunet et al. 2013; Bertolasi et al. 2015), fenómeno también reportado en U. glabra (Cox et al. 2014).

Por otra parte, diferentes tipos de metabolitos secundarios, tales como flavonoides, glicósidos, ácidos grasos y terpenoides, han sido empleados en estudios de quimiotaxonomía en plantas (Heimler et al. 1990). Así, en la década de los 70, el empleo de sesquiterpenos permitió diferenciar secciones dentro del Ulmus (Rowe et al. 1972). Así mismo, con objeto de inferir relaciones dentro de las ulmáceas también se han utilizado flavonoides (Sherman \& Giannasi 1988; Bate-Smith \& Richens 1973; Giannasi 1978). Los flavonoides también se han empleado en la diferenciación de híbridos entre diferentes especies (p.e., U. minor y U. pumila) (Heimler et al. 1993). En la península ibérica, se han analizado los triterpenos en las tres especies ibéricas (U. glabra, U. minor y $U$. laevis) junto con $U$. pumila y sus híbridos (Martín Benito et al. 2005).

El análisis de proteínas esenciales, isoenzimas, también han sido muy empleados en estudios de diversidad. Así, existen trabajos que han tenido como objeto el estudio la variabilidad en el género Ulmus empleando peroxidasas (Pearce \& Richens 1977), isoperoxidasas (Richens \& Pearce 1984) y numerosas aloenzimas (Machon et al. 1997). Igualmente, la utilización de diferentes sistemas isoenzimáticos en poblaciones francesas de olmo permitieron distinguir entre U. laevis, U. glabra, $U$. minor y los híbridos de estas dos últimas especies (Machon et al. 1995). También se han realizado estudios similares en poblaciones germanas de estas tres especies de olmo, permitiendo distinguir $U$. laevis de las otras dos especies europeas (Gehle \& Krabel 2002). Las aloenzimas también se han empleado en el estudio de la diversidad de poblaciones finlandesas de U. laevis, estudio que desveló un alto grado de diferenciación genética entre mismas (Vakkari et al. 2009). Por último, cabe destacar el único trabajo hasta la fecha con este tipo de marcadores realizado en las poblaciones de U. glabra del Sistema Central. En él, se estudiaron 14 poblaciones con 15 marcadores isoenzimáticos, revelando un alto polimorfismo (Bascuñana 2010). 


\subsection{Caracterización molecular}

En las últimas décadas se han desarrollado numerosos marcadores moleculares que permiten llevar a cabo un análisis directo del polimorfismo a nivel de la molécula de ADN. Los primeros marcadores de este tipo fueron los RFLPs (Restriciton Fragment Length Polymorphisms), que se basan en la digestión del ADN con una enzima de restricción y la posterior detección de los fragmentos mediante sondas marcadas (Botstein et al. 1980).

Posteriormente, la aparición de la reacción en cadena de la polimerasa o PCR (Polymerase Chain Reaction (Mullis et al. 1992), supuso un punto de inflexión en el desarrollo de nuevas técnicas de caracterización molecular. Este tipo de marcadores tienen ventajas sobre la caracterización morfológica y bioquímica, esencialmente, el que pueden detectar un mayor nivel de polimorfismo, con lo que su capacidad de discriminación es superior y, por ello, permiten obtener una información más precisa de la diversidad y las relaciones genéticas existentes en los organismos analizados. Los diferentes tipos de marcadores moleculares desarrollados suelen diferir en sus requerimientos técnicos, nivel de polimorfismo detectado, reproducibilidad y coste económico (Weising et al. 2005).

\subsubsection{Caracterización a nivel del ADN nuclear}

En general, según el nivel de información genética que aportan, los marcadores moleculares pueden ser considerados como dominantes o bien como codominantes; de manera que estos últimos son más informativos, ya que pueden diferenciar genotipos homocigóticos y heterocigóticos, mientras que los primeros sólo pueden analizarse como datos binarios de presencia/ausencia (Tanksley 1983).

Una de las primeras técnicas en desarrollarse fueron los RAPD (Random Amplified Polymorphic DNA) (Williams et al. 1990), marcadores de carácter dominante, que se basan en la amplificación de fragmentos de $A D N$ al azar mediante la utilización de un único cebador o primer decámero y de secuencia arbitraria. En el género Ulmus, esta técnica ha sido empleada para estudios de identificación y análisis genético en U. americana L. (Kamalay \& Carey 1995), así como para el análisis de las relaciones genéticas de U. plotii de Gran Bretaña, (Coleman et al. 2000), o para estimar la diversidad genética en genotipos seleccionados de U. villosa Brandis ex Gamble (Thakur et al. 2014). Los RAPDs también se han utilizado para la identificación de genes de resistencia al hongo ascomiceto responsable del ennegrecimiento de la hoja en U. parviflora Jacq. (Benet et al. 1995). Entre los estudios a nivel poblacional, destacan los trabajos en los que se ha analizado la diversidad y estructura genética en poblaciones de U. pumila (Wesche et al. 2011; Li et al. 2008). 
Los microsatélites o SSR (Simple Requence Repeat) son secuencias de ADN de motivos cortos (1-6 pares de bases), repetidos en tándem, distribuidos ampliamente a lo largo de todo el genoma y con altos niveles de variabilidad en cuanto al número de repeticiones por locus (Wang et al. 1994). Una de las técnicas basadas en dichas secuencias son los ISSR (Inter-Simple Sequence Repeat), que se caracterizan por ser marcadores dominantes y emplear un único primer de tipo microsatélite en la reacción de PCR (Zietkiewicz et al. 1994). Este tipo de marcador ha sido muy utilizado para estudios de variabilidad genética en poblaciones de diferentes especies de olmo, como p.e. U. davidiana var. japonica (Rehder) Nakai en Corea del Sur (Kim et al. 2011), U. glabra, U. minor y U. laevis en la República Checa (Čurn et al. 2014) o U. elongata L. K. Fu \& C. S. Ding en China (Ai et al. 2015).

Otro tipo de marcadores dominantes desarrollados más recientemente son los SRAP (SequenceRelated Amplified Polymorphism), que permiten la amplificación de regiones génicas al azar, incluyendo exones, intrones e incluso promotores, mediante el empleo de un par de primers semiarbitrarios (Li \& Quiros 2001). Este tipo de marcador ha sido utilizado recientemente en el estudio de poblaciones naturales de U. lamellosa C. Wang \& S.L. Chang en China (Liu et al. 2016).

Por último, otros marcadores de carácter dominante y con una elevada capacidad para la detección de polimorfismos son los AFLP (Amplified Fragment Length Polymorphism), que combinan la utilización de enzimas de restricción junto con la amplificación mediante PCR (Vos et al. 1995). Esta técnica ha demostrado ser muy útil en la detección de introgresión entre $U$. americana L. y otras especies de olmo en EE.UU. (Pooler \& Townsend 2005), o entre U. glabra y U. minor en Bélgica (Cox et al. 2012; Cox et al. 2014). Asimismo, los AFLP han sido empleados en un amplio estudio de olmos europeos, permitiendo detectar la amplia dispersión de un linaje de $U$. minor de origen italiano mediada por el hombre (Gil et al. 2004).

Dentro de los marcadores de carácter codominante, la abundancia de las regiones repetitivas de tipo microsatélite ha permitido desarrollar marcadores moleculares basados en la PCR altamente polimórficos y reproducibles, que son utilizados con mucha frecuencia en estudios de caracterización molecular (Agarwal et al. 2008). Esta metodología, denominada comúnmente como "microsatélites 0 SSR", permite detectar el polimorfismo existente en la variación de la longitud de la repetición para un determinado locus de un microsatélite; siendo el principal inconveniente de la técnica que se requiere información previa sobre las secuencias que flanquean al locus microsatélite concreto para poder diseñar los dos cebadores específicos que se van a utilizar en la amplificación mediante PCR.

En el genoma nuclear, se han generado numerosos marcadores de tipo microsatélite en diferentes especies del género Ulmus (Whiteley et al. 2003; Collada et al. 2004; Zalapa et al. 2008b; Geng et al. 
2016a; Geng et al. 2016b). Los primeros marcadores de este tipo se desarrollaron en especies europeas de olmo; de manera que, Whiteley et al. (2003) diseñaron siete parejas de cebadores para amplificar sendas regiones SSR en $U$. laevis, habiéndose comprobado su transferibilidad a otras especies de Ulmus, como U. americana, U. minor, U. pumila y U. glabra. En el olmo de montaña, tres de esos loci SSR (Ulm6, Ulm12 y Ulm19) generaron patrones de amplificación poco claros, dos (UIm3 y Ulm9) resultaron ser monomórficos y, únicamente, Ulm2 y Ulm8 fueron polimórficos. Posteriormente, Collada et al. (2004) desarrollaron 12 pares de cebadores para amplificar microsatélites; uno de los loci fue monomórfico, seis generaron patrones de múltiples bandas y sólo cinco loci fueron polimórficos en U. minor (Ulmi1-11, Ulmi1-21, Ulmi1-98, Ulmi1-165 y Ulmi2-16). Dichos microsatélites fueron probados en las otras dos especies de olmo nativas de Europa, de manera que en U. laevis fueron transferibles tres de ellos, siendo polimórficos únicamente dos (Ulmi1-98 y Ulmi2-16), y en U. glabra también amplificaron tres loci (Ulmi1-21, Ulmi1-98 y Ulmi1-165), siendo Ulmi1-165 especialmente polimórfico.

También se han desarrollados microsatélites en especies de olmo nativas de otras regiones. Así, en $U$. rubra Muhl. se describieron 11 microsatélites que generaron patrones de alelos claros y consistentes tanto en U. rubra como en U. pumila (Zalapa et al. 2008b). Desafortunadamente, la transferibilidad de estos microsatélites a las especies europeas no fue testada, por lo que desconocemos su utilidad en U. glabra. La distancia filogenética existente entre las distintas especies de Ulmus (Wiegrefe et al. 1994), es la causa más probable del diferente nivel de transferibilidad de los microsatélites. En este sentido, teniendo en cuenta que U. glabra está más próximo filogenéticamente hablando a U. rubra que p.e. a U. laevis (Wiegrefe et al. 1994), cabe la posibilidad de que algunos de los loci desarrollados en U. rubra sean transferibles a U. glabra.

Por último, mencionar que, más recientemente, se han desarrollado numerosos loci SSR en especies de olmo asiáticas, 12 en U. chenmoui W. C. Cheng (Geng et al. 2016a) y 11 en U. gaussenii W. C. Cheng (Geng et al. 2016b), para los cuales aún no se ha comprobado su posible transferibilidad a otras especies de olmos.

Los microsatélites desarrollados en U. laevis (Whiteley et al. 2003), U. minor (Collada et al. 2004) y U. rubra (Zalapa et al. 2008b), han sido frecuentemente utilizados en estudios de hibridación e introgresión entre especies de olmo próximas, especialmente a aquellas que implican a U. pumila, debido a la supuesta resistencia de esta especie a la grafiosis. En este sentido, algunos de estos microsatélites se han utilizado para detectar posible introgresión de U. pumila como especie invasiva en poblaciones naturales de U. rubra de EE.UU. (Zalapa et al. 2009); o para estudiar el impacto en la diversidad genética y en la estructura poblacional que la hibridación entre $U$. pumila y U. rubra genera en las poblaciones nativas de U. rubra (Zalapa et al. 2010). También existen trabajos en los que se ha 
analizado el nivel de introgresión entre U. pumila y diferentes poblaciones italianas de U. minor (Brunet et al. 2013).

Los microsatélites también han resultado ser muy útiles para estudios de diversidad genética, flujo génico y estructura genética espacial en poblaciones de distintas especies de olmos. En este sentido, se ha analizado cómo afecta al flujo génico la localización de $U$. glabra en campo abierto o bien en un entorno forestal (Nielsen \& Kjær 2010b). Igualmente, el estudio de poblaciones escandinavas de $U$. laevis utilizando microsatélites ha permitido detectar en las mismas la existencia de una baja diversidad genética y una fuerte estructura genética espacial (Nielsen \& Kjær 2010a). En U. minor, recientemente, se ha publicado un estudio sobre diversidad genética en poblaciones naturales de Croacia (Zebec et al. 2016), habiéndose encontrando que la grafiosis parece haber afectado gravemente a la diversidad poblacional. Asimismo, un estudio de las poblaciones de U. minor en las Islas Baleares ha permitido vislumbrar el origen nativo del olmo común en estas islas (Fuentes-Utrilla et al. 2014a). Por último, señalar que los SSR también se han empleado para estudiar la diversidad existente en accesiones de U. pumila resistentes a la grafiosis (Zalapa et al. 2008a).

Centrándonos en las poblaciones ibéricas de olmo, los microsatélites han sido utilizados en estudios sobre la diversidad genética en poblaciones de $U$. laevis, en los que se ha analizado cómo ha afectado la antropización a la estructura genética espacial de dos poblaciones ibéricas de dicha especie de olmo (Venturas et al. 2013b); o bien, en un estudio con numerosas poblaciones europeas, en el que los resultados obtenidos han respaldado la idea de que $U$. laevis es nativo de la península ibérica (Fuentes-Utrilla et al. 2014b). Por otra parte, mencionar que Gil et al. (2001) han desarrollado el estudio más amplio llevado a cabo hasta la fecha sobre poblaciones europeas de U. minor y U. glabra. En él, se incluían diversas poblaciones ibéricas, aunque tan solo cinco de U. glabra y, de ellas, una sola localizada en el Sistema Central. Dicho trabajo permitió descubrir la amplia distribución de individuos clónicos de U. minor de origen italiano (clon Atinio), especialmente en Bretaña.

\subsubsection{Caracterización a nivel del ADN de cloroplastos}

Además del genoma nuclear, en el citoplasma existen orgánulos, como mitocondrias y cloroplastos, que presentan sus propias moléculas de ADN, las cuales también han sido utilizadas ampliamente en estudios de sistemática, evolución y filogeografía (Hewitt 1999; Palmer et al. 1988).

En el caso del ADN presente en los cloroplastos (ADNcp), se sabe que, en angiospermas, en general, presenta herencia materna (Conde et al. 1979; Dumolin-Lapègue et al. 1995). Asimismo, su tasa de cambio evolutivo es menor que la del ADN nuclear (Wolfe et al. 1987), por lo que el ADNcp suele tener una estructura muy conservada entre la mayoría de las plantas. Dicha estructura se 
caracteriza por presentar dos regiones claramente diferenciadas, la denominada Large Single-Copy Region (LSC) o región larga de copia única, y la Small Single-Copy Region (SSC) o región pequeña de copia única, que se encuentran separadas por dos regiones repetidas e invertidas entre sí, denominadas Inverted Repeat $I R_{A}$ e $I_{B}$ (Shinozaki et al. 1986).

Con respecto al género Ulmus, hay que mencionar que, recientemente, se ha publicado la secuencia completa del genoma de cloroplastos de cuatro especies asiáticas de dicho género (Zuo et al. 2017). En la Figura 1.7 se muestra la estructura del ADNcp de una de esas especies, U. macrocarpa Hance, la más próxima de las cuatro filogenéticamente hablando a U. glabra (Wiegrefe et al. 1994).

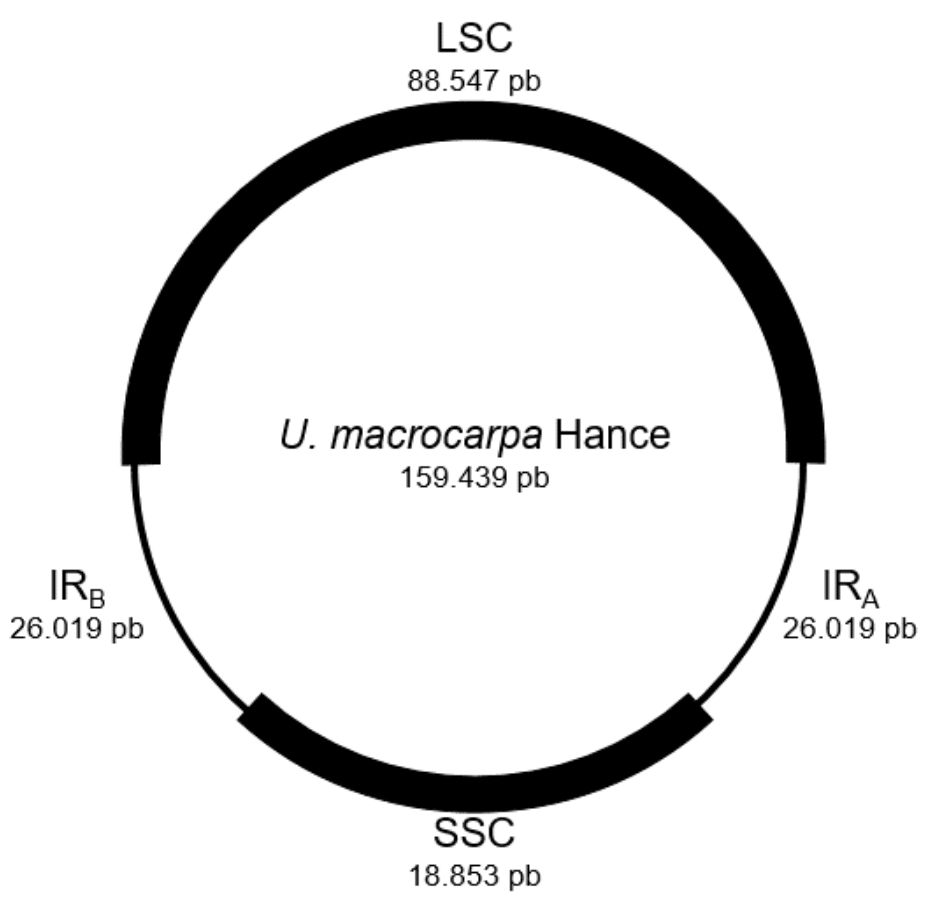

Figura 1.7. Estructura del ADN de cloroplastos en U. macrocarpa, especie filogenéticamente más próxima a $U$. glabra cuyo genoma de cloroplastos ha sido secuenciado. Fuente: elaboración propia a partir de Zuo et al. (2017).

De las distintas regiones que constituyen el ADNcp, la que presenta mayor potencial para llevar a cabo estudios a niveles taxonómicos por debajo de especie, es la región larga de copia única (LSC), al contener zonas no codificantes relativamente menos conservadas que el resto del ADNcp (Clegg et al. 1991). Por este motivo, sobre esta región LSC se han diseñado diferentes marcadores moleculares, de los que, a continuación, hablaremos sobre sus características y su utilización en estudios de diversidad en poblaciones naturales.

Una de las técnicas más utilizadas en este sentido es la que es conocida como PCR-RFLP, 0 también como CAPS (Cleaved Amplified Polymorphic Sequence). Dicha técnica se basa en la amplificación mediante PCR de un fragmento específico, para después detectar los polimorfismos 
mediante la digestión del mismo con enzimas de restricción (Dumolin-Lapègue et al. 1997). Se trata de una metodología que permite evaluar grandes regiones del genoma de manera sencilla, reproducible, en un corto periodo de tiempo y a un bajo coste económico. En general, el tipo de polimorfismos que pueden detectarse con esta técnica son pequeñas inserciones o deleciones en el fragmento amplificado, aunque también se pueden detectar mutaciones puntuales en el sitio de reconocimiento de la enzima de restricción (Demesure et al. 1996; King \& Ferris 1998).

Teniendo en cuenta el elevado grado de conservación que presentan las secuencias codificantes del ADNcp, han sido numerosos los pares de cebadores que se han diseñado sobre la región LSC en la década de los 90 (Taberlet et al. 1991; Dumolin-Lapègue et al. 1997; Heinze 1998; Demesure et al. 1995), los cuales suelen presentar un cierto carácter universal y, por ello, han podido ser utilizados en un amplio rango de taxones. En la actualidad, y gracias al diseño de 20 nuevos pares de cebadores sobre la región LSC (Grivet et al. 2001), es posible llevar a cabo la amplificación completa de la región LSC mediante 38 fragmentos solapantes (ver Figura 1.8). Algunos de esos 38 pares de cebadores en combinación con diferentes enzimas de restricción, se han empleado mediante la técnica PCR-RFLP en numerosos trabajos filogeográficos a nivel de poblaciones (McCauley 1995; Demesure et al. 1996; Segraves et al. 1999; Grivet et al. 2001; Mohanty et al. 2002; Mohanty et al. 2003; Fineschi et al. 2000; El Mousadik \& Petit 1996).

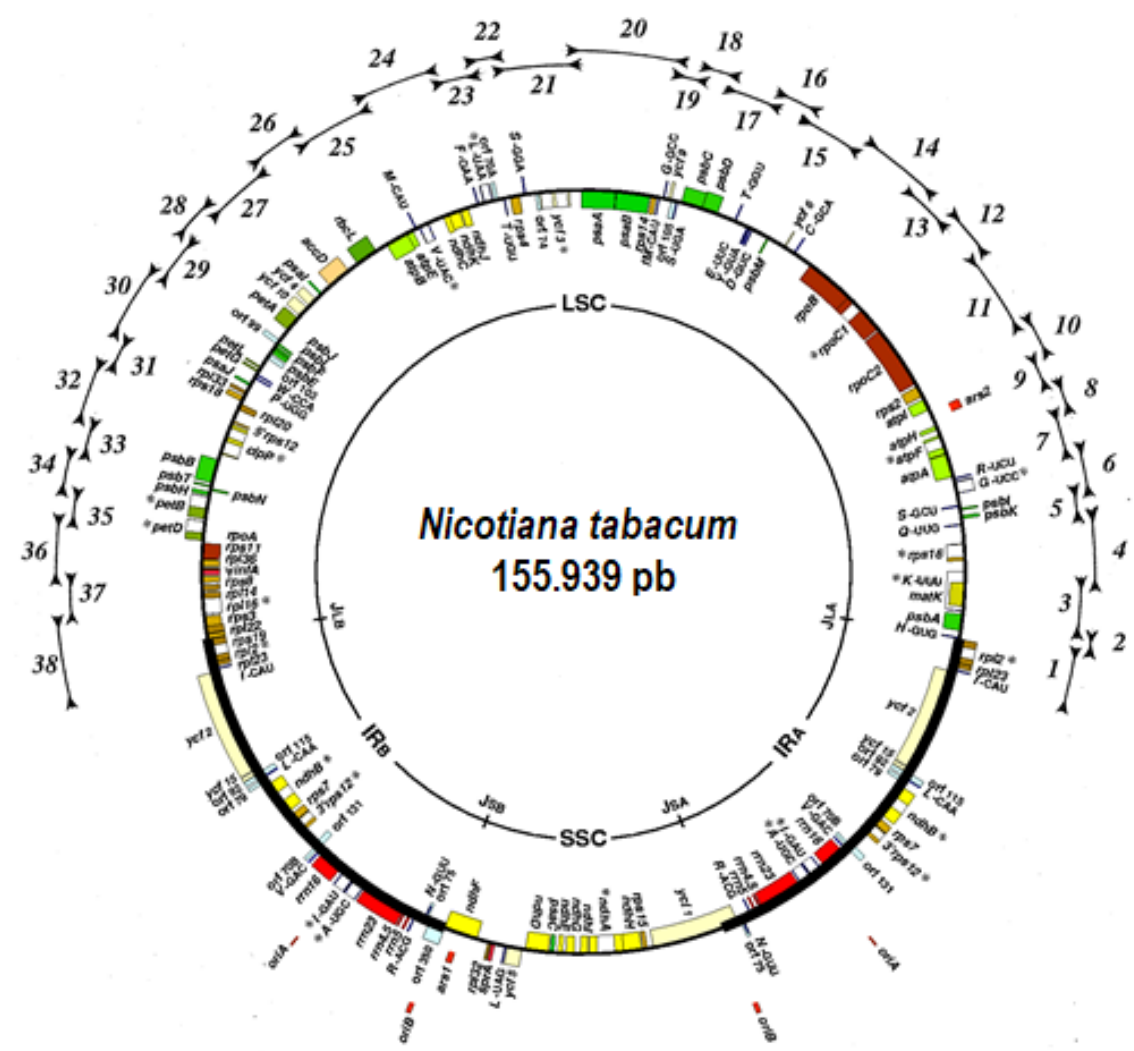

Figura 1.8. Localización de las 38 parejas de cebadores sobre la región larga de copia única (LSC) del ADN de cloroplastos de tabaco. Fuente: modificado de Grivet et al. (2001). 
Algunos trabajos en los que se ha utilizado la técnica de PCR-RFLP se han centrado en la diferenciación de especies; como p.e. Brunner et al. (2001), que analizaron la variabilidad existente en el intrón trnL del ADNcp para diferenciar material vegetativo de raíz procedente de distintas especies arbóreas, incluido U. glabra. En otros trabajos más recientes, es más habitual analizar un elevado número de zonas de la región LSC; tal es el caso del estudio realizado por Fukatsu et al. (2012), donde se analizó la filogenia del género Zelkova Spach. (Ulmaceae) y la estructura filogeográfica de Z. serrata (Thunb.) Makino en Japón, empleando nueve (3-K $\mathrm{K}_{1} \mathrm{~K}_{2}$, 13-rpo $\mathrm{C}_{1}-\mathrm{rpoB}, 15-\mathrm{CD}$, 23-TF, 25-VL, 29-petAfpsbEr, 31-rps18-clpp y 34- $\mathrm{B}_{2} \mathrm{~B}_{3}$; ver Figura 1.8) de los 38 pares de cebadores descritos previamente por Grivet et al. (2001).

En el género Ulmus, existen varios estudios en los que se analiza la diversidad poblacional en diferentes fragmentos de la región LSC del ADNcp mediante PCR-RFLP. En este sentido, cinco de esas regiones (2-HK, 3-K $\mathrm{K}_{2}, 16-\mathrm{DT}, 19-\mathrm{Sf}_{\mathrm{M}}$ y 25-VL; ver Figura 1.8) demostraron ser muy eficaces para estudiar la variabilidad genética del ADNcp en poblaciones europeas de U. minor y U. glabra (Gil et al. 2004). En dicho estudio se detectaron hasta 38 haplotipos o clorotipos diferentes, agrupados en cuatro linajes principales: el linaje A, localizado en Grecia; el linaje B, ubicado en el norte de la península itálica; el linaje D, dominante en el oeste de Europa; y mención especial para el linaje $C$, originario de Italia, mayoritario en Reino Unido y abundante en Iberia. Los resultados obtenidos en estos trabajos han permitido dilucidar la expansión y domesticación sufrida por U. minor gracias al Imperio Romano (López de Heredia et al. 2005; Fuentes-Utrilla 2008).

Cuatro de las regiones anteriores $\left(\mathrm{K}_{1} \mathrm{~K}_{2}, \mathrm{VL}, \mathrm{Sf}_{\mathrm{M}} \mathrm{y} \mathrm{DT}\right)$ también fueron analizadas para estudiar la diversidad del ADNcp en poblaciones noruegas de olmo de montaña (Myking \& Yakovlev 2006). En este caso, sólo las regiones $\mathrm{Sf}_{\mathrm{M}}$ y DT resultaron ser polimórficas, de manera que permitieron detectar dos haplotipos, uno mayoritario y aparentemente procedente del oeste de Europa (western haplotype), y un segundo clorotipo presente únicamente en dos de las 16 poblaciones estudiadas, procedente del sur de Europa (southern haplotype).

En las poblaciones europeas de U. laevis, la diversidad detectada mediante PCR-RFLP ha sido aún menor, únicamente las regiones $\mathrm{Sf}_{\mathrm{M}}$ y $\mathrm{HK}$ resultaron ser polimórficas y permitieron diferenciar tres clorotipos (Whiteley 2004). En un estudio similar sobre poblaciones ibéricas de dicha especie, donde también se analizó la región DT junto con $\mathrm{Sf}_{\mathrm{M}}$ y $\mathrm{HK}$, únicamente el polimorfismo detectado en el fragmento $\mathrm{Sf}_{\mathrm{M}}$ permitió diferenciar dos de los tres clorotipos descritos para las poblaciones europeas (Fuentes-Utrilla 2008; Fuentes-Utrilla et al. 2014b). Dicho fragmento fue secuenciado, diseñándose cebadores específicos que permitieron diferenciar los dos clorotipos presentes en la península ibérica mediante una única reacción de amplificación por PCR. Posteriormente, estos marcadores también han 
sido empleados en el estudio de los posibles cambios inducidos por el hombre en la estructura genética de dos poblaciones de U. laevis del centro de la península (Venturas et al. 2013b).

Además de la técnica de PCR-RFLP, también es muy habitual estudiar la diversidad en el ADN de cloroplastos mediante el análisis del polimorfismo en regiones de microsatélites presentes en el genoma de cloroplastos (SSRcp). Los SSRcp son relativamente abundantes en el ADNcp de angiospermas y gimnospermas, aunque de forma menos común que en el ADN nuclear (Powell et al. 1995). De manera que han sido descritas numerosas parejas de cebadores para amplificar secuencias con microsatélites, la mayoría de ellas con un carácter universal, al poder ser utilizadas en un elevado número de especies tanto de angiospermas como de gimnospermas. Los primeros diez pares de cebadores para amplificar microsatélites en el genoma de cloroplastos fueron descritos por Weising \& Gardner (1999) (ccmp1 a ccmp10); habiéndose comprobado en numerosos trabajos su universalidad, ya que han funcionado perfectamente para un gran número de especies vegetales (Magri et al. 2007; Castro et al. 2013; Rendell \& Ennos 2003). Por otra parte, Chung \& Staub (2003) diseñaron 23 pares de cebadores para amplificar microsatélites en el ADNcp (ccSSR-1 a ccSSR-23), tomando como referencia la secuencia del genoma de cloroplastos de tabaco. La utilidad de dichas parejas de cebadores para el análisis genético fue probada en diferentes especies de solanáceas, cucurbitáceas, fabáceas, apiáceas, crucíferas, liliáceas y gramíneas, en general, con excelentes resultados.

Son numerosos los trabajos en los que se han empleado microsatélites de cloroplastos en estudios genéticos de diferentes especies forestales, especialmente, dentro del grupo de las coníferas, como p.e. en distintas especies del género Pinus (Powell et al. 1995; Echt et al. 1998; Morgante et al. 1998) o del género Abies Mill. (Vendramin et al. 1999), revelando, en algunos casos, la existencia de una estructura filogeográfica de los haplotipos asociada a fenómenos de migración en periodos postglaciales.

En especies de angiospermas arbóreas, algunos de estos marcadores moleculares han sido empleados con éxito en diferentes tipos de estudios, p.e. para analizar la estructura filogeográfica en poblaciones de Nothofagus obliqua (Mirb.) Blume en Sudamérica (Azpilicueta et al. 2009), para conocer el origen y dispersión de cultivares de avellanos (Boccacci \& Botta 2009) o para la detección de refugios glaciales en diferentes especies de la familia Fagaceae (Fineschi et al. 2005; Magri et al. 2007; Papageorgiou et al. 2008). En la mayoría de los trabajos, son de uso habitual los microsatélites de la serie ccmp1 a 10 descritos por Weising \& Gardner (1999), mientras que los marcadores ccSSR-1 a 23 descritos por Chung \& Staub (2003) han sido muy poco utilizados. Aun así, podemos mencionar que estos últimos han sido empleados en distintos estudios filogenéticos llevados a cabo en Avena L. (Li et 
al. 2009), en Hordeum L. y Triticum L. (Martín et al. 2008), en diversos géneros de cucurbitáceas (Chung et al. 2003; Chung et al. 2006; Decker-Walters et al. 2004) o en Primula L. (Wang et al. 2008).

Finalmente, indicar que son muy escasos los trabajos en los que los SSRcp han sido utlizados para el análisis genético en ulmáceas. Uno de estos estudios, combina diferentes marcadores moleculares, entre ellos los microsatélites ccmp2, ccmp3, ccmp4, ccmp5, ccmp7 y ccmp10 de (Weising \& Gardner 1999), con objeto de analizar el grado de diferenciación genética existente entre las poblaciones dos especies relícticas, Zelkova abelicea (Lam.) Boiss. y Z. sicula Di Pasq. (Fineschi et al. 2002), no habiéndose detectado polimorfismo intraespecífico con ninguno de los seis SSRcp, y sólo dos de ellos permitieron diferenciar ambas especies. En el género Ulmus, sólo se ha encontrado una cita en la que los microsatélites de cloroplastos han sido utilizados para analizar una muestra de individuos de U. laevis, en la que no se llegó a detectar diversidad haplotípica (Fuentes-Utrilla 2008).

\subsection{Caracterización ecogeográfica}

La geografía de especies o ecogeografía ha sido definida como "el estudio del escenario adaptativo de un individuo, población o especie, mediante el análisis de los factores bióticos y abióticos que condicionan su supervivencia" (Parra-Quijano et al. 2012). Para ello, utiliza combinación de datos climáticos, ecológicos y geográficos (Peeters et al. 1990). En últimos años, el estudio de la información ambiental ha ganado importancia, debido a que nos muestra los factores ambientales más importantes en la adaptación de una especie (Parra-Quijano et al. 2012). Por ello, la ecogeografía es una herramienta esencial en los programas de conservación, especialmente útil en la selección de áreas que requieren protección (Maxted 1999).

A diferencia de la caracterización molecular, que tiene un elevado coste financiero y logístico. La caracterización ambiental puede suponer una herramienta de gran utilidad, simple, de bajo coste y transferible (Parra-Quijano et al. 2012). La utilidad de estos estudios en conservación va implícita en la definición de estudios ecogeográficos propuesta por Maxted et al. 1995: "Un estudio ecogeográfico es un proceso de recolección y síntesis de información ecológica, geográfica y taxonómica. Los resultados son predictivos y pueden usarse para ayudar en la formulación de prioridades de conservación y recolección".

La modelización de la distribución potencial de una especie ha ganado interés en las últimas décadas, especialmente en regiones altamente modificadas por el hombre. Estos modelos son de gran ayuda a la hora de establecer estrategias de conservación y manejo forestal (Garzón et al. 2006), y valorar los efectos del hombre sobre los patrones de diversidad biológica (Guisan \& Thuiller 2005). Para 
la elaboración de estos modelos, es necesario recopilar la información ecogeográfica existente en la literatura, en los herbarios y bancos de germoplasma, así como en las bases de datos online. Con un número bajo de datos ecogeográficos, la modelización permite la extrapolación al área potencial de la especie, creando modelos predictivos de presencia actual o de áreas con características ecológicas adecuadas, aunque no esté presente el taxón en la actualidad (Guisan \& Thuiller 2005; Guisan \& Zimmermann 2000; Araújo \& Guisan 2006).

Los primeros trabajos sobre modelización de la distribución de las especies fueron los de Johnston (1924) e Hintikka (1963), ambos citados en Pearson \& Dawson (2003), los cuales toman como base variables climáticas. Posteriormente, con el desarrollo de la informática, aparecen los primeros modelos computacionales (Nix et al. 1977). A partir de la década de los 80 , el número de trabajos se incrementa y la modelización se convierte en una herramienta indispensable en estudios de evolución, ecología, biogeografía y, por supuesto, conservación (Guisan \& Thuiller 2005). El gran desarrollo de estas técnicas se debe principalmente a la aparición de los programas de Sistemas de Información Geográfica (SIG). Los SIG han integrado herramientas para el procesado de datos y el análisis estadístico, que facilita el estudio de los datos georreferenciados y la expresión de los resultados en mapas fácilmente interpretables (Parra-Quijano et al. 2012).

Desde entonces, son numerosos los trabajos de modelización sobre la vegetación potencial en Europa (Hickler et al. 2012; Koca et al. 2006), o sobre especies arbóreas en concreto (Huntley et al. 1995; Sykes et al. 1996; Svenning et al. 2008). En la península ibérica, destacan los trabajos sobre el área potencial de varias especies incluyendo algunos taxones anemógamos como Pinus sylvestris y Quercus spp.; realizados tanto a pasado, como proyecciones presentes y a futuro (Garzón et al. 2008; Garzón et al. 2006; Garzón et al. 2007).

También son muy conocidos los estudios de modelización en el macizo lbérico de RuizLabourdette y colaboradores. En el primero de ellos, modeliza el Sistema Ibérico teniendo en cuenta los escenarios de cambio climático (Ruiz-Labourdette et al. 2011). En un segundo trabajo, hizo proyecciones con los modelos de cambio climático en la distribución potencial de 15 especies arbóreas, dentro de las cuales destacan especies como F. sylvatica y llex aquifolium L. (Ruiz-Labourdette et al. 2013). Estos dos estudios son los únicos ejemplos de modelización que existen específicamente sobre el Sistema Central. En ambos casos, los autores predicen una reducción del hábitat de las especies eurosiberianas debido al cambio climático, especialmente en las zonas de piedemonte y de media altitud debido al incremento del estrés hídrico previsto. Por el contrario, parece que los taxones más mediterráneos presentarán un área de distribución mayor (Ruiz-Labourdette et al. 2011; RuizLabourdette et al. 2013). 
Por último, cabe destacar los tres únicos trabajos hasta la fecha de modelización en especies de olmo. Uno de ellos, sobre U. lamellosa, especie china, estudiada mediante marcadores moleculares y técnicas de modelización (Liu et al. 2017). En el trabajo fue posible relacionar los resultados filogeográficos con los datos paleobotánicos, sugiriendo la persistencia de U. lamellosa en múltiples microrrefugios dentro de su área de distribución actual.

Más destacable aún es el trabajo de Svenning et al. (2008), donde elaboran modelos de distribución para las tres especies de olmo nativas de Europa, entre otras 19 especies arbóreas. Tanto $U$. laevis como $U$. glabra, las especies más eurosiberianas, muestran preferencia por el centro y norte de Europa, especialmente el olmo de montaña. U. minor, por el contrario, parece preferir zonas no tan norteñas, localizándose principalmente en el centro europeo, pero también en el sur (ver Figura 1.9 a). En este trabajo, también se muestran modelos de área potencial para las tres especies de olmo durante el máximo glacial (ver Figura 1.9 b). En ellos, se muestra que su área potencial de distribución se localizaba a latitudes sustancialmente más bajas que las actuales. Así pues, la península ibérica queda señalada como uno de los principales refugios para el género Ulmus, especialmente para el olmo de montaña y para el olmo común. En el caso concreto de $U$. glabra, las principales zonas de refugio peninsulares se sitúan en las zonas costeromediterráneas y en el tercio noroeste de la península (ver Figura 1.9).

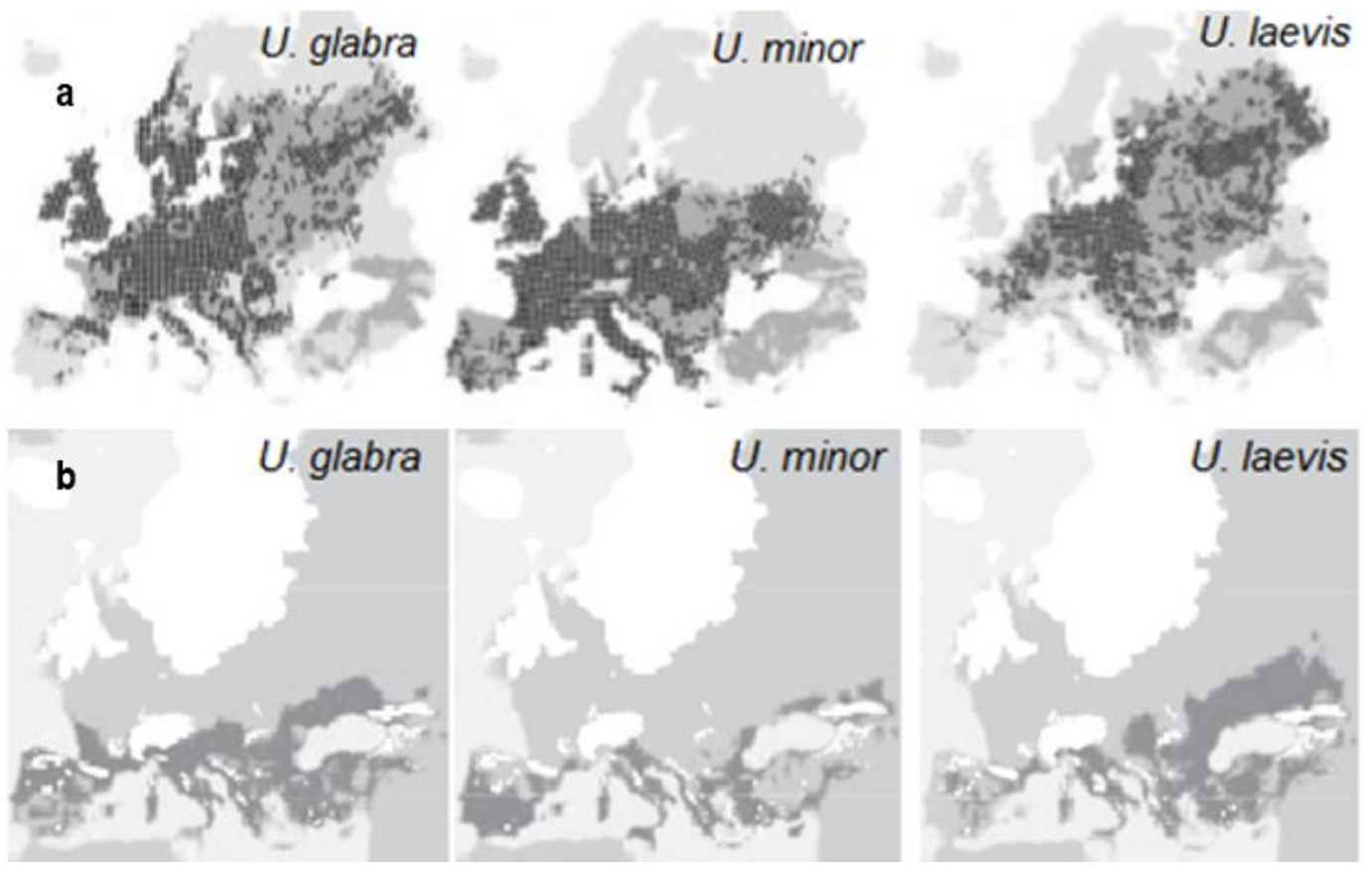

Figura 1.9. Modelos de distribución potencial actual (a) y durante el último máximo glacial (b), para U. glabra, $U$. laevis y U. minor. Fuente: modificado de Svenning et al. (2008). 
El tercero y último de los trabajos es un estudio muy extenso que realiza proyecciones hacia el futuro, y aborda la vulnerabilidad y la capacidad de adaptación de numerosos taxones en la península ibérica ante los escenarios previstos de cambio climático (Felicísimo et al. 2011). Entre sus conclusiones, se prevé una reducción importante en el área potencial de algunas especies en los diferentes escenarios de cambio climático. Para el caso concreto del olmo de montaña, se prevé una mayor vulnerabilidad en el futuro, categorizándose como C, tercera categoría de mayor preocupación. En este escenario se encuentran las poblaciones de olmo de montaña del Sistema Central, que se ven especialmente perjudicadas al reducirse drásticamente su área potencial y, por tanto, es previsible un incremento de la fragmentación de sus poblaciones.

\section{3. Conservación y gestión}

En las últimas décadas ha crecido notablemente la preocupación por la conservación del medio ambiente en general y de las especies en particular. En este último campo destaca la labor que viene realizando hace años la Comisión de Supervivencia de las Especies (CSE), un numeroso grupo de expertos de la Unión Internacional para la Conservación de la Naturaleza (UICN). Este grupo ha elaborado una propuesta de Categorías de Amenaza y Criterios para catalogar a las especies en función del grado de amenaza a su supervivencia (UICN 2012a; UICN 2012b). Con estos criterios, los diferentes comités regionales y nacionales han confeccionado las conocidas Listas Rojas de especies Amenazadas (http://www.iucnredlist.org/). Esta idea ha tenido gran aceptación entre la comunidad científica internacional, por lo que ha sido usada en diferentes países de todo el mundo. La repetición periódica de estos trabajos a lo largo del tiempo ha permitido, además, tener una visión de la tendencia del estado de conservación/amenaza de las especies. A escala internacional los datos indican que en la mayoría de los grupos biológicos evaluados la tendencia es negativa, ya que se viene registrando sistemáticamente un aumento del número de especies catalogadas en las categorías de amenaza: CR, Críticamente Amenazadas; EN, En Peligro y VU, Vulnerable (UICN 2016).

En España contamos con dos Listas Rojas de Flora Vascular amenazada publicadas en los años 2000 (VV. AA. 2000) y 2008 (Moreno 2008), actualizada en el año 2010 (Moreno 2011). El balance entre ambas obras es también negativo, ya que ha aumentado el número de especies incluidas en las categorías de amenaza CR, EN y VU.

Las Listas Rojas son documentos científicos muy útiles, entre otras cosas, para la definición de prioridades de conservación y para la elaboración de planes de gestión. 


\subsection{Situación legal y de amenaza de UImus glabra en el Sistema Central}

La situación de amenaza y protección de la especie es compleja, como consecuencia de la distribución política y administrativa del territorio del Sistema Central. En Portugal no cuentan con Lista Roja nacional que nos pueda dar datos sobre el estado de amenaza de la especie, y tampoco se encuentra protegida.

En el conjunto de España, la especie no está amenazada, ya que no figura en ninguna de las Listas Rojas de Flora Vascular publicadas hasta la actualidad (VV. AA. 2000; Moreno 2008; Moreno 2011).

Desde el punto de vista legal, tampoco se encuentra protegida a nivel estatal en el Listado de Especies Silvestres en Régimen de Protección Especial y del Catálogo Español de Especies Amenazadas (LESPE) (VV. AA. 2011). A nivel autonómico, de las cuatro comunidades en las que se reparte el Sistema Central, U. glabra está protegido sólo en dos de ellas. No está ni en el catálogo de Castilla y León (VV. AA. 2007a) ni en el de Extremadura (VV. AA. 2001). En la comunidad de CastillaLa Mancha está catalogada en la categoría IV "Especies de Interés Especial" (VV. AA. 1998a), y en el catálogo de especies protegidas de la Comunidad de Madrid, en la segunda categoría de protección: "Sensible a la Alteración de su Hábitat". Para estas especies, la administración competente en Medio Ambiente está obligada a elaborar y aprobar Planes de Conservación del Hábitat (V. AA. 1992), pero hasta el momento, el correspondiente a U. glabra todavía no se ha realizado.

\subsection{Conservación de especies y de poblaciones}

Tradicionalmente, el objetivo de la conservación se ha dirigido a proteger espacios naturales y, más recientemente, a las especies. Los criterios utilizados para la identificación de los espacios a proteger han sido, en muchos o la mayoría de los casos, paisajísticos.

El otro gran objetivo de la conservación ha sido las especies en su conjunto. Pero sabemos que muchas especies tienen áreas de distribución que no son homogéneas y que la distribución de sus efectivos tampoco lo es (ya sea por causas naturales o antrópicas), sino que se distribuyen en núcleos total o parcialmente aislados (poblaciones). Éstas a su vez pueden tener diferentes comportamientos en función de su situación, demografía, amenazas, etc. En definitiva, muchas especies se componen de diferentes poblaciones sometidas a diferentes procesos, lo cual ha generado un interesante debate en el campo de la conservación.

Por ejemplo, las Listas Rojas elaboradas a escala nacional evalúan el estado de amenaza de una especie en el conjunto del territorio. Esto en el caso de España, con territorios diferentes desde el punto 
de vista ecológico, identificados como Regiones ecológicas o biogeográficas, y de especies como el olmo de montaña, que cuenta con poblaciones en más de una de ellas, la evaluación del conjunto de la especie puede enmascarar la situación de amenaza de una parte importante de la misma. Efectivamente, al evaluar de manera conjunta una especie, con poblaciones que se encuentran en buena situación y otras presentan problemas para su supervivencia, no suelen detectarse los problemas de conservación que afectan a estas últimas. En consecuencia, el taxón no se catalogaría en alguna categoría de amenaza.

A esto hay que sumar que hasta hace unos años las poblaciones periféricas no se tenían en cuenta o no se valoraban lo suficiente, muy probablemente debido a que hasta ahora se pensaba que los mayores valores de diversidad se encontraban en las poblaciones del centro de distribución. Además, siempre se ha considerado que las poblaciones periféricas tienen una alta probabilidad de desaparecer al encontrarse aisladas, con bajo número de efectivos y soportando condiciones ecológicas adversas (Hampe \& Petit 2005; Vucetich \& Waite 2003). Actualmente, se ha demostrado en muchos casos que la diversidad en las poblaciones periféricas no es menor que en las del centro de su área de distribución y que en la mayoría de los casos el declive de las poblaciones periféricas es consecuencia de las actividades humanas (Channell \& Lomolino 2000b; Lesica \& Allendorf 1995; Vucetich \& Waite 2003; Channell \& Lomolino 2000a). Así pues, el estudio de la dinámica poblacional y la variabilidad genética de las poblaciones relícticas se está revelando como un elemento clave para conocer el comportamiento de las especies en su conjunto (Channell \& Lomolino 2000a; Hampe \& Petit 2005).

Lo dicho anteriormente implica que la investigación y conservación de las poblaciones periféricas, como es el caso de las de U. glabra del Sistema Central, es prioritaria para la conservación a largo plazo de la diversidad genética, la historia filogenética y de su potencial evolutivo (Hampe \& Petit 2005; Lesica \& Allendorf 1995), sobre todo teniendo en cuenta los escenarios previstos de cambio climático (IPCC 2007; IPCC 2013).

Por tanto, para diseñar estrategias de conservación eficaces de las especies, es imprescindible conocer la distribución de sus poblaciones periféricas, su situación demográfica, su estructura genética y el grado de amenaza que enfrentan. Estos datos deben ser parte fundamental de los criterios que se utilicen para establecer las medidas de conservación in situ y ex situ, es decir, los planes de gestión que aseguren la persistencia de las especies y por extensión de la biodiversidad. 


\subsection{Conservación in situ}

La conservación in situ de la diversidad biológica es llevada a cabo en las zonas donde ésta ocurre de forma natural, con objeto de mantener la diversidad de los organismos vivos, sus hábitats y las interrelaciones entre los organismos y su ambiente (Spellerberg 1992). Se trata de una conservación dinámica, dado que la evolución de las especies ocurre en el ambiente en que se han desarrollado, manteniéndose la continuidad de los procesos de coevolución (p.e. planta-herbívoro y planta-patógeno) (Martín Martínez 2001).

Con relación a la especie objeto de estudio, algunas iniciativas de conservación in situ en España se han centrado en la protección de especies próximas a U. glabra. Tal es el caso de la declaración de Árbol Singular a la formación olmeda "Los Baselisos" en el Parque Municipal Las Veguillas, en Extremadura (VV. AA. 2004); que cuenta con cerca de 300 individuos de U. minor de gran desarrollo. Otro ejemplo es la declaración de microrreserva a la olmeda de "Fuente La Reina" en la Comunidad Valenciana (VV. AA. 1998c). La Comunidad Valenciana fue pionera en la creación de la figura de Microrreserva para proteger espacios pequeños de importancia para la flora, integrando una serie de medidas básicas para la protección (VV. AA. 1994).

Otras de las medidas que se han llevado a cabo en Ulmus, incluyendo U. glabra, son las translocaciones (Ministerio de Agricultura, Alimentación y Medio Ambiente 2015). En especies forestales, se emplean las llamadas "regiones de procedencia de las semillas" para la selección del material. Para una especie o subespecie determinadas, dichas regiones consisten en "la zona o el grupo de zonas sujetas a condiciones ecológicas suficientemente uniformes en las que se encuentran fuentes semilleras 0 rodales que presentan características fenotípicas 0 genéticas semejantes, teniendo en cuenta límites de altitud, cuando proceda" (VV. AA. 2003). Aunque tienen en cuenta criterios genéticos y ecológicos, no se trata de divisiones de unidades genéticas de la especie. Las regiones de procedencia son especialmente útiles en la elección de los materiales para reforestación, ya que esta medida se ha de basar en numerosos criterios, entre los que destacan los ecológicos y los genéticos (Alía Miranda et al. 2009). La Resolución de 28 de julio de 2009 de la Dirección General de Recursos Agrícolas y Ganaderos, establece las regiones de procedencia tanto para U. glabra como para U. minor (ver Figura 1.10). En el caso de Portugal, no cuenta con regiones de procedencia definidas para especies de olmo. 

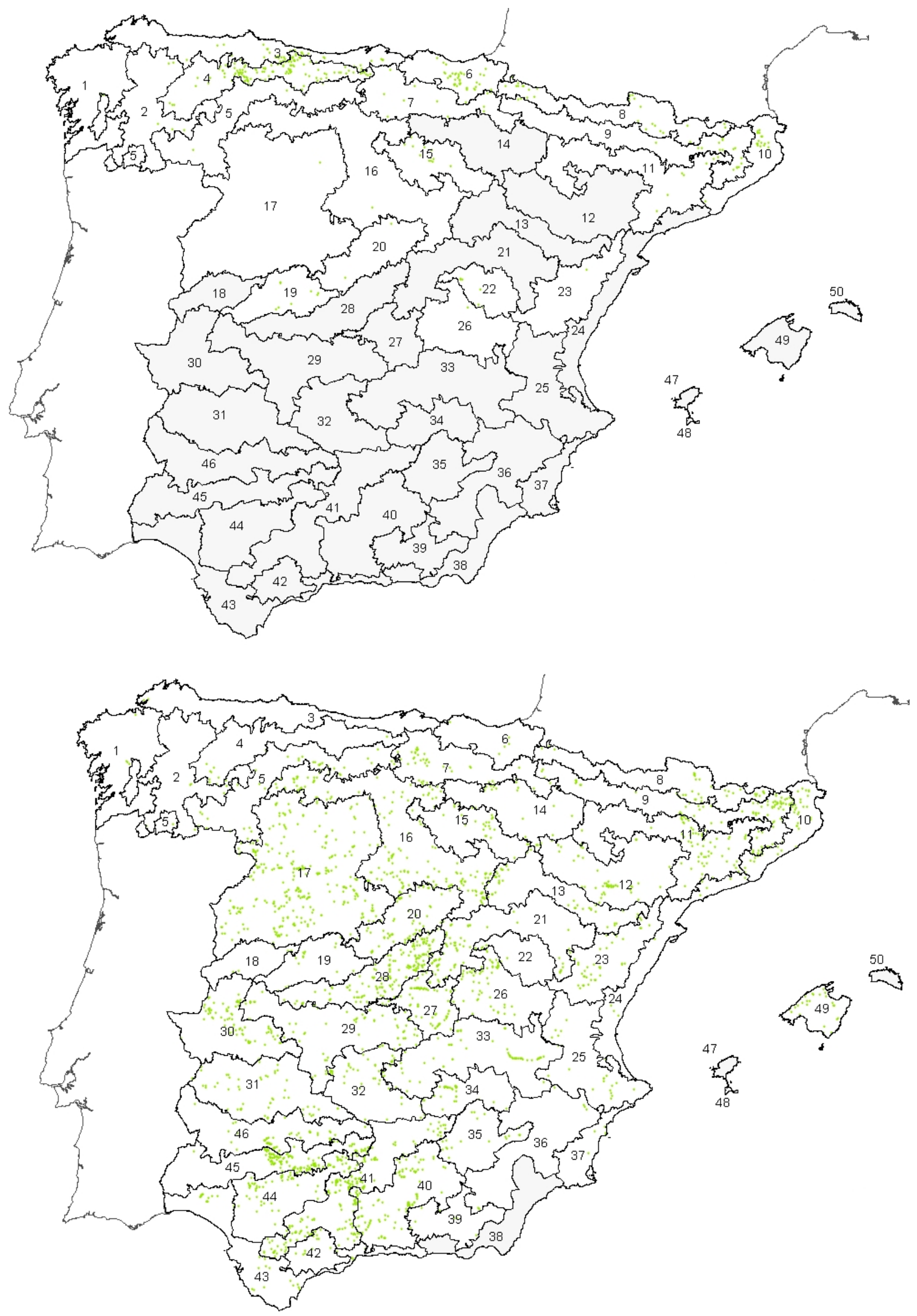

Figura 1.10. Regiones de procedencia de U. glabra (arriba) y de U. minor (abajo). Aparecen sombreadas las regiones que no aplican para la especie correspondiente. Fuente: Alía Miranda et al. (2009). 


\subsection{Conservación ex situ}

La conservación ex situ es la conservación de genes o genotipos de plantas fuera de su ambiente natural, para su uso futuro; lo cual forma parte de las actividades de gestión de los recursos fitogenéticos (Engle 1992). A pesar de que la conservación de especies a través de la gestión de las poblaciones silvestres y sus hábitats naturales (conservación in situ) es mucho más eficaz, las técnicas ex situ son complementarias y esenciales para la conservación. Es por ello por lo que la conservación ex situ ha sido incluida en el Convenio sobre Diversidad Biológica y en la Estrategia Global para la Conservación Vegetal (Sarasan et al. 2006).

Dentro de las diferentes metodologías de conservación ex situ (p.e. colecciones de campo, bancos de germoplasma, crioconservación, etc.), en especies de olmo se han empleado fundamentalmente dos: la conservación de semillas en banco de germoplasma y la colección en campo; aunque también se han desarrollado protocolos para la crioconservación en especies de olmo europeas incluyendo $U$. glabra (Chmielarz 2010; Harvengt et al. 2004). El tipo de semilla que presentan los olmos en general, y U. glabra en particular, es ortodoxa (Royal Botanic Gardens 2002), por lo que fácilmente se pueden establecer colecciones a largo plazo.

Por último, señalar que en diferentes especies de olmo se han desarrollado protocolos para la micropropagación (Mu et al. 2016; Shukla et al. 2012; Anagnostakis 1977; Conde et al. 2004; Corredoira et al. 2002), dentro de las cuales se encuentra U. glabra (Biroščíková et al. 2004). Las técnicas de micropropagación en olmos son esenciales en la lucha contra la grafiosis; por ejemplo, para U. minor, esta metodología ha permitido la obtención de clones resistentes a la grafiosis (Martín et al. 2015). Dichos clones se están empleando en reintroducciones en numerosas poblaciones españolas, convirtiéndose en una valiosa herramienta para la preservación de la especie (Ministerio de Agricultura, Alimentación y Medio Ambiente 2015). 


\section{OBJETIVOS}

El objetivo principal de la presente tesis doctoral es el estudio del olmo de montaña (UImus glabra Hudson) en el Sistema Central ibérico, desde el punto de vista de la caracterización molecular y ambiental de sus poblaciones, con el fin de proponer planes adecuados para su gestión y conservación.

Para la consecución de este objetivo general, se han planteado los siguientes objetivos parciales:

1. Analizar la diversidad y estructura genética, tanto a nivel intrapoblacional como interpoblacional, mediante el empleo de marcadores moleculares en el ADN nuclear y en el genoma de cloroplastos.

2. Identificar posibles eventos demográficos o procesos de introgresión que pudieran influir en la diversidad y estructura genética de las poblaciones.

3. Conocer las principales variables ambientales que determinan el hábitat de U. glabra, tanto en la península ibérica como en el Sistema Central, que permitirán elaborar un modelo predictivo de distribución de la especie.

4. Evaluar el estado de amenaza de la especie a escala regional, utilizando los criterios UICN.

5. Elaboración de medidas de gestión y conservación para estas poblaciones, que ayuden a la persistencia de la especie en el Sistema Central. 


\section{MATERIAL Y MÉTODOS}

\section{1. Material vegetal}

Para llevar a cabo la caracterización molecular, se colectó material foliar de 427 individuos procedentes de 22 de las 27 poblaciones de Ulmus glabra localizadas en el Sistema Central (ver Tabla 1.1 y Tabla 3.1). Únicamente, en cinco núcleos poblacionales no fue posible la recolección de material vegetal (MZR, SCV, CVH, ARL y VAL; ver Tabla 1.1), debido a que fueron localizados y visitados posteriormente a la realización de los análisis moleculares. Para cada una de las 22 poblaciones estudiadas, se recolectó material foliar de una muestra de individuos representativa. De este modo, en general, se muestrearon entre 20 y 60 individuos por población, salvo en las poblaciones con un bajo número de efectivos, en las que se procuró recolectar material de todos ellos (ver Tabla 3.1). En los casos en los que la población contaba con un elevado número de individuos, se trató de llevar a cabo un muestreo espaciado para disminuir el riesgo de muestrear individuos procedentes de rebrote. De esta manera, como puede verse en la Tabla 3.1, el número de individuos muestreados por población varió desde un único individuo (CNT y PAU) hasta los 57 de IRU.

Tabla 3.1. Número de individuos muestreados $(\mathrm{Nm})$ y censados o estimados (Nt; entre paréntesis) en cada en cada una de las 22 poblaciones de U. glabra del Sistema Central analizadas (ver Tabla 1.1 para los códigos de población).

\begin{tabular}{lll|lll|lll}
\hline $\mathbf{N}^{0}$ & Código & $\mathbf{N m}(\mathbf{N t})$ & $\mathbf{N}^{0}$ & Código & $\mathbf{N m}(\mathbf{N t})$ & $\mathbf{N}^{0}$ & Código & $\mathbf{N m}(\mathbf{N t})$ \\
\hline 1 & CNT & $1(1)$ & 9 & CER & $6(6)$ & 16 & CVA & $11(17)$ \\
2 & CNJ & $38(194)$ & 10 & ROZ & $46(46)$ & 17 & MOM & $10(18)$ \\
3 & BOC & $4(8)$ & 11 & TIE & $42(91)$ & 18 & CAN & $8(11)$ \\
4 & RZA & $22(27)$ & 12 & IRU & $57(>6500)$ & 19 & ALD & $10(11)$ \\
5 & NAV & $14(14)$ & 13 & CAS & $21(78)$ & 20 & VIL & $15(22)$ \\
6 & MON & $7(9)$ & 14 & PIE & $7(14)$ & 21 & STR & $29(>3000)$ \\
7 & RAS & $33(37)$ & 15 & CVJ & $20(60)$ & 22 & BEN & $25(195)$ \\
8 & PAU & $1(1)$ & & & & & & \\
\hline
\end{tabular}

Por otra parte, con objeto de comparar con U. minor, como especie más próxima filogenéticamente hablando a $U$. glabra, y detectar posible introgresión entre ambas especies, también se recolectó material foliar de 15 individuos de U. minor procedentes de tres localidades ubicadas a lo largo del Sistema Central, lo suficientemente separadas entre sí como para que pudieran constituir una parte representativa de la variabilidad de la especie (ver Tabla 3.2). 
Tabla 3.2. Localización y número de individuos muestreados $(\mathrm{Nm})$ de $U$. minor en cada una de las tres localidades ubicadas en el Sistema Central.

\begin{tabular}{llllllrl}
\hline Código Localidad & Provincia & Sector & Latitud & Longitud & Altitud (m) & Nm \\
\hline PAUm & El Paular & Madrid & Guadarrama & 40,88794 & $-3,88643$ & 1164 & 5 \\
VILm & Villamiel & Cáceres & Sierra de Gata & 40,16955 & $-6,79228$ & 573 & 5 \\
ESBm & Escalos de Baixo & Castelo Branco & Serra da Estrela & 39,87995 & $-7,38771$ & 374 & 5 \\
& & (Portugal) & & & & & \\
\hline
\end{tabular}

El material foliar colectado para los 427 individuos de U. glabra y los 15 de U. minor se conservó a $-80^{\circ} \mathrm{C}$ hasta la posterior extracción de ADN.

\section{2. Extracción y cuantificación de ADN}

Del material foliar colectado en cada uno de los 442 individuos muestreados (427 de U. glabra y 15 de U. minor) se tomaron aproximadamente $100 \mathrm{mg}$ para llevar a cabo la extracción de ADN genómico total mediante el kit comercial “NucleoSpin® Plant II" (MACHEREY-NAGEL GmbH \& Co. KG, Alemania; http://www.mn-net.com), siguiendo el protocolo facilitado por la misma casa comercial. Tras realizar las correspondientes extracciones, el ADN se resuspendió en un volumen de $100 \mu$ le tampón PE suministrado por el kit (Tris-HCl $5 \mathrm{mM}, \mathrm{pH} 8,5$ ) y, a continuación, se almacenó a $-20{ }^{\circ} \mathrm{C}$ hasta su posterior cuantificación.

La cuantificación del ADN se llevó a cabo mediante electroforesis en geles de agarosa al 1,2\% (p/v), en tampón TBE 1X (Tris-ácido bórico 90 mM y EDTA 2 mM, pH 8,0) y posterior tinción en una solución de bromuro de etidio $(0,5 \mu \mathrm{g} / \mathrm{ml})$. Las imágenes de los geles se tomaron con una cámara digital (Kodak DC 290), y la concentración del ADN se determinó mediante comparación de la intensidad de las bandas obtenidas con la de bandas de concentraciones conocidas (50, 100, 200 y $400 \mathrm{ng} / \mu \mathrm{l}$ ) procedentes de ADN del fago lambda. Por último, se prepararon diluciones de trabajo para cada muestra, en agua bidestilada estéril y a una concentración aproximada de $10 \mathrm{ng} / \mathrm{\mu l}$. Estas diluciones se guardaron a $4^{\circ} \mathrm{C}$, mientras que las soluciones de la extracción se almacenaron a $-20^{\circ} \mathrm{C}$ y sólo se descongelaron cuando se requirió preparar una nueva dilución de trabajo.

Para los análisis preliminares en las diferentes técnicas moleculares empleadas, se seleccionó una muestra representativa de individuos. En concreto, 32 individuos de U. glabra, uno por cada población con al menos 20 efectivos y dos para las poblaciones con más de 20 individuos; además de tres individuos de $U$. minor, uno por cada localidad incluida en este estudio. 


\section{3. Caracterización molecular a nivel del ADN nuclear}

\subsection{Selección de los loci de microsatélites}

Inicialmente, se probaron un total de 22 pares de cebadores de microsatélites (ver Tabla 3.3): siete loci SSR desarrollados en U. laevis (Whiteley et al. 2003), cuatro de los descritos para U. minor (Collada et al. 2004) y los 11 diseñados en U. rubra (Zalapa et al. 2008b). Estos microsatélites eran prácticamente casi todos los que se habían descrito en especies del género Ulmus hasta la fecha en la que se llevó a cabo el presente estudio.

Finalmente, para el estudio de todas las muestras, se seleccionaron nueve loci SSR: UIm2, UIm3, Ulm8, Ulmi1-21, Ulmi1-98, Ulmi1-165, UR123, UR153 y UR175, al presentar patrones interpretables y polimórficos tanto en olmo de montaña como en olmo común. Asimismo, también fueron seleccionados los loci UR138 y UR173a para el análisis en U. glabra, pero no para U minor, donde en ambos casos se generaron patrones de múltiples bandas difíciles de interpretar. 
Tabla 3.3. Secuencias de los pares de cebadores ( $F$, forward; $R$, reverse) utilizados para amplificar los 22 loci SSR probados inicialmente en el presente estudio. Se indica el motivo repetido de cada microsatélite.

\begin{tabular}{|c|c|c|}
\hline Loci SSR & Secuencias (5'- 3') & Motivo repetido \\
\hline Ulm2 a & $\begin{array}{l}\text { F: GCGTCTCAGAACAACAGCTTCA } \\
\text { R: GGCTGCAAGATTGAACTTGAT }\end{array}$ & $(\mathrm{CAG})_{8}$ \\
\hline Ulm3 a & $\begin{array}{l}\text { F: TCCTGTTTCAGAGACATGCA } \\
\text { R: GGACCATCTCTTCGCTGTTGT }\end{array}$ & 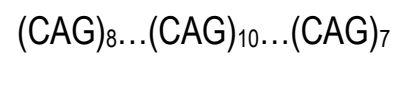 \\
\hline Ulm6 a & $\begin{array}{l}\text { F: CCTTCATGATTGCAATCGGTA } \\
\text { R: ACAATAATCGTAACCATCTT }\end{array}$ & $(\mathrm{CA})_{13}$ \\
\hline Ulm8 a & $\begin{array}{l}\text { F: GCATAGATGGAGATTGGGAT } \\
\text { R: GCCTCAAACACAATCCCACCT }\end{array}$ & $(\mathrm{GCT})_{12} \mathrm{CTT}(\mathrm{GCT})_{2}$ \\
\hline Ulm9 a & $\begin{array}{l}\text { F: GCATGAGCTTATTCGTTATAC } \\
\text { R: CAAAAGAAATCAGTATTAGGA }\end{array}$ & $(G A)_{23}$ \\
\hline Ulm12 a & $\begin{array}{l}\text { F: *CGTGGACTAACAGCAAACATT } \\
\text { R: AGTGCACCCGCGCACTCA }\end{array}$ & $(\mathrm{GT})_{41}$ \\
\hline Ulm19 a & $\begin{array}{l}\text { F: *ACAAGCATCCTTTATACACAC } \\
\text { R: TCTATCTCTCTTCAATTTCTG }\end{array}$ & 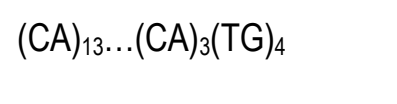 \\
\hline Ulmi2-16 b & $\begin{array}{l}\text { F: GATTTAGGGGGCATTTAT } \\
\text { R: AAAGTGTATAAATAGGGTAT }\end{array}$ & $(\mathrm{TA})_{12}(\mathrm{CA})_{6}$ \\
\hline Ulmi1-21 b & $\begin{array}{l}\text { F: GCGGTCTTACGTGAGCTTTC } \\
\text { R: AAAGAGGCAGACGAAGATGG }\end{array}$ & $(\mathrm{CT})_{10}$ \\
\hline Ulmi1-98 b & $\begin{array}{l}\text { F: AAATGGCCGGAATGTGTTAC } \\
\text { R: TGGGTGAGAGGACAAGTGAA }\end{array}$ & $(\mathrm{CT})_{6} \mathrm{~N}_{14}(\mathrm{CT})_{7}$ \\
\hline Ulmi1-165 b & $\begin{array}{l}\text { F: CTCTTCCATTCGTCCTCACC } \\
\text { R: GAGGTGCCATAAGCCAAGAA }\end{array}$ & $(\mathrm{CT})_{9}$ \\
\hline UR101 ${ }^{c}$ & $\begin{array}{l}\text { F: GGGAAGTCAAATTCCCATGA } \\
\text { R: CTCCAATGGCATCTTCACAA }\end{array}$ & $(\mathrm{TA})_{5}(\mathrm{CA})_{9}$ \\
\hline UR123 c & $\begin{array}{l}\text { F: AGCAATAAACCTTGTGTCGTG } \\
\text { R: GAGCTTGCTATGCTTCGTCTC }\end{array}$ & $(\mathrm{CA})_{4} \mathrm{CG}(\mathrm{CA})_{5}(\mathrm{TTA})_{5}$ \\
\hline UR138 c & $\begin{array}{l}\text { F: CTAGAACCCCCTTCGAAACC } \\
\text { R: ACAAAAAGCCCACACACCTC }\end{array}$ & $(\mathrm{GA})_{8}$ \\
\hline UR141 c & $\begin{array}{l}\text { F: TTGTGTTTGCGTGAAAAGGA } \\
\text { R: GTTCCATGGGTTTTCATTGG }\end{array}$ & $(G A)_{10}$ \\
\hline UR153 c & $\begin{array}{l}\text { F: AGATTTCATGCCTCCAGTCG } \\
\text { R: CCTTTCGAAATGCAGAGGTAG }\end{array}$ & $(\mathrm{CTT})_{7}$ \\
\hline UR158 c & $\begin{array}{l}\text { F: TTCTTCATAGGCGCTGAGGT } \\
\text { R: TGCACCCTGTCAAAGCTAAA }\end{array}$ & $(\mathrm{TGTA})_{5}$ \\
\hline UR159 c & $\begin{array}{l}\text { F: TGCATGAACATGGACTTCATT } \\
\text { R: GATGTTAAGATAAGAAGTCATTAGGA }\end{array}$ & $(\mathrm{CTA})_{5}$ \\
\hline UR173a c & $\begin{array}{l}\text { F: ATAAAGGACGCTAAGGCAGTCA } \\
\text { R: AGACAAACTCTTCGCCATCAAT }\end{array}$ & $(\mathrm{CT})_{19}$ \\
\hline UR173b c & $\begin{array}{l}\text { F: CCGTGCAACTTTCCTGCTAC } \\
\text { R: TGACTGCCTTAGCGTCCTTTAT }\end{array}$ & $(\text { TATTT })_{3}$ \\
\hline UR175 c & $\begin{array}{l}\text { F: TGCCAATTTGTTGAAATTTACG } \\
\text { R: TTGTTGGTTGTGGTTTGTGA }\end{array}$ & $(\mathrm{TG})_{8}$ \\
\hline UR188a c & $\begin{array}{l}\text { F: AAAACTAACGCGTCCCTTCC } \\
\text { R: ATTTCGCTTCAATTGCGAGT }\end{array}$ & $(A C)_{15}$ \\
\hline
\end{tabular}

a Whiteley et al. 2003. b Collada et al. 2004. ' Zalapa et al. 2008 


\subsection{Amplificación mediante PCR y detección de polimorfismos}

Las reacciones de amplificación se llevaron a cabo en un volumen final de $20 \mu$ y contenían aproximadamente $20 \mathrm{ng}$ de $\mathrm{ADN}$ molde, 0,5 $\mu \mathrm{M}$ de cada cebador (forward y reverse, uno de los dos de cada par fue marcado con un fluorocromo: 6-FAM ${ }^{T M}, V{ }^{\circledR}$, NED $^{T M}$ o PET ${ }^{T M} ;$ Applied Biosystems, CA, USA), 0,15 mM de cada desoxinucleótido trifosfato (dNTP), $2 \mathrm{mM}$ de $\mathrm{MgCl}_{2}$ y $0,8 \mathrm{U}$ de Tth ADNpolimerasa en $1 \mathrm{X}$ del buffer de reacción de la casa comercial (Biotools, B\&M Labs S.A., Madrid, España). Las amplificaciones se realizaron en un termociclador PTC-100 (MJ Research, Inc., Waltham, MA, USA), utilizando el mismo protocolo para todos los microsatélites: un ciclo inicial de desnaturalización del $\mathrm{ADN}$ de 4 min a $94{ }^{\circ} \mathrm{C}$; seguido de 35 ciclos de $45 \mathrm{~s}$ a $94{ }^{\circ} \mathrm{C}, 1 \mathrm{~min}$ a $50{ }^{\circ} \mathrm{C}$ y 1 min 30 s a $72{ }^{\circ} \mathrm{C}$; por último, se realizó un ciclo final de extensión a $72^{\circ} \mathrm{C}$ durante 10 min. Finalizadas las amplificaciones, se verificó la calidad y cantidad de los productos amplificados mediante electroforesis en geles de agarosa al 1,5\% (p/v), empleando como marcador una escalera de 50 pares de bases (50 Base-Pair Ladder, Pharmacia).

Tras la verificación de la amplificación, los productos de la misma se resolvieron en un secuenciador automático de electroforesis capilar ABI PRISM ${ }^{\circledR} 3730$ DNA analyzer (Applied Biosystems, CA, USA), empleándose como marcador interno GeneScan-500LIZ (Applied Biosystems, CA, USA), para estimar los tamaños de los fragmentos amplificados. El análisis de los resultados se llevó a cabo utilizando el programa Peak Scanner ${ }^{\mathrm{TM}} 1.0$ (Applied Biosystems, CA, USA), con objeto de asignar el tamaño de los fragmentos (alelos); de manera que se elaboró una hoja Excel con los tamaños de los alelos (en pares de bases) asignados a cada uno de los 442 individuos estudiados para los diferentes loci SSR analizados.

\subsection{Análisis de datos}

\subsubsection{Diversidad genética}

Los parámetros de diversidad genética se calcularon con los datos obtenidos para los 11 loci SSR analizados en las 427 muestras de $U$. glabra procedentes de las 22 poblaciones estudiadas. Por una parte, para cada uno de los loci analizados se calcularon los siguientes parámetros utilizando el programa GenAlEx 6.5 (Peakall \& Smouse 2006; Peakall \& Smouse 2012): frecuencias alélicas, número total de alelos $\left(\mathrm{N}_{\mathrm{A}}\right)$, número efectivo de alelos $\left(\mathrm{N}_{\mathrm{E}}\right)$, número de genotipos diferentes observados $\left(\mathrm{G}_{\mathrm{O}}\right)$, heterocigosidad observada $\left(\mathrm{H}_{\mathrm{O}}\right)$ y esperada $\left(\mathrm{H}_{\mathrm{E}}\right)$, e índice de información de Shannon $(\mathrm{I})$.

También se calculó el contenido de información polimórfica (PIC; Bostein et al. 1980), así como el poder de discriminación (D; Jones 1972; Lamboy \& Alpha 1998) para cada uno de los microsatélites 
analizados. Este último parámetro es una estima de la probabilidad de que dos muestras escogidas al azar puedan distinguirse por su patrón de alelos, y se calculó para cada locus como $D=1-C$, donde $C$ es la probabilidad de coincidencia para ese locus de dos muestras tomadas al azar. Dicha probabilidad de coincidencia se calculó como $\mathrm{C}=\Sigma \mathrm{P}_{\mathrm{i}}{ }^{2}$, donde $\mathrm{P}_{\mathrm{i}}$ es la frecuencia de cada uno de los 'i' genotipos observados para un locus. El poder de discriminación para el conjunto de todos los loci se calculó como $D_{T}=1-C_{T}$, donde $C_{T}=\Pi C_{m}$ representa la probabilidad de coincidencia acumulada para los $m=11$ loci analizados.

Por otra parte, para cada una de las poblaciones estudiadas se calculó el porcentaje de loci polimórficos $(\mathrm{P})$ y el número de genotipos (combinaciones alélicas diferentes considerando conjuntamente los 11 loci) observados (Go), al igual que la media para el conjunto de todos los loci del número efectivo de alelos $\left(\mathrm{N}_{\mathrm{E}}\right)$, del índice de diversidad de Shannon (I), de la heterocigosidad observada $\left(H_{0}\right)$ y esperada $\left(H_{E}\right)$ y del índice de fijación $(F)$. Todos estos parámetros también se calcularon con el programa GenAIEx 6.5.

\subsubsection{Relaciones entre poblaciones}

Con objeto de conocer las relaciones genéticas existentes entre las poblaciones de $U$. glabra del Sistema Central, se construyó un dendrograma para las 19 poblaciones, de las 22 estudiadas, que al menos tenían seis individuos muestreados. Para ello, se generó una matriz de distancias genéticas de Nei (Nei 1972), con la que se obtuvo un dendrograma por el método UPGMA (Unweighted Pair Group Method with Arithmetic Mean), utilizando el programa NTSYS-pc 2.2 (Rohlf 2008). Para conocer la bondad de ajuste de los agrupamientos obtenidos se calculó la correlación cofenética mediante un test de Mantel con 10000 permutaciones, utilizando nuevamente el programa NTSYS-pc 2.2. Asimismo, la consistencia de los agrupamientos en el dendrograma también se evaluó mediante 10000 bootstraps, para lo cual se empleó el programa Phylip 3.6 (Felsenstein 1993).

Por otro lado, para estimar la partición de la diversidad genética entre poblaciones y dentro de las poblaciones, y su significación, se llevó a cabo un análisis molecular de la varianza (AMOVA) (Excoffier et al. 1992). Para ello, se utilizó el programa GenAlEx 6.5 (Peakall \& Smouse 2006; Peakall \& Smouse 2012), estimando los componentes de la varianza y su nivel de significación mediante un procedimiento no paramétrico con 10000 permutaciones. Además, este mismo análisis también permitió calcular la diferenciación genética $\left(F_{S T}\right)$ entre poblaciones, tanto para el conjunto de todas ellas como entre todos los pares de poblaciones, así como su significación mediante 10000 permutaciones. 


\subsubsection{Análisis demográfico}

Con el fin de tener una visión más completa del estado de conservación en el que se encuentran las poblaciones de olmo de montaña en el Sistema Central, se realizó un análisis demográfico centrado en obtener una estimación del tamaño efectivo de las poblaciones $\left(N_{e}\right)$, así como en detectar la posible existencia de cuellos de botella en las mismas, los cuales afectarían evidentemente al tamaño poblacional. Para la detección de posibles cuellos de botella se empleó una doble metodología, con objeto de detectar bien cuellos de botella recientes, o bien ancestrales; en ambos casos se analizaron sólo 15 de las poblaciones de U. glabra, al requerirse datos de al menos diez individuos por población (ver Tabla 3.1).

Por un lado, para la detección de cuellos de botella recientes se utilizó el estadístico $T_{2}$, empleando el programa BOTTLENECK 1.2 (Cornuet \& Luikart 1996; Piry et al. 1999). Dicho estadístico representa una media sobre todos los loci de la desviación de la heterocigosidad actual respecto de la esperada en función del número de alelos en la población asumiendo la existencia de equilibrio mutación-deriva para una población de tamaño constante. Es decir, las poblaciones que han sufrido un cuello de botella reciente es habitual que presenten una reducción tanto en el número de alelos como en la heterocigosidad; de manera que, la reducción en el número de alelos es más rápida que la que se produce en la heterocigosidad, ya que principalmente se pierden alelos raros, que apenas contribuyen a la heterocigosidad. Por lo tanto, en las poblaciones que han sufrido un cuello de botella reciente es habitual detectar un exceso de heterocigosidad respecto a la esperada en equilibrio mutación-deriva (Piry et al. 1999; Luikart et al. 1998).

El programa BOTTLENECK permite calcular el estadístico $T_{2}$ para detectar la existencia de un exceso de heterocigosidad utilizando diferentes modelos de mutación, como SMM (Stepwise Mutation Model), IAM (Infinite Allele Model) o TPM (Two-Phase Model). Para datos de microsatélites, el modelo TPM se ha sugerido como el más apropiado (Di Rienzo et al. 1994; Piry et al. 1999; Williamson-Natesan 2005). Por tanto, en nuestro caso utilizamos el modelo TPM, asumiendo un $95 \%$ de mutaciones de un solo paso y un $5 \%$ de mutaciones de múltiples pasos, además de una varianza de 26 entre múltiples pasos, tal y como recomienda Piry et al. (1999). De manera que, valores positivos del estadístico $\mathrm{T}_{2}$ serían indicativos de la existencia de un cuello de botella reciente, mientras que valores negativos implicarían la existencia de recientes expansiones demográficas. Asimismo, considerando el número de loci polimórficos empleados en este estudio (<20), Piry et al. (1999) recomiendan una prueba no paramétrica, como el test de rangos con signo de Wilcoxon, para determinar la significación del estadístico T 2 (Piry et al. 1999). Dicho test se realizó con 10000 iteraciones. 
Por otra parte, para detectar reducciones en el tamaño efectivo de las poblaciones, también fue utilizado el estadístico M-valor (Garza \& Williamson-Natesan 2001). El M-valor, a diferencia del estadístico $\mathrm{T}_{2}$, detecta reducciones del tamaño poblacional producidas a una escala de tiempo mayor, por lo que permite detectar cuellos de botella ancestrales (Williamson-Natesan 2005; Garza \& Williamson-Natesan 2001). El M-valor se calculó utilizando el software Arlequin 3.5 (Excoffier \& Lischer 2010), como la relación del número de alelos respecto al rango de tamaños alélicos encontrados para cada loci SSR (Garza \& Williamson-Natesan 2001). En general, se ha comprobado empíricamente que para estudios poblacionales con siete 0 más loci analizados, si el M-valor es menor a 0,68, puede asumirse que en estos casos las poblaciones han sufrido un cuello de botella (Fuentes-Utrilla et al. 2014b; Garza \& Williamson-Natesan 2001).

Posteriormente, se estimó el tamaño efectivo de las poblaciones utilizando dos métodos diferentes, uno basado en la información del desequilibrio de ligamiento y otro en aproximaciones computacionales bayesianas. En ambos casos, por requerimientos de los programas utilizados, sólo se analizaron las diez poblaciones de U. glabra que contaban al menos con 20 individuos muestreados (ver Tabla 3.1).

En primer lugar, se empleó el programa LDNe 1.31 (Waples \& Do 2008), que utiliza información del desequilibrio de ligamiento entre alelos para los diferentes loci causado por deriva genética en poblaciones finitas. Además, este programa permite corregir los sesgos derivados del análisis de poblaciones de pequeño tamaño (Waples \& Do 2008; England et al. 2006). El valor de $N_{e}$ fue estimado asumiendo apareamiento al azar y excluyendo alelos con frecuencias inferiores a 0,05 (Waples \& Do 2010). Además, los intervalos de confianza al $95 \%$ se calcularon utilizando el método Jackknife, siguiendo la recomendación de Waples \& Do (2008).

El segundo método empleado para estimar el $\mathrm{N}_{\mathrm{e}}$ es el implementado en el programa ONeSAMP 1.1 (Tallmon et al. 2008). Dicho software utiliza métodos bayesianos para estimar la varianza de $N_{e}$ a partir de un resumen de estadísticos relacionados con el tamaño efectivo de las poblaciones. El programa parte de una información previa facilitada por el usuario (concretamente, valores estimados de los límites superior e inferior de $N_{e}$ en las poblaciones analizadas), para generar de forma aleatoria 50.000 simulaciones de poblaciones a partir de dichos valores proporcionados previamente por el usuario. El programa calcula un resumen de estadísticos y los compara con los datos actuales, generando una estima de $N_{e}$ mediante una regresión local ponderada (Tallmon et al. 2008). Inicialmente, se probaron varias estimas de los límites superior e inferior de $N_{e}$ para cada población. Finalmente, para estimar los valores de $N_{e}$ y sus intervalos de confianza al $95 \%$, se seleccionaron como 
valores previos los límites 2-7000 para las dos poblaciones más numerosas (STR e IRU; $\mathrm{Nt}>3000$, ver Tabla 1.1), y 2-200 para las ocho restantes ( $\mathrm{Nt}<200$, ver Tabla 1.1).

\subsubsection{Estructura genética espacial}

Con los datos obtenidos para los 11 microsatélites nucleares se realizó un análisis espacial de la diversidad genética, tanto a nivel global para los 427 individuos de U. glabra muestreados a lo largo del Sistema Central como a nivel poblacional; en este último caso, sólo en las diez poblaciones con al menos 20 individuos muestreados (ver Tabla 3.1), tratando con ello de disminuir la variación estocástica debida a un número de datos relativamente reducido.

En una primera aproximación, tanto a nivel global como a nivel poblacional, se realizó un test de Mantel (Mantel 1967) utilizando el programa GenAIEx 6.5, para calcular la correlación entre la matriz de distancias geográficas y la de distancias genéticas lineares entre individuos (Peakall et al. 1995; Smouse \& Peakall 1999). El nivel de significación se obtuvo mediante un test de 10000 permutaciones.

A continuación, se llevó a cabo un análisis de autocorrelación espacial siguiendo la metodología descrita por Smouse \& Peakall (1999), y empleando también el programa GenAlEx 6.5. Dicha metodología difiere de los análisis de autocorrelación espacial clásicos en que emplea un enfoque multivariado, que evalúa simultáneamente diferentes loci y alelos. El análisis de autocorrelación espacial genera un gráfico de correlación (correlograma), en el que se representa el coeficiente de autocorrelación $(r)$ frente a las diferentes clases de distancia seleccionadas.

Para cada uno de los correlogramas se realizó un test no paramétrico de heterogeneidad (Smouse et al. 2008), con el fin de evaluar la homogeneidad de los mismos. Se trata de un test del nivel de significación del correlograma, en el que se obtiene un valor omega $(\Omega)$ y una probabilidad de que dicho valor sea mayor que el esperado bajo la hipótesis nula de correlograma homogéneo (Banks \& Peakall 2012).

Para evaluar el nivel de significación de la autocorrelación se empleó una doble metodología (Peakall et al. 2003): permutaciones aleatorias y remuestreo o bootstrap. En el primer caso, bajo la hipótesis nula de no existencia de estructura espacial, el coeficiente de correlación se calcula mezclando al azar todos los individuos para las diferentes clases de distancia; en nuestro caso, empleamos 10000 permutaciones aleatorias, tanto para obtener los valores estimados de $r$ y compararlos con los observados, como para definir los límites superior (U-upper) e inferior (L-lower) de los intervalos de confianza al 95\% para cada clase de distancia. En el segundo método, se establece un intervalo de confianza para cada estima de $r$ mediante remuestreo dentro del conjunto de pares de 
comparaciones entre individuos en cada clase de distancia. En este caso, se utilizaron 10000 remuestreos para estimar los coeficientes de correlación para cada clase de distancia, así como para definir sus límites superior (Ur) e inferior ( $(\mathrm{r})$ del intervalo de confianza al 95\%.

Por otra parte, cuando existe estructura genética espacial positiva, el primer punto de intercepción del gráfico del coeficiente de autocorrelación con el eje del valor de $r=0$ se suele interpretar como una estima de hasta donde llegaría dicha estructura genética (Peakall et al. 2003).

El número y tamaño de las clases de distancia escogidas para los análisis de autocorrelación espacial global y poblacional fue diferente. En ambos casos, previamente, se realizaron numerosas pruebas tratando de obtener una resolución espacial precisa sin comprometer el número de datos por clase o intervalo. Así, para el análisis global de los 427 individuos en el Sistema Central, se empleó de 0-1 km como primera clase y para las siguientes clases se hicieron intervalos de distancia de $2 \mathrm{~km}$ hasta los 10 primeros kilómetros y, posteriormente, el tamaño de las clases de distancia se incrementó duplicándose la distancia máxima de la clase anterior (es decir, intervalos de clase hasta los 20, 40, 80, 160, 320 y 640 km). Para el análisis de las diez poblaciones, debido al tamaño muestral relativamente reducido de la mayoría de esas poblaciones, se empleó la opción "Even simple size" en el programa GenAIEx 6.5 para que todas las clases de distancia tuvieran un número similar de datos, y procurando que cada clase de distancia contuviese al menos 30 datos o pares de comparaciones, tratando así de disminuir la variación estocástica (Degen \& Roubik 2004; Cavers et al. 2005).

Finalmente, para aquellas poblaciones en las que se detectó la existencia de estructura genética espacial positiva y significativa, se llevó a cabo un análisis de autocorrelación espacial más fina, a menor escala, empleando las opciones "2D-LSA" y "NN Dist" del programa GenAIEx 6.5. En este tipo de análisis se calcula el coeficiente de autocorrelación (y su significación) de cada individuo de la población con sus "N" vecinos más próximos, con objeto de ver cuáles son los individuos de la población que más contribuyen a la existencia de esa estructura genética espacial positiva y significativa (Double et al. 2005). Para la elección del número de vecinos más próximos en cada población, se tuvo en cuenta el valor del punto de intercepción obtenido en el autocorrelograma; eligiendo siempre los $\mathrm{N}$ vecinos más próximos cuya distancia media fuera igual o ligeramente inferior al valor de intercepción.

\subsubsection{Introgresión entre U. glabra y U. minor}

Con objeto de identificar posibles grupos genéticos dentro de los individuos de U. glabra, así como su relación con los genotipos de U. minor, se llevó a cabo un análisis empleando el programa STRUCTURE 2.3.4 (Pritchard et al. 2000). Dicho programa utiliza una metodología Bayesiana para asignar los distintos individuos a $K$ grupos genéticos basándose en las frecuencias alélicas de cada 
locus. En primer lugar, se realizó un análisis con las 427 muestras de olmo de montaña empleando los datos obtenidos para los 11 microsatélites. El rango de posibles grupos $(K)$ que se probó varió entre 1 y 25 , correspondiente al número inicial de poblaciones más tres, siguiendo las recomendaciones de Evanno et al. (2005). Posteriormente, para inferir posibles relaciones entre los genotipos del olmo de montaña y los del olmo común, se realizó un segundo análisis añadiendo a las 427 muestras de $U$. glabra las 15 de U. minor, utilizando en este caso solamente los datos obtenidos con los 9 loci SSR que amplificaron en ambas especies. Asimismo, teniendo en cuenta los resultados del primer análisis, el número de grupos que se probaron en este segundo varió de 1 a 10.

La estima del número óptimo de grupos genéticos $(K)$ se obtuvo mediante el cálculo del estadístico ad hoc $\Delta K$ (Evanno et al. 2005). Así, si se representa $\Delta K$ frente al número de grupos, aquel valor de $K$ en el que $\Delta K$ muestre un máximo claro será el óptimo valor de $K$, es decir, la mejor estima del número de grupos en los que se estructura la diversidad genética de las muestras estudiadas.

En el análisis realizado, los valores de la mayoría de los parámetros se seleccionaron por defecto, siguiendo las recomendaciones de Pritchard \& Wen (2010). De este modo, se seleccionó un modelo de "mezclas" (admixture model) con la opción de frecuencias alélicas correlacionadas entre los grupos, ya que ésta suele ser considerada la mejor configuración incluso en el caso de que sólo existiera una débil estructura genética (Falush et al. 2003). El grado de mezcla (alpha) se infirió a partir de los datos, mientras que el parámetro de la distribución de las frecuencias alélicas (lambda) se fijó con un valor constante de 1 (Evanno et al. 2005; Falush et al. 2003). Por otra parte, el programa se configuró para que realizase 20 repeticiones independientes para cada uno de los valores de $K$. En cada repetición se realizaron 10000 iteraciones antes de comenzar a tomar los datos para el análisis (proceso conocido como burn-in), con objeto de minimizar el efecto de la configuración inicial y, posteriormente, se llevaron a cabo 100.000 simulaciones MCMC (Markov chain Monte Carlo) para estimar los diferentes parámetros. Por último, una vez estimado el óptimo número de grupos, entre las 20 repeticiones realizadas para ese valor de $K$, aquella que presentó el mayor valor de probabilidad posterior de los datos se seleccionó para obtener los coeficientes o probabilidades de asignación posterior $(q)$ para cada uno de los individuos analizados a cada uno de los $K$ grupos establecidos (Worthington et al. 2012).

En el segundo análisis realizado con el programa STRUCTURE, los individuos considerados como mezcla podrían representar híbridos putativos entre U. glabra y U. minor. Por ello y para corroborar su posible carácter híbrido, se llevó a cabo un nuevo análisis más específico para la detección de posibles individuos híbridos utilizando el programa NewHybrids 1.1 (Anderson \& Thompson 2002). Este programa también emplea métodos estadísticos bayesianos, con objeto de estimar las probabilidades 
posteriores de que cada individuo pertenezca a una de las clases parentales (U. glabra o U. minor) o a alguna de las categorías híbridas $\left(F_{1}, F_{2} 0\right.$ ambos retrocruzamientos, $F_{1} \times U$. glabra y $F_{1} \times U$. minor). Para este análisis, se empleó información de la asignación de cada individuo a los grupos genéticos previamente obtenidos con el programa STRUCTURE. El análisis se realizó utilizando los parámetros por defecto del programa y considerando las seis clases genotípicas anteriores; con 10 repeticiones independientes, cada una de ellas con un burn-in de 100.000 iteraciones seguido de 600.000 simulaciones MCMC.

\section{4. Caracterización molecular a nivel del ADN de cloroplastos}

\subsection{PCR-RFLP en la región LSC}

Inicialmente se probaron 38 parejas de cebadores universales (ver Tabla 3.4), que fueron diseñadas para llevar a cabo la amplificación completa de la región larga de copia única o LSC del ADN de cloroplastos (ADNcp) y que se encuentran descritas en Grivet et al. (2001).

Las reacciones de amplificación se llevaron a cabo en un volumen final de $20 \mu$, que contenía 20 ng de ADN molde, 0,15 $\mathrm{MM}$ de cada cebador (forward y reverse), 0,15 $\mathrm{mM}$ de cada desoxinucleótido trifosfato (dNTP), $2 \mathrm{mM}$ de $\mathrm{MgCl}_{2}$ y $1 \mathrm{U}$ de Tth ADN-polimerasa en $1 \mathrm{X}$ del buffer de reacción suministrado por la casa comercial (Biotools, B\&M Labs S.A., Madrid, España). Para las amplificaciones se empleó un termociclador PTC-100 (MJ Research, Inc., Waltham, Mass.), utilizando un ciclo inicial de desnaturalización del ADN de 4 min a $94{ }^{\circ} \mathrm{C}$, seguido de 30 ciclos de $45 \mathrm{~s}$ a $94{ }^{\circ} \mathrm{C}, 45 \mathrm{~s}$ a la temperatura correspondiente de annealing o unión (ver Tabla 3.4) y una elongación o extensión a 72 ${ }^{\circ} \mathrm{C}$ durante un tiempo de variable según el tamaño esperado del fragmento a amplificar (ver Tabla 3.4), con un último ciclo de extensión de $10 \mathrm{~min}$ a $72^{\circ} \mathrm{C}$. Para comprobar la existencia de amplificación y estimar el tamaño de los fragmentos amplificados, los productos de amplificación obtenidos se resolvieron en geles de agarosa al 1,2\% (p/v) y posterior tinción con una solución de bromuro de etidio. El tamaño de los fragmentos se estimó utilizando como marcador la escalera de tamaños moleculares de 1-KiloBase (Pharmacia).

En este análisis preliminar, tras la amplificación, los fragmentos generados fueron digeridos con la enzima de restricción Hinfl, al ser una de las enzimas más habituales y eficaces en la metodología de PCR-RFLP (Dumolin-Lapègue et al. 1997; Heinze 1998; Mohanty et al. 2003; Gil et al. 2004; Myking \& Yakovlev 2006). Las reacciones de restricción se llevaron a cabo en un volumen final de $10 \mu l$, con $7,5 \mu$ del producto de PCR y $2,5 \mu$ de la mezcla de restricción, la cual contenía $2 U$ de la enzima de restricción en $1 \mathrm{X}$ del buffer de reacción de la casa comercial (Takara Biotech., USA). La incubación se llevó a cabo en una estufa a $37^{\circ} \mathrm{C}$, durante $15-20 \mathrm{~h}$ para asegurar una digestión enzimática completa. 
Los fragmentos de restricción generados se resolvieron mediante electroforesis en geles de agarosa al 2,5\% (p/v). Para estimar el tamaño de los productos de digestión se empleó un marcador en escalera de 100 pares de bases (100 Base-Pair Ladder; Pharmacia).

El análisis preliminar con las 38 parejas de cebadores y la enzima Hinfl permitió seleccionar 10 fragmentos o regiones (CP2, CP5, CP7, CP8, C16, CP19, CP28, CP29, CP34 y CP38; ver Tabla 3.4) para ser analizadas en el conjunto de las 427 muestras de $U$. glabra y las 15 de $U$. minor, al haberse detectado en ellas la existencia de diferencias inter- y/o intraespecíficas.

En este análisis se utilizaron las mismas condiciones de amplificación que las indicadas anteriormente en el análisis preliminar. Con respecto a la posterior digestión de los fragmentos amplificados, teniendo en cuenta los resultados obtenidos en trabajos previos con poblaciones de $U$. glabra (Gil et al. 2004; Myking \& Yakovlev 2006), se seleccionaron dos enzimas de restricción, Hinfl y Taql (para la región CP19 se empleó la enzima Mval en lugar de Taql). Las reacciones de restricción se llevaron a cabo con las mismas condiciones indicadas previamente para Hinfl, utilizando una temperatura de incubación de $37^{\circ} \mathrm{C}$ para Hinfl y Mval, y de $65^{\circ} \mathrm{C}$ para Taql. 
Tabla 3.4. Denominación y secuencias de los 38 pares de cebadores universales empleados para amplificar los correspondientes fragmentos (CP1 a CP38) de la región larga de copia única del ADNcp. Se indica la temperatura de annealing o unión (TA) y el tiempo de elongación o extensión (TE) utilizados para la amplificación de cada fragmento.

\begin{tabular}{|c|c|c|c|c|c|c|c|}
\hline \multirow{2}{*}{\multicolumn{2}{|c|}{$\begin{array}{l}\begin{array}{l}\text { Fragmentos } \\
\text { amplificados }\end{array} \\
\text { Código Nombre }\end{array}$}} & \multirow[t]{2}{*}{$\begin{array}{l}\text { Cebador } \\
\text { forward }\end{array}$} & \multirow[t]{2}{*}{ Secuencia 5'- 3' } & \multirow[t]{2}{*}{$\begin{array}{l}\text { Cebador } \\
\text { reverse }\end{array}$} & \multirow[t]{2}{*}{ Secuencia 5'- 3' } & \multirow[t]{2}{*}{$\begin{array}{l}\text { TA } \\
\left({ }^{\circ} \mathrm{C}\right)\end{array}$} & \multirow[t]{2}{*}{$\begin{array}{l}\text { TE } \\
(\mathrm{min})\end{array}$} \\
\hline & & & & & & & \\
\hline $\begin{array}{ll}\text { CP1 a } \\
\end{array}$ & & $r p / 23$ & taagacagaaataaagcattgcgtcgaac & psbA3' & ctagcactgaaaaccgtctt & 45 & 4 \\
\hline $\mathrm{CP} 2 \mathrm{~b},{ }^{*}$ & HK & $\operatorname{trnH}$ & acgggaattgaacccgcgca & trnk & ccgactagttccgggttcga & 62 & 2,5 \\
\hline CP3 b & $\mathrm{K}_{1} \mathrm{~K}_{2}$ & trnK & gggttgcccgggactcgaac & trnk & caacggtagagtactcggctttta & 53,5 & 3 \\
\hline $\mathrm{CP} 4 \mathrm{c}$ & $\mathrm{K}_{2} \mathrm{Q}$ & trnK & taaaagccgagtactctaccgttg & trnq & ctattcggaggttcgaatccttcc & 45 & 4 \\
\hline $\mathrm{CP} 5 \mathrm{c},{ }^{*}$ & QS & $\operatorname{trn} Q$ & gggacggaaggattcgaacc & $\operatorname{trnS}$ & attgcgtccaataggatttgaa & 50 & 2,5 \\
\hline $\mathrm{CP6} \mathrm{c}^{\mathrm{C}}$ & SR & $\operatorname{trnS}$ & cgccgctttagtccactca & $\operatorname{trn} R$ & attgcgtccaataggatttgaa & 50 & 3 \\
\hline $\mathrm{CP} 7 \mathrm{~g},{ }^{*}$ & & $\operatorname{trn} R$ & ggtataggttcaaatcctattggac & ccmp4-U & aatgctgaatcgaygaccta & 45 & 3 \\
\hline CP8 g, ${ }^{*}$ & & ccmp4-L & ccaaaatattbggaggactct & $\operatorname{atpH}$ & gccgcttccgttattgctgctgg & 55 & 2,5 \\
\hline $\mathrm{CPgh}$ & & atpH & ccagcagcaataacggaagc & atpl & ataggtgaatccatggaggg & 50 & 2,5 \\
\hline $\mathrm{CP} 10^{\mathrm{h}}$ & & atpl & gatgrccctccatggattcacc & rpoC2 & gcgagttttcaagaaactgctcg & 50 & 3 \\
\hline $\mathrm{CP} 11^{\mathrm{h}}$ & & rpoC2-f & cgagcagtttcttgraaactcgc & rpoC2-r & gaggattaatgkcrgatccwcaagg & 50 & 4 \\
\hline $\mathrm{CP} 12^{\mathrm{h}}$ & & rpoc2 & ccttgwggatcygmcattaatcctc & rpoc1 & tgtctattaccwgttcttcctcc & 50 & 3 \\
\hline $\mathrm{CP} 13^{\mathrm{h}}$ & & rpoc1 & ctggtaatarrcacaaaaccatcc & $r p o B$ & gttacacaacaaccccttagagg & 55 & 3 \\
\hline CP14 c & $\mathrm{C}_{1} \mathrm{C}$ & rpoC1 & gcacaaattccrcttttatrgg & $\operatorname{trnC}$ & cgacacccrgatttgaactgg & 45 & 5,5 \\
\hline CP15 b & $\mathrm{CD}$ & $\operatorname{trn} C$ & ccagttcaaatctgggtgtc & $\operatorname{trn} D$ & gggattgtagttcaattggt & 55 & 4 \\
\hline CP16 b, * & DT & $\operatorname{trn} D$ & accaattgaactacaatccc & $\operatorname{trnT}$ & ctaccactgagttaaaaggg & 52 & 2,5 \\
\hline $\mathrm{CP} 17^{\circ}$ & $\mathrm{TC}$ & $\operatorname{trnT}$ & gcccttttaactcagtggta & $p s b C$ & gagcttgagaagcttctggt & 50 & 4 \\
\hline CP18 b & CS & $p s b C$ & ggtcgtgaccaagaaaccac & $\operatorname{trnS}$ & ggttcgaatccctctctctc & 55 & 2,5 \\
\hline CP19b, * & $\mathrm{Sf}_{\mathrm{M}}$ & $\operatorname{trnS}$ & gagagagagggattcgaacc & $\operatorname{trnf}_{M}$ & cataaccttgaggtcacggg & 62 & 2,5 \\
\hline $\mathrm{CP} 20^{\circ}$ & $f_{M} A$ & $\operatorname{trnf}_{M}$ & gaacccgtgacctcaaggttatg & psaA & attcgttcgccggaaccagaagt & 47,5 & 5,5 \\
\hline $\mathrm{CP} 21^{\mathrm{b}}$ & AS & $p s a A$ & acttctggttccggcgaacgaa & $\operatorname{trnS}$ & aaccactcggccatctctccta & 55 & 4,5 \\
\hline $\mathrm{CP} 22^{b}$ & ST & $\operatorname{trnS}$ & cgagggttcgaatccctctc & $\operatorname{trn} T$ & agagcatcgcatttgtaatg & 50 & 2,5 \\
\hline CP23 d & TF & $\operatorname{trn} T$ & cattacaaatgcgatgctct & $\operatorname{trn} F$ & atttgaactggtgacacgag & 50 & 3 \\
\hline CP24 c & $\mathrm{FV}$ & $\operatorname{trnF}$ & ctcgtgtcaccagttcaaat & $\operatorname{trn} V$ & ccgagaaggtctacggttcg & 50 & 4 \\
\hline $\mathrm{CP} 25^{\circ}$ & VL & $\operatorname{trnV}$ & cgaaccgtagaccttctcgg & $r b c L$ & gctttagtctctgtttgtgg & 55 & 4,5 \\
\hline $\mathrm{CP} 26^{\mathrm{e}}$ & & $r b c L f$ & atgtcaccacaaacagaaactaagcaagt & orf106 & actacagatctcatactacccc & 50 & 4 \\
\hline $\mathrm{CP} 27^{\mathrm{h}}$ & & orf512 & agtatgggatccgtagtmgg & orf184 & ggccycggatttccatataaag & 50 & 3 \\
\hline $\mathrm{CP} 28^{h, *}$ & $O A$ & orf184 & tggcgatcagaacayatatggatag & petA & ccctckgaaacaagaagtt & 50 & 3 \\
\hline CP29 f, * & & petAf & gcatctgttatttggcaca & $p s b E r$ & taccttccctattcattgcg & 40 & 3 \\
\hline $\mathrm{CP} 30^{\mathrm{h}}$ & & $p s b L$ & gaaaataaaacagcaagtac & $r p s 18$ & ggtaacaaagataaaatacgagc & 40 & 4,5 \\
\hline $\mathrm{CP} 31^{\mathrm{h}}$ & & rps18 & gctcgtattttatctttgttacc & $c l p p$ & aacctgctagttcttwttat & 45 & 3 \\
\hline $\mathrm{CP} 32^{\mathrm{h}}$ & & $c l p p$ & ataawaagaactagcaggtt & $p s b B$ & atayacccaatgccaratag & 45 & 3 \\
\hline CP33 ${ }^{h}$ & $\mathrm{~B}_{1} \mathrm{~B}_{2}$ & $p s b B$ & tgccttggtatcgtgttcatac & $p s b B$ & cytgtcttyttgtagttggat & 50 & 3 \\
\hline CP34 h, ${ }^{*}$ & $\mathrm{~B}_{2} \mathrm{~B}_{3}$ & $p s b B$ & cagaagcttggtctaaaattcc & petB & grtcccaagggaargaataaccagt & 50 & 3 \\
\hline CP35 h & & petB & ctatcgtccraccgttacwgaggct & petD & caaayggataygcaggttcacc & 50 & 3 \\
\hline CP36 ${ }^{h}$ & & petD & tccagtagtaattctaggta & rps8 & taaaatacttttacgagaag & 40 & 3,5 \\
\hline CP37 h & & rps8 & tgaacaatatttcggtaat & $r p / 16$ & aaccagatttcgtaaacaac & 45 & 2 \\
\hline $\mathrm{CP} 38 \mathrm{~h},{ }^{*}$ & & $r p / 16$ & tgtttacgaaatctggttct3 & $r p / 2$ & ccatagaatacgaccctaat & 50 & 4,5 \\
\hline
\end{tabular}

a Heinze, 1998; b Demesure et al. 1995; c Dumolin-Lapègue et al. 1997; ' Taberlet et al. 1991; e Arnold et al. 1991; fFofona et al. 1997; g Weising \& Gardner, 1999; ' h Grivet et al. 2001.

${ }^{*}$ Fragmentos o regiones seleccionadas para el análisis de las 427 muestras de $U$. glabra y las 15 de U. minor. 


\subsection{Microsatélites}

En un análisis preliminar se probaron un total de 18 loci de microsatélites del genoma de cloroplastos (SSRcp): ccmp2, ccmp3, ccmp4, ccmp5, ccmp6, ccmp7 y ccmp10 (Weising \& Gardner 1999); ccSSR4, ccSSR7, ccSSR9, ccSSR12, ccSSR13, ccSSR16, ccSSR19, ccSSR20, ccSSR21, ccSSR22 y ccSSR23 (Chung \& Staub 2003). Los resultados preliminares mostraron que nueve de esos 18 loci SSRcp fueron monomórficos tanto en el olmo de montaña como en el olmo común; de manera que, para el estudio de las 442 muestras (427 de U. glabra y 15 de U. minor) se utilizaron únicamente los nueve loci que sí mostraron polimorfismo inter- y/o intraespecífico: ccmp2 y ccmp5 (Weising \& Gardner 1999); ccSSR-4, ccSSR-7, ccSSR-9, ccSSR-12, ccSSR-20, ccSSR-21 y ccSSR-23 (Chung \& Staub 2003).

Para las reacciones de amplificación, un cebador de cada una de las nueve parejas seleccionadas se marcó con un fluorocromo: 6-FAM ${ }^{T M}$, VIC ${ }^{\circledR}$, NED $^{T M}$ o PET ${ }^{T M}$ (Applied Biosystems, CA, USA). Dichas reacciones, al igual que las del análisis preliminar, se realizaron en un volumen final de $15 \mu$, con 15 ng de ADN molde, 0,4 $\mu \mathrm{M}$ de cada cebador, 0,15 mM de cada dNTP, $2 \mathrm{mM}$ de $\mathrm{MgCl}_{2}$ y 0,5 U de Tth ADN-polimerasa en $1 \mathrm{X}$ del buffer de reacción de la casa comercial (Biotools, B\&M Labs S.A., Madrid, España). Las amplificaciones se llevaron a cabo en un termociclador PTC-100 (MJ Research, Inc., Waltham, MA, USA), utilizando el mismo protocolo para todos los microsatélites: un ciclo inicial de desnaturalización del ADN de 3 min a $94^{\circ} \mathrm{C}$; seguido de 30 ciclos de $45 \mathrm{~s}$ a $94^{\circ} \mathrm{C}, 45 \mathrm{~s}$ a $50{ }^{\circ} \mathrm{C}$ y 1 min a $72{ }^{\circ} \mathrm{C}$; con un ciclo final de extensión a $72^{\circ} \mathrm{C}$ durante 5 min. Posteriormente, se verificó la calidad y cantidad de los productos amplificados mediante electroforesis en geles de agarosa al $2 \%(\mathrm{p} / \mathrm{v})$, empleando como marcador de tamaños moleculares una escalera de 50 pares de bases (50 Base-Pair Ladder, Pharmacia).

A continuación, los productos de la amplificación se resolvieron en un secuenciador automático de electroforesis capilar ABI PRISM ${ }^{\circledR} 3730$ DNA analyzer (Applied Biosystems, CA, USA), utilizándose como marcador interno GeneScan-500LIZ (Applied Biosystems, CA, USA), para estimar los tamaños de los fragmentos amplificados. El análisis de los resultados se llevó a cabo utilizando el programa Peak Scanner ${ }^{\mathrm{TM}} 1.0$ (Applied Biosystems, CA, USA), con objeto de asignar el tamaño de los fragmentos (alelos), lo cual permitió generar una hoja Excel con los tamaños de los alelos (en pares de bases) asignados a cada uno individuos estudiados para los diferentes loci SSRcp analizados. 


\subsection{Análisis de datos}

\subsubsection{Diversidad genética}

Las diferentes combinaciones de los fragmentos de restricción polimórficos generados mediante PCR-RFLP, al igual que las distintas combinaciones de alelos obtenidas con los microsatélites de cloroplastos, tanto en U. glabra como en U. minor, fueron consideradas como diferentes clorotipos 0 haplotipos de cloroplastos.

Para el análisis de la diversidad en el genoma de cloroplastos de U. glabra se utilizaron de forma conjunta los resultados obtenidos mediante PCR-RFLP y SSRcp. El programa Contrib 1.02 (Petit et al. 1998) se empleó para calcular la contribución a la diversidad total de cada una de las 19 poblaciones de U. glabra estudiadas con más de cinco individuos muestreados, mediante el cálculo de los parámetros de diversidad haplotípica $(\mathrm{Hd})$ y riqueza haplotípica $(\mathrm{Hr})$. Respecto a la riqueza haplotípica, con objeto de poder comparar entre poblaciones con diferente número de muestras, dicho parámetro se calculó después de aplicar la rarefacción, en este caso para un tamaño muestral de $\mathrm{Nm}=6$, correspondiente a la población que presentó el menor número de individuos analizados (Cercedilla CER, ver Tabla 3.1). Asimismo, el programa Permut 2.0 (Pons \& Petit 1996; Burban et al. 1999) se utilizó para estimar la diversidad total $\left(h_{\top}\right)$, la diversidad intrapoblacional media $\left(h_{\mathrm{S}}\right)$, así como el nivel de diferenciación genética entre poblaciones (GST).

Igualmente, mediante el programa Haplodiv (Petit 2012), se calcularon las frecuencias haplotípicas en el conjunto de poblaciones de U. glabra analizadas.

Por otra parte, también se obtuvieron las relaciones existentes entre los distintos clorotipos detectados en las poblaciones de olmo de montaña mediante la construcción de una red haplotípica de máxima parsimonia (maximum parsimony haplotype network) empleando el programa NETWORK 5.0 (Bandelt et al. 1999).

\subsubsection{Estructura filogeográfica}

Mediante el programa Permut 2.0 se estimaron, por un lado, los parámetros de diversidad y diferenciación genética considerando que todos los haplotipos son igualmente divergentes $\left(h_{\mathrm{T}}, h_{\mathrm{S}} \mathrm{y}\right.$ $\left.G_{S T}\right)$, y, por otra parte, los parámetros equivalentes teniendo en cuenta las distancias entre haplotipos $\left(v_{T}, V_{S}\right.$ y $\left.N_{S T}\right)$. Posteriormente, dichos valores fueron comparados mediante un test de 10000 permutaciones utilizando el programa Permut 2.0; de manera que, un valor de $N_{S T}$ significativamente mayor que el de $G_{S T}$ indicaría la existencia de una estructura filogeográfica significativa, es decir, los haplotipos genéticamente más relacionados se encontrarían con mayor frecuencia en poblaciones 
geográficamente próximas, mientras que las distancias haplotípicas aumentarían con el incremento de la distancia geográfica entre las poblaciones (El Mousadik \& Petit 1996).

Asimismo, con objeto de determinar la posible existencia de aislamiento por distancia (Wright 1943), se realizó un test de Mantel (Mantel 1967) empleando el programa GenAlEx 6.5 (Peakall \& Smouse 2006; Peakall \& Smouse 2012), para calcular la correlación entre la matriz de distancias geográficas y la de distancias genéticas de Nei (Nei 1972) entre las poblaciones de U. glabra analizadas. El nivel de significación se obtuvo mediante un test de 10000 permutaciones.

El análisis de la estructura genética de las poblaciones de U. glabra a nivel del ADNcp se completó con un análisis espacial de la varianza molecular (SAMOVA) y un análisis de la varianza molecular (AMOVA).

El análisis espacial de la varianza molecular se llevó a cabo empleando el programa SAMOVA 2.0 (Dupanloup et al. 2002) en las 19 poblaciones de olmo de montaña estudiadas que presentaron un $\mathrm{Nm}>5$. Dicho programa permite inferir grupos de poblaciones filogeográficamente homogéneas y con la máxima diferenciación genética entre ellos, teniendo en cuenta las distancias geográficas. El método implementado en este software se basa en un algoritmo de búsqueda metaheurística, denominado simulated annealing, que tiene como objetivo identificar los $\mathrm{K}$ grupos con máxima diferenciación en función de las barreras genéticas existentes, maximizando el valor de $\mathrm{F}_{\mathrm{CT}}$ (proporción de la varianza genética total que es debida a las diferencias entre los grupos de poblaciones).

Para determinar el número óptimo de grupos o clústeres $(K)$, se han de tener en cuenta dos criterios diferentes. En el primero de ellos, se considera como valor óptimo de $\mathrm{K}$ aquel para el cual el valor de $\mathrm{F}_{\text {ст }}$ alcanza su máximo o, en su caso, se estabiliza en su incremento. El segundo criterio afecta a la configuración interna de los K-clústeres, de manera que considera que las configuraciones con uno o más clústeres constituidos por una única población no se deben de tener en cuenta, ya que ello es indicativo de que la estructura de grupos está desapareciendo (Heuertz et al. 2004; Shi et al. 2010; Magri et al. 2006).

El análisis se realizó para valores de $\mathrm{K}$ de 2 a 10 para identificar el número más probable de grupos en las 19 poblaciones estudiadas, habiéndose utilizado 10000 simulaciones MCMC (Markov chain Monte Carlo). Para que la configuración final de los $\mathrm{K}$ grupos no se vea afectada por una configuración inicial dada, el proceso de simulated annealing fue repetido 500 veces, comenzando cada vez desde una configuración inicial aleatoria de las 19 poblaciones en cada uno de los K grupos.

Finalmente, se llevaron a cabo diversos análisis de la varianza molecular (AMOVA). En primer lugar, uno de carácter general, considerando sólo las 19 poblaciones de U. glabra, sin distinguir 
agrupamientos. En un segundo análisis se consideraron los grupos definidos por SAMOVA y, por último, análisis individuales para cada uno de esos clústeres o grupos. Todos estos análisis fueron llevados a cabo utilizando el programa Arlequin 3.5 (Excoffier et al. 2006). Con objeto de determinar el nivel de significación de la partición de la diversidad entre grupos, entre poblaciones dentro de los grupos y entre individuos dentro de las poblaciones, se realizaron test de 10000 permutaciones.

\section{5. Datos de presencia de U. glabra en la península ibérica}

Para llevar a cabo la modelización ecológica se procedió a recopilar datos de poblaciones georreferenciadas de olmo de montaña en la península ibérica. Para ello, se consultó el principal proveedor de datos de diversidad (Global Biodiversity Information Facility, GBIF; fecha de consulta: 08/05/2017). Actualmente esta herramienta dispone de un total de 2029 datos georreferenciados de presencia de U. glabra en España y tan solo 18 en Portugal. La información es facilitada por 35 proveedores diferentes de datos entre los que destacan el Real Jardín Botánico de Madrid-CSIC, el Banco de datos de cormófitos de Cataluña y el Banco de datos de la Comunidad Valenciana; los cuales aportan más del $75 \%$ de los datos facilitados a través de GBIF.

Para completar la información, también se procedió a la solicitud de datos a otros proveedores que no necesariamente sirven datos a través de GBIF como el Sistema de Información de la Vegetación Ibérica y Macaronésica (SIVIM), el Banc de Dades de la Biodiversitat de Catalunya (BDBC), el Servicio de Montes y Espacios Naturales de la Junta de Comunidad de Castilla-La Mancha, el herbario de Jaca, el Banco de Datos Biodiversidad de la Comunidad Valenciana (BDDB) y el Herbario de la Universidad de Murcia (MUB).

A continuación, se procedió a la depuración de errores y eliminación de datos sin concordancia entre las coordenadas y la descripción de localidad, así como la eliminación de referencias con precisión insuficiente. También, en la medida de lo posible, se trató de asignar a una de las cuatro cuadrículas UTM $500 \mathrm{~m}$ los datos con precisión de $1 \mathrm{~km}$, teniendo en cuenta los detalles de localidad facilitados.

Para completar la matriz de datos se añadieron los obtenidos en campo por el equipo de investigación mediante prospecciones realizadas en los últimos años en el Sistema Central. Estos datos, de gran precisión, fueron tomados mediante la georreferenciación con GPS in situ. En total se han localizado 1047 individuos en un total de 27 poblaciones.

Finalmente, un total de 2117 presencias georreferenciadas de U. glabra fueron empleadas para la generación de una matriz de presencias. Para ello, se generó una malla de 2332999 cuadrículas de 
$500 \mathrm{~m}$ cubriendo toda la península ibérica, sobre la cual se superpuso los datos de presencias de olmo de montaña. Los más de 2000 datos de presencia de olmo de montaña ocuparon un total de 774 celdas de $500 \mathrm{~m}$.

\section{6. Caracterización ecogeográfica}

\subsection{Variables ambientales}

Para llevar a cabo la caracterización ecológica y la modelización de U. glabra, se emplearon datos tanto climatológicos como geológicos. Las variables climáticas se obtuvieron del Atlas Climático Ibérico (AEMET \& IM 2011) realizado conjuntamente por la Agencia Estatal de Meteorología (AEMET) y el Instituto Português do Mar e da Atmosfera (IPMA). Estos datos modelizan la normal climática 19712000 (Global Estándar Climate Normal, World Meteorological Organization) para la península ibérica a una resolución de celdas de 500 m por regresión múltiple (stepwise multivariate regression) de los valores de la red de estaciones climatológicas de España (AEMET) y Portugal (IPMA) incorporando valores de un total de 4540 estaciones pluviométricas y 1503 estaciones termométricas. Estas estaciones se caracterizan por tener la mayor estabilidad temporal (series temporales para el periodo base), densidad (cobertura espacial) y homogeneidad (Test de Mann) para la serie temporal escogida.

Los datos puntuales procedentes de las estaciones meteorológicas (variable dependiente) fueron interpolados a partir de la información geográfica (latitud, la distancia al océano y la altitud; ver Tabla 3.5) al conjunto de la península ibérica, para una resolución espacial de $500 \mathrm{~m}$ de cuadrícula. De este modo, cada mapa obtenido tiene asociado un valor de precisión, calculado mediante regresión múltiple entre los datos independientes observados y los valores predichos. El método de regresión utilizado fue una regresión múltiple con corrección residual. Una vez elaborado el modelo para cada variable climática, se calculan y cartografían los residuos mediante interpolación, para finalmente corregir el modelo climático realizado. De este modo, se mejora la modelización de cada una de las variables climáticas al asociar a cada mapa obtenido un valor de precisión (Ruiz-Labourdette et al. 2013; Ninyerola et al. 2007a; Ninyerola et al. 2007b). La combinación de los modelos globales obtenidos con regresión múltiple junto con la interpolación de los residuos ha mostrado presentar los resultados de mayor precisión (Ninyerola et al. 2007a).

Por otro lado, las 11 clases litológicas empleadas fueron obtenidas del mapa geológico de mayor resolución para la península ibérica a escala 1:1000000 (Instituto Tecnológico Geominero Español y del Laboratório Nacional de Energia e Geología Portugués, 2015). 
Tabla 3.5. Factores abióticos empleados en los análisis. Los factores climáticos y geológicos fueron modelados mediante CHAID para obtener el modelo de ausencia/presencia de U. glabra. Stepwise multivariate regression fue empleada en los factores geográficos para obtener mapas climáticos.

\begin{tabular}{ll}
\hline Factores & Variables \\
\hline Modelización de presencia/ausencia de U. glabra mediante CHAID \\
Climáticos (Continuos) & Pluviosidad en primavera \\
& Pluviosidad en verano \\
& Pluviosidad en otoño \\
& Pluviosidad en invierno \\
& Pluviosidad conjunta en primavera, otoño e invierno \\
& Pluviosidad anual \\
& Temperatura media anual \\
& Media de diaria las temperaturas máximas en verano \\
& Media diaria de las temperaturas mínimas diarias en invierno \\
& Oscilación térmica anual (diferencia de temperatura media \\
& entre febrero-julio) \\
& Pre-Hercínica \\
& Proterozoica \\
& Hercínica \\
Proterozoica-Paleozoica & Palaeozoica \\
Peoleozoica-Mesozoica \\
Pesozoica \\
Mescticia) \\
Mesozoica-Cenozoica \\
Terciaria \\
Terciria-Cuaternaria \\
Cuaternaria \\
Altitud \\
Distancia al litoral \\
Latitud \\
\\
\hline
\end{tabular}

\subsection{Caracterización ambiental de U. glabra}

Una vez representadas las 2117 localidades de olmo de montaña (ver Figura 1.3), se procedió a la extracción de la información de las diez variables climáticas, así como la categoría litológica y la altitud de cada una de las localidades (presencias) (ver Figura 1.3) mediante el software ArcGis 10.3 (ESRI, 2014). Para las variables climáticas y la altitud, se calculó la media y la desviación estándar para 
dos grupos de datos de presencia: 1) la península ibérica en su conjunto y, 2) las poblaciones del Sistema Central. Para ello, se realizó una prueba no paramétrica de $U$ de Wilcoxon-Mann-Whitney (Wilcoxon 1945; Mann \& Whitney 1947) con el programa Statgraphics Centurion XVII (StatPoint Inc.). El objetivo es evaluar la existencia de diferencias significativas $(P<0,05)$ entre las dos regiones. También se analizó la existencia de diferencias significativas en la categoría litológica de los dos grupos, mediante una prueba de contingencia $X^{2}$ (Pearson 1900) para variables categóricas.

\subsection{Elaboración del modelo de distribución de U. glabra}

El modelo de distribución para olmo de montaña en el Sistema Central fue obtenido mediante modelos de extracción de datos (Chi-square automatic interaction detection, CHAID; Kass 1980; ver Tabla 3.5). Para ello, se emplearon los softwares ArcGis 10.3 (ESRI, 2014) para el análisis espacial (modelo probabilístico y proyección binaria de ausencias y presencias) y SPSS 23 (IBM, 2014) para el análisis estadístico. Este modelo es una variante del método AID (Automatic Interaction Detection) (Friedman 1999) diseñado para una variable dependiente categorizada, del que se diferencia principalmente en que incluye un test de significanción incorporado, por lo que emplea el predictor más significativo en vez del más explicativo; que usa desviaciones multidisciplinarias en vez de binarias; y el empleo de un nuevo tipo de predictor útil en el manejo de la información faltante. Por tanto, el análisis CHAID construye un modelo predictivo o árbol que ayuda a determinar cómo las variables se unen mejor para explicar los resultados en una variable dependiente dada. Además, en este análisis se pueden emplear datos nominales, ordinales y continuos, siendo divididos los predictores continuos en categorías con aproximadamente igual número de observaciones. El análisis CHAID es capaz de crear todas las posibles divisiones para cada predictor categórico hasta obtener los mejores resultados; es decir, no es posible realizar ninguna división adicional.

Con objeto de comprobar la robustez de nuestro modelo, se realizó una evaluación independiente (validación cruzada o k-fold cross-validation) en la que se retiene una fracción de los datos utilizando una fracción de $k$ veces (o subconjuntos) el set de datos original (Kohavi 1995). En nuestro caso, empleamos $k=10$ subconjuntos de datos. Para cada uno de los $k$ análisis, empleamos $k$-1 subconjuntos de datos para la capacitación ( $90 \%$ de los datos) mientras que el 10\% restante (un $k$ subconjunto) se empleó para testar. A diferencia de otros métodos, todos los datos se emplean para la capacitación y el testeo; empleando en cada $k$ análisis parte de los datos para modelar y parte para evaluar el modelo obtenido. Esto hace que sea de especial utilidad cuando se dispone de pocos datos (Ruiz-Labourdette et al. 2011). Finalmente, con objeto de generar una proyección consenso binaria de 
ausencias/presencias, se elaboró la matriz de confusión (ver Tabla 3.6), que maximiza el valor umbral del TSS (Allouche et al. 2006).

Tabla 3.6. Matriz de confusión empleada para el cálculo de los principales estadísticos que valoran la bondad de los modelos de predicción de presencia-ausencia. En ella, a y d representan el número de veces que el resultado esperado coincide con el observado; mientras que $b$ y $c$ se corresponden con el número de veces en las que no coinciden. A partir de la suma de estos, se calculan los valores $n_{1}(a+c), n_{0}(b+d), m_{1}(a+b), m_{0}(c+d)$ y $n(a+b+c+d)$.

\begin{tabular}{l|lll}
\cline { 2 - 4 } & Resultado & Observado & Total \\
\hline Resultado Esperado & Presencia & Ausencia & \\
Presencia & $\mathrm{a}$ & $\mathrm{b}$ & $\mathrm{m}_{1}$ \\
Ausencia & $\mathrm{c}$ & $\mathrm{d}$ & $\mathrm{m}_{0}$ \\
Total & $\mathrm{n}_{1}$ & $\mathrm{n}_{0}$ & $\mathrm{n}$ \\
\hline
\end{tabular}

A partir de esta matriz se calcularon parámetros esenciales como la sensibilidad del modelo $\left(a / n_{1}\right)$ o la especificidad $\left(d / n_{0}\right)$, la prevalencia $\left(n_{1} / n\right)$, el acierto $((a+d) / n)$, el riesgo (1-acierto) o el propio estadístico TSS (sensibilidad+especificidad-1) (Allouche et al. 2006) (ver Tabla 3.6). Aunque tradicionalmente se ha empleado el valor kappa ( $\mathrm{k}$ ) para evaluar el rendimiento de la predicción de los modelos generados de presencia-ausencia, este estadístico es dependiente de la prevalencia; es decir, dependiente del número de datos de presencia recopilados (Allouche et al. 2006; Viera \& Garrett 2005). El estadístico TSS es independiente de la prevalencia y además es una medida simple e intuitiva para evaluar la bondad de ajuste de los modelos de ausencia-presencia (Allouche et al. 2006).

\section{7. Evaluación del grado de amenaza}

A la hora de elaborar propuestas de gestión enfocadas a la conservación de una especie 0 , en este caso a las poblaciones del olmo de montaña del Sistema Central, primero es necesario conocer su estado de amenaza. Para ello utilizamos las categorías y los criterios establecidos por la UICN (2012a). Aunque el método está diseñado para evaluar a las especies en su conjunto, la propia UICN permite la evaluación de los taxones a nivel regional entendiendo como tal cualquier zona geográfica que forme parte de su distribución, como un continente, país, estado o provincia (UICN 2012b). Los criterios que toma en consideración esta metodología son:
A. Reducción del contingente total de individuos maduros
B. Distribución geográfica reducida
C. Número de individuos maduros y disminución continua 


\section{Número de individuos maduros}

E. Análisis cuantitativo que señale probabilidad de extinción

Para llevar a cabo la evaluación del taxón con cada uno de estos criterios es necesario la obtención de los siguientes datos:

1. La extensión de presencia y el área de ocupación de la especie en el territorio, calculados con el software ArcGIS 10.3 (ESRI, 2014).

2. Censo de los individuos maduros. El equipo de investigación, además de determinar la corología de la especie en el Sistema Central también realizó un censo de la especie en el 2008, trabajo que se ha ido completando a lo largo de este tiempo con nuevas poblaciones localizadas en estos años. El censo se hizo combinando conteo directo en aquellos núcleos con pocos ejemplares y estimaciones en los enclaves donde la densidad era muy alta. De todos los ejemplares censados se midió su talla y diámetro a la altura de 1,30 m (datos no publicados). Estos datos sirvieron de base para el cálculo del número de ejemplares maduros en cada población. Para este cálculo, se consideró el crecimiento anual del diámetro medio calculado para una población del Sistema Central (1,44 cm/año en Valle de Iruelas) (Maqueda 2006); junto con los datos de la primera floración estimada en olmos (7 años) (López Almansa \& Gil 2003). Por tanto, a los 7 años, cuando un ejemplar florece y puede producir semillas, es decir se puede considerar como maduro, alcanza un diámetro aproximado de $10 \mathrm{~cm}$.

3. Otro dato importante para la evaluación es determinar el número de subpoblaciones en las que se distribuyen los efectivos de la especie. Según la UICN, se consideran subpoblaciones independientes a todo conjunto de individuos ubicados a más de una distancia umbral que imposibilita el intercambio genético o éste es despreciable (UICN 2012a). Actualmente carecemos de un estudio específico de Ulmus glabra que muestre con precisión la distancia a la que puede tener intercambio génico. Ante esta carencia hemos utilizado como referencia aceptable la distancia máxima de flujo polínico (1200 m) descrita en U. laevis (Nielsen \& Kjær 2010a). Por tanto, se consideraron como subpoblaciones diferentes a los individuos ubicados a una distancia mayor de 1,2 km.

4. Un factor de riesgo importante es el grado de fragmentación de la población. Para ello hay que calcular el número de subpoblaciones cuyo número de individuos maduros es inferior a la Población Mínima Viable (conocido por sus siglas en inglés MVP). Para ello hemos utilizado la metodología y recomendaciones establecidas en el proyecto Atlas de Flora Vascular Amenazada de España (Blanca \& Marrero 2004). La MVP es el número de individuos en una población requeridos para tener una probabilidad de persistencia en un periodo dado de tiempo; usualmente un $99 \%$ de probabilidad de persistencia para un periodo de 100 años o 40 generaciones (Brook et al. 2008). Actualmente falta un 
trabajo específico sobre Ulmus glabra que nos informe de su MVP. En estos casos, la metodología de la AFA estableció unos números orientativos de población mínima viable (MVP) (Blanca \& Marrero 2004), que se han aplicado a los estudios del proyecto Atlas y Libro Rojo de la Flora Vascular Amenazada de España (Bañares et al. 2004). Estos valores se basan en la longevidad del taxón y en su papel en la dinámica de la vegetación (p.e. si es una especie propia de comunidades pioneras, climácicas, etc.). Esto supuso un problema adicional, ya que hasta la fecha no se ha determinado con precisión cuantos años puede vivir Ulmus glabra, aunque hay algunas referencias que afirman que puede vivir unos 300 años, pero sin aportar datos que respalden esa afirmación. El papel geobotánico de Ulmus glabra es más sencillo ya que se trata de una especie arbórea propia de bosques maduros. Por tanto, sus valores de MVP son: 100 individuos si consideramos que es una especie Medianamente longeva (25-100 años), o 50 individuos, si consideramos que es una especie Muy longeva (>100 años). Ante esta incertidumbre, se analizó el MVP bajo estos dos supuestos. 


\section{RESULTADOS}

\section{1. Diversidad genética nuclear}

El análisis realizado con los 11 microsatélites en las 442 muestras de olmo (427 de U. glabra y 15 de U. minor) reveló 101 alelos, de los cuales 92 se detectaron en U. glabra (Tabla 4.1). Más de la mitad de esos alelos (50 de los 92) presentaron frecuencias inferiores a 0,05 ; mientras que sólo cinco de ellos mostraron frecuencias superiores a 0,5 (ver Tabla 4.1)

Los resultados de diversidad genética obtenidos para los 11 loci SSR analizados en las poblaciones de $U$. glabra se muestran en la Tabla 4.2. El número de alelos por locus $\left(\mathrm{N}_{\mathrm{A}}\right)$ varió entre 3 para UR123 y 23 en el caso de Ulmi1-165; mientras que la media fue de 8,4 alelos por locus. Por otro lado, la media del número efectivo de alelos por locus $\left(\mathrm{N}_{\mathrm{E}}\right)$ fue de 3,6 , variando entre 10,4 para Ulmi1-165 y 1,2 en el caso de Ulm2. El número medio de genotipos diferentes observados (Go) en cada población fue de 23,6, siendo el valor máximo (95) nuevamente para Ulmi1-165 y el mínimo (5) para UR123 (Tabla 4.2).

En cuanto a los niveles de diversidad, los valores medios de la heterocigosidad observada $\left(H_{0}\right)$ y esperada $\left(H_{E}\right)$ fueron, respectivamente, 0,477 y 0,566 ; en ambos casos, los valores máximos se obtuvieron para Ulmi1-165, mientras que los valores más bajos fueron reportados para Ulm2 (Tabla 4.2). El índice de información de Shannon (I) para el conjunto total de los loci analizados fue 1,272; alcanzando un valor máximo $(2,639)$ para Ulmi1-165 y mínimo $(0,356)$ para Ulm2. Resultados similares se obtuvieron para el contenido de información polimórfica (PIC) y el poder de discriminación (D). En el primer caso (PIC), el valor máximo y el valor mínimo fueron para Ulmi1-165 $(0,899)$ y Ulm2 $(0,141)$, respectivamente, con un valor medio de 0,539 . En el segundo caso (D), los valores máximo y mínimo fueron nuevamente para Ulmi1-165 $(0,974)$ y para Ulm2 $(0,269)$; con una probabilidad acumulada global prácticamente de 1 (ver Tabla 4.2). De forma general, los microsatélites desarrollados en U. minor (serie Ulmi1-SSR) mostraron mayores valores de $\mathrm{N}_{\mathrm{A}}, \mathrm{N}_{\mathrm{E}}, \mathrm{Go}$, heterocigosidad, PIC y D, mientras que los valores más bajos fueron para los Ulm-SSR, descritos sobre U. laevis. 
Tabla 4.1. Tamaño de los alelos (en pares de bases, pb) detectados y sus frecuencias para cada uno de los 11 loci de microsatélites analizados en 427 muestras de $U$. glabra y 15 de U. minor del Sistema Central.

\begin{tabular}{|c|c|c|c|c|c|c|c|c|c|c|c|c|c|c|c|}
\hline Loci & $\begin{array}{l}\text { Alelos } \\
\text { (pb) }\end{array}$ & U. glabra & U. minor & Loci & $\begin{array}{l}\text { Alelos } \\
\text { (pb) }\end{array}$ & U. glabra & U. minor & Loci & $\begin{array}{l}\text { Alelos } \\
(\mathrm{pb})\end{array}$ & U. glabra & U. minor & Loci & $\begin{array}{l}\text { Alelos } \\
\text { (pb) }\end{array}$ & U. glabra & U. minor \\
\hline \multirow[t]{6}{*}{ Ulm2 } & 99 & --- & 0,167 & \multirow[t]{6}{*}{ Ulmi1-21 } & 212 & 0,071 & --- & \multirow[t]{17}{*}{ Ulmi1-165 } & 167 & 0,012 & -- & \multirow[t]{3}{*}{ UR138 a } & 236 & 0,060 & PM \\
\hline & 102 & 0,002 & 0,433 & & 214 & 0,030 & --- & & 169 & 0,039 & --- & & 242 & 0,311 & PM \\
\hline & 105 & 0,924 & --- & & 216 & 0,335 & --- & & 171 & 0,094 & --- & & 244 & 0,157 & PM \\
\hline & 108 & 0,023 & 0,333 & & 218 & 0,075 & --- & & 173 & 0,002 & --- & \multirow[t]{7}{*}{ UR153 } & 177 & 0,135 & --- \\
\hline & 111 & 0,014 & --- & & 220 & 0,062 & --- & & 175 & 0,116 & --- & & 183 & --- & 0,333 \\
\hline & 114 & 0,036 & 0,067 & & 224 & 0,100 & --- & & 177 & 0,068 & --- & & 186 & 0,004 & 0,667 \\
\hline \multirow[t]{10}{*}{ Ulm3 } & 164 & 0,011 & --- & \multirow[t]{11}{*}{ Ulmi1-98 } & 123 & --- & 0,333 & & 179 & 0,040 & --- & & 188 & 0,438 & --- \\
\hline & 167 & 0,082 & --- & & 145 & 0,033 & --- & & 183 & 0,011 & --- & & 191 & 0,272 & --- \\
\hline & 170 & 0,001 & --- & & 147 & 0,023 & --- & & 185 & 0,093 & --- & & 194 & 0,009 & --- \\
\hline & 173 & 0,046 & --- & & 151 & 0,059 & 0,633 & & 187 & 0,009 & --- & & 202 & 0,143 & --- \\
\hline & 176 & 0,005 & --- & & 154 & 0,237 & --- & & 189 & 0,025 & --- & \multirow[t]{9}{*}{ UR173a a } & 151 & 0,057 & PM \\
\hline & 179 & 0,009 & 0,033 & & 155 & 0,041 & 0,033 & & 191 & 0,028 & --- & & 154 & 0,566 & PM \\
\hline & 182 & 0,834 & 0,933 & & 156 & 0,206 & --- & & 195 & 0,009 & --- & & 156 & 0,035 & PM \\
\hline & 185 & 0,008 & --- & & 158 & 0,343 & --- & & 197 & 0,104 & --- & & 158 & 0,016 & PM \\
\hline & 190 & --- & 0,033 & & 160 & 0,005 & --- & & 199 & 0,033 & --- & & 170 & 0,268 & PM \\
\hline & 200 & 0,005 & --- & & 164 & 0,008 & --- & & 201 & 0,023 & --- & & 172 & 0,004 & PM \\
\hline \multirow[t]{5}{*}{ Ulm8 } & 189 & --- & 0,067 & & 166 & 0,046 & --- & & 205 & 0,004 & --- & & 174 & 0,008 & PM \\
\hline & 192 & 0,061 & 0,933 & Ulmi1-165 & 144 & -.-- & 0,400 & UR123 & 250 & --- & 0,033 & & 181 & 0,016 & PM \\
\hline & 195 & 0,864 & --- & & 152 & 0,027 & 0,033 & & 252 & 0,845 & 0,500 & & 185 & 0,029 & PM \\
\hline & 201 & 0,063 & --- & & 155 & --- & 0,333 & & 254 & 0,105 & 0,433 & \multirow[t]{7}{*}{ UR175 } & 216 & 0,337 & --- \\
\hline & 204 & 0,012 & --- & & 157 & 0,204 & 0,067 & & 256 & 0,049 & 0,033 & & 218 & 0,190 & --- \\
\hline \multirow[t]{5}{*}{ Ulmi1-21 } & 200 & 0,090 & --- & & 159 & 0,008 & --- & \multirow[t]{5}{*}{ UR138 } & 220 & 0,055 & PM & & 220 & 0,358 & --- \\
\hline & 206 & --- & 0,367 & & 161 & 0,007 & 0,067 & & 232 & 0,352 & PM & & 222 & 0,036 & 0,533 \\
\hline & 208 & 0,114 & 0,633 & & 163 & 0,035 & 0,100 & & 233 & 0,028 & PM & & 224 & 0,001 & 0,467 \\
\hline & 210 & 0,123 & --- & & 165 & 0,011 & -- & & 235 & 0,036 & PM & & 233 & 0,073 & -- \\
\hline & & & & & & & & & & & & & 236 & 0,005 & --- \\
\hline
\end{tabular}

a Loci microsatéllites que presentaron patrones multibanda (PM) en U. minor, por lo que no pudieron ser analizados en esta especie. 
Tabla 4.2. Parámetros de diversidad genética para los 11 loci SSR analizados en 427 individuos de $U$. glabra del Sistema Central.

\begin{tabular}{lrrrrrcccc}
\hline Loci & $\mathrm{N}_{\mathbf{A}}$ & $\mathrm{N}_{\mathrm{E}}$ & $\mathbf{G}_{\mathrm{O}}$ & $\mathrm{H}_{\mathrm{O}}$ & $\mathrm{H}_{\mathrm{E}}$ & $\mathbf{I}$ & $\mathbf{P I C}$ & $\mathbf{C}$ & $\mathbf{D}$ \\
\hline Ulm2 & 5 & 1,169 & 6 & 0,148 & 0,144 & 0,356 & 0,141 & 0,731 & 0,269 \\
UIm3 & 9 & 1,420 & 13 & 0,260 & 0,296 & 0,687 & 0,283 & 0,525 & 0,475 \\
Ulm8 & 4 & 1,325 & 6 & 0,246 & 0,245 & 0,523 & 0,234 & 0,577 & 0,423 \\
Ulmi1-21 & 9 & 5,757 & 34 & 0,520 & 0,826 & 1,979 & 0,809 & 0,068 & 0,932 \\
Ulmi1-98 & 10 & 4,444 & 32 & 0,670 & 0,775 & 1,736 & 0,743 & 0,091 & 0,909 \\
Ulmi1-165 & 23 & 10,365 & 95 & 0,806 & 0,904 & 2,639 & 0,899 & 0,026 & 0,974 \\
UR123 & 3 & 1,373 & 5 & 0,234 & 0,272 & 0,527 & 0,252 & 0,599 & 0,401 \\
UR138 & 7 & 3,928 & 18 & 0,712 & 0,745 & 1,570 & 0,706 & 0,109 & 0,891 \\
UR153 & 6 & 3,287 & 15 & 0,604 & 0,696 & 1,327 & 0,646 & 0,137 & 0,863 \\
UR173a & 9 & 2,514 & 20 & 0,539 & 0,602 & 1,254 & 0,552 & 0,196 & 0,804 \\
UR175 & 7 & 3,512 & 16 & 0,513 & 0,715 & 1,393 & 0,665 & 0,135 & 0,865 \\
Media & 8,4 & 3,554 & 23,6 & 0,477 & 0,566 & 1,272 & 0,539 & --- & --- \\
Acumulado & 92 & --- & 260 & --- & --- & -- & -- & $8,4 \times 10^{-9}$ & 0,999999992 \\
\hline
\end{tabular}

$\mathrm{N}_{A}$, número de alelos; $\mathrm{N}_{E}$, número efectivo de alelos; $\mathrm{G}_{\mathrm{O}}$, número de genotipos observados; $\mathrm{H}_{\mathrm{O}}$, heterocigosidad observada; $\mathrm{H}_{\mathrm{E}}$, heterocigosidad esperada; I, índice de diversidad de Shannon; PIC, contenido de información polimórfica; $C$, probabilidad de coincidencia; D, poder de discriminación.

El número de genotipos diferentes detectados gracias al empleo conjunto de los 11 SSR en los 427 individuos de U. glabra fue muy elevado (360; ver Anexo I). Únicamente 25 de esos 360 genotipos detectados fueron genotipos repetidos, presentes en más de una muestra. Si considerásemos sólo los tres loci Ulmi1-SSR, dichos loci presentan un poder de discriminación conjunto de 0,99984 y permiten distinguir 301 genotipos diferentes, en torno al $84 \%$ de los 360 genotipos detectados con los 11 loci microsatélites.

En la Tabla 4.3 se muestran los resultados del análisis de diversidad en las 22 poblaciones de U. glabra estudiadas. El porcentaje de loci polimórficos $(P)$ varió entre el $100 \%$ en ROZ, IRU y CVJ, y el $46 \%$ en CNT. En cuanto al número de genotipos detectados en cada una de las poblaciones, fue muy similar al número de individuos muestreados, salvo en CER, ROZ y MOM, donde $\mathrm{Go}_{0}$ fue menor del $30 \%$ de los individuos colectados (Tabla 4.3). Los mayores valores de número efectivo de alelos $\left(\mathrm{N}_{\mathrm{E}}=2,803\right)$, índice de diversidad de Shannon $(\mathrm{I}=1,047)$ y heterocigosidad esperada $\left(H_{E}=0,590\right)$ fueron observados en $R O Z$, mientras que los valores más bajos se detectaron en $\operatorname{RAS}\left(\mathrm{N}_{\mathrm{E}}=1,711, \mathrm{l}=0,547\right.$ and $\mathrm{H}_{\mathrm{E}}=0,310$; Tabla 4.3). También cabe destacar que los núcleos de ROZ y MOM mostraron los mayores valores de heterocigosidad observada 
( $H_{0}=0,838$ y 0,709 , respectivamente), los cuales se corresponden con un valor muy negativo del índice de fijación (F=-0,412 y -0,575, respectivamente; Tabla 4.3).

Por otra parte, también se observó la existencia de alelos exclusivos de población. En concreto, se detectaron 10 alelos exclusivos en siete de los 22 núcleos poblacionales analizados (NAV, MON, RAS, IRU, CAS, CVJ y MOM; ver Anexo I). Tres de esos diez alelos exclusivos fueron muy abundantes (Ulm2-111, Ulm3-164 y UR173a-185, descritos en CAS, MON y RAS, respectivamente), con frecuencias superiores al $50 \%$.

Tabla 4.3. Parámetros de diversidad genética calculados para las 22 poblaciones de U. glabra muestreadas en el Sistema Central usando datos de los 11 loci de microsatélites. Ver Tabla 1.1 para los códigos de población.

\begin{tabular}{lrrrrrrr}
\hline Población & $\mathbf{P}(\%)$ & $\mathbf{G}_{\mathrm{O}}(\mathrm{Nm})$ & \multicolumn{1}{c}{$\mathbf{N}_{\mathrm{E}}$} & $\mathbf{I}$ & $\mathbf{H}_{\mathrm{O}}$ & $\mathbf{H}_{\mathrm{E}}$ & $\mathbf{F}$ \\
\hline CNT & 46 & $1(1)$ & --- & -- & 0,455 & --- & --- \\
CNJ & 82 & $38(38)$ & 1,959 & 0,678 & 0,428 & 0,393 & $-0,086$ \\
BOC & 64 & $2(4)$ & --- & --- & 0,568 & --- & --- \\
RZA & 82 & $22(22)$ & 2,090 & 0,751 & 0,397 & 0,413 & 0,038 \\
NAV & 82 & $14(14)$ & 1,897 & 0,640 & 0,429 & 0,399 & $-0,090$ \\
MON & 73 & $7(7)$ & 2,045 & 0,728 & 0,416 & 0,404 & $-0,028$ \\
RAS & 82 & $29(33)$ & 1,711 & 0,547 & 0,309 & 0,310 & 0,017 \\
PAU & 64 & $1(1)$ & --- & --- & 0,636 & --- & --- \\
CER & 64 & $1(6)$ & --- & --- & 0,636 & --- & -- \\
ROZ & 100 & $13(46)$ & 2,803 & 1,047 & 0,838 & 0,590 & $-0,412$ \\
TIE & 73 & $39(42)$ & 2,213 & 0,769 & 0,394 & 0,443 & 0,089 \\
IRU & 100 & $56(57)$ & 2,222 & 0,867 & 0,445 & 0,435 & 0,006 \\
CAS & 82 & $21(21)$ & 2,136 & 0,695 & 0,398 & 0,376 & $-0,024$ \\
PIE & 73 & $5(7)$ & 2,048 & 0,666 & 0,442 & 0,371 & $-0,185$ \\
CVJ & 100 & $17(20)$ & 2,078 & 0,848 & 0,482 & 0,435 & $-0,089$ \\
CVA & 82 & $10(11)$ & 2,187 & 0,672 & 0,405 & 0,385 & $-0,052$ \\
MOM & 82 & $2(10)$ & 2,083 & 0,717 & 0,709 & 0,450 & $-0,575$ \\
CAN & 91 & $7(8)$ & 2,505 & 0,847 & 0,409 & 0,444 & 0,026 \\
ALD & 73 & $10(10)$ & 2,020 & 0,655 & 0,455 & 0,388 & $-0,132$ \\
VIL & 73 & $12(15)$ & 1,890 & 0,637 & 0,394 & 0,355 & $-0,097$ \\
STR & 82 & $28(29)$ & 2,161 & 0,807 & 0,464 & 0,434 & $-0,074$ \\
BEN & 91 & $25(25)$ & 2,233 & 0,828 & 0,491 & 0,475 & $-0,061$ \\
\hline
\end{tabular}

$P$, porcentaje de loci polimórficos; $G_{0}$, número de genotipos observados para el conjunto de todos los loci; $\mathrm{Nm}$, número de individuos muestreados; $\mathrm{N}_{\mathrm{E}}$, número efectivo de alelos medio; I, índice de información de Shannon medio; $\mathrm{H}_{\mathrm{O}}$, heterocigosidad observada media; $\mathrm{H}_{\mathrm{E}}$ heterocigosidad esperada media; F, índice de fijación calculado sobre todos los loci. Los parámetros $\mathrm{N}_{E}, \mathrm{I}, \mathrm{H}_{\mathrm{E}}$ y $\mathrm{F}$ no fueron calculados para las poblaciones con un tamaño de muestra inferior a 5 (CNT, BOC y PAU) o con un único genotipo (CER). 


\section{2. Relaciones genéticas entre poblaciones}

Las relaciones entre las 19 poblaciones de olmo de montaña con más de 5 individuos muestreados aparecen en el dendrograma UPGMA (ver Figura 4.1). El test de Mantel reveló una buena y significativa correlación cofenética $(r=0,87 ; P=0,0001)$, indicando un buen ajuste de las relaciones establecidas en el dendrograma y la matriz de distancias genéticas con la que se generó (Rohlf 2008). El dendrograma mostró a las poblaciones agrupadas en dos clústeres principales, separados a un nivel de distancia genética del 0,48 (Figura 4.1). En el primero de estos dos grupos, las poblaciones de ROZ y MOM aparecen juntas con un soporte del $66,5 \%$, mientras que, en el segundo clúster, aparecen las 17 poblaciones restantes con un soporte del 54,3\%. En este segundo clúster, las poblaciones de CER, RAS y MON aparecen como las más distanciadas de los otros 14 núcleos. Además, las poblaciones situadas más al oeste (VIL, STR y BEN) se agruparon juntas, especialmente VIL y STR, que se localizan en el mismo subgrupo y separadas del resto con un soporte del $72,4 \%$ (Figura 4.1).

Por otro lado, los resultados del AMOVA revelaron una elevada y significativa diferenciación entre las 19 poblaciones de U. glabra $(24 \% ; P=0,0001)$. La mayor parte de la varianza molecular se detectó dentro de las poblaciones (76\%). También fueron calculados los valores de diferenciación genética (FST) entre pares de poblaciones (Tabla 4.4), habiendo resultado todos ellos altamente significativos $(P<0,0005)$. El mayor valor de $F_{S T}$ fue observado entre RAS y MON $(46,3 \%)$ y los valores menores fueron para CAS-CAN y RZA-CAN (8,5\% en ambos casos; ver Tabla 4.4). 
Figura 4.1. Dendrograma generado con el método UPGMA, en el que se muestran las relaciones entre las 19 poblaciones de U. glabra del Sistema Central con al menos seis individuos muestreados, basadas en los datos de 11 loci SSR y usando la distancia genética de Nei. Los números en los nodos muestran el soporte del agrupamiento (>50\%) obtenido mediante análisis de bootstrap (10000 réplicas). Ver Tabla 1.1 para los códigos de población.
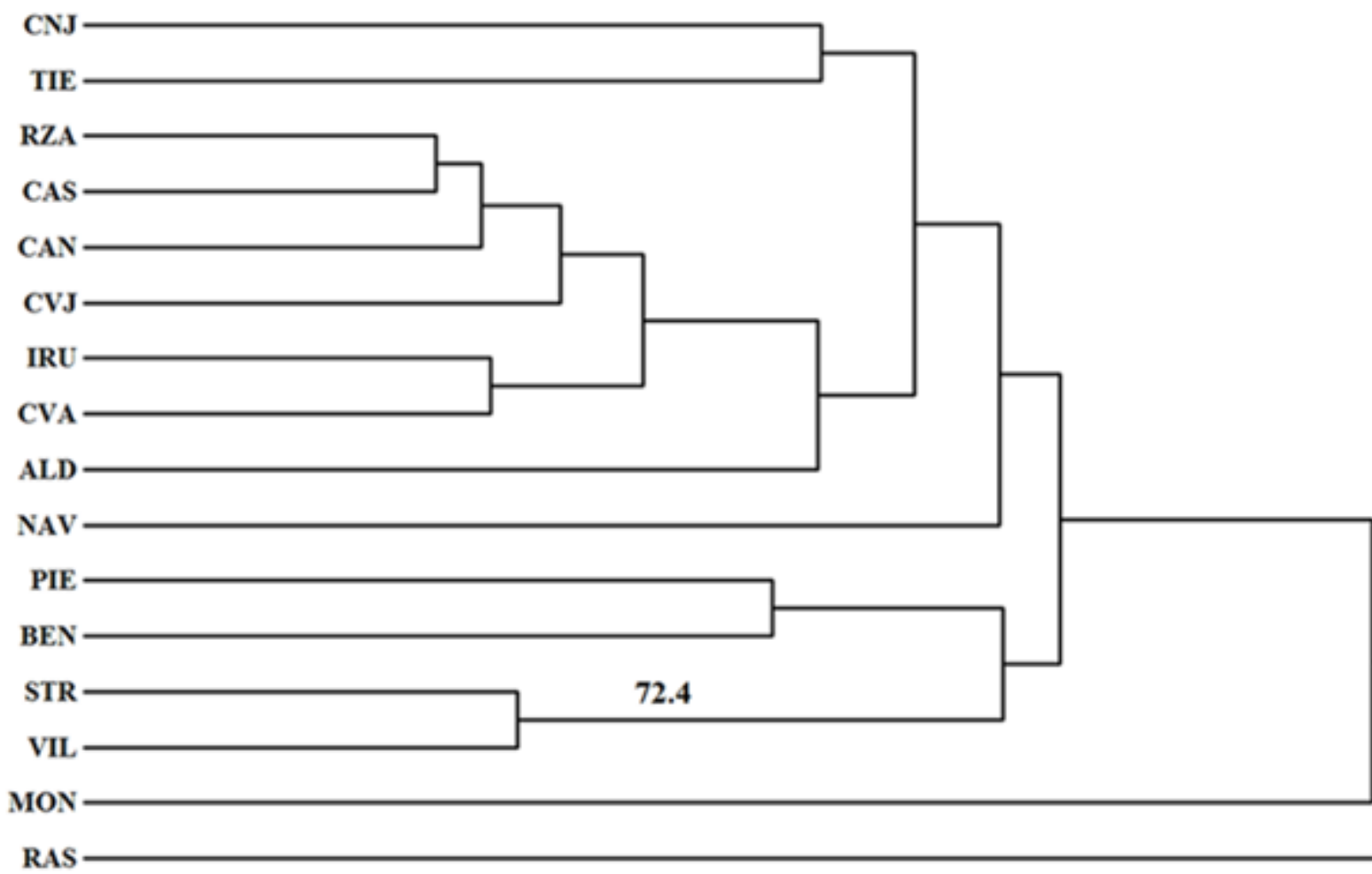

CER

$\mathrm{ROZ}$

MOM

0.0

0.1

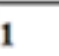

$(2$

Distancia genética de Nei 
Tabla 4.4. Valores de diferenciación genética ( $F_{\text {ST; }}$ debajo de la diagonal) y su significación ( $P$; sobre la diagonal), obtenidos entre las 19 poblaciones de $U$. glabra analizadas (poblaciones con Nm<5 -CNT, BOC y PAU- no se incluyeron en este análisis) con los datos de 11 loci SSR y usando el método AMOVA. La significación se obtuvo con 10000 permutaciones. El mayor valor de FST se muestra en negrita y los dos valores más bajos subrayados. Ver Tabla 1.1 para los códigos de población.

\begin{tabular}{|c|c|c|c|c|c|c|c|c|c|c|c|c|c|c|c|c|c|c|c|}
\hline & NJ & RZA & NAV & MON & RAS & CER & ROZ & TIE & IRU & CAS & PIE & CVJ & CVA & MOM & CAN & ALD & VIL & STR & BEN \\
\hline CNJ & & 0,0001 & 0,0001 & 0,0001 & 0,0001 & 0,0001 & 0,0001 & 0,0001 & 0,0001 & 0,0001 & 0,0001 & 0,0001 & 0,0001 & 0,0001 & 0,0001 & 0,0001 & 0,0001 & 0,0001 & 0,0001 \\
\hline RZA & 0,1812 & & 0,0001 & 0,0001 & 0,0001 & 0001 & 0001 & 0,0001 & 0,0001 & 0,0001 & 0,0001 & 0,0001 & 0,0001 & 0,0001 & 0,0001 & 0,0001 & 0,0001 & 0,0001 & 0,0001 \\
\hline NAV & 0,2952 & 0,1847 & & 0,0001 & 0,0001 & 0001 & 0001 & 0,0001 & 0,0001 & 0,0001 & 0,0001 & 0,0001 & 0,0001 & 0,0001 & 0,0001 & 0,0001 & 0,0001 &, 0001 & 0,0001 \\
\hline MON & 0,3279 & 0,2621 & 0,2253 & & 0,0001 & 0,0001 & 0,0001 & 0,0001 & 0,0001 & 0,0001 & 0,0001 & 0,0001 & 0,0001 & 0,0001 & 0,0001 & 0,0001 & 0001 & 0001 & 0,0001 \\
\hline RAS & 0,3788 & 3505 & 0,3373 & 0,3407 & & 0,0001 & 0001 & 0,0001 & 0,0001 & 0,0001 & 0,0001 & 0,0001 & 0,0001 & 0,0001 & 0,0001 & 0,0001 & 0001 & 0001 & 0,0001 \\
\hline CER & 2913 & 3073 & 3319 & 0,3239 & 0,4075 & & 0,0001 & 0,0001 & 0,0001 & 0,0001 & 0,0001 & & & & 0,0001 & 0,0001 & 0,0001 & & \\
\hline ROZ & 629 & 671 & 2806 & 0,3121 & 0,3358 & 0,2789 & & 0,0001 & & & & & & & & & & & \\
\hline & & 1945 & 2128 & 0,2493 & 0,3266 & 0,3101 & 0,2810 & & & & & & & & & & & & \\
\hline & & 0936 & & 0,2447 & 0,3234 & 0,2834 & & 0,1547 & & & & & & & & & & & \\
\hline CAS & 0,2557 & 0,0969 & 0,2175 & 0,2781 & 0,3506 & 0,3521 & 0,2768 & 0,2146 & 0,1613 & & 0,0001 & 0,0001 & 0,0001 & 0,0001 & 0,0003 & 0,0001 & 0,0001 & 0,0001 & 0,0001 \\
\hline PIE & 0,2959 & 0,1774 & 0,1767 & 0,2722 & 0,3385 & 0,3258 & 0,2394 & 0,2563 & 0,1529 & 0,2009 & & 0,0002 & 0,0001 & 0,0001 & 0,0001 & 0,0001 & 0,0001 & 0,0001 & 0,0001 \\
\hline CVJ & 0,2470 & 0,1208 & 0,2160 & 0,2424 & 0,2832 & 0,3234 & 0,2221 & 0,1811 & 0,1280 & 0,1182 & 0,1311 & & 0,0001 & 0,0001 & 0,0003 & 0,0001 & 0,0001 & 0,0001 & 0,0001 \\
\hline CVA & 0,2147 & 0,1266 & 0,1852 & 0,2853 & 0,3465 & 0,3610 & 0,2527 & 0,1535 & 0,0989 & 0,1639 & 0,2616 & 0,1345 & & 0,0001 & 0,0001 & 0,0001 & 0,0001 & 0,0001 & 0,0001 \\
\hline MOM & 0,3054 & 0,2930 & 0,3104 & 0,3466 & 0,4356 & 0,3701 & 0,1830 & 0,2394 & 0,2505 & 0,2997 & 0,3289 & 0,2738 & 0,2102 & & 0,0002 & 0,0001 & 0,0001 & 0,0001 & 0,0001 \\
\hline CAN & 0,2159 & $\underline{0,0845}$ & 0,1761 & 0,2117 & 0,3242 & 0,2568 & 0,2149 & 0,1513 & 0,1322 & $\underline{0,0845}$ & 0,1629 & 0,0921 & 0,1351 & 0,2020 & & 0,0001 & 0,0001 & 0,0001 & 0,0001 \\
\hline ALD & 0,2358 & 0,1881 & 0,2019 & 0,2457 & 0,3054 & 0,3042 & 0,2403 & 0,1830 & 0,1436 & 0,1903 & 0,2177 & 0,1461 & 0,2052 & 0,2859 & 0,1521 & & 0,0001 & 0,0001 & 0,0001 \\
\hline VIL & 0,3031 & 0,2785 & 0,2629 & 0,2368 & 0,3562 & 0,3577 & 0,3157 & 0,2193 & 0,2599 & 0,2836 & 0,2718 & 0,2326 & 0,3292 & 0,3294 & 0,2058 & 0,2390 & & 0,0001 & 0,0001 \\
\hline & & 2197 & 0,2397 & 0,2559 & 0,3416 & 0,3329 & 0,2863 & 0,1811 & 0,1672 & 0,2253 & 0,1997 & 0,1566 & 0,2366 & 0,2919 & 0,1398 & 0,1497 & 0,1162 & & 0,0001 \\
\hline BEN & 0,2120 & 2254 & 0,2184 & 0,2166 & 0,2580 & 0,1991 & 0,2216 & 0,1814 & 0,1664 & 0,2411 & 0,1380 & 0,1713 & 0,2122 & 0,2527 & 0,1577 & 0,1939 & 0,1924 & 0,1667 & \\
\hline
\end{tabular}




\section{3. Análisis demográfico}

En las Tablas 4.5 y 4.6 se muestran los resultados del análisis demográfico. En primer lugar, cabe destacar que al aplicar el test de rangos con signo de Wilcoxon sobre el estadístico $T_{2}$ calculado bajo el modelo mutacional TPM implementado en el programa BOTTLENECK, se detectó la existencia de cuellos de botella recientes y significativos $(P<0,05)$ en cuatro de las 15 poblaciones analizadas (NAV, ROZ, TIE y MOM; ver Tabla 4.5). Por otro lado, las 15 poblaciones analizadas mostraron evidencias de haber pasado por cuellos de botella ancestrales seguidos de posibles recuperaciones demográficas, tal y como indican los M-valores obtenidos, todos ellos inferiores a 0,68 (Tabla 4.5).

Tabla 4.5. Detección de cuellos de botella en las 15 poblaciones de U. glabra con al menos diez individuos muestreados, empleando el estadístico $T_{2}$ y los valores de $P$ obtenidos al aplicar el test de Wilcoxon bajo el modelo TPM (two-phase model) implementado en BOTTLENECK 1.2, así como los valores medios para el conjunto de todos los loci obtenidos para el M-valor calculado con Arlequin 3.5. Ver Tabla 1.1 para los códigos de población.

\begin{tabular}{cccc}
\hline Población & Estadístico $\mathrm{T}_{2}$ & Test de Wilcoxon $\left(\boldsymbol{P}\right.$ valores) $^{1}$ & M-valor \\
\hline CNJ & 0,2056 & 0,2480 & 0,2950 \\
RZA & 0,0192 & 0,5000 & 0,2725 \\
NAV & 0,6597 & 0,0068 & 0,3559 \\
RAS & $-0,1479$ & 0,7148 & 0,2892 \\
ROZ & 0,6865 & 0,0061 & 0,3702 \\
TIE & 0,6194 & 0,0195 & 0,2643 \\
IRU & $-1,6151$ & 0,9976 & 0,2780 \\
CAS & 0,0206 & 0,3672 & 0,2867 \\
CVJ & $-0,9445$ & 0,9976 & 0,3193 \\
CVA & 0,3550 & 0,1250 & 0,3320 \\
MOM & 0,9936 & 0,0010 & 0,2902 \\
ALD & 0,5103 & 0,1563 & 0,2149 \\
VIL & $-0,0650$ & 0,4727 & 0,2798 \\
STR & $-0,1423$ & 0,5898 & 0,2749 \\
BEN & 0,3321 & 0,1377 & 0,3196 \\
\hline
\end{tabular}

${ }^{1}$ Los valores significativos $(P<0,05)$ se muestran en cursiva.

Los valores del tamaño efectivo $\left(N_{e}\right)$ de las diez poblaciones que fueron analizadas se muestran en la Tabla 4.6. Los valores de $N_{e}$ obtenidos con los dos programas utilizados fueron, en general, muy bajos: inferiores a 20 en ocho (con el programa ONeSAMP) y en siete (con el 
programa LDNe) de las diez poblaciones analizadas. El valor más bajo de $N_{e}$ en ambos casos se obtuvo para ROZ (Tabla 4.6).

Tabla 4.6. Tamaño efectivo poblacional $\left(N_{e}\right)$ estimado en las 10 poblaciones de $U$. glabra con al menos 20 individuos muestreados, usando una aproximación computacional bayesiana (ONeSAMP 1.1) y un método de desequilibrio de ligamiento (LDNe 1.31). Entre paréntesis se muestran los valores del intervalo de confianza (IC) al 95\%. Ver Tabla 1.1 para los códigos de población.

\begin{tabular}{crr}
\hline Población & \multicolumn{2}{c}{$N_{e}(\mathbf{9 5 \%}$ IC) } \\
\cline { 2 - 3 } & \multicolumn{1}{c}{ ONeSAMP } & \multicolumn{1}{c}{ LDNe } \\
\hline CNJ & $18,3(14,7-24,6)$ & $11,4(4,7-23,1)$ \\
RZA & $17,9(14,0-26,2)$ & $12,8(7,3-25)$ \\
RAS & $16,6(12,4-24,5)$ & $2,2(1,4-3,3)$ \\
ROZ & $9,3(7,3-12,1)$ & $0,9(0,8-1,1)$ \\
TIE & $15,9(12,8-23,1)$ & $3(1,8-6,8)$ \\
IRU & $668,0(253,4-5277,2)$ & $16,6(10,9-25,2)$ \\
CAS & $18,5(15,3-24,2)$ & $29,1(11,6-1550,5)$ \\
CVJ & $10,0(8,1-12,8)$ & $1,2(1-1,4)$ \\
STR & $36,7(21,4-96,4)$ & $51,3(18,8-\infty)$ \\
BEN & $18,8(15,6-26,9)$ & $48,4(19,3-\infty)$ \\
\hline
\end{tabular}

\section{4. Estructura genética espacial}

En este apartado se detallan los resultados obtenidos del análisis de la estructura genética desde un punto de vista espacial en las poblaciones de olmo de montaña del Sistema Central, tanto a nivel global como poblacional.

\subsection{Estructura espacial global en el Sistema Central}

El análisis de la estructura genética espacial de U. glabra a lo largo de todo el Sistema Central (427 individuos muestreados en 22 poblaciones) se llevó a cabo mediante dos aproximaciones diferentes. En primer lugar, el test de correlación de Mantel entre la matriz de distancias geográficas y la matriz de distancias genéticas entre todos los individuos del Sistema Central muestreados resultó ser altamente significativo, a pesar de que la correlación obtenida fue baja $(r=0,150 ; P<0,0001)$.

Los resultados de la segunda aproximación, el análisis de autocorrelación espacial global, se muestran en la Figura 4.2 y en la Tabla 4.7. Cabe destacar que el número de pares de comparaciones empleados para cada clase de distancia fue alto ( $N>500$; ver Tabla 4.7), siendo 
suficientes para tener una buena resolución de la estructura genética espacial. El correlograma (Figura 4.2) resultó ser significativo para el test de heterogeneidad $(\Omega=209,237 ; P<0,001)$. Además, se observó que el coeficiente de autocorrelación $(r)$ disminuyó rápidamente con el incremento de la distancia en las primeras clases, siendo indicativo de la existencia de estructura espacial positiva significativa para dichas clases de distancia (Peakall et al. 2003). En la Figura 4.2 y en la Tabla 4.7 se aprecia que la correlación positiva significativa se da en las tres primeras clases de distancia (0-1 km, 1-2 km y 2-4 km; $P<0,001)$, siendo más elevados los valores del coeficiente de autocorrelación en las dos primeras clases ( $r=0,405$ y $r=0,229$, respectivamente). El punto de máximo alcance de la correlación positiva puede estimarse a partir de la intercepción de $r$ con el eje $\mathrm{x}$ de la hipótesis nula ( $r=0$, no existe estructura genética espacial); en este caso, a los 5,171 km (Figura 4.2 y Tabla 4.7). Asimismo, se ha detectado correlación negativa para las clases de distancia restantes (desde la clase de 4-6 km hasta la de 320-640 km; $P<0,05$ ), aunque en estos casos los valores de restimados son relativamente bajos, inferiores a 0,1 (Tabla 4.7).

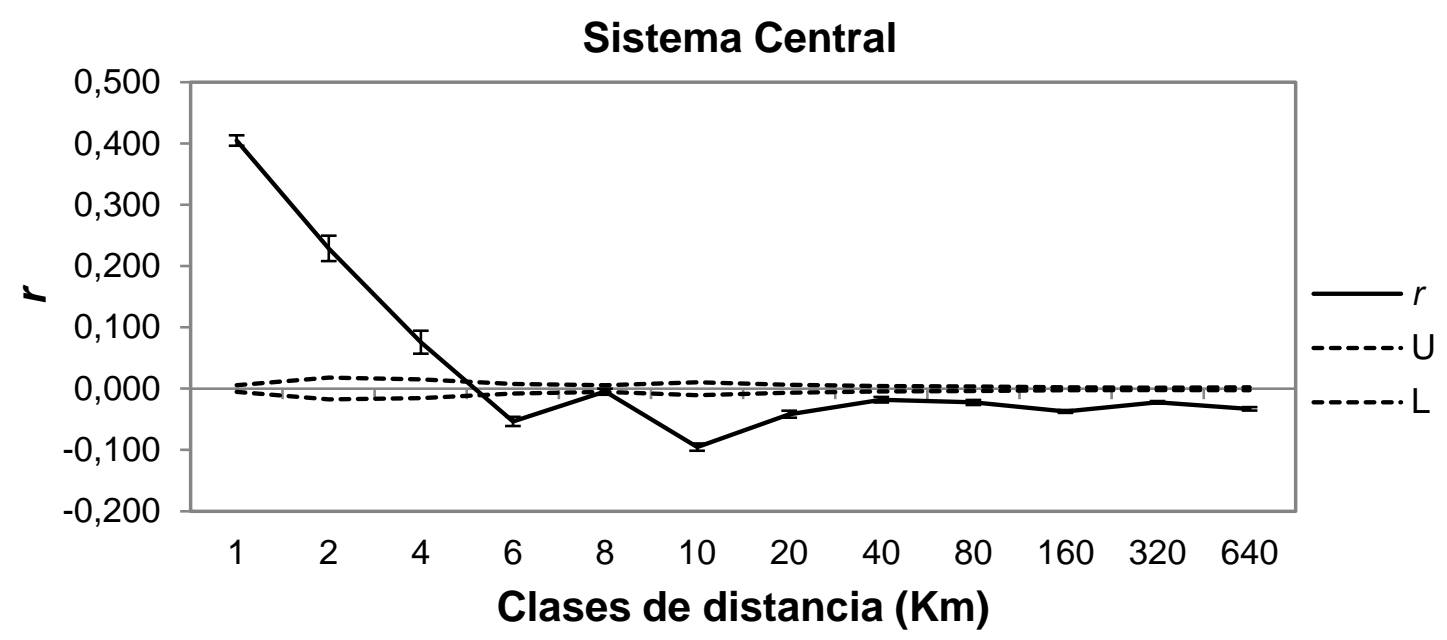

Figura 4.2. Correlograma obtenido del análisis espacial de la estructura genética para los 427 individuos de U. glabra del Sistema Central analizados con los datos de 11 loci de microsatélites. La línea continua representa los valores del coeficiente de autocorrelación (r) calculado para cada una de las 12 clases de distancia definidas (de 0-1 km a 320-640 km). Las líneas discontinuas indican los límites superior (U) e inferior $(L)$ del intervalo de confianza al $95 \%$ bajo la hipótesis nula de no existencia de estructura espacial $(r=0)$, obtenidos mediante 10000 permutaciones. Las barras verticales hacen referencia a las barras de error para cada estima de $r$, calculadas para un intervalo de confianza del $95 \%$ mediante 10000 remuestreos (bootstrap). 
Tabla 4.7. Análisis de autocorrelación espacial global para las 427 muestras de U. glabra del Sistema Central analizados con los datos de 11 loci de microsatélites. $\mathrm{N}$ : número de pares de comparaciones para cada una de las 12 clases de distancia definidas (de 0-1 km a 320-640 km); $r$ : coeficiente de autocorrelación; U y L : límites superior e inferior del intervalo de confianza al 95\% para aceptar la hipótesis nula de no existencia de estructura espacial $(r=0)$, obtenidos a partir de 10000 permutaciones; $P$ : probabilidad de existencia de autocorrelación positiva, $r_{\mathrm{e}}$ ( $r$ estimada) $\geq r_{0}(r$ observada), 0 de autocorrelación negativa, $r_{\mathrm{e}} \leq r_{\mathrm{o}} ; r_{\mathrm{B}}$ : valor medio de $r$ estimado por remuestreo (bootstrap); Ur y $L r$ : límites superior e inferior del intervalo de confianza al $95 \%$, determinados mediante 10000 remuestreos. En negrita se señalan los valores de $r$ que resultaron ser significativos $(P<0,05)$, así como su nivel de significación $(P)$. También se indica el punto de intercepción en km.

\begin{tabular}{|c|c|c|c|c|c|c|c|c|c|c|c|c|}
\hline $\begin{array}{l}\text { Clases de } \\
\text { distancia }(\mathrm{km})\end{array}$ & 1 & 2 & 4 & 6 & 8 & 10 & 20 & 40 & 80 & 160 & 320 & 640 \\
\hline $\mathbf{N}$ & 5566 & 563 & 655 & 2533 & 5061 & 1499 & 3550 & 5450 & 8901 & 17324 & 26069 & 13780 \\
\hline$r$ & 0,405 & 0,229 & 0,076 & $-0,053$ & $-0,005$ & $-0,095$ & $-0,042$ & $-0,018$ & $-0,022$ & $-0,037$ & $-0,022$ & $-0,033$ \\
\hline U & 0,006 & 0,018 & 0,015 & 0,008 & 0,005 & 0,010 & 0,006 & 0,004 & . 0,004 & 0,002 & 0,002 & 0,002 \\
\hline L & $-0,005$ & $-0,017$ & $-0,015$ & $-0,008$ & $-0,005$ & $-0,011$ & $-0,007$ & $-0,005$ & $-0,004$ & $-0,003$ & $-0,002$ & $-0,003$ \\
\hline$P\left(r_{\mathrm{e}} \geq r_{0}\right)$ & $<0,001$ & & $<0,001$ & 1,000 & 0,963 & 1,000 & 1,000 & 1,000 & 1,000 & 1,000 & 1,000 & 1,0000 \\
\hline$P\left(r_{\mathrm{e}} \leq r_{\mathrm{o}}\right)$ & 1,000 & 1,000 & 1,000 & $<0,001$ & 0,037 & $<0,001$ & $<0,001$ & $<0,001$ & $<0,001$ & $<0,001$ & $<0,001$ & $<0,001$ \\
\hline$x_{0}$ & 0,405 & 0,229 & 0,076 & $-0,054$ & $-0,005$ & $-0,095$ & $-0,042$ & $-0,018$ & $-0,022$ & $-0,037$ & $-0,022$ & $-0,033$ \\
\hline Ur & 0,008 & 0,021 & 0,019 & 0,008 & 0,005 & 0,006 & 0,006 & 0,005 & 0,004 & 0,002 & 0,002 & 0,0029 \\
\hline 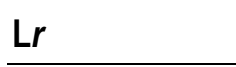 & 0,009 & 0,021 & 0,018 & 0,007 & 0,005 & 0,006 & 0,006 & 0,004 & 0,004 & 0,002 & 0,002 & 0,0028 \\
\hline
\end{tabular}

Intercepción $\quad 5,171$

\subsection{Estructura espacial poblacional}

Las dos aproximaciones llevadas a cabo sobre el total de muestras de U. glabra (test de Mantel y análisis de autocorrelación espacial), también fueron empleadas de forma particular en cada una de las diez poblaciones que contaban con al menos 20 individuos muestreados (ver Tabla 3.1). El test de Mantel arrojó resultados significativos en cinco de ellas: RZA $(r=0,166$; $P<0,05)$, ROZ $(r=0,649 ; P<0,0001)$, TIE $(r=0,526 ; P<0,0001)$, IRU $(r=0,234 ; P<0,01)$ y CAS $(r=0,214 ; P<0,05)$, indicando que existe aislamiento por distancia dentro de las mismas. Por el contrario, las poblaciones de CNJ, RAS, CVJ, STR y BEN no mostraron correlación significativa $(P>0,05)$.

Igualmente, para estas diez poblaciones se analizó la posible existencia de estructura genética espacial. En cuatro de las diez poblaciones analizadas (CNJ, RAS, CAS y STR) no se detectó estructura genética espacial significativa $(P>0,05)$; sin embargo, las seis poblaciones restantes (RZA, ROZ, TIE, IRU, CVJ y BEN) sí que mostraron una estructura genética espacial. A continuación, se describe con detalle los resultados obtenidos para cada una de estas seis poblaciones. 
En la Figura 4.3 y en la Tabla 4.8 se muestran los resultados obtenidos para el análisis de autocorrelación espacial realizado en la población de Riaza-Becerril (RZA). El número de individuos muestreados en RZA ( $\mathrm{Nm}=22$ ) permitió generar un total de seis clases de distancia con más de 30 pares de comparaciones dentro de cada una de ellas (Tabla 4.8). El test de heterogeneidad para el correlograma obtenido en RZA resultó ser no significativo $(\Omega=20,254$; $P>0,05)$; indicando que se trata de un correlograma homogéneo. A pesar de ello, sí que se detectó una baja autocorrelación positiva $(r=0,132)$ pero significativa $(P<0,01)$ para la primera clase de distancia (0-52 m). La distancia máxima hasta la que se puede intuir dicha estructura genética espacial, marcada por el punto de intercepción, está próxima a los 109 m (Figura 4.3 y Tabla 4.8). Además, cabe destacar que RZA no presentó autocorrelación negativa significativa en ninguna de las clases de distancia analizadas (ver Figura 4.3 y Tabla 4.8).

\section{RZA}

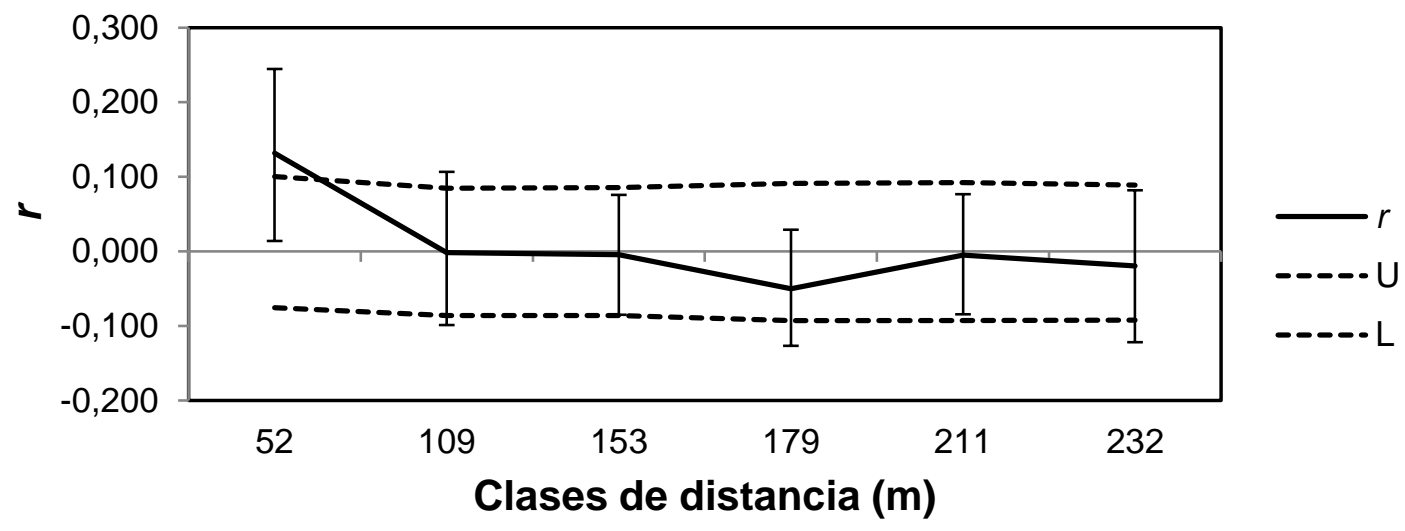

Figura 4.3. Correlograma obtenido del análisis espacial de la estructura genética para los 22 individuos de U. glabra de la población de Riaza-Becerril (RZA) analizados con los datos de 11 loci de microsatélites. La línea continua representa los valores del coeficiente de autocorrelación $(r)$ calculado para cada una de las seis clases de distancia definidas (de 0-52 $\mathrm{m}$ a 211-232 $\mathrm{m}$ ). Las líneas discontinuas indican los límites superior $(U)$ e inferior $(L)$ del intervalo de confianza al $95 \%$ bajo la hipótesis nula de no existencia de estructura espacial $(r=0)$, obtenidos mediante 10000 permutaciones. Las barras verticales hacen referencia a las barras de error para cada estima de $r$, calculadas para un intervalo de confianza del $95 \%$ mediante 10000 remuestreos (bootstrap). 
Tabla 4.8. Análisis de autocorrelación espacial para los 22 individuos de $U$. glabra pertenecientes a la población de Riaza-Becerril (RZA) analizados con los datos de 11 loci de microsatélites. $\mathrm{N}$ : número de pares de comparaciones para cada una de las seis clases de distancia definidas (de 0-52 $\mathrm{m}$ a 211-232 m); $r$ : coeficiente de autocorrelación; U y L : límites superior e inferior del intervalo de confianza al $95 \%$ para aceptar la hipótesis nula de no existencia de estructura espacial $(r=0)$, obtenidos a partir de 10000 permutaciones; $P$ : probabilidad de existencia de autocorrelación positiva, $r_{\mathrm{e}}(r$ estimada $) \geq r_{0}(r$ observada), 0 de autocorrelación negativa, $r_{\mathrm{e}} \leq r_{0}, r_{\mathrm{B}}$ : valor medio de $r$ estimado por remuestreo (bootstrap); Ur y $\mathrm{L} r$ : límites superior e inferior del intervalo de confianza al 95\%, determinados mediante 10000 remuestreos. En negrita se señalan los valores de $r$ que resultaron ser significativos $(P<0,05)$, así como su nivel de significación $(P)$. También se indica el punto de intercepción en $\mathrm{m}$.

\begin{tabular}{lrrrrrr}
\hline Clases de distancia $(\mathbf{m})$ & $\mathbf{5 2}$ & $\mathbf{1 0 9}$ & $\mathbf{1 5 3}$ & $\mathbf{1 7 9}$ & $\mathbf{2 1 1}$ & $\mathbf{2 3 2}$ \\
$\mathbf{N}$ & 33 & 35 & 35 & 34 & 33 & 33 \\
\hline $\boldsymbol{r}$ & $\mathbf{0 , 1 3 2}$ & $-0,002$ & $-0,004$ & $-0,050$ & $-0,005$ & $-0,020$ \\
$\mathbf{U}$ & 0,100 & 0,085 & 0,086 & 0,091 & 0,092 & 0,089 \\
$\mathrm{~L}$ & $-0,076$ & $-0,086$ & $-0,086$ & $-0,093$ & $-0,093$ & $-0,092$ \\
$\boldsymbol{P}\left(r_{\mathrm{e}} \geq r_{\mathrm{o}}\right)$ & $\mathbf{0 , 0 0 9}$ & 0,517 & 0,539 & 0,859 & 0,548 & 0,674 \\
$\boldsymbol{P}\left(r_{\mathrm{e}} \leq r_{\mathrm{o}}\right)$ & 0,992 & 0,483 & 0,461 & 0,142 & 0,452 & 0,327 \\
$r_{B}$ & 0,132 & $-0,002$ & $-0,005$ & $-0,052$ & $-0,004$ & $-0,019$ \\
$\mathrm{Ur}$ & 0,113 & 0,108 & 0,080 & 0,079 & 0,082 & 0,102 \\
$\mathrm{~L} r$ & 0,118 & 0,097 & 0,081 & 0,077 & 0,079 & 0,102 \\
\hline Intercepción & 108,308 & & & & &
\end{tabular}

Por otro lado, el análisis más fino de autocorrelación espacial (2D-LSA) en RZA se realizó para los seis vecinos más próximos, ya que la distancia media para $N=6(93,930 \mathrm{~m})$ fue la que resultó ser ligeramente inferior al valor del punto de intercepción (108,308 m; ver Tabla 4.8). En este caso, el análisis fino reveló la existencia de siete individuos que presentaron coeficientes de autocorrelación positivos y significativos $(P<0,05)$ con sus seis vecinos más próximos (Tabla 4.9). En la Figura 4.4 se observa como la distribución de estos siete individuos en la población no es homogénea, localizándose en dos grupos (en el norte y en el este, respectivamente).

Tabla 4.9. Individuos de la población de Riaza-Becerril (RZA) que presentaron correlación $(r)$ significativa $(P<0,05)$ con sus $\mathrm{N}=6$ vecinos más próximos. Ver Anexo I para los códigos de cada individuo.

\begin{tabular}{|c|c|c|c|c|c|}
\hline Individuo & $r$ & $P$ & Individuo & $r$ & $P$ \\
\hline RZA09 & 0,300 & 0,001 & RZA19 & 0,189 & 0,016 \\
\hline RZA17 & 0,196 & 0,012 & RZA18 & 0,173 & 0,017 \\
\hline RZA01 & 0,193 & 0,011 & RZA20 & 0,127 & 0,046 \\
\hline RZA02 & 0,190 & 0,014 & & & \\
\hline
\end{tabular}




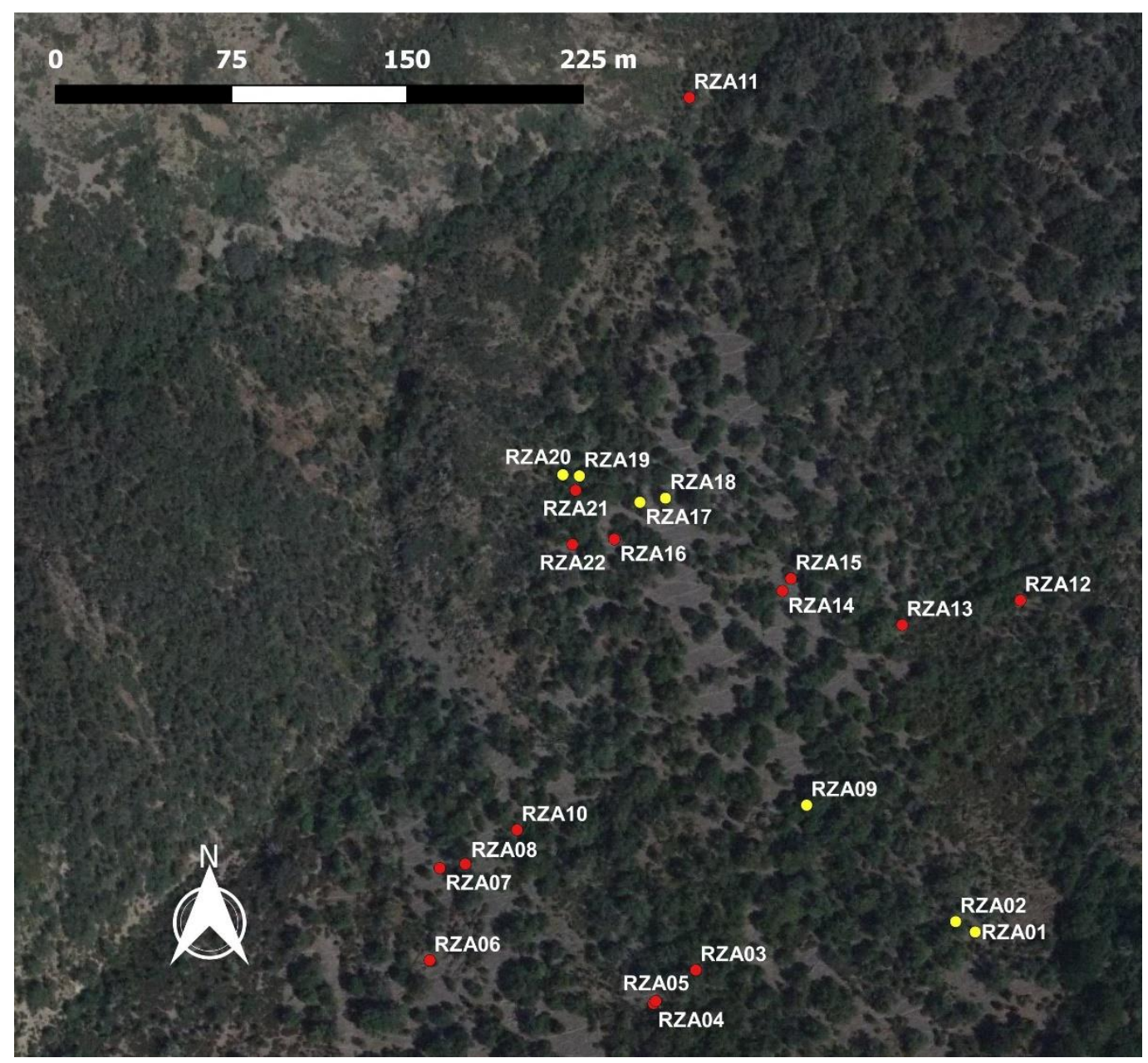

Figura 4.4. Localización de los 22 individuos pertenecientes a la población de Riaza-Becerril (RZA). En amarillo se muestran los siete individuos con correlación positiva significativa $(P<0,05)$ con sus $\mathrm{N}=6$ vecinos más próximos. Ver Anexo I para los códigos de cada individuo.

Otra de las poblaciones que presentó estructura genética espacial fue la de Rozas de Puerto Real (ROZ) (ver Figura 4.5 y Tabla 4.10). En dicha población se analizaron 14 clases de distancia, cada una de ellas con un número de pares de comparaciones superior a 55 (Tabla 4.10), suficientes como para asegurar la consistencia de los resultados. El correlograma obtenido en este caso fue heterogéneo, tal y como indica el resultado del test de heterogeneidad $(\Omega=222,202$; $P<0,0001)$. Los resultados obtenidos muestran la existencia de una elevada autocorrelación positiva $(r=0,855$ a 0,362$)$ y muy significativa $(P<0,001)$ en las cinco primeras clases de distancia, hasta los $25 \mathrm{~m}$ (ver Figura 4.5 y Tabla 4.10). La distancia máxima hasta la que se puede apreciar esa correlación positiva y que viene determinada por el punto de intercepción, es inferior a los 50 m (Figura 4.5 y Tabla 4.10). Además, la población de ROZ también presentó una marcada correlación espacial negativa $(r=-0,647$ a $-0,259)$ y muy significativa $(P \leq 0,001)$ desde la clase de distancia de 25-56 m hasta la de 73-81 m (ver Figura 4.5 y Tabla 4.10). 
El análisis fino de autocorrelación espacial para ROZ se realizó para los 20 vecinos más próximos, debido a que éstos presentaron una distancia media de 39,747 m, ligeramente inferior al valor del punto de intercepción (42,630 m; ver Tabla 4.10). Este análisis mostró que 42 de los 46 individuos de ROZ presentaban coeficientes de correlación positivos y significativos $(P<0,05)$ con sus $\mathrm{N}=20$ vecinos más próximos (Tabla 4.11). Es decir, existe un elevado número de individuos como responsables principales de la autocorrelación positiva detectada en esta población. En la Figura 4.6, donde se representa la distribución de todos los individuos muestreados en ROZ, podemos observar cómo estos 42 individuos se agrupan principalmente en dos subnúcleos, dentro de los cuales, estas muestras se encuentran muy próximas unas a otras.

\section{ROZ}

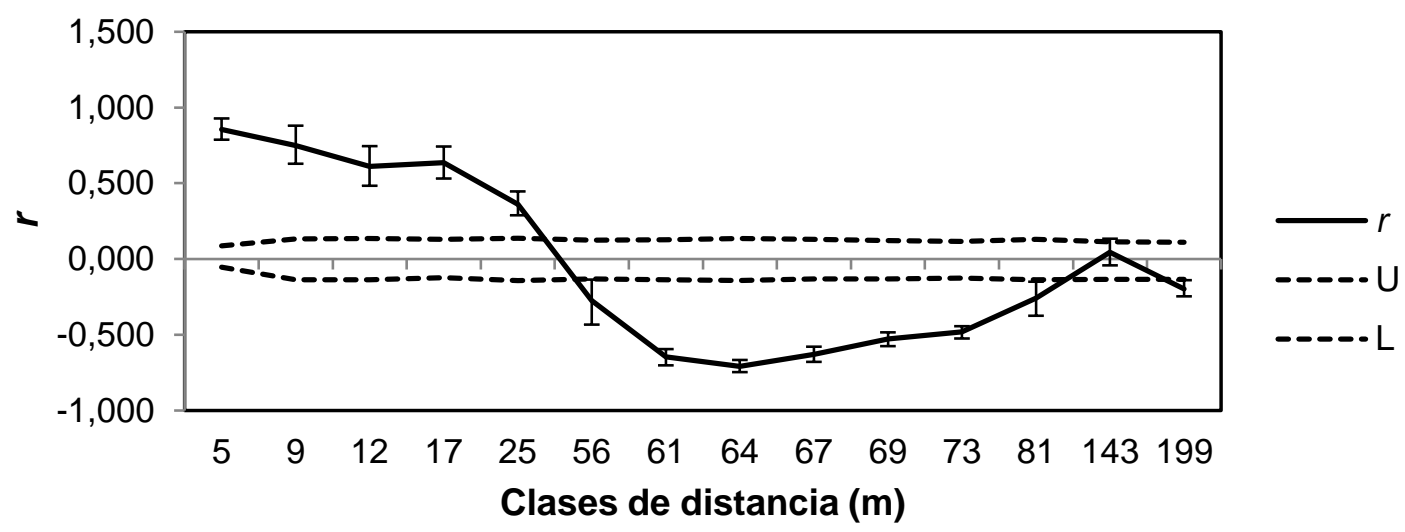

Figura 4.5. Correlograma obtenido del análisis espacial de la estructura genética para los 46 individuos de U. glabra de la población de Rozas de Puerto Real (ROZ) analizados con los datos de 11 loci de microsatélites. La línea continua representa los valores del coeficiente de autocorrelación $(r)$ calculado para cada una de las 14 clases de distancia definidas (de 0-5 m a 143-199 m). Las líneas discontinuas indican los límites superior $(U)$ e inferior $(L)$ del intervalo de confianza al $95 \%$ bajo la hipótesis nula de no existencia de estructura espacial $(r=0)$, obtenidos mediante 10000 permutaciones. Las barras verticales hacen referencia a las barras de error para cada estima de $r$, calculadas para un intervalo de confianza del $95 \%$ mediante 10000 remuestreos (bootstrap). 
Tabla 4.10. Análisis de autocorrelación espacial para los 46 individuos de U. glabra pertenecientes a la población de Rozas de Puerto Real (ROZ) analizados con los datos de 11 loci de microsatélites. $\mathrm{N}$ : número de pares de comparaciones para cada una de las 14 clases de distancia definidas (de 0-5 m a 143-199 m); $r$ : coeficiente de autocorrelación; U y L : límites superior e inferior del intervalo de confianza al 95\% para aceptar la hipótesis nula de no existencia de estructura espacial $(r=0)$, obtenidos a partir de 10000 permutaciones; $P$ : probabilidad de existencia de autocorrelación positiva, $r_{\mathrm{e}}(r$ estimada $) \geq r_{0}\left(\right.$ robservada), o de autocorrelación negativa, $r_{\mathrm{e}} \leq r_{0} ;, r_{\mathrm{B}}$ : valor medio de $r$ estimado por remuestreo (bootstrap); Ur y Lr: límites superior e inferior del intervalo de confianza al $95 \%$, determinados mediante 10000 remuestreos. En negrita se señalan los valores de $r$ que resultaron ser significativos $(P<0,05)$, así como su nivel de significación $(P)$. También se indica el punto de intercepción en $\mathrm{m}$.

\begin{tabular}{|c|c|c|c|c|c|c|c|c|c|c|c|c|c|c|}
\hline Clases de distancia (m) & 5 & 9 & 12 & 17 & 25 & 56 & 61 & 64 & 67 & 69 & 73 & 81 & 143 & 199 \\
\hline $\mathbf{N}$ & 159 & 65 & 60 & 68 & 58 & 58 & 63 & 61 & 69 & 75 & 74 & 62 & 58 & 59 \\
\hline$r$ & 0,855 & 0,750 & 0,611 & 0,636 & 0,362 & $-0,274$ & $-0,647$ & $-0,709$ & $-0,628$ & $-0,527$ & $-0,482$ & $-0,259$ & 0,045 & $-0,197$ \\
\hline U & 0,087 & 0,134 & 0,135 & 0,129 & 0,137 & 0,126 & 0,128 & 0,136 & 0,131 & 0,121 & 0,116 & 0,130 & 0,114 & 0,112 \\
\hline $\mathrm{L}$ & $-0,054$ & $-0,137$ & $-0,138$ & $-0,124$ & $-0,141$ & $-0,133$ & $-0,136$ & $-0,142$ & $-0,133$ & $-0,132$ & $-0,126$ & $-0,138$ & $-0,134$ & $-0,135$ \\
\hline$P\left(r_{\mathrm{e}} \geq r_{\mathrm{o}}\right)$ & $<0,001$ & $<0,001$ & $<0,001$ & $<0,001$ & $<0,001$ & 0,999 & 1,000 & 1,000 & 1,000 & 1,000 & 1,000 & 0,999 & 0,213 & 0,994 \\
\hline$P\left(r_{\mathrm{e}} \leq r_{\mathrm{o}}\right)$ & 1,000 & 1,000 & 1,000 & 1,000 & 1,000 & 0,001 & $<0,001$ & $<0,001$ & $<0,001$ & $<0,001$ & $<0,001$ & 0,001 & 0,788 & 0,006 \\
\hline$r_{B}$ & 0,857 & 0,754 & 0,613 & 0,638 & 0,363 & $-0,279$ & $-0,649$ & $-0,709$ & $-0,629$ & $-0,527$ & $-0,482$ & $-0,261$ & 0,045 & $-0,197$ \\
\hline $\mathrm{Ur}$ & 0,073 & 0,130 & 0,134 & 0,107 & 0,085 & 0,139 & 0,053 & 0,042 & 0,050 & 0,043 & 0,039 & 0,109 & 0,089 & 0,058 \\
\hline $\mathrm{L} r$ & 0,068 & 0,121 & 0,128 & 0,105 & 0,073 & 0,158 & 0,055 & 0,038 & 0,051 & 0,048 & 0,043 & 0,116 & 0,087 & 0,049 \\
\hline
\end{tabular}


Tabla 4.11. Individuos de la población de Rozas de Puerto Real (ROZ) que presentaron correlación ( $r$ ) significativa $(P<0,05)$ con sus $\mathrm{N}=20$ vecinos más próximos. Ver Anexo I para los códigos de cada individuo.

\begin{tabular}{|c|c|c|c|c|c|c|c|c|c|c|c|}
\hline Individuo & $r$ & $P$ & Individuo & $r$ & $P$ & Individuo & $r$ & $P$ & Individuo & $r$ & $P$ \\
\hline ROZ25 & 1,000 & $<0,001$ & ROZ35 & 1,000 & $<0,001$ & ROZO6 & 0,524 & $<0,001$ & ROZ23 & 0,516 & $<0,001$ \\
\hline ROZ26 & 1,000 & $<0,001$ & ROZ36 & 1,000 & $<0,001$ & ROZ07 & 0,516 & $<0,001$ & ROZ02 & 0,295 & 0,004 \\
\hline ROZ27 & 1,000 & $<0,001$ & ROZ37 & 1,000 & $<0,001$ & ROZ08 & 0,516 & $<0,001$ & ROZO3 & 0,295 & 0,004 \\
\hline ROZ28 & 1,000 & $<0,001$ & ROZ38 & 1,000 & $<0,001$ & ROZO9 & 0,516 & $<0,001$ & ROZO4 & 0,295 & 0,004 \\
\hline ROZ29 & 1,000 & $<0,001$ & ROZ39 & 1,000 & $<0,001$ & ROZ10 & 0,516 & $<0,001$ & ROZ16 & 0,290 & 0,004 \\
\hline ROZ30 & 1,000 & $<0,001$ & ROZ40 & 1,000 & $<0,001$ & ROZ13 & 0,516 & $<0,001$ & ROZ24 & 0,248 & 0,011 \\
\hline ROZ31 & 1,000 & $<0,001$ & ROZ41 & 1,000 & $<0,001$ & ROZ18 & 0,516 & $<0,001$ & ROZ17 & 0,247 & 0,012 \\
\hline ROZ32 & 1,000 & $<0,001$ & ROZ42 & 1,000 & $<0,001$ & ROZ19 & 0,516 & $<0,001$ & ROZ12 & 0,246 & 0,012 \\
\hline ROZ33 & 1,000 & $<0,001$ & ROZ43 & 1,000 & $<0,001$ & ROZ20 & 0,516 & $<0,001$ & ROZ01 & 0,168 & 0,048 \\
\hline ROZ34 & 1,000 & $<0,001$ & ROZ44 & 1,000 & $<0,001$ & ROZ21 & 0,516 & $<0,001$ & & & \\
\hline ROZ46 & 1,000 & $<0,001$ & ROZ45 & 1,000 & $<0,001$ & ROZ22 & 0,516 & $<0,001$ & & & \\
\hline
\end{tabular}

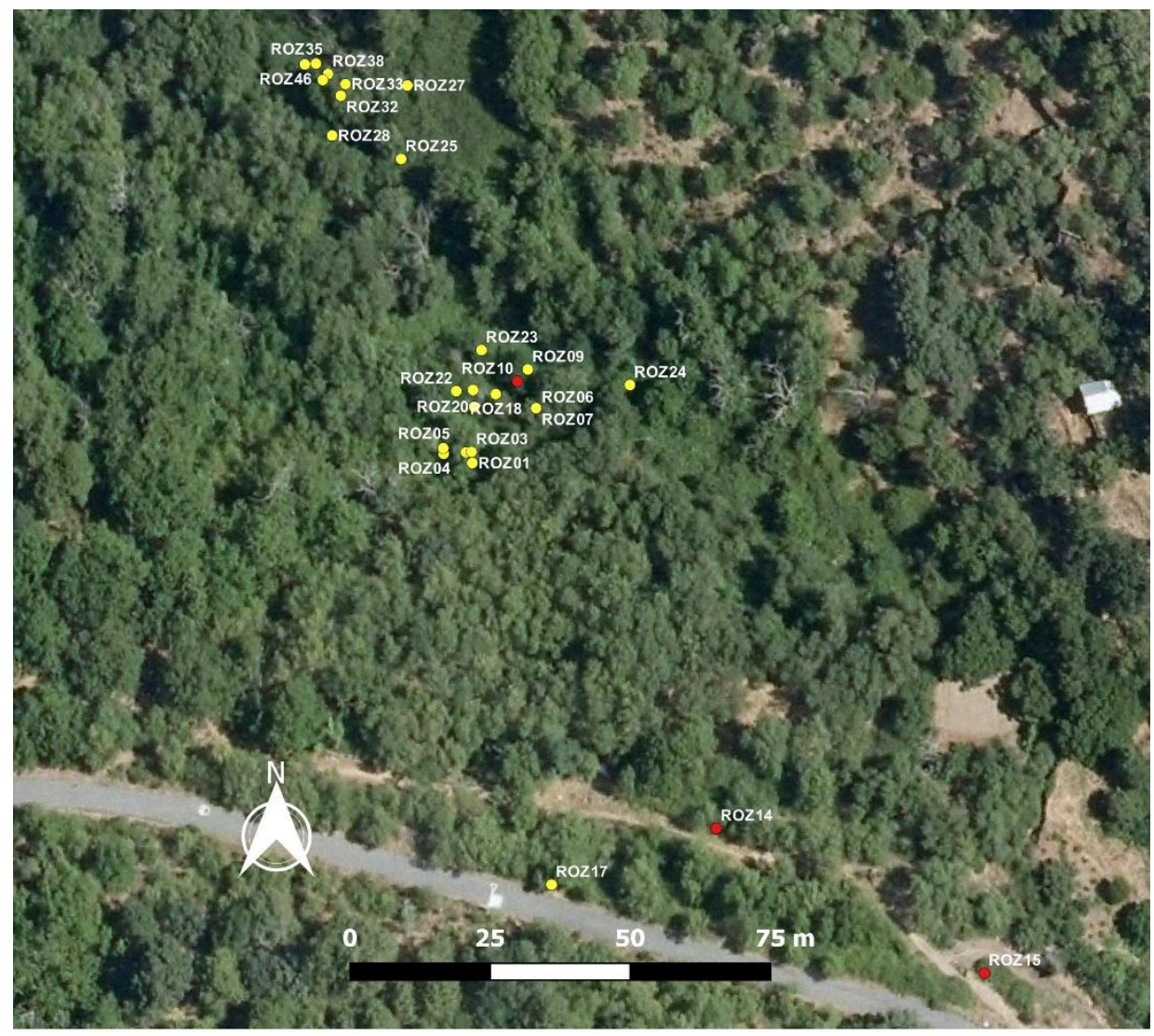

Figura 4.6. Localización de los 46 individuos pertenecientes a la población de Rozas de Puerto Real (ROZ). En amarillo se muestran los 42 individuos con correlación positiva significativa $(P<0,05)$ con sus $N=20$ vecinos más próximos. Ver Anexo I para los códigos de cada individuo. 
La población de El Tiemblo (TIE), en la que también se detectó estructura genética espacial, presentó un correlograma (Figura 4.7) significativo para el test de heterogeneidad $(\Omega=369,435$; $P<0,001)$. En dicho correlograma se analizaron hasta 25 clases de distancia, cada una de ellas con más de 30 pares de comparaciones, con objeto de asegurar la consistencia de los resultados. Esos resultados muestran la existencia de una correlación espacial positiva (valores de $r 0,320$ ) y claramente significativa $(P<0,001)$ para las nueve primeras clases de distancia, hasta los $141 \mathrm{~m}$ (ver Figura 4.7 y Tabla 4.12). La máxima distancia hasta la que se puede intuir la existencia de esa correlación espacial positiva serían los 186,428 m del punto de intercepción (Figura 4.7 y Tabla 4.12). Asimismo, en esta población también se detectó correlación negativa $(r=-0,280$ a $-0,433)$ y altamente significativa $(P \leq 0,001)$ desde aproximadamente los $800 \mathrm{~m}$ hasta casi los $1000 \mathrm{~m}$ (ver Figura 4.7 y Tabla 4.12).

\section{TIE}

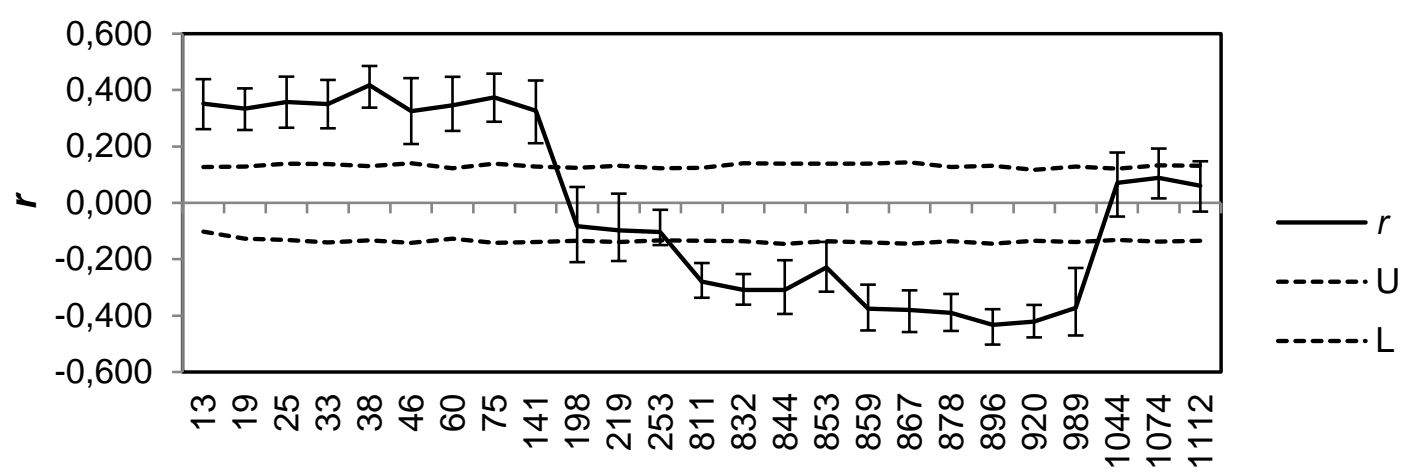

Clases de distancia $(m)$

Figura 4.7. Correlograma obtenido del análisis espacial de la estructura genética para los 42 individuos de U. glabra de la población de EI Tiemblo (TIE) analizados con los datos de 11 loci de microsatélites. La línea continua representa los valores del coeficiente de autocorrelación $(r)$ calculado para cada una de las 25 clases de distancia definidas (de 0-13 m a 1074-1112 m). Las líneas discontinuas indican los límites superior $(U)$ e inferior (L) del intervalo de confianza al $95 \%$ bajo la hipótesis nula de no existencia de estructura espacial $(r=0)$, obtenidos mediante 10000 permutaciones. Las barras verticales hacen referencia a las barras de error para cada estima de $r$, calculadas para un intervalo de confianza del $95 \%$ mediante 10000 remuestreos (bootstrap). 
Tabla 4.12. Análisis de autocorrelación espacial para los 42 individuos de U. glabra pertenecientes a la población de El Tiemblo (TIE) analizados con los datos de 11 loci de microsatélites. N : número de pares de comparaciones para cada una de las 25 clases de distancia definidas (de 0-13 m a 920-989 m); $r$ : coeficiente de autocorrelación; U y L : límites superior e inferior del intervalo de confianza al 95\% para aceptar la hipótesis nula de no existencia de estructura espacial $(r=0)$, obtenidos a partir de 10000 permutaciones; $P$ : probabilidad de existencia de autocorrelación positiva, $r_{\mathrm{e}}(r$ estimada $) \geq r_{0}\left(\right.$ robservada), o de autocorrelación negativa, $r_{\mathrm{e}} \leq r_{0} ;, r_{\mathrm{B}}:$ valor medio de $r$ estimado por remuestreo (bootstrap); Ury Lr: límites superior e inferior del intervalo de confianza al 95\%, determinados mediante 10000 remuestreos. En negrita se señalan los valores de $r$ que resultaron ser significativos $(P<0,05)$, así como su nivel de significación $(P)$. También se indica el punto de intercepción en $\mathrm{m}$.

\begin{tabular}{|c|c|c|c|c|c|c|c|c|c|c|c|c|c|}
\hline $\begin{array}{l}\text { Clases de } \\
\text { distancia }(\mathrm{m})\end{array}$ & 13 & 19 & 25 & 33 & 38 & 46 & 60 & 75 & 141 & 198 & 219 & 253 & 811 \\
\hline $\mathrm{N}$ & 47 & 39 & 35 & 32 & 36 & 33 & 38 & 32 & 32 & 33 & 32 & 32 & 32 \\
\hline$r$ & 0,352 & 0,333 & 0,358 & 0,350 & 0,417 & 0,324 & 0,347 & 0,374 & 0,326 & $-0,083$ & $-0,098$ & $-0,104$ & $-0,280$ \\
\hline U & 0,127 & 0,128 & 0,139 & 0,137 & 0,130 & 0,140 & 0,123 & 0,139 & 0,129 & 0,124 & 0,132 & 0,123 & 0,124 \\
\hline L & $-0,102$ & $-0,128$ & $-0,132$ & $-0,141$ & $-0,132$ & $-0,141$ & $-0,127$ & $-0,142$ & $-0,139$ & $-0,134$ & $-0,139$ & $-0,133$ & $-0,135$ \\
\hline$P\left(r_{e} \geq r_{0}\right)$ & $<0,001$ & $<0,001$ & $<0,001$ & $<0,001$ & $<0,001$ & $<0,001$ & $<0,001$ & $<0,001$ & $<0,001$ & 0,902 & 0,923 & 0,946 & 1,000 \\
\hline$P\left(r_{\mathrm{e}} \leq r_{0}\right)$ & 1,000 & 1,000 & 1,000 & 1,000 & 1,000 & 1,000 & 1,000 & 1,000 & 1,000 & 0,098 & 0,077 & 0,054 & $<0,001$ \\
\hline$r_{B}$ & 0,352 & 0,334 & 0,358 & 0,350 & 0,416 & 0,325 & 0,346 & 0,380 & 0,335 & $-0,084$ & $-0,092$ & $-0,099$ & $-0,281$ \\
\hline $\mathrm{U} r$ & 0,086 & 0,073 & 0,089 & 0,085 & 0,068 & 0,118 & 0,101 & 0,084 & 0,108 & 0,139 & 0,131 & 0,079 & 0,066 \\
\hline $\mathrm{Lr} r$ & 0,091 & 0,075 & 0,092 & 0,086 & 0,080 & 0,116 & 0,091 & 0,086 & 0,115 & 0,127 & 0,108 & 0,046 & 0,057 \\
\hline $\begin{array}{l}\text { Clases de } \\
\text { distancia (m) }\end{array}$ & 832 & 844 & 853 & 859 & 867 & 878 & 896 & 920 & 989 & 1044 & 1074 & 1112 & 832 \\
\hline $\mathrm{N}$ & 32 & 32 & 33 & 33 & 32 & 35 & 32 & 36 & 32 & 35 & 32 & 33 & 32 \\
\hline$r$ & $-0,310$ & $-0,308$ & $-0,228$ & $-0,376$ & $-0,380$ & $-0,391$ & $-0,433$ & $-0,422$ & $-0,373$ & 0,071 & 0,089 & 0,061 & $-0,310$ \\
\hline U & 0,141 & 0,139 & 0,138 & 0,139 & 0,144 & 0,127 & 0,132 & 0,117 & 0,129 & 0,121 & 0,133 & 0,132 & 0,141 \\
\hline L & $-0,137$ & $-0,146$ & $-0,137$ & $-0,140$ & $-0,145$ & $-0,136$ & $-0,145$ & $-0,135$ & $-0,138$ & $-0,132$ & $-0,137$ & $-0,134$ & $-0,137$ \\
\hline$P\left(r_{\mathrm{e}} \geq r_{\mathrm{o}}\right)$ & 1,000 & 1,000 & 0,999 & 1,000 & 1,000 & 1,000 & 1,000 & 1,000 & 1,000 & 0,116 & 0,089 & 0,171 & 1,000 \\
\hline$P\left(r_{\mathrm{e}} \leq r_{0}\right)$ & $<0,001$ & $<0,001$ & 0,001 & $<0,001$ & $<0,001$ & $<0,001$ & $<0,001$ & $<0,001$ & $<0,001$ & 0,884 & 0,912 & 0,829 & $<0,001$ \\
\hline$r_{B}$ & $-0,312$ & $-0,305$ & $-0,228$ & $-0,374$ & $-0,381$ & $-0,390$ & $-0,431$ & $-0,421$ & $-0,374$ & 0,072 & 0,099 & 0,060 & $-0,312$ \\
\hline $\mathrm{Ur}$ & 0,057 & 0,105 & 0,090 & 0,086 & 0,070 & 0,067 & 0,056 & 0,060 & 0,142 & 0,107 & 0,103 & 0,087 & 0,057 \\
\hline $\mathrm{L} r$ & 0,052 & 0,086 & 0,087 & 0,077 & 0,078 & 0,064 & 0,070 & 0,055 & 0,098 & 0,120 & 0,073 & 0,092 & 0,052 \\
\hline
\end{tabular}

Intercepción 186,428 
En la población de El Tiemblo, el análisis fino de autocorrelación espacial se llevó a cabo para los $\mathrm{N}=18$ vecinos más próximos, que son los que presentaron una distancia media de 149,230 m, ligeramente inferior a los 186,428 m del punto de intercepción (ver Tabla 4.12). Dicho análisis reveló que 35 de los 42 individuos muestreados presentaban coeficientes de correlación positivos y significativos $(P<0,05)$ con sus 18 vecinos más próximos (Tabla 4.13). En la Figura 4.8 se muestra la localización de esos 35 individuos dentro de la población. Los siete individuos restantes, que no presentaron correlación positiva significativa con sus 18 vecinos más próximos, se localizan esencialmente en el norte de la población, muy próximos entre sí y junto al camino (Figura 4.8).

Tabla 4.13. Individuos de la población de El Tiemblo (TIE) que presentaron correlación (r) significativa $(P<0,05)$ con sus $\mathrm{N}=18$ vecinos más próximos. Ver Anexo I para los códigos de cada individuo.

\begin{tabular}{lcc|lcc|lcc}
\hline Individuo & $\boldsymbol{r}$ & $\boldsymbol{P}$ & Individuo & $\boldsymbol{r}$ & $\boldsymbol{P}$ & Individuo & $\boldsymbol{r}$ & $\boldsymbol{P}$ \\
\hline TIE02 & 0,540 & $<0,001$ & TIE07 & 0,411 & $<0,001$ & TIE41 & 0,348 & $<0,001$ \\
TIE04 & 0,505 & $<0,001$ & TIE32 & 0,411 & $<0,001$ & TIE08 & 0,347 & $<0,001$ \\
TIE11 & 0,505 & $<0,001$ & TIE12 & 0,409 & $<0,001$ & TIE40 & 0,345 & $<0,001$ \\
TIE14 & 0,476 & $<0,001$ & TIE28 & 0,408 & $<0,001$ & TIE34 & 0,337 & $<0,001$ \\
TIE17 & 0,471 & $<0,001$ & TIE30 & 0,404 & $<0,001$ & TIE24 & 0,311 & $<0,001$ \\
TIE25 & 0,467 & $<0,001$ & TIE37 & 0,398 & $<0,001$ & TIE19 & 0,303 & $<0,001$ \\
TIE05 & 0,459 & $<0,001$ & TIE10 & 0,394 & $<0,001$ & TIE33 & 0,260 & 0,001 \\
TIE06 & 0,459 & $<0,001$ & TIE15 & 0,370 & $<0,001$ & TIE13 & 0,239 & 0,002 \\
TIE36 & 0,451 & $<0,001$ & TIE29 & 0,369 & $<0,001$ & TIE09 & 0,238 & 0,002 \\
TIE03 & 0,447 & $<0,001$ & TIE27 & 0,364 & $<0,001$ & TIE42 & 0,224 & 0,003 \\
TIE16 & 0,437 & $<0,001$ & TIE26 & 0,363 & $<0,001$ & TIE35 & 0,163 & 0,018 \\
TIE38 & 0,430 & $<0,001$ & TIE01 & 0,348 & $<0,001$ & & & \\
\hline
\end{tabular}




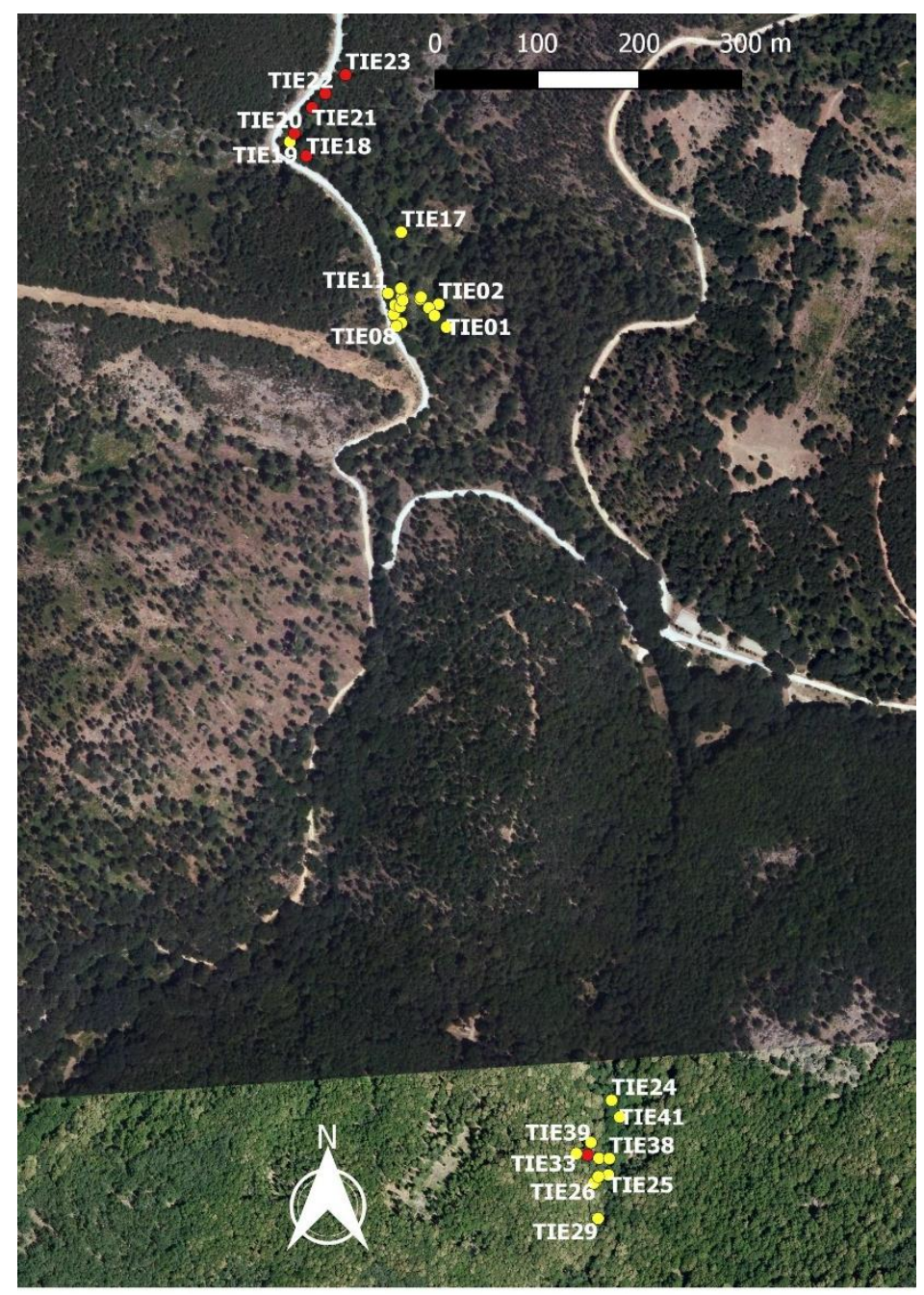

Figura 4.8. Localización de los 42 individuos pertenecientes a la población de El Tiemblo (TIE). En amarillo se muestran los 35 individuos con correlación positiva significativa $(P<0,05)$ con sus $\mathrm{N}=18$ vecinos más próximos. Ver Anexo I para los códigos de cada individuo.

Una cuarta población que presentó estructura genética espacial fue la de El Barraco-Valle de Iruelas (IRU) (ver Figura 4.9 y Tabla 4.14). El test de heterogeneidad del correlograma obtenido para IRU resultó ser significativo $(\Omega=228,948 ; P<0,001)$. Los 57 individuos muestreados en esta población permitieron que se pudieran generar hasta 29 clases de distancia con más de 50 pares de comparaciones dentro de cada una de ellas (ver Tabla 4.14). En las cuatro primeras clases de distancia (hasta los $128 \mathrm{~m}$ ), se detectó una baja autocorrelación positiva $(r=0,082-0,166)$ pero significativa $(P<0,01)$. Además, de las seis poblaciones con estructura genética espacial analizadas, IRU presentó la máxima distancia hasta la que sería detectable dicha estructura espacial (punto de intercepción $=237,949$ m; ver Figura 4.9 y Tabla 4.14). Por otra parte, en IRU también se detectó una pequeña correlación negativa $(r=-0,134$ a $-0,077)$ y significativa $(P<0,01)$ para varias clases de distancia por encima de los $1900 \mathrm{~m}$ (ver Figura 4.9 y Tabla 4.14). 


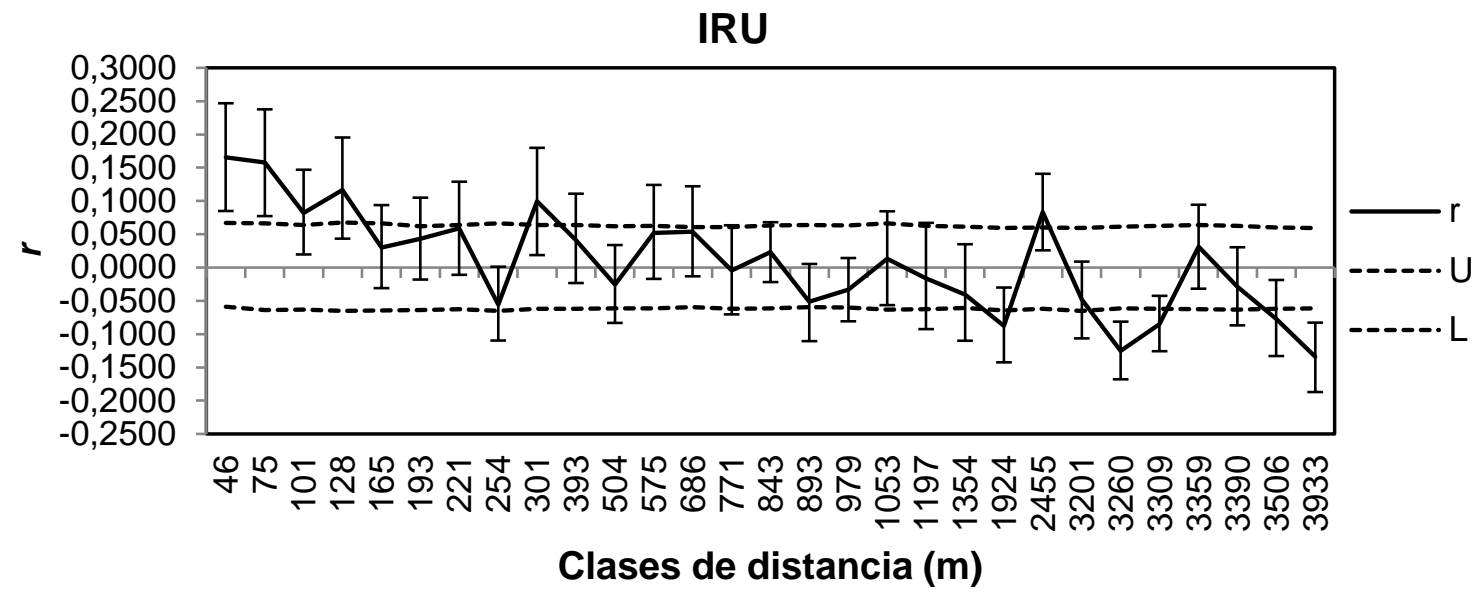

Figura 4.9. Correlograma obtenido del análisis espacial de la estructura genética para los 57 individuos de U. glabra de la población de El Barraco-Valle de Iruelas (IRU) analizados con los datos de 11 loci de microsatélites. La línea continua representa los valores del coeficiente de autocorrelación $(r)$ calculado para cada una de las 29 clases de distancia definidas (de 0-46 m a 3309-3933 m). Las líneas discontinuas indican los límites superior $(U)$ e inferior $(L)$ del intervalo de confianza al $95 \%$ bajo la hipótesis nula de no existencia de estructura espacial $(r=0)$, obtenidos mediante 10000 permutaciones. Las barras verticales hacen referencia a las barras de error para cada estima de $r$, calculadas para un intervalo de confianza del $95 \%$ mediante 10000 remuestreos (bootstrap).

Para el análisis fino de autocorrelación espacial en IRU se emplearon los $N=7$ vecinos más próximos, cuya distancia media fue de 237,943 m, muy similar al valor del punto de intercepción (237,949 m; ver Tabla 4.14). Este análisis reveló que 26 de los 57 individuos presentaban coeficientes de correlación positivos y significativos $(P<0,05)$ con sus siete vecinos más próximos (Tabla 4.15). La localización de estos 26 individuos se muestra en la Figura 4.10, donde se puede apreciar que dichos individuos aparecen distribuidos por los tres subnúcleos poblacionales en los que se realizó el muestreo para IRU. 
Tabla 4.14. Análisis de autocorrelación espacial para los 57 individuos de U. glabra pertenecientes a la población de El Barraco-Valle de Iruelas (IRU) analizados con los datos de 11 loci de microsatélites. $\mathrm{N}$ : número de pares de comparaciones para cada una de las 29 clases de distancia definidas (de 0-46 m a 3506-3933 m); $r:$ coeficiente de autocorrelación; U y L : límites superior e inferior del intervalo de confianza al 95\% para aceptar la hipótesis nula de no existencia de estructura espacial ( $r=0)$, obtenidos a partir de 10000 permutaciones; $P$ : probabilidad de existencia de autocorrelación positiva, $r_{\mathrm{e}}\left(r\right.$ estimada) $\geq r_{\mathrm{o}}\left(r\right.$ observada), o de autocorrelación negativa, $r_{\mathrm{e}} \leq r_{0} ;, r_{\mathrm{B}}$ : valor medio de r estimado por remuestreo (bootstrap); Ury Lr $r$ l límites superior e inferior del intervalo de confianza al 95\%, determinados mediante 10000 remuestreos. En negrita se señalan los valores de $r$ que resultaron ser significativos $(P<0,05)$, así como su nivel de significación $(P)$. También se indica el punto de intercepción en $\mathrm{m}$.

\begin{tabular}{|c|c|c|c|c|c|c|c|c|c|c|c|c|c|c|c|}
\hline $\begin{array}{l}\text { Clases de } \\
\text { distancia (m) }\end{array}$ & 46 & 75 & 101 & 128 & 165 & 193 & 221 & 254 & 301 & 393 & 504 & 575 & 686 & 771 & 843 \\
\hline $\mathrm{N}$ & 57 & 53 & 56 & 53 & 53 & 53 & 54 & 53 & 54 & 53 & 53 & 53 & 53 & 53 & 53 \\
\hline$r$ & 0,166 & 0,158 & 0,082 & 0,116 & 0,030 & 0,043 & 0,059 & $-0,056$ & 0,099 & 0,042 & $-0,026$ & 0,052 & 0,054 & $-0,004$ & 0,023 \\
\hline U & 0,067 & 0,067 & 0,064 & 0,068 & 0,067 & 0,062 & 0,064 & 0,066 & 0,064 & 0,064 & 0,062 & 0,063 & 0,061 & 0,061 & 0,063 \\
\hline $\mathrm{L}$ & $-0,059$ & $-0,064$ & $-0,063$ & $-0,065$ & $-0,064$ & $-0,064$ & $-0,063$ & $-0,065$ & $-0,062$ & $-0,062$ & $-0,061$ & $-0,061$ & $-0,059$ & $-0,062$ & $-0,061$ \\
\hline$P\left(r_{\mathrm{e}} \geq r_{\mathrm{o}}\right)$ & $<0,001$ & $<0,001$ & 0,006 & 0,001 & 0,177 & 0,086 & 0,036 & 0,954 & 0,001 & 0,094 & 0,806 & 0,050 & 0,041 & 0,555 & 0,228 \\
\hline$P\left(r_{\mathrm{e}} \leq r_{0}\right)$ & 1,000 & 1,000 & 0,994 & 0,999 & 0,823 & 0,915 & 0,964 & 0,046 & 0,999 & 0,907 & 0,195 & 0,950 & 0,959 & 0,445 & 0,772 \\
\hline$r_{B}$ & 0,165 & 0,158 & 0,082 & 0,116 & 0,030 & 0,043 & 0,059 & $-0,055$ & 0,098 & 0,042 & $-0,026$ & 0,052 & 0,054 & $-0,004$ & 0,023 \\
\hline Ur & 0,081 & 0,080 & 0,065 & 0,079 & 0,064 & 0,062 & 0,070 & 0,057 & 0,080 & 0,069 & 0,060 & 0,072 & 0,068 & 0,068 & 0,045 \\
\hline $\mathrm{Lr} r$ & 0,081 & 0,080 & 0,062 & 0,073 & 0,061 & 0,061 & 0,070 & 0,054 & 0,081 & 0,065 & 0,057 & 0,069 & 0,067 & 0,066 & 0,045 \\
\hline
\end{tabular}

\begin{tabular}{|c|c|c|c|c|c|c|c|c|c|c|c|c|c|c|}
\hline $\begin{array}{l}\text { Clases de } \\
\text { distancia (m) }\end{array}$ & 893 & 979 & 1053 & 1197 & 1354 & 1924 & 2455 & 3201 & 3260 & 3309 & 3359 & 3390 & 3506 & 3933 \\
\hline $\mathrm{N}$ & 55 & 53 & 53 & 53 & 53 & 53 & 53 & 53 & 54 & 53 & 54 & 52 & 54 & 54 \\
\hline$r$ & $-0,051$ & $-0,033$ & 0,013 & $-0,016$ & $-0,041$ & $-0,087$ & 0,083 & $-0,048$ & $-0,125$ & $-0,085$ & 0,031 & $-0,028$ & $-0,077$ & $-0,134$ \\
\hline U & 0,064 & 0,063 & 0,066 & 0,062 & 0,061 & 0,060 & 0,060 & 0,060 & 0,062 & 0,063 & 0,064 & 0,062 & 0,060 & 0,059 \\
\hline $\mathrm{L}$ & $-0,059$ & $-0,060$ & $-0,063$ & $-0,062$ & $-0,061$ & $-0,064$ & $-0,062$ & $-0,065$ & $-0,061$ & $-0,062$ & $-0,062$ & $-0,063$ & $-0,062$ & $-0,061$ \\
\hline$P\left(r_{\mathrm{e}} \geq r_{0}\right)$ & 0,954 & 0,858 & 0,342 & 0,694 & 0,913 & 0,995 & 0,005 & 0,934 & 1,000 & 0,996 & 0,167 & 0,813 & 0,992 & 1,000 \\
\hline$P\left(r_{\mathrm{e}} \leq r_{0}\right)$ & 0,046 & 0,142 & 0,658 & 0,306 & 0,088 & 0,005 & 0,995 & 0,067 & $<0,001$ & 0,005 & 0,833 & 0,187 & 0,008 & $<0,001$ \\
\hline$r_{B}$ & $-0,052$ & $-0,034$ & 0,013 & $-0,016$ & $-0,040$ & $-0,087$ & 0,083 & $-0,048$ & $-0,125$ & $-0,085$ & 0,031 & $-0,028$ & $-0,076$ & $-0,134$ \\
\hline $\mathrm{Ur}$ & 0,057 & 0,048 & 0,071 & 0,083 & 0,076 & 0,057 & 0,058 & 0,057 & 0,044 & 0,043 & 0,063 & 0,059 & 0,058 & 0,051 \\
\hline $\mathrm{Lr} r$ & 0,059 & 0,047 & 0,070 & 0,076 & 0,069 & 0,055 & 0,057 & 0,058 & 0,043 & 0,040 & 0,063 & 0,058 & 0,056 & 0,053 \\
\hline
\end{tabular}

Intercepción $\quad 237,949$ 
Tabla 4.15. Individuos de la población de El Barraco-Valle de Iruelas (IRU) que presentaron correlación $(r)$ significativa $(P<0,05)$ con sus $\mathrm{N}=7$ vecinos más próximos. Ver Anexo I para los códigos de cada individuo.

\begin{tabular}{ccc|lcc|ccc|ccc}
\hline Individuo & $\boldsymbol{r}$ & $\boldsymbol{P}$ & Individuo & $\boldsymbol{r}$ & $\boldsymbol{P}$ & Individuo & $\boldsymbol{r}$ & $\boldsymbol{P}$ & Individuo & $\boldsymbol{r}$ & $\boldsymbol{P}$ \\
\hline IRU53 & 0,529 & 0,001 & IRU31 & 0,304 & 0,001 & IRU42 & 0,212 & 0,003 & $\mathrm{IRU} 04$ & 0,160 & 0,040 \\
IRU54 & 0,494 & 0,001 & IRU55 & 0,302 & 0,001 & IRU33 & 0,209 & 0,006 & IRU07 & 0,154 & 0,017 \\
IRU48 & 0,458 & 0,001 & IRU32 & 0,283 & 0,001 & IRU40 & 0,209 & 0,011 & IRU21 & 0,151 & 0,033 \\
IRU51 & 0,408 & 0,001 & IRU49 & 0,262 & 0,004 & IRU34 & 0,205 & 0,013 & IRU43 & 0,147 & 0,036 \\
IRU52 & 0,399 & 0,001 & IRU36 & 0,258 & 0,001 & IRU38 & 0,188 & 0,018 & IRU41 & 0,144 & 0,031 \\
IRU50 & 0,379 & 0,001 & IRU56 & 0,229 & 0,001 & IRU08 & 0,182 & 0,017 & IRU06 & 0,135 & 0,046 \\
IRU35 & 0,304 & 0,001 & IRU11 & 0,213 & 0,006 & & & & & & \\
\hline
\end{tabular}

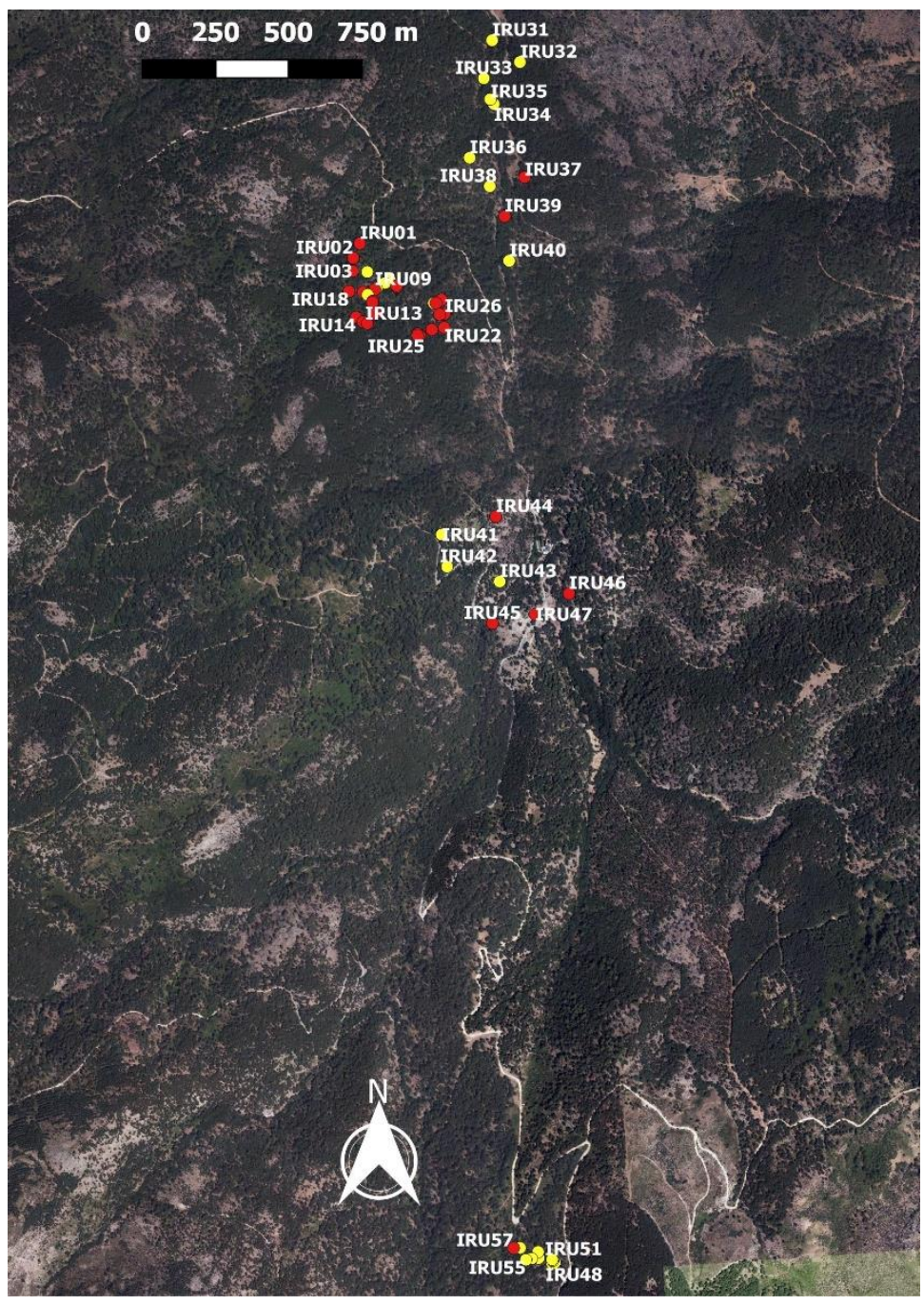

Figura 4.10. Localización de los 57 individuos pertenecientes a la población de El Barraco-Valle de Iruelas (IRU). En amarillo se muestran los 26 individuos con correlación positiva significativa $(P<0,05)$ con sus $\mathrm{N}=7$ vecinos más próximos. Ver Anexo I para los códigos de cada individuo. 
Casavieja (CVJ) es la quinta y última de las poblaciones españolas que mostraron autocorrelación espacial significativa (ver Figura 4.11 y Tabla 4.16). El bajo número de individuos muestreados $(\mathrm{Nm}=20)$, limitó a cinco el número de clases de distancia analizables, al tener en cuenta el criterio de que al menos existieran 30 pares de comparaciones en cada clase de distancia (Tabla 4.16). El correlograma (Figura 4.11) fue significativo para el test de heterogeneidad $(\Omega=28,322 ; P<0,001)$. En este caso, únicamente se detectó una pequeña autocorrelación positiva y significativa $(r=0,124 ; P<0,05)$ en la primera clase de distancia analizada, hasta los $22 \mathrm{~m}$ (Figura 4.11 y Tabla 4.16). La distancia máxima hasta la que sería detectable esa correlación positiva según el punto de intercepción, llegaría a los 67,844 m (ver Figura 4.11 y Tabla 4.16). Por otro lado, también se detectó una pequeña autocorrelación negativa y significativa $(r=-0,112 ; P<0,01)$ en la última clase de distancia analizada, de 114 a 173 m (Figura 4.11 y Tabla 4.16).

\section{CVJ}

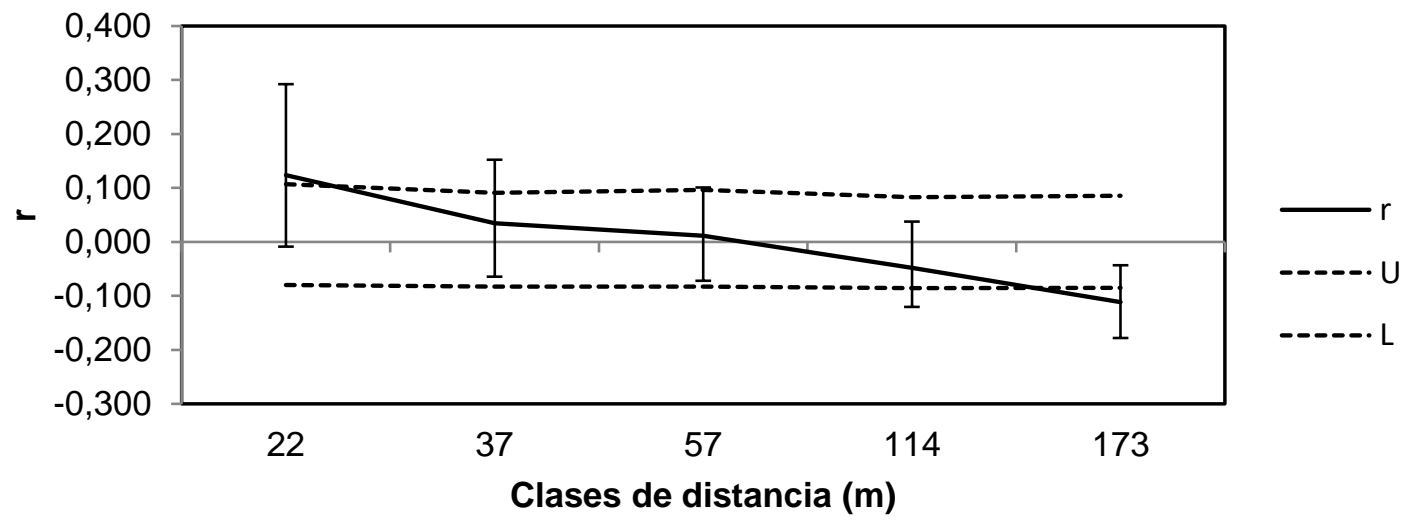

Figura 4.11. Correlograma obtenido del análisis espacial de la estructura genética para los 20 individuos de U. glabra de la población de Casavieja (CVJ) analizados con los datos de 11 loci de microsatélites. La línea continua representa los valores del coeficiente de autocorrelación $(r)$ calculado para cada una de las cinco clases de distancia definidas (de 0-22 $\mathrm{m}$ a 114-173 $\mathrm{m}$ ). Las líneas discontinuas indican los límites superior $(U)$ e inferior $(L)$ del intervalo de confianza al $95 \%$ bajo la hipótesis nula de no existencia de estructura espacial $(r=0)$, obtenidos mediante 10000 permutaciones. Las barras verticales hacen referencia a las barras de error para cada estima de $r$, calculadas para un intervalo de confianza del $95 \%$ mediante 10000 remuestreos (bootstrap). 
Tabla 4.16. Análisis de autocorrelación espacial para los 20 individuos de U. glabra pertenecientes a la población de Casavieja (CVJ) analizados con los datos de 11 loci de microsatélites. $\mathrm{N}$ : número de pares de comparaciones para cada una de las cinco clases de distancia definidas (de 0-2 m a 114-173 m); $r$ : coeficiente de autocorrelación; $U$ y $L$ : límites superior e inferior del intervalo de confianza al 95\% para aceptar la hipótesis nula de no existencia de estructura espacial $(r=0)$, obtenidos a partir de 10000 permutaciones; $P$ : probabilidad de existencia de autocorrelación positiva, $r_{\mathrm{e}}(r$ estimada $) \geq r_{0}(r$ observada), 0 de autocorrelación negativa, $r_{\mathrm{e}} \leq r_{0}, r_{\mathrm{B}}$ : valor medio de $r$ estimado por remuestreo (bootstrap); Ur y $L r$ : límites superior e inferior del intervalo de confianza al 95\%, determinados mediante 10000 remuestreos. En negrita se señalan los valores de $r$ que resultaron ser significativos $(P<0,05)$, así como su nivel de significación $(P)$. También se indica el punto de intercepción en $\mathrm{m}$.

\begin{tabular}{lrrrrr}
\hline $\begin{array}{l}\text { Clases de } \\
\text { distancia (m) }\end{array}$ & $\mathbf{2 2}$ & 37 & $\mathbf{5 7}$ & 114 & $\mathbf{1 7 3}$ \\
$\mathbf{N}$ & 33 & 32 & 35 & 32 & 32 \\
\hline$r$ & $\mathbf{0 , 1 2 4}$ & 0,035 & 0,011 & $-0,048$ & $-\mathbf{0 , 1 1 2}$ \\
$\mathrm{U}$ & 0,107 & 0,091 & 0,096 & 0,083 & 0,086 \\
$\mathrm{~L}$ & $-0,080$ & $-0,083$ & $-0,083$ & $-0,086$ & $-0,085$ \\
$\mathbf{P}\left(r_{\mathrm{e}} \geq r_{\mathrm{o}}\right)$ & $\mathbf{0 , 0 1 4}$ & 0,234 & 0,385 & 0,875 & 0,996 \\
$\boldsymbol{P}\left(r_{\mathrm{e}} \leq r_{\mathrm{o}}\right)$ & 0,986 & 0,766 & 0,615 & 0,125 & $\mathbf{0 , 0 0 4}$ \\
$r_{\mathrm{B}}$ & 0,124 & 0,037 & 0,012 & $-0,048$ & $-0,111$ \\
$\mathrm{Ur}$ & 0,169 & 0,118 & 0,090 & 0,085 & 0,068 \\
$\mathrm{Lr}$ & 0,132 & 0,099 & 0,083 & 0,073 & 0,066 \\
\hline Intercepción & 67,844 & & & &
\end{tabular}

Para el análisis más fino de autocorrelación espacial se utilizaron los $\mathrm{N}=8$ vecinos más próximos, debido a que la distancia media entre ellos $(66,125 \mathrm{~m})$ fue muy similar al valor del punto de intercepción (67,844 m; ver Tabla 4.16). Se identificaron sólo dos individuos con coeficientes de correlación positivos y significativos (CVJ01 y CVJ02; $r=0,238, P<0,001$ ) con sus ocho vecinos más próximos. En la Figura 4.12 se muestra la localización de estos dos individuos en la población, situados en el grupo más numeroso de árboles y junto al camino. 


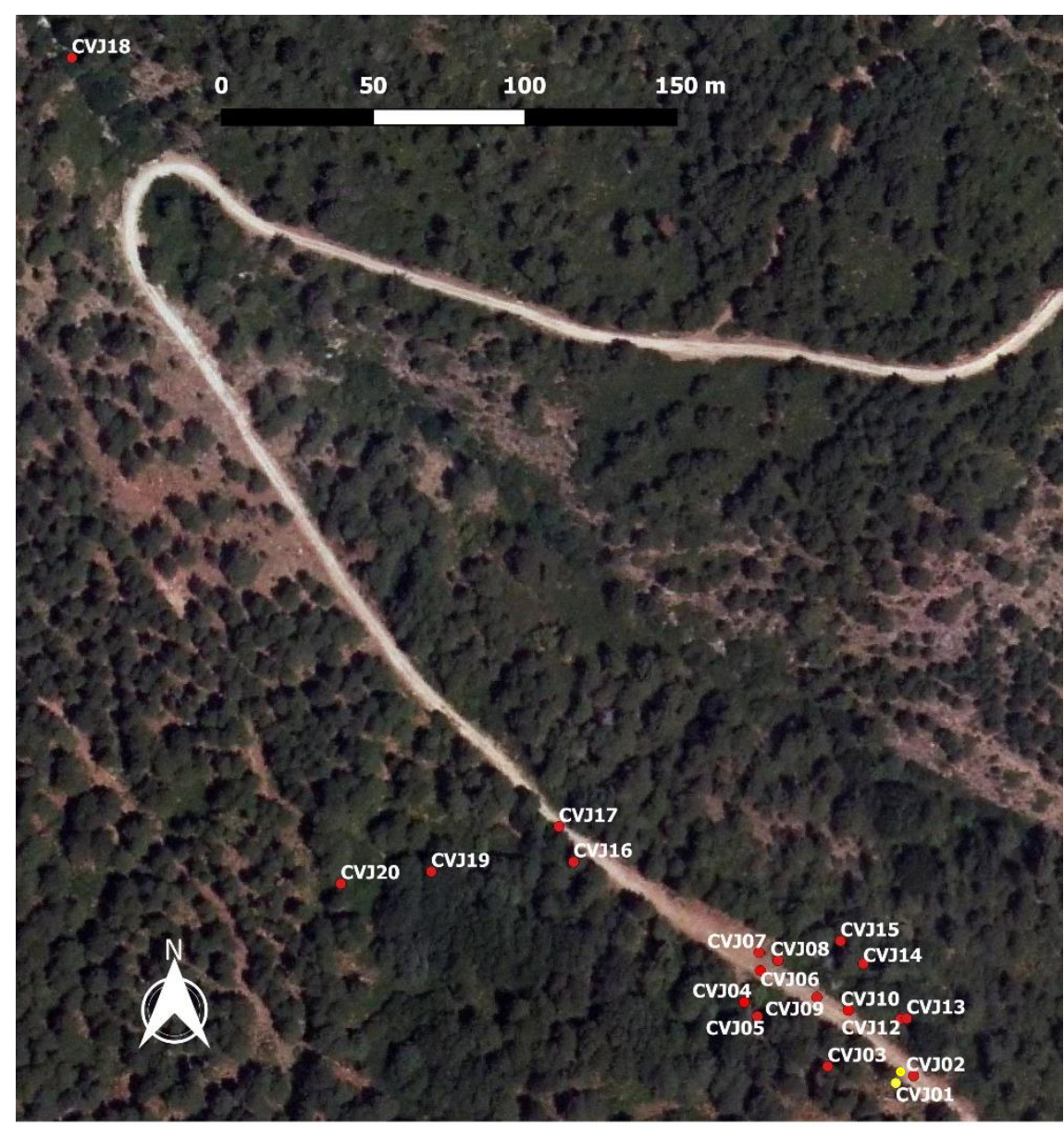

Figura 4.12. Localización de los 20 individuos pertenecientes a la población de Casavieja (CVJ). En amarillo se muestran los dos individuos con correlación positiva significativa $(P<0,001)$ con sus $\mathrm{N}=8$ vecinos más próximos. Ver Anexo I para los códigos de cada individuo.

Por último, en la Figura 4.13 y en la Tabla 4.17 se presentan los resultados obtenidos para el análisis de autocorrelación espacial llevado a cabo en la población portuguesa de Benfeita (BEN). En ella, se analizaron ocho clases de distancia, todas ellas con más de 30 pares de comparaciones (Tabla 4.17). El correlograma obtenido resultó ser significativo para el test de heterogeneidad $(\Omega=54,746 ; P<0,0001)$, observándose en él la existencia de una baja autocorrelación positiva $(r=0,097$ a 0,149$)$ pero significativa $(P<0,01)$ para las dos primeras clases de distancia, hasta los $74 \mathrm{~m}$ (ver Figura 4.13 y Tabla 4.17). Dicha correlación positiva sería detectable hasta los 101,309 $\mathrm{m}$ definidos por el punto de intercepción (Figura 4.13 y Tabla 4.17). Al igual que en otros casos, en la población de Benfeita también se detectó una pequeña autocorrelación negativa y significativa $(r=-0,109$ a $-0,094 ; P<0,05)$ para distancias entre 134 y 208 m (ver Figura 4.13 y Tabla 4.17). 
BEN

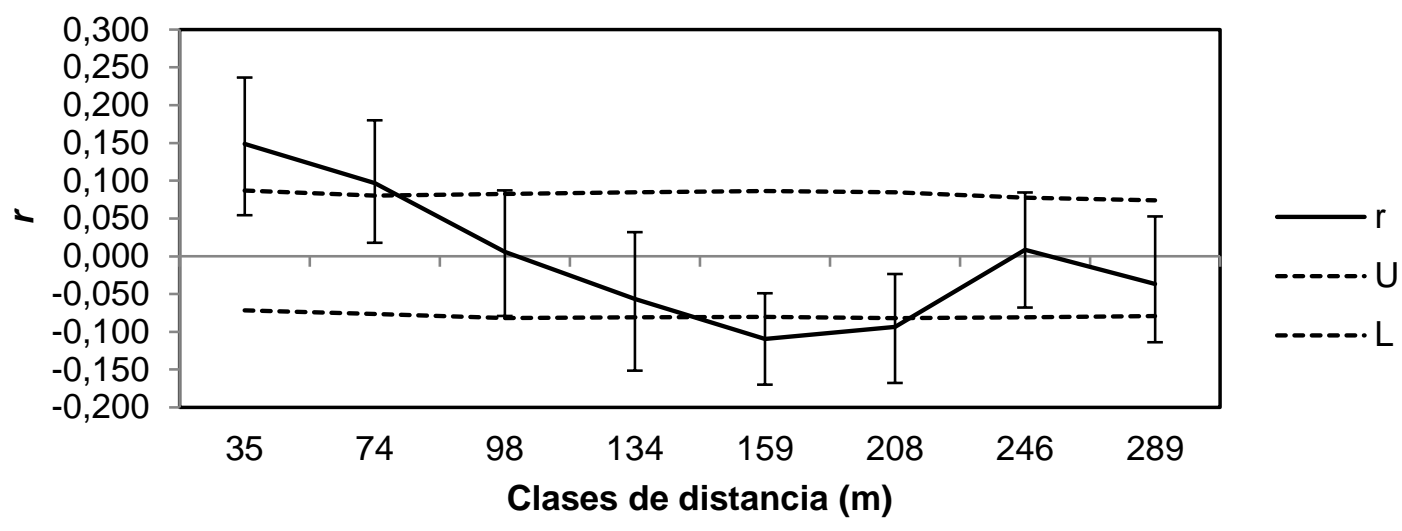

Figura 4.13. Correlograma obtenido del análisis espacial de la estructura genética para los 25 individuos de U. glabra de la población de Benfeita (BEN) analizados con los datos de 11 loci de microsatélites. La línea continua representa los valores del coeficiente de autocorrelación $(r)$ calculado para cada una de las ocho clases de distancia definidas (de 0-35 $\mathrm{m}$ a 246-289 $\mathrm{m}$ ). Las líneas discontinuas indican los límites superior $(U)$ e inferior $(L)$ del intervalo de confianza al $95 \%$ bajo la hipótesis nula de no existencia de estructura espacial $(r=0)$, obtenidos mediante 10000 permutaciones. Las barras verticales hacen referencia a las barras de error para cada estima de $r$, calculadas para un intervalo de confianza del $95 \%$ mediante 10000 remuestreos (bootstrap).

Tabla 4.17. Análisis de autocorrelación espacial para los 25 individuos de U. glabra pertenecientes a la población de Benfeita (BEN) analizados con los datos de 11 loci de microsatélites. $\mathrm{N}$ : número de pares de comparaciones para cada una de las cinco clases de distancia definidas (de 0-35 m a 246-289 m); $r$ : coeficiente de autocorrelación; $U$ y $L$ : límites superior e inferior del intervalo de confianza al 95\% para aceptar la hipótesis nula de no existencia de estructura espacial $(r=0)$, obtenidos a partir de 10000 permutaciones; $P$ : probabilidad de existencia de autocorrelación positiva, $r_{\mathrm{e}}\left(r\right.$ estimada) $\geq r_{0}(r$ observada), 0 de autocorrelación negativa, $r_{\mathrm{e}} \leq r_{0}, r_{\mathrm{B}}$ : valor medio de $r$ estimado por remuestreo (bootstrap); Ur y $L r$ : límites superior e inferior del intervalo de confianza al 95\%, determinados mediante 10000 remuestreos. En negrita se señalan los valores de $r$ que resultaron ser significativos $(P<0,05)$, así como su nivel de significación $(P)$. También se indica el punto de intercepción en $\mathrm{m}$.

\begin{tabular}{lrrrrrrrr}
\hline $\begin{array}{l}\text { Clases de } \\
\text { distancia (m) }\end{array}$ & $\mathbf{3 5}$ & $\mathbf{7 4}$ & $\mathbf{9 8}$ & $\mathbf{1 3 4}$ & $\mathbf{1 5 9}$ & $\mathbf{2 0 8}$ & $\mathbf{2 4 6}$ & $\mathbf{2 8 9}$ \\
$\mathbf{N}$ & 34 & 34 & 33 & 33 & 33 & 34 & 34 & 33 \\
\hline $\boldsymbol{r}$ & $\mathbf{0 , 1 4 9}$ & $\mathbf{0 , 0 9 7}$ & 0,006 & $-0,056$ & $-\mathbf{0 , 1 0 9}$ & $-0,094$ & 0,008 & $-0,037$ \\
$\mathbf{U}$ & 0,087 & 0,081 & 0,083 & 0,085 & 0,086 & 0,085 & 0,077 & 0,074 \\
$\mathrm{~L}$ & $-0,072$ & $-0,077$ & $-0,082$ & $-0,081$ & $-0,080$ & $-0,082$ & $-0,081$ & $-0,079$ \\
$P\left(r_{\mathrm{e}} \geq r_{\mathrm{o}}\right)$ & $\mathbf{0 , 0 0 2}$ & $\mathbf{0 , 0 0 9}$ & 0,444 & 0,913 & 0,998 & 0,988 & 0,417 & 0,829 \\
$\boldsymbol{P}\left(r_{\mathrm{e}} \leq r_{\mathrm{o}}\right)$ & 0,998 & 0,991 & 0,556 & 0,087 & $\mathbf{0 , 0 0 3}$ & $\mathbf{0 , 0 1 2}$ & 0,583 & 0,171 \\
$r_{\mathrm{B}}$ & 0,146 & 0,096 & 0,006 & $-0,057$ & $-0,110$ & $-0,094$ & 0,010 & $-0,036$ \\
$\mathrm{Ur}$ & 0,088 & 0,083 & 0,081 & 0,088 & 0,060 & 0,070 & 0,076 & 0,089 \\
$\mathrm{Lr}$ & 0,094 & 0,079 & 0,085 & 0,095 & 0,060 & 0,074 & 0,076 & 0,077 \\
\hline Intercepción & 101,309 & & & & & & &
\end{tabular}


En el análisis fino de autocorrelación espacial en $B E N$ se consideraron $\mathrm{N}=8$ vecinos más próximos, debido a que la distancia media entre ellos $(94,883 \mathrm{~m})$ es la que resultó ser ligeramente inferior al valor del punto de intercepción (101,309 m; ver Tabla 4.17). En dicho análisis se identificaron siete de las 25 muestras de la población con coeficientes de correlación positivos y significativos $(P<0,05)$ respecto a sus ocho vecinos más próximos (Tabla 4.18$)$.

Tabla 4.18. Individuos de la población de Benfeita (BEN) que presentaron correlación $(r)$ significativa $(P<0,05)$ con sus $\mathrm{N}=8$ vecinos más próximos. Ver Anexo I para los códigos de cada individuo.

\begin{tabular}{ccc|ccc}
\hline Individuo & $\boldsymbol{r}$ & $\boldsymbol{P}$ & Individuo & $\boldsymbol{r}$ & $\boldsymbol{P}$ \\
\hline BEN14 & 0,311 & $<0,001$ & BEN03 & 0,162 & 0,021 \\
BEN13 & 0,230 & 0,002 & BEN22 & 0,149 & 0,028 \\
BEN17 & 0,224 & 0,002 & BEN04 & 0,136 & 0,030 \\
BEN19 & 0,175 & 0,008 & & & \\
\hline
\end{tabular}

La distribución espacial de esas siete muestras en la población de Benfeita se muestra en la Figura 4.14. Dichos individuos se localizan fundamentalmente en el este de la población, algunos de ellos muy próximos a un arroyo (BEN14, BEN17 y BEN19).

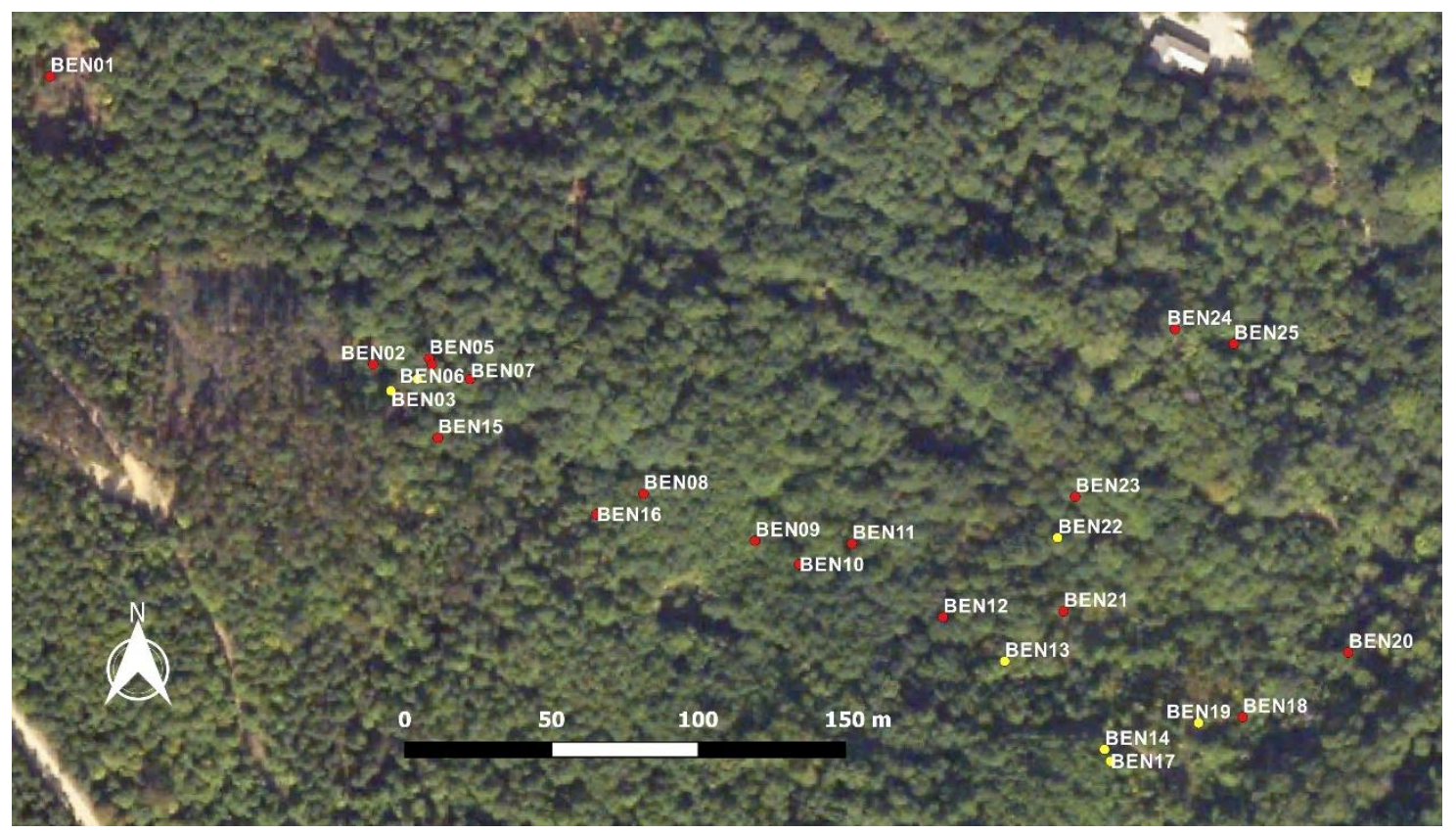

Figura 4.14. Localización de los 25 individuos pertenecientes a la población de Benfeita (BEN). En amarillo se muestran los 7 individuos con correlación positiva significativa $(P<0,05)$ con sus $\mathrm{N}=8$ vecinos más próximos. Ver Anexo I para los códigos de cada individuo. 


\section{5. Introgresión entre U. glabra y U. minor}

Con objeto de analizar la existencia de posible introgresión entre $U$. glabra y U. minor, se utilizaron los datos obtenidos con el análisis de los nueve loci SSR que amplificaron en ambas especies. En dicho análisis, se detectaron 76 alelos en los 427 individuos de las 22 poblaciones de olmo de montaña y 28 alelos en las 15 muestras de olmo común estudiadas (ver Tabla 4.1). Ambas especies compartieron 19 de dichos alelos, dos de los cuales (Ulm3-182 y UR123-252) presentaron una elevada frecuencia $(\geq 0,5$; ver Tabla 4.1). Asimismo, cabe destacar que todas las muestras de U. glabra compartieron al menos dos alelos con los individuos de U. minor (ver Tabla 4.1).

El análisis llevado a cabo con el programa STRUCTURE en las 427 muestras de U. glabra con los datos de los 11 loci SSR, mostró que el valor modal de la distribución de $\Delta K$, es decir, la mejor estima del número de grupos, fue $K=2$ (Figura 4.15a). Resultados similares fueron obtenidos en el segundo análisis, en el que se consideraron únicamente 9 de los 11 loci SSR con las 442 muestras (427 individuos de U. glabra y 15 de U. minor; Figura 4.15b). 

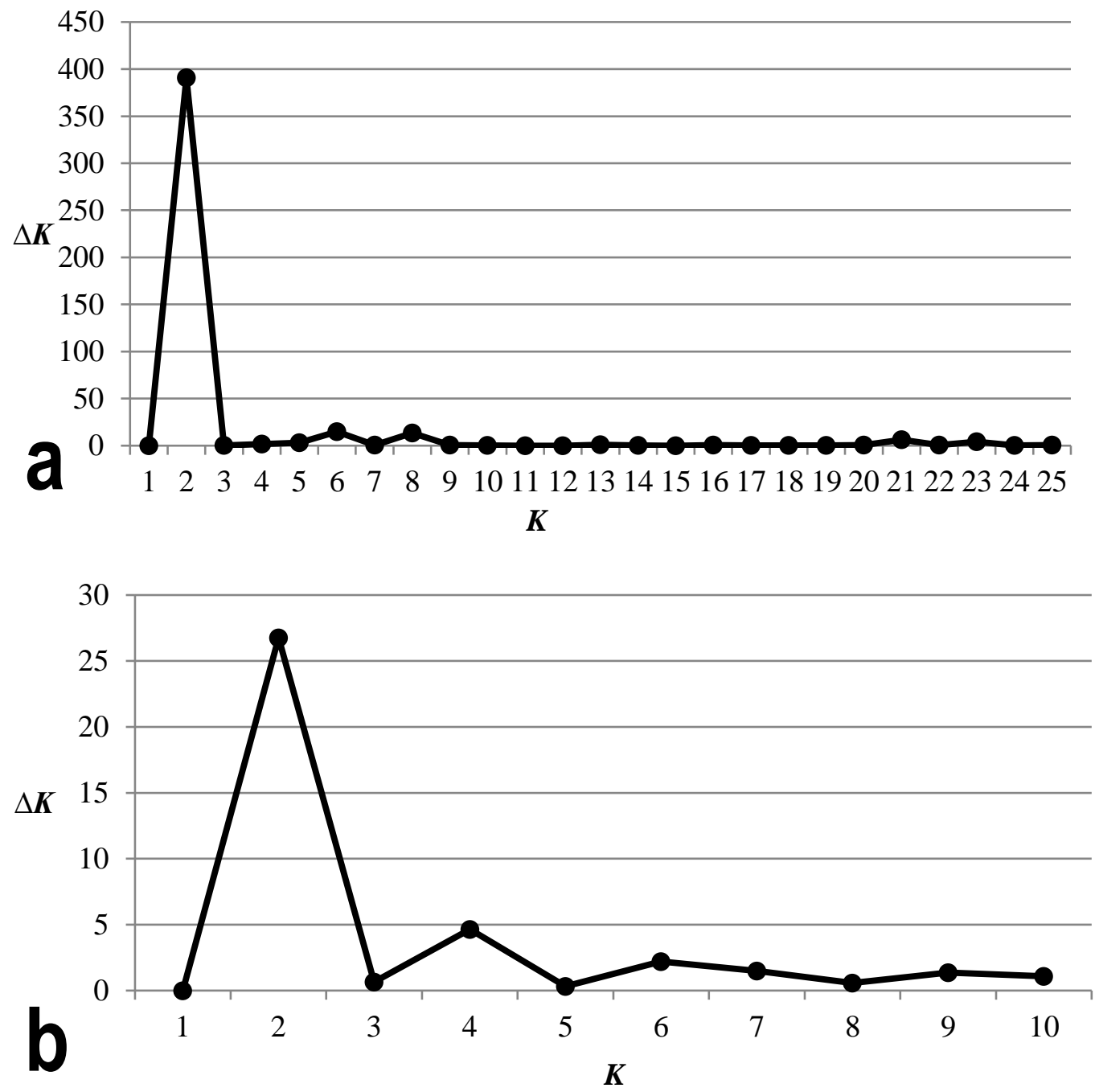

Figura 4.15. Estimación del número óptimo de grupos genéticos $(K)$ basados en la tasa de cambio en el estadístico $\Delta K$ entre los sucesivos valores de $K$ (Evanno et al. 2005) para (a) $K=1-25$ (usando los datos de los 11 loci SSR analizados en las 427 muestras de U. glabra) y (b) $K=1-10$ (usando los datos de los 9 loci SSR que amplificaron en los 427 individuos de $U$. glabra y en los 15 de $U$. minor).

Con respecto a los 427 individuos de olmo de montaña, el análisis de STRUCTURE reveló la existencia de dos grupos claramente definidos (clústeres A y B; ver Anexo Il y Tabla 4.19), basados en coeficientes de asignación $q \geq 0,9$ para cada uno de los grupos (Vähä \& Primmer 2006). De este modo, 368 individuos fueron asignados al grupo genético $A$ y 47 al clúster $B$, mientras que los 12 restantes fueron considerados como "individuos mezcla" al mostrar valores de $q$ inferiores a 0,9 (Anexo II y Tabla 4.19). Los 15 individuos de U. minor quedaron asignados al clúster $B$, junto con las 47 muestras de U. glabra (ver Anexo II). 
Tabla 4.19. Número y porcentaje de individuos asignados a los clústeres $A$ y $B, 0$ considerados individuos mezcla, para cada una de las poblaciones analizadas, en función de los resultados obtenidos mediante el análisis de STRUCTURE. Ver Tabla 1.1 para los códigos de población.

\begin{tabular}{lrrcc}
\hline Población & Nm & Clúster A (\%) & Clúster B (\%) & Individuos mezcla \\
\hline CNT & 1 & $1(100)$ & --- & --- \\
CNJ & 38 & $37(97,4)$ & --- & $1(2,6 \%)$ \\
BOC & 4 & $4(100)$ & --- & --- \\
RZA & 22 & $22(100)$ & --- & --- \\
NAV & 14 & $14(100)$ & --- & --- \\
MON & 7 & $7(100)$ & --- & -- \\
RAS & 33 & $33(100)$ & --- & --- \\
PAU & 1 & $1(100)$ & --- & -- \\
CER & 6 & $6(100)$ & --- & --- \\
ROZ & 46 & $1(2,2)$ & $38(82,6)$ & $7(15,2)$ \\
TIE & 42 & $42(100)$ & --- & --- \\
IRU & 57 & $55(96,5)$ & --- & $2(3,5)$ \\
CAS & 21 & $21(100)$ & --- & --- \\
PIE & 7 & $7(100)$ & --- & -- \\
CVJ & 20 & $18(90,0)$ & $2(10,0)$ & --- \\
CVA & 11 & $11(100)$ & --- & --- \\
MOM & 10 & $3(30,0)$ & $7(70,0)$ & --- \\
CAN & 8 & $7(87,5)$ & --- & $1(12,5)$ \\
ALD & 10 & $10(100)$ & --- & --- \\
VIL & 15 & $15(100)$ & --- & --- \\
STR & 29 & $29(100)$ & --- & -- \\
BEN & 25 & $24(96,0)$ & -- & \\
\hline
\end{tabular}

A continuación, para el análisis con el programa NewHybrids, los 368 individuos de U. glabra que fueron asignados al clúster $A$ (en el análisis con STRUCTURE) y los 15 individuos de U. minor asignados al clúster $B$ (en el análisis con STRUCTURE), se emplearon como muestras de referencia para U. glabra y U. minor, respectivamente. De igual forma que para el análisis de STRUCTURE, todos aquellos individuos que presentaron una probabilidad de asignación $p \geq 0,9$ para alguna de las seis clases genotípicas predefinidas (las clases parentales U. glabra y U. minor, y las categorías híbridas $F_{1}, F_{2} 0$ ambos retrocruzamientos de $F_{1}$ ) fueron asignados a dicha clase (ver Anexo II). De esta manera, 372 individuos quedaron asignados a la clase parental de $U$. glabra; 22 muestras de ROZ, que además presentaron el mismo genotipo, junto con los 15 individuos de U. minor, fueron asignados a la clase parental U. minor; mientras que 26 individuos fueron clasificados como individuos híbridos $F_{1}$ ( 16 de ROZ, 7 de MOM, 2 de CVJ y 1 de IRU). Los 
restantes siete individuos ( 5 de ROZ, 1 de IRU y 1 de CAN) mostraron valores de probabilidad de asignación posterior por debajo de 0,9 y, por tanto, no fueron asignados a ninguna clase (ver Anexo II). Los 55 individuos (22 de $\mathrm{ROZ}+26$ híbridos $\mathrm{F}_{1}+7$ no asignados) que no fueron clasificados dentro de la clase parental U. glabra con este análisis de NewHybrids, mostraron los mayores números de loci heterocigóticos (de siete a diez; ver Anexo I) y, además, compartieron con U. minor de cinco a diez alelos (ver Anexo I).

\section{6. PCR-RFLP en la región LSC del ADNcp}

\subsection{Amplificación}

En la Figura 4.16 se muestran ejemplos de los resultados obtenidos en la amplificación de algunos de los fragmentos de la región larga de copia única o LSC del ADN de cloroplastos en U. glabra.

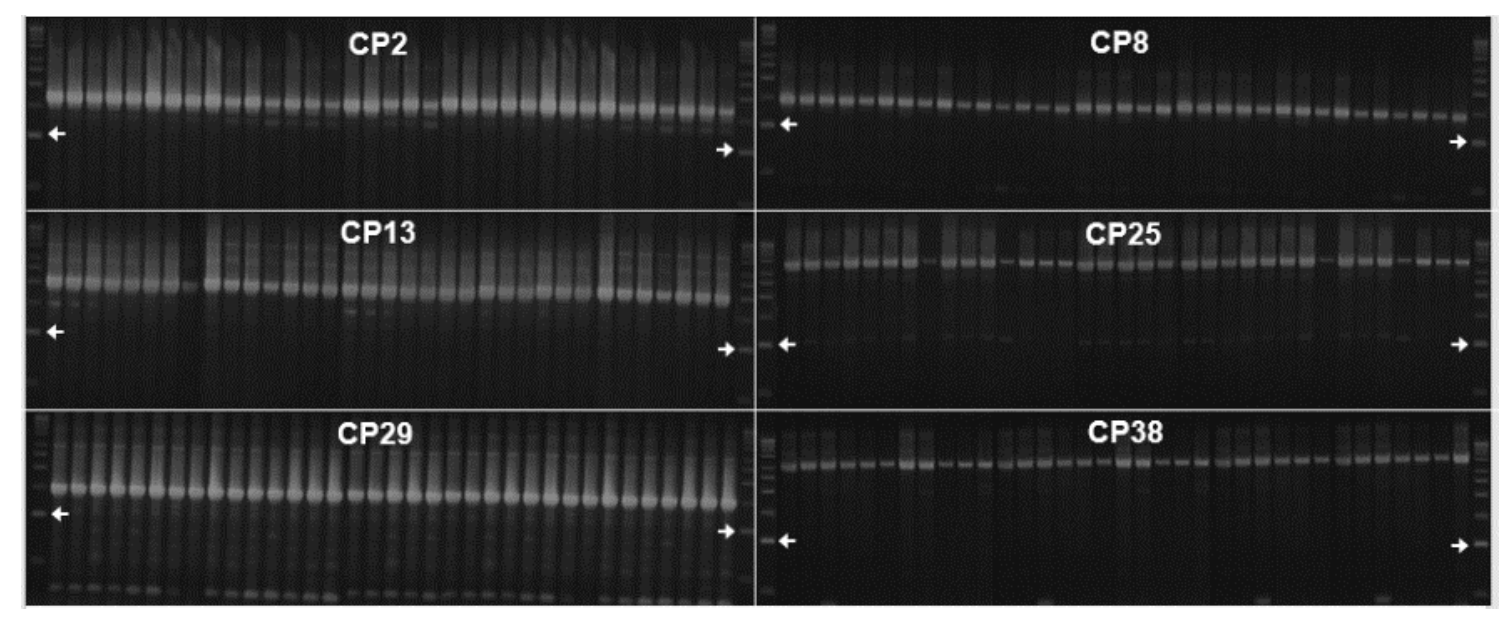

Figura 4.16. Amplificaciones obtenidas en 35 muestras de Ulmus para seis (CP2, CP8, C13, CP25, CP29 y CP38; ver Tabla 3.4 para los códigos) de los 38 fragmentos analizados de la región larga de copia única del ADN de cloroplastos. Marcador: escalera de 1-KiloBase (Pharmacia), las flechas indican la banda de 1000 pares de bases. En todos los casos, el orden de las muestras se corresponde con el siguiente: CNT01, CNJ03, CNJ07 BOC01, RZA04, RZA05, NAV04, MON02, RAS07, RAS08, PAU01, CER01, ROZ11, ROZ40, TIE11, TIE12, IRU19, IRU20, CAS20, CAS21, PIE04, CVJ06, CVJ07, CVA02, MOM02, CAN05, ALD10, VIL10, STR22, STR23, BEN02 y BEN03 de U. glabra; PAUm01, VILm03 y BENm05 de U. minor. Ver Tablas 1.1 y 3.2 para el código de las poblaciones.

Los resultados del análisis preliminar se muestran en la Tabla 4.20. En primer lugar, cabe destacar el elevado nivel de transferibilidad de los pares de cebadores utilizados sobre el genoma de cloroplastos del género Ulmus, ya que 25 de los 38 pares amplificaron fragmentos en ambas especies, sólo en 13 de las regiones analizadas no se obtuvo amplificación (ver Tabla 4.20). El 
tamaño de los productos amplificados fue similar para las dos especies, y varió entre 850 pb (CP9) y 5000 pb (CP20) (Tabla 4.20). El grado de amplificación fue, en general, muy bueno (16 de las 25 regiones amplificadas) o bueno (8 de las 25 regiones) (Tabla 4.20). Únicamente la región CP14 presentó un grado de amplificación débil.

La suma de todos los fragmentos amplificados fue de 58750 pb, lo que supone más del $66 \%$ de la región LSC de U. macrocarpa (88547pb) (Zuo et al. 2017), que es la especie de olmo más próxima a U. glabra (Wiegrefe et al. 1994) de la que se dispone de dicha información.

En general, los tamaños estimados para los fragmentos amplificados en U. glabra se pueden correlacionar con los tamaños obtenidos para la especie habitualmente utilizada como referencia, Nicotiana tabacum L.; únicamente las regiones CP9, CP28 y CP29 presentaron diferencias significativas (>300 pb) con respecto a los fragmentos del ADNcp de N. tabacum (Grivet et al. 2001).

Tabla 4.20. Grado de amplificación (NA, no amplifica; +, débil; ++, buena; +++, muy buena) y tamaño estimado en pares de bases (pb) para los 38 fragmentos de la región LSC amplificados en las 35 muestras de Ulmus (32 de U. glabra y 3 de U. minor) para el análisis preliminar.

\begin{tabular}{lrr|lrr}
\hline $\begin{array}{l}\text { Fragmentos } \\
\text { amplificados }\end{array}$ & $\begin{array}{c}\text { Grado de } \\
\text { amplificación }\end{array}$ & $\begin{array}{c}\text { Tamaño } \\
(\mathbf{p b})\end{array}$ & $\begin{array}{l}\text { Fragmentos } \\
\text { amplificados }\end{array}$ & $\begin{array}{c}\text { Grado de } \\
\text { amplificación }\end{array}$ & $\begin{array}{c}\text { Tamaño } \\
(\mathbf{p b})\end{array}$ \\
\hline CP1 & NA & --- & CP20 & ++ & 5000 \\
CP2 & +++ & 1750 & CP21 & NA & --- \\
CP3 & +++ & 2600 & CP22 & NA & --- \\
CP4 & NA & --- & CP23 & NA & -- \\
CP5 & +++ & 1450 & CP24 & NA & --- \\
CP6 & NA & --- & CP25 & ++ & 3800 \\
CP7 & ++ & 2600 & CP26 & ++ & 3300 \\
CP8 & ++ & 1400 & CP27 & +++ & 2000 \\
CP9 & ++ & 850 & CP28 & +++ & 2800 \\
CP10 & +++ & 2200 & CP29 & +++ & 1500 \\
CP11 & +++ & 3400 & CP30 & NA & --- \\
CP12 & +++ & 1950 & CP31 & NA & --- \\
CP13 & +++ & 1950 & CP32 & NA & --- \\
CP14 & + & 4900 & CP33 & +++ & 1500 \\
CP15 & NA & -- & CP34 & +++ & 2700 \\
CP16 & ++ & 1300 & CP35 & +++ & 1600 \\
CP17 & NA & --- & CP36 & NA & --- \\
CP18 & +++ & 1600 & CP37 & +++ & 1200 \\
CP19 & +++ & 1400 & CP38 & ++ & 4000 \\
\hline
\end{tabular}




\subsection{Digestión con enzimas de restricción}

En el estudio preliminar, los fragmentos resultantes de la amplificación en las 25 de las 38 regiones analizadas fueron sometidos a una digestión enzimática con Hinfl. Algunos de los patrones de restricción obtenidos se muestran en la Figura 4.17.

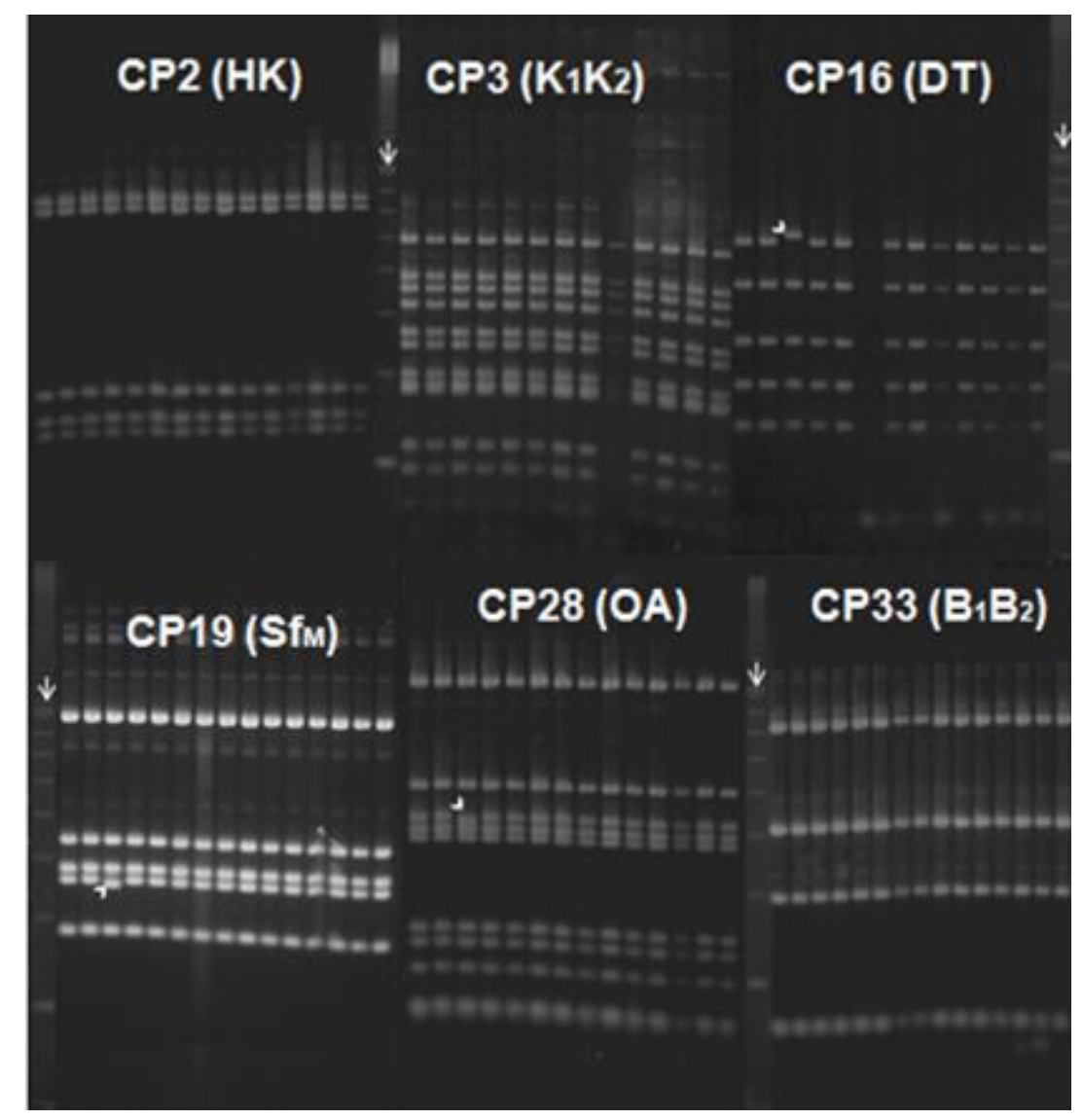

Figura 4.17. Patrones de restricción obtenidos al digerir los fragmentos $\mathrm{CP} 2(\mathrm{HK}), \mathrm{CP} 3\left(\mathrm{~K}_{1} \mathrm{~K}_{2}\right), \mathrm{CP} 16(\mathrm{DT})$, $\mathrm{CP} 19\left(\mathrm{Sf}_{\mathrm{M}}\right), \mathrm{CP} 28(\mathrm{OA})$ y $\mathrm{CP} 33\left(\mathrm{~B}_{1} \mathrm{~B}_{2}\right)$ con la enzima de restricción Hinfl. En todos los casos, cada muestra se corresponde consecutivamente con RZA04, NAV04, CER01, MON02, RAS07, ROZ11, TIE11, IRU19, CAS21, PIE04, CVA02, MOM02, CAN05, ALD10 y STR22. Ver Tabla 1.1 para el código de las poblaciones. Marcador: escalera de 100 pares de bases (100 Base-Pair Ladder; Pharmacia), las flechas indican la banda de 800 pares de bases. Algunos de los polimorfismos detectados se han señalado con puntas de flecha.

En este análisis preliminar, sólo se obtuvieron patrones de restricción polimórficos inter y/o intraespecíficos para 10 de las 25 regiones analizadas (CP2, CP5, CP7, CP8, C16, CP19, CP28, CP29, CP34 y CP38). En siete de ellas (CP5, CP7, CP8, CP16, CP29, CP34 y CP38) se detectaron diferencias entre U. glabra y U. minor (ver Tabla 4.21). A nivel intraespecífico, los polimorfismos detectados en los fragmentos CP16, CP19 y CP28 permitieron diferenciar la población de Cercedilla del resto de las poblaciones de olmo de montaña (ver Tabla 4.21). Sólo se observó polimorfismo a nivel intrapoblacional en U. glabra para la población de Casavieja (CVJ) en el 
fragmento CP2 (ver Tabla 4.21). En U. minor también se detectó polimorfismo intrapoblacional en las muestras de Villamiel (VILm) para los fragmentos CP2; donde se observaron los mismos fragmentos polimórficos que en los U. glabra de CVJ, y CP29 (ver Tabla 4.21).

Tabla 4.21. Tamaños de los fragmentos de restricción (en pares de bases) y haplotipos detectados mediante la técnica de PCR-RFLP con las 18 combinaciones región de ADNcp-enzima de restricción que resultaron ser polimórficas en las dos especies de UImus (I a III = haplotipos de U. glabra; i a ii = haplotipos de U. minor). Se indica el número de individuos (entre paréntesis), y en casos específicos las poblaciones, en donde fueron detectados los distintos haplotipos para ambas especies. Ver Tablas 1.1 y 3.2 para el código de las poblaciones.

\begin{tabular}{|c|c|c|c|c|c|}
\hline \multirow[b]{2}{*}{$\begin{array}{l}\text { Combinaciones } \\
\text { polimórficas }\end{array}$} & \multicolumn{5}{|c|}{ Fragmentos de restricción } \\
\hline & \multicolumn{3}{|c|}{ Ulmus glabra } & \multicolumn{2}{|c|}{ Ulmus minor } \\
\hline CP2-Hinfl & 610 & 610 & 630 & 610 & 630 \\
\hline CP5-Hinfl & 250 & 250 & 250 & 220 & 220 \\
\hline CP5-TaqI & 240 & 240 & 240 & 210 & 210 \\
\hline CP7-Hinfl & 350 & 350 & 350 & 370 & 370 \\
\hline CP8-Hinfl & 470 & 470 & 470 & 450 & 450 \\
\hline CP16-Hinfl & 450 & 470 & 450 & 430 & 430 \\
\hline CP16-Taql & 680 & 700 & 680 & 660 & 660 \\
\hline CP19-Hinfl & 180 & 170 & 180 & 180 & 180 \\
\hline CP19-Mval & 340 & 310 & 340 & 340 & 340 \\
\hline CP28-Hinfl & 320 & 310 & 320 & 320 & 320 \\
\hline CP28-Taql & 120 & 110 & 120 & 120 & 120 \\
\hline CP29-Hinfl_1 & 300 & 300 & 300 & 290 & 290 \\
\hline CP29-Hinfl_2 & 240 & 240 & 240 & 260 & 250 \\
\hline CP29-TaqI_1 & 630 & 630 & 630 & 620 & 620 \\
\hline CP29-TaqI_2 & 150 & 150 & 150 & 170 & 160 \\
\hline CP34-Hinfl & 620 & 620 & 620 & 660 & 660 \\
\hline CP34-Taql & 0 & 0 & 0 & 200 & 200 \\
\hline CP38-Hinfl & 300 & 300 & 300 & 290 & 290 \\
\hline Haplotipos & $I$ & II & III & $i$ & ii \\
\hline Distribución & $\begin{array}{r}\text { Mayoritario } \\
(408) \\
\end{array}$ & $\begin{array}{r}\text { CER } \\
(6) \\
\end{array}$ & $\begin{array}{l}\text { CVJ } \\
(13)\end{array}$ & $\begin{array}{r}\text { Mayoritario } \\
(11) \\
\end{array}$ & $\begin{array}{r}\text { VILm } \\
(4) \\
\end{array}$ \\
\hline
\end{tabular}

En consecuencia, tras el análisis preliminar, las 10 regiones en las que se detectaron diferencias inter y/o intraespecíficas fueron seleccionadas para llevar a cabo el estudio completo en las 427 muestras de $U$. glabra y las 15 de $U$. minor, utilizándose en este caso dos enzimas de restricción (Hinfl y Taql; y Mval para CP19). Los resultados obtenidos se presentan en la Tabla 
4.21. Se detectaron un total de 18 combinaciones "fragmento de ADNcp - enzima de restricción" polimórficas; 13 de las cuales permitieron diferenciar ambas especies, siete fueron polimórficas en el olmo de montaña y tres en el olmo común (Tabla 4.21). Aparentemente, la mayoría de los polimorfismos parecían deberse a diferencias del tipo inserción/deleción (indel) de pequeños fragmentos de ADN (en general $\leq 40 \mathrm{pb}$; ver Tabla 4.21). Considerando conjuntamente las 18 combinaciones de PCR-RFLP polimórficas se han obtenido tres diferentes clorotipos o haplotipos en el ADNcp para el olmo de montaña (denominados I, II y III; ver Tabla 4.21) y dos en U. minor (denominados i y ii; ver Tabla 4.21).

\section{Fragmento CP2}

La digestión del fragmento CP2 sólo reveló polimorfismo con la enzima Hinfl y a nivel intraespecífico, tanto en U. glabra como en U. minor, ya que el polimorfismo detectado no permitió diferenciar entre ambas especies (ver Tabla 4.21 y Figura 4.18). Por un lado, la mayoría de los $U$. glabra analizados (414 individuos con los haplotipos / y II), así como la mayoría de los U. minor (11 individuos con el haplotipo i) presentaron el mismo tamaño estimado del fragmento polimórfico (610 pb; Tabla 4.21 y Figura 4.18). Por otro, 13 de los 20 individuos de olmo de montaña de Casavieja (con el haplotipo III) junto con cuatro individuos de U. minor de Villamiel (con el haplotipo ii) presentaron el mismo tamaño estimado (630 pb) para ese fragmento de restricción (Tabla 4.21 y Figura 4.18).

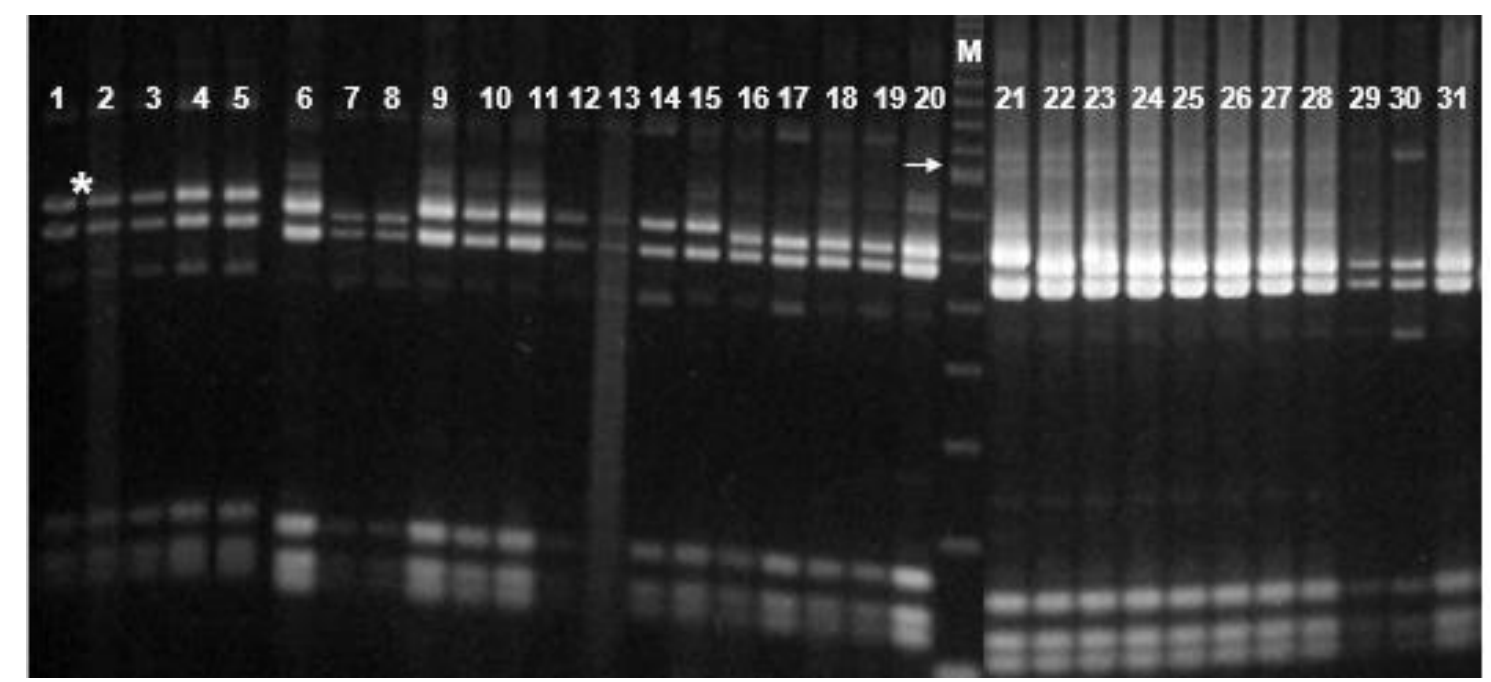

Figura 4.18. Patrones de restricción obtenidos para la región CP2 con la enzima Hinfl. M, Marcador: escalera de 100 pares de bases (100 Base-Pair Ladder; Pharmacia); la flecha indica la banda de $800 \mathrm{pb}$ y el asterisco señala la zona de fragmentos polimórficos. Pocillos 1 a 20, individuos de Casavieja (CVJ); pocillos 21 a 25, individuos de U. minor de Villamiel (VILm); pocillos 26 a 28, de individuos de U. glabra (CNJ03, TIE12 y BEN02); pocillos 29 a 31, individuos de U. minor (PAUm01, PAUm03 y ESBm02). Ver Tablas 1.1 y 3.2 para el código de las poblaciones. 


\section{Fragmento CP5}

La digestión de la amplificación de la región CP5 reveló resultados similares con ambas enzimas, permitiendo distinguir únicamente entre olmo de montaña y olmo común. Todas las muestras de U. glabra presentaron fragmentos de $250 \mathrm{pb}$ para CP5-Hinfl y 240 pb para CP5-Taql (Tabla 4.21); mientras que los 15 individuos de U. minor mostraron fragmentos de 220 pb para CP5-Hinfl y 210 pb para CP5-Taql (Tabla 4.21).

\section{Fragmento CP7}

La región CP7 sólo reveló polimorfismo al digerir el producto de amplificación con la enzima Hinfl. Los fragmentos de restricción obtenidos tras esa digestión permitieron diferenciar las dos especies analizadas. Las 427 muestras de olmo de montaña mostraron un fragmento de menor tamaño (350 pb) que el que presentaron las 15 muestras de U. minor (370 pb) (Tabla 4.21).

\section{Fragmento CP8}

Nuevamente, en esta región sólo se detectó polimorfismo tras la digestión del producto amplificado con la enzima Hinfl, que permitió diferenciar entre especies al obtenerse una banda polimórfica de 470 pb en los 427 individuos de U. glabra y de 450 pb en los 15 de U. minor (Tabla 4.21).

\section{Fragmento CP16}

La región CP16 resultó especialmente interesante debido a que, tras la amplificación, los productos de la digestión con ambas enzimas no sólo permitieron diferenciar entre olmo de montaña y olmo común, sino que también detectaron polimorfismo dentro de U. glabra. Por una parte, los 15 individuos de U. minor mostraron fragmentos de 430 pb y de 660 pb (para CP16-Hinfl y CP16-Taql, respectivamente; ver Tabla 4.21). Mientras que, en U. glabra, la mayoría de las muestras analizadas (421 individuos con los haplotipos I y III; ver Tabla 4.21) presentaron unos fragmentos de 450 pb (para CP16-Hinfl; Figura 4.19a) y 680 pb (para CP16-Taql; Figura 4.19b). Sin embargo, los seis individuos de la población de Cercedilla (con el haplotipo II) se caracterizaron por presentar tamaños algo mayores para ambos fragmentos (470 pb para CP16-Hinfl y 700 pb para CP16-Taql; ver Tabla 4.21 y Figura 4.19a,b). 

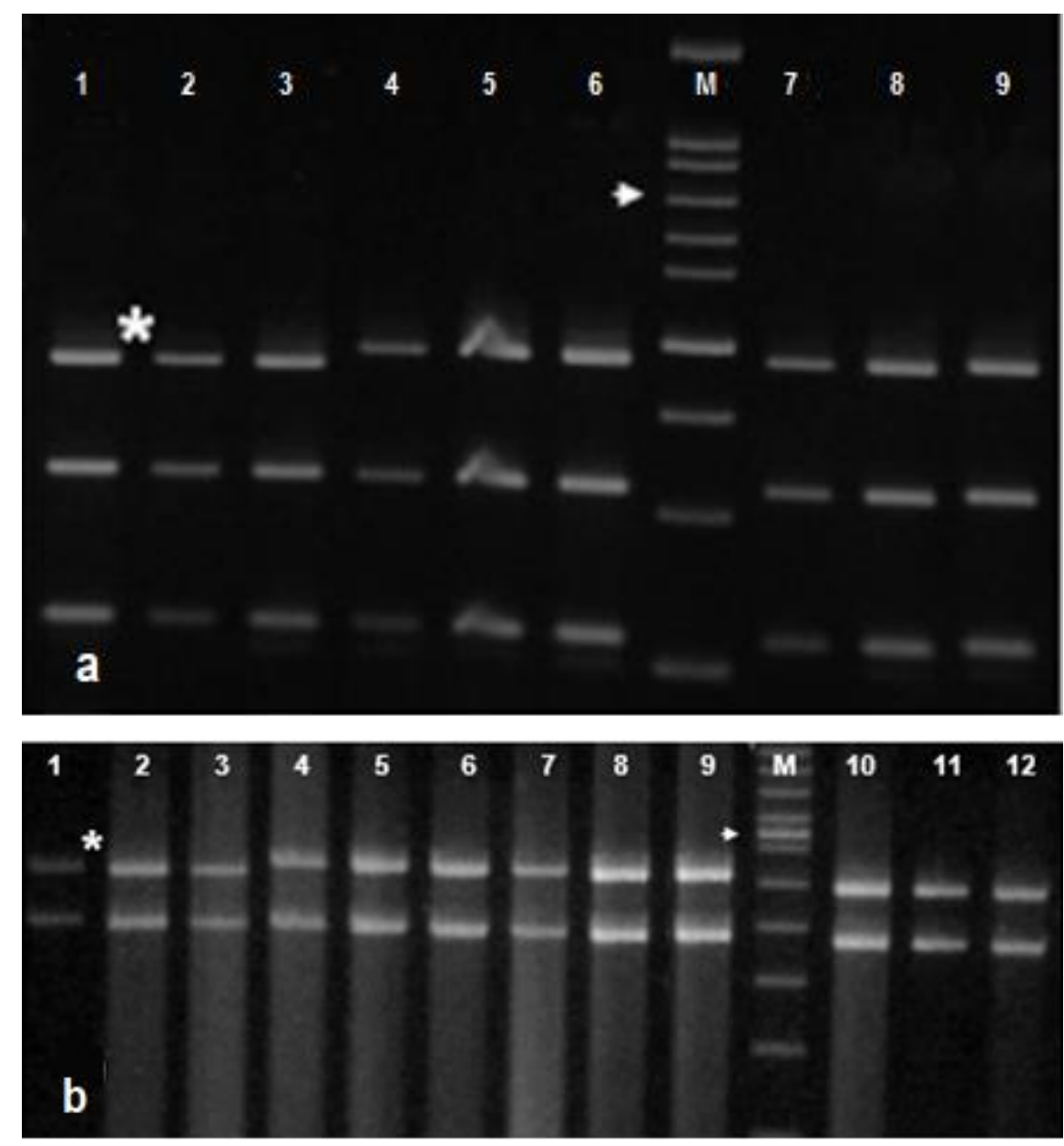

Figura 4.19. Patrones de restricción obtenidos para la región CP16. Combinación CP16-Hinfl (a). M, Marcador: escalera de 100 pares de bases (100 Base-Pair Ladder; Pharmacia); la flecha indica la banda de $800 \mathrm{pb}$ y el asterisco señala la zona de fragmentos polimórficos. pocillos 1 a 3 , individuos de $U$. glabra (CNJ03, TIE12 y BEN02); pocillos 29 a 31, individuos de U. minor (PAUm01, PAUm03 y ESBm02); pocillos 4 a 9, individuos de Cercedilla (CER). Combinación CP16-Taql (b). M, Marcador: escalera de 100 pares de bases (100 Base-Pair Ladder; Pharmacia); la flecha indica la banda de $800 \mathrm{pb}$ y el asterisco señala la zona de fragmentos polimórficos. Pocillos 1 a 3 y 10 a 12, individuos de U. glabra (CNJ03, RZA04, ROZ40, TIE12, ALD10 y BEN02); pocillos 29 a 31, individuos de U. minor (PAUm01, PAUm03 y ESBm02); pocillos 4 a 9, individuos de CER. Ver Tabla 1.1 para el código de las poblaciones.

\section{Fragmento CP19}

La amplificación y posterior digestión con las enzimas Hinfl y Mval del fragmento CP19 no permitió diferenciar entre las dos especies de olmo analizadas; sin embargo, con ambas enzimas se detectó polimorfismo en U. glabra. La mayoría de las muestras de U. glabra (421), junto con los 15 individuos de U. minor, presentaron los mismos fragmentos de restricción (180 pb para CP19Hinfl y 340 pb para CP19-Mval; ver Tabla 4.21 y Figura 4.20a,b). Únicamente los seis individuos de la población de olmo de montaña de Cercedilla mostraron diferencias en dichos fragmentos de restricción: 170 pb para CP19-Hinfl y 310 pb para CP19-Mval (ver Tabla 4.21 y Figura 4.20a,b). 

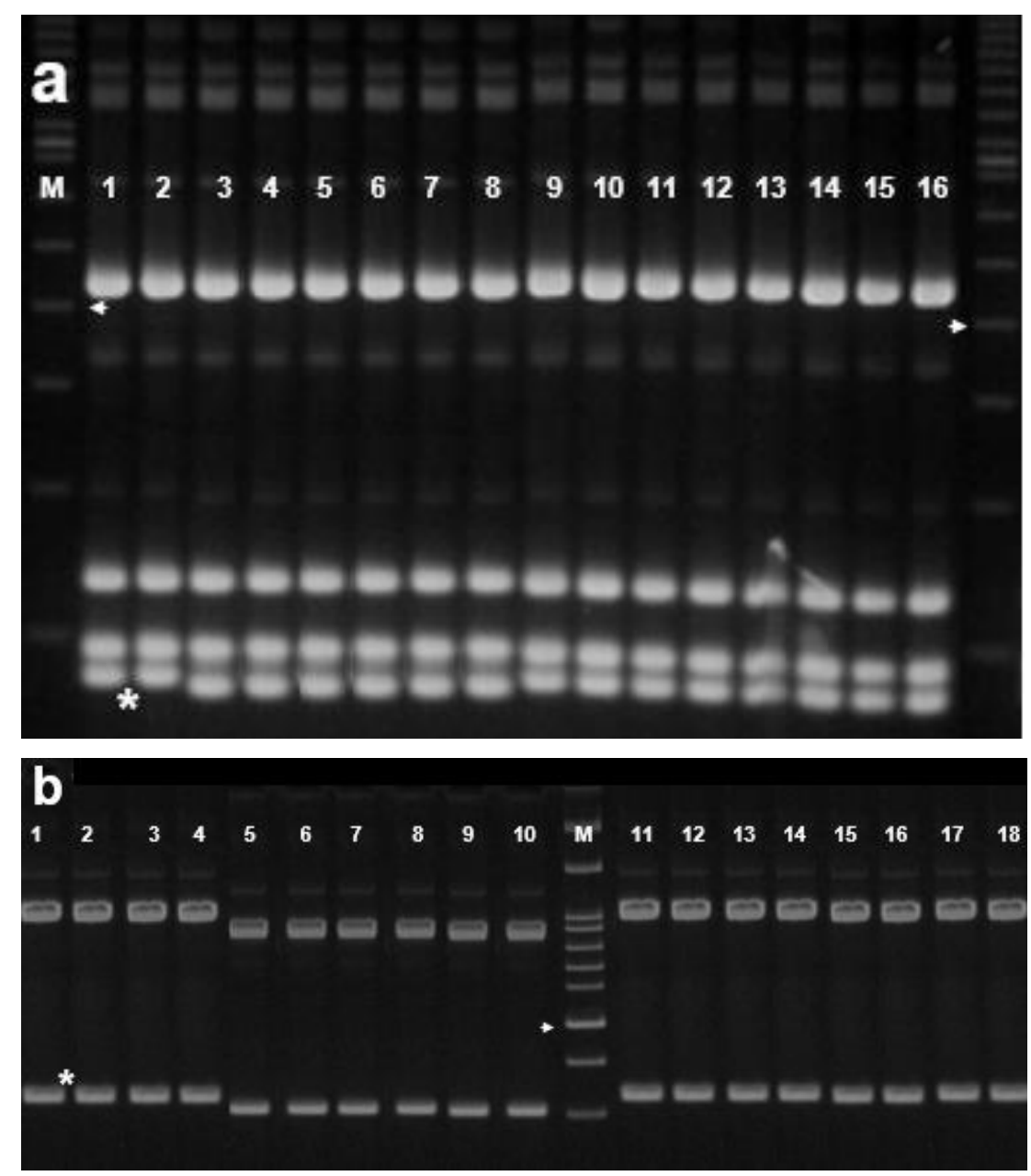

Figura 4.20. Patrones de restricción obtenidos para la región CP19. Combinación CP19-Hinfl (a). M, Marcador: escalera de 100 pares de bases (100 Base-Pair Ladder; Pharmacia); la flecha indica la banda de $500 \mathrm{pb}$ y el asterisco señala la zona de fragmentos polimórficos. Pocillos 1 a 2 y 9 a 16 , individuos de U. glabra (CNJ03, BOC01, RZA04, MON02, ROZ40, CVA02, TIE12, ALD10, STR22 y BEN02); pocillos 3 a 8, individuos de Cercedilla (CER). Combinación CP19-Mval (b). M, Marcador: escalera de 100 pares de bases (100 Base-Pair Ladder; Pharmacia); la flecha indica la banda de $500 \mathrm{pb}$ y el asterisco señala la zona de fragmentos polimórficos. Pocillos 1 a 4 y 11 a 18, individuos de U. glabra (CNJ03, BOC01, RZA04, MON02, RAS07, ROZ40, MOM02, CVA02, TIE12, ALD10, STR22 y BEN02); pocillos 5 a 10, individuos de CER. Ver Tabla 1.1. para el código de las poblaciones.

\section{Fragmento CP28}

Al igual que CP16 y CP19, la región CP28 permitió diferenciar mediante PCR-RFLP la población de Cercedilla del resto. En este caso, todos los demás individuos analizados de olmo de montaña y los de $U$. minor mostraron el mismo tamaño de los fragmentos de restricción para CP28-Hinfl (320 pb) y CP28-Taql (120 pb), mientras que las seis muestras de CER presentaron fragmentos de 310 pb para CP28-Hinfl y 110 pb para CP28-Taql (Tabla 4.21 y Figura 4.21a,b). 

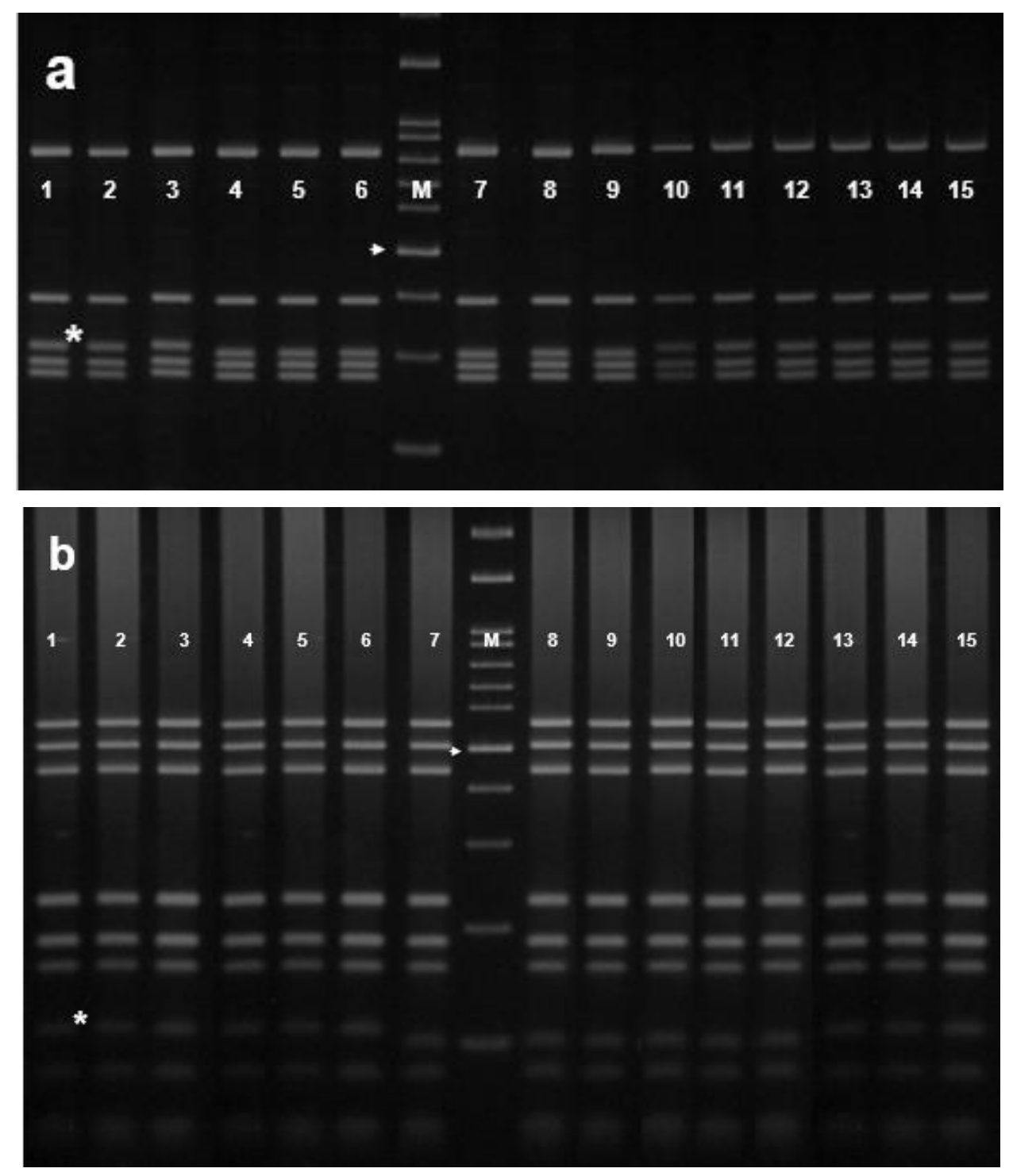

Figura 4.21. Patrones de restricción obtenidos para la región CP28. Combinación CP28-Hinfl (a). M, Marcador: escalera de 100 pares de bases (100 Base-Pair Ladder; Pharmacia); la flecha indica la banda de $500 \mathrm{pb}$ y el asterisco señala la zona de fragmentos polimórficos. Pocillos 1 a 3 y 10 a 15 , individuos de U. glabra (CNJ03, BOC01, RZA04, MON02, ROZ40, CVA02, TIE12, ALD10 y BEN02); Pocillos 4 a 9, individuos de Cercedilla (CER). Combinación CP28-Taql (b). M, Marcador: escalera de 100 pares de bases (100 Base-Pair Ladder; Pharmacia); la flecha indica la banda de $500 \mathrm{pb}$ y el asterisco señala la zona de fragmentos polimórficos. Pocillos 1 a 6 y 13 a 15, individuos de U. glabra (CNJ03, BOC01, RZA04, MON02, ROZ40, CVA02, TIE12, ALD10 y BEN02); pocillos 7 a 12, individuos de CER. Ver Tabla 1.1. para el código de las poblaciones.

\section{Fragmento CP29}

Tras la digestión con Hinfl y con Taql del producto de amplificación obtenido para la región CP29, en ambos casos se detectaron dos fragmentos polimórficos que permitieron diferenciar entre especies (Tabla 4.21). Por un lado, la combinación CP29-Hinfl generó un fragmento de 300 pb en U. glabra y otro de 290 pb en U. minor. Un segundo fragmento polimórfico obtenido tras la 
digestión con Hinfl mostró un tamaño de 240 pb en el olmo de montaña, mientras que en U. minor se detectó un fragmento de 260 pb para la mayoría de los individuos (los 11 que presentaron haplotipo I) y otro de $250 \mathrm{pb}$ para los cuatro individuos de VILm con haplotipo ii (ver Tabla 4.21).

La digestión del fragmento CP29 con Taql generó unos resultados similares a los obtenidos con Hinfl. De manera que se obtuvieron fragmentos de $630 \mathrm{pb}$ y $150 \mathrm{pb}$ para todas las muestras de $U$. glabra, mientras que en $U$. minor fueron de $620 \mathrm{pb}$ y $170 \mathrm{pb}$ para 11 de las muestras, y de 620 pb y 160 pb para los cuatro individuos de VILm (ver Tabla 4.21).

\section{Fragmento CP34}

CP34 es otra de las regiones que generó patrones de restricción diferentes entre ambas especies, tanto con Hinfl como con Taql (Tabla 4.21). La digestión con Hinfl produjo una banda polimórfica de $620 \mathrm{pb}$ en U. glabra y de $660 \mathrm{pb}$ en U. minor, mientras que en la digestión con Taql se detectó una banda de 200 pb en U. minor, ausente en U. glabra (ver Tabla 4.21).

\section{Fragmento CP38}

Esta última región también mostró patrones de restricción que únicamente diferenciaron las dos especies de olmo (Tabla 4.21). Por un lado, todos los individuos de U. glabra mostraron una banda de $300 \mathrm{pb}$; mientras que, por otra parte, los $15 \mathrm{U}$. minor analizados presentaron una banda de $290 \mathrm{pb}$ (ver Tabla 4.21).

\section{7. Microsatélites en el ADNcp}

En el análisis preliminar llevado a cabo en una muestra representativa de 35 muestras, nueve de los 18 SSRcp analizados resultaron ser monomórficos: ccmp3, ccmp4, ccmp6, ccmp7 y ccmp10 (Weising \& Gardner 1999); ccSSR-13, ccSSR-16, ccSSR-19 y ccSSR-22 (Chung \& Staub 2003) (ver Tabla 4.22). Estos SSRcp no detectaron variación intra ni interespecífica, mostrando un único alelo común tanto para U. glabra como U. minor.

De los 18 loci de microsatélites del genoma de cloroplastos que se analizaron en el estudio preliminar, la mitad de ellos resultaron ser monomórficos, concretamente: ccmp3, ccmp4, ccmp6, ccmp7 y ccmp10 (Weising \& Gardner 1999); ccSSR-13, ccSSR-16, ccSSR-19 y ccSSR-22 (Chung \& Staub 2003). Estos loci SSRcp no presentaron ninguna variación intra- ni interespecífica, habiendo mostrando cada uno de ellos un mismo alelo para U. glabra y U. minor (Tabla 4.22). 
Tabla 4.22. Tamaño de los alelos (en pares de bases) de los nueve loci SSRcp que fueron monomórficos en el estudio preliminar llevado a cabo en 35 muestras (32 U. glabra y $3 U$. minor).

\begin{tabular}{rrrrrrrrr}
\hline ccmp3 & ccmp4 & ccmp6 & ccmp7 & ccmp10 & ccSSR-13 & ccSSR-16 & ccSSR-19 & ccSSR-22 \\
\hline 95 & 118 & 103 & 129 & 120 & 320 & 350 & 310 & 186 \\
\hline
\end{tabular}

Los otros nueve SSRcp (ccmp2 y ccmp5, Weising \& Gardner 1999; ccSSR-4, ccSSR-7, ccSSR-9, ccSSR-12, ccSSR-20, ccSSR-21 y ccSSR-23, Chung \& Staub 2003) presentaron algún tipo de polimorfismo, inter y/o intraespecífico, por lo que fueron utilizados para llevar a cabo el análisis en el total de 442 muestras (427 de U. glabra y 15 de U. minor). Los resultados obtenidos para dicho análisis se muestran en la Tabla 4.23. En cinco (ccmp2, ccmp5, ccSSR-9, ccSSR-21 y ccSSR-23) de los nueve loci SSRcp se detectó polimorfismo entre las muestras de olmo de montaña; mientras que tres (ccmp5, ccSSR-7 y ccSSR-9) de los nueve fueron polimórficos en olmo común. Además, siete de los nueve SSRcp permitieron diferenciar U. glabra y U. minor, sólo los microsatélites ccSSR-7 y ccSSR-21 presentaron alelos compartidos por ambas especies.

El análisis conjunto de los nueve loci SSRcp polimórficos permitió distinguir siete haplotipos en el ADNcp o clorotipos en U. glabra (denominados de $A$ a $G$ ) y tres en U. minor (denominados como $a, b$ y $c$ ) (ver Tabla 4.23). En el olmo de montaña, el clorotipo $A$ estaba presente a lo largo de todo el Sistema Central, en la mayoría de las muestras (344) y en 19 de las 22 poblaciones analizadas. El segundo clorotipo más numeroso $(F)$ fue detectado en 62 individuos de las tres poblaciones localizadas más al oeste del Sistema Central (VIL, STR y BEN). El clorotipo C estuvo presente en 12 de las 57 muestras de IRU, y el $B$ fue exclusivo de las seis muestras de CER. Además, se detectaron tres clorotipos minoritarios, cada uno de ellos presente en un único individuo: $D$ (CVJ18), E (CVA10) y G (STR23) (Tabla 4.23). En U. minor, el clorotipo mayoritario (a) estuvo presente en las tres localidades y en nueve de las 15 muestras analizadas; mientras que cuatro de las cinco muestras de VILm presentaron el clorotipo $b$, y dos de las muestras de ESBm el clorotipo c (Tabla 4.23). 
Tabla 4.23. Tamaños de los alelos (en pares de bases) y haplotipos detectados para el conjunto de los nueve loci SSRcp polimórficos en Ulmus ( $A$ - $G=$ haplotipos en U. glabra; $a-c=$ haplotipos en U. minor). Se indica el número de individuos que presentaron cada haplotipo $\left(\mathrm{N}_{\mathrm{h}}\right)$ y su distribución en las poblaciones estudiadas. Ver Tablas 1.1 y 3.2 para el código de las poblaciones.

\begin{tabular}{|c|c|c|c|c|c|c|c|c|c|c|c|c|}
\hline Especie & ccmp2 & ccmp5 & ccSSR-4 & ccSSR-7 & ccSSR-9 & ccSSR-12 & ccSSR-20 & ccSSR-21 & ccSSR-23 & Haplotipos & $\mathrm{N}_{\mathrm{h}}$ & Distribución \\
\hline \multirow[t]{7}{*}{ U. glabra } & 233 & 121 & 385 & 360 & 320 & 208 & 317 & 283 & 343 & $A$ & 344 & Mayoritario \\
\hline & 233 & 118 & 385 & 360 & 320 & 208 & 317 & 283 & 336 & $B$ & 6 & CER \\
\hline & 234 & 122 & 385 & 360 & 320 & 208 & 317 & 283 & 343 & $C$ & 12 & IRU \\
\hline & 233 & 121 & 385 & 360 & 333 & 208 & 317 & 283 & 343 & $D$ & 1 & CVJ \\
\hline & 233 & 121 & 385 & 360 & 332 & 208 & 317 & 283 & 343 & $E$ & 1 & CVA \\
\hline & 235 & 120 & 385 & 360 & 307 & 208 & 317 & 284 & 336 & $F$ & 62 & VIL, STR, BEN \\
\hline & 235 & 120 & 385 & 360 & 307 & 208 & 317 & 284 & 349 & G & 1 & STR \\
\hline \multirow[t]{3}{*}{ U. minor } & 213 & 124 & 401 & 360 & 302 & 202 & 316 & 283 & 334 & $a$ & 9 & Mayoritario \\
\hline & 213 & 125 & 401 & 361 & 295 & 202 & 316 & 283 & 334 & $b$ & 4 & VILm \\
\hline & 213 & 124 & 401 & 360 & 294 & 202 & 316 & 283 & 334 & $c$ & 2 & ESBm \\
\hline
\end{tabular}




\section{8. Diversidad genética en el genoma de cloroplastos}

El empleo conjunto de los datos de PCR-RFLP y SSRcp en las 442 muestras de olmo analizadas permitió detectar ocho haplotipos diferentes en los 427 individuos y 22 poblaciones de U. glabra ( $\mathrm{H} 1 \mathrm{a} \mathrm{H} 8$; Tabla 4.24) y tres en las 15 muestras pertenecientes a tres localidades de $U$. minor.

La diversidad detectada en U. glabra mediante PCR-RFLP fue menor (tres clorotipos) a la encontrada empleando SSRcp (siete clorotipos). De los ocho haplotipos definidos conjuntamente, siete ya fueron detectados únicamente mediante $\operatorname{SSRcp}(\mathrm{H} 1=A, \mathrm{H} 2=B, \mathrm{H} 3=C, \mathrm{H} 5=D, \mathrm{H} 6=E, \mathrm{H} 7=F$ y H8=G; ver Tabla 4.24). La técnica de PCR-RFLP sólo permitió distinguir un nuevo haplotipo (H4), al diferenciar 13 individuos de CVJ que presentaron el haplotipo mayoritario $(A)$ en el análisis de SSRcp (Tabla 4.24).

Respecto a los ocho clorotipos globales detectados en U. glabra, cabe destacar que el haplotipo $\mathrm{H} 1$ fue el más frecuente $(0,749)$, estando presente a lo largo de todo el Sistema Central, ya que se localizó en 325 individuos y en 19 de las 22 poblaciones analizadas (Tabla 4.24). El haplotipo $\mathrm{H} 7$ fue el mayoritario en las tres poblaciones más occidentales (VIL, STR y BEN), con una frecuencia de 0,144 y presente en 62 individuos (Tabla 4.25). Los seis haplotipos restantes fueron exclusivos de un individuo $(\mathrm{H} 5, \mathrm{H} 6$ y $\mathrm{H} 8)$ o de una población. En este último caso, cabe destacar el H2, presente en todos los individuos de la población de CER; mientras que el H3 fue encontrado en 12 de los 57 individuos de IRU, y el H4 en 13 de los 20 individuos de CVJ (Tabla 4.24).

En general, la diversidad detectada en el genoma de cloroplastos de las poblaciones de olmo de montaña del Sistema Central no fue muy elevada. Únicamente cinco de las poblaciones fueron polimórficas (IRU, CVJ, CVA, STR y BEN), todas ellas con dos haplotipos diferentes, salvo CVJ que presentó tres (Tabla 4.24). Por ello, la población de CVJ fue la que presentó los mayores valores de diversidad haplotípica y riqueza alélica (0,511 y 1,222, respectivamente; Tabla 4.24). En la Tabla 4.25 se muestran los parámetros de diversidad y diferenciación genética en el ADNcp calculados con el programa Permut 2.0. Coincidiendo con los datos anteriores, se obtuvieron unos valores no muy elevados de diversidad total $\left(h_{T}=0,433\right)$, siendo muy baja la diversidad intrapoblacional media $\left(h_{s}=0,078\right)$ y muy alto el nivel de diferenciación genética entre las poblaciones $\left(G_{S T}=0,820\right)$. 
Tabla 4.24. Distribución de los ocho haplotipos $(\mathrm{H} 1$ a H8) obtenidos con los datos combinados de PCRRFLP (clorotipos I, II y III) y SSRcp (clorotipos $A$ a $G$ ) en las 19 poblaciones analizadas (con $\mathrm{Nm}>5$ ). Se indica el número de individuos por haplotipo, así como las frecuencias globales de cada haplotipo, calculadas con el programa Haplodiv. Nm, número de individuos muestreados; $\mathrm{Hd}$, diversidad haplotípica y error estándar (e. s.) entre paréntesis; Hr, riqueza haplotípica, obtenida tras aplicar la rarefacción para $\mathrm{Nm}=6$. Ver Tabla 1.1 para los códigos de las poblaciones.

\begin{tabular}{|c|c|c|c|c|c|c|c|c|c|c|c|c|}
\hline Población & $\begin{array}{l}\mathrm{H} 1 \\
\mathrm{~A}+\mathrm{I}\end{array}$ & $\begin{array}{c}\mathrm{H} 2 \\
B+I I\end{array}$ & $\begin{array}{l}\mathrm{H} 3 \\
\mathrm{C}+\mathrm{I}\end{array}$ & $\begin{array}{c}\mathrm{H} 4 \\
\mathrm{~A}+\text { III }\end{array}$ & $\begin{array}{l}\mathrm{H} 5 \\
\mathrm{D}+\mathrm{I}\end{array}$ & $\begin{array}{l}\mathrm{H} 6 \\
\mathrm{E}+\mathrm{I}\end{array}$ & $\begin{array}{l}\mathrm{H} 7 \\
\mathrm{~F}+\mathrm{I}\end{array}$ & $\begin{array}{l}\mathrm{H} 8 \\
\mathrm{G}+\mathrm{I}\end{array}$ & $\mathrm{Nm}$ & $\begin{array}{l}\mathrm{N}^{0} \text { de } \\
\text { haplotipos }\end{array}$ & $\begin{array}{l}\text { Hd } \\
\text { (e. s.) }\end{array}$ & $\begin{array}{l}\mathrm{Hr} \\
(\mathrm{N}=6)\end{array}$ \\
\hline CNJ & 38 & 0 & 0 & 0 & 0 & 0 & 0 & 0 & 38 & 1 & $\begin{array}{r}0,000 \\
(0,000)\end{array}$ & 0,000 \\
\hline RZA & 22 & 0 & 0 & 0 & 0 & 0 & 0 & 0 & 22 & 1 & $\begin{array}{r}0,000 \\
(0,000)\end{array}$ & 0,000 \\
\hline NAV & 14 & 0 & 0 & 0 & 0 & 0 & 0 & 0 & 14 & 1 & $\begin{array}{r}0,000 \\
(0,000)\end{array}$ & 0,000 \\
\hline MON & 7 & 0 & 0 & 0 & 0 & 0 & 0 & 0 & 7 & 1 & $\begin{array}{r}0,000 \\
(0,000)\end{array}$ & 0,000 \\
\hline RAS & 33 & 0 & 0 & 0 & 0 & 0 & 0 & 0 & 33 & 1 & $\begin{array}{r}0,000 \\
(0,000)\end{array}$ & 0,000 \\
\hline CER & 0 & 6 & 0 & 0 & 0 & 0 & 0 & 0 & 6 & 1 & $\begin{array}{r}0,000 \\
(0,000)\end{array}$ & 0,000 \\
\hline ROZ & 46 & 0 & 0 & 0 & 0 & 0 & 0 & 0 & 46 & 1 & $\begin{array}{r}0,000 \\
(0,000)\end{array}$ & 0,000 \\
\hline TIE & 42 & 0 & 0 & 0 & 0 & 0 & 0 & 0 & 42 & 1 & $\begin{array}{r}0,000 \\
(0,000)\end{array}$ & 0,000 \\
\hline IRU & 45 & 0 & 12 & 0 & 0 & 0 & 0 & 0 & 57 & 2 & $\begin{array}{r}0,338 \\
(0,063)\end{array}$ & 0,776 \\
\hline CAS & 21 & 0 & 0 & 0 & 0 & 0 & 0 & 0 & 21 & 1 & $\begin{array}{r}0,000 \\
(0,000)\end{array}$ & 0,000 \\
\hline PIE & 7 & 0 & 0 & 0 & 0 & 0 & 0 & 0 & 7 & 1 & $\begin{array}{r}0,000 \\
(0,000)\end{array}$ & 0,000 \\
\hline CVJ & 6 & 0 & 0 & 13 & 1 & 0 & 0 & 0 & 20 & 3 & $\begin{array}{r}0,511 \\
(0,091)\end{array}$ & 1,222 \\
\hline CVA & 10 & 0 & 0 & 0 & 0 & 1 & 0 & 0 & 11 & 2 & $\begin{array}{r}0,182 \\
(0,144)\end{array}$ & 0,545 \\
\hline MOM & 10 & 0 & 0 & 0 & 0 & 0 & 0 & 0 & 10 & 1 & $\begin{array}{r}0,000 \\
(0,000)\end{array}$ & 0,000 \\
\hline CAN & 8 & 0 & 0 & 0 & 0 & 0 & 0 & 0 & 8 & 1 & $\begin{array}{r}0,000 \\
(0,000)\end{array}$ & 0,000 \\
\hline ALD & 10 & 0 & 0 & 0 & 0 & 0 & 0 & 0 & 10 & 1 & $\begin{array}{r}0,000 \\
(0,000)\end{array}$ & 0,000 \\
\hline VIL & 0 & 0 & 0 & 0 & 0 & 0 & 15 & 0 & 15 & 1 & $\begin{array}{r}0,000 \\
(0,000)\end{array}$ & 0,000 \\
\hline STR & 0 & 0 & 0 & 0 & 0 & 0 & 28 & 1 & 29 & 2 & $\begin{array}{r}0,069 \\
(0,063)\end{array}$ & 0,207 \\
\hline BEN & 6 & 0 & 0 & 0 & 0 & 0 & 19 & 0 & 25 & 2 & $\begin{array}{r}0,380 \\
(0,091)\end{array}$ & 0,847 \\
\hline Individuos/haplotipo & 325 & 6 & 12 & 13 & 1 & 1 & 62 & 1 & 421 & & & \\
\hline Frecuencia (Haplodiv) & 0,749 & 0,053 & 0,011 & 0,034 & 0,003 & 0,0050 & 0,144 & 0,002 & & & & \\
\hline
\end{tabular}


Tabla 4.25. Parámetros de diversidad y diferenciación genética en el ADNcp calculados con el programa Permut 2.0 para las 19 poblaciones de U. glabra analizadas. Los errores estándar se muestran entre paréntesis.

\begin{tabular}{ll}
\hline Parámetro & Valor \\
\hline$N^{0}$ poblaciones & 19 \\
Media & 22,16 \\
Media armónica & 14,14 \\
$h_{S}$ & $0,078(0,036)$ \\
$h_{T}$ & $0,433(0,119)$ \\
$G_{S T}$ & $0,820(0,077)$ \\
$V_{S}$ & $0,041(0,024)$ \\
$V_{T}$ & $0,435(0,146)$ \\
$N_{S T}$ & $0,906(0,056)$ * \\
\hline
\end{tabular}

$h_{\mathrm{T}}$, diversidad total; $h_{\mathrm{S}}$, diversidad intrapoblacional media; y $\mathrm{G}_{\mathrm{ST}}$, diferenciación genética entre poblaciones, calculados considerando todos los haplotipos igualmente divergentes. $v_{T}, v_{S}$ y $N_{S T}$, parámetros equivalentes a los anteriores estimados teniendo en cuenta las distancias entre haplotipos. ${ }^{*} N_{\text {ST }}$ es significativamente mayor que $G_{S T}(P=0,01)$.

\section{9. Distribución de los haplotipos y estructura filogeográfica}

La red haplotípica de máxima parsimonia (maximum parsimony haplotype network) obtenida con el programa NETWORK 5.0 para los ocho haplotipos detectados en U. glabra se muestra en la Figura 4.22. En ella, se pueden diferenciar tres grupos de haplotipos. En el primero aparecen cinco haplotipos que se encuentran distribuidos a lo largo de todo el Sistema Central: H1 (mayoritario), H3 (12/57 individuos en IRU), H4 (13/20 en CVJ), H5 (1/20 en CVJ) y H6 (1/11 en CVA) (ver Tabla 4.24). El segundo grupo lo componen dos haplotipos localizados en las poblaciones más occidentales del Sistema Central: H7 (10/10 muestras en VIL, 28/29 en STR y 19/25 en BEN) y H8 (1/29 en STR) (ver Tabla 4.24). El tercer y último grupo, muy distante de los otros dos grupos, está compuesto exclusivamente por el haplotipo H2, presente sólo en las seis muestras de CER (Tabla 4.24). 


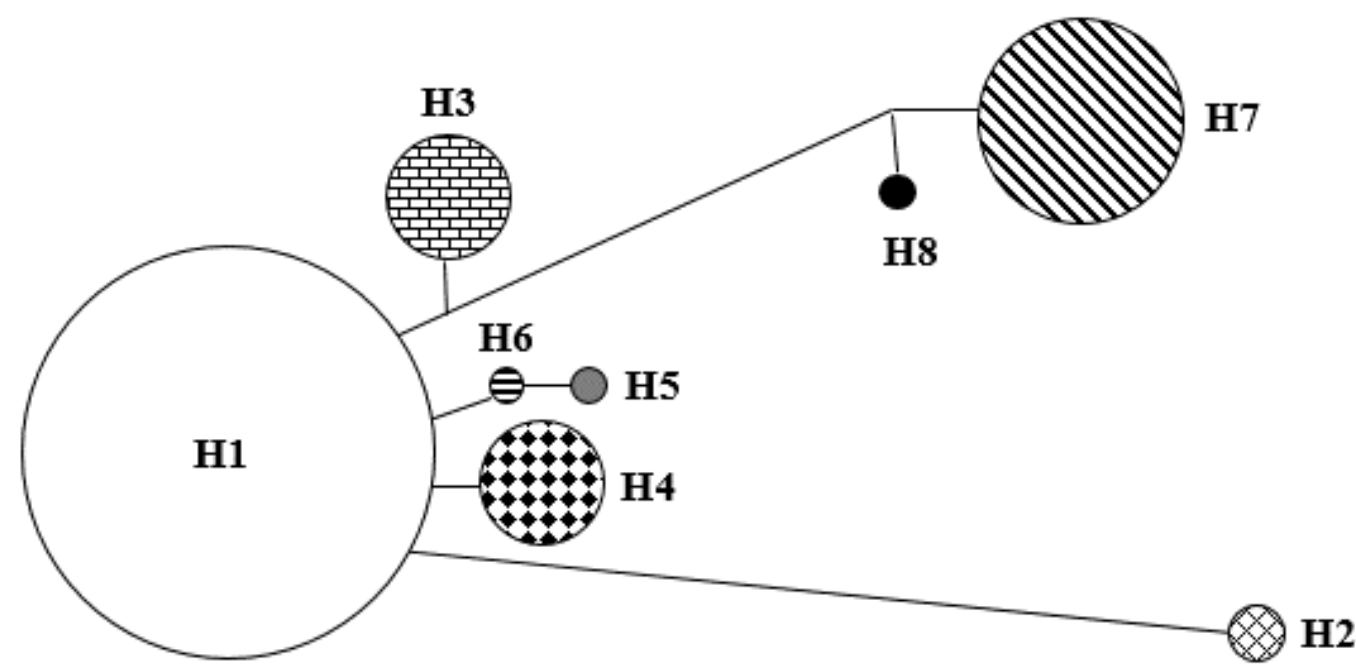

Figura 4.22. Red haplotípica de máxima parsimonia (maximum parsimony haplotype network) obtenida con el programa NETWORK 5.0 para los ocho haplotipos $(\mathrm{H} 1$ a $\mathrm{H} 8)$ detectados en las poblaciones de U. glabra del Sistema Central. Los tamaños de los círculos son proporcionales a la frecuencia del haplotipo (ver Tabla 4.24 para las frecuencias haplotípicas).

Por otra parte, el valor de la diferenciación genética entre poblaciones calculado considerando todos los haplotipos igualmente divergentes $\left(G_{S T}=0,820\right)$ fue significativamente $(P=0,01)$ menor que el estimado teniendo en cuenta las distancias entre haplotipos $\left(N_{\mathrm{ST}}=0,906\right)$ (ver Tabla 4.25), lo cual es indicativo de la existencia de una estructura filogeográfica en las poblaciones de olmo de montaña del Sistema Central.

Asimismo, el test de Mantel reveló la existencia de una correlación positiva y altamente significativa $(r=0,612 ; P=0,0001)$ entre la matriz de distancias geográficas y la de distancias genéticas de Nei entre poblaciones, lo cual es indicativo de la existencia de aislamiento por distancia en dichas poblaciones del Sistema Central.

Los resultados obtenidos en el análisis espacial de la varianza molecular con el programa SAMOVA 2.0 para las 19 poblaciones con más de cinco individuos muestreados se detallan en la Tabla 4.26. El máximo valor de $\mathrm{F}_{\mathrm{CT}}$ (estadístico que mide el grado de diferenciación entre clústeres de poblaciones) es alcanzado para $\mathrm{K}=4\left(\mathrm{~F}_{\mathrm{CT}}=0,930\right) \mathrm{y}$, posteriormente, los valores de $\mathrm{F}_{\mathrm{CT}}$ van disminuyendo desde $K=5$ a $K=10$. Por otra parte, como se puede observar en la Tabla $4.27, K=2$ es el único caso en que los grupos estimados no contuvieron poblaciones únicas, el resto de los análisis ( $\mathrm{K}=3$ a 10) mostraron al menos un clúster con una única población, lo cual es indicativo de que la estructura de grupos se está perdiendo (Magri et al. 2006). 
Por lo tanto, para determinar el número óptimo de grupos o clústeres, teniendo en cuenta sólo el criterio del mayor valor detectado para $\mathrm{F}_{\mathrm{CT}}$, éste fue obtenido para $\mathrm{K}=4$ clústeres (Tabla 4.26). En ese caso, como puede observarse en la Tabla 4.26 y en la Figura 4.23a, el clúster mayoritario o principal (Clúster 1) estaba conformado por 15 de las 19 poblaciones analizadas; el Clúster 2 estada constituido únicamente por una sola población (CER); en el Clúster 3 se agruparon las poblaciones de STR y VIL; y la población de BEN conformó el Clúster 4.

Sin embargo, para $\mathrm{K}=4$ vemos que existen dos clústeres compuestos por una única población, lo cual incumple el segundo criterio que hay que considerar para determinar el valor óptimo de K. Así, como ya ha sido mencionado, el único caso en el que los clústeres detectados por SAMOVA no incluían una única población fue para $\mathrm{K}=2$. En este caso, el grupo mayoritario (Clúster 1) estaba compuesto por 16 de las 19 poblaciones, mientras que en el Clúster 2 quedaron agrupadas las tres poblaciones más occidentales (VIL, STR y BEN) (ver Tabla 4.26 y Figura 4.23b).

Tabla 4.26. Índices de fijación ( $F_{S C}$, diferenciación entre poblaciones dentro de los grupos o clústeres; $F_{S T}$, diferenciación entre poblaciones respecto al total; $F_{C T}$, diferenciación entre clústeres de poblaciones) y composición poblacional de los clústeres obtenidos para valores de $\mathrm{K}$ de 2 a 10 con el programa SAMOVA 2.0, utilizando 10000 iteraciones MCMC (Markov chain Monte Carlo) y 500 repeticiones, sobre las 19 poblaciones de $U$. glabra con un tamaño muestral $>5$. En todos los casos, los tres índices de fijación fueron altamente significativos $(P<0,00000)$. Los clústeres que van apareciendo desde $\mathrm{K}=3$ a $\mathrm{K}=10$ por primera vez en el análisis se muestran en negrita. En negrita aparece el máximo valor de $\mathrm{F}_{\mathrm{CT}}$ obtenido.

\begin{tabular}{rrrrl}
\hline $\mathbf{K}$ & $\mathbf{F}_{\text {SC }}$ & $\mathbf{F}_{\text {ST }}$ & $\mathbf{F}_{\text {CT }}$ & Composición \\
\hline 2 & 0,498 & 0,945 & 0,891 & Mayoritario / VIL, STR, BEN \\
3 & 0,255 & 0,946 & 0,927 & Mayoritario / CER / VIL, STR, BEN \\
4 & 0,205 & 0,944 & $\mathbf{0 , 9 3 0}$ & Mayoritario / CER / VIL, STR / BEN \\
5 & 0,063 & 0,933 & 0,929 & Mayoritario / CER / CVJ / VIL, STR / BEN \\
6 & 0,070 & 0,932 & 0,927 & Mayoritario / CER / CVJ / VIL / STR / BEN \\
7 & 0,074 & 0,928 & 0,923 & Mayoritario / MON / CER / CVJ / VIL / STR / BEN \\
8 & 0,078 & 0,924 & 0,918 & Mayoritario / MON / CER / PIE / CVJ / VIL / STR / BEN \\
9 & 0,083 & 0,920 & 0,913 & Mayoritario / MON / CER / PIE / CVJ / CAN / VIL / STR / BEN \\
10 & 0,089 & 0,915 & 0,906 & Mayoritario / MON / CER / PIE / CVJ / CAN / ALD / VIL / STR / BEN \\
\hline
\end{tabular}



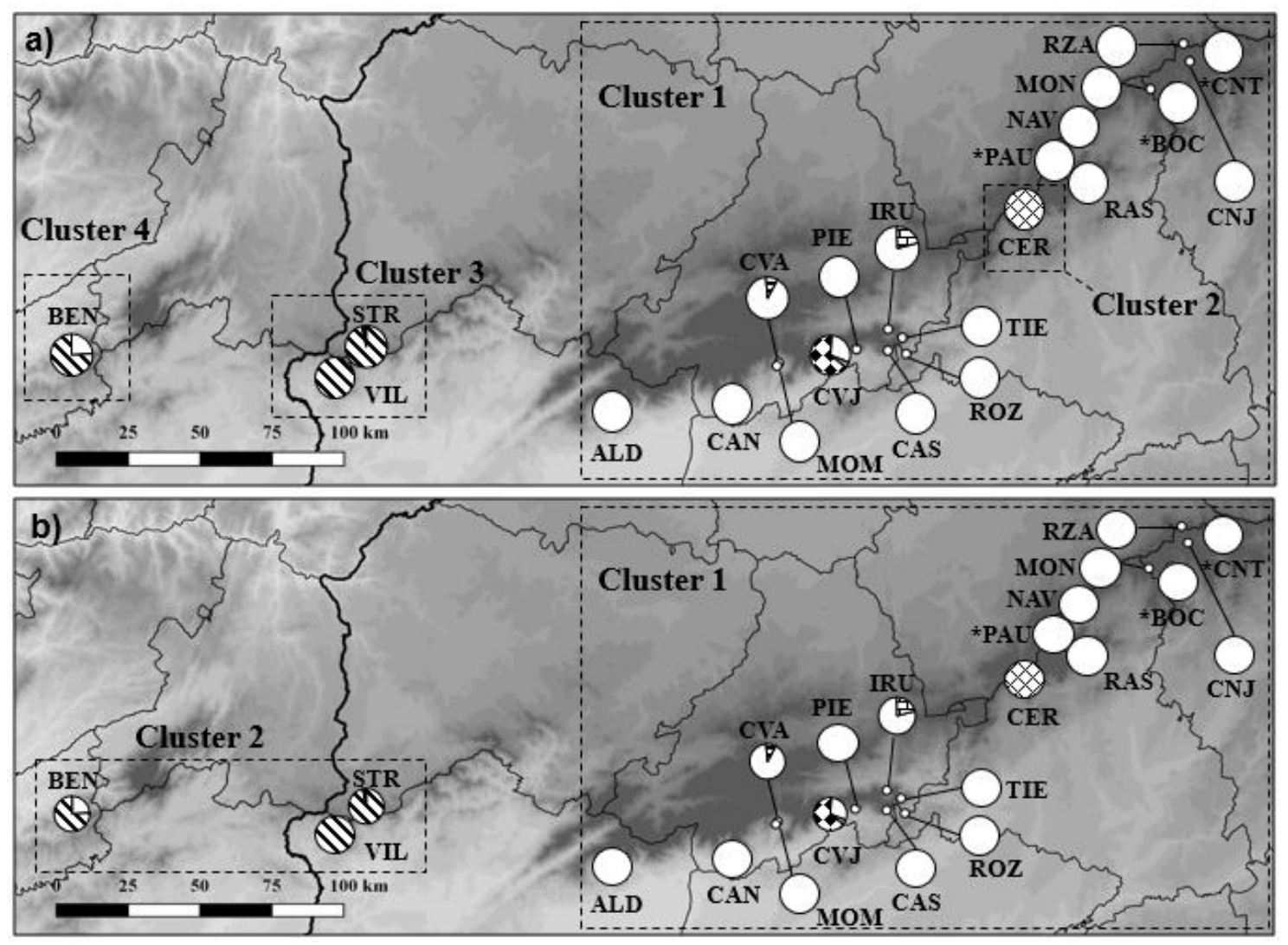

Figura 4.23. Estructura filogeográfica detectada en el análisis espacial de la varianza molecular realizado con el programa SAMOVA 2.0 con los datos del ADNcp en las 19 poblaciones del Sistema Central con $\mathrm{N}_{\mathrm{m}}>5$. Grupos o clústeres detectados para $\mathrm{K}=4$ (a); grupos o clústeres obtenidos para $\mathrm{K}=2$ (b). El relleno de los círculos de las poblaciones es proporcional a la frecuencia de los haplotipos detectados en ellas (ver Tabla 4.25). * Poblaciones que no fueron incluidas en este análisis, al contar con menos de cinco individuos muestreados. Ver Tabla 1.1 para los códigos de las poblaciones y Figura 4.22 para identificar los símbolos de cada haplotipo.

Los agrupamientos detectados por el programa SAMOVA para $\mathrm{K}=4$ y $\mathrm{K}=2$, fueron considerados para llevar cabo diferentes análisis de la varianza molecular (AMOVA). Los resultados de estos análisis se muestran en la Tabla 4.27. En primer lugar, se realizó un análisis general sin distinguir grupos para las 19 poblaciones estudiadas con más de cinco muestras, en el que, como cabría esperar, la mayor parte de la variación molecular se distribuyó entre poblaciones $(80,9 \%)$ más que dentro de las poblaciones $(19,1 \%)$. Cuando consideramos los clústeres detectados por SAMOVA para $\mathrm{K}=4$, la mayoría de la varianza molecular fue debida a diferencias entre los cuatro grupos establecidos (93,0\%), siendo muy escasa la variación atribuida a la diferenciación existente entre las poblaciones dentro de los grupos $(1,4 \%)$ y algo mayor la debida a la diferenciación dentro de las poblaciones (5,6\%) (Tabla 4.27). Si consideramos los clústeres detectados por SAMOVA para K=2, la varianza debida a diferencias entre los dos grupos de poblaciones disminuyó ligeramente respecto al caso anterior $(89,1 \%)$, en favor de la variación 
entre poblaciones dentro de los clústeres $(5,4 \%)$, siendo muy similar a la existente dentro de las poblaciones (5,5\%) (Tabla 4.27). En ambos casos, los valores estimados de $F_{S T}$ fueron muy elevados $\left(\mathrm{K}=4, \mathrm{~F}_{\mathrm{ST}}=0,944 ; \mathrm{K}=2, \mathrm{~F}_{\mathrm{ST}}=0,945\right)$ y altamente significativos $(P<0,00000)$.

Asimismo, se realizó un AMOVA para cada uno de los dos clústeres detectados por SAMOVA para $\mathrm{K}=2$. En el Clúster 1, constituido por 16 de las 19 poblaciones, el 62,7\% de la varianza molecular se debió a la diferenciación entre poblaciones, mientras que el 37,3\% restante fue atribuido a diferencias existentes dentro de las poblaciones ( $F_{S T}=0,673 ; P<0,0000$; Tabla 4.27). Sin embargo, las tres poblaciones más occidentales que conformaron el Clúster 2 (VIL, STR y BEN) presentaron un elevado porcentaje de la variación molecular debido a diferencias entre individuos dentro de ellas $(80,8 \%)$, siendo muy baja $(19,2 \%)$ la varianza atribuida a la diferenciación entre las poblaciones ( $\mathrm{F}_{\mathrm{ST}}=0,192 ; P<0,01$; Tabla 4.27).

Por último, un AMOVA para cada uno de los grupos detectados por SAMOVA con $\mathrm{K}=4$, sólo sería posible y tendría sentido para el Clúster 1, constituido por 15 de las 19 poblaciones, y equivalente al Clúster 1 para $\mathrm{K}=2$ pero sin la población de CER (ver Tabla 4.26). En este análisis, la varianza debida a las diferencias existentes entre las poblaciones se redujo notablemente respecto a cuando CER estaba incluida en el Clúster (32,0\% sin CER frente al 62,7\% con CER), incrementándose por tanto el porcentaje de la varianza atribuida a las diferencias dentro de las poblaciones (68,0\% sin CER frente al 37,3\% con CER) ( $F_{S T}=0,320 ; P<0,00000$; ver Tabla 4.27). 
Tabla 4.27. Análisis de la varianza molecular (AMOVA) con los datos de los haplotipos detectados en el ADNcp para las poblaciones de $U$. glabra sin el establecimiento de grupos de poblaciones, o bien considerando los clústeres detectados en el análisis con SAMOVA para K=4 y K=2 (ver Tabla 4.26).

\begin{tabular}{llrrrrr}
\hline & Fuente de Variación & $\begin{array}{l}\text { Grados de } \\
\text { libertad }\end{array}$ & $\begin{array}{l}\text { Suma de } \\
\text { cuadrados }\end{array}$ & Varianza Porcentaje & F \\
& Entre poblaciones & 18 & 126,893 & 0,323 & $80,9 \%$ & 0,809 \\
& Dentro de las poblaciones & 402 & 30,588 & 0,076 & $19,1 \%$ & $P=0,0001$ \\
& Total & 420 & 157,481 & 0,399 & & \\
\hline SAMOVA & Entre grupos & 3 & 267,300 & 2,032 & 93,0 & 0,944 \\
cuatro & Entre poblaciones dentro & 15 & 12,326 & 0,032 & 1,4 & $P<0,00000$ \\
clústeres & de los grupos & & & & & \\
(K=4) & Dentro de las poblaciones & 402 & 49,122 & 0,122 & 5,6 & \\
& Total & 420 & 328,748 & 2,186 & & \\
\hline SAMOVA & Entre grupos & 1 & 233,481 & 1,995 & 89,1 & 0,945 \\
dos & Entre poblaciones dentro & 17 & 46,145 & 0,121 & 5,4 & $P<0,00000$ \\
clústeres & de los grupos & & & & & \\
(K=2) & Dentro de las poblaciones & 402 & 49,122 & 0,122 & 5,5 & \\
& Total & 420 & 328,748 & 2,238 & & \\
\hline SAMOVA & Entre poblaciones & 15 & 41,621 & 0,127 & 62,7 & 0,627 \\
Clúster 1 & Dentro de las poblaciones & 336 & 25,356 & 0,075 & 37,3 & $P<0,00000$ \\
(K=2) & Total & 351 & 66,977 & 0,202 & & \\
\hline SAMOVA & Entre poblaciones & 2 & 4,524 & 0,086 & 19,2 & 0,192 \\
Clúster 2 & Dentro de las poblaciones & 66 & 23,766 & 0,360 & 80,8 & $P<0,01$ \\
(K=2) & Total & 68 & 28,290 & 0,446 & & \\
\hline SAMOVA & Entre poblaciones & 14 & 12,314 & 0,036 & 32,0 & 0,320 \\
Clúster 1 & Dentro de las poblaciones & 331 & 25,356 & 0,077 & 68,0 & $P<0,00000$ \\
sin CER & Total & 345 & 37,671 & 0,113 & & \\
(K=2) & & & & & & \\
\hline
\end{tabular}

\section{10. Caracterización ambiental de U. glabra}

Los resultados de la caracterización ambiental de las poblaciones de olmo de montaña en la península ibérica y de las localizadas en el Sistema Central, se muestran en la Tabla 4.28. En general, cabe destacar que no existen diferencias significativas en la precipitación anual, precipitación de primavera y la altitud de las poblaciones de la península ibérica y los núcleos del Sistema Central. Por el contrario, se detectaron diferencias significativas entre estos dos grupos de poblaciones en las siguientes variables: precipitación media en invierno, verano y durante el periodo lluvioso (invierno, primavera y otoño), temperatura media anual, temperatura media de las máximas diarias en verano, temperatura media de las mínimas diarias en invierno, en la oscilación térmica (febrero-julio) y en la litología (ver Tabla 4.28).

Centrándonos en las precipitaciones, las poblaciones de U. glabra del Sistema Central muestran valores mayores y significativos $(P<0,001)$ al resto de las poblaciones peninsulares para las lluvias recibidas en invierno (385,14 $\mathrm{mm}$ y $348,19 \mathrm{~mm}$ respectivamente) y las acumuladas durante la temporada lluviosa (primavera, otoño e invierno; 936,90 mm frente a 913,85 mm (ver 
Tabla 4.28). Sin embargo, las lluvias recibidas durante los meses de verano $(86,11 \mathrm{~mm})$, son significativamente $(P<0,001)$ menores a las que presentan, de media, las poblaciones peninsulares $(125,46 \mathrm{~mm}$; ver Tabla 4.28). En cuanto a las variables relacionadas con la temperatura, tanto la temperatura media anual $\left(11,83^{\circ} \mathrm{C}\right)$, como de la media de las máximas diarias en verano $(27,63$ $\left.{ }^{\circ} \mathrm{C}\right)$ y la media de las mínimas diarias en invierno $\left(0,56{ }^{\circ} \mathrm{C}\right)$ fueron significativamente $(P<0,001)$ superiores a las mismas temperaturas en las poblaciones del resto de la península $\left(11,17^{\circ} \mathrm{C}\right.$; $26,25^{\circ} \mathrm{C}$ y $0,17^{\circ} \mathrm{C}$ respectivamente; ver Tabla 4.28). Además, las poblaciones del Sistema Central presentaron mayor oscilación térmica (febrero-julio) $\left(20,94^{\circ} \mathrm{C}\right.$ ) que la que presentaron las del resto de la península $\left(19,72^{\circ} \mathrm{C}\right.$; ver Tabla 4.28$)$.

Por último, se detectaron diferencias significativas $(P<0,001)$ en la variable litológica, constatando un predominio de rocas hercínicas, predominantemente ácidas ( $>50 \%$ en el Sistema Central, respecto del resto de la península $(<30 \%)$.

En general, las poblaciones del Sistema Central viven en unas condiciones climáticas más secas y cálidas en verano; y con mayor amplitud térmica a lo largo del año, mostrando una clara preferencia por suelos ácidos.

Tabla 4.28. Media, rango y desviación estándar (D.E.) de las variables ecológicas empleadas en la modelización de $U$. glabra en la península ibérica y para las 27 poblaciones del Sistema Central. P, precipitación $(\mathrm{mm})$; $\mathrm{T}$, temperatura $\left({ }^{\circ} \mathrm{C}\right)$.

\begin{tabular}{|c|c|c|c|c|c|c|}
\hline \multirow[b]{2}{*}{ Variable } & \multicolumn{3}{|c|}{ península ibérica } & \multicolumn{3}{|c|}{ Sistema Central } \\
\hline & Media & Rango & D.E. & Media & Rango & D.E. \\
\hline$P$ anual ns & 1039,45 & $\begin{array}{l}348,58- \\
2555,77\end{array}$ & 272,32 & $1.023,06$ & $\begin{array}{l}731,76- \\
1453,34\end{array}$ & 134,60 \\
\hline$P$ invierno *** & 348,19 & $71,87-835,53$ & 115,06 & 385,14 & $225,09-574,20$ & 74,38 \\
\hline P primavera ns & 277,24 & $101,48-712,72$ & 72,41 & 266,67 & $204,05-355,20$ & 24,34 \\
\hline P verano *** & 125,46 & $53,18-416,66$ & 63,48 & 86,11 & $56,53-135,12$ & 20,69 \\
\hline P otoño ns & 288,42 & $94,28-680,92$ & 78,61 & 285,09 & $185,43-440,36$ & 52,38 \\
\hline $\begin{array}{l}\text { P primavera, otoño e } \\
\text { invierno }{ }^{* * *}\end{array}$ & 913,85 & $\begin{array}{r}267,63- \\
2139,02\end{array}$ & 272,25 & 936,90 & $\begin{array}{r}630,82- \\
1368,27\end{array}$ & 139,69 \\
\hline T media anual ${ }^{* * *}$ & 11,17 & $3,73-16,07$ & 2,21 & 11,83 & $7,17-15,93$ & 2,02 \\
\hline $\begin{array}{l}\text { T media diaria } \\
\text { máximas verano *** }\end{array}$ & 26,25 & $14,94-33,14$ & 2,83 & 27,63 & $21,84-33,14$ & 2,09 \\
\hline $\begin{array}{l}\text { T media diaria mínimas } \\
\text { T invierno *** }\end{array}$ & 0,17 & $-8,39-6,86$ & 7,41 & 0,56 & $-3,73-3,39$ & 2,27 \\
\hline $\begin{array}{l}\text { Oscilación térmica } \\
\text { anual **t }\end{array}$ & 19,72 & $8,90-24,01$ & 2,89 & 20,94 & $16,99-24,01$ & 2,13 \\
\hline Altitud ns & 1031 & $1-2368$ & 366,49 & 1084 & $414-1670$ & 319,16 \\
\hline Litología *** & $\begin{array}{l}11 \text { clases } \\
\text { hercínicas }\end{array}$ & $\begin{array}{l}\text {; >30\% Rocas } \\
\text {; plutónicas }\end{array}$ & & $\begin{array}{l}6 \text { clases; } \\
\text { plutónicas }\end{array}$ & $>50 \%$ Rocas h & cínicas \\
\hline
\end{tabular}


ns No significativo; ${ }^{* * *}(P<0,001)$ entre las medias de las poblaciones del Sistema Central y la península ibérica; ns, no significativo.

Las poblaciones del Sistema Central se sitúan en ocho de los sectores climáticos descritos (Ruiz-Labourdette et al. 2011). Tal y como se puede observar en la Tabla 4.29, las poblaciones de Guadarrama-Ayllón se localizan en los sectores climáticos eurosiberiano interior de media altura, eurosiberiano interior templado de media montaña y eurosiberiano interior frío de media montaña; mientras que las poblaciones de Gredos se localizan en los sectores oceánico-mediterráneo cálido de piedemonte, mediterráneo interior de baja montaña, mediterráneo interior cálido de piedemonte y mediterráneo interior cálido de piedemonte.

Tabla 4.29. Sectorización y características climáticas según Ruiz-Labourdette et al. (2011) para las poblaciones del Sistema Central (ver Tabla 1.1 para los códigos de población). Entre paréntesis, aparece el número de individuos para las poblaciones que se localizan en más de un sector climático. STR, VIL y BEN, sin datos.

\begin{tabular}{|c|c|c|}
\hline Sector & Características & Poblaciones \\
\hline 1 & Oceánico-mediterráneo cálido de piedemonte & CAN, VAL, y ALD \\
\hline 2 & Oceánico-mediterráneo de baja montaña & $\begin{array}{l}\operatorname{IRU}(33), \operatorname{PIE}(1), \text { CVA, CAN (3) y } \\
\operatorname{STR}(6)\end{array}$ \\
\hline 4 & Mediterráneo interior de baja montaña & $\begin{array}{l}\text { TIE, IRU (53), CAS, PIE (12), CVJ y } \\
\text { ARL }\end{array}$ \\
\hline 5 & Mediterráneo interior cálido de piedemonte & ROZ, IRU (12), PIE (1), CVH y MOM \\
\hline 8 & Sub-mediterráneo interior de media montaña & $\operatorname{IRU}(12)$ \\
\hline 9 & Eurosiberiano interior de media altura & CNJ (78), RZA (24), y NAV \\
\hline 11 & $\begin{array}{l}\text { Eurosiberiano interior templado de media } \\
\text { montaña }\end{array}$ & $\begin{array}{l}\text { CNJ (29), BOC, MON (8), RAS, } \\
\text { MZR, CER y PAU }\end{array}$ \\
\hline 13 & Eurosiberiano interior frío de media montaña & CNT, CNJ (1), RZA (3) y MON (1) \\
\hline
\end{tabular}

Los resultados de la caracterización ambiental de las 12 variables para las 27 poblaciones del Sistema Central pueden verse en la Tabla 4.30.

\section{Precipitaciones}

En primer lugar, cabe destacar que los mayores índices de pluviosidad en general, a excepción de la precipitación en verano, fueron localizados en Serra da Estrela y Sierra de Gata, y las zonas más suroccidentales de Gredos (ver Tabla 4.30). En el extremo contrario se localizaron las poblaciones más orientales del Sistema Central, con valores muy bajos de precipitación media anual (ver Tabla 4.30), pero con los valores más altos de precipitación en verano (ver Figura 4.24). En este sentido cabe destacar a las poblaciones de ARL, ALD y STR como las poblaciones de 
mayor precipitación anual (>1200 mm; ver Tabla 4.30), precipitación de invierno (>450 mm; ver Tabla 4.30) y de precipitación acumulada durante la temporada lluviosa (primavera, otoño e invierno; >1180 mm; ver Figura 4.25). Los núcleos de CNT y NAV presentaron los valores más bajos de precipitación anual $(<770 \mathrm{~mm})$, precipitación de otoño (<200 mm) y precipitación acumulada durante la temporada lluviosa (primavera, otoño e invierno; <655 mm; ver Tabla 4.30 y ver Figura 4.25). Las poblaciones con mayor precipitación durante el verano fueron CNJ, RZA y MON (>125 mm; ver Tabla 4.30 y Figura 4.24); mientras que aquellas con los valores más bajos fueron ROZ, CAN y VIL (ver Tabla 4.30 y Figura 4.24). Además, ROZ destacó por mostrar los valores bajos en todos los índices de pluviosidad (ver Tabla 4.30).

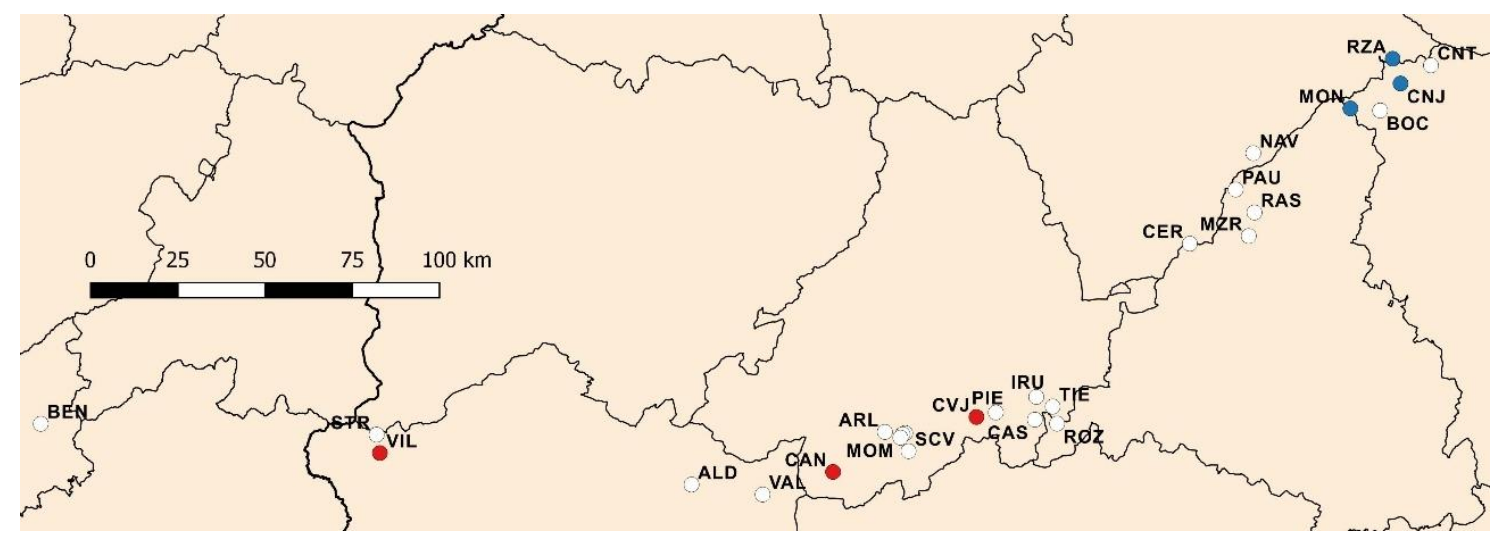

Figura 4.24. Poblaciones con mayor (en azul) y menor (rojo) precipitación acumulada durante los meses de verano. Ver Tabla 1.1 para los códigos de población.

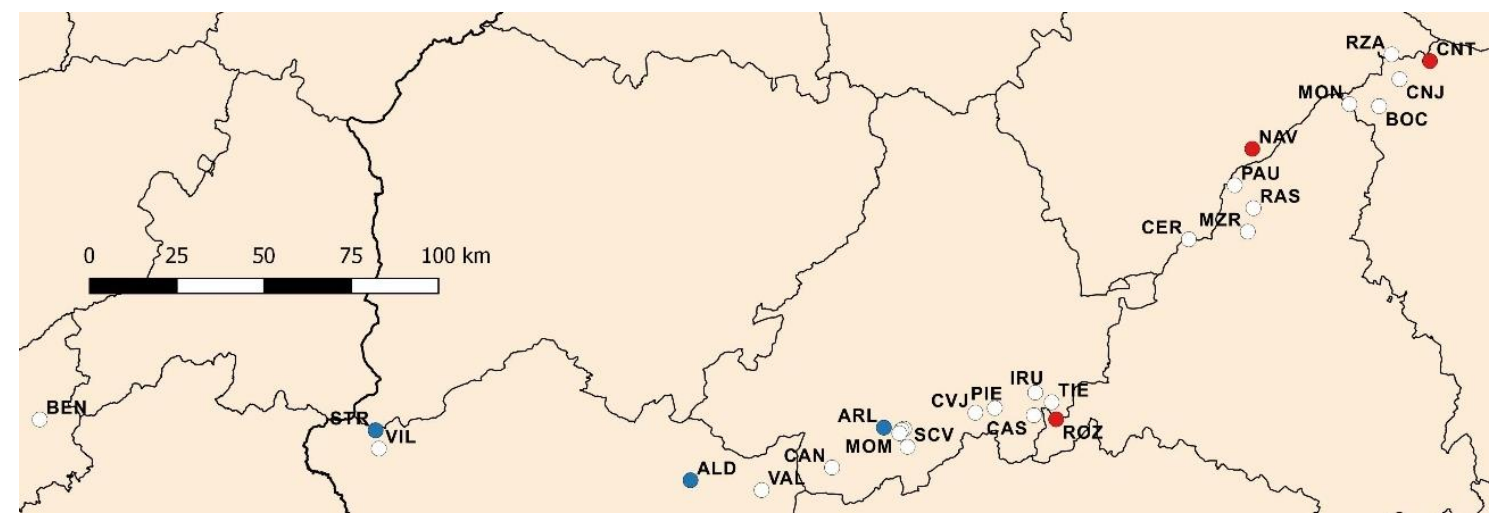

Figura 4.25. Poblaciones con mayor (en azul) y menor (rojo) precipitación acumulada durante la temporada lluviosa (primavera, otoño e invierno) anual. Ver Tabla 1.1 para los códigos de población. 
Tabla 4.30. Media y rango de las 12 variables ecológicas empleadas en la modelización de las poblaciones de U. glabra en en el Sistema Central (ver Tabla 1.1 para los códigos de población). P: precipitación (mm), T: temperatura $\left({ }^{\circ} \mathrm{C}\right)$. Sombreado oscuro: valores máximos; sombreado claro, valores mínimos.

\begin{tabular}{|c|c|c|c|c|c|c|c|c|c|c|c|}
\hline Variabl & $P$ anual & $P$ invierno & P primavera & P verano & P otoño & $\begin{array}{l}\text { P temporada } \\
\text { Iluviosa }\end{array}$ & $\begin{array}{c}\text { T media } \\
\text { anual }\end{array}$ & $\begin{array}{c}\text { T media diaria } \\
\text { máximas verano }\end{array}$ & $\begin{array}{c}\text { T media diaria } \\
\text { mínimas invierno }\end{array}$ & $\begin{array}{l}\text { Oscilación } \\
\text { térmica anual }\end{array}$ & Litología \\
\hline CNT & 769,85 & 225,09 & 231,80 & 120,06 & 197,00 & 653,89 & 9,79 & 26,44 & $-3,68$ & 21,67 & 1393 Mesozoico \\
\hline CNJ & 993,00 & 307,07 & 289,16 & 135,00 & 260,41 & 856,64 & 7,97 & 24,77 & $-3,68$ & 21,83 & 1557 Paleozoico \\
\hline $\mathrm{BOC}$ & 1001,85 & 317,32 & 284,64 & 124,12 & 270,16 & 872,12 & 9,17 & 25,78 & $-2,42$ & 21,44 & 1314 Proterozoico-Paleozoico \\
\hline RZA & 862,21 & 259,48 & 256,92 & 129,25 & 221,14 & 737,54 & 8,22 & 24,77 & $-3,48$ & 21,18 & 1556 Paleozoico \\
\hline NAV & 731,76 & 241,33 & 210,38 & 101,04 & 185,43 & 637,15 & 8,07 & 24,55 & $-3,39$ & 20,74 & 1512 Proterozoico-Paleozoico \\
\hline MON & 978,90 & 307,37 & 282,27 & 125,30 & 257,29 & 846,94 & 8,91 & 25,50 & $-2,65$ & 21,19 & 1463 Proterozoico-Paleozoico \\
\hline RAS & 925,19 & 324,42 & 237,16 & 101,84 & 253,57 & 815,15 & 8,08 & 24,05 & $-3,12$ & 19,97 & 1451 Rocas plutónicas prehercínicas \\
\hline MZR & 886,46 & 299,44 & 237,99 & 101,89 & 244,13 & 781,55 & 8,48 & 24,74 & $-2,75$ & 20,61 & 1598 Proterozoico-Paleozoico \\
\hline PAU & 861,68 & 296,21 & 223,28 & 103,90 & 230,34 & 749,82 & 7,36 & 23,36 & $-3,73$ & 20,04 & 1670 Proterozoico-Paleozoico \\
\hline CER & 1199,83 & 401,48 & 318,84 & 117,91 & 346,62 & 1066,94 & 7,17 & 21,84 & $-2,49$ & 20,54 & 1260 Rocas plutónicas prehercínicas \\
\hline ROZ & 810,90 & 300,16 & 199,91 & 68,11 & 226,89 & 726,96 & 13,41 & 28,17 & 2,76 & 20,57 & 801 Rocas plutónicas hercínicas \\
\hline TIE & 886,04 & 325,25 & 226,57 & 78,11 & 240,62 & 792,44 & 11,72 & 28,16 & 0,13 & 22,53 & $\begin{array}{l}1163 \text { Rocas plutónicas hercínicas } \\
\text { Proterozoico-Paleozoico }\end{array}$ \\
\hline IRU & 939,17 & 242.35 & 242,35 & 76.97 & 255,21 & 843,06 & 12,66 & 28.94 & 0.91 & 22.30 & 1260 Rocas plutónicas hercínicas \\
\hline CAS & 946,74 & 356,52 & 239,51 & 80,87 & 253,34 & 849,37 & 12,52 & 29,91 & 0,52 & 23,42 & 955 Rocas plutónicas hercínicas \\
\hline PIE & 932,33 & 337,68 & 226,76 & 71,22 & 280,67 & 845,11 & 12,33 & 29,73 & 0,15 & 23,42 & 1042 Rocas plutónicas hercínicas \\
\hline CVJ & 1046,41 & 393,69 & 242,44 & 75,42 & 309,15 & 945,28 & 11,93 & 23,12 & $-0,22$ & 23,12 & 1170 Rocas plutónicas hercínicas \\
\hline SCV & 1163,80 & 463,27 & 249,70 & 72,72 & 348,63 & 1061,59 & 12,97 & 30,95 & 0,38 & 23,88 & 948 Rocas plutónicas hercínicas \\
\hline CVA & 1187,30 & 445,88 & 259,23 & 75,58 & 380,99 & 1086,10 & 13,89 & 31,55 & 1,41 & 23,45 & 797 Rocas plutónicas hercínicas \\
\hline $\mathrm{CVH}$ & 1182,81 & 442,30 & 260,17 & 76,54 & 377,59 & 1080,07 & 13,88 & 31,53 & 1,40 & 23,42 & 797 Rocas plutónicas hercínicas \\
\hline ARL & 1293,25 & 453,28 & 295,25 & 88,95 & 440,36 & 1188,89 & 12,17 & 30,13 & $-0,25$ & 23,70 & 1014 Rocas plutónicas hercínicas \\
\hline MOM & 1178,21 & 449,21 & 253,81 & 72,56 & 375,55 & 1078,58 & 14,13 & 31,75 & 1,64 & 23,40 & 757 Rocas plutónicas hercínicas \\
\hline CAN & 1100,53 & 469,41 & 221,82 & 61,08 & 320,93 & 1012,16 & 15,21 & 32,60 & 2,68 & 23,13 & 654 Rocas plutónicas hercínicas \\
\hline VAL & 1201,43 & 473,58 & 263,51 & 69,30 & 364,93 & 1102,02 & 15,27 & 32,14 & 2,95 & 22,67 & 414 Rocas plutónicas hercínicas \\
\hline ALD & 1453,34 & 574,20 & 316,78 & 84,57 & 438,88 & 1329,86 & 13,86 & 29,65 & 2,50 & 21,92 & 696 Rocas plutónicas hercínicas \\
\hline $\mathrm{VIL}$ & 1086,34 & 434,07 & 236,87 & 66,95 & 323,92 & 994,86 & 13,87 & 29,96 & 3,09 & 19,70 & 680 Rocas plutónicas hercínicas \\
\hline STR & 1238,77 & 499,82 & 266,90 & 76,37 & 369,54 & 1136,26 & 13,05 & 27,96 & 2,14 & 19,98 & 820 Rocas plutónicas hercínicas \\
\hline BEN & 1049,43 & 435,38 & 237,37 & 77,79 & 272,49 & 945,24 & 12,80 & 26,28 & 2,79 & 17,20 & 546 Proterozoico \\
\hline
\end{tabular}




\section{Temperaturas}

En cuanto a los valores de temperatura (ver Tabla 4.30), de forma general, las poblaciones situadas en la mitad más occidental mostraron los valores más elevados de temperatura media anual (MOM, CAN, VAL; $>14,10^{\circ} \mathrm{C}$ ), temperatura media diaria de las máximas en verano (MOM, $\mathrm{CAN}, \mathrm{VAL} ;>31,70^{\circ} \mathrm{C}$ ), temperatura media de las mínimas de invierno (VAL, VIL y BEN; $>2,70^{\circ} \mathrm{C}$; ver Figura 4.26) y de oscilación térmica (VIL, STR y BEN; $\left.<20^{\circ} \mathrm{C}\right)$. Por el contrario, las localidades más orientales se caracterizaron por presentar valores más bajos para la temperatura media anual (NAV, PAU y CER; $<8,10^{\circ} \mathrm{C}$ ), temperatura media diaria de las máximas en verano (PAU, CER y $\mathrm{CVJ} ;<23,40^{\circ} \mathrm{C}$ ) y temperatura media media de las mínimas de invierno (CNT, CNJ y PAU; $<-3,60$ $\left.{ }^{\circ} \mathrm{C}\right)$. La mayor oscilación térmica la presentaron poblaciones localizadas en el centro del Sistema Central (CAS, PIE, CVH y ARL; $>23,40^{\circ} \mathrm{C}$; ver Figura 4.26).

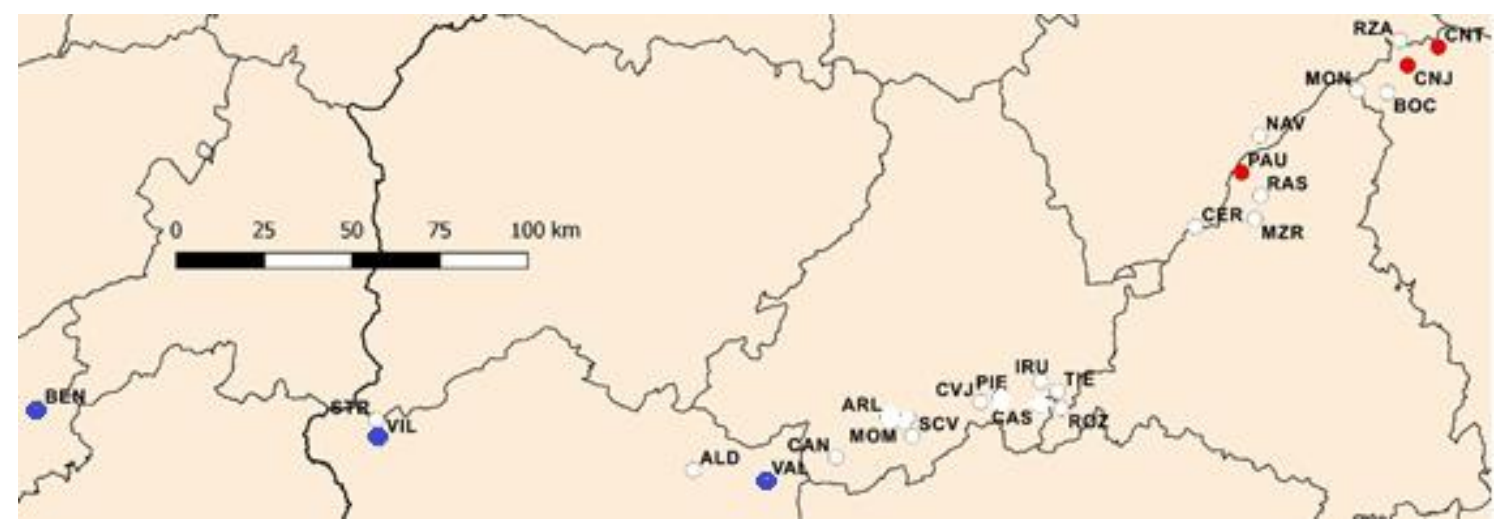

Figura 4.26. Poblaciones con mayor (en azul) y menor (rojo) temperatura media diaria mínimas invierno. Ver Tabla 1.1 para los códigos de población

\section{Altitud}

Respecto a esta variable, cabe destacar que los núcleos que se localizan a una mayor altitud (CNJ, MZR y PAU; >1550 m), se sitúan en las estribaciones más orientales del Sistema Central. Las poblaciones de CAN, VAL y BEN son las que se ubican a menor altitud de todo el Sistema Central (<660 m; ver Tabla 4.30).

\section{Litología}

La clase litológica predominante son las rocas plutónicas de origen hercínico o prehercínico, terrenos predominantemente silíceos; aunque también hay representadas otras clases litológicas (Mesozoico, Paleozoico, Proterozoico-Paleozoico; ver Tabla 4.30). 


\section{11. Modelo de distribución potencial de $U$. glabra en la península ibérica}

Los métodos de clasificación empleados para la construcción del modelo de área potencial de olmo de montaña seleccionaron seis de las 12 variables inicialmente probadas: precipitación acumulada durante los meses de primavera, precipitación acumulada durante los meses de verano, media de las máximas en verano, la media de las mínimas en invierno, oscilación térmica anual y la litología.

La robustez del modelo predictivo obtenido puede ser medida a través de la matriz de confusión (ver Tabla 4.31). A pesar de que partimos de un valor muy bajo de cuadrículas con presencia $(774)$, la sensibilidad del modelo $(0,859)$, la especificidad $(0,836)$, la prevalencia $(0,999)$, el acierto $(0,859)$, el bajo riesgo $(0,001)$ y el estadístico TSS $(0,695)$, indican que el modelo obtenido tiene un buen nivel de precisión (Allouche et al. 2006; Schlaepfer et al. 2012).

Tabla 4.31. Matriz de confusión con la clasificación de las cuadrículas de presencia de U. glabra en la península ibérica observadas-esperadas y principales estimadores de la calidad del modelo.

\begin{tabular}{|c|c|c|c|}
\hline & \multicolumn{2}{|c|}{ Presencia observada } & \multirow[t]{2}{*}{ Total } \\
\hline Presencia esperada & No & $\mathrm{Si}$ & \\
\hline No & 2003533 & 127 & 2003660 \\
\hline \multirow[t]{2}{*}{ Si } & 328692 & 647 & 329339 \\
\hline & 2332225 & 774 & 2332999 \\
\hline Sensibilidad & \multicolumn{3}{|c|}{$0,859(2003533 / 2332225)$} \\
\hline Especificidad & \multicolumn{3}{|c|}{$0,836(647 / 774)$} \\
\hline Prevalencia & \multicolumn{3}{|c|}{0,999 (2332225/2332999) } \\
\hline Acierto & \multicolumn{3}{|c|}{$0,859((2003533+647) / 2332999)$} \\
\hline Riesgo & \multicolumn{3}{|c|}{$0,001(1-0,999)$} \\
\hline TSS & \multicolumn{3}{|c|}{$0,695(0,859+0,836-1)$} \\
\hline
\end{tabular}

El modelo de probabilidad para el olmo de montaña en la península se muestra en la Figura 4.27. Este mapa refleja las probabilidades para cada cuadrícula de $500 \mathrm{~m}$ teniendo en cuenta las seis variables empleadas en el modelo. A partir de este mapa, obtuvimos el mapa de distribución potencial predicha para el valor máximo del estadístico TSS (0,695, ver Tabla 4.31).

El modelo de distribución obtenido clasificó correctamente el $87,11 \%$ de los datos e identificó un área potencial en la península de $82334,740 \mathrm{~km}^{2}$, mucho mayor que la presencia actual de la especie (ver Figura 4.28). En este mapa destaca el territorio del norte de España, especialmente 
en Galicia y en el eje cántabro-pirenaico. Otras áreas importantes son el Sistema Ibérico, entre las Sierras de la Demanda y del Moncayo, Sierra de Albarracín y la Serranía de Cuenca.

Más al sur, el área susceptible de albergar a esta especie se enrarece. Aparecen pequeños enclaves en los Montes de Toledo y en la provincia de Cádiz; y otro conjunto en las cordilleras prebéticas de las Sierras de Cazorla y Segura. En último lugar, también cabe destacar la importante área potencial para la especie en Portugal, especialmente en el norte, en las Sierras de Tras os Montes y Marao y en el extremo occidental del Sistema Central (ver Figura 4.28).

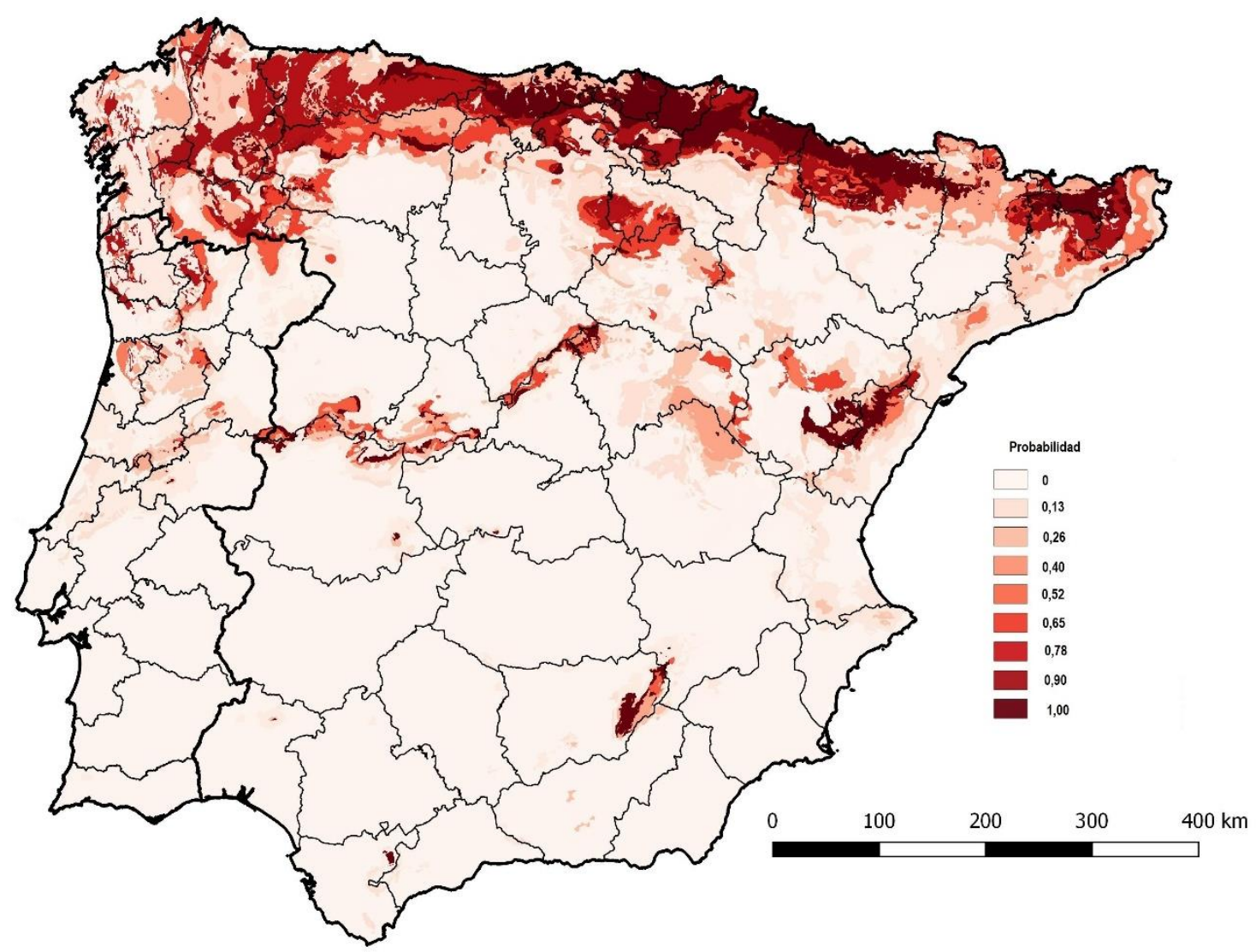

Figura 4.27. Mapa de probabilidades de presencia de U. glabra en la península ibérica obtenido para un tamaño de malla de $500 \mathrm{~m}$. ArcGis 10.3 (ESRI, 2014).

En el Sistema Central, el modelo muestra un área potencial de $5193 \mathrm{~km}^{2}$ en las que hay condiciones adecuadas para la presencia del olmo de montaña (ver Figura 4.29). El mapa de este territorio muestra un área continua en altitudes medias, especialmente en Ayllón, conectando con Guadarrama a través de Somosierra. Áreas potenciales importantes también se pueden observar en Gredos, Sierra de Béjar y Sierra de Gata, sin que exista conexión alguna entre ellas. Por último, a pesar de que en la portuguesa Serra da Estrela tan solo hay descrita una población (BEN), se 
detectó numerosas regiones potenciales pequeñas y aisladas para esta especie, aunque menor que en el resto de la cordillera.

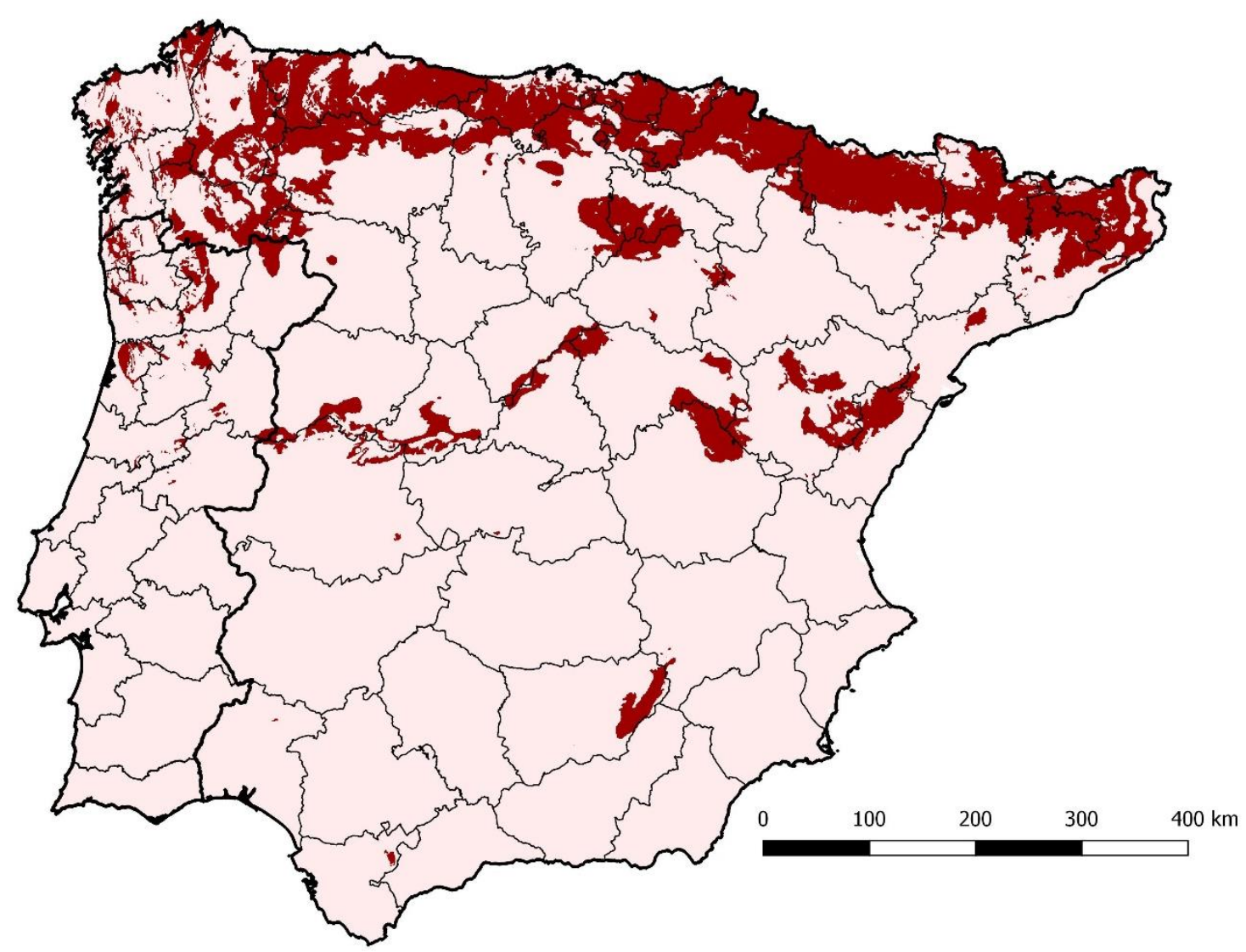

Figura 4.28. Modelo de distribución de U. glabra en la península ibérica obtenido para un tamaño de malla de $500 \mathrm{~m}$ para el valor máximo de TSS. ArcGis 10.3 (ESRI, 2014).

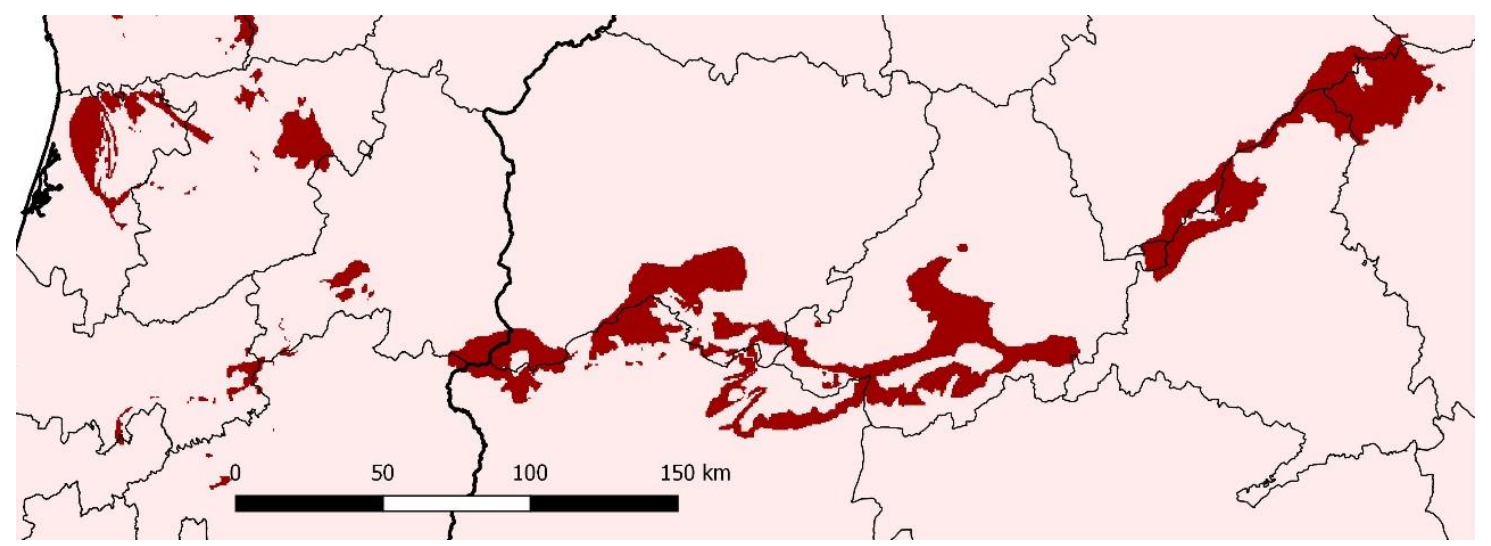

Figura 4.29. Modelo de distribución potencial para U. glabra en el Sistema Central obtenido para una malla de 500m, obtenida para el valor máximo de TSS. ArcGis 10.3 (ESRI, 2014).

La mayoría de las poblaciones descritas en el Sistema Central se localizan dentro del área potencial detectada; únicamente NAV, PAU, CER, ROZ, VAL y BEN se sitúan fuera del área de 
distribución potencial. La mayoría de éstas se encuentran muy cerca del límite, con la única excepción de ROZ, que se sitúa en una zona muy alejada del área potencial.

Aproximadamente, el 38\% del área potencial de U. glabra en el Sistema Central se localiza dentro de áreas protegidas. En concreto, 20 de las 27 poblaciones están total o parcialmente dentro de zonas protegidas y/o de interés como el Sitio de Interés Natural Hayedo de Montejo de la Sierra (MON), Parque Natural de la Sierra Norte de Guadarrama (NAV), Parque Nacional Sierra de Guadarrama (RAS, PAU, CER, MZR), Reserva Natural Valle de Iruelas (IRU y TIE), Parque Regional Sierra de Gredos (SCV, ARL y CAN) o Paisagem Protegida da Serra do Açor (BEN); otras tantas poblaciones se localizan en zonas LIC o ZEPA (p.e. STR).

\section{12. Estatus de amenaza}

La Extensión de Presencia calculada para U. glabra en el Sistema Central es de 19028,5 km² (ver Figura 4.30). El Área de Ocupación de los 27 núcleos poblacionales identificados es inferior a los $20 \mathrm{~km}^{2}\left(18,6 \mathrm{~km}^{2}\right)$ (ver Tabla 4.32).

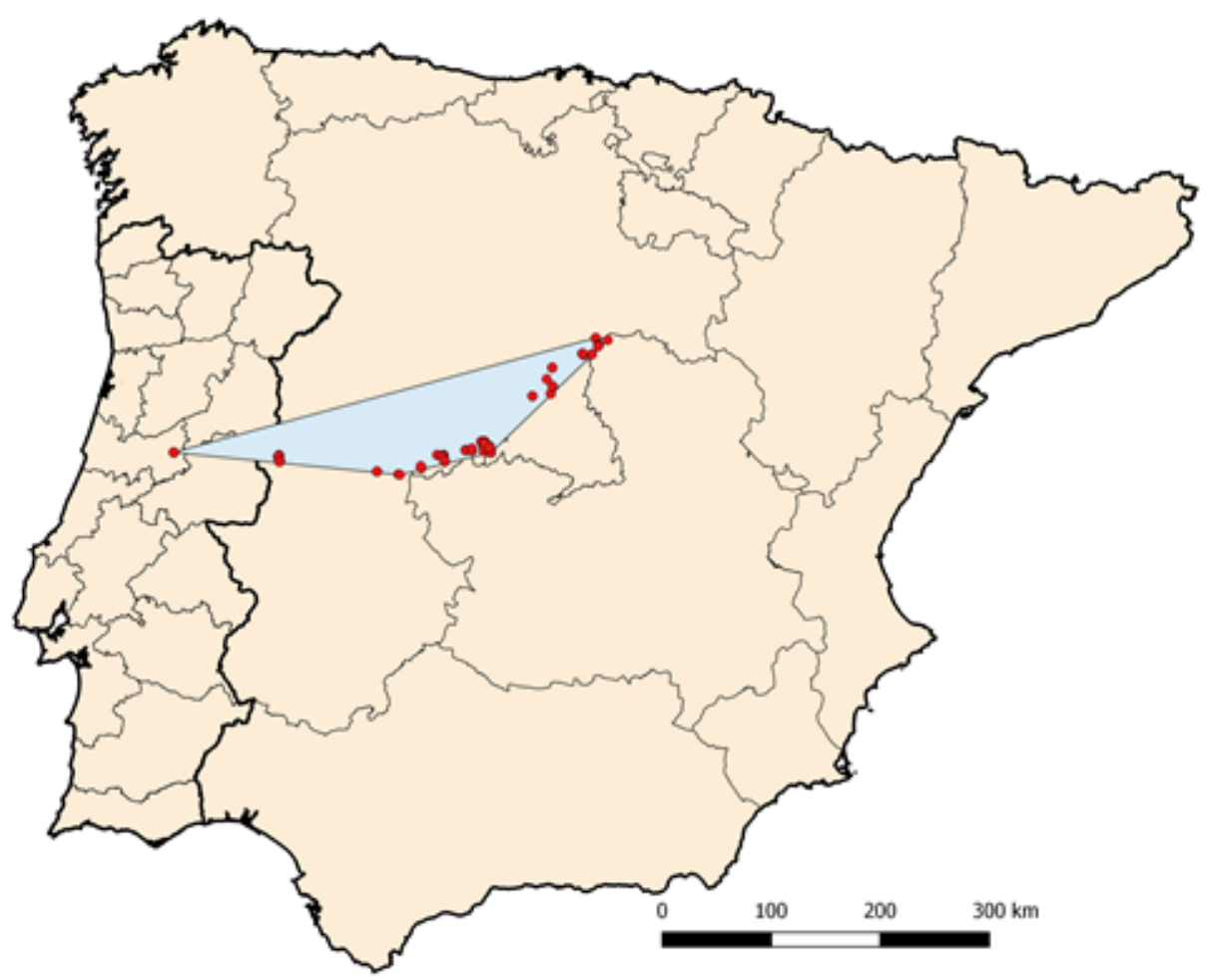

Figura 4.30. Extensión de Presencia de U. glabra en el Sistema Central. ArcGIS 10.3 (ESRI, 2014).

Analizando la distancia a la que se encuentran los ejemplares de la especie, y agrupando aquellos que se encuentran a menos de $1200 \mathrm{~m}$ (en ausencia de barreras geográfica insalvables) (Nielsen \& Kjær 2010a), podemos establecer que U. glabra en el Sistema Central se distribuye en 
25 subpoblaciones (ver Tabla 4.32). Únicamente los núcleos de CVA, CVH y MOM se encuentran a una distancia inferior a los $1200 \mathrm{~m}$ y, por tanto, constituyen una única subpoblación.

Tabla 4.32. Código, Área de Ocupación, número de subpoblaciones (Subpob), número estimado de individuos (Nt), número de individuos maduros estimados (diámetro $\geq 10 \mathrm{~cm}$ ); poblaciones con número de individuos maduros mayor o menor al MVP (Población Mínima Viable). Ver Tabla 1.1 para los códigos de población.

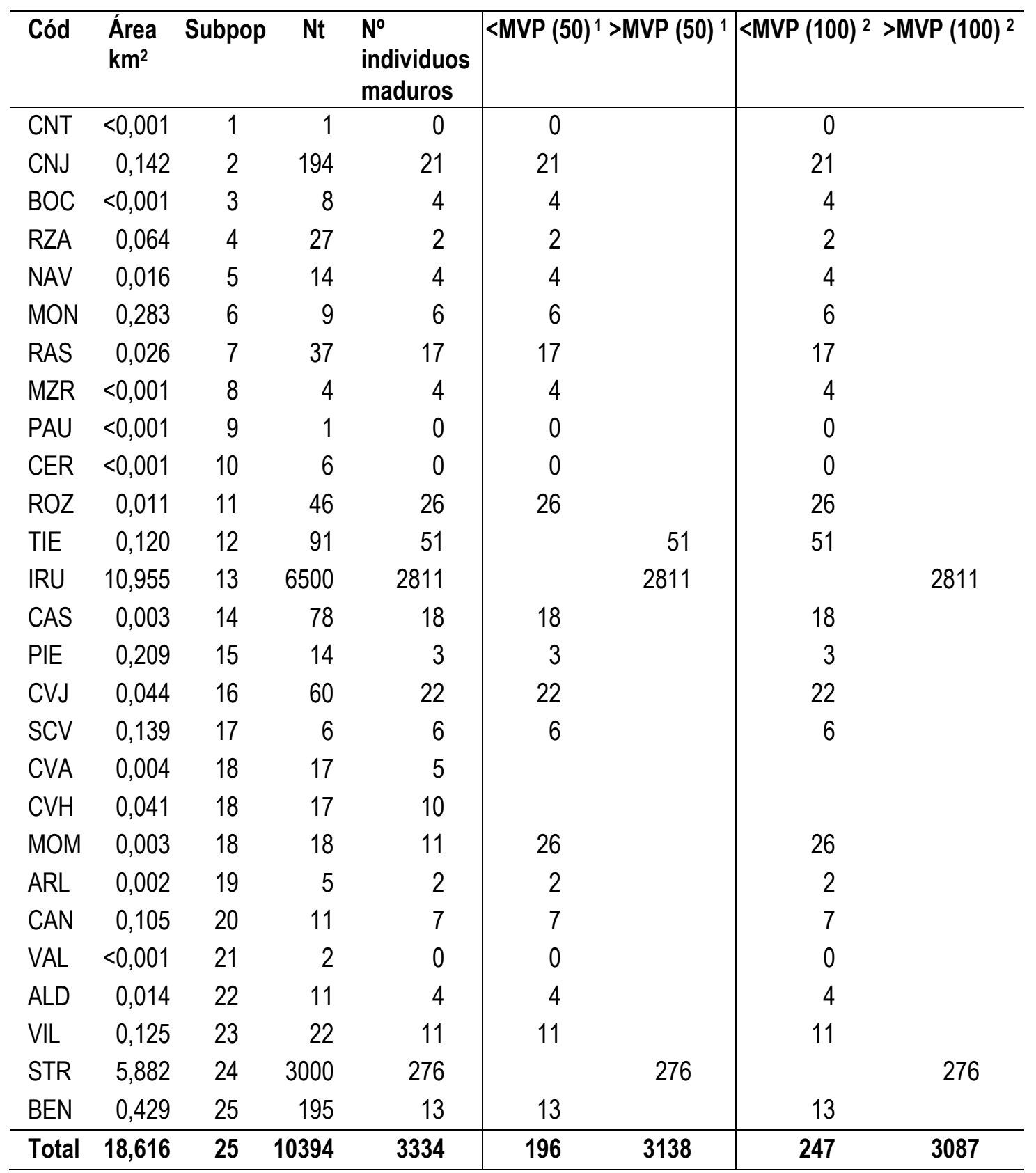

${ }^{1}$ MVP para especie Muy longeva (>100 años; 50 individuos). ${ }^{2}$ MVP para especie Medianamente longeva (25-100 años; >100 individuos).

El número de subpoblaciones de U. glabra con número de individuos maduros inferior al MVP fueron calculados para dos supuestos. Si consideramos que es una especie Medianamente 
longeva (25-100 años), la MVP es 100 individuos; mientras que si consideramos que es una especie Muy longeva (>100 años), la MVP es de 50 individuos (Blanca \& Marrero 2004; ver Tabla 4.33).

Bajo el primer supuesto, especie Medianamente longeva, encontramos que 23 de las 25 subpoblaciones cuentan con un número de efectivos por debajo del MVP $(<100$ individuos maduros). En este caso, el $93 \%$ de los individuos maduros se localizan en las dos subpoblaciones que superan el umbral de la MVP (IRU y STR; ver Tabla 4.32 y Tabla 4.33). Estos valores apenas varían en el supuesto de que la especie sea Muy longeva, ya que el $94 \%$ de los individuos maduros se concentran en las tres subpoblaciones (TIE, IRU y STR; ver Tabla 4.32) que superan la MVP (50 individuos; ver Tabla 4.33). Por tanto, en ambos supuestos de longevidad de la especie, la gran mayoría de los individuos maduros se concentran en pocas subpoblaciones (dos o tres respectivamente; ver Tabla 4.33) y con porcentajes muy altos que apenas varían.

Tabla 4.33. Número de subpoblaciones y de individuos maduros (diámetro $\geq 10 \mathrm{~cm}$ ), número de subpoblaciones con número de individuos maduros mayor o menor que la MVP (Población Mínima Viable) suponiendo que es una especie Muy longeva (100 años; MVP 50 individuos maduros) o Medianamente longeva (25-100 años; MVP 100 individuos maduros).

\begin{tabular}{lllll}
\hline $\mathbf{N}^{0}$ maduros estimados & $<$ MVP (50) & >MVP (50) & $<$ MVP (100) & $>$ MVP (100) \\
\hline N $^{0}$ subpoblaciones & 22 & 3 & 23 & 2 \\
$\mathrm{~N}^{0}$ Individuos maduros & 196 & 3138 & 247 & 3087 \\
$\%$ del total & 6 & 94 & 7 & 93 \\
\hline
\end{tabular}




\section{DISCUSIÓN}

El presente estudio es el primero que se lleva a cabo en las poblaciones relictas y fragmentadas de $U$. glabra en el Sistema Central ibérico, empleando conjuntamente la caracterización molecular y ambiental de las mismas. Aunque existen trabajos previos de la especie en otras regiones europeas utilizando marcadores moleculares, éstos consistieron en el análisis de una única población (Nielsen \& Kjær 2010b), o bien analizaron pocos individuos y se centraron principalmente en detectar introgresión con especies próximas (Cox et al. 2014).

Las poblaciones localizadas en los límites de distribución de una especie son importantes desde el punto de vista biogeográfico y paleobotánico, además de esenciales a la hora de conocer su comportamiento general (Channell \& Lomolino 2000a; Hampe \& Petit 2005). Las poblaciones localizadas en los límites sur de aquellas especies de distribución septentrional son más susceptibles a los cambios estocásticos, genéticos y demográficos (Ganopoulos et al. 2011), y más considerando los escenarios previstos de cambio climático (IPCC 2007; IPCC 2013). Como consecuencia de estas previsiones de evolución climática futura que muestran los modelos del IPCC, se esperan cambios en los límites de distribución y en la fenología de las especies, que afectarán muy especialmente a las poblaciones relictas de los márgenes de distribución (Matias 2012).

Los estudios de diversidad genética son fundamentales para llevar a cabo medidas de conservación, ya que éstos son la base para conocer el potencial evolutivo de la especie para responder a los cambios ambientales (Toro \& Caballero 2005). En este sentido, los marcadores moleculares basados en la PCR se han convertido en una herramienta esencial en los estudios de diversidad genética en poblaciones naturales de plantas (Mondini et al. 2009; Karp 1997).

Otra herramienta fundamental para evaluar la situación de este tipo de poblaciones y llevar a cabo medidas de conservación son los estudios de caracterización ambiental. La identificación del hábitat de cada especie es la base para el conocimiento de su autoecología y del desarrollo de modelos predictivos. Éstos a su vez permiten identificar áreas susceptibles de albergar ejemplares o poblaciones de la especie estudiada y así orientar los esfuerzos de prospección, con objeto de evaluar los impactos ambientales e informar de los requerimientos fisiológicos de la especie (Wiser et al. 1998), y finalmente, establecer prioridades de gestión, p.e. identificando los entornos adecuados e interesantes para llevar a cabo reintroducciones o reforzamientos (Osborne \& Seddon 2012). 


\section{1. Caracterización molecular}

\subsection{Diversidad en el genoma nuclear}

Los niveles de diversidad genética detectados en las poblaciones de olmo de montaña analizadas en este estudio se puede decir que fueron moderados ( $\left.\mathrm{Nm}=427, \mathrm{H}_{0}=0,477, \mathrm{H}_{E}=0,566\right)$, aunque inferiores a los obtenidos en un estudio similar sobre una única población danesa de $U$. glabra localizada en el bosque de Suserup ( $\mathrm{Nm}=29, \mathrm{H}_{0}=0,759, \mathrm{H}_{\mathrm{E}}=0,774$; Nielsen \& Kjær 2010b). Entre ambos trabajos existe una notable diferencia en el número de muestras analizadas. Asumiendo este inconveniente metodológico, los resultados de los dos trabajos parecen apuntar a que las condiciones en el norte de Europa favorecen la presencia de un mayor número de individuos y mayores índices de diversidad que en el Sistema Central. En U. laevis también se ha observado una menor diversidad nuclear (riqueza alélica) en las poblaciones del suroeste que en las del centro de Europa. Este hecho parece estar relacionado con la autoecología del taxón, ya que en Centroeuropa las condiciones climáticas son más favorables a la especie, por lo que permiten la presencia de poblaciones más grandes (Fuentes-Utrilla et al. 2014b).

Al igual que en otros trabajos previos (Nielsen \& Kjær 2010b), los loci SSR que detectaron mayor polimorfismo en olmo de montaña fueron, en general, los desarrollados en U. minor (Collada et al. 2004). Dentro de ellos, el locus que resultó ser más polimórfico e informativo fue con diferencia Ulmi1-165; sugiriendo que este locus es apropiado para estudios de diversidad en $U$. glabra. Por otro lado, el locus Ulm2 descrito en U. laevis (Whiteley et al. 2003) fue el que menos diversidad detectó. Resultados similares fueron obtenidos por Nielsen \& Kjaer (2010b) en la población danesa de olmo de montaña.

Las poblaciones del Sistema Central ibérico con mayor número de individuos (IRU, Nt>6500; y STR, Nt>3000) presentaron mayores índices de diversidad (ver Tabla 4.3). Sin embargo, esta tendencia no puede generalizarse, ya que poblaciones pequeñas mostraron elevados valores de diversidad (p.e. MOM y CAN). La localización de IRU y STR en áreas protegidas (Reserva Natural de Valle de Iruelas y LIC_Lugar de Importancia Comunitaria-de Sierra de Gata, respectivamente), entre otras razones, ha ayudado a mantener el elevado número de individuos con el que cuentan. En ambos casos, al igual que la mayoría de las poblaciones del Sistema Central, gran parte de sus efectivos proceden de rebrote (Rossignoli 1999; Arche 2010), y presentan un diámetro inferior a los $10 \mathrm{~cm}$. Rossignoli \& Génova (2003) han descrito problemas de reproducción sexual en muchas de las poblaciones, que pueden ser debidos al predominio de individuos procedentes de rebrote reciente (de pocos años), puesto que se ha descrito que, en 
olmos, hasta los 7 años no se suele producir la primera floración (López Almansa \& Gil 2003) y hasta los 30-40 no se da un incremento en la producción de semilla viable (Alía Miranda et al. 2009). El predominio de individuos procedentes de rebrote puede haber sido causado por la grafiosis, enfermedad que se ha detectado en la mayoría de los núcleos (Rossignoli 1999; Arche 2010). La grafiosis tiene un impacto diferente en los árboles en función de su tamaño, ya que el escolítido vector del hongo tiene preferencia por los individuos con troncos de más de $10 \mathrm{~cm}$ de diámetro (Sengonca \& Leisse 1984; Webber 2004).

Otra de las poblaciones a destacar es CER, que ocupa una superficie de unos $20 \mathrm{~m}^{2}$ y cuenta con tan solo seis individuos, todos ellos con el mismo genotipo. Este hecho sugiere que se trate en realidad de rebrotes de un mismo ejemplar de gran tamaño, ya muerto, que fue encontrado en la zona (Guardias Forestales, comunicación personal). En general, la presencia de rebrote de cepa también fue detectada en todas las poblaciones analizadas en este trabajo. El olmo de montaña no muestra rebrote de raíz, pero el rebrote de cepa en individuos jóvenes sí que ha sido descrito con anterioridad (Cox et al. 2014). La propagación vegetativa por rebrote ayuda a disminuir los efectos de la fragmentación de las poblaciones y de la deriva génica, evitando la pérdida alélica (Wei \& Jiang 2012) y contribuyendo al restablecimiento clonal de $U$. glabra en ambientes modificados (Nielsen \& Kjær 2010b).

De forma general, se han detectado signos de aislamiento poblacional y bajo flujo génico entre estas poblaciones $\left(F_{S T}=0,239\right)$ en comparación con otras especies de polinización anemófila como Quercus garryana Douglas ex Hook (Marsico et al. 2009), Populus euphratica Olivier (Wang et al. 2011), Fraxinus excelsior L. (Beatty et al. 2015) o Castanea sativa Mill. (Lusini et al. 2014). Además, se obtuvieron elevados y significativos valores de $F_{S T}$ entre pares de poblaciones, indicando una alta diferenciación genética y una baja diversidad media dentro de las poblaciones, probablemente debido al pequeño tamaño poblacional de la mayoría de ellas. Las distancias geográficas existentes entre las poblaciones del Sistema Central, parecen haber favorecido el elevado grado de diferenciación observado, puesto que en olmos se han estimado distancias de flujo polínico de 1.200 m (Nielsen \& Kjær 2010a).

El árbol UPGMA (ver Figura 4.1) mostró un grupo principal de 17 poblaciones; y otros dos núcleos poblacionales (ROZ y MOM) formando un grupo separado, probablemente debido a que en esas dos poblaciones se detectó un elevado número de híbridos putativos con U. minor (38/46 en ROZ y 7/10 en MOM) y al bajo valor de Fst detectado entre ellas. Dentro del clúster mayoritario, MON y RAS aparecen alejadas del resto, probablemente debido a que son poblaciones geográficamente aisladas. Además, ambas presentaron una elevada frecuencia de alelos 
exclusivos. La presencia de alelos exclusivos ha sido asociada a un bajo flujo génico y a la existencia de aislamiento poblacional (Tero et al. 2003; Slatkin 1985). Dentro del grupo principal, dos de los núcleos más suroccidentales (STR y VIL) aparecen próximos entre ellos y alejados a su vez del resto de localidades. La ubicación de BEN en el clúster principal, sugiere su proximidad genética al resto de poblaciones del Sistema Central, apoyando la idea de que la presencia del olmo de montaña en Portugal es natural (Monteiro-Henriques et al. 2010) y no introducida (Navarro \& Castroviejo 1993). Los resultados del dendrograma están relacionados con el aislamiento geográfico, y parecen sugerir la existencia de un descenso en el flujo génico entre poblaciones debido a grandes distancias geográficas (Sexton et al. 2014).

\section{Introgresión e hibridación}

Procesos de introgresión e hibridación entre U. glabra y U. minor han sido descritos en otras poblaciones europeas de olmo de montaña (Cox et al. 2014; Petrokas \& Baliuckas 2012). Dos elementos fundamentales facilitan estos procesos: la proximidad genética entre las dos especies (Wiegrefe et al. 1994) y la ausencia de barreras reproductivas entre ambas (Cox et al. 2014). Estos dos factores también son los responsables del elevado número de alelos compartidos detectados en estas dos especies, algunos de ellos en elevada frecuencia.

En el Sistema Central también hemos detectado introgresión entre U. glabra y U. minor. Los híbridos putativos fueron detectados en cinco (ROZ, IRU, CVJ, MOM y CAN) de las 22 poblaciones analizadas, constituyendo aproximadamente el $13 \%$ de los ejemplares ( $<55$ de 427 individuos). A pesar de la significativa introgresión observada, ésta fue menor que la detectada en otras poblaciones naturales en Bélgica (46\%) (Cox et al. 2014). Las razones por las cuales este fenómeno sea más habitual en Bélgica podrían ser que U. glabra es más abundante en el centro y norte de Europa (Caudullo \& de Rigo 2016) y que se localiza frecuentemente junto con U. minor a la misma altitud (Cox et al. 2014). Sin embargo, en el Sistema Central la presencia de U. glabra es más escasa y se sitúa a una altitud media de 1115 m, llegando incluso a rozar los $1800 \mathrm{~m}$ (Navarro \& Castroviejo 1993), mientras que U. minor no suele sobrepasar los $1200 \mathrm{~m}$ (Venturas et al. 2013c). En consecuencia, el contacto entre ambos taxones es más bien escaso y, por ello, la introgresión en el Sistema Central se ve limitada.

Además de la coexistencia de las dos especies a la misma altitud, la introgresión está influenciada por las actividades humanas (Ellstrand \& Schierenbeck 2000; Rhymer \& Simberloff 1996; Hoban et al. 2012). Desde épocas romanas, U. minor se ha empleado en horticultura y viticultura (Fuentes-Utrilla et al. 2004), por lo que de forma habitual se ha plantado, especialmente 
en zonas urbanas y de cultivo, caminos y bordes de carreteras y, además, se naturaliza con facilidad (Navarro \& Castroviejo 1993). Algunas de las poblaciones analizadas se encuentran próximas a zonas muy antropizadas, como es el caso de ROZ y MOM, por lo que los fenómenos de hibridación con U. minor se han podido ver potenciados.

Otro de los fenómenos que ha podido ayudar a la elevada presencia de híbridos putativos en estas poblaciones es su localización en el sector climático más cálido (Mediterráneo cálido interior de piedemonte; Ruiz-Labourdette et al. 2011) y por tanto más favorable para U. minor. Aunque algún individuo de otras poblaciones, como PIE e IRU, se localizó en este mismo sector, ROZ, $\mathrm{CVH}$ (no analizada molecularmente) y MOM son las únicas en las que todos sus efectivos se sitúan en esta región. Estos factores probablemente son los que han producido un máximo de hibridación (38/46 individuos en ROZ y 7/10 individuos en MOM). La presencia de un elevado número de híbridos en ROZ y MOM es la causa de la elevada heterocigosidad observada y, en general, de los altos valores estimados de diversidad. Además, estas poblaciones también presentaron valores muy negativos del índice de fijación, indicativo de un exceso de heterocigosidad (Valero et al. 2001). Resultados similares fueron obtenidos por Zalapa et al. (2010), en los que el grado de hibridación en las poblaciones naturalizadas de $U$. pumila influyó en la diversidad genética detectada.

En el área de estudio, 26 individuos fueron identificados como posibles híbridos F1 por el análisis con NewHybrids. Estas muestras fueron heterocigotas para la mayoría de los loci analizados (9 0 10 de los 11 loci estudiados), tal y como cabría esperar en individuos híbridos. Zalapa et al. (2010) obtuvieron un incremento similar en la diversidad genética debido a la hibridación entre $U$. pumila y $U$. rubra. Además, los individuos híbridos putativos que detectamos mostraron numerosos alelos compartidos con U. minor, algunos de los cuales estuvieron presentes en las muestras de $U$. minor en elevada frecuencia y fueron poco comunes en $U$. glabra; este hecho puede ser indicativo de introgresión asimétrica de U. minora U. glabra. Ello ha podido ocurrir debido a que a menos de $1200 \mathrm{~m}$ de altitud en el Sistema Central U. minor es más abundante que U. glabra, lo cual puede facilitar el flujo génico asimétrico. Un flujo génico asimétrico debido a diferencias en abundancia de las especies parentales se ha observado en otros estudios (Burgess et al. 2005; Lepais et al. 2009).

El programa NewHybrids clasificó a 22 individuos de U. glabra de la población de ROZ, que presentaron el mismo genotipo, dentro de la clase parental U. minor. La falta de un número suficiente de alelos exclusivos de especie puede complicar la clasificación llevada a cabo por el programa NewHybrids (Anderson \& Thompson 2002). En nuestro estudio, las 15 muestras de $U$. 
minor analizadas (que presentaron seis genotipos diferentes y ocho alelos exclusivos) podrían haber sido insuficientes para la correcta asignación de algunos individuos híbridos. Morfológicamente estos 22 individuos no mostraron caracteres diferentes a los del resto de muestras de olmo de montaña. Los caracteres morfológicos han evidenciado ser cuestionables en la clasificación del género Ulmus, especialmente en individuos híbridos (Zalapa et al. 2010; Brunet et al. 2013; Goodall-Copestake et al. 2005; Buiteveld et al. 2016; Bertolasi et al. 2015). Estas muestras presentaron un elevado número de alelos compartidos con U. minor (nueve de 18 alelos posibles) y fueron heterocigotas para la mayoría de los loci analizados (10 de 11). Por tanto, estos 22 individuos probablemente sean el resultado de un elevado grado de introgresión con U. minor.

En el presente trabajo detectamos la presencia de clones en la mayoría de las poblaciones del Sistema Central, siendo este fenómeno especialmente importante en ROZ y MOM, donde los clones forman parches que ocupan una superficie de entre 50 y $100 \mathrm{~m}^{2}$. En ellas observamos rebrote de raíz en los individuos híbridos putativos, tal y como ocurre en U. minor (Cox et al. 2014). Esto también ha sido detectado con anterioridad en individuos híbridos entre U. glabra y U. minor en poblaciones belgas (Cox et al. 2014). Este fenómeno ha podido favorecer la clonalidad en ambos núcleos, que presentaron únicamente 13 genotipos diferentes en las 46 muestras analizadas de ROZ y dos en las 10 de MOM.

Por otra parte, no identificamos ningún individuo $\mathrm{F}_{2}$ con el programa NewHybrids. Cox et al. (2014) tampoco detectaron descendencia $F_{2}$ de los híbridos $F_{1}$ entre los olmos muestreados en el norte de Bélgica. Una posible explicación de esto podría ser el incremento de incompatibilidad en homocigosis en los individuos $F_{2}$ que produciría una pérdida de fitness (Turelli \& Orr 2000). También cabe la posibilidad de que exista incompatibilidad polen-estigma en los híbridos $F_{1}$ al contener alelos S procedentes de los dos parentales (Zalapa et al. 2009), o que la pérdida de aptitud sea debida a depresión híbrida (Edmands 2007).

Uno de los aspectos negativos de la hibridación es que puede contribuir a la desaparición poblacional a través de la eliminación demográfica del parental minoritario y su asimilación por parte de la especie más abundante (Levin et al. 1996). Esto quizá es lo que está ocurriendo en las poblaciones de ROZ y MOM, que presentaron únicamente tres individuos asignados por NewHybrids como U. glabra en cada una de ellas.

\section{Estructura genética espacial}

En nuestro estudio hemos detectado la existencia de una correlación positiva baja, pero significativa, entre las matrices de distancias geográficas y genéticas de poblaciones; es decir, 
existiría aislamiento por distancia entre las poblaciones del Sistema Central. Curiosamente, en un amplio estudio con ISSR y RAPD de las tres especies de olmo nativas de Europa, no llegaron a detectar señales de aislamiento por distancia (Goodall-Copestake et al. 2005). Sin embargo, sí que se han encontrado correlaciones bajas y significativas entre la matriz de distancias geográficas y la de distancias genéticas en poblaciones de U. lamellosa con SRAPs (Liu et al. 2016), donde se realizó un amplio muestreo poblacional en un área de distribución más restringida y similar a la nuestra. El obtener valores de correlación bajos puede deberse a que el test de Mantel es muy eficiente a la hora de detectar una correlación evidente en áreas grandes, pero presenta más problemas a la hora de detectar estructura genética en regiones más pequeñas o a escala local (Smouse et al. 1986).

El análisis de las poblaciones del Sistema Central mostró la existencia de una significativa Estructura Genética Espacial (EGE) positiva hasta una distancia $4 \mathrm{~km}$, siendo aún perceptible hasta los 5,17 km. Las distancias entre individuos (entre $17 \mathrm{~m}$ en CER y $\sim 200 \mathrm{~m}$ en IRU) sugieren que la correlación espacial positiva se debe mayoritariamente a las relaciones de proximidad genética y geográfica entre los individuos dentro de cada una de las poblaciones. En poblaciones fragmentadas, como es el caso de las del Sistema Central, el flujo génico entre ellas disminuye, lo que acelerará aún más los efectos negativos derivados del aislamiento poblacional (Nielsen \& Kjær 2010a).

En general, las poblaciones en las que detectamos aislamiento por distancia, también presentaron EGE. Este fue el caso de RZA, ROZ, TIE e IRU, en las que la EGE detectada es consistente con el modelo de aislamiento por distancia. Éste dice que aquellos individuos separados por pequeñas distancias están más relacionados genéticamente entre sí, y menos con aquellos otros con los que se encuentran más separados. Esto puede ser el resultado de la existencia de un bajo flujo génico intrapoblacional consecuencia de una baja capacidad dispersiva del polen y de las semillas (Van Rossum \& Triest 2006). Únicamente en los casos de CVJ y BEN, poblaciones en las que sí se encontró EGE en distancias cortas, no se detectó aislamiento por distancia en ellas. Esto puede ser debido a que en distancias cortas los individuos más próximos son más similares genéticamente, pero esa estructura genética se pierde en distancias más grandes.

En el análisis poblacional de algunas de las localidades (CNJ, RAS, CAS y STR) no se detectó correlación espacial positiva. En estudios similares con otras especies de olmo, p.e. $U$ laevis, tampoco se ha detectado EGE en alguna de las poblaciones analizadas (Venturas 2013; Venturas et al. 2013b). 
Las poblaciones en las que sí detectamos EGE fueron RZA, ROZ, TIE, IRU, CVJ y BEN, para las cuales se estimaron distancias de flujo génico de entre 42 y $238 \mathrm{~m}$. Estas estimas son similares a las descritas en poblaciones relictas de U. laevis ( $40 \mathrm{~m}$ ) (Venturas et al. 2013b; Nielsen \& Kjær 2010a) o incluso a las descritas en U. glabra ( 100 m) (Nielsen \& Kjær 2010b). Las diferencias en el flujo génico han sido relacionadas con la fragmentación del hábitat, con la disposición espacial de los individuos, con el uso del suelo, el entorno en el que se sitúa la población (Hoban et al. 2014) o con la densidad poblacional (Vekemans \& Hardy 2004; Hoban et al. 2014; de Lucas et al. 2009; de Lucas 2009).

La deforestación y el uso del suelo por parte del hombre puede hacer desaparecer la EGE, al reducir la densidad vegetal, aumentar la porosidad del bosque y eliminar las barreras físicas, favoreciendo la dispersión del polen (Biscaia de Lacerda, et al. 2008; Jones et al. 2006). Son numerosos los trabajos en especies forestales en los que se ha descrito la influencia del factor humano sobre la EGE (Hoban et al. 2014; Rajendra et al. 2014; Lind-Riehl \& Gailing 2015). En U. laevis se ha descrito la ausencia de EGE en una de las dos poblaciones analizadas (Quitapesares), sugiriéndose que uno de los factores responsables sea una menor densidad forestal, que favorece el flujo génico (Venturas et al. 2013b). Esto ha podido ocurrir en CAS, en la que no se detectó EGE a pesar de que sí se observó aislamiento por distancia. Su localización a escasos 150 m del núcleo urbano de Casillas, en un entorno muy antropizado, rodeados de huertas y cultivos, ha podido contribuir a la pérdida de EGE en esta población.

La existencia de estructura genética a nivel espacial está relacionada con el flujo génico entre individuos y nos da una idea de la capacidad dispersiva del polen y de las semillas. Un flujo génico limitado puede dar lugar a la aparición de EGE, que no es más que la distribución no al azar de los genotipos en el espacio (Barluenga et al. 2011). Teniendo en cuenta que se ha estimado que el flujo de polen en olmos puede llegar a alcanzar los 1.200 m en U. laevis (Nielsen \& Kjær 2010a), parece que el factor limitante en la dispersión son las semillas, como muestran los resultados de algunos trabajos que reflejan la baja capacidad dispersiva de las mismas ( $<30 \mathrm{~m}$ en $U$. laevis y $<45$ m en U. thomasii) (Venturas 2013; Venturas et al. 2013a; Crow 1990).

En nuestro estudio, los resultados del análisis a nivel del ADN de cloroplastos también han aportado información en este sentido, ya que en las poblaciones de CVJ y BEN se ha podido inferir la capacidad dispersiva de las semillas y sus efectos en la EGE. Así, en CVJ, donde se detectó un clorotipo exclusivo $(\mathrm{H} 4)$ en algunos de los individuos analizados, la distancia máxima a la que se observó EGE positiva (<68 m) se aproxima a la distancia máxima a la que se encuentran entre sí los individuos con dicho clorotipo ( 63 m). En el análisis a escala local o más fina, se ha obtenido 
que dos de los individuos con el clorotipo $\mathrm{H} 4$ son los que contribuyen significativamente a la EGE positiva detectada. Estos conforman con sus ocho vecinos más próximos, quienes también presentan el haplotipo $\mathrm{H} 4$, un clúster o hot spot, siendo un reflejo del éxito reproductivo que han producido esos parches de individuos genéticamente parecidos (Double et al. 2005). Este fenómeno también fue observado en BEN, donde los seis individuos que presentaron el haplotipo mayoritario $(\mathrm{H} 1)$ se localizaron próximos entre sí $(2-130 \mathrm{~m})$ coincidiendo con la distancia máxima a la cual es detectable la EGE ( 100 m).

Aunque las sámaras presentan una baja capacidad de dispersión a través del viento, éstas pueden recorrer mayores distancias gracias a los cursos de agua (Venturas 2013; Venturas et al. 2013a; Crow 1990). El incremento de la capacidad dispersiva por hidrocoría ha sido descrito en otras especies forestales anemófilas como Fraxinus mandshurica Rupr. (Hu et al. 2010). Este fenómeno ha podido darse en algunas de las poblaciones estudiadas, lo que puede explicar que no hayamos detectado EGE en ellas. Tal es el caso de los núcleos de CNJ y STR, situados en las orillas del arroyo de la Zarza y del río de la Vega; y de RAS, cuyos individuos se localizan en dos barrancos de corrientes de agua estacionales que dan al arroyo de Santa Ana.

En la mayoría de las poblaciones el test de Mantel mostró una correlación baja pero significativa; únicamente los núcleos de ROZ y TIE mostraron un elevado coeficiente de correlación. Éstas también presentaron unos coeficientes de autocorrelación elevados y EGE significativa tanto positiva como negativa. La marcada correlación positiva en ROZ parece estar determinada por la elevada clonalidad detectada, que afectó principalmente a dos de los genotipos híbridos putativos. Debido a ello, un elevado número de individuos contribuyeron a la EGE positiva (42 de 46). La reproducción vegetativa en plantas ha sido asociada con la existencia de una fuerte EGE en poblaciones naturales (Van Rossum et al. 2004; Hoebee et al. 2006; Namroud et al. 2005). La máxima distancia que alcanzó la correlación positiva $(\sim 3 \mathrm{~m})$ coincide con las distancias entre clones del mismo genotipo. A su vez, la correlación negativa detectada en las clases de distancia entre 56 y $81 \mathrm{~m}$, parece estar inducida principalmente por los pares de comparaciones entre los diferentes genotipos clónicos híbridos putativos, que muestran una gran proximidad genética respecto a las distancias a las que se encuentran.

En TIE la mayoría de los individuos (35 de 42) contribuyeron significativamente a la EGE detectada y mostraron una correlación positiva con sus vecinos más próximos. Estos 35 individuos se localizaron en los dos subnúcleos principales. Los pares de distancias dentro de cada subnúcleo se aproximan a la distancia máxima de correlación positiva detectada ( 185 m), lo que sugiere que el flujo génico ocurre principalmente entre individuos dentro de cada uno de los dos 
subnúcleos. Con respecto a la EGE negativa detectada, habría que comentar que durante la construcción de un camino forestal se translocaron individuos juveniles de olmo de montaña desde el subnúcleo del sur al del norte a los bordes del camino (Javier, Guarda Mayor de El Tiemblo, comunicación personal) (ver Figura 4.8). En plantas, se ha observado que las translocaciones pueden afectar a los patrones espaciales (Halbur et al. 2014). Por lo tanto, la translocación de individuos en TIE podría ser la causa de la EGE negativa significativa detectada, al eliminar las relaciones de proximidad genética de los individuos translocados con sus vecinos más próximos. En efecto, las distancias existentes entre dichos individuos translocados y el subnúcleo del sur, con el que parecen guardar una mayor proximidad genética, coincide con la distancia en la cual detectamos EGE negativa (811-898 m).

Otro de los factores que pueden afectar a la EGE intrapoblacional en especies forestales es la fragmentación de las formaciones boscosas (Young \& Merriam 1994). La localidad de IRU presenta a sus individuos agrupados en cuatro subnúcleos. En ella se detectó que la EGE positiva era apreciable hasta los $\sim 240 \mathrm{~m}$, distancia que se corresponde con las separaciones entre individuos dentro cada subnúcleo. Esto es indicativo de que el flujo génico se produce principalmente dentro de cada uno de los subnúcleos, a través de varios individuos que contribuyen a la EGE.

\subsection{Diversidad en el genoma de cloroplastos}

En primer lugar, cabe destacar la elevada transferibilidad de los marcadores moleculares empleados en el ADNcp de U. glabra, a pesar de haber sido desarrollados en otras especies filogenéticamente alejadas. La transferibilidad ha sido descrita con anterioridad en diversas especies (Chung et al. 2003; Weising \& Gardner 1999) e incluso algunas de las regiones analizadas mediante PCR-RFLP ya se emplearon con éxito en UImus (Gil et al. 2004; Whiteley 2004; Fuentes-Utrilla et al. 2014b).

En PCR-RFLP, se amplificaron 25 de las 38 regiones inicialmente probadas; mientras que para todos los 18 loci SSRcp testados se obtuvieron productos de amplificación. Otro de los resultados a destacar es que una parte importante de las regiones analizadas en el ADNcp no permitieron distinguir entre U. glabra y U. minor; muy probablemente porque esas regiones están muy conservadas entre las dos especies, debido a su proximidad genética (Wiegrefe et al. 1994). Los SSRcp fueron de mayor utilidad a la hora de detectar polimorfismos, que la técnica de PCRRFLP; ya que sólo diez de las 38 regiones PCR-RFLP resultaron polimórficas en Ulmus, mientras que nueve de los 18 loci SSRcp lograron detectar polimorfismo. Dentro de estos últimos, los loci 
que mejor funcionaron fueron ccmp5, que diferenció cuatro de ocho haplotipos detectados en $U$. glabra y dos de los tres en U. minor; y ccSSR-9 (4/8 haplotipos en U. glabra y los tres de U. minor), siendo ambos recomendados para análisis futuros en el ADNcp de olmos.

Cabe destacar que ninguna muestra de $U$. glabra ni ninguno de los híbridos putativos detectados compartieron clorotipos con $U$. minor. Teniendo en cuenta que el ADNcp es de herencia materna en angiospermas (Conde et al. 1979), este fenómeno nuevamente apunta a que se está produciendo una introgresión asimétrica de $U$. minor a $U$. glabra, en la que $U$. glabra actuaría como receptor del polen de U. minor.

Centrándonos en la diversidad genética del ADNcp en olmo de montaña, la combinación de polimorfismos encontrados en cuatro regiones de PCR-RFLP junto con los de cinco loci SSRcp, permitieron detectar ocho haplotipos en las 22 poblaciones analizadas. Esta diversidad es mayor que la obtenida para poblaciones noruegas (dos haplotipos en 16 poblaciones) (Myking \& Yakovlev 2006) y también mayor que la detectada en algunas poblaciones ibéricas de U. glabra (Gil et al. 2004). Hasta el presente trabajo, en la península ibérica sólo se habían analizado cinco poblaciones de olmo de montaña, para las que se habían descrito dos haplotipos, estando el mayoritario presente en la única población de la Cordillera Central que fue analizada (Gil et al. 2004; López de Heredia et al. 2005). Estudios similares en poblaciones relictas peninsulares de $U$. laevis, también detectaron una menor diversidad en el genoma de cloroplastos que en nuestro trabajo (Fuentes-Utrilla et al. 2014b). Por otra parte, la diversidad total detectada en U. glabra $\left(h_{\top}=0,433\right)$ fue inferior a la descrita para otras especies anemófilas (Brundu et al. 2008; Fineschi et al. 2005; Grivet \& Petit 2003).

La causa más probable por la que hemos detectado mayor número de haplotipos que en los otros trabajos citados, puede deberse a que hemos analizado un elevado número de fragmentos dentro de la región LSC combinado con la utilización de numerosos SSRcp. En general, los microsatélites aportan mayor resolución que la técnica PCR-RFLP a la hora de detectar diversidad en cloroplastos (Provan et al. 2001). Esto es lo que ocurrió en nuestro estudio, donde los SSRcp detectaron siete de los ocho clorotipos presentes en U. glabra; mientras que con PCR-RFLP, a pesar de analizar más del $66 \%$ de la región LSC, sólo se detectaron tres de los ocho haplotipos.

La mayoría de las poblaciones de U. glabra del Sistema Central fueron monomórficas (17), tan solo cinco presentaron polimorfismo: IRU, CVA, STR y BEN, con dos haplotipos diferentes, y CVJ con tres. El haplotipo H1 resultó ser mayoritario al estar presente en 19 de las 22 poblaciones analizadas y se localizó a lo largo de todo el Sistema Central. En este haplotipo, dos de las 
regiones de PCR-RFLP analizadas (CP16 y CP19) mostraron el patrón de restricción característico de poblaciones del sur de Europa (a su vez minoritario en las poblaciones del norte de Europa) (Myking \& Yakovlev 2006). La presencia de un haplotipo mayoritario en las poblaciones ibéricas de U. glabra ya ha sido descrita con anterioridad, habiendo sido también detectado en el Sistema Central (Gil et al. 2004). También cabe destacar que detectamos un haplotipo mayoritario (H7) y exclusivo de las poblaciones más occidentales del Sistema Central (VIL, STR y BEN). Por último, mencionar el haplotipo H2, presente en CER y que apareció aislado del resto en la red haplotípica de máxima parsimonia. Los patrones de restricción obtenidos para este haplotipo en los fragmentos CP16 y CP19 fueron idénticos a los detectados en la mayoría de poblaciones de $U$. glabra de Escandinavia (Myking \& Yakovlev 2006).

La distribución espacial de los clorotipos dio lugar a la existencia de una estructura filogeográfica significativa en las poblaciones del Sistema Central, tal y como se refleja en la obtención de un valor de $\mathrm{N}_{\mathrm{ST}}$ significativamente mayor que el de $\mathrm{G}_{\mathrm{ST}}$. La presencia de estructura filogeográfica en otras especies arbóreas anemófilas ha sido asociada a la fragmentación y a la existencia de refugios durante los periodos más fríos del Pleistoceno (Magri et al. 2006; Grivet \& Petit 2003; Naydenov et al. 2016; Jadwiszczak et al. 2015).

La existencia de grupos de poblaciones filogeográficamente homogéneas y con la máxima diferenciación genética entre dichos grupos, teniendo en cuenta las distancias geográficas, fue corroborada con el programa SAMOVA (Dupanloup et al. 2002). Dicho programa identificó cuatro grupos de poblaciones: 1) el que agrupó a la mayoría de las poblaciones y en las cuales se detectó el haplotipo mayoritario (H1) en el Sistema Central; 2) el que reúne a las poblaciones que presentaron el clorotipo característico del oeste de la cordillera $(\mathrm{H} 7)$; y dos grupos de poblaciones únicas, 3) BEN, población portuguesa donde se identificó tanto el haplotipo mayoritario (H1) como el haplotipo del oeste (H7); y 4) CER, que presentó el haplotipo mayoritario del norte de Europa. Un agrupamiento más restrictivo, identificó dos grupos correspondientes a la distribución de los dos principales haplotipos detectados: el grupo mayoritario, que incluyó a 16 de las 19 poblaciones analizadas (también a CER), y el grupo más occidental (VIL, STR y BEN).

La estructura filogeográfica inferida por SAMOVA coincide parcialmente con las regiones de procedencia descritas para especies forestales (Alía Miranda et al. 2009). La separación de las poblaciones más occidentales respecto al resto de localidades y, a su vez, la separación de BEN del grupo compuesto por VIL y STR (para $K=4$ ) coincide con las regiones de procedencia empleadas para BEN (Serra da Estrela) y para STR y VIL (Sierra de Gata). También coinciden con los datos obtenidos mediante el análisis de ADN nuclear. Sin embargo, las regiones de 
procedencia para U. glabra de la Sierra de Guadarrama-Ayllón y de la Sierra de Gredos no se pudieron distinguir genéticamente, ya que tanto el dendrograma obtenido con los datos del ADN nuclear como los resultados de SAMOVA en el ADN de cloroplastos mostraron agrupadas a casi todas las poblaciones de ambas regiones, lo cual demuestra que los núcleos situados en estas dos sierras son bastante homogéneos desde el punto de vista genético.

\section{2. Caracterización ambiental}

La caracterización del ambiente ecológico en el que se desarrollan las especies es importante. También lo es conocer las particularidades ecológicas que afectan a sus poblaciones periféricas, situadas normalmente en ambientes más exigentes. Esto es decisivo a la hora de determinar el estado de conservación de la especie teniendo en cuenta todas sus poblaciones, y también, en su caso, para elaborar medidas de gestión adecuadas, más aun considerando los escenarios de cambio climático (IPCC 2007; IPCC 2013). En el presente trabajo, hemos realizado una caracterización ambiental de $U$. glabra en dos niveles de detalle: 1) en el conjunto de la península ibérica, y 2) de las poblaciones del Sistema Central.

Las variables más importantes y que explican la distribución de $U$. glabra en la península ibérica fueron la precipitación en primavera, precipitación en verano, la media de las máximas en verano, la media de las mínimas en invierno, la oscilación térmica anual y la litología. Estas variables pueden responder a exigencias fisiológicas, como las necesidades hídricas en primavera al coincidir con los meses de floración y fructificación (López Almansa \& Gil 2003). Otras responden a características más generales de la especie, como la necesidad de veranos frescos y elevada humedad (Caudullo \& de Rigo 2016) y una baja tolerancia al estrés hídrico en verano (Ceballos \& Fernández 2001), por lo que las temperaturas deben de ser suaves y la precipitación en época estival importante. En cuanto a la litología, algunos autores han descrito su preferencia por suelos ácidos (García Nieto et al. 2000), siendo para otros intolerante a los suelos calcáreos (Peterken 1993).

Nuestros resultados muestran que las poblaciones de la península ibérica se localizan en un amplio rango altitudinal, desde el nivel del mar hasta superar los $2300 \mathrm{~m}$, en zonas con una precipitación anual de cerca de $1000 \mathrm{~mm}$, aunque toleran un rango más amplio. Esto es coherente con los valores descritos previamente para la especie $(800-1000 \mathrm{~mm}$ ) (Ceballos \& Fernández 2001). La mayor parte de las precipitaciones se concentran en la temporada lluviosa (primavera, otoño e invierno), especialmente en invierno ( $350 \mathrm{~mm})$; mientras que en verano sufren sequía 
estival más o menos pronunciada ( $130 \mathrm{~mm})$, valor inferior a los $200 \mathrm{~mm}$ descritos para U. glabra (Ceballos \& Fernández 2001). En cuanto al régimen térmico se puede decir que el olmo de montaña requiere temperaturas suaves, ya que sus poblaciones ibéricas se localizan mayoritariamente en zonas con heladas poco frecuentes, tal y como indican la media de las mínimas de invierno $\left(>0{ }^{\circ} \mathrm{C}\right)$. En cambio, esta especie es algo más tolerante con las máximas de verano $\left(\sim 27^{\circ} \mathrm{C}\right)$.

Desde el punto de vista de la litología, la mayoría de las poblaciones peninsulares se localizaron en suelos ácidos (hercínicos o prehercínicos). Algunas de las poblaciones analizadas, también se situaron en terrenos calizos, sugiriendo que esta especie es indiferente edáfica, aunque con una clara preferencia por los suelos silíceos; tal y como apuntaba García Nieto et al. (2000).

El análisis de la ecología de las poblaciones del Sistema Central muestra que se encuentran bajo unas condiciones ambientales más exigentes que las que soportan el resto de las poblaciones ibéricas. Especialmente cabe destacar el déficit hídrico estival que soportan, con escasas precipitaciones $\left(<90 \mathrm{~mm}\right.$ ) y temperaturas altas (media de las máximas diarias $>27^{\circ} \mathrm{C}$ ). Para compensar este déficit de precipitaciones, sus poblaciones se encuentran en enclaves con elevada humedad edáfica: zonas próximas a ríos, barrancos sombríos o zonas de elevada humedad (Rossignoli \& Génova 2003). Otra de las características climáticas que muestran diferencias entre las poblaciones ibéricas y las del Sistema Central es la distribución de las precipitaciones a lo largo del año. En ambos casos se concentran mayoritariamente en la temporada lluviosa (primavera, otoño e invierno), siendo por tanto más escasas en el periodo estival. Esta diferencia en precipitaciones entre ambos periodos es más acusada en el Sistema Central.

La situación geográfica del Sistema Central de la península ibérica implica que el clima al que está sometido tenga una clara influencia del océano Atlántico. Se trata de una cadena montañosa orientada en términos generales de oeste a este y con dos grandes masas de agua: el océano Atlántico y el mar Mediterráneo que contribuyen a suavizar las temperaturas y por otro, generan nubes que proporcionan precipitaciones en el interior del territorio. Esto genera un clima suave y húmedo en la costa que se va perdiendo progresivamente a medida que nos adentramos hacia el interior peninsular. En verano, en cambio, el anticiclón de las Azores tiene un efecto contrario ya que genera un clima soleado, estable y sin precipitaciones, y por tanto produce una importante sequía estival.

Esto produce que el sector más occidental de la cordillera presente un clima de temperaturas suaves, especialmente en invierno, y buenas precipitaciones. Es lo que observamos en la única 
población presente en la Serra da Estrela, que mostró valores intermedios para las variables de precipitación y de temperatura, siendo el sector con menor oscilación térmica anual, debido a la modulación que produce su proximidad al océano Atlántico. Además, la altitud media fue la más baja de todas. En Sierra de Gata, las poblaciones de VIL y STR superan los $1000 \mathrm{~mm}$ de precipitación anual, al contrario de lo que ocurre en verano, para los que presentaron los valores más bajos ( $75 \mathrm{~mm})$. En las estribaciones más orientales, la Sierra de Ayllón presentó, en general, valores bajos de precipitación analizados de todas las poblaciones, con la salvedad de la precipitación de verano, para la cual, mostraron los valores más elevados (>125 mm). Las poblaciones de Guadarrama-Ayllón se localizan por encima de los $1200 \mathrm{~m}$, en ambientes en los que las temperaturas mínimas de invierno no superan los $-2,5^{\circ} \mathrm{C}$.

Por último, los núcleos de olmo de montaña localizados en el sector Sierra de Gredos mostraron valores intermedios de precipitación y temperatura en general, y los valores más bajos para la precipitación de primavera y verano, la mayor oscilación térmica y las mayores máximas en verano (ver Tabla 4.30). Especialmente destacan las poblaciones de Gredos, ROZ, MOM y $\mathrm{CVH}$, localizadas en un ambiente de características más mediterráneas (sector Mediterráneo cálido de piedemonte) (Ruiz-Labourdette et al. 2011), con muy bajas precipitaciones, especialmente en verano $(68-76 \mathrm{~mm})$. La presencia de un elevado grado de hibridación en las dos poblaciones analizadas molecularmente (ROZ y MOM) ha podido facilitar la ocupación de este nuevo ambiente, tal y como se ha descrito para fenómenos de introgresión en otras especies de plantas (Rieseberg et al. 2007).

La mayoría de las poblaciones de olmo de montaña en la Cordillera Central se localizan en zonas climáticas de clara connotación eurosiberiana, en las que se da una sequía estival menos pronunciada. En estos enclaves también se encuentran algunas poblaciones periféricas de taxones eurosiberianos (Ruiz-Labourdette et al. 2011), lo cual indica que estamos ante pequeños territorios que han funcionado en los últimos siglos como auténticos refugios climáticos que han permitido la persistencia de poblaciones relictas.

Área potencial de U. glabra en la península ibérica

El modelo de distribución potencial obtenido (Figura 4.28) presentó un bajo riesgo (próximo a cero), un elevado porcentaje de acierto (>85\%) y un buen nivel de precisión (Allouche et al. 2006; Schlaepfer et al. 2012) (ver Tabla 4.31), por tanto podemos afirmar que representa con un grado de precisión aceptable el área de distribución potencial de la especie en el ámbito ibérico. Un buen indicador del ajuste del modelo es el hecho de que la mayoría de las poblaciones descritas en el 
Sistema Central se situaron dentro del área potencial detectada. La localización de algunas poblaciones fuera del área potencial, aunque muy próximas a los límites del mismo, puede atribuirse a condiciones microclimáticas particulares que escapan del modelo, como la existencia de pequeños arroyos o ambientes húmedos, los cuales favorecerían la presencia de esta especie.

Este modelo identificó importantes áreas de distribución potencial en la península, mayores a las descritas en otros modelos anteriores (Svenning et al. 2008; Felicísimo et al. 2011). Esto puede deberse al amplio conjunto de datos analizados en este trabajo, al mayor grado de resolución empleado (cuadrículas de $500 \mathrm{~m}$ de lado) y especialmente a la precisión de los datos de partida para elaborar el modelo colectados, especialmente los de las poblaciones relictas y periféricas. Mientras que el modelo de Felicísimo et al. (2011) cuenta con escasos datos de poblaciones periféricas, nuestro modelo cuenta con numerosos datos muy fiables de todas las poblaciones marginales peninsulares conocidas hasta la fecha. Unas, como las del Sistema Central recopiladas y comprobadas por nuestro equipo, y otras procedentes de instituciones botánicas (p.e. los datos en Sierra de Cazorla). Así pues, los modelos generados con anterioridad son más conservadores, al faltar datos de presencia (Mateo et al. 2011). Este hecho puede ser el responsable de que los trabajos de Felicísimo (2011) y de Svenning et al. (2008) hayan detectado pequeños enclaves de condiciones adecuadas fuera del eje cantabropirenaico; en cambio, nuestro modelo muestra un área potencial mayor para la especie en el centro y sur peninsular (ver Figura 4.27).

El modelo obtenido detectó una importante área potencial en el norte de España, especialmente en Galicia y en el eje cántabro-pirenaico; en el Sistema Ibérico, entre las Sierras de la Demanda y del Moncayo, Sierra de Albarracín y la Serranía de Cuenca; en las Sierras de Tras os Montes y Marão (Portugal); pequeños enclaves en los Montes de Toledo y en la provincia de Cádiz; y otro conjunto en las cordilleras prebéticas de las Sierras de Cazorla y Segura (ver Figura 4.28).

En el Sistema Central el mapa de distribución potencial muestra un área menor que la detectada en el norte peninsular, aunque mucho mayor que la cartografiada en los modelos anteriores (Svenning et al. 2008; Felicísimo et al. 2011), mostrando áreas potenciales importantes entre Ayllón-Somosierra-Guadarrama, Gredos, Béjar-Francia, Gata y Estrela, en esta última de pequeño tamaño (ver Figura 4.29). Nuestro trabajo contó con núcleos de la mayoría de estas importantes áreas potenciales; con la salvedad de Sierra de Béjar-Francia, territorio en la que no localizamos ninguna población, a pesar de que el área potencial de distribución en este sector es muy importante. Es por ello que consideramos necesario realizar futuras prospecciones en él. 


\section{3. Análisis demográfico y estructura filogeográfica}

Los estudios palinológicos muestran la presencia continuada del género Ulmus en la península desde el Mioceno, manteniéndose a través del Pleistoceno y el Holoceno hasta nuestros días (López 2003). En este periodo, la península habría servido como reservorio de la diversidad para los olmos, tal y como se ha comprobado en estudios previos (Gil et al. 2004; López de Heredia et al. 2005; Fuentes-Utrilla et al. 2014b). Desgraciadamente, el polen de los olmos es indistinguible entre las diferentes especies (Stafford 1995), por lo que tenemos que hablar de forma general. Aun así, contamos con otras fuentes de información que nos permiten reconstruir la historia reciente de la especie: los modelos de área potencial. Estos muestran que U. glabra tuvo un área potencial mayor durante el último máximo glacial ( 21000 años atrás), muy especialmente en la mitad noroeste de la península (Svenning et al. 2008). Algo similar parece que ocurrió en el Sistema Central, donde se dan enclaves cuyas características climáticas les han permitido actuar como refugios para numerosos taxones durante los periodos más fríos del Pleistoceno (Costa Tenorio et al. 1990; Carrión et al. 1995; Abel Schaad et al. 2014).

Posteriormente, con la mejora climática y la retirada de los hielos, la recolonización del continente se habría producido a partir de las áreas que actuaron como refugios para el género Ulmus, localizadas en la penínsulas ibérica e itálica, y en la zona de los Balcanes-Grecia (Gil et al. 2004). Rutas similares de recolonización postglacial han sido descritas para otras especies arbóreas (Heuertz et al. 2004; Grivet \& Petit 2003; Taberlet et al. 1998). De esta forma, el linaje característico de la península se extendió por el suroeste de Europa, siendo el linaje predominante y, a su vez, el minoritario de las poblaciones del noreste (Gil et al. 2004; Myking \& Yakovlev 2006).

Como excepción que merece un análisis particular, tenemos la población de CER, que presentó el haplotipo mayoritario del norte europeo $(\mathrm{H} 2)$ y en el análisis con SAMOVA apareció en un clúster diferente (ver Figura 4.23a). Estas características de CER apuntan a dos posibilidades: su llegada a la península durante la última glaciación o la posible plantación en épocas recientes de esta población. A pesar de que no podemos descartar totalmente el factor humano, la ubicación de la población y la antigüedad del ejemplar del que parece provienen los que actualmente la constituyen, hace pensar que lo más probable es que este haplotipo haya sobrevivido desde el último máximo glacial hasta nuestros días, y por tanto podríamos estar ante una población única y relicta que alberga la última representación de este haplotipo en el Sistema Central. Con los datos que actualmente contamos es difícil confirmar esta hipótesis. Aun así, y hasta que se aclare 
definitivamente su origen, debemos aplicar el principio de precaución y tomar medidas de conservación que impidan la desaparición de esta singular población.

Después del último máximo glacial, hace aproximadamente 20000 años, los estudios paleoclimáticos y paleobotánicos confirman un incremento de la temperatura desde el Tardiglacial y durante el Holoceno en Europa (Jalut et al. 2009; Carrión et al. 2010; Carrión et al. 2012). En la península ibérica se produjo en paralelo la expansión del clima mediterráneo y, consecuentemente, la vegetación eurosiberiana sufrió un retroceso latitudinal y altitudinal (Costa Tenorio et al. 1990; Costa Tenorio et al. 1997). En este sentido, los estudios palinológicos sobre el Sistema Central muestran una expansión de taxones más xerófilos, especialmente durante el Holoceno tardío (hace 4500-2800 años) (Franco Múgica et al. 1998; Dorado Valiño et al. 2001; López Sáez et al. 2014). Los modelos de distribución de U. laevis y U. minor (Svenning et al. 2008) y de U. glabra (Svenning et al. 2008; Felicísimo et al. 2011) muestran que el área que ocupan estas especies en la actualidad es menor que su área potencial, tanto en la península como en el Sistema Central. Por tanto, se puede asumir que en la Cordillera Central se ha ido produciendo una disminución del área de ocupación real de la especie, unida a una pérdida progresiva de efectivos. Esto generaría una fragmentación de las poblaciones y consecuentemente una reducción del flujo génico interpoblacional, que explicaría la elevada diferenciación genética que presentan sus poblaciones actuales.

Un fenómeno asociado a la regresión de las especies son los fenómenos de deriva génica y el desarrollo de cuellos de botella. Este último se ha detectado en poblaciones relictas ibéricas de U. laevis, habiendo sido ligados a las glaciaciones pleistocenas (Venturas et al. 2013b) o como consecuencia de la expansión postglacial de hábitats más xéricos (Fuentes-Utrilla et al. 2014b). En U. glabra, detectamos también cuellos de botella ancestrales y continuados (Garza \& Williamson-Natesan 2001; Williamson-Natesan 2005) en 16 de las poblaciones del Sistema Central. La existencia de un área potencial durante el último máximo glacial mayor que el que presenta la especie en la actualidad (Svenning et al. 2008), parece indicar que los cuellos de botella ancestrales observados en las poblaciones del Sistema Central probablemente estén asociados al retroceso de la flora eurosiberiana en lberia durante el periodo postglaciar y el Holoceno, tal y como sugiere Fuentes-Utrilla et al. (2014b). Aun así, no podemos descartar que los mismos se produjeran mucho antes, durante las glaciaciones pleistocenas, tal y como ha sido propuesto por Venturas et al. (2013b). Esta reducción del área potencial, probablemente produjera el aislamiento y separación de las poblaciones más occidentales (VIL, STR y BEN), del resto de 
núcleos, lo cual puede explicar los resultados obtenidos tanto en el análisis del ADN nuclear como del genoma de cloroplastos.

El efecto sobre la vegetación del cambio climático ocurrido a lo largo del Tardiglaciar y el Holoceno, no es el único factor que ha actuado sobre la vegetación de la Cordillera Central. Además de este componente, en los últimos milenios, viene actuando otro más, y de gran importancia: la explotación antrópica de los recursos naturales. La suma de ambos explica en gran medida la situación actual de la vegetación y la flora del territorio, especialmente de las poblaciones relictas. Diversos trabajos han demostrado que en muchas ocasiones el declive de poblaciones marginales ha sido producido por el hombre (Lesica \& Allendorf 1995; Channell \& Lomolino 2000a; Vucetich \& Waite 2003; Channell \& Lomolino 2000b). Existen evidencias de la antropización del Sistema Central desde hace al menos 3000-4000 años (Dorado Valiño et al. 2001; Van der Knaap \& Van Leeuwen 1995). Los trabajos polínicos informan de una deforestación continua desde entonces que se intensifica desde hace unos 1000 años (Franco Múgica et al. 1998). Posteriormente, durante el periodo feudal y con el surgimiento de La Mesta (López Sáez et al. 2014), se produce un incremento de la transformación de las tierras altas del Sistema Central. A lo largo de estos siglos se ha ido produciendo una intensa transformación de los paisajes ibéricos en general y del Sistema Central en particular. Por tanto, el paisaje actual del Sistema Central es fruto en gran medida de una intensa actividad antrópica continuada durante siglos que ha dado lugar a un mosaico de manchas forestales, matorrales y pastizales (López Merino et al. 2009). Esto ha tenido consecuencias en todas las especies, especialmente en las de ambientes forestales como ocurre con el olmo de montaña, que ha ido reduciendo sus efectivos y su área de distribución a lo largo del Sistema Central. Esto explica por qué el área potencial identificado en este trabajo es mucho mayor a la presencia real actual de la especie, que se reduce a menos de $20 \mathrm{~km}^{2}$ y 27 núcleos.

En estudios de poblaciones relictas de $U$. laevis, además de un bajo número de poblaciones e individuos, también se detectaron tamaños efectivos bajos y signos de cuellos de botella recientes (Venturas 2013; Venturas et al. 2013b). En nuestro caso, también detectamos un reducido número efectivo de individuos, al igual que signos de cuellos de botella recientes en cuatro (NAV, ROZ, TIE y MOM) de las 15 poblaciones analizadas, tal y como reveló el estadístico $\mathrm{T}_{2}$ y la prueba de los rangos con signo de Wilcoxon. En los dos primeros casos, NAV, localizada en el Pinar de Navafría y TIE en el término municipal de EI Tiemblo, los cuellos de botella con toda probabilidad se deban a actuaciones recientes en el entorno de las poblaciones (últimas décadas), 
incrementando en ellas la diferenciación intrapoblacional que existiera con anterioridad a la intervención (Torres-Díaz et al. 2007).

Los cuellos de botella detectados en ROZ y MOM y el bajo número efectivo de individuos que presentaron son debidos a la elevada tasa de rebrote en ellas observada. La propagación vegetativa causa una reducción del número efectivo de individuos que el programa BOTTLENECK identifica como cuellos de botella. Otro factor que afecta a la detección de cuellos de botella en etas dos poblaciones es el exceso de heterocigosidad observada. El programa BOTTLENECK se basa en que las poblaciones que han experimentado una reducción en el tamaño efectivo poblacional $\left(N_{e}\right)$, presentan un exceso de la heterocigosidad observada $\left(\mathrm{H}_{0}\right)$ respecto a la esperada $\left(H_{E}\right)$ en el equilibrio mutación-deriva (Cornuet \& Luikart 1996).

Tanto los datos obtenidos en este trabajo, como las referencias bibliográficas y la presencia de núcleos e individuos dispersos por toda la cordillera, hacen pensar que en el pasado existió una metapoblación más continua de la especie en el Sistema Central. Posteriormente, y debido tanto a factores climáticos como antrópicos, se produjo una reducción de su área de distribución y la pérdida de efectivos, provocando la aparición de fenómenos de deriva y la fragmentación actual de los núcleos. Esto puede explicar tanto el agrupamiento de la mayoría de las poblaciones en el mismo clúster del árbol UPGMA, como la presencia del haplotipo mayoritario (H1) a lo largo de toda la Cordillera Central.

\section{4. Evaluación del grado de amenaza en el Sistema Central}

Los datos acumulados en este trabajo y otros anteriores permiten abordar el análisis del estado de amenaza del taxón en el ámbito regional del Sistema Central. Éste se realiza evaluando la especie con los cinco criterios establecidos por la UICN.

\section{A. Reducción del contingente total de individuos maduros}

Carecemos de censos completos en diferentes años que nos permitan analizar numéricamente su evolución. Los datos del modelo potencial de distribución obtenido para la especie en la Cordillera Central, muestran indicios de que la especie ha sufrido, y viene sufriendo una reducción de su contingente de individuos maduros $y$, al menos también, de su área de ocupación. Además, tenemos datos que sugieren pérdida de hábitat, reducción del Área de Ocupación y quizá de la Extensión de Presencia. El contingente de individuos maduros está sufriendo una severa reducción en algunas subpoblaciones como consecuencia de la grafiosis 
(Arche 2010; Rossignoli 1999; Maqueda 2006); en algunas subpoblaciones también hemos detectado hibridación con U. minor, ROZ y MOM principalmente, aunque también se ha detectado en menor medida en IRU, CVJ y CAN.

A pesar de los indicios expuestos no tenemos datos adecuados para evaluar si la especie está experimentando una reducción de sus efectivos, tal y como pide este criterio.

\section{B: Distribución geográfica reducida}

B1. Extensión de Presencia. Esta especie en el Sistema Central presenta una extensión de presencia de $\sim 19000 \mathrm{~km}^{2}$, por lo que cumple con la categoría VU $\left(<20.000 \mathrm{~km}^{2}\right)$.

B2. Área de Ocupación. El conjunto de la especie en este territorio ocupa $\sim 19 \mathrm{~km}^{2}$, estando por debajo del umbral de los $500 \mathrm{~km}^{2}$ establecido para ser catalogada como EN. Pero esta condición no es suficiente, además, debe cumplir dos de las siguientes condiciones:

a.- Severamente fragmentada o Número de localidades

Se considera que un taxón se encuentra severamente fragmentado cuando más del $50 \%$ de sus efectivos se localizan en subpoblaciones cuyo número de individuos maduros es inferior a la Población Mínima Viable (MVP) asignado a la especie (Blanca \& Marrero 2004). Teniendo en cuenta la distancia máxima a la que se puede dispersar el polen en olmos (1200 m) (Nielsen \& Kjær 2010a) y la escasa movilidad de las semillas que, por lo general, se ha descrito en olmo (Venturas 2013), el número de subpoblaciones en el Sistema Central es de 25 (ver Tabla 4.32). Este dato estaría reforzado por los obtenidos por nosotros mismos en el Sistema Central, donde la EGE deja de ser detectable a partir de los $\sim 5,100 \mathrm{~km}$ y donde las sámaras por lo general, no presentan una gran movilidad. Además, independientemente de si consideramos a la especie Moderadamente longeva o Muy longeva, los resultados apenas varían, concentrándose el 930 $94 \%$ de los individuos maduros en dos o tres poblaciones. En definitiva, que los resultados no se ven alterados si este árbol se considera medianamente longevo o muy longevo, y muestran que la especie en el Sistema Central no cumple con el requisito para considerar que su población se encuentra severamente fragmentada.

El método establecido considera factor de riesgo tanto la fragmentación severa como la concentración de los efectivos en pocas subpoblaciones (Blanca \& Marrero 2004). En nuestro caso, más del $50 \%$ de los individuos maduros se concentran en dos o tres subpoblaciones, en función de si consideramos que se trate de una especie que vive 25-100 años o más de 100 (ver 
Tabla 4.32). Por tanto, la especie presenta un riesgo alto aplicable a la categoría EN (Blanca \& Marrero 2004) y cumple con el subcriterio a).

Según la UICN el término 'localidad' es un área geográfica o ecológica en la cual un solo acontecimiento amenazante puede afectar rápidamente a todos los individuos del taxón presente (UICN 2012b). Por tanto, el tamaño de una localidad depende del área cubierta por la amenaza y puede incluir parte de una o muchas subpoblaciones del taxón. En el caso que nos ocupa la grafiosis es un factor de amenaza que sabemos está actuando sobre la mayoría de sus subpoblaciones. Además, existen otros factores de amenaza como es la pérdida de hábitat y la hibridación que nos permite afirmar que la especie en el Sistema Central cuenta con menos de 5 localidades. En definitiva, podemos considerar que se cumple este subcriterio, y la categoría de amenaza para estas poblaciones es EN. Esta es condición necesaria pero no suficiente ya que aún debe cumplir con otro de los subcriterios siguientes:

b.- Disminución continúa estimada, inferida o proyectada de:

(i) Extensión de presencia. La modelización realizada en esta Tesis Doctoral muestra un área potencial para la especie en el Sistema Central mucho mayor que la que actualmente ocupa. Asumiendo que es una aproximación, sí podemos utilizar el dato para estimar e inferir que la especie pudo vivir en un área mayor que el que actualmente ocupa, y por tanto lo que observamos en la actualidad es el resultado de un proceso de reducción del área que ocupó.

(ii) Área de ocupación. En algunas subpoblaciones (p.e. IRU, RAS, etc.) se ha constatado la muerte de muchos ejemplares en un pasado reciente debido a la incidencia de la grafiosis (Arche 2010; Rossignoli 1999). Este descenso en el censo implica la reducción de su área de ocupación efectiva.

(iii) Área, extensión y calidad del hábitat. El Sistema Central ha sufrido una intensa alteración por parte del hombre (López Merino et al. 2009), modificando de forma más o menos intensa el paisaje. Algunas de las subpoblaciones subsisten en entornos muy antropizados, entre cultivos (p.e. ROZ, MOM, CAS), que ha degradado de forma notable el hábitat en el que viven estos núcleos. Otras, se localizan próximas a entornos forestales que han sufrido repoblaciones de pino (p.e. CNJ, PAU o RAS) que de igual forma ha podido alterar el hábitat en el que se encuentran.

(iv) Número de localidades o subpoblaciones. No disponemos de datos suficientes para evaluar este apartado.

(v) Número de individuos maduros. Tenemos información parcial de una quincena de subpoblaciones (p.e. IRU, RAS o STR) que nos permiten inferir este dato y también realizar una 
proyección a futuro. De ellas, contamos con datos de mortandad por grafiosis (Arche 2010; Rossignoli 1999; Maqueda 2006), tanto por observación directa como por información de los servicios forestales (aunque sin poder concretar el número de ejemplares muertos). En RAS, tenemos datos de observación directa de que en el año 2008 el número de individuos vivos ascendía a 54, mientras que esta cifra se redujo un 25\% para pasar a 40 en 2014. Mediante cultivo se pudo comprobar que esta mortandad fue causada fundamentalmente por la grafiosis (Martínez García 2014). Otro indicio que refuerza la idea de la reducción de efectivos en un pasado reciente son los datos de cuello de botella detectados en este trabajo, que están asociados a una reducción de efectivos en las poblaciones.

\section{C: Número de individuos maduros y disminución continua}

Según nuestras estimaciones y censos el número de individuos maduros es algo menor de 4000 , por tanto, se incluiría dentro de los límites de la categoría VU $(<10000)$. Para que este criterio sea considerado, además del pequeño tamaño poblacional, debe cumplir al menos uno de los siguientes subcriterios:

C1. Disminución continúa observada, estimada o proyectada del 10\% en 3 generaciones. Los indicios que disponemos (reducción de hábitat, existencia de cuellos de botella ancestrales y recientes, etc.) permiten suponer que esta disminución se viene dando, y que en un futuro se seguirá produciendo, pero carecemos de datos numéricos sólidos para afirmarlo.

C2. Disminución continua, observada, estimada, proyectada o inferida y por lo menos una de las siguientes tres condiciones:

a) Número de individuos maduros en cada subpoblación.

(i) Número de individuos maduros en cada subpoblación. De las 22 subpoblaciones tan solo IRU cuenta con más de 1000 individuos maduros, con algo más de 2800. Por tanto, no cumple el requisito, pero se sitúa muy cerca de cumplirlo, puesto que 24 de 25 subpoblaciones tienen un número de individuos maduros inferior a 300.

(ii) Porcentaje de individuos en una sola subpoblación. No se cumple, puesto que el porcentaje que presenta la población que aglutina al mayor número de individuos maduros (IRU, $78 \%$ ), está muy por debajo de los valores asociados a cada una de las categorías de amenaza.

b) Fluctuaciones extremas en el número de individuos maduros. No aplica para esta especie. 


\section{D: Población muy pequeña o restringida}

D1. Número de individuos maduros. Éste es muy superior al umbral establecido de 1000 ejemplares maduros (>3300), por tanto, no cumple los requisitos para ser catalogado por este criterio en ninguna de las categorías de amenaza.

D2. Solo aplicable a la categoría VU. El área de ocupación ha de ser inferior a $20 \mathrm{~km}^{2} 0$ presentar un número de localidades $\leq 5$ para ser considerada como VU. Ambos requisitos los cumple, al tener un área de ocupación próxima a los $19 \mathrm{~km}^{2}$ y al presentar menos de 5 localidades, como hemos explicado anteriormente.

\section{E: Análisis cuantitativo que señale probabilidad de extinción}

Carecemos de datos censales para analizar la especie con este criterio.

En conclusión, el resultado de la evaluación del olmo de montaña en el Sistema Central con todos los criterios establecidos por la UICN (2012a, b) y aplicando el principio de precaución nos lleva a afirmar que el taxón a esta escala regional, se encuentra ante un elevado riesgo para su supervivencia ya que cumple los requisitos establecidos en el criterio B. En consecuencia, lo podemos catalogar en la Categoría En Peligro, con la fórmula EN: B2 a, b (i, ii, iii, v).

\section{5. Propuestas de gestión y conservación}

En el hemisferio norte, y más en concreto en Europa, las poblaciones periféricas situadas en los límites sur de distribución de las especies, por su historia filogenética, son esenciales para la conservación de la diversidad y el potencial evolutivo del conjunto de la especie. En consecuencia, en cualquier plan de gestión, su conservación debe de ser prioritaria (Hampe \& Petit 2005).

Este es el caso de Ulmus glabra en la península ibérica donde se localizan sus poblaciones más suroccidentales, como las del Sistema Central. Este territorio actúa como una isla climática con algunas zonas óptimas para el crecimiento de esta especie rodeada de un territorio de clima hostil. Además, los modelos ambientales para U. glabra muestran una clara reducción de su hábitat en un futuro inmediato (Felicísimo et al. 2011) ante los escenarios previstos con el cambio climático (IPCC 2007; IPCC 2013).

A estas predicciones, hay que sumar los numerosos factores de amenaza que están afectando a estas poblaciones (p.e. fragmentación, bajo número de efectivos), que al actuar de manera conjunta multiplican su efecto. Una sinergia positiva entre todos los factores de amenaza, 
potencia los efectos negativos de cada amenaza por separado, multiplicándolos y empujando a las poblaciones a valores por debajo del MVP de la especie, incrementando el riesgo de extinción (Brook et al. 2008; Mora et al. 2007).

Otro dato importante, que refuerza la idea del riesgo para la supervivencia de la especie en el Sistema Central es el resultado de la catalogación como En Peligro, la segunda categoría de mayor amenaza que significa que afronta un "riesgo de extinción muy alto" (UICN 2012a).

En definitiva, la importancia corológica de estas poblaciones, el grado de amenaza en el que se encuentran, la falta de protección de este taxón a nivel nacional y en algunas de las autonomías y que ésta es una especie incluida en la Estrategia Española para la Conservación y el uso sostenible de los Recursos Genéticos Forestales (Iglesias et al. 2006), muestran la necesidad urgente del desarrollo de acciones encaminadas a evitar la desaparición del olmo de montaña en el Sistema Central y asegurar su persistencia a largo plazo en hábitats adecuados.

Por ello y teniendo en cuenta la información previa y los resultados de este trabajo, proponemos una serie de medidas encaminadas a la gestión de la especie:

\subsection{Acciones legales}

En primer lugar, consideramos necesaria la inclusión de $U$. glabra en los catálogos de especies protegidas. Actualmente Portugal carece de catálogo de especies protegidas, por lo tanto, en el momento que se elabore, consideramos que esta especie debería evaluarse como candidata para su inclusión, al menos de la población del Sistema Central.

En España, la legislación vigente la establece que se puede proteger especies y/o poblaciones (VV. AA. 2007b; VV. AA. 2015). Por ello, proponemos que las poblaciones de olmo de montaña del Sistema Central se incluyan en el LESPRE (Listado de Especies Silvestres en Régimen de Protección Especial). Por el grado de amenaza, en nuestra opinión debería también estar incluido en el CEEA (Catálogo Español de Especies Amenazadas). Para determinar la categoría de amenazada (Vulnerable o En Peligro) se requiere un estudio específico y la elaboración del informe preceptivo con los criterios establecidos para ello (V. AA. 2017).

A escala autonómica, para ser coherentes con el grado de amenaza en el que clasificamos a la especie a nivel regional (EN) debemos proponer que en las comunidades autónomas donde se encuentra el Sistema Central, la especie sea protegida con la máxima categoría que establecen las respectivas leyes autonómicas: EN. Por tanto, para Madrid y Castilla-La Mancha, en las que ya está protegida, proponemos elevar su categoría de especie de Interés Especial (VV. AA. 1998a) 
o Sensible a la Alteración del Hábitat (VV. AA. 1992) a EN respectivamente (al menos para las poblaciones del Sistema Central). Para las comunidades autónomas de Castilla y León y Extremadura, en cuyos catálogos no figura, proponemos su inclusión en la categoría EN.

La inclusión de una especie en un catálogo de protección con la categoría EN implica que las comunidades están obligadas a elaborar un Plan de Recuperación (VV. AA. 2007b). Estos son planes de gestión en los cuales hay que reunir la información básica de la especie (corología, censo, ...) e identificar los factores de amenaza que han llevado a la especie a la situación de riesgo. Una vez identificados estos, se proponen medidas adecuadas para su eliminación. Esto nos da pie a los siguientes apartados que formarían parte de esos planes de gestión. Una de las acciones interesantes que podemos plantear en ellos es evaluar periódicamente el estado de conservación de la especie (tal y como se hace con las especies incluidas en el LESPE).

Además, en dos comunidades autónomas hay herramientas legales muy interesantes para este tipo de poblaciones de pequeñas dimensiones: son las denominadas Microrreservas. Ideadas en la Comunidad Valenciana (Laguna Lumbreras 2008), posteriormente adoptadas por otras comunidades autónomas españolas, incluso con proyección internacional (Kadis et al. 2013). En la Comunidad Valenciana se ha creado una red de Microrreservas para el estudio y la conservación de flora rara, endémica y amenazada (Laguna Lumbreras 2008; Laguna Lumbreras et al. 2016) que puede ser un buen modelo a seguir.

A nuestro juicio, dadas las características ecológicas y demográficas de la especie, se trata de una herramienta muy útil y adecuada para la gestión de las poblaciones que nos ocupan: núcleos generalmente pequeños y con pocos individuos. En este sentido proponemos la creación de esta figura en las otras dos comunidades autónomas que aún no la tienen en sus respectivas leyes autonómicas (Comunidad de Madrid y Extremadura). De esta manera se podría crear una red de microrreservas en todo el conjunto del Sistema Central. En la Comunidad de Madrid la población más destacable merecedora de esta figura es RAS. En el caso de Extremadura, aunque no cuenta con la figura de Microrreserva, sí existe una figura de protección temporal denominada "Lugar de interés científico" (VV. AA. 1998b). Se trata de "espacios generalmente aislados y de reducidas dimensiones, que reciben una protección en atención al interés científico de alguno de sus elementos naturales 0 a la existencia de especímenes o poblaciones animales o vegetales amenazadas de extinción o merecedoras de medidas específicas de protección". Su protección ha de ser temporal y una de las medidas propuestas es la inclusión de las especies de interés en el Banco de Diversidad Genética y la elaboración de un Plan de Manejo. Teniendo en cuenta la singularidad de STR, proponemos su inclusión bajo esta figura. Dada la importancia que tiene el 
río de la Vega en la dispersión de sámaras en esta población, y a la distribución de la mayoría de los individuos a lo largo del mismo, consideramos que dicho plan debe de incluir medidas destinadas a la no alteración del cauce.

En Castilla-La Mancha existe la figura de Microrreserva (VV. AA. 1999), por ello proponemos la declaración de Microrreserva "Arroyo de la Zarza" con objeto de establecer un seguimiento que permita la evolución natural de la población de CNJ. Se trata de la cuarta población de mayor tamaño de todo el Sistema Central, con casi 200 individuos, pero corre un elevado riesgo de desaparición ya que esta cifra está por debajo del MVP de la especie. Atendiendo a la importancia que tiene el cauce del arroyo en la dispersión de las semillas en esta población, proponemos que la Microrreserva incluya toda la longitud del arroyo de la Zarza. Esta declaración ha de acompañarse por un Plan de Acciones que deberá de poner especial atención a aquellas actividades que perturben el cauce del arroyo, para no afectar a la capacidad dispersiva de las sámaras a través del cauce.

En Castilla y León, igualmente, proponemos la creación de dos Microrreservas de Flora, atendiendo al reglamento castellanoleonés (VV. AA. 2007a):

- Microrreserva Valle de Iruelas. Considerando que IRU aglutina a más del $80 \%$ de los individuos maduros del Sistema Central, proponemos la declaración como Microrreserva al espacio que contiene la mayoría de los individuos de IRU, aprovechando los $2 \mathrm{~km}^{2}$ de extensión máxima que han de tener las Microrreservas en esta comunidad.

- Microrreserva "Garganta de la Yedra", con objeto de incrementar el nivel de protección de la población de TIE, la segunda población más grade de Castilla y León y una de las poblaciones con valores por encima del MVP. Consideramos que esta población es especialmente vulnerable, al encontrarse en los límites de la Reserva Natural Valle de Iruelas.

\subsection{Otras medidas}

Prospección y estudio

Consideramos necesaria la búsqueda de posibles nuevas poblaciones 0 individuos en nuevos enclaves del Sistema Central. Debido a los costes derivados de la prospección en campo, se propone dar prioridad a los esfuerzos dentro de los límites del área potencial cartografiada en este trabajo, especialmente en las Sierras de Las Hurdes, Las Batuecas-Sierra de Francia, localizadas entre Cáceres y Salamanca; en las Sierras de la Paramera y de la Serrota (en Ávila) y en la portuguesa Serra da Estrela. Además de los territorios prioritarios, otras zonas que han de 
ser valoradas para futuras prospecciones son el resto de las sierras en las que el modelo ha detectado áreas de condiciones óptimas para el crecimiento y desarrollo de la especie

\section{Medidas preventivas en la gestión ganadera y forestal}

Dado que algunas de las poblaciones se localizaron en pinares de uso maderero y en algunos casos, se observaron daños producidos por la maquinaria extractiva (como en ARL), se debe de limitar el uso de las mismas en sus proximidades.

Otra de las actividades a controlar es la ganadería. El efecto sobre las poblaciones de olmo de montaña es doble: en algunas se ha observado el ramoneo de individuos (como en CNT, IRU, CER, ...) y en otras, además, el exceso de pisoteo puede estar relacionado con la baja tasa de reclutamiento. En estos casos, como medida preventiva temporal, se pueden establecer vallados de exclusión ganadera que se han mostrado eficaces en otras experiencias de conservación en especies arbóreas (Sánchez del Álamo et al. 2011).

\section{Medidas de conservación ex situ}

También proponemos la recolección de sámaras del mayor número posible de individuos de cada población; de todos los núcleos conocidos con la salvedad de ROZ, MOM y CVH, al tratarse de poblaciones híbridas (ROZ y MOM) o al ser necesario un estudio para descartar esa posibilidad $(\mathrm{CVH})$. Como norma general, se ha recomendado no sobrepasar el $20 \%$ de la producción del individuo (Way 2003). Esta medida debe de tener una alta prioridad o al menos, centrarse en los núcleos con mayor número de individuos maduros (TIE, IRU y STR). Las semillas recolectadas proponemos que se envíen a bancos de germoplasma, como los pertenecientes a la Red de Centros de Mejora Genética Forestal, dependientes del INIA (p.e. CMGF Puerta del Hierro) para su conservación ex situ. Este material podrá servir en un futuro como base para reintroducciones o reforzamientos. Además, dada la baja viabilidad observada y su variabilidad anual, consideramos necesario realizar ensayos de germinación con objeto de valorar su capacidad germinativa. De igual manera, creemos necesario el desarrollo de proyectos de investigación con objeto de conocer mejor las características reproductivas de la especie, dado que se han detectado problemas para la regeneración natural (Rossignoli \& Génova 2003), un alto porcentaje de semillas vanas (Arche 2010) y una pérdida muy rápida de la viabilidad de la semilla (Crocker 1938; Gosling 2007). Aunque no se han descrito mecanismos de dormición en ellas (Cicek \& Tilki 2007), cabe esta posibilidad.

Como actividad complementaria a la recolección de semillas, consideramos necesaria la toma de material vegetal para llevar a cabo propagación vegetativa ex situ. Dados los problemas 
de producción y viabilidad de semillas, consideramos que, de igual forma, se debería colectar material de aquellas poblaciones con mayor número de individuos (CNJ, TIE, IRU, CAS, CVJ, STR y BEN) o al menos, de individuos que muestren una tolerancia aparente a la grafiosis. Las plántulas obtenidas mediante germinación o estaquillado se han de mantener hasta obtener plantas suficientes y de tamaño adecuado para llevar a cabo reforzamientos e introducciones. Éstas, pueden ser empleadas para la obtención de clones resistentes a la grafiosis, una de las amenazas más graves que afectan a estas poblaciones. Proyectos similares han sido llevados a cabo con éxito en U. minor (Martín et al. 2015).

\section{Medidas de conservación in situ}

Un factor importante de amenaza es la fragmentación y el aislamiento de las poblaciones. Para paliar sus efectos negativos es necesario incrementar la conectividad poblacional mediante el diseño y ejecución de un plan combinado de translocaciones que contemple el refuerzo de los núcleos y en su caso de reintroducciones y creación de nuevos núcleos que permitan un mayor flujo genético. En definitiva, un plan que contemple la producción de ejemplares suficientes y su introducción en el medio. Iniciativas de este tipo se han realizado tanto en animales como en plantas (Soorae 2013; Draper Munt et al. 2016) con éxito dispar (Godefroid et al. 2011). Para llevar a cabo cualquier tipo de translocación la Comisión para la Supervivencia de las especies de la UICN ha elaborado una guía con recomendaciones útiles para realizarlas (IUCN/SSC 2013).

En España contamos con instrumentos legales para establecer este tipo de medidas ya que están contempladas en la Ley 42/2007 y el Real Decreto 139/2011. Para el desarrollo de este último la Administración elaboró un documento técnico en el que se recogen instrucciones y recomendaciones para llevar a cabo este tipo de acciones (Anónimo 2013). Atendiendo a estas consideraciones, proponemos aumentar el número de efectivos poblacionales y ampliar la actual distribución de la especie mediante reforzamientos e introducciones. Las mismas se deben de realizar seleccionando enclaves idóneos para las plantaciones, atendiendo muy especialmente a los requerimientos hídricos de esta especie y a las características climáticas del Sistema Central. Con objeto de limitar los efectos negativos de la sequía estival, proponemos realizar las plantaciones en zonas próximas a arroyos, barrancos, bosques en galería o surgencias de agua, ambientes donde se localiza de forma natural el olmo de montaña en el Sistema Central (Rossignoli \& Génova 2003). En función de los resultados derivados de las prospecciones, sugerimos que las mismas sean llevadas a cabo en el entorno del LIC Sierra de Ayllón, en el Parque Nacional Sierra de Guadarrama, en el Parque Natural Sierra Norte de Guadarrama, en el 
Parque Regional Sierra de Gredos y en el LIC Valle del Tiétar y Sierra de Gredos, el LIC Sierra de Gata, LIC Las Hurdes, LIC Granadilla y el LIC Sierra de Gredos y Valle del Jerte, zonas donde se ha detectado una importante área potencial para la especie.

El material para llevar a cabo las reintroducciones o reforzamientos debe de tener en cuenta los resultados derivados del estudio genético de estas poblaciones. Tradicionalmente, se ha recomendado el uso de material local cuando los fines de la repoblación son conservadores, tratando de recolectar semilla bastantes individuos que, además, no estén emparentados (Alía Miranda et al. 2009). Para U. minor se ha propuesto la recolección de semillas fomentando la diversidad genética, recolectando semillas de pocos individuos en muchas poblaciones. También se ha sugerido la recolección de semillas de poblaciones en las que no se haya detectado síntomas de grafiosis (Venturas et al. 2013c), algo difícil en nuestro caso, puesto que esta enfermedad fue detectada en casi todas ellas. Ahora bien, surge la duda de qué material emplear en poblaciones pequeñas, o que presentan problemas reproductivos, o cuando lo que se quiere hacer es la reintroducción en áreas donde actualmente no existe ninguna población próxima. En estos casos, a la hora de escoger el material para las reintroducciones o reforzamientos se deben utilizar las regiones de procedencia. Los resultados de nuestros análisis genéticos revelan que las regiones de procedencia para U. glabra en el Sistema Central deben ser modificadas ya que han mostrado que, a efectos prácticos, las poblaciones pertenecientes a las regiones de procedencia Guadarrama-Ayllón y Gredos, son homogéneas. En principio se podría emplear material de cualquiera de ellas en reintroducciones en ambos sectores, con la excepción de CER, debido a que ésta presenta una identidad propia diferenciada del resto de las poblaciones de la región. Las regiones de procedencia Sierra de Gata y Serra de Estrela mostraron ser diferentes entre sí, por lo que a la hora de hacer reintroducciones en estos territorios proponemos que se haga con material colectado en la región de procedencia correspondiente.

Otro punto importante que hay que tener en cuenta a la hora de seleccionar el material de procedencia para llevar a cabo reintroducciones o reforzamientos, es la existencia de posible introgresión con U. minor. En este estudio hemos localizado algunos individuos híbridos putativos en varias poblaciones, fundamentalmente en ROZ y MOM, poblaciones que resultaron ser híbridas en su práctica totalidad. Por ello, consideramos que no se debe recolectar material con tal fin procedente de estas poblaciones. También se debe de evitar recoger material que se sospeche puede provenir de individuos introgresivos, bien por proximidad a individuos de U. minor o bien porque en el sector climático en el que se encuentran, pueda existir un elevado grado de hibridación. Este puede ser el caso de CVH, población que se localizó en el mismo ambiente que 
ROZ y MOM, y que podría tratarse de una población con elevada presencia de híbridos. Sugerimos, además, realizar su análisis en el futuro con objeto de descartar esta posibilidad. En este sentido, consideramos necesaria la regulación de la plantación de individuos de $U$. minor en las proximidades de las poblaciones naturales de U. glabra, con objeto de disminuir el riesgo de introgresión entre ambas; especialmente en aquellas poblaciones localizadas a baja altitud ( $<1000$ m). La distancia máxima detectada de flujo polínico puede ser la distancia mínima excluyente para la plantación de U. minor. Esta distancia puede variar en función del entorno en el que se localizan los núcleos, pudiendo ser 80-100 m bajo cubierta forestal o cercana a los $1200 \mathrm{~m}$ en campo abierto (Nielsen \& Kjær 2010a).

Medidas contra la grafiosis y otras enfermedades y plagas

Por último, estimamos oportuno la realización de un seguimiento periódico sobre la afección por grafiosis y otras enfermedades que puedan incidir en los núcleos; especialmente en aquellas poblaciones con un elevado número de individuos maduros (TIE, IRU y STR) dada su importancia. Para combatir la grafiosis, se ha aconsejado la toma de las siguientes medidas: 1. Saneamiento para destruir los focos de la infección. 2. Compartimentalización mediante heridas que desaceleren la infección, aconsejada solo para árboles singulares. 3. Destrucción de raíces-puente, una de las formas de propagación desde árboles enfermos a otros sanos. 4. Aplicación de insecticidas para controlar la presencia de escolítidos. 5. Uso de feromonas y árboles cebo, para atraer y capturar a los vectores escolítidos. 6. Aplicación de fungicidas para acabar con el hongo 7. Control biológico introduciendo enemigos del hongo o de los escolítidos. 8. Control integrado, combinando varias de las técnicas anteriores (Martínez de Azagra et al. 1988). En nuestro caso, consideramos que al menos se ha de plantear el saneamiento y el control de las poblaciones de escolítidos. 


\section{CONCLUSIONES}

Las principales conclusiones del presente trabajo son:

1. El olmo de montaña en el Sistema Central presenta unos niveles de diversidad genética moderados, a pesar de existir un bajo número de poblaciones, fragmentadas y constituidas, en general, por pocos individuos.

2. El grado de diferenciación genética entre las poblaciones de Ulmus glabra del Sistema Central es elevado, lo cual es indicativo de su nivel de aislamiento y fragmentación. En este sentido, el flujo génico entre poblaciones parece ser inexistente, quedándose prácticamente reducido a nivel intrapoblacional.

3. Se ha detectado introgresión con $U$. minor en al menos cinco de las poblaciones estudiadas, siendo especialmente elevado dicho fenómeno en las poblaciones de Rozas de Puerto Real y Mombeltrán. Como consecuencia de ello, estas poblaciones ven incrementados sus niveles de diversidad (es decir, número efectivo de alelos, heterocigosidad e índice de Shannon). Asimismo, el análisis del ADN de cloroplastos, indica que se trataría de un proceso de introgresión asimétrica de U. minor a U. glabra, en el que U. glabra actuaría como receptor del polen de U. minor.

4. En seis de las poblaciones estudiadas se ha detectado estructura genética espacial, habiéndose estimado en ellas distancias de flujo génico entre 42 y 238 m. La existencia o no de estructura espacial parece deberse a factores como el entorno de la población, la disposición y abundancia de los individuos, el uso del suelo o incluso a fenómenos de introgresión con U. minor.

5. Los marcadores moleculares, tanto a nivel nuclear como de cloroplastos, confirman que en Benfeita existe una población natural de olmo de montaña, por lo que U. glabra también se puede considerar especie autóctona en Portugal.

6. La diversidad detectada en el genoma de cloroplastos, aún sin ser muy elevada, ha sido mayor que la descrita para otras poblaciones de U. glabra, tanto ibéricas como del norte de Europa. Asimismo, la distribución espacial de los clorotipos detectados es consistente 
con la existencia de una estructura filogeográfica significativa en las poblaciones del Sistema Central.

7. Los datos moleculares, junto con los modelos de distribución potencial de la especie publicados hasta la fecha y una distribución de núcleos poblacionales a lo largo de toda la cordillera, parecen indicar que pudiera haber existido una metapoblación distribuida a lo largo de todo el territorio entre finales del Pleistoceno y las primeras fases postglaciares.

8. Se han identificado tres principales grandes áreas genéticamente diferentes para $U$. glabra en el Sistema Central: 1) Sierra de Guadarrama-Ayllón y Sierra de Gredos, 2) Sierra de Gata y 3) Serra da Estrela. Estos tres grupos de poblaciones deberían ser tenidos en cuenta como regiones a la hora de establecer medidas de gestión, tales como la colecta de germoplasma para refuerzos poblacionales, reintroducciones 0 introducciones.

9. En comparación con la distribución del olmo de montaña en el resto de la península, las poblaciones localizadas en el Sistema Central se encuentran bajo condiciones ambientales más exigentes, entre las que destaca el déficit hídrico estival. Lo cual explicaría que la presencia del olmo de montaña en este Sistema se vea limitada a zonas próximas a ríos, barrancos o con elevada humedad.

10. El área potencial de la especie en el Sistema Central es mucho mayor que la que ocupa en la actualidad, ya que recientemente parece haber sufrido una importante disminución corológica y demográfica.

11. Se han detectado cuellos de botella, tanto ancestrales como recientes, probablemente debidos al cambio climático postglacial desde finales del Pleistoceno los primeros y al impacto de las actividades antrópicas los segundos.

12. A escala regional del Sistema Central, la especie se encuentra En Peligro de extinción, EN: B2 a, b (i, ii, iii, v). Sus principales amenazas son: el bajo número de subpoblaciones (la mayoría aisladas) e individuos; el escaso número de ejemplares maduros en la mayor parte de las subpoblaciones, muchas de ellas por debajo del MVP; la existencia de 
introgresión con $U$. minor, la grafiosis, que afecta a una buena parte de las subpoblaciones; y la alteración de su hábitat por parte del hombre.

13. Se proponen las siguientes medidas de conservación: 1) Incluir las poblaciones de $U$. glabra del Sistema Central en el LESPE (España); 2) Incluir U. glabra con la máxima categoría de protección (EN) en los catálogos de especies protegidas de las comunidades autónomas; 3) La creación de Microrreservas; y 4) La elaboración de planes de Recuperación, en los que se incluyan medidas de conservación ex situ (almacenamiento de semillas en Bancos de Germoplasma) e in situ (reforzamientos, reintroducciones, etc). 


\section{BIBLIOGRAFÍA}

Abel Schaad D, Pulido F, López Sáez JA, et al (2014) Persistence of tree relicts in the Spanish Central System through the Holocene. Lazaroa, 35, 107-131.

AEMET, IM (2011) Atlas climático ibérico Agencia Estatal de Meteorología, Ministerio de Medio Ambiente y Rural y Marino, Instituto de Meteorologia de Portugal, Madrid, España.

Agarwal M, Shrivastava N, Padh H (2008) Advances in molecular marker techniques and their applications in plant sciences. Plant Cell Reports, 27, 617-631.

Ai J, Zhu X, Yu L (2015) ISSR analysis of genetic diversity of rare or endangered species Ulmus elongata. Southwest China Journal of Agricultural Sciences, 28, 1251-1256.

Alía Miranda R, García del Barrio, J M, Iglesias S, et al (2009) Regiones de procedencia de especies forestales en España Organismo Autónomo Parques Nacionales, Madrid, España.

Allouche 0, Tsoar A, Kadmon R (2006) Assessing the accuracy of species distribution models: prevalence, kappa and the true skill statistic (TSS). Journal of Applied Ecology, 43, 1223-1232.

Allue JL (1990) Atlas Fitoclimático de España. Taxonomías. Ministerio de Agricultura, Pesca y Alimentación. Instituto Nacional de Investigaciones Agrarias. Departamento de Sistemas Forestales, Madrid, España.

Anagnostakis SL (1977) In vitro culture of immature embryos of American elm (Ulmus americana). HortScience, 1, 44.

Anderson EC, Thompson EA (2002) A model-based method for identifying species hybrids using multilocus genetic data. Genetics, 160, 1217-1229.

Anónimo (2013) Directrices técnicas para el desarrollo de Programas de reintroducción y otras Traslocaciones con fines de conservación de Especies Silvestres en España. Versión aprobada por la Comisión Estatal para el Patrimonio Natural y la Biodiversidad el 24 de julio de 2013 y por la Conferencia Sectorial el 7 de octubre de 2013. Ministerio de Agricultura y Pesca, Alimentación y Medio Ambiente, Madrid, España.

APG (1998) An ordinal classification for the families of flowering plants. Annals of the Missouri Botanical Garden, 85, 531-553.

Araújo MB, Guisan A (2006) Five (or so) challenges for species distribution modelling. Journal of Biogeography, 33, 1677-1688.

Arche J (2010) Censo, corología y estudio dendrométrico de Ulmus glabra Huds. en el Sistema Central español. Estado de Conservación. E.T.S.I. Montes. Universidad Politécnica de Madrid.

Arnold ML, Buckner CM, Robinson JJ (1991) Pollen-mediated introgression and hybrid speciation in Louisiana irises. Proceedings of the National Academy of Sciences, 88, 1398-1402.

Azpilicueta MM, Marchelli P, Gallo LA (2009) The effects of Quaternary glaciations in Patagonia as evidenced by chloroplast DNA phylogeography of Southern beech Nothofagus obliqua. Tree Genetics and Genomes, 5, 561-571.

Bacles CFE, Burczyk J, Lowe AJ, Ennos RA, Williams R (2005) Historical and contemporary mating patterns in remnant populations of the forest tree Fraxinus excelsior L. Evolution, 59, 979-990. 
Bañares Á, Blanca G, Güemes J, Moreno JC, Ortiz S (2004) Atlas y Libro Rojo de la Flora Vascular Amenazada de España Dirección General de Conservación de la Naturaleza, Madrid, España.

Bandelt HJ, Forster P, Rohl A (1999) Median-joining networks for inferring intraspecific phylogenies. Molecular Biology and Evolution, 16, 37-48.

Banks SC, Peakall R (2012) Genetic spatial autocorrelation can readily detect sex-biased dispersal. Molecular Ecology, 21, 2092-2105.

Barluenga M, Austerlitz F, Elzinga JA, Teixeira S, Goudet J, Bernasconi G (2011) Fine-scale spatial genetic structure and gene dispersal in Silene latifolia. Heredity, 106, 13-24.

Bascuñana S (2010) Variabilidad genética de las poblaciones de Ulmus glabra Hudson del Sistema Central. E.T.S.I. Agrónomos. Universidad Politécnica de Madrid.

Bate-Smith EC, Richens RH (1973) Flavonoid chemistry and taxonomy in Ulmus. Biochemical systematics and ecology, 1, 141-146.

Beatty GE, Brown JA, Cassidy EM, et al (2015) Lack of genetic structure and evidence for long-distance dispersal in ash (Fraxinus excelsior) populations under threat from an emergent fungal pathogen: implications for restorative planting. Tree Genetics and Genomes, 11, 53.

Benet H, Guries RP, Boury S, Smalley EB (1995) Identification of RAPD markers linked to a black leaf spot resistance gene in Chinese elm. Theoretical and Applied Genetics, 90, 1068-1073.

Bertolasi B, Leonarduzzi C, Piotti A, et al (2015) A last stand in the Po valley: genetic structure and gene flow patterns in Ulmus minor and U. pumila. Annals of Botany, 115, 683-692.

Biroščíková M, Spišáková K, Lipták Š, Pichler V, Ďurkovič J (2004) Micropropagation of mature wych elm (Ulmus glabra Huds.). Plant Cell Reports, 22, 640-644.

Biscaia de Lacerda AE, Kanashiro M, Sebbenn AM (2008) Effects of Reduced Impact Logging on genetic diversity and spatial genetic structure of a Hymenaea courbaril population in the Brazilian Amazon Forest. Forest Ecology and Management, 255, 1034-1043.

Black-Samuelsson S, Whiteley RE, Junzhan G (2003) Growth and leaf morphology response to drought stress in the riparian broadleaved tree, Ulmus laevis (Pall.). Silvae Genetica, 52, 292-299.

Blanca G, Marrero M (2004) Capítulo I. Metodología. Las categorías de la UICN: algunas reflexiones y comentarios. In: Atlas y Libro Rojo de la Flora Vascular Amenazada de España (eds. Bañares Á, Blanca G, Güemes J, Moreno JC, . Ortiz S) pp. 41-45 Dirección General de Conservación de la Naturaleza, Madrid, España.

Boccacci P, Botta R (2009) Investigating the origin of hazelnut (Corylus avellana L.) cultivars using chloroplast microsatellites. Genetic Resources and Crop Evolution, 56, 851-859.

Botstein D, White RL, Skolnick M, Davis RW (1980) Construction of a genetic linkage map in man using restriction fragment length polymorphisms. American Jorunal of Human Genetics, 32, 314-331.

Brook BW, Navjot SS, Bradshaw CJA (2008) Synergies among extinction drivers under global change. Trends in Ecology and Evolution, 23, 453-460.

Brundu G, Lupi R, Zapelli I, et al (2008) The origin of clonal diversity and structure of Populus alba in Sardinia: evidence from nuclear and plastid microsatellite markers. Annals of Botany, 102, 997-1006. 
Brunet J, Zalapa JE, Pecori F, Santini A (2013) Hybridization and introgression between the exotic Siberian elm, Ulmus pumila, and the native Field elm, U. minor, in Italy. Biological Invasions, 15, 2717-2730.

Brunner I, Brodbeck S, Büchler U, Sperisen C (2001) Molecular identification of fine roots of trees from the Alps: reliable and fast DNA extraction and PCR-RFLP analyses of plastid DNA. Molecular Ecology, 10, 2079-2087.

Buchel A (2000) The species of the genus Ulmus L. In: The elms. Breeding, conservation and disease management. (ed. Dunn CP) pp. 351-358 Kluwer Academic Publishers, Boston, EEUU.

Buiteveld J, Vanden Broeck A, Cox K, Collin E (2016) Human impact on the genetic diversity of Dutch field elm (Ulmus minor) populations in the Netherlands: implications for conservation. Plant Ecology and Evolution, 149, 165-176.

Burban C, Petit RJ, Carcreff E, Jactel H (1999) Rangewide variation of the maritime pine bast scale Matsucoccus feytaudi Duc. (Homoptera: Matsucoccidae) in relation to the genetic structure of its host. Molecular Ecology, 8, 1593-1602.

Burgess KS, Morgan M, Deverno LL, Husband BC (2005) Asymmetrical introgression between two Morus species (M. alba, M. rubra) that differ in abundance. Molecular Ecology, 14, 3471-3483.

Carrión JS, Dupré M, Fumanal MP, Montes R (1995) A palaeoenvironmental study in semi-arid southeastern Spain: the palynological and sedimentological sequence at Perneras Cave (Lorca, Murcia). Journal of Archaeological Science, 22, 355-367.

Carrión JS, Fernández S, González Sampériz P, et al (2010) Expected trends and surprises in the Lateglacial and Holocene vegetation history of the Iberian Peninsula and Balearic Islands. Review of Palaeobotany and Palynology, 162, 458-475.

Carrión JS, Fernández S, González Sampériz P, et al (2012) Paleoflora y paleovegetación de la Península Ibérica e islas Baleares: Plioceno-Cuaternario Ministerio Economía y Competitividad y la Universidad de Murcia, Murcia, España.

Castro I, Pinto-Carnide O, Ortiz JM, Martín JP (2013) Chloroplast genome diversity in Portuguese grapevine (Vitis vinifera L.) cultivars. Molecular Biotechnology, 54, 528-540.

Caudullo G, de Rigo D (2016) Ulmus - elms in Europe: distribution, habitat, usage and threats. In: European Atlas of Forest Tree Species (eds. San-Miguel-Ayanz J, de Rigo D, Caudullo G, Houston Durrant T, Mauri A) pp. 137-139 Publication Office of the European Union, Luxemburgo, Bélgica.

Cavers S, Degen B, Caron H, et al (2005) Optimal sampling strategy for estimation of spatial genetic structure in tree populations. Heredity, 95, 281-289.

Ceballos L, Fernández JR (2001) Árboles y arbustos de la España peninsular Instituto Forestal de Investigaciones y Experiencias, Madrid, España.

Channell R, Lomolino MV (2000a) Dynamic biogeography and conservation of endangered species. Nature, 403, 84-86.

Channell R, Lomolino MV (2000b) Trajectories to extinction: spatial dynamics of the contraction of geographical ranges. Journal of Biogeography, 27, 169-179.

Cheng WC, Chang SY, Hong T, Chu CD (1963) Species novae et nomina emendata arborun utilium Chinae. Scientia Silvae, 8, 1-14. 
Chmielarz P (2010) Cryopreservation of the non-dormant orthodox seeds of Ulmus glabra. Acta Biologica Hungarica, 61, 224-233.

Chung SM, Decker-Walters DS, Staub JE (2003) Genetic relationships within the Cucurbitaceae as assessed by consensus chloroplast simple sequence repeats (ccSSR) marker and sequence analyses. Canadian Journal of Botany, 81, 814-832.

Chung SM, Staub JE (2003) The development and evaluation of consensus chloroplast primer pairs that possess highly variable sequence regions in a diverse array of plant taxa. Theoretical and Applied Genetics, $107,757-767$.

Chung SM, Staub JE, Chen JF (2006) Molecular phylogeny of Cucumis species as revealed by consensus chloroplast SSR marker length and sequence variation. Genome, 49, 219-229.

Cicek E, Tilki F (2007) Seed germination of three Ulmus species from Turkey as influenced by temperature and light. Journal of Environmental Biology, 28, 423.

Clegg MT, Learn GH, Golenberg EM (1991) Molecular evolution of chloroplast DNA. In: Molecular systematics of plants. (eds. Soltis PS, Soltis DE, Doyle JJ) pp. 1-13 Chapman \& Hall, Nueva York, EEUU.

Cogolludo MA, López RA, Agúndez D, Gil L (2000) Caracterización de los olmos ibéricos mediante marcadores moleculares y caracteres morfológicos. In: Los olmos ibéricos. Conservación y mejora frente a la grafiosis. (ed. Gil L) pp. 159-183 Organismo Autónomo de Parques Nacionales, Madrid, España.

Coleman M, Hollingsworth ML, Hollingsworth PM (2000) Application of RAPDs to the critical taxonomy of the English endemic elm Ulmus plotii Druce. Botanical Journal of the Linnean Society, 133, 241-262.

Collada C, Fuentes-Utrilla P, Gil L, Cervera MT (2004) Characterization of microsatellite loci in Ulmus minor Miller and cross-amplification in U. glabra Hudson and U. laevis Pall. Molecular Ecology Notes, 4, 731-732.

Collin E, Bilger I, Eriksson G, Turok J (2000) The conservation of elms genetics resources in Europe. In: The elms: Breeding, conservation, and disease management (ed. Dunn CP) pp. 281-293 Kluwer Academic Publisher, Boston, EEUU.

Conde MF, Pring DR, Levings CS (1979) Maternal inheritance of organelle DNA's in Zea mays-Zea perennis reciprocal crosses. Journal of Heredity, 70, 2-4.

Conde P, Loureiro J, Santos C (2004) Somatic embryogenesis and plant regeneration from leaves of Ulmus minor Mill. Plant Cell Reports, 22, 632-639.

Cornuet JM, Luikart G (1996) Description and power analysis of two tests for detecting recent population bottlenecks from allele frequency data. Genetics, 144, 2001-2014.

Corredoira E, Vieitez AM, Ballester A (2002) Somatic embryogenesis in elm. Annals of Botany, 89, 637-644.

Costa Tenorio M, García Antón M, Morla Juaristi C, Sainz Ollero H (1990) La evolución de los bosques en la Península Ibérica: una interpretación basada en datos paleobiográficos. Ecología, 1, Fuera de Serie, 31 58.

Costa Tenorio M, Morla Juaristi C, Saiz Moreno JC, et al (1997) Los bosques Ibéricos. Una interpretación geobotánica, Costa Tenorio, M.; Morla Juaristi, C.; Saiz Moreno, J.C.; edn. Editorial Planeta, Barcelona, España.

Cox K, Broeck AV, Vander Mijnsbrugge K (2012) Genetic variation in European elms. Genetic characterisation of populations of Ulmus laevis and of the U. minor-U. glabra complex. Rapporten van het Instituut voor Natuuren Bosonderzoek. Instituut voor Natuur. Bruselas, 54, 66. 
Cox K, Broeck AV, Vander Mijnsbrugge K, et al (2014) Interspecific hybridisation and interaction with cultivars affect the genetic variation of Ulmus minor and Ulmus glabra in Flanders. Tree Genetics and Genomes, 10, 813-826.

Crocker W (1938) Life-span of seeds. The Botanical Review, 4, 235.

Crow TR (1990) Rock elm. In: Silvics of North America (eds. Burns RM, Honkala BH) pp. 821-825 Hardwoods, Agricultural Handbooks. USDA, Forest service, Washington DC, EEUU.

Čurn V, Dědouchová M, Kubátová B, Malá J, Máchová P, Cvrčková H (2014) Assessment of genetic variability in autochthonous elm populations using ISSR markers. Journal of Forest Science, 60, 511-518.

de Lucas Al (2009) Flujo genético, demografía y variabilidad genética en una conífera mediterránea emblemática, el pino negral o rodeno. Universidad de Valladolid.

de Lucas Al, González Martínez S, Vendramin GG, Hidalgo E, Heuertz M (2009) Spatial genetic structure in continuous and fragmented populations of Pinus pinaster Aiton.. Molecular Ecology, 18, 4564-4576.

Decker-Walters DS, Wilkins-Ellert M, Chung SM, Staub JE (2004) Cover Article: Discovery and Genetic Assessment of Wild Bottle Gourd [Lagenaria Siceraria (Mol.) Standley; Cucurbitaceae] from Zimbabwe. Economic Botany, 58, 501-508.

Degen B, Roubik DW (2004) Effects of animal pollination on pollen dispersal, selfing, and effective population size of tropical trees: a simulation study 1. Biotropica, 36, 165-179.

Demesure B, Comps B, Petit RJ (1996) Chloroplast DNA phylogeography of the common beech (Fagus sylvatica L.) in Europe. Evolution, 50, 2515-2520.

Demesure B, Sodzi N, Petit RJ (1995) A set of universal primers for amplification of polymorphic non-coding regions of mitochondrial and chloroplast DNA in plants. Molecular Ecology, 4, 129-134.

Di Rienzo A, Peterson AC, Garza JC, Valdés AM, Slatkin M, Freimer NB (1994) Mutational processes of simple-sequence repeat loci in human populations. Proceedings of the National Academy of Sciences of the United States of America, 91, 3166-3170.

Dorado Valiño M, Valdeolmillos Rodríguez A, Ruiz Zapata MB (2001) Actividad humana y dinámica de la vegetación en la Sierra de Ávila (Sistema Central Español) desde el Bronce Medio. Polen, 11, 39-49.

Double MC, Peakall R, Beck NR, Cockburn A (2005) Dispersal, philopatry, and infidelity: dissecting local genetic structure in superb fairy-wrens (Malurus cyaneus). Evolution, 59, 625-635.

Draper Munt D, Marques I, Iriondo JM (2016) Acquiring baseline information for successful plant translocations when there is no time to lose: the case of the neglected Critically Endangered Narcissus cavanillesii (Amaryllidaceae). Plant Ecology, 217, 193-206.

Dumolin-Lapègue S, Demesure B, Petit RJ (1995) Inheritance of chloroplast and mitochondrial genomes in pedunculate oak investigated with an efficient PCR method. Theoretical and Applied Genetics, 91, 12531256.

Dumolin-Lapègue S, Pemonge MH, Petit RJ (1997) An enlarged set of consensus primers for the study of organelle DNA in plants. Molecular Ecology, 6, 393-397.

Dupanloup I, Schneider S, Excoffier L (2002) A simulated annealing approach to define the genetic structure of populations. Molecular Ecology, 11, 2571-2581. 
Dutech C, Sork VL, Irwin AJ, Smouse PE, Davis FW (2005) Gene flow and fine-scale genetic structure in a wind-pollinated tree species, Quercus lobata (Fagaceaee). American Journal of Botany, 92, 252-261.

Echt CS, Deverno LL, Anzidei M, Vendramin GG (1998) Chloroplast microsatellites reveal population genetic diversity in red pine, Pinus resinosa Ait. Molecular Ecology, 7, 307-316.

Edmands S (2007) Between a rock and a hard place: evaluating the relative risks of inbreeding and outbreeding for conservation and management. Molecular Ecology, 16, 463-475.

El Mousadik A, Petit RJ (1996) Chloroplast DNA phylogeography of the argan tree of Morocco. Molecular ecology, 5, 547-555.

Ellstrand NC, Schierenbeck KA (2000) Hybridization as a stimulus for the evolution of invasiveness in plants? Proceedings of the National Academy of Sciences of the United States of America, 97, 7043-7050.

Elowsky CG, Jordon-Thaden IE, Kaul RB (2013) A morphological analysis of a hybrid swarm of native Ulmus rubra and introduced U. pumila (Ulmaceae) in southeastern Nebraska. Phytoneuron., 44, 1-23.

England PR, Cornuet JM, Berthier P, Tallmon DA, Luikart G (2006) Estimating effective population size from linkage disequilibrium: severe bias in small samples. Conservation Genetics, 7, 303-308.

Engle LM (1992) Introduction to concepts of germplasm conservation. In: Germplasm collection, evaluation, documentation, and conservation (eds. Chadna ML, Anzad Hossain, A. M. K., Monowar Hossain SM) pp. 11-17.

Evanno G, Regnaut S, Goudet J (2005) Detecting the number of clusters of individuals using the software STRUCTURE: a simulation study. Molecular Ecology, 14, 2611-2620.

Excoffier L, Laval G, Schneider S (2006) An integrated software package for population genetics data analysis, version 3.01. Evolutionary Bioinformatics Online, 1, 47-50.

Excoffier L, Lischer HEL (2010) Arlequin suite ver 3.5: a new series of programs to perform population genetics analyses under Linux and Windows. Molecular Ecology Resources, 10, 564-567.

Excoffier L, Smouse PE, Quattro JM (1992) Analysis of molecular variance inferred from metric distances among DNA haplotypes: application to human mitochondrial DNA restriction data. Genetics, 131, 479-491.

Falush D, Stephens M, Pritchard JK (2003) Inference of population structure using multilocus genotype data: linked loci and correlated allele frequencies. Genetics, 164, 1567-1587.

Felicísimo ÁM, Muñoz J, Villalba CJ, Mateo RG (2011) Impactos, vulnerabilidad y adaptación al cambio climático de la biodiversidad española. 2. Flora y vegetación., Felicísimo, Á. M.;Muñoz, J.;Villalba, C. J.;Mateo, R. G; edn. Ministerio de Medio Ambiente y Medio Rural y Marino, Madrid, España.

Felsenstein J (1993) PHYLIP (Phylogeny Inference Package) version 3.6.

Fineschi S, Anzidei M, Cafasso D, et al (2002) Molecular markers reveal a strong genetic differentiation between two European relic tree species: Zelkova abelicea (Lam.) Boissier and Z. sicula Di Pasquale, Garfi \& Quézel (Ulmaceae). Conservation Genetics, 3, 145-153.

Fineschi S, Cozzolino S, Migliaccio M, Musacchio A, Innocenti M, Vendramin GG (2005) Sicily represents the Italian reservoir of chloroplast DNA diversity of Quercus ilex L.(Fagaceae). Annals of Forest Science, $62,79-84$.

Fitch WH (1965) Illustrations of the British flora, Fitch, Walter Hood; edn. Reeve \& Co, Londres, Reino Unido. 
Fofana B, Harvengt L, Baudoin JP, Du Jardin P (1997) New primers for the polymerase chain amplification of cpDNA intergenic spacers in Phaseolus phylogeny. Belgian Journal of Botany, 129, 118-122.

Franco Múgica F, García Antón M, Sainz Ollero H (1998) Vegetation dynamics and human impact in the Sierra de Guadarrama, Central System, Spain. The Holocene, 8, 69-82.

Friedman JH (1999) Stochastic gradient boosting. Computational Statistics and Data Analysis, 38, 367-378.

Fukatsu E, Watanabe A, Nakada R, et al (2012) Phylogeographical structure in Zelkova serrata in Japan and phylogeny in the genus Zelkova using the polymorphisms of chloroplast DNA. Conservation Genetics, 13, 1109-1118.

Fuentes-Utrilla P (2008) Estudio de la variabilidad genética del género Ulmus mediante marcadores moleculares. E.T.S.I. Montes. Universidad Politécnica de Madrid.

Fuentes-Utrilla P, López Rodríguez RA, Gil L (2004) The historical relationship of elms and vines. Forest Systems, 13, 7-15.

Fuentes-Utrilla P, Valbuena-Carabaña M, Ennos RA, Gil L (2014a) Population clustering and clonal structure evidence the relict state of Ulmus minor Mill. in the Balearic Islands. Heredity, 113, 21-31.

Fuentes-Utrilla P, Venturas M, Hollingsworth PM, et al (2014b) Extending glacial refugia for a European tree: genetic markers show that Iberian populations of white elm are native relicts and not introductions. Heredity, 112, 105-113.

Ganopoulos I, Aravanopoulos FA, Argiriou A, Kalivas A, Tsaftaris A (2011) Is the genetic diversity of small scattered forest tree populations at the southern limits of their range more prone to stochastic events? A wild cherry case study by microsatellite-based markers. Tree Genetics and Genomes, 7, 1299-1313.

García Nieto ME, Génova M, Morla Juaristi C, Rossignoli A (2000) Los olmos en el paisaje vegetal de la Península Ibérica. In: Los olmos ibéricos. Conservación y mejora frente a la grafiosis (eds. Gil L, Solla A, Iglesias S) pp. 129-158 Ministerio de Medio Ambiente, Madrid, España.

Garza JC, Williamson-Natesan EG (2001) Detection of reduction in population size using data from microsatellite loci. Molecular Ecology, 10, 305-318.

Garzón MB, Blazek R, Neteler M, Sánchez de Dios R, Sainz Ollero H, Furlanello C (2006) Predicting habitat suitability with machine learning models: the potential area of Pinus sylvestris $L$. in the Iberian Peninsula. Ecological Modelling, 197, 383-393.

Garzón MB, Sánchez de Dios R, Sainz Ollero H (2008) Effects of climate change on the distribution of Iberian tree species. Applied Vegetation Science, 11, 169-178.

Garzón MB, Sánchez de Dios R, Sainz Ollero H (2007) Predictive modelling of tree species distributions on the Iberian Peninsula during the Last Glacial Maximum and Mid-Holocene. Ecography, 30, 120-134.

Gehle T, Krabel D (2002) Genetic differentiation of elm (Ulmus minor Mill., Ulmus laevis Pallas) in mixed stands from the Elbe flood-plains. Forest Genetics, 9, 39-46.

Geng QF, He J, Yang J, et al (2016a) Development and characterization of microsatellite markers for Ulmus chenmoui (Ulmaceae), an endangered tree endemic to eastern China. Genetics and Molecular Research, 15, 10.4238/gmr.15027985.

Geng QF, Yang J, He J, et al (2016b) Microsatellite markers for the critically endangered elm species Ulmus gaussenii (Ulmaceae). Genes and Genetic Systems, 91, 11-14. 
Génova M, Rossignoli A (2001) Ulmus glabra, una especie en peligro en el Sistema Central Español. 1, $135-141$

Giannasi DE (1978) Generic relationships in the Ulmaceae based on flavonoid chemistry. Taxon, 27, 331344.

Gil L, Fuentes-Utrilla P, Soto Á, Cervera MT, Collada C (2004) English elm is a 2,000-year-old Roman clone. Nature, 431, 1053-1053.

Gil L, López RA, García Nieto ME (2000) Historia de los olmos en la Península Ibérica. In: Los olmos ibéricos. Conservación y mejora frente a la grafiosis. (eds. Gil L, Solla A, Iglesias S) pp. 83-114 Organismo Autónomo de Parques Naturales, Madrid, España.

Godefroid S, Piazza C, Rossi G, et al (2011) How successful are plant species reintroductions? Biological Conservation, 144, 672-682.

González GL (2006) Los árboles y arbustos de la Península Ibérica e Islas Baleares: especies silvestres y las principales cultivadas Mundi-Prensa Libros, Madrid, España.

Goodall-Copestake WP, Hollingsworth ML, Hollingsworth PM, Jenkins GI, Collin E (2005) Molecular markers and ex situ conservation of the European elms (Ulmus spp.). Biological Conservation, 122, 537-546.

Gosling P (2007) Raising trees and shrubs from seed: practice guide. Forestry Commission, Edinburgo, Reino Unido.

Grivet D, Heinze B, Vendramin GG, Petit RJ (2001) Genome walking with consensus primers: application to the large single copy region of chloroplast DNA. Molecular Ecology Notes, 1, 345-349.

Grivet D, Petit RJ (2003) Chloroplast DNA phylogeography of the hornbeam in Europe: evidence for a bottleneck at the outset of postglacial colonization. Conservation Genetics, 4, 47-56.

Guisan A, Thuiller W (2005) Predicting species distribution: offering more than simple habitat models. Ecology Letters, 8, 993-1009.

Guisan A, Zimmermann NE (2000) Predictive habitat distribution models in ecology. Ecological Modelling, $135,147-186$.

Halbur MM, Sloop CM, Zanis MJ, Emery NC (2014) The population biology of mitigation: impacts of habitat creation on an endangered plant species. Conservation Genetics, 15, 679-695.

Hampe A, Petit RJ (2005) Conserving biodiversity under climate change: the rear edge matters. Ecology Letters, 8, 461-467.

Harvengt L, Meier-Dinkel A, Dumas E, Collin E (2004) Establishment of a cryopreserved gene bank of European elms. Canadian Journal of Forest Research, 34, 43-55.

Heimler D, Mittempergher L, Buzzini P, Boddi V (1990) Quantitative HPTLC separation of flavonoid glycosides in the taxonomy of elm (Ulmus spp.). Chromatographia, 29, 16-20.

Heimler D, Pieroni A, Mittempergher L, Buzzini P (1993) The use of flavonoid glycosides for the identification of elm hybrids. Canadian Journal of Forest Research, 23, 611-616.

Heinze B (1998) PCR-based chloroplast DNA assays for the identification of native Populus nigra and introduced poplar hybrids in Europe. Forest Genetics (Slovak Republic)., 5, 31-38. 
Heuertz M, Fineschi S, Anzidei M, et al (2004) Chloroplast DNA variation and postglacial recolonization of common ash (Fraxinus excelsior L.) in Europe. Molecular Ecology, 13, 3437-3452.

Hewitt GM (1999) Post-glacial re-colonization of European biota. Biological Journal of the Linnean Society, 68, 87-112.

Heybroek HM (2000) Los olmos en la historia y la cultura de centroeuropa. In: Los olmos ibéricos. Conservación y mejora frente a la grafiosis. (eds. Gil L, Solla A, Iglesias S) pp. 23-48 Organismo Autónomo de Parques Nacionales, Madrid, España.

Hickler T, Vohland K, Feehan J, et al (2012) Projecting the future distribution of European potential natural vegetation zones with a generalized, tree species-based dynamic vegetation model. Global Ecology and Biogeography, 21, 50-63.

Hintikka V (1963) Über das Grossklima einiger Pflanzenareale in zwei Klimacoordinatensystemen dargestellt. Annales Botanici Societatis Zoologicæ-Botanicæ Fennicæ "Vanamo", 34, 64.

Hoban SM, McCleary TS, Schlarbaum SE, Anagnostakis SL, Romero-Severson J (2012) Human-impacted landscapes facilitate hybridization between a native and an introduced tree. Evolutionary applications, 5, $720-731$

Hoban SM, McCleary TS, Schlarbaum SE, Romero-Severson J (2014) Spatial genetic structure in 21 populations of butternut, a temperate forest tree (Juglans cinerea L.), is correlated to spatial arrangement, habitat, and land-use history. Forest Ecology and Management, 314, 50-58.

Hoebee SE, Menn C, Rotach P, Finkeldey R, Holderegger R (2006) Spatial genetic structure of Sorbus torminalis: The extent of clonal reproduction in natural stands of a rare tree species with a scattered distribution. Forest Ecology and Management, 226, 1-8.

Hu L, Uchiyama K, Shen H, Ide Y (2010) Multiple-scaled spatial genetic structures of Fraxinus mandshurica over a riparian-mountain landscape in Northeast China. Conservation Genetics, 11, 77-87.

Huntley B, Berry PM, Cramer W, McDonald AP (1995) Special paper: modelling present and potential future ranges of some European higher plants using climate response surfaces. Journal of Biogeography, 22, 9671001.

Iglesias S, Sancho PJ, Alía Miranda R, Monfort NA (2006) Estrategia española para la conservación y el uso sostenible de los recursos genéticos forestales Ministerio de Agricultura, Alimentación y Medio Ambiente, Madrid, España.

IPCC (2013) Climate Change 2013: The Physical Science Basis. Contribution of Working Group I to the Fifth Assessment Report of the Intergovernmental Panel on Climate Change. Cambridge University Press, Cambridge, Reino Unido y New York, Estados Unidos.

IPCC (2007) Climate Change 2007: Impacts, Adaptation and Vulnerability. Southern Europe. Working Group II Contribution to the Intergovernmental Panel on Climate Change. United Nations Environmental Program. Cambridge University Press, Cambridge.

Ipinza Carmona R, Gil L (1987) Algunos aspectos teóricos de la epidemia causada por la grafiosis. Boletín de Sanidad Vegetal-Plagas, 13, 395-408.

IUCN/SSC (2013) Guidelines for reintroductions and other conservation translocations. Version 1.0 IUCN Species Survival Commission, Gland, Suiza. 
Jadwiszczak KA, Banaszek A, Chrzanowska A, Kłosowski S, Sozinov OV (2015) The admixture zone of Betula humilis Schrk. phylogenetic lineages follows the eastern central European suture zone. Plant Ecology and Diversity, 8, 323-329.

Jalut G, Dedoubat JJ, Fontugne M, Otto T (2009) Holocene circum-Mediterranean vegetation changes: climate forcing and human impact. Quaternary International, 200, 4-18.

Jeffers JNR (1999) Leaf variation in the genus Ulmus. Forestry, 72, 183-190.

Jeffers JNR, Richens RH (1970) Multivariate analysis of the English elm population. Silvae Genetica, 19, 31-38.

Johnston TH (1924) The relation of the climate to the spread of prickly pear. Transactions of the Royal Society of South Australia, 48, 269-295.

Jones DA (1972) Blood samples: probability of discrimination. Forensic Science Society, 12, 355-359.

Jones FA, Hamrick JL, Peterson CJ, Squiers ER (2006) Inferring colonization history from analyses of spatial genetic structure within populations of Pinus strobus and Quercus rubra. Molecular Ecology, 15, 851-861.

Kadis C, Thanos CA, Laguna Lumbreras E (2013) Plant micro-reserves: from theory to practice. Experiences gained from EU LIFE and other related projects Utopia Publishing, Athens.

Kamalay JC, Carey DW (1995) Application of RAPD-PCR markers for identification and genetic analysis of American elm (Ulmus americana L.) selections. Journal of Environmental Horticulture, 8, 149-157.

Karp A (1997) Molecular tools in plant genetic resources conservation: a guide to the technologies Bioversity International, Roma, Italia.

Kass GV (1980) An exploratory technique for investigating large quantities of categorical data. Applied statistics, 29, 119-127.

Kim JH, Yang BH, Kang JT, Hong YP (2011) Genetic variation of Japanese elm (Ulmus davidiana var. japonica) employing ISSR markers. In: Proceedings of the 31st Southern Forest Tree Improvement Conference; 14-16 June 2011. Biloxi, Mississippi. http://www.sftic.org, pp. x-y., , 128-133.

Koca D, Smith B, Sykes MT (2006) Modelling regional climate change effects on potential natural ecosystems in Sweden. Climatic Change, 78, 381-406.

Kohavi R (1995) A study of cross-validation and bootstrap for accuracy estimation and model selection. 14, 1137-1145.

Laguna Lumbreras E (2008) La conservación de la Biodiversidad aplicada a pequeña escala: La red valenciana de microrreservas de flora. In: Biodiversidad (ed. Grisolía S) pp. 249-263 Presidència de la Generalitat fundación premios rey Jaime I. Generalitat Valenciana, Valencia, España.

Laguna Lumbreras E, Fos S, Jiménez J, Volis S (2016) Role of micro-reserves in conservation of endemic, rare and endangered plants of the Valencian region (Eastern Spain). Israel Journal of Plant Sciences, 63, $1-13$.

Leliveld JA (1935) Cytological studies in the genus Ulmus. II. The embryo sac and seed development in the common Dutch elm. Recueil des travaux botaniques néerlandais, 32, 543-573.

Lepais O, Petit RJ, Guichoux E, et al (2009) Species relative abundance and direction of introgression in oaks. Molecular ecology, 18, 2228-2242. 
Lesica P, Allendorf FW (1995) When are peripheral populations valuable for conservation? Conservation Biology, 9, 753-760.

Levin DA, Francisco-Ortega J, Jansen RK (1996) Hybridization and the extinction of rare plant species. Conservation Biology, 10, 10-16.

Li F, Wan T, Yi W, Cai P (2008) RAPD Analysis on Genetic Diversity of Ulmus pumila L. var. sabulosa [J]. Journal of Agricultural Science and Technology, 3, 016.

Li G, Quiros CF (2001) Sequence-related amplified polymorphism (SRAP), a new marker system based on a simple PCR reaction: its application to mapping and gene tagging in Brassica. Theoretical and Applied Genetics, 103, 455-461.

Li W, Peng Y, Wei Y, Baum BR, Zheng Y (2009) Relationships among Avena species as revealed by consensus chloroplast simple sequence repeat (ccSSR) markers. Genetic Resources and Crop Evolution, 56, 465-480.

Lind-Riehl J, Gailing O (2015) Fine-scale spatial genetic structure of two red oak species, Quercus rubra and Quercus ellipsoidalis. Plant Systematics and Evolution, 301, 1601-1612.

Liu L, Chen W, Yan D, Li J, Liu L, Wang Y (2017) Molecular phylogeography and paleodistribution modeling of the boreal tree species Ulmus lamellosa (T. Wang et SL Chang) (Ulmaceae) in China. Tree Genetics and Genomes, 13, 11.

Liu L, Chen W, Zheng X, et al (2016) Genetic diversity of Ulmus lamellosa by morphological traits and sequence-related amplified polymorphism (SRAP) markers. Biochemical Systematics and Ecology, 66, 272280.

López Almansa JC, Gil L (2003) Biología reproductiva de los olmos ibéricos. In: Los olmos Ibéricos: conservación y mejora frente a la grafiosis (eds. Gil L, Solla A, Iglesias S) pp. 213-236 Ministerio de Medio Ambiente. Dirección General de la Conservación de la Naturaleza. Organismo Autónomo de Parques Nacionales, Madrid, España.

López Almansa JC, Pannell JR, Gil L (2003) Female sterility in Ulmus minor (Ulmaceae): a hypothesis invoking the cost of sex in a clonal plant. American Journal of Botany, 90, 603-609.

López Almansa JC, Yeung EC, Gil L (2004) Abortive seed development in Ulmus minor (Ulmaceae). Botanical Journal of the Linnean Society, 145, 455-467.

López de Heredia U, Robledo Arnuncio JJ, Fuentes-Utrilla P, Valbuena-Carabaña M, Gil L (2005) Contrasting genetic diversity of tree species in Spain: from Tertiary relicts to domestication. Forest Systems, $14,318-333$.

López Merino L, López Sáez JA, Alba Sánchez F, Pérez Díaz S, Carrión JS (2009) 2000 years of pastoralism and fire shaping high-altitude vegetation of Sierra de Gredos in central Spain. Review of Palaeobotany and Palynology, 158, 42-51.

López Sáez JA, Abel Schaad D, Pérez Díaz S, et al (2014) Vegetation history, climate and human impact in the Spanish Central System over the last 9000 years. Quaternary International, 353, 98-122.

López RA (2003) Paleobotánica de los olmos. In: Los olmos ibéricos. Conservación y mejora frente a la grafiosis (eds. Gil L, Solla A, Iglesias S) pp. 49-68 Organismo Autónomo Parques Nacionales, Madrid, España.

Ludwig S, Robertson A, Rich TC, et al (2013) Breeding systems, hybridization and continuing evolution in Avon Gorge Sorbus. Annals of Botany, 111, 563-575. 
Luikart G, Allendorf FW, Cornuet JM, Sherwin WB (1998) Distortion of allele frequency distributions provides a test for recent population bottlenecks. The Journal of Heredity, 89, 238-247.

Lusini I, Velichkov I, Pollegioni P, et al (2014) Estimating the genetic diversity and spatial structure of Bulgarian Castanea sativa populations by SSRs: implications for conservation. Conservation Genetics, 15, 283-293.

Machon N, Lefranc M, Bilger I, Henry JP (1995) Isoenzymes as an aid to clarify the taxonomy of French elms. Heredity, 74, 39-47.

Machon N, Lefranc M, Bilger I, Mazer SJ, Sarr A (1997) Allozyme variation in Ulmus species from France: analysis of differentiation. Heredity, 78, 12-20.

Magri D, Fineschi S, Bellarosa R, et al (2007) The distribution of Quercus suber chloroplast haplotypes matches the palaeogeographical history of the western Mediterranean. Molecular Ecology, 16, 5259-5266.

Magri D, Vendramin GG, Comps B, et al (2006) A new scenario for the Quaternary history of European beech populations: palaeobotanical evidence and genetic consequences. New Phytologist, 171, 199-221.

Mann HB, Whitney DR (1947) On a test of whether one of two random variables is stochastically larger than the other. The Aannals of Mathematical Statistics, 18, 50-60.

Mantel N (1967) The detection of disease clustering and a generalized regression approach. Cancer Research, 27, 209-220.

Maqueda A (2006) Estudio de la población de olmo de montaña (Ulmus glabra Huds) en el valle de Iruelas. E.T.S.I. Montes. Universidad Politécnica de Madrid.

Marsico TD, Hellmann JJ, Romero-Severson J (2009) Patterns of seed dispersal and pollen flow in Quercus garryana (Fagaceae) following post-glacial climatic changes. Journal of Biogeography, 36, 929-941.

Martín Benito D, García-Vallejo MC, Pajares JA, López D (2005) Triterpenes in elms in Spain. Canadian journal of forest research, 35, 199-205.

Martín Martínez I (2001) Conservación de recursos fitogenéticos Hojas Divulgadoras del Ministerio de Agricultura, Pesca y Alimentación, Madrid, España.

Martín AC, Atienza SG, Barro F (2008) Use of ccSSR markers for the determination of the purity of alloplasmic wheat in different Hordeum cytoplasms. Plant Breeding, 127, 470-475.

Martín JA, Solla A, Venturas M, et al (2015) Seven Ulmus minor clones tolerant to Ophiostoma novo-ulmi registered as forest reproductive material in Spain. iForest-Biogeosciences and Forestry, 8, 172.

Martínez de Azagra A, Ipinza R, Monteagudo FJ, Gil L (1988) Técnicas para el tratamiento preventivo y curativo de la enfermedad de la grafiosis agresiva. Boletín de Sanidad Vegetal-Plagas, 14, 567-593.

Martínez García F (2014) Conservación de la población de olmo de montaña (Ulmus glabra) del arroyo de Santa Ana (término municipal de Rascafría). Parque Nacional Sierra de Guadarrama. Comunidad de Madrid.

Mateo RG, Felicísimo ÁM, Muñoz J (2011) Modelos de distribución de especies: Una revisión sintética. Revista Chilena de Historia Natural, 84, 217-240.

Matias L (2012) Cambios en los límites de distribución de especies arbóreas como consecuencia de las variaciones climáticas. Revista Ecosistemas, 21, 91-96. 
Maxted N (1999) Ecogeography and genetic conservation. In: Genetic resources of Mediterranean pasture and forage legumes (ed. Bennett SJ) pp. 53-66 Kluwer Academic Publisher, Holanda.

Maxted N, Van Slagerem MW, Rihan JR (1995) Ecogeographic surveys. In: Collecting plant genetic diversity. Technical guidelines (eds. Guarino L, Rao VR, Reid R) Centre for Agricultural Bioscience International, Wallingford, Reino Unido.

McCauley DE (1995) The use of chloroplast DNA polymorphism in studies of gene flow in plants. Trends in Ecology and Evolution, 10, 198-202.

Melville R (1939) The application of biometrical methods to the study of elms. 151, 152-159.

Ministerio de Agricultura, Alimentación y Medio Ambiente (2015) El Ministerio de Agricultura, Alimentación y Medio Ambiente participa en la recuperación de olmos y olmedas en paseos, riberas y plazas de los pueblos. Nota de prensa MAGRAMA, 17/03/2015, 1-3.

Mittempergher L, La Porta N (1991) Hybridization studies in the Eurasian species of elm (Ulmus spp.). Silvae Genetica, 40, 237-243.

Mohanty A, Martín JP, Aguinagalde I (2002) Population genetic analysis of European Prunus spinosa (Rosaceae) using chloroplast DNA markers. American Journal of Botany, 89, 1223-1228.

Mohanty A, Martín JP, Gonzalez LM, Aguinagalde I (2003) Association between chloroplast DNA and mitochondrial DNA haplotypes in Prunus spinosa L. (Rosaceae) populations across Europe. Annals of Botany, 92, 749-755.

Møller AP (1999) Elm, Ulmus glabra, leaf asymmetry and Dutch elm disease. Oikos, En Prensa, 109-116.

Møller AP (1995) Leaf-mining insects and fluctuating asymmetry in elm Ulmus glabra leaves. Journal of Animal Ecology, 64, 697-707.

Mondini L, Noorani A, Pagnotta MA (2009) Assessing plant genetic diversity by molecular tools. Diversity, $1,19-35$

Monteiro-Henriques T, Costa JC, Bellu A, Aguiar C (2010) Fraxino Angustifoliae-Ulmetum Glabrae: an original endemic and extremely localized forest from mainland Portugal. Braun-Blanquetia, 46, 323-327.

Mora C, Metzger R, Rollo A, Myer RA (2007) Experimental simulations about the effects of overexploitation and habitat fragmentation on populations facing environmental warming. Proceeding of the Royal Society, 274, 1023-1028.

Moreno JC (2011) Lista Roja de la Flora Vascular Española 2008. Actualización con los datos de la Adenda 2010 al Atlas y Libro Rojo de la Flora Vascular Amenazada Dirección General de Conservación de la Naturaleza. Sociedad Española de Biología de la Conservación de Plantas, Madrid, España.

Moreno JC (2008) Lista Roja 2008 de la flora vascular española. Ministerio de Medio Ambiente y Medio Rural y Marino. Sociedad Española de Biología de la Conservación de Plantas, Madrid, España.

Morgante M, Felice N, Vendramin GG (1998) Analysis of hypervariable chloroplast microsatellites in Pinus halepensis reveals a dramatic genetic bottleneck. In: Molecular tools for screening biodiversity (eds. Karp A, Isaac PG, Ingram DS) pp. 407-412 Chapman and Hall, Londres, Reino Unido.

Mu D, Zwiazek JJ, Li Z, Zhang W (2016) Genotypic variation in salt tolerance of Ulmus pumila plants obtained by shoot micropropagation. Acta Physiologiae Plantarum, 38, 188. 
Mullis KB, Faloona FA, Scharf SJ, Saiki RK, Horn GT, Erlich H (1992) Specific enzymatic amplification of DNA in vitro: the polymerase chain reaction. Biotechnology Series, LI, 263-273.

Myking T, Yakovlev I (2006) Variation in leaf morphology and chloroplast DNA in Ulmus glabra in the northern suture zone: Effects of distinct glacial refugia. Scandinavian Journal of Forest Research, 21, 99107.

Namroud M, Park A, Tremblay F, Bergeron Y (2005) Clonal and spatial genetic structures of aspen (Populus tremuloides Michx.). Molecular ecology, 14, 2969-2980.

Navarro C, Castroviejo S (1993a) Ulmaceae. In: Flora iberica: plantas vasculares de la Peninsula Iberica e Islas Baleares (eds. Castroviejo S, Aedo C, Laínz M, et al) Real Jardín Botánico, Madrid.

Navarro C, Castroviejo S (1993b) Ulmus L. In: Flora ibérica III (eds. Castroviejo S, Aedo C, Laínz M, et al) pp. 244-248 Real Jardín Botánico-CSIC, Madrid.

Naydenov KD, Naydenov MK, Alexandrov A, et al (2016) Ancient split of major genetic lineages of European Black Pine: evidence from chloroplast DNA. Tree Genetics and Genomes, 12, 1-18.

Nei M (1972) Genetic distance between populations. The American Naturalist, 106, 283-292.

Nielsen LR, Kjær ED (2010a) Fine-scale gene flow and genetic structure in a relic Ulmus laevis population at its northern range. Tree Genetics and Genomes, 6, 643-649.

Nielsen LR, Kjær ED (2010b) Gene flow and mating patterns in individuals of Wych elm (Ulmus glabra) in forest and open land after the influence of Dutch elm disease. Conservation Genetics, 11, 257-268.

Ninyerola M, Pons X, Roure JM (2007a) Monthly precipitation mapping of the Iberian Peninsula using spatial interpolation tools implemented in a Geographic Information System. Theoretical and Applied Climatology, 89, 195-209.

Ninyerola M, Pons X, Roure JM (2007b) Objective air temperature mapping for the lberian Peninsula using spatial interpolation and GIS. International Journal of Climatology, 27, 1231-1242.

Nix H, McMahon J, Mackenzie D (1977) Potential areas of production and the future of pigeon pea and other grain legumes in Australia. In: The potential for pigeon pea in Australia. Proceedings of Pigeon Pea (Cajanus cajan (L.) Millsp.) Field Day (eds. Wallis ES, Whiteman PC) pp. 5-12Queensland, Australia.

Osborne PE, Seddon PJ (2012) Selecting suitable habitats for reintroductions: variation, change and the role of species distribution modelling. In: Reintroduction biology: integrating science and management. (eds. Ewen JG, Armstrong DP, Parker KA, Seddon PJ) pp. 73-104 Blackwell Publishing Ltd., Chichester.

Pajares JA (1987) Contribución al conocimiento de los escolítidos vectores de la grafiosis en la península ibérica. E.T.S.I. Montes. Universidad Politécnica de Madrid.

Palmer JD, Jansen RK, Michaels HJ, Chase MW, Manhart JR (1988) Chloroplast DNA variation and plant phylogeny. Annals of the Missouri Botanical Garden, 75, 1180-1206.

Parra-Quijano M, Iriondo JM, Torres E (2012) Review. Applications of ecogeography and geographic information systems in conservation and utilization of plant genetic resources. Spanish Journal of Agricultural Research, 10, 419-429.

Peakall R, Ruibal M, Lindenmayer DB (2003) Spatial autocorrelation analysis offers new insights into gene flow in the Australian bush rat, Rattus fuscipes. Evolution, 57, 1182-1195. 
Peakall R, Smouse PE (2012) GenAIEx 6.5: genetic analysis in Excel. Population genetic software for teaching and research-an update. Bioinformatics, 28, 2537-2539.

Peakall R, Smouse PE (2006) GenAlEx 6: genetic analysis in Excel. Population genetic software for teaching and research. Molecular Ecology Notes, 6, 288-295.

Peakall R, Smouse PE, Huff DR (1995) Evolutionary implications of allozyme and RAPD Variation in diploid populations of dioecious buffalograss Buchloe dactyloides Molecular Ecology, 4, 135-147.

Pearce NJ, Richens RH (1977) Peroxidase isozymes in some elms (Ulmus L.) of eastern England. Watsonia, 11, 382-383.

Pearson K (1900) On the criterion that a given system of deviations from the probable in the case of a correlated system of variables is such that it can be reasonably supposed to have arisen from random sampling. The London, Edinburgh, and Dublin Philosophical Magazine and Journal of Science, 50, 157-175.

Pearson RG, Dawson TP (2003) Predicting the impacts of climate change on the distribution of species: are bioclimate envelope models useful? Global Ecology and Biogeography, 12, 361-371.

Peeters JP, Wilkes HG, Galwey NW (1990) The use of ecogeographical data in the exploitation of variation from gene banks. Theoretical and Applied Genetics, 80, 110-112.

Peterken GF (1993) Woodland conservation and management Springer Science and Business Media, Londres, Reino Unido.

Petit RJ (2012) Haplodiv: A Pascal program for the Analysis of diversity for haploid data.

Petit RJ, El Mousadik A, Pons O (1998) Identifying populations for conservation on the basis of genetic markers. Conservation Biology, 12, 844-855.

Petrokas R, Baliuckas V (2012) Natural Hybridisation within Elms (Ulmus L.) in Lithuania. Baltic Forestry, 18, 237-246.

Piry S, Luikart G, Cornuet JM (1999) BOTTLENECK: A computer program for detecting recent reductions in the effective population size suing allele frequency data. Journal of Heredity, 90, 502-503.

Pons O, Petit RJ (1996) Measuring and testing genetic differentiation with ordered versus unordered alleles. Genetics, 144, 1237-1245.

Pooler MR, Townsend AM (2005) DNA fingerprinting of clones and hybrids of American elm and other elm species with AFLP markers. Journal of Environmental Horticulture, 23, 113-117.

Powell W, Morgante M, McDevitt R, Vendramin GG, Rafalski JA (1995) Polymorphic simple sequence repeat regions in chloroplast genomes: applications to the population genetics of pines. Proceedings of the National Academy of Sciences of the United States of America, 92, 7759-7763.

Pritchard JK, Stephens M, Donnelly P (2000) Inference of population structure using multilocus genotype data. Genetics, 155, 945-959.

Pritchard JK, Wen W, Falush D (2003) Documentation for STRUCTURE software: version 2, Universidad de Chicago, Chicago, EEUU.

Provan J, Powell W, Hollingsworth PM (2001) Chloroplast microsatellites: new tools for studies in plant ecology and evolution. Trends in Ecology and Evolution, 16, 142-147. 
Rajendra KC, Seifert S, Prinz K, Gailing O, Finkeldey R (2014) Subtle human impacts on neutral genetic diversity and spatial patterns of genetic variation in European beech (Fagus sylvatica). Forest Ecology and Management, 319, 138-149.

Rendell S, Ennos RA (2003) Chloroplast DNA diversity of the dioecious European tree Ilex aquifolium L.(English holly). Molecular Ecology, 12, 2681-2688.

Rhymer JM, Simberloff D (1996) Extinction by hybridization and introgression. Annual Review of Ecology and Systematics, 27, 83-109.

Richens RH (1980) On Fine Distinctions in Ulmus L. Taxon, 29, 305-320.

Richens RH (1983) Elm Cambridge University Press, Cambridge, Reino Unido.

Richens RH (1955) Studies on Ulmus. I. The range of variation of east anglian elms. Commonwealth Bureau of Plant Breeding and Genetics, 3, 138-153.

Richens RH, Jeffers JNR (1986) Numerical taxonomy and ethnobotany of the elms of northern Spain. Anales del Jardín Botánico de Madrid, 42, 325-341.

Richens RH, Jeffers JNR (1978) Multivariate analysis of the elms of northern France. II. Pooled analysis of the elm populations of northern France and England. Silvae Genetica, 27, 85-95.

Richens RH, Pearce NJ (1984) Isoperoxidase variation in Ulmus L. Forestry, 57, 75-84.

Rieseberg LH, Kim S, Randell RA, et al (2007) Hybridization and the colonization of novel habitats by annual sunflowers. Genetica, 129, 149-165.

Rohlf FJ (2008) NTSYSpc: Numerical Taxonomy System. Exeter Publishing, Ltd, 2.20.

Rossignoli A (1999) Corología de Ulmus glabra Huds. en España y estado actual de las poblaciones del Sistema Central. ETSI Montes. Universidad Politécnica de Madrid.

Rossignoli A, Génova M (2003) Corología y hábitat de Ulmus glabra Huds, en la Península lbérica. Ecología, $17,99-121$.

Rowe JW, Seikel MK, Roy DN, Jorgensen E (1972) Chemotaxonomy of Ulmus. Phytochemistry, 11, 25132517.

Royal Botanic Gardens (2002) Electronic Plant Information Centre. 2017.

Ruiz de la Torre (2006) Flora mayor Organismo Autónomo de Parques Nacionales. Dirección General para la Biodiversidad, Madrid, España.

Ruiz-Labourdette D, Martínez García F, Martín López B, Montes C, Pineda F (2011) Equilibrium of vegetation and climate at the European rear edge. A reference for climate change planning in mountainous Mediterranean regions. International Journal of Biometeorology, 55, 285-301.

Ruiz-Labourdette D, Schmitz MF, Pineda F (2013) Changes in tree species composition in Mediterranean mountains under climate change: indicators for conservation planning. Ecological Indicators, 24, 310-323.

Sánchez del Álamo C, Sardinero S, Bouso V, Hernández Palacios G, Pérez Badia R, Fernández-González F (2011) Los abedulares del parque nacional de cabañeros: sistemática, demografía, biología reproductiva y estrategias de conservación. In: Proyectos de investigación en parques nacionales: 2006-2009 (eds. 
Ramírez L, Asensio B) pp. 275-309 Organismo Autónomo Parques Nacionales, Serie investigación en la Red, Madrid, España.

Sarasan V, Cripps R, Ramsay MM, et al (2006) Conservation in vitro of threatened plants-progress in the past decade. In Vitro Cellular and Developmental Biology-Plant, 42, 206-214.

Schlaepfer DR, Lauenroth WK, Bradford JB (2012) Effects of ecohydrological variables on current and future ranges, local suitability patterns, and model accuracy in big sagebrush. Ecography, 35, 374-384.

Schneider C (1910) Beiträge zur Kenntnis der gattung Ulmus I: Gliederung der gattung und Übersicht der arten. Österreichische Botanische Zeitschrift, 66, 21-34.

Scialabba A, Melati MR, Raimondo FM (1997) Taxonomic studies on the Sicilian elms: leaf structure of their species and hybrids. Bocconea, 5, 493-504.

Segraves KA, Thompson JN, Soltis PS, Soltis DE (1999) Multiple origins of polyploidy and the geographic structure of Heuchera grossulariifolia. Molecular Ecology, 8, 253-262.

Sengonca Ç, Leisse N (1984) Bedeutung der Borkenkäfer (Col., Scolytidae) bei der Verbreitung des Erregers der Holländischen Ulmenkrankheit im Raum Euskirchen. Journal of Applied Entomology, 98, 413423.

Sexton JP, Hangartner SB, Hoffmann AA (2014) Genetic isolation by environment or distance: which pattern of gene flow is most common? Evolution, 68, 1-15.

Sherman SL, Giannasi DE (1988) Foliar flavonoids of Ulmus in eastern North America. Biochemical Systematics and Ecology, 16, 51-56.

Shi W, Kerdelhué C, Ye H (2010) Population genetic structure of the oriental fruit fly, Bactrocera dorsalis (Hendel) (Diptera: Tephritidae) from Yunnan province (China) and nearby sites across the border. Genetica, $138,377-385$.

Shinozaki K, Ohme M, Tanaka M, et al (1986) The complete nucleotide sequence of the tobacco chloroplast genome: its gene organization and expression. The EMBO journal, 5, 2043-2049.

Shukla MR, Jones AMP, Sullivan JA, Liu C, Gosling S, Saxena PK (2012) In vitro conservation of American elm (Ulmus americana): potential role of auxin metabolism in sustained plant proliferation. Canadian Journal of Forest Research, 42, 686-697.

Slatkin M (1985) Rare alleles as indicators of gene flow. Evolution, 39, 53-65.

Smouse PE, Long JC, Sokal RR (1986) Multiple regression and correlation extensions of the Mantel test of matrix correspondence. Systematic Zoology, 35, 627-632.

Smouse PE, Peakall R (1999) Spatial autocorrelation analysis of individual multiallele and multilocus genetic structure. Heredity, 82, 561-573.

Smouse PE, Peakall R, Gonzales E (2008) A heterogeneity test for fine-scale genetic structure. Molecular ecology, 17, 3389-3400.

Solla A, Burón M, Iglesias S, Gil L (2000) Spanish program for the conservation and breeding of elms against DED. In: The Elms: Breeding, Conservation and Disease Management (ed. Dunn CP) pp. 295-303 Kluwer Academic Publications, Boston, EEUU.

Soorae PS (2013) Global re-introduction perspectives: 2013: further case-studies from around the globe IUCN/SSC Re-introduction Specialist Group (RSG), Gland, Suiza. 
Spellerberg IF (1992) The importance and value of biodiversity. In: Evaluation and Assessment for Conservationpp. 1-35 Springer, Holanda.

Stafford PJ (1995) Marsileaceae: the Northwest European Pollen Flora, 52. Review of palaeobotany and palynology, 88, 3-24.

Svenning JC, Normand S, Kageyama M (2008) Glacial refugia of temperate trees in Europe: insights from species distribution modelling. Journal of Ecology, 96, 1117-1127.

Sykes MT, Prentice IC, Cramer W (1996) A bioclimatic model for the potential distributions of north European tree species under present and future climates. Journal of Biogeography, 23, 203-233.

Taberlet P, Fumagalli L, Wust-Saucy AG, Cosson JF (1998) Comparative phylogeography and postglacial colonization routes in Europe. Molecular Ecology, 7, 453-464.

Taberlet P, Gielly L, Pautou G, Bouvet J (1991) Universal primers for amplification of three non-coding regions of chloroplast DNA. Plant Molecular Biology, 17, 1105-1109.

Tallmon DA, Koyuk A, Luikart G, Beaumont MA (2008) Computer Programs: ONeSAMP: a program to estimate effective population size using approximate Bayesian computation. Molecular Ecology Resources, 8, 299-301.

Tanksley SD (1983) Molecular markers in plant breeding. Plant Molecular Biology Reporter, 1, 3-8.

Tero N, Aspi J, Siikamäki $P$, Jäkäläniemi $A$, Tuomi J (2003) Genetic structure and gene flow in a metapopulation of an endangered plant species, Silene tatarica. Molecular Ecology, 12, 2073-2085.

Thakur S, Thakur IK, Singh NB, Sharma JP, Sankanur M (2014) Estimation of Genetic Diversity in Progenies of Selected Genotypes of Ulmus villosa Brandis Using Rapd Markers. Indian Forester, 140, 1221-1229.

Toro MA, Caballero A (2005) Characterization and conservation of genetic diversity in subdivided populations. Philosophical transactions of the Royal Society of London. Series B, Biological sciences, $\mathbf{3 6 0}$, 1367-1378.

Torres-Díaz C, Ruiz E, González F, Fuentes G, Cavieres LA (2007) Genetic diversity in Nothofagus alessandrii (Fagaceae), an endangered endemic tree species of the coastal maulino forest of Central Chile. Annals of Botany, 100, 75-82.

Townsend AM (1975) Crossability patterns and morphological variation among elm species and hybrids. Silvae Genetica, 24, 18-23.

Turelli M, Orr HA (2000) Dominance, epistasis and the genetics of postzygotic isolation. Genetics, 154, 1663-1679.

Tutin TG, Walters SM (1993) Ulmaceae. In: Flora Europaea (eds. Tutin TG, Heywood VH, Burges NA, Valentine DH, Walters SM, Webb DA) pp. 76-77 Cambridge University Press, Cambridge, Reino Unido.

UICN (2016) Red List version 2016-2. Section Trends in the status of biodiversity on the IUCN Red List website. 2016.

UICN (2012a) Categorías y Criterios de la Lista Roja de la UICN: Versión 3.1, $2^{\text {a }}$ edn. UICN, Gland, Suiza y Cambridge, Reino Unido.

UICN (2012b) Directrices para el uso de los Criterios de la Lista Roja de la UICN a nivel regional y nacional: Versión 4.0. UICN, Gland, Suiza y Cambridge, Reino Unido. 
Vähä JP, Primmer CR (2006) Efficiency of model-based Bayesian methods for detecting hybrid individuals under different hybridization scenarios and with different numbers of loci. Molecular Ecology, 15, 63-72.

Vakkari P, Rusanen M, Kärkkäinen K (2009) High genetic differentiation in marginal populations of European white elm (Ulmus laevis). Silva Fennica, 43, 185-196.

Valero M, Engel C, Billot C, Kloareg B, Destombe C (2001) Concept and issues of population genetics in seaweeds. Cahiers de Biologie Marine, 42, 53-62.

Van der Knaap, W. O., Van Leeuwen, J. F. N. (1995) Holocene vegetation succession and degradation as responses to climatic change and human activity in the Serra de Estrela, Portugal. Review of Palaeobotany and Palynology, 89, 153-211.

Van Rossum F, Triest L (2006) Fine-scale genetic structure of the common Primula elatior (Primulaceae) at an early stage of population fragmentation. American Journal of Botany, 93, 1281-1288.

Van Rossum F, Bonnin I, Fenart S, Pauwels M, Petit D, Saumitou-Laprade P (2004) Spatial genetic structure within a metallicolous population of Arabidopsis halleri, a clonal, self-incompatible and heavy-metal-tolerant species. Molecular Ecology, 13, 2959-2967.

Vekemans X, Hardy OJ (2004) New insights from fine-scale spatial genetic structure analyses in plant populations. Molecular ecology, 13, 921-935.

Vendramin GG, Degen B, Petit RJ, Anzidei M, Madaghiele A, Ziegenhagen B (1999) High level of variation at Abies alba chloroplast microsatellite loci in Europe. Molecular Ecology, 8, 1117-1126.

Venturas M (2013) Estudio de la ecología de Ulmus laevis Pallas en la Península Ibérica. E.T.S.I. Montes. Universidad Politécnica de Madrid.

Venturas M, Collada C, Gil L (2013a) Guía técnica para la conservación genética y utilización para la conservación genética y utilización del negrillo (Ulmus laevis) en España, Madrid, España.

Venturas M, Fuentes-Utrilla P, Ennos RA, Collada C, Gil L (2013b) Human-induced changes on fine-scale genetic structure in Ulmus laevis Pallas wetland forests at its SW distribution limit. Plant Ecology, 214, 317327.

Venturas M, Iglesias S, Nicolás Peragón JL, Martín García JA, Gil L (2013c) Ulmus minor Mill. In: Producción y manejo de semillas y plantas forestales. Tomo II (eds. Pemán J, Navarro RM, Nicolás Peragón JL, Prada MA, Serrada R) pp. 575-597 Organismo Autónomo de Parques Nacionales. Ministerio de Agricultura, Alimentación y Medio Ambiente, Madrid, España.

Viera AJ, Garrett JM (2005) Understanding interobserver agreement: the kappa statistic. Family medicine, 37, 360-363.

Vos P, Hogers R, Bleeker M, et al (1995) AFLP: a new technique for DNA fingerprinting. Nucleic Acids Research, 23, 4407-4414.

Vucetich JA, Waite TA (2003) Spatial patterns of demography and genetic processes across the species' range: null hypotheses for landscape conservation genetics. Conservation Genetics, 4, 639-645.

VV. AA. (2017) Resolución de 6 de marzo de 2017, de la Dirección General de Calidad y Evaluación Ambiental y Medio Natural, por la que se publica el Acuerdo del Consejo de Ministros de 24 de febrero de 2017, por el que se aprueban los criterios orientadores para la inclusión de taxones y poblaciones en el Catálogo Español de Especies Amenazadas. BOE, 65, 19743-19756. 
V. AA. (2015) Ley 33/2015, de 21 de septiembre, por la que se modifica la Ley 42/2007, de 13 de diciembre, del Patrimonio Natural y de la Biodiversidad. BOE, 227, 83588-83632.

VV. AA. (2011) Real Decreto 139/2011, de 4 de febrero, para el desarrollo del Listado de Especies Silvestres en Régimen de Protección Especial y del Catálogo Español de Especies Amenazadas. BOE, 46, 2091220951.

VV. AA. (2007a) Decreto 63/2007, de 14 de junio, por el que se crean el Catálogo de Flora Protegida de Castilla y León y la figura de protección denominada Microrreserva de Flora. BOCYL, 119, 13197-13204.

VV. AA. (2007b) Ley 42/2007, de 13 de diciembre, del Patrimonio Natural y de la Biodiversidad. BOE, 299, 51275-51327.

VV. AA. (2004) Decreto 76/2004, de 18 de mayo, por el que se declaran 18 nuevos árboles singulares de Extremadura. BOE, 59, 6563-6565.

VV. AA. (2003) Real Decreto 289/2003, de 7 de marzo, sobre comercialización de los materiales forestales de reproducción. BOE, 58, 9262-9299.

VV. AA. (2001) Decreto 37/2001, de 6 de marzo, por el que se regula el Catálogo Regional de Especies Amenazadas de Extremadura. BOE, 30, 2343-2364.

VV. AA. (2000) Lista roja de flora vascular española (valoración según categorías UICN). Conservación Vegetal, 6 (extra), 1-44.

VV. AA. (1999) Ley 9/1999, de 26 de mayo, de Conservación de la Naturaleza de Castilla-La Mancha. BOE, $179,28086-28110$.

V. AA. (1998a) Decreto 33/1998, de 05-05-1998, por el que crea el Catálogo Regional de Especies Amenazadas de Castilla-La Mancha. BOCLM, 22, 3391-3398.

VV. AA. (1998b) Ley 8/1998, de 26 de junio, de Conservación de la Naturaleza y de Espacios Naturales de Extremadura. BOE, 200, 28606-28628.

VV. AA. (1998c) Orden de 16 de noviembre de 1998, de la Consellería de Medio Ambiente, por la que se declaran 14 microrreservas vegetales en la provincia de Castellón. DOCV, 3385, 19159-19173.

VV. AA. (1994) Decreto 218/1994, de 17 de octubre, del Gobierno Valenciano, por el que se crea la figura de protección de especies silvestres denominada microrreserva vegetal. DOCV, 2379, 12948-12951.

VV. AA. (1992) Decreto por el que se aprueba el catálogo regional de especies Amenazadas de fauna y flora silvestres y se crea la categoría de Árboles singulares de la Comunidad de Madrid. BOCM, 85, 5-11.

Wang FY, Ge XJ, Gong X, Hu CM, Hao G (2008) Strong genetic differentiation of Primula sikkimensis in the East Himalaya-Hengduan Mountains. Biochemical genetics, 46, 75-87.

Wang J, Li Z, Guo Q, Ren G, Wu DY (2011) Genetic variation within and between populations of a desert poplar (Populus euphratica) revealed by SSR markers. Annals of Forest Science, 68, 1143-1149.

Wang Z, Weber JL, Zhong G, Tanksley SD (1994) Survey of plant short tandem DNA repeats. TAG Theoretical and Applied Genetics, 88, 1-6.

Waples RS, Do C (2010) Linkage disequilibrium estimates of contemporary Ne using highly variable genetic markers: a largely untapped resource for applied conservation and evolution. Evolutionary applications, 3, 244-262. 
Waples RS, Do C (2008) LDNe: a program for estimating effective population size from data on linkage disequilibrium. Molecular Ecology Resources, 8, 753-756.

Way MJ (2003) Collecting seed from non-domesticated plants for long-term conservation. In: Seed conservation: turning science into practice (eds. Smith RD, Dickie JB, Linington SH, Pritchard HW, Probert RJ) pp. 165-201 Royal Botanic Gardens, Kew, Reino Unido.

Webber JF (2004) Experimental studies on factors influencing the transmission of Dutch elm disease. Forest System, 13, 197-205.

Wei X, Jiang M (2012) Limited genetic impacts of habitat fragmentation in an "old rare" relict tree, Euptelea pleiospermum (Eupteleaceae). Plant Ecology, 213, 909-917.

Weising K, Gardner RC (1999) A set of conserved PCR primers for the analysis of simple sequence repeat polymorphisms in chloroplast genomes of dicotyledonous angiosperms. Genome, 42, 9-19.

Weising K, Nybom H, Wolff K, Kahl G (2005) DNA fingerprinting in plants: principles, methods, and applications, $2^{\mathrm{a}}$ edn. Taylor and FrancisGroup, Nuea York, EEUU.

Wesche K, Walther D, Von Wehrden H, Hensen I (2011) Trees in the desert: Reproduction and genetic structure of fragmented UImus pumila forests in Mongolian drylands. Flora, 206, 91-99.

Whiteley RE (2004) Quantitative and molecular genetic variation in Ulmus laevis Pall. Acta Universitatis agriculturae Sueciae.

Whiteley RE, Black-Samuelsson S, Clapham D (2003) Development of microsatellite markers for the European white elm (Ulmus laevis Pall.) and cross-species amplification within the genus Ulmus. Molecular Ecology Notes, 3, 598-600.

Wiegrefe SJ, Sytsma KJ, Guries RP (1994) Phylogeny of elms (Ulmus, Ulmaceae): molecular evidence for a sectional classification. Systematic Botany, 19, 590-612.

Wilcoxon F (1945) Individual comparisons by ranking methods. Biometrics bulletin, 1, 80-83.

Williams JG, Kubelik AR, Livak KJ, Rafalski JA, Tingey SV (1990) DNA polymorphisms amplified by arbitrary primers are useful as genetic markers. Nucleic Acids Research, 18, 6531-6535.

Williamson-Natesan EG (2005) Comparison of methods for detecting bottlenecks from microsatellite loci. Conservation Genetics, 6, 551-562.

Wiser SK, Peet RK, White PS (1998) Prediction of rare-plant occurrence: a southern appalachian example. Ecological Applications, 8, 909-920.

Wolfe KH, Li WH, Sharp PM (1987) Rates of nucleotide substitution vary greatly among plant mitochondrial, chloroplast, and nuclear DNAs. Proceedings of the National Academy of Sciences of the United States of America, 84, 9054-9058.

Worthington M, Soleri D, Aragón-Cuevas F, Gepts P (2012) Genetic composition and spatial distribution of farmer-managed Phaseolus bean plantings: an example from a village in Oaxaca, Mexico. Crop Science, 52, 1721-1735.

Wright S (1943) Isolation by Distance. Genetics, 28, 114-138.

Young AG, Merriam HG (1994) Effects of forest fragmentation on the spatial genetic structure of Acer saccharum Marsh. (sugar maple) populations. Heredity, 72, 201-207. 
Zalapa JE, Brunet J, Guries RP (2010) The extent of hybridization and its impact on the genetic diversity and population structure of an invasive tree, Ulmus pumila (Ulmaceae). Evolutionary applications, 3, 157168.

Zalapa JE, Brunet J, Guries RP (2009) Patterns of hybridization and introgression between invasive Ulmus pumila (Ulmaceae) and native U. rubra. American Journal of Botany, 96, 1116-1128.

Zalapa JE, Brunet J, Guries RP (2008a) Genetic diversity and relationships among Dutch elm disease tolerant Ulmus pumila L. accessions from China. Genome, 51, 492-500.

Zalapa JE, Brunet J, Guries RP (2008b) Isolation and characterization of microsatellite markers for red elm (Ulmus rubra Muhl.) and cross-species amplification with Siberian elm (UImus pumila L.). Molecular Ecology Resources, 8, 109-112.

Zavada MS, Kim M (1996) Phylogenetic analysis of Ulmaceae. Plant Systematics and Evolution, 200, $13-$ 20.

Zebec M, Idžojtić M, Šatović Z, Poljak I, Liber Z (2016) Alive and kicking, or, living on borrowed time?Microsatellite diversity in natural populations of the endangered Ulmus minor Mill. sensu latissimo from Croatia. Acta Botanica Croatica, 75, 53-59.

Zietkiewicz E, Rafalski A, Labuda D (1994) Genome fingerprinting by simple sequence repeat (SSR)anchored polymerase chain reaction amplification. Genomics, 20, 176-183.

Zuo L, Shang A, Zhang S, et al (2017) The first complete chloroplast genome sequences of Ulmus species by de novo sequencing: Genome comparative and taxonomic position analysis. PloS one, 12, e0171264. 


ANEXOS 


\section{Anexol}

\section{RESULTADOS DEL GENOTIPADO CON LOCI DE MICROSATÉLITES NUCLEARES}

Tamaño de los alélos (en pares de bases) asignados para cada uno de los 11 loci SSR (UIm2, UIm3, Ulm8, Ulmi1-21, Ulmi1-98, Ulmi1-165, UR123, UR138, UR153, UR173a y UR175) analizados en los 427 individuos de las 22 poblaciones de U. glabra y en los 15 individuos de U. minor procedentes de tres localizaciones del Sistema Central. Los alelos exclusivos de una población de U. glabra se indican en negrita y de ellos, los compartidos con U. minor también se muestran en cursiva.

COD: Códigos de individuos, constituidos por el código de la población (ver Tabla 1.1) más el número asignado a cada individuo dentro de la misma; G: Genotipos o combinaciones alélicas diferentes, obtenidas considerando el conjunto de todos los loci analizados (1 a 366); LH: Número de loci heterocigotos para cada individuo; AC: Número de alelos compartidos por cada individuo de U. glabra con algún individuo de U. minor y viceversa.

a Loci de microsatélites no analizados en U. minor, ya que mostraron patrones multibanda (PM). 


\begin{tabular}{|c|c|c|c|c|c|c|c|c|c|c|c|c|c|c|c|c|c|c|c|c|c|c|c|c|c|c|}
\hline No & CÓD & & n2 & & n3 & Ulr & & Ulm & 1-21 & Ulm & & Ulmi & -165 & UR & 123 & & & & 153 & & $3 a^{a}$ & UR & 175 & G & LH & $A C$ \\
\hline 1 & CNT01 & 105 & 105 & 182 & 182 & 195 & 195 & 216 & 216 & 156 & 160 & 165 & 185 & 252 & 252 & 242 & 242 & 191 & 202 & 154 & 156 & 218 & 220 & 1 & 5 & 4 \\
\hline 2 & CNJ01 & 105 & 105 & 182 & 182 & 195 & 195 & 200 & 216 & 154 & 156 & 157 & 197 & 252 & 252 & 232 & 242 & 177 & 202 & 154 & 170 & 218 & 218 & 2 & 6 & 5 \\
\hline 3 & CNJ02 & 105 & 105 & 182 & 182 & 195 & 195 & 200 & 216 & 154 & 154 & 157 & 197 & 252 & 252 & 232 & 242 & 177 & 177 & 154 & 170 & 218 & 218 & 3 & 4 & 5 \\
\hline 4 & CNJ03 & 105 & 105 & 182 & 182 & 195 & 195 & 210 & 216 & 154 & 154 & 157 & 157 & 252 & 254 & 232 & 242 & 177 & 202 & 154 & 170 & 220 & 220 & 4 & 5 & 6 \\
\hline 5 & CNJ04 & 105 & 105 & 182 & 182 & 195 & 195 & 200 & 200 & 154 & 156 & 157 & 157 & 252 & 254 & 232 & 242 & 177 & 177 & 170 & 170 & 218 & 218 & 5 & 3 & 6 \\
\hline 6 & CNJ05 & 105 & 105 & 182 & 182 & 195 & 195 & 200 & 216 & 154 & 154 & 157 & 197 & 252 & 252 & 242 & 242 & 177 & 177 & 170 & 170 & 218 & 220 & 6 & 3 & 5 \\
\hline 7 & CNJ06 & 105 & 105 & 182 & 182 & 195 & 195 & 200 & 200 & 156 & 156 & 177 & 197 & 252 & 254 & 232 & 242 & 177 & 177 & 154 & 170 & 218 & 220 & 7 & 5 & 4 \\
\hline 8 & CNJ07 & 105 & 105 & 182 & 182 & 195 & 195 & 200 & 216 & 154 & 156 & 157 & 197 & 252 & 254 & 242 & 242 & 188 & 191 & 170 & 170 & 218 & 220 & 8 & 6 & 5 \\
\hline 9 & CNJ08 & 105 & 105 & 182 & 182 & 195 & 195 & 210 & 216 & 154 & 154 & 157 & 199 & 252 & 254 & 242 & 242 & 191 & 202 & 170 & 170 & 220 & 220 & 9 & 4 & 5 \\
\hline 10 & CNJ09 & 105 & 105 & 182 & 182 & 195 & 195 & 200 & 200 & 156 & 156 & 189 & 201 & 252 & 252 & 232 & 242 & 177 & 177 & 154 & 170 & 218 & 218 & 10 & 3 & 4 \\
\hline 11 & CNJ10 & 105 & 105 & 182 & 182 & 195 & 195 & 200 & 220 & 156 & 158 & 197 & 197 & 252 & 252 & 242 & 242 & 177 & 177 & 154 & 170 & 218 & 220 & 11 & 4 & 4 \\
\hline 12 & CNJ11 & 105 & 105 & 182 & 182 & 195 & 195 & 216 & 216 & 154 & 156 & 157 & 201 & 252 & 252 & 242 & 242 & 177 & 188 & 154 & 154 & 218 & 220 & 12 & 4 & 5 \\
\hline 13 & CNJ12 & 105 & 105 & 182 & 182 & 195 & 195 & 200 & 200 & 156 & 156 & 157 & 201 & 252 & 254 & 242 & 242 & 177 & 202 & 154 & 170 & 218 & 220 & 13 & 5 & 5 \\
\hline 14 & CNJ13 & 105 & 105 & 182 & 182 & 195 & 195 & 200 & 216 & 154 & 156 & 197 & 201 & 252 & 254 & 232 & 242 & 177 & 188 & 154 & 170 & 218 & 218 & 14 & 7 & 4 \\
\hline 15 & CNJ14 & 105 & 105 & 182 & 182 & 195 & 195 & 200 & 200 & 156 & 15 & 197 & 201 & 252 & 252 & 232 & 242 & 177 & 202 & 154 & 154 & 218 & 218 & & 3 & 4 \\
\hline 16 & CNJ15 & 105 & 105 & 182 & 182 & 195 & 195 & 200 & 200 & 154 & 158 & 157 & 157 & 252 & 252 & 232 & 242 & 188 & 202 & 154 & 170 & 218 & 220 & 16 & 5 & 6 \\
\hline 17 & CNJ16 & 105 & 105 & 182 & 182 & 195 & 195 & 200 & 200 & 154 & 156 & 157 & 197 & 252 & 254 & 232 & 242 & 177 & 202 & 154 & 170 & 218 & 218 & 17 & 6 & 5 \\
\hline 18 & CNJ17 & 105 & 105 & 182 & 182 & 195 & 195 & 200 & 200 & 156 & 156 & 157 & 157 & 252 & 254 & 232 & 242 & 177 & 177 & 170 & 170 & 218 & 218 & 18 & 2 & 6 \\
\hline 19 & CNJ18 & 105 & 105 & 182 & 182 & 195 & 195 & 200 & 216 & 154 & 154 & 157 & 201 & 252 & 252 & 242 & 242 & 177 & 177 & 154 & 170 & 218 & 218 & 19 & 3 & 5 \\
\hline 20 & CNJ19 & 105 & 105 & 182 & 182 & 195 & 195 & 200 & 216 & 154 & 154 & 157 & 201 & 252 & 254 & 242 & 242 & 177 & 202 & 154 & 170 & 218 & 218 & 20 & 5 & 5 \\
\hline 21 & CNJ20 & 105 & 105 & 182 & 182 & 195 & 195 & 200 & 220 & 154 & 158 & 197 & 197 & 252 & 252 & 232 & 242 & 177 & 188 & 154 & 170 & 218 & 220 & 21 & 6 & 4 \\
\hline 22 & CNJ21 & 105 & 105 & 182 & 182 & 195 & 195 & 200 & 220 & 156 & 158 & 157 & 157 & 252 & 252 & 242 & 242 & 177 & 188 & 154 & 154 & 218 & 220 & 22 & 4 & 6 \\
\hline 23 & CNJ22 & 105 & 105 & 182 & 182 & 195 & 195 & 200 & 216 & 154 & 156 & 169 & 197 & 252 & 252 & 232 & 232 & 177 & 202 & 154 & 170 & 218 & 218 & 23 & 5 & 4 \\
\hline 24 & CNJ23 & 105 & 105 & 182 & 182 & 195 & 195 & 216 & 216 & 154 & 154 & 157 & 197 & 252 & 252 & 242 & 242 & 177 & 188 & 154 & 170 & 220 & 220 & 24 & 3 & 5 \\
\hline 25 & CNJ24 & 105 & 105 & 182 & 182 & 195 & 195 & 200 & 216 & 154 & 156 & 157 & 197 & 252 & 252 & 242 & 242 & 177 & 188 & 154 & 170 & 218 & 218 & 25 & 5 & 5 \\
\hline 26 & CNJ25 & 105 & 105 & 182 & 182 & 195 & 195 & 200 & 200 & 156 & 158 & 197 & 197 & 252 & 252 & 232 & 242 & 188 & 202 & 154 & 154 & 218 & 218 & 26 & 3 & 4 \\
\hline 27 & CNJ26 & 105 & 105 & 182 & 182 & 195 & 195 & 200 & 210 & 154 & 154 & 197 & 197 & 252 & 254 & 232 & 242 & 191 & 202 & 170 & 170 & 218 & 220 & 27 & 5 & 4 \\
\hline 28 & CNJ27 & 105 & 105 & 182 & 182 & 195 & 195 & 200 & 220 & 154 & 156 & 157 & 197 & 252 & 252 & 242 & 242 & 177 & 177 & 154 & 170 & 218 & 220 & 28 & 5 & 5 \\
\hline
\end{tabular}




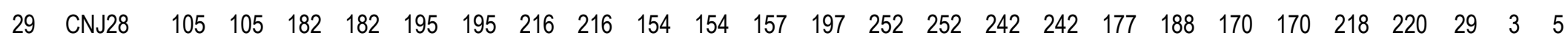

$\begin{array}{lllllllllllllllllllllllllll}30 & \text { CNJ29 } & 105 & 105 & 182 & 182 & 195 & 195 & 200 & 210 & 154 & 156 & 191 & 197 & 252 & 254 & 232 & 242 & 177 & 191 & 154 & 154 & 218 & 218 & 30 & 6 & 4\end{array}$

$\begin{array}{lllllllllllllllllllllllllll}31 & \text { CNJ30 } & 105 & 105 & 182 & 182 & 195 & 195 & 200 & 200 & 154 & 156 & 177 & 197 & 252 & 252 & 232 & 232 & 177 & 202 & 154 & 170 & 218 & 220 & 31 & 5 & 4\end{array}$

$\begin{array}{llllllllllllllllllllllllllll}32 & \text { CNJ31 } & 105 & 105 & 182 & 182 & 195 & 195 & 200 & 216 & 154 & 156 & 157 & 197 & 252 & 252 & 232 & 242 & 177 & 202 & 154 & 170 & 218 & 220 & 32 & 7 & 5\end{array}$

$\begin{array}{lllllllllllllllllllllllllll}33 & \text { CNJ32 } & 105 & 105 & 182 & 182 & 195 & 204 & 216 & 216 & 154 & 164 & 157 & 177 & 252 & 252 & 242 & 242 & 177 & 191 & 154 & 170 & 218 & 220 & 33 & 6 & 5\end{array}$

$\begin{array}{llllllllllllllllllllllllllll}34 & \text { CNJ33 } & 105 & 105 & 182 & 182 & 195 & 195 & 210 & 216 & 154 & 154 & 157 & 199 & 252 & 254 & 242 & 242 & 188 & 191 & 154 & 170 & 218 & 220 & 34 & 6 & 5\end{array}$

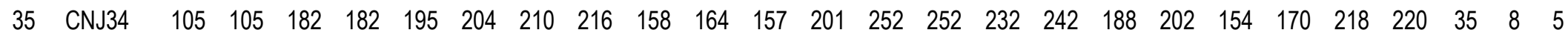

$\begin{array}{llllllllllllllllllllllllllll}36 & \text { CNJ35 } & 105 & 105 & 182 & 182 & 195 & 195 & 200 & 216 & 154 & 158 & 157 & 197 & 252 & 252 & 242 & 242 & 188 & 202 & 154 & 170 & 220 & 220 & 36 & 5 & 5\end{array}$

$\begin{array}{llllllllllllllllllllllllllll}37 & \text { CNJ36 } & 105 & 105 & 182 & 182 & 195 & 195 & 200 & 210 & 156 & 158 & 197 & 201 & 252 & 252 & 232 & 242 & 188 & 202 & 154 & 154 & 218 & 218 & 37 & 5 & 4\end{array}$

$\begin{array}{llllllllllllllllllllllllllll}38 & \text { CNJ37 } & 105 & 105 & 182 & 182 & 195 & 195 & 210 & 216 & 154 & 158 & 157 & 201 & 252 & 252 & 242 & 242 & 177 & 191 & 154 & 170 & 218 & 220 & 38 & 6 & 5\end{array}$

\begin{tabular}{lllllllllllllllllllllllllll}
39 & CNJ38 & 105 & 105 & 182 & 182 & 195 & 195 & 216 & 216 & 147 & 156 & 157 & 175 & 254 & 254 & 242 & 242 & 177 & 191 & 154 & 154 & 218 & 218 & 39 & 3 & 5 \\
\hline 40 & BOC01 & 105 & 105 & 179 & 182 & 195 & 204 & 210 & 216 & 156 & 158 & 189 & 199 & 252 & 252 & 242 & 242 & 191 & 202 & 154 & 181 & 220 & 220 & 40 & 7 & 4
\end{tabular}

$\begin{array}{llllllllllllllllllllllllllll}41 & \text { BOC02 } & 105 & 105 & 179 & 182 & 195 & 204 & 210 & 216 & 156 & 158 & 189 & 199 & 252 & 252 & 242 & 242 & 191 & 202 & 154 & 181 & 220 & 220 & 40 & 7 & 4\end{array}$

$\begin{array}{llllllllllllllllllllllllllllll}42 & \text { BOC03 } & 105 & 105 & 179 & 182 & 195 & 204 & 210 & 216 & 156 & 158 & 189 & 199 & 252 & 252 & 242 & 242 & 191 & 202 & 154 & 181 & 220 & 220 & 40 & 7 & 4\end{array}$

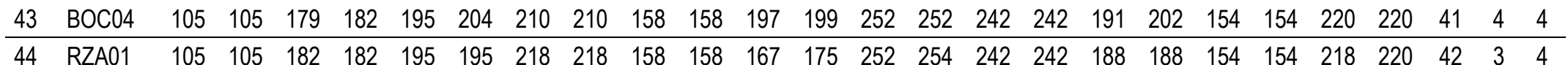

\begin{tabular}{|c|c|c|c|c|c|c|c|c|c|c|c|c|c|c|c|c|c|c|c|c|c|c|c|c|c|}
\hline 45 & ZA02 & 105 & 105 & 182 & 182 & 195 & 195 & 200 & 218 & 154 & 158 & 175 & 185 & 252 & 254 & 242 & 244 & 188 & 188 & 154 & 154 & 220 & 220 & 43 & 5 \\
\hline 46 & RZA03 & 105 & 105 & 182 & 182 & 195 & 195 & 200 & 216 & 154 & 158 & 167 & 197 & 252 & 252 & 242 & 242 & 177 & 188 & 154 & 154 & 220 & 220 & 44 & 4 \\
\hline 4 & RZA04 & 105 & 105 & 167 & 182 & 195 & 195 & 200 & 218 & 154 & 158 & 185 & 197 & 252 & 252 & 232 & 244 & 177 & 188 & 154 & 154 & 220 & 220 & 45 & 0 \\
\hline & RZA05 & 105 & 105 & 182 & 182 & 195 & 195 & 200 & 218 & 154 & 158 & 165 & 197 & 252 & 252 & 232 & 242 & 177 & 188 & 154 & 154 & 218 & 218 & 46 & \\
\hline 4 & RZA06 & 105 & 105 & 167 & 182 & 195 & 195 & 216 & 216 & 156 & 156 & 157 & 197 & 252 & 252 & 244 & 244 & 188 & 191 & 154 & 156 & 220 & 220 & 47 & 4 \\
\hline & RZA07 & 105 & 105 & 167 & 167 & 195 & 195 & 216 & 224 & 154 & 156 & 175 & 197 & 252 & 252 & 244 & 244 & 188 & 188 & 154 & 154 & 220 & 236 & 48 & 4 \\
\hline & RZA08 & 105 & 105 & 182 & 182 & 195 & 195 & 216 & 224 & 154 & 154 & 175 & 175 & 252 & 252 & 242 & 244 & 188 & 191 & 154 & 154 & 218 & 236 & 49 & 4 \\
\hline & RZA09 & 105 & 105 & 182 & 182 & 195 & 195 & 216 & 218 & 158 & 158 & 167 & 185 & 252 & 254 & 242 & 242 & 188 & 188 & 154 & 154 & 220 & 220 & 50 & 3 \\
\hline & RZA10 & 105 & 105 & 167 & 182 & 195 & 195 & 218 & 218 & 154 & 156 & 173 & 175 & 252 & 252 & 242 & 244 & 188 & 188 & 154 & 154 & 218 & 220 & 51 & 5 \\
\hline & RZA11 & 105 & 105 & 182 & 182 & 195 & 195 & 218 & 218 & 158 & 158 & 165 & 175 & 252 & 252 & 242 & 242 & 188 & 188 & 154 & 154 & 220 & 220 & 52 & 1 \\
\hline & RZA12 & 105 & 105 & 182 & 182 & 195 & 195 & 200 & 216 & 154 & 160 & 157 & 185 & 252 & 252 & 232 & 244 & 188 & 191 & 154 & 154 & 220 & 220 & 53 & 5 \\
\hline & RZA13 & 105 & 105 & 167 & 167 & 195 & 195 & 210 & 210 & 154 & 154 & 175 & 175 & 252 & 252 & 242 & 244 & 188 & 188 & 154 & 170 & 220 & 220 & 54 & 2 \\
\hline & RZA14 & & 105 & 167 & 182 & 195 & & 216 & 218 & & 158 & 185 & 197 & 252 & 252 & 242 & 244 & 188 & 188 & 154 & 154 & 220 & 220 & 55 & 5 \\
\hline & RZA15 & 105 & 105 & 182 & 182 & 195 & 195 & 16 & 218 & 56 & 158 & 157 & 175 & 252 & 54 & 242 & 244 & 188 & 188 & 154 & 156 & 218 & 220 & 56 & \\
\hline
\end{tabular}




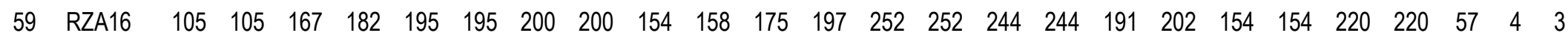

$\begin{array}{lllllllllllllllllllllllllllll}60 & \text { RZA17 } & 105 & 105 & 167 & 182 & 195 & 195 & 216 & 216 & 154 & 160 & 175 & 197 & 252 & 252 & 242 & 244 & 188 & 188 & 154 & 170 & 218 & 220 & 58 & 6 & 3\end{array}$

$\begin{array}{llllllllllllllllllllllllllll}61 & \text { RZA18 } & 105 & 105 & 167 & 182 & 195 & 195 & 216 & 216 & 154 & 156 & 175 & 197 & 252 & 252 & 242 & 244 & 188 & 188 & 154 & 170 & 220 & 220 & 59 & 5 & 3\end{array}$

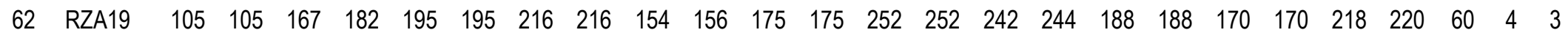

$\begin{array}{lllllllllllllllllllllllllll}63 & \text { RZA20 } & 105 & 105 & 167 & 182 & 195 & 195 & 216 & 216 & 154 & 156 & 157 & 197 & 252 & 252 & 242 & 242 & 191 & 202 & 170 & 170 & 220 & 220 & 61 & 4 & 4\end{array}$

$\begin{array}{lllllllllllllllllllllllllllll}64 & \text { RZA21 } & 105 & 105 & 167 & 182 & 195 & 195 & 200 & 200 & 154 & 158 & 185 & 197 & 252 & 252 & 242 & 244 & 202 & 202 & 154 & 170 & 218 & 220 & 62 & 6 & 3\end{array}$

\begin{tabular}{lllllllllllllllllllllllllll}
65 & RZA22 & 105 & 105 & 167 & 182 & 195 & 195 & 216 & 218 & 158 & 160 & 175 & 175 & 252 & 252 & 244 & 244 & 188 & 188 & 154 & 154 & 218 & 220 & 63 & 4 & 3 \\
\hline 66 & NAV01 & 105 & 105 & 167 & 182 & 195 & 201 & 208 & 224 & 156 & 156 & 185 & 185 & 252 & 254 & 232 & 242 & 188 & 191 & 154 & 154 & 216 & 220 & 64 & 7 & 4
\end{tabular}

$\begin{array}{llllllllllllllllllllllllllllll}67 & \text { NAV02 } & 105 & 105 & 167 & 182 & 195 & 195 & 208 & 216 & 154 & 156 & 161 & 183 & 252 & 254 & 232 & 242 & 188 & 191 & 154 & 154 & 216 & 220 & 65 & 8 & 5\end{array}$

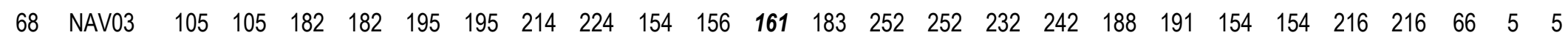

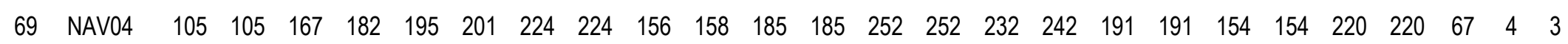

$\begin{array}{lllllllllllllllllllllllllll}70 & \text { NAV05 } & 105 & 105 & 167 & 182 & 195 & 195 & 208 & 214 & 154 & 156 & 183 & 185 & 252 & 252 & 232 & 242 & 188 & 188 & 154 & 154 & 216 & 220 & 68 & 6 & 4\end{array}$

$\begin{array}{llllllllllllllllllllllllllll}71 & \text { NAV06 } & 105 & 105 & 167 & 167 & 195 & 201 & 214 & 214 & 154 & 154 & 171 & 185 & 252 & 252 & 232 & 232 & 188 & 191 & 154 & 154 & 216 & 216 & 69 & 3 & 2\end{array}$

$\begin{array}{llllllllllllllllllllllllllll}72 & \text { NAV07 } & 105 & 105 & 167 & 182 & 195 & 201 & 216 & 224 & 156 & 156 & 161 & 185 & 252 & 252 & 232 & 232 & 188 & 188 & 154 & 154 & 216 & 220 & 70 & 5 & 4\end{array}$

$\begin{array}{llllllllllllllllllllllllllll}73 & \text { NAV08 } & 105 & 105 & 182 & 182 & 195 & 195 & 214 & 214 & 154 & 154 & 161 & 171 & 252 & 252 & 232 & 232 & 188 & 191 & 154 & 154 & 216 & 216 & 71 & 2 & 5\end{array}$

$\begin{array}{llllllllllllllllllllllllllll}74 & \text { NAV09 } & 105 & 105 & 167 & 182 & 195 & 195 & 214 & 224 & 154 & 156 & 161 & 185 & 252 & 252 & 232 & 232 & 188 & 191 & 154 & 154 & 216 & 220 & 72 & 6 & 4\end{array}$

$\begin{array}{lllllllllllllllllllllllllllll}75 & \text { NAV10 } & 105 & 105 & 167 & 182 & 195 & 201 & 208 & 224 & 156 & 156 & 161 & 183 & 252 & 254 & 242 & 244 & 188 & 188 & 154 & 154 & 216 & 220 & 73 & 7 & 5\end{array}$

$\begin{array}{lllllllllllllllllllllllllll}76 & \text { NAV11 } & 105 & 105 & 167 & 182 & 195 & 195 & 208 & 224 & 156 & 156 & 185 & 185 & 252 & 252 & 242 & 242 & 188 & 188 & 154 & 154 & 216 & 220 & 74 & 3 & 4\end{array}$

$\begin{array}{lllllllllllllllllllllllllll}77 & \text { NAV12 } & 105 & 105 & 167 & 182 & 195 & 195 & 208 & 224 & 156 & 156 & 171 & 185 & 252 & 252 & 232 & 242 & 188 & 188 & 154 & 154 & 216 & 216 & 75 & 4 & 4\end{array}$

$\begin{array}{lllllllllllllllllllllllllll} & \text { NAV13 } & 105 & 105 & 167 & 182 & 195 & 201 & 224 & 224 & 156 & 156 & 185 & 185 & 252 & 252 & 232 & 242 & 191 & 191 & 154 & 154 & 220 & 220 & 76 & 3 & 3\end{array}$

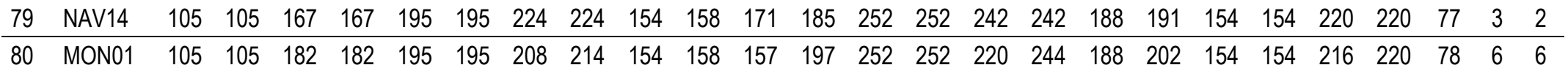

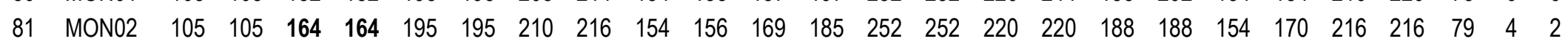

$\begin{array}{lllllllllllllllllllllllllll}82 & \text { MON03 } & 105 & 105 & 164 & 164 & 195 & 195 & 210 & 210 & 156 & 156 & 165 & 169 & 252 & 252 & 220 & 220 & 188 & 191 & 158 & 170 & 216 & 216 & 80 & 3 & 2\end{array}$

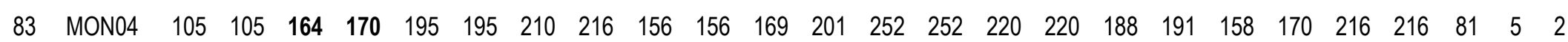

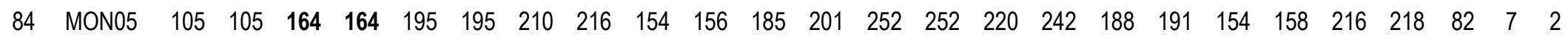

$\begin{array}{llllllllllllllllllllllllllll}85 & \text { MON06 } & 105 & 105 & 182 & 182 & 195 & 195 & 208 & 210 & 156 & 164 & 185 & 185 & 252 & 252 & 242 & 244 & 188 & 188 & 158 & 158 & 216 & 216 & 83 & 3 & 5\end{array}$

\begin{tabular}{lllllllllllllllllllllllllll}
86 & MON07 & 105 & 105 & 164 & 164 & 195 & 195 & 208 & 208 & 154 & 156 & 185 & 185 & 252 & 252 & 220 & 220 & 188 & 191 & 154 & 158 & 216 & 220 & 84 & 4 & 4 \\
\hline 87 & RAS01 & 105 & 105 & 167 & 182 & 195 & 195 & 208 & 216 & 155 & 156 & 177 & 197 & 252 & 252 & 232 & 232 & 188 & 188 & 185 & 185 & 216 & 216 & 85 & 4 & 5
\end{tabular}

$\begin{array}{llllllllllllllllllllllllllll}88 & \text { RAS02 } & 105 & 105 & 167 & 182 & 195 & 195 & 208 & 224 & 156 & 166 & 171 & 185 & 252 & 254 & 232 & 232 & 191 & 191 & 154 & 185 & 216 & 220 & 86 & 7 & 4\end{array}$ 


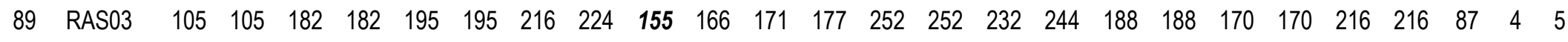

$\begin{array}{lllllllllllllllllllllllllll}90 & \text { RAS04 } & 105 & 105 & 182 & 182 & 195 & 195 & 224 & 224 & 155 & 166 & 177 & 197 & 252 & 252 & 232 & 244 & 188 & 188 & 170 & 185 & 216 & 216 & 88 & 4 & 5\end{array}$

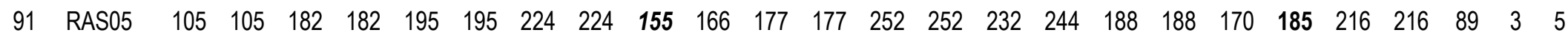

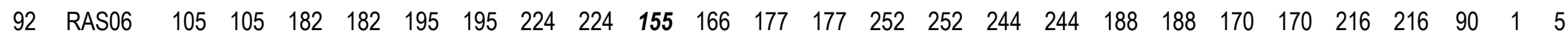

$\begin{array}{lllllllllllllllllllllllllll}93 & \text { RAS07 } & 105 & 105 & 182 & 182 & 195 & 195 & 210 & 210 & 155 & 166 & 177 & 177 & 252 & 252 & 232 & 244 & 188 & 188 & 170 & 185 & 216 & 216 & 91 & 3 & 5\end{array}$

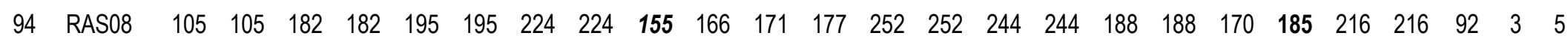

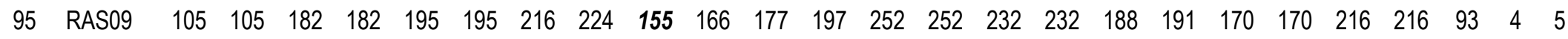

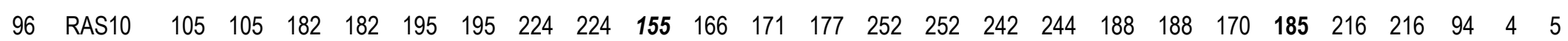

$\begin{array}{lllllllllllllllllllllllllll}97 & \text { RAS11 } & 105 & 105 & 182 & 182 & 195 & 195 & 224 & 224 & 155 & 166 & 171 & 177 & 252 & 252 & 232 & 242 & 188 & 188 & 170 & 185 & 216 & 216 & 95 & 4 & 5\end{array}$

$\begin{array}{llllllllllllllllllllllllllll}98 & \text { RAS12 } & 105 & 105 & 167 & 182 & 195 & 195 & 208 & 208 & 156 & 156 & 177 & 177 & 252 & 252 & 232 & 242 & 188 & 191 & 185 & 185 & 216 & 216 & 96 & 3 & 5\end{array}$

$99 \begin{array}{lllllllllllllllllllllllllll} & \text { RAS13 } & 105 & 105 & 182 & 182 & 195 & 195 & 216 & 216 & 155 & 155 & 171 & 177 & 252 & 252 & 232 & 244 & 188 & 188 & 170 & 170 & 216 & 216 & 97 & 2 & 6\end{array}$

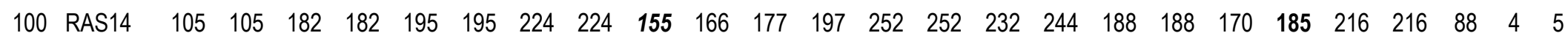

$\begin{array}{llllllllllllllllllllllllllll}101 & \text { RAS15 } & 105 & 105 & 182 & 182 & 195 & 195 & 210 & 210 & 155 & 155 & 177 & 177 & 252 & 252 & 232 & 242 & 188 & 188 & 185 & 185 & 216 & 216 & 98 & 1 & 6\end{array}$

$\begin{array}{lllllllllllllllllllllllllll}102 & \text { RAS16 } & 105 & 105 & 182 & 182 & 195 & 195 & 224 & 224 & 155 & 166 & 171 & 177 & 252 & 252 & 242 & 242 & 188 & 188 & 170 & 170 & 216 & 216 & 99 & 2 & 5\end{array}$

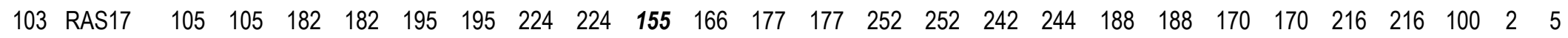

$\begin{array}{lllllllllllllllllllllllllll}104 & \text { RAS18 } & 105 & 105 & 182 & 182 & 195 & 195 & 216 & 224 & 155 & 166 & 177 & 197 & 252 & 252 & 242 & 242 & 188 & 188 & 170 & 170 & 216 & 216 & 101 & 3 & 5\end{array}$

$\begin{array}{llllllllllllllllllllllllll}105 & 105 & 182 & 182 & 195 & 195 & 224 & 224 & 155 & 166 & 171 & 177 & 252 & 252 & 232 & 244 & 188 & 188 & 170 & 185 & 216 & 216 & 102 & 4 & 5\end{array}$

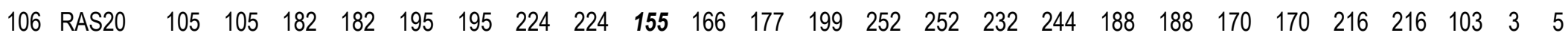

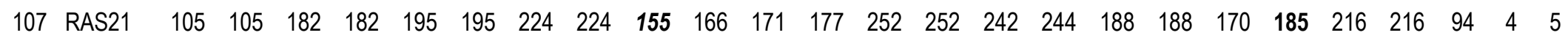

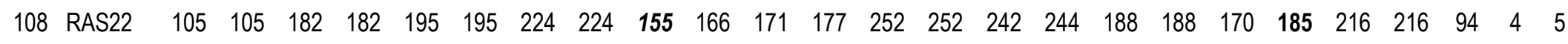

$\begin{array}{lllllllllllllllllllllllllll}109 & \text { RAS23 } & 105 & 105 & 182 & 182 & 195 & 195 & 224 & 224 & 166 & 166 & 177 & 177 & 252 & 252 & 232 & 244 & 188 & 188 & 170 & 170 & 216 & 216 & 104 & 1 & 4\end{array}$

$\begin{array}{lllllllllllllllllllllllllll}110 & \text { RAS24 } & 105 & 105 & 182 & 182 & 195 & 195 & 224 & 224 & 155 & 166 & 177 & 197 & 252 & 252 & 242 & 242 & 188 & 188 & 170 & 185 & 216 & 216 & 105 & 3 & 5\end{array}$

$\begin{array}{lllllllllllllllllllllllllll}111 & \text { RAS25 } & 105 & 105 & 182 & 182 & 195 & 195 & 216 & 216 & 155 & 155 & 197 & 197 & 252 & 254 & 242 & 244 & 188 & 191 & 154 & 154 & 216 & 216 & 106 & 3 & 6\end{array}$

$\begin{array}{llllllllllllllllllllllllllll}112 & \text { RAS26 } & 105 & 105 & 182 & 182 & 195 & 195 & 224 & 224 & 155 & 166 & 171 & 177 & 252 & 252 & 232 & 244 & 188 & 188 & 170 & 185 & 216 & 216 & 102 & 4 & 5\end{array}$

$\begin{array}{lllllllllllllllllllllllllll}113 & \text { RAS27 } & 105 & 105 & 182 & 182 & 195 & 195 & 224 & 224 & 155 & 166 & 177 & 177 & 252 & 252 & 232 & 242 & 188 & 188 & 170 & 185 & 216 & 216 & 107 & 3 & 5\end{array}$

$\begin{array}{lllllllllllllllllllllllllll}114 & \text { RAS28 } & 105 & 105 & 182 & 182 & 195 & 195 & 216 & 216 & 155 & 155 & 177 & 197 & 252 & 252 & 220 & 232 & 188 & 191 & 154 & 185 & 216 & 220 & 108 & 5 & 6\end{array}$

$\begin{array}{lllllllllllllllllllllllllll}115 & \text { RAS29 } & 105 & 105 & 182 & 182 & 195 & 195 & 216 & 216 & 155 & 155 & 171 & 197 & 252 & 252 & 232 & 244 & 188 & 188 & 170 & 185 & 216 & 216 & 109 & 3 & 6\end{array}$

$\begin{array}{lllllllllllllllllllllllllll}116 & \text { RAS30 } & 105 & 105 & 167 & 182 & 195 & 195 & 208 & 216 & 155 & 156 & 177 & 185 & 252 & 252 & 220 & 232 & 191 & 191 & 154 & 185 & 216 & 216 & 110 & 6 & 5\end{array}$

$\begin{array}{lllllllllllllllllllllllllll}117 & \text { RAS31 } & 105 & 105 & 182 & 182 & 195 & 195 & 216 & 216 & 155 & 155 & 171 & 177 & 252 & 252 & 232 & 244 & 188 & 188 & 170 & 185 & 216 & 216 & 111 & 3 & 6\end{array}$

$\begin{array}{lllllllllllllllllllllllllll}118 & \text { RAS32 } & 105 & 105 & 182 & 182 & 195 & 195 & 224 & 224 & 166 & 166 & 171 & 197 & 252 & 252 & 232 & 244 & 188 & 191 & 170 & 170 & 216 & 216 & 112 & 3 & 4\end{array}$ 


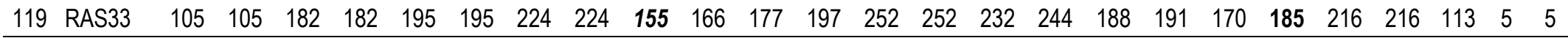

\begin{tabular}{|c|c|c|c|c|c|c|c|c|c|c|c|c|c|c|c|c|c|c|c|c|c|c|c|c|c|c|}
\hline 120 & PAU01 & 105 & 105 & 182 & 182 & 195 & 204 & 216 & 218 & 154 & 158 & 165 & 187 & 252 & 254 & 244 & 244 & 188 & 191 & 154 & 170 & 216 & 216 & 114 & 7 & \\
\hline 121 & CER01 & 105 & 105 & 182 & 182 & 195 & 195 & 200 & 218 & 154 & 154 & 169 & 177 & 252 & 254 & 220 & 232 & 188 & 191 & 154 & 174 & 216 & 218 & 115 & 7 & \\
\hline 122 & CER02 & 105 & 105 & 182 & 182 & 195 & 195 & 200 & 218 & 154 & 154 & 169 & 177 & 252 & 254 & 220 & 232 & 188 & 191 & 154 & 174 & 216 & 218 & 115 & 7 & \\
\hline 123 & CER03 & 105 & 105 & 182 & 182 & 195 & 195 & 200 & 218 & 154 & 154 & 169 & 177 & 252 & 254 & 220 & 232 & 188 & 191 & 154 & 174 & 216 & 218 & 115 & 7 & \\
\hline 124 & CERO4 & 105 & 105 & 182 & 182 & 195 & 195 & 200 & 218 & 154 & 154 & 169 & 177 & 252 & 254 & 220 & 232 & 188 & 191 & 154 & 174 & 216 & 218 & 115 & 7 & \\
\hline 125 & CER05 & 105 & 105 & 182 & 182 & 195 & 195 & 200 & 218 & 154 & 154 & 169 & 177 & 252 & 254 & 220 & 232 & 188 & 191 & 154 & 174 & 216 & 218 & 115 & 7 & \\
\hline 126 & CER06 & 105 & 105 & 182 & 182 & 195 & 195 & 200 & 218 & 154 & 154 & 169 & 177 & 252 & 254 & 220 & 232 & 188 & 191 & 154 & 174 & 216 & 218 & 115 & 7 & \\
\hline 127 & ROZ01 & 105 & 108 & 182 & 182 & 192 & 195 & 216 & 224 & 158 & 158 & 152 & 175 & 252 & 256 & 233 & 235 & 188 & 191 & 151 & 170 & 220 & 233 & 116 & 9 & 7 \\
\hline 128 & ROZ02 & 105 & 108 & 182 & 182 & 192 & 195 & 212 & 216 & 151 & 158 & 152 & 177 & 254 & 256 & 232 & 233 & 177 & 188 & 151 & 170 & 220 & 233 & 117 & 10 & 8 \\
\hline 129 & ROZ03 & 105 & 108 & 182 & 182 & 192 & 195 & 212 & 216 & 151 & 158 & 152 & 177 & 254 & 256 & 232 & 233 & 177 & 188 & 151 & 170 & 220 & 233 & 117 & 10 & 8 \\
\hline 130 & ROZO4 & 105 & 108 & 182 & 182 & 192 & 195 & 212 & 216 & 151 & 158 & 152 & 177 & 254 & 256 & 232 & 233 & 177 & 188 & 151 & 170 & 220 & 233 & 117 & 10 & 8 \\
\hline 131 & ROZ05 & 105 & 105 & 176 & 182 & 195 & 195 & 210 & 216 & 147 & 158 & 152 & 171 & 252 & 256 & 232 & 233 & 188 & 191 & 170 & 170 & 220 & 220 & 118 & 7 & 4 \\
\hline 132 & ROZO6 & 105 & 108 & 182 & 182 & 192 & 195 & 212 & 216 & 151 & 156 & 152 & 157 & 252 & 256 & 232 & 233 & 177 & 188 & 151 & 170 & 233 & 233 & 119 & 9 & $y$ \\
\hline 133 & ROZ07 & 105 & 108 & 182 & 182 & 192 & 195 & 212 & 216 & 151 & 156 & 152 & 157 & 252 & 256 & 232 & 233 & 177 & 188 & 151 & 154 & 233 & 233 & 120 & 9 & 9 \\
\hline 134 & ROZ08 & 105 & 108 & 182 & 182 & 192 & 195 & 212 & 216 & 151 & 156 & 152 & 157 & 252 & 256 & 232 & 233 & 177 & 188 & 151 & 154 & 233 & 233 & 120 & 9 & $y$ \\
\hline 135 & ROZO9 & 105 & 108 & 182 & 182 & 192 & 195 & 212 & 216 & 151 & 156 & 152 & 157 & 252 & 256 & 232 & 233 & 177 & 188 & 151 & 154 & 233 & 233 & 120 & 9 & g \\
\hline 136 & ROZ10 & 105 & 108 & 182 & 182 & 192 & 195 & 212 & 216 & 151 & 156 & 152 & 157 & 252 & 256 & 232 & 233 & 177 & 188 & 151 & 154 & 233 & 233 & 120 & 9 & g \\
\hline 137 & ROZ11 & 105 & 108 & 182 & 182 & 192 & 195 & 210 & 216 & 147 & 158 & 152 & 171 & 252 & 256 & 232 & 233 & 188 & 188 & 170 & 170 & 218 & 220 & 121 & 8 & 7 \\
\hline 138 & ROZ12 & 105 & 108 & 176 & 182 & 195 & 195 & 210 & 212 & 147 & 151 & 157 & 177 & 252 & 254 & 232 & 233 & 188 & 188 & 151 & 170 & 233 & 233 & 122 & 8 & 6 \\
\hline 139 & ROZ13 & 105 & 108 & 182 & 182 & 192 & 195 & 212 & 216 & 151 & 156 & 152 & 157 & 252 & 256 & 232 & 233 & 177 & 188 & 151 & 154 & 233 & 233 & 120 & 9 & 9 \\
\hline 140 & ROZ14 & 105 & 105 & 182 & 182 & 195 & 195 & 210 & 216 & 147 & 158 & 171 & 177 & 252 & 254 & 232 & 233 & 188 & 188 & 170 & 170 & 218 & 220 & 123 & 6 & 4 \\
\hline 141 & ROZ15 & 105 & 114 & 182 & 182 & 195 & 195 & 216 & 218 & 145 & 156 & 171 & 191 & 252 & 254 & 232 & 232 & 188 & 191 & 156 & 170 & 218 & 218 & 124 & 7 & 5 \\
\hline 142 & ROZ16 & 105 & 108 & 182 & 182 & 192 & 195 & 216 & 216 & 156 & 158 & 157 & 177 & 252 & 252 & 232 & 232 & 177 & 191 & 154 & 170 & 220 & 233 & 125 & 7 & 7 \\
\hline 143 & ROZ17 & 105 & 105 & 176 & 182 & 192 & 195 & 216 & 218 & 145 & 156 & 152 & 177 & 254 & 256 & 232 & 233 & 177 & 188 & 154 & 156 & 233 & 233 & 126 & 9 & 5 \\
\hline 144 & ROZ18 & 105 & 108 & 182 & 182 & 192 & 195 & 212 & 216 & 151 & 156 & 152 & 157 & 252 & 256 & 232 & 233 & 177 & 188 & 151 & 154 & 233 & 233 & 120 & 9 & 9 \\
\hline 145 & ROZ19 & 105 & 108 & 182 & 182 & 192 & 195 & 212 & 216 & 151 & 156 & 152 & 157 & 252 & 256 & 232 & 233 & 177 & 188 & 151 & 154 & 233 & 233 & 120 & 9 & 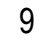 \\
\hline 146 & ROZ20 & 105 & 108 & 182 & 182 & 192 & 195 & 212 & 216 & 151 & 156 & 152 & 157 & 252 & 256 & 232 & 233 & 177 & 188 & 151 & 154 & 233 & 233 & 120 & 9 & $y$ \\
\hline 147 & ROZ21 & 105 & 108 & 182 & 182 & 192 & 195 & 212 & 216 & 151 & 156 & 152 & 157 & 252 & 256 & 232 & 233 & 177 & 188 & 151 & 154 & 233 & 233 & 120 & 9 & $y$ \\
\hline 148 & ROZ22 & 105 & 108 & 182 & 182 & 192 & 195 & 212 & 216 & 151 & 156 & 152 & 157 & 252 & 256 & 232 & 233 & 177 & 188 & 151 & 154 & 233 & 233 & 120 & 9 & $y$ \\
\hline
\end{tabular}




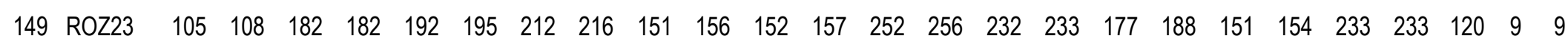
$\begin{array}{lllllllllllllllllllllllllll}150 & \text { ROZ24 } & 105 & 105 & 182 & 182 & 195 & 195 & 216 & 216 & 154 & 156 & 152 & 177 & 252 & 252 & 232 & 233 & 188 & 188 & 154 & 158 & 220 & 233 & 127 & 5 & 5\end{array}$

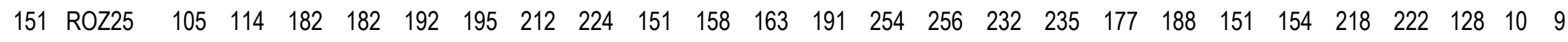
$\begin{array}{lllllllllllllllllllllllllll}152 & \text { ROZ26 } & 105 & 114 & 182 & 182 & 192 & 195 & 212 & 224 & 151 & 158 & 163 & 191 & 254 & 256 & 232 & 235 & 177 & 188 & 151 & 154 & 218 & 222 & 128 & 10 & 9\end{array}$ $\begin{array}{lllllllllllllllllllllllllll}153 & \text { ROZ27 } & 105 & 114 & 182 & 182 & 192 & 195 & 212 & 224 & 151 & 158 & 163 & 191 & 254 & 256 & 232 & 235 & 177 & 188 & 151 & 154 & 218 & 222 & 128 & 10 & 9\end{array}$ $\begin{array}{llllllllllllllllllllllllllll}154 & \text { ROZ28 } & 105 & 114 & 182 & 182 & 192 & 195 & 212 & 224 & 151 & 158 & 163 & 191 & 254 & 256 & 232 & 235 & 177 & 188 & 151 & 154 & 218 & 222 & 128 & 10 & 9\end{array}$

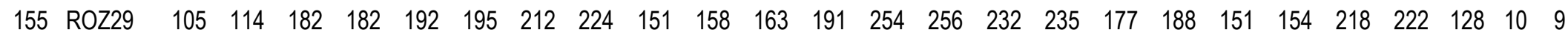

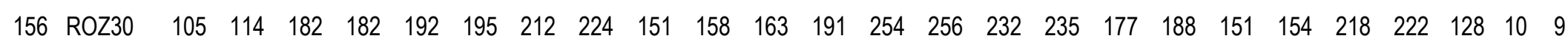
$\begin{array}{lllllllllllllllllllllllllll}157 & \text { ROZ31 } & 105 & 114 & 182 & 182 & 192 & 195 & 212 & 224 & 151 & 158 & 163 & 191 & 254 & 256 & 232 & 235 & 177 & 188 & 151 & 154 & 218 & 222 & 128 & 10 & 9\end{array}$

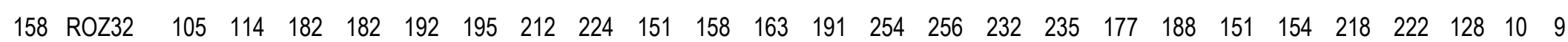
$\begin{array}{lllllllllllllllllllllllllllll}159 & \text { ROZ33 } & 105 & 114 & 182 & 182 & 192 & 195 & 212 & 224 & 151 & 158 & 163 & 191 & 254 & 256 & 232 & 235 & 177 & 188 & 151 & 154 & 218 & 222 & 128 & 10 & 9\end{array}$ $\begin{array}{llllllllllllllllllllllllllll}160 & \text { ROZ34 } & 105 & 114 & 182 & 182 & 192 & 195 & 212 & 224 & 151 & 158 & 163 & 191 & 254 & 256 & 232 & 235 & 177 & 188 & 151 & 154 & 218 & 222 & 128 & 10 & 9\end{array}$ $\begin{array}{lllllllllllllllllllllllllllll}161 & \text { ROZ35 } & 105 & 114 & 182 & 182 & 192 & 195 & 212 & 224 & 151 & 158 & 163 & 191 & 254 & 256 & 232 & 235 & 177 & 188 & 151 & 154 & 218 & 222 & 128 & 10 & 9\end{array}$ $\begin{array}{lllllllllllllllllllllllllll}162 & \text { ROZ36 } & 105 & 114 & 182 & 182 & 192 & 195 & 212 & 224 & 151 & 158 & 163 & 191 & 254 & 256 & 232 & 235 & 177 & 188 & 151 & 154 & 218 & 222 & 128 & 10 & 9\end{array}$ $\begin{array}{llllllllllllllllllllllllllll}163 & \text { ROZ37 } & 105 & 114 & 182 & 182 & 192 & 195 & 212 & 224 & 151 & 158 & 163 & 191 & 254 & 256 & 232 & 235 & 177 & 188 & 151 & 154 & 218 & 222 & 128 & 10 & 9\end{array}$ $\begin{array}{llllllllllllllllllllllllllll}164 & \text { ROZ38 } & 105 & 114 & 182 & 182 & 192 & 195 & 212 & 224 & 151 & 158 & 163 & 191 & 254 & 256 & 232 & 235 & 177 & 188 & 151 & 154 & 218 & 222 & 128 & 10 & 9\end{array}$ $\begin{array}{lllllllllllllllllllllllllllll}165 & \text { ROZ39 } & 105 & 114 & 182 & 182 & 192 & 195 & 212 & 224 & 151 & 158 & 163 & 191 & 254 & 256 & 232 & 235 & 177 & 188 & 151 & 154 & 218 & 222 & 128 & 10 & 9\end{array}$ $\begin{array}{llllllllllllllllllllllllllll}166 & \text { ROZ40 } & 105 & 114 & 182 & 182 & 192 & 195 & 212 & 224 & 151 & 158 & 163 & 191 & 254 & 256 & 232 & 235 & 177 & 188 & 151 & 154 & 218 & 222 & 128 & 10 & 9\end{array}$ $\begin{array}{lllllllllllllllllllllllllllll}167 & \text { ROZ41 } & 105 & 114 & 182 & 182 & 192 & 195 & 212 & 224 & 151 & 158 & 163 & 191 & 254 & 256 & 232 & 235 & 177 & 188 & 151 & 154 & 218 & 222 & 128 & 10 & 9\end{array}$ $\begin{array}{llllllllllllllllllllllllllll}168 & \text { ROZ42 } & 105 & 114 & 182 & 182 & 192 & 195 & 212 & 224 & 151 & 158 & 163 & 191 & 254 & 256 & 232 & 235 & 177 & 188 & 151 & 154 & 218 & 222 & 128 & 10 & 9\end{array}$ $\begin{array}{llllllllllllllllllllllllllllll}169 & \text { ROZ43 } & 105 & 114 & 182 & 182 & 192 & 195 & 212 & 224 & 151 & 158 & 163 & 191 & 254 & 256 & 232 & 235 & 177 & 188 & 151 & 154 & 218 & 222 & 128 & 10 & 9\end{array}$ $\begin{array}{lllllllllllllllllllllllllllll}170 & \text { ROZ44 } & 105 & 114 & 182 & 182 & 192 & 195 & 212 & 224 & 151 & 158 & 163 & 191 & 254 & 256 & 232 & 235 & 177 & 188 & 151 & 154 & 218 & 222 & 128 & 10 & 9\end{array}$ $\begin{array}{llllllllllllllllllllllllllll}171 & \text { ROZ45 } & 105 & 114 & 182 & 182 & 192 & 195 & 212 & 224 & 151 & 158 & 163 & 191 & 254 & 256 & 232 & 235 & 177 & 188 & 151 & 154 & 218 & 222 & 128 & 10 & 9\end{array}$ \begin{tabular}{lllllllllllllllllllllllllll}
172 & ROZ46 & 105 & 114 & 182 & 182 & 192 & 195 & 212 & 224 & 151 & 158 & 163 & 191 & 254 & 256 & 232 & 235 & 177 & 188 & 151 & 154 & 218 & 222 & 128 & 10 & 9 \\
\hline 173 & $T$ & &
\end{tabular} \begin{tabular}{lllllllllllllllllllllllllll}
\hline 173 & TIE01 & 105 & 105 & 182 & 182 & 195 & 195 & 214 & 214 & 158 & 158 & 157 & 179 & 252 & 252 & 232 & 242 & 191 & 202 & 170 & 170 & 216 & 220 & 129 & 4 & 5
\end{tabular}

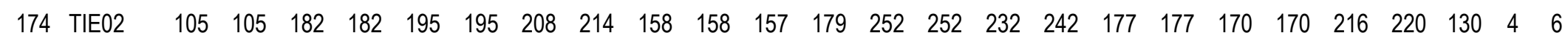
$\begin{array}{lllllllllllllllllllllllllll}175 & \text { TIE03 } & 105 & 105 & 182 & 182 & 195 & 195 & 208 & 208 & 158 & 158 & 157 & 157 & 252 & 252 & 232 & 242 & 177 & 202 & 170 & 170 & 216 & 216 & 131 & 2 & 8\end{array}$

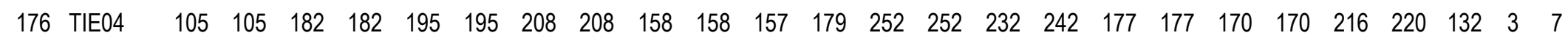
$\begin{array}{lllllllllllllllllllllllllllll}177 & \text { TIE05 } & 105 & 105 & 173 & 182 & 195 & 195 & 208 & 214 & 158 & 158 & 157 & 179 & 252 & 252 & 242 & 242 & 177 & 202 & 154 & 170 & 216 & 220 & 133 & 6 & 5\end{array}$ $\begin{array}{lllllllllllllllllllllllllllll}178 & \text { TIE06 } & 105 & 105 & 173 & 182 & 195 & 195 & 208 & 214 & 158 & 158 & 157 & 179 & 252 & 252 & 242 & 242 & 177 & 202 & 154 & 170 & 216 & 220 & 133 & 6 & 5\end{array}$ 
$\begin{array}{lllllllllllllllllllllllllll}179 & \text { TIEE7 } & 105 & 105 & 173 & 182 & 195 & 195 & 214 & 214 & 158 & 158 & 179 & 179 & 252 & 252 & 232 & 242 & 177 & 202 & 170 & 170 & 216 & 220 & 134 & 4 & 3\end{array}$ $\begin{array}{lllllllllllllllllllllllllllll}180 & \text { TIE08 } & 105 & 105 & 182 & 182 & 195 & 195 & 208 & 214 & 158 & 158 & 179 & 179 & 252 & 252 & 232 & 242 & 177 & 191 & 154 & 154 & 216 & 216 & 135 & 3 & 5\end{array}$ $\begin{array}{lllllllllllllllllllllllllll}181 & \text { TIE09 } & 105 & 105 & 182 & 185 & 195 & 195 & 208 & 208 & 158 & 158 & 179 & 189 & 252 & 252 & 232 & 244 & 188 & 202 & 154 & 154 & 216 & 220 & 136 & 5 & 5\end{array}$

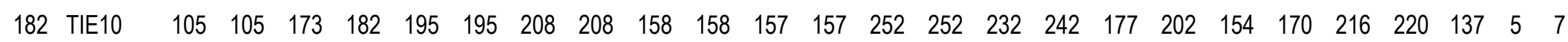

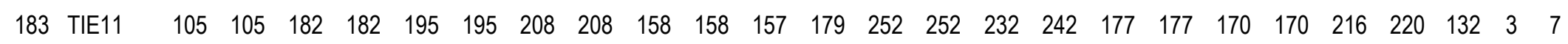
$\begin{array}{lllllllllllllllllllllllllll}184 & \text { TIE12 } & 105 & 105 & 182 & 182 & 195 & 195 & 208 & 214 & 158 & 158 & 179 & 179 & 252 & 252 & 232 & 242 & 177 & 177 & 154 & 154 & 216 & 220 & 138 & 3 & 5\end{array}$ $\begin{array}{lllllllllllllllllllllllllllll}185 & \text { TIE13 } & 105 & 105 & 182 & 182 & 195 & 195 & 214 & 216 & 154 & 158 & 157 & 179 & 252 & 252 & 232 & 232 & 188 & 202 & 170 & 170 & 216 & 220 & 139 & 5 & 5\end{array}$ $\begin{array}{lllllllllllllllllllllllllll}186 & \text { TIE14 } & 105 & 105 & 173 & 182 & 195 & 195 & 208 & 208 & 158 & 158 & 157 & 179 & 252 & 252 & 232 & 242 & 177 & 177 & 154 & 170 & 216 & 216 & 140 & 4 & 6\end{array}$ $\begin{array}{lllllllllllllllllllllllllll}187 & \text { TIE15 } & 105 & 105 & 173 & 182 & 195 & 195 & 214 & 214 & 158 & 158 & 157 & 157 & 252 & 252 & 232 & 242 & 177 & 202 & 170 & 170 & 216 & 220 & 141 & 4 & 5\end{array}$

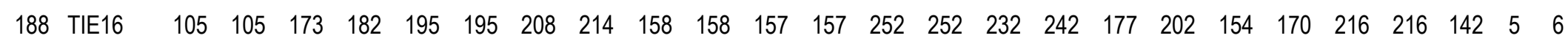

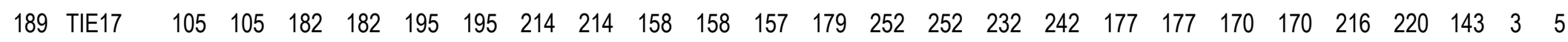

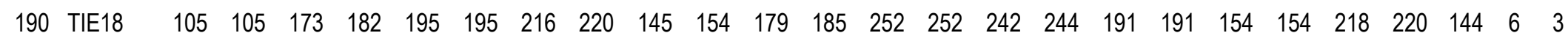
$\begin{array}{lllllllllllllllllllllllllll}191 & \text { TIE19 } & 105 & 105 & 173 & 182 & 195 & 195 & 208 & 208 & 158 & 158 & 157 & 179 & 252 & 252 & 232 & 242 & 177 & 177 & 154 & 170 & 216 & 216 & 140 & 4 & 6\end{array}$

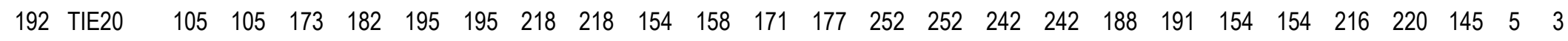
$\begin{array}{lllllllllllllllllllllllllll}193 & \text { TIE21 } & 105 & 105 & 173 & 182 & 195 & 195 & 218 & 218 & 156 & 156 & 157 & 171 & 252 & 252 & 242 & 242 & 191 & 191 & 170 & 170 & 218 & 220 & 146 & 3 & 4\end{array}$ $\begin{array}{llllllllllllllllllllllllllll}194 & \text { TIE22 } & 105 & 105 & 173 & 182 & 195 & 195 & 218 & 218 & 158 & 158 & 157 & 179 & 252 & 252 & 242 & 242 & 191 & 191 & 154 & 170 & 220 & 220 & 147 & 3 & 4\end{array}$

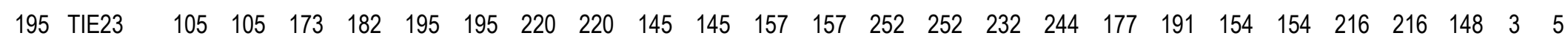
$\begin{array}{lllllllllllllllllllllllllll}196 & \text { TIE24 } & 105 & 105 & 173 & 182 & 195 & 195 & 218 & 218 & 156 & 156 & 179 & 185 & 252 & 252 & 232 & 232 & 191 & 202 & 154 & 170 & 218 & 220 & 149 & 5 & 3\end{array}$ $\begin{array}{lllllllllllllllllllllllllllll}197 & \text { TIE25 } & 105 & 105 & 173 & 182 & 195 & 195 & 216 & 218 & 154 & 156 & 157 & 171 & 252 & 252 & 232 & 242 & 191 & 191 & 154 & 170 & 218 & 220 & 150 & 7 & 4\end{array}$ $\begin{array}{lllllllllllllllllllllllllll}198 & \text { TIE26 } & 105 & 105 & 173 & 182 & 195 & 195 & 218 & 218 & 156 & 156 & 157 & 179 & 252 & 252 & 232 & 232 & 191 & 191 & 154 & 170 & 216 & 220 & 151 & 4 & 4\end{array}$

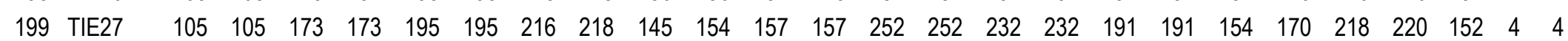
$\begin{array}{lllllllllllllllllllllllllll}200 & \text { TIE28 } & 105 & 105 & 173 & 173 & 195 & 195 & 216 & 218 & 156 & 156 & 157 & 157 & 252 & 252 & 232 & 242 & 191 & 191 & 154 & 170 & 220 & 220 & 153 & 3 & 4\end{array}$ $\begin{array}{llllllllllllllllllllllllllll}201 & \text { TIE29 } & 105 & 105 & 173 & 182 & 195 & 195 & 218 & 218 & 145 & 156 & 157 & 179 & 252 & 252 & 232 & 244 & 191 & 191 & 154 & 154 & 218 & 218 & 154 & 4 & 4\end{array}$ $\begin{array}{lllllllllllllllllllllllllll}202 & \text { TIE30 } & 105 & 105 & 173 & 182 & 195 & 195 & 216 & 218 & 156 & 156 & 157 & 157 & 252 & 252 & 232 & 242 & 191 & 191 & 154 & 170 & 220 & 220 & 155 & 4 & 5\end{array}$ $\begin{array}{lllllllllllllllllllllllllll}203 & \text { TIE31 } & 105 & 105 & 173 & 182 & 195 & 195 & 208 & 220 & 145 & 158 & 171 & 185 & 252 & 252 & 232 & 242 & 191 & 202 & 154 & 170 & 216 & 218 & 156 & 8 & 4\end{array}$ $\begin{array}{llllllllllllllllllllllllllll}204 & \text { TIE32 } & 105 & 105 & 173 & 182 & 195 & 195 & 218 & 218 & 145 & 156 & 157 & 179 & 252 & 252 & 232 & 232 & 191 & 191 & 154 & 154 & 218 & 220 & 157 & 4 & 4\end{array}$ $\begin{array}{llllllllllllllllllllllllllll}205 & \text { TIE33 } & 105 & 105 & 182 & 182 & 195 & 195 & 216 & 218 & 154 & 156 & 157 & 157 & 252 & 252 & 242 & 244 & 191 & 191 & 154 & 170 & 220 & 220 & 158 & 4 & 6\end{array}$ $\begin{array}{llllllllllllllllllllllllllll}206 & \text { TIE34 } & 105 & 105 & 173 & 173 & 195 & 195 & 216 & 218 & 154 & 156 & 157 & 179 & 252 & 252 & 232 & 232 & 191 & 191 & 170 & 170 & 218 & 220 & 159 & 4 & 3\end{array}$

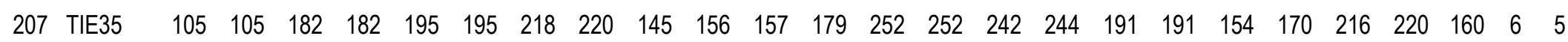
$\begin{array}{llllllllllllllllllllllllllll}208 & \text { TIE36 } & 105 & 105 & 173 & 182 & 195 & 195 & 218 & 218 & 156 & 156 & 157 & 157 & 252 & 252 & 232 & 242 & 191 & 191 & 154 & 170 & 218 & 220 & 161 & 4 & 5\end{array}$ 


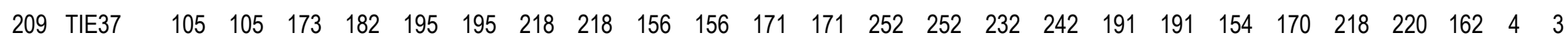
$\begin{array}{llllllllllllllllllllllllllll}210 & \text { TIE38 } & 105 & 105 & 173 & 173 & 195 & 195 & 218 & 218 & 145 & 156 & 157 & 179 & 252 & 252 & 232 & 242 & 191 & 191 & 154 & 154 & 218 & 220 & 163 & 4 & 3\end{array}$ $\begin{array}{lllllllllllllllllllllllllll}211 & \text { TIE39 } & 105 & 105 & 173 & 182 & 195 & 195 & 208 & 218 & 158 & 158 & 157 & 185 & 252 & 252 & 220 & 242 & 188 & 191 & 154 & 170 & 216 & 218 & 164 & 7 & 5\end{array}$

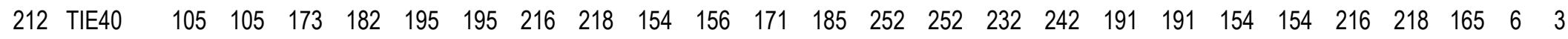
$\begin{array}{lllllllllllllllllllllllllll}213 & \text { TIE41 } & 105 & 105 & 173 & 173 & 195 & 195 & 216 & 218 & 154 & 156 & 157 & 171 & 252 & 252 & 242 & 242 & 191 & 191 & 154 & 170 & 220 & 220 & 166 & 4 & 3\end{array}$ \begin{tabular}{llllllllllllllllllllllllllll}
214 & TIE42 & 105 & 105 & 173 & 182 & 195 & 195 & 216 & 216 & 154 & 154 & 157 & 171 & 252 & 252 & 242 & 244 & 191 & 191 & 154 & 154 & 220 & 220 & 167 & 3 & 4 \\
\hline 215 & IRU01 & 105 & 105 & 107 & 182 & 195 & 195 & 200 & 200 & 154 & 156 & 169 & 175 & 252 & 252 & 232 & 242 & 191 & 202 & 154 & 154 & 218 & 220 & 168 & 6 & 3
\end{tabular} $\begin{array}{lllllllllllllllllllllllllllllllllll}216 & \text { IRU02 } & 105 & 105 & 182 & 182 & 195 & 195 & 216 & 220 & 156 & 158 & 171 & 175 & 252 & 252 & 232 & 242 & 191 & 191 & 154 & 170 & 220 & 220 & 169 & 5 & 4\end{array}$ $\begin{array}{llllllllllllllllllllllllllll}217 & \text { IRU03 } & 105 & 105 & 182 & 182 & 195 & 195 & 216 & 216 & 154 & 158 & 157 & 197 & 252 & 252 & 220 & 242 & 191 & 194 & 154 & 181 & 218 & 220 & 170 & 6 & 5\end{array}$ $\begin{array}{lllllllllllllllllllllllllll}218 & \text { IRU04 } & 105 & 105 & 182 & 182 & 195 & 195 & 216 & 216 & 154 & 158 & 175 & 185 & 252 & 252 & 220 & 242 & 188 & 191 & 154 & 154 & 220 & 220 & 171 & 4 & 4\end{array}$

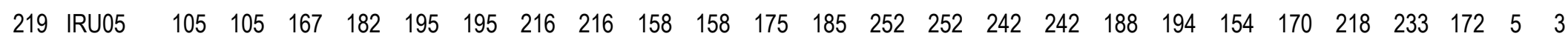
$\begin{array}{lllllllllllllllllllllllllllll}220 & \text { IRU06 } & 105 & 105 & 182 & 182 & 195 & 201 & 216 & 216 & 158 & 158 & 175 & 185 & 252 & 252 & 232 & 242 & 188 & 191 & 154 & 170 & 220 & 220 & 173 & 5 & 4\end{array}$ $\begin{array}{lllllllllllllllllllllllllll}221 & \text { IRU07 } & 105 & 105 & 182 & 182 & 195 & 195 & 216 & 216 & 158 & 158 & 169 & 185 & 252 & 252 & 242 & 242 & 188 & 191 & 154 & 154 & 220 & 220 & 174 & 2 & 4\end{array}$

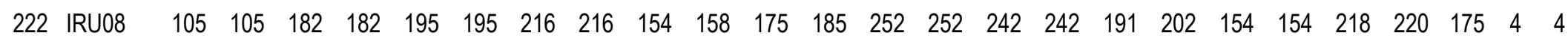
$\begin{array}{lllllllllllllllllllllllllll}223 & \text { IRU09 } & 105 & 105 & 182 & 182 & 195 & 201 & 200 & 216 & 154 & 156 & 169 & 175 & 252 & 252 & 220 & 242 & 191 & 191 & 154 & 181 & 218 & 220 & 176 & 7 & 4\end{array}$ $\begin{array}{lllllllllllllllllllllllllll}224 & \text { IRU10 } & 105 & 105 & 167 & 182 & 195 & 195 & 200 & 216 & 156 & 158 & 175 & 175 & 252 & 252 & 242 & 242 & 191 & 191 & 154 & 154 & 216 & 233 & 177 & 4 & 3\end{array}$

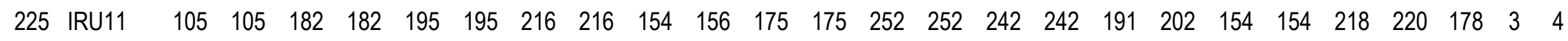
$\begin{array}{llllllllllllllllllllllllllll}226 & \text { IRU12 } & 105 & 105 & 182 & 182 & 195 & 195 & 216 & 216 & 158 & 158 & 175 & 199 & 252 & 252 & 232 & 242 & 188 & 191 & 154 & 154 & 218 & 220 & 179 & 4 & 4\end{array}$ $\begin{array}{lllllllllllllllllllllllllll}227 & \text { IRU13 } & 105 & 105 & 182 & 182 & 195 & 195 & 216 & 216 & 154 & 158 & 175 & 197 & 252 & 254 & 242 & 244 & 188 & 191 & 154 & 170 & 218 & 220 & 180 & 7 & 4\end{array}$ $\begin{array}{lllllllllllllllllllllllllll}228 & \text { IRU14 } & 105 & 105 & 182 & 182 & 195 & 201 & 216 & 216 & 158 & 158 & 169 & 175 & 252 & 252 & 232 & 242 & 191 & 191 & 154 & 154 & 220 & 220 & 181 & 3 & 4\end{array}$ $\begin{array}{lllllllllllllllllllllllllll}229 & \text { IRU15 } & 105 & 114 & 167 & 182 & 192 & 195 & 212 & 216 & 151 & 154 & 152 & 185 & 252 & 252 & 235 & 242 & 177 & 188 & 151 & 170 & 218 & 218 & 182 & 9 & 7\end{array}$

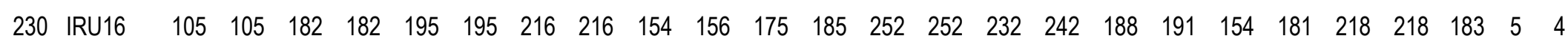
$\begin{array}{lllllllllllllllllllllllllll}231 & \text { IRU17 } & 105 & 105 & 182 & 182 & 195 & 195 & 200 & 216 & 156 & 158 & 169 & 169 & 252 & 252 & 220 & 242 & 191 & 202 & 154 & 154 & 220 & 220 & 184 & 4 & 4\end{array}$ $\begin{array}{lllllllllllllllllllllllllll}232 & \text { IRU18 } & 105 & 105 & 182 & 182 & 195 & 195 & 200 & 216 & 156 & 158 & 175 & 197 & 252 & 252 & 242 & 244 & 188 & 202 & 154 & 170 & 218 & 220 & 185 & 7 & 4\end{array}$

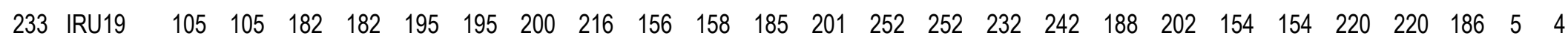
$\begin{array}{lllllllllllllllllllllllllll}234 & \text { IRU20 } & 105 & 105 & 182 & 182 & 195 & 195 & 216 & 216 & 156 & 158 & 175 & 185 & 252 & 252 & 242 & 244 & 188 & 191 & 154 & 154 & 218 & 233 & 187 & 5 & 4\end{array}$ $\begin{array}{llllllllllllllllllllllllllll}235 & \text { IRU21 } & 105 & 105 & 167 & 182 & 195 & 195 & 200 & 200 & 154 & 158 & 169 & 189 & 252 & 252 & 242 & 244 & 188 & 188 & 154 & 154 & 220 & 233 & 188 & 5 & 3\end{array}$ $\begin{array}{lllllllllllllllllllllllllllll}236 & \text { IRU22 } & 105 & 105 & 182 & 182 & 195 & 201 & 216 & 216 & 154 & 156 & 185 & 197 & 252 & 252 & 220 & 242 & 191 & 194 & 154 & 181 & 218 & 220 & 189 & 7 & 4\end{array}$ $\begin{array}{lllllllllllllllllllllllllll}237 & \text { IRU23 } & 105 & 105 & 167 & 182 & 195 & 195 & 216 & 216 & 154 & 158 & 157 & 185 & 252 & 252 & 232 & 242 & 188 & 188 & 154 & 154 & 218 & 233 & 190 & 5 & 4\end{array}$

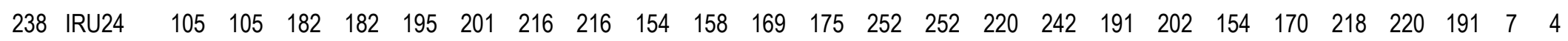


239 IRU25 240 IRU26 241 IRU27 242 IRU28 243 IRU29 244 IRU30 245 IRU31 246 IRU32 247 IRU33 248 IRU34 249 IRU35 250 IRU36 251 IRU37 252 IRU38 253 IRU39 254 IRU40 $\underline{x}$

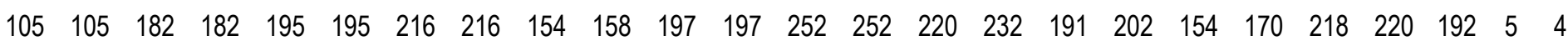
$\begin{array}{lllllllllllllllllllllllll}105 & 105 & 182 & 182 & 195 & 195 & 216 & 216 & 158 & 158 & 185 & 197 & 252 & 252 & 232 & 244 & 188 & 202 & 154 & 154 & 218 & 220 & 193 & 4 & 4\end{array}$ $\begin{array}{llllllllllllllllllllllllll}105 & 105 & 182 & 182 & 195 & 195 & 216 & 216 & 154 & 158 & 185 & 197 & 252 & 252 & 232 & 242 & 188 & 188 & 154 & 154 & 220 & 220 & 194 & 3 & 4\end{array}$ $\begin{array}{lllllllllllllllllllllllllll}105 & 105 & 167 & 182 & 195 & 195 & 210 & 210 & 154 & 156 & 157 & 189 & 252 & 252 & 232 & 242 & 191 & 202 & 154 & 154 & 220 & 233 & 195 & 6 & 4\end{array}$ $\begin{array}{llllllllllllllllllllllllllll}105 & 105 & 167 & 182 & 195 & 195 & 210 & 210 & 154 & 156 & 175 & 197 & 252 & 252 & 232 & 242 & 188 & 191 & 154 & 154 & 218 & 233 & 196 & 6 & 3\end{array}$ $\begin{array}{llllllllllllllllllllllllll}105 & 105 & 182 & 182 & 195 & 195 & 216 & 216 & 154 & 158 & 175 & 197 & 252 & 252 & 220 & 242 & 188 & 191 & 154 & 154 & 220 & 220 & 197 & 4 & 4\end{array}$ $\begin{array}{lllllllllllllllllllllllll}105 & 105 & 182 & 182 & 195 & 195 & 216 & 216 & 154 & 156 & 157 & 197 & 252 & 252 & 232 & 232 & 191 & 202 & 154 & 154 & 216 & 218 & 198 & 4 & 5\end{array}$ $\begin{array}{llllllllllllllllllllllllll}105 & 105 & 167 & 182 & 195 & 195 & 216 & 216 & 154 & 158 & 185 & 197 & 252 & 252 & 232 & 232 & 191 & 202 & 154 & 154 & 218 & 218 & 199 & 4 & 3\end{array}$ $\begin{array}{llllllllllllllllllllllllllll}105 & 105 & 167 & 182 & 195 & 195 & 216 & 216 & 156 & 158 & 169 & 197 & 252 & 252 & 242 & 242 & 188 & 202 & 154 & 154 & 218 & 220 & 200 & 5 & 3\end{array}$ $\begin{array}{lllllllllllllllllllllllll}105 & 105 & 182 & 182 & 195 & 195 & 210 & 210 & 156 & 156 & 169 & 197 & 252 & 252 & 242 & 242 & 188 & 202 & 154 & 154 & 218 & 218 & 201 & 2 & 4\end{array}$ $\begin{array}{lllllllllllllllllllllllll}105 & 105 & 182 & 182 & 195 & 195 & 216 & 216 & 156 & 158 & 197 & 201 & 252 & 252 & 232 & 244 & 188 & 202 & 154 & 181 & 218 & 233 & 202 & 6 & 4\end{array}$ $\begin{array}{lllllllllllllllllllllllll}105 & 105 & 182 & 182 & 195 & 195 & 216 & 216 & 156 & 158 & 197 & 197 & 252 & 252 & 232 & 232 & 188 & 202 & 154 & 154 & 218 & 233 & 203 & 3 & 4\end{array}$ $\begin{array}{llllllllllllllllllllllllll}105 & 105 & 182 & 182 & 195 & 195 & 216 & 216 & 154 & 158 & 185 & 197 & 252 & 252 & 232 & 242 & 188 & 202 & 154 & 154 & 218 & 220 & 204 & 5 & 4\end{array}$ $\begin{array}{lllllllllllllllllllllllll}105 & 105 & 182 & 182 & 195 & 195 & 216 & 216 & 154 & 156 & 175 & 197 & 252 & 252 & 220 & 242 & 188 & 194 & 154 & 154 & 218 & 218 & 205 & 4 & 4\end{array}$ $\begin{array}{llllllllllllllllllllllllll}105 & 105 & 167 & 182 & 192 & 195 & 208 & 220 & 151 & 158 & 175 & 175 & 252 & 256 & 220 & 232 & 186 & 191 & 170 & 174 & 220 & 224 & 206 & 9 & 8\end{array}$ $\begin{array}{lllllllllllllllllllllllllll}105 & 105 & 167 & 182 & 195 & 195 & 210 & 210 & 154 & 156 & 175 & 197 & 252 & 252 & 232 & 242 & 188 & 202 & 154 & 154 & 218 & 233 & 207 & 6 & 3\end{array}$ $\begin{array}{lllllllllllllllllllllllll}105 & 105 & 182 & 182 & 195 & 195 & 220 & 220 & 156 & 158 & 175 & 189 & 252 & 252 & 232 & 232 & 191 & 191 & 170 & 170 & 220 & 233 & 208 & 3 & 4\end{array}$ $\begin{array}{lllllllllllllllllllllllllll}105 & 105 & 182 & 182 & 195 & 195 & 216 & 220 & 156 & 158 & 157 & 175 & 252 & 252 & 220 & 232 & 191 & 191 & 170 & 170 & 220 & 233 & 209 & 5 & 5\end{array}$ $\begin{array}{llllllllllllllllllllllllll}105 & 105 & 182 & 182 & 195 & 195 & 216 & 216 & 158 & 158 & 175 & 197 & 252 & 252 & 232 & 242 & 188 & 191 & 154 & 154 & 233 & 233 & 210 & 3 & 4\end{array}$ $\begin{array}{lllllllllllllllllllllllllll}105 & 105 & 182 & 182 & 195 & 195 & 216 & 216 & 158 & 166 & 185 & 197 & 252 & 252 & 220 & 242 & 188 & 191 & 154 & 154 & 216 & 220 & 211 & 5 & 4\end{array}$ $\begin{array}{lllllllllllllllllllllllllll}105 & 105 & 182 & 182 & 195 & 195 & 216 & 216 & 158 & 166 & 175 & 197 & 252 & 252 & 232 & 242 & 188 & 191 & 154 & 154 & 220 & 233 & 212 & 5 & 4\end{array}$ $\begin{array}{llllllllllllllllllllllllll}105 & 105 & 182 & 182 & 195 & 195 & 216 & 216 & 158 & 158 & 171 & 197 & 252 & 252 & 232 & 242 & 191 & 202 & 154 & 170 & 220 & 220 & 213 & 4 & 4\end{array}$ $\begin{array}{lllllllllllllllllllllllllll}105 & 105 & 182 & 182 & 195 & 195 & 216 & 216 & 158 & 158 & 175 & 197 & 252 & 254 & 232 & 242 & 188 & 191 & 154 & 170 & 216 & 220 & 214 & 6 & 4\end{array}$ $\begin{array}{lllllllllllllllllllllllllll}105 & 105 & 173 & 182 & 195 & 195 & 216 & 216 & 154 & 166 & 175 & 185 & 252 & 254 & 232 & 242 & 191 & 191 & 154 & 154 & 216 & 233 & 215 & 6 & 3\end{array}$ $\begin{array}{lllllllllllllllllllllllllll}105 & 105 & 182 & 182 & 195 & 195 & 216 & 216 & 158 & 158 & 185 & 185 & 252 & 254 & 232 & 242 & 188 & 191 & 154 & 154 & 216 & 220 & 216 & 4 & 4\end{array}$ $\begin{array}{llllllllllllllllllllllllll}105 & 105 & 182 & 182 & 195 & 195 & 216 & 216 & 158 & 166 & 169 & 175 & 254 & 254 & 220 & 232 & 188 & 191 & 154 & 154 & 216 & 216 & 217 & 4 & 4\end{array}$ $\begin{array}{llllllllllllllllllllllllll}105 & 105 & 182 & 182 & 195 & 195 & 216 & 216 & 156 & 158 & 175 & 185 & 252 & 254 & 232 & 242 & 191 & 191 & 154 & 170 & 216 & 220 & 218 & 6 & 4\end{array}$ $\begin{array}{lllllllllllllllllllllllllll}105 & 105 & 173 & 182 & 195 & 195 & 216 & 216 & 158 & 166 & 175 & 185 & 252 & 252 & 232 & 242 & 191 & 191 & 154 & 154 & 216 & 233 & 219 & 5 & 3\end{array}$ $\begin{array}{lllllllllllllllllllllllllll}105 & 105 & 173 & 182 & 195 & 195 & 216 & 216 & 158 & 166 & 175 & 175 & 252 & 254 & 242 & 242 & 191 & 191 & 154 & 170 & 216 & 220 & 220 & 5 & 3\end{array}$ $\begin{array}{lllllllllllllllllllllllll}105 & 105 & 173 & 182 & 195 & 195 & 216 & 216 & 158 & 166 & 175 & 175 & 252 & 254 & 242 & 242 & 191 & 191 & 154 & 170 & 216 & 220 & 220 & 5 & 3\end{array}$ 


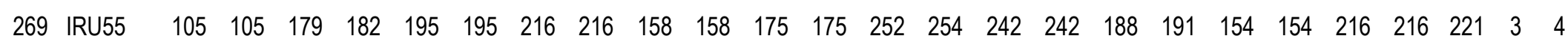
$\begin{array}{lllllllllllllllllllllllllll}270 & \text { IRU56 } & 105 & 105 & 182 & 182 & 195 & 195 & 216 & 216 & 156 & 158 & 171 & 175 & 252 & 252 & 232 & 242 & 191 & 202 & 154 & 170 & 216 & 216 & 222 & 5 & 4\end{array}$ \begin{tabular}{llllllllllllllllllllllllllll}
271 & IRU57 & 105 & 105 & 182 & 182 & 195 & 204 & 216 & 216 & 158 & 166 & 185 & 185 & 252 & 252 & 220 & 242 & 188 & 191 & 170 & 172 & 220 & 220 & 223 & 5 & 4 \\
\hline
\end{tabular} $\begin{array}{llllllllllllllllllllllllllllll}273 & \text { CAS02 } & 105 & 111 & 182 & 182 & 195 & 195 & 208 & 208 & 154 & 154 & 157 & 199 & 252 & 252 & 232 & 244 & 188 & 188 & 154 & 154 & 220 & 220 & 225 & 3 & 7\end{array}$ $\begin{array}{llllllllllllllllllllllllllll}274 & \text { CAS03 } & 105 & 111 & 182 & 182 & 195 & 195 & 208 & 208 & 154 & 154 & 197 & 199 & 252 & 252 & 232 & 242 & 188 & 188 & 154 & 154 & 220 & 220 & 226 & 3 & 6\end{array}$ $\begin{array}{lllllllllllllllllllllllllll}275 & \text { CAS04 } & 105 & 111 & 182 & 182 & 195 & 195 & 208 & 208 & 154 & 158 & 197 & 197 & 252 & 252 & 242 & 244 & 188 & 188 & 154 & 154 & 216 & 220 & 227 & 4 & 6\end{array}$ $\begin{array}{llllllllllllllllllllllllllll}276 & \text { CAS05 } & 105 & 111 & 182 & 185 & 195 & 195 & 208 & 216 & 154 & 158 & 157 & 195 & 252 & 252 & 232 & 244 & 188 & 188 & 154 & 154 & 220 & 220 & 228 & 6 & 5\end{array}$ $\begin{array}{lllllllllllllllllllllllllllll}277 & \text { CAS06 } & 105 & 105 & 176 & 182 & 195 & 195 & 216 & 216 & 158 & 158 & 175 & 195 & 252 & 252 & 232 & 244 & 188 & 188 & 154 & 154 & 220 & 220 & 229 & 3 & 3\end{array}$

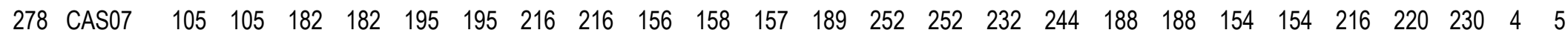

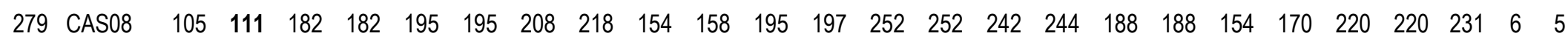

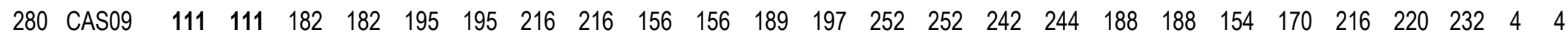
$\begin{array}{lllllllllllllllllllllllllll}281 & \text { CAS10 } & 105 & 111 & 182 & 182 & 195 & 195 & 208 & 216 & 154 & 156 & 185 & 197 & 252 & 252 & 242 & 244 & 188 & 188 & 170 & 170 & 220 & 220 & 233 & 5 & 5\end{array}$ $\begin{array}{lllllllllllllllllllllllllll}282 & \text { CAS11 } & 105 & 105 & 182 & 182 & 195 & 195 & 208 & 216 & 154 & 156 & 169 & 199 & 252 & 252 & 242 & 242 & 188 & 188 & 154 & 170 & 216 & 220 & 234 & 5 & 5\end{array}$ $\begin{array}{lllllllllllllllllllllllllll}283 & \text { CAS12 } & 105 & 111 & 182 & 182 & 195 & 195 & 208 & 218 & 158 & 158 & 157 & 187 & 252 & 252 & 232 & 242 & 188 & 202 & 170 & 170 & 220 & 220 & 235 & 5 & 6\end{array}$ $\begin{array}{llllllllllllllllllllllllllll}284 & \text { CAS13 } & 105 & 111 & 182 & 182 & 195 & 195 & 208 & 208 & 154 & 156 & 157 & 197 & 252 & 252 & 232 & 244 & 188 & 191 & 154 & 154 & 220 & 220 & 236 & 5 & 7\end{array}$ $\begin{array}{lllllllllllllllllllllllllllll}285 & \text { CAS14 } & 105 & 105 & 182 & 182 & 195 & 195 & 208 & 220 & 154 & 158 & 175 & 195 & 252 & 252 & 244 & 244 & 188 & 188 & 154 & 154 & 216 & 220 & 237 & 4 & 5\end{array}$

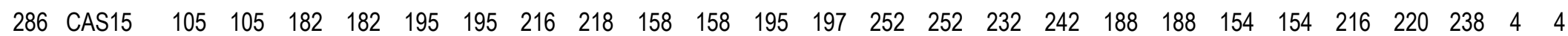
$\begin{array}{llllllllllllllllllllllllllll}287 & \text { CAS16 } & 105 & 111 & 182 & 182 & 195 & 195 & 208 & 216 & 154 & 158 & 195 & 197 & 252 & 252 & 220 & 244 & 188 & 202 & 154 & 154 & 220 & 220 & 239 & 6 & 5\end{array}$ $\begin{array}{lllllllllllllllllllllllllll}288 & \text { CAS17 } & 105 & 105 & 182 & 182 & 195 & 195 & 208 & 208 & 154 & 158 & 157 & 197 & 252 & 252 & 244 & 244 & 188 & 188 & 154 & 154 & 220 & 220 & 240 & 2 & 7\end{array}$ $\begin{array}{lllllllllllllllllllllllllll}289 & \text { CAS18 } & 105 & 105 & 182 & 182 & 195 & 195 & 208 & 220 & 154 & 158 & 175 & 199 & 252 & 252 & 242 & 244 & 188 & 188 & 154 & 154 & 216 & 220 & 241 & 5 & 5\end{array}$

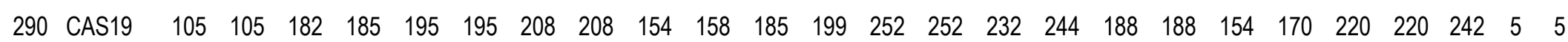
$\begin{array}{llllllllllllllllllllllllllll}291 & \text { CAS20 } & 105 & 105 & 182 & 182 & 195 & 195 & 208 & 208 & 154 & 156 & 189 & 189 & 252 & 252 & 220 & 244 & 191 & 191 & 154 & 154 & 220 & 220 & 243 & 2 & 6\end{array}$ \begin{tabular}{lllllllllllllllllllllllllll}
292 & CAS21 & 105 & 111 & 182 & 182 & 195 & 195 & 208 & 216 & 154 & 156 & 175 & 189 & 252 & 252 & 232 & 244 & 188 & 191 & 154 & 154 & 220 & 220 & 244 & 6 & 5 \\
\hline 293 & PIE01 & 105 & 105 & 167 & 182 & 195 & 195 & 216 & 216 & 154 & 154 & 157 & 185 & 252 & 252 & 242 & 244 & 188 & 188 & 154 & 170 & 218 & 218 & 245 & 4 & 4
\end{tabular}

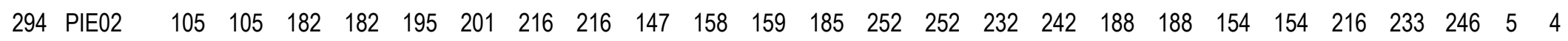
$\begin{array}{llllllllllllllllllllllllllll}295 & \text { PIE03 } & 105 & 105 & 167 & 182 & 195 & 201 & 216 & 218 & 154 & 158 & 171 & 189 & 252 & 252 & 232 & 232 & 188 & 188 & 154 & 154 & 216 & 220 & 247 & 6 & 3\end{array}$

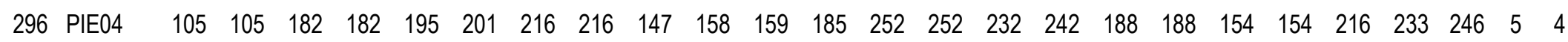
$\begin{array}{lllllllllllllllllllllllllll}297 & \text { PIE05 } & 105 & 105 & 167 & 182 & 195 & 201 & 216 & 218 & 154 & 158 & 171 & 189 & 252 & 252 & 232 & 232 & 188 & 188 & 154 & 154 & 216 & 220 & 247 & 6 & 3\end{array}$

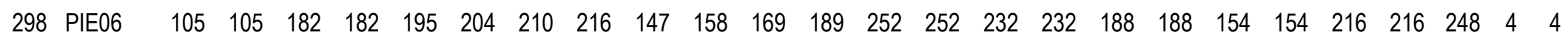




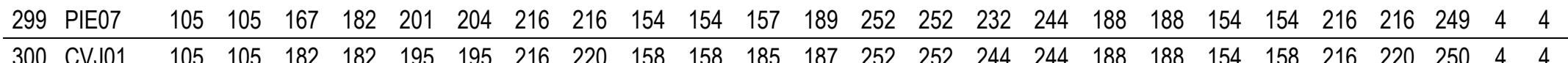
$\begin{array}{llllllllllllllllllllllllllllll}301 & \text { CVJ02 } & 105 & 105 & 182 & 182 & 195 & 195 & 216 & 220 & 158 & 158 & 185 & 187 & 252 & 252 & 244 & 244 & 188 & 188 & 154 & 158 & 216 & 220 & 250 & 4 & 4\end{array}$

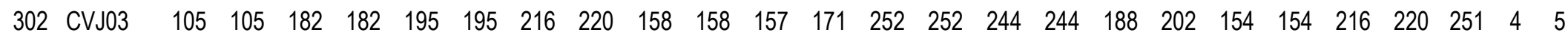
$\begin{array}{lllllllllllllllllllllllllllll}303 & \text { CVJ04 } & 105 & 105 & 182 & 182 & 195 & 195 & 216 & 220 & 158 & 158 & 157 & 187 & 252 & 252 & 232 & 244 & 188 & 202 & 154 & 154 & 216 & 220 & 252 & 5 & 5\end{array}$ $\begin{array}{lllllllllllllllllllllllllll}304 & \text { CVJ05 } & 105 & 105 & 182 & 182 & 195 & 195 & 216 & 216 & 158 & 164 & 185 & 187 & 252 & 252 & 232 & 242 & 188 & 202 & 170 & 170 & 216 & 220 & 253 & 5 & 4\end{array}$ $\begin{array}{llllllllllllllllllllllllllll}305 & \text { CVJ06 } & 105 & 105 & 200 & 200 & 195 & 195 & 216 & 216 & 158 & 158 & 157 & 185 & 252 & 252 & 244 & 244 & 188 & 188 & 154 & 154 & 216 & 220 & 254 & 2 & 3\end{array}$ $\begin{array}{llllllllllllllllllllllllllll}306 & \text { CVJ07 } & 102 & 105 & 182 & 185 & 192 & 195 & 208 & 216 & 145 & 151 & 152 & 159 & 252 & 252 & 232 & 233 & 186 & 188 & 151 & 156 & 218 & 222 & 255 & 10 & 10\end{array}$ $\begin{array}{llllllllllllllllllllllllllll}307 & \text { CVJ08 } & 102 & 105 & 182 & 185 & 192 & 195 & 208 & 216 & 145 & 151 & 152 & 159 & 252 & 252 & 232 & 233 & 186 & 188 & 151 & 156 & 218 & 222 & 255 & 10 & 10\end{array}$

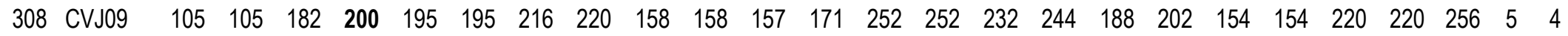
$\begin{array}{llllllllllllllllllllllllllllll}309 & \text { CVJ10 } & 105 & 105 & 182 & 182 & 195 & 195 & 216 & 216 & 154 & 158 & 157 & 171 & 252 & 252 & 244 & 244 & 188 & 188 & 154 & 158 & 216 & 220 & 257 & 4 & 5\end{array}$ $\begin{array}{llllllllllllllllllllllllllll}310 & \text { CVJ11 } & 105 & 105 & 182 & 182 & 195 & 195 & 216 & 220 & 158 & 158 & 171 & 185 & 252 & 252 & 232 & 244 & 188 & 188 & 154 & 154 & 220 & 220 & 258 & 3 & 4\end{array}$ $\begin{array}{llllllllllllllllllllllllllll}311 & \text { CVJ12 } & 105 & 105 & 182 & 182 & 195 & 195 & 200 & 216 & 154 & 156 & 185 & 187 & 252 & 252 & 232 & 244 & 188 & 188 & 154 & 158 & 216 & 220 & 259 & 6 & 4\end{array}$ $\begin{array}{lllllllllllllllllllllllllllllll}312 & \text { CVJ13 } & 105 & 105 & 182 & 182 & 195 & 195 & 216 & 220 & 158 & 164 & 157 & 171 & 252 & 252 & 242 & 244 & 188 & 202 & 154 & 170 & 216 & 220 & 260 & 7 & 5\end{array}$ $\begin{array}{llllllllllllllllllllllllllll}313 & \text { CVJ14 } & 105 & 105 & 182 & 200 & 195 & 195 & 216 & 220 & 158 & 158 & 157 & 171 & 252 & 252 & 244 & 244 & 188 & 191 & 154 & 154 & 216 & 216 & 261 & 4 & 4\end{array}$ $\begin{array}{lllllllllllllllllllllllllllll}314 & \text { CVJ15 } & 105 & 105 & 182 & 182 & 195 & 195 & 200 & 220 & 156 & 158 & 157 & 171 & 252 & 252 & 232 & 244 & 188 & 188 & 154 & 154 & 220 & 220 & 262 & 4 & 5\end{array}$ $\begin{array}{llllllllllllllllllllllllllll}315 & \text { CVJ16 } & 105 & 105 & 182 & 182 & 195 & 195 & 216 & 220 & 145 & 164 & 171 & 171 & 252 & 254 & 232 & 232 & 188 & 188 & 154 & 170 & 216 & 220 & 263 & 5 & 4\end{array}$ $\begin{array}{lllllllllllllllllllllllllll}316 & \text { CVJ17 } & 105 & 105 & 167 & 182 & 195 & 195 & 216 & 220 & 158 & 158 & 171 & 171 & 252 & 252 & 232 & 242 & 188 & 191 & 154 & 170 & 216 & 233 & 264 & 6 & 3\end{array}$ $\begin{array}{lllllllllllllllllllllllllllll}317 & \text { CVJ18 } & 105 & 105 & 182 & 182 & 195 & 195 & 200 & 220 & 156 & 158 & 171 & 187 & 252 & 252 & 232 & 244 & 188 & 188 & 154 & 170 & 218 & 220 & 265 & 6 & 4\end{array}$ $\begin{array}{lllllllllllllllllllllllllll}318 & \text { CVJ19 } & 105 & 105 & 182 & 182 & 195 & 195 & 216 & 220 & 145 & 158 & 171 & 171 & 252 & 254 & 232 & 244 & 188 & 202 & 154 & 170 & 220 & 220 & 266 & 6 & 4\end{array}$

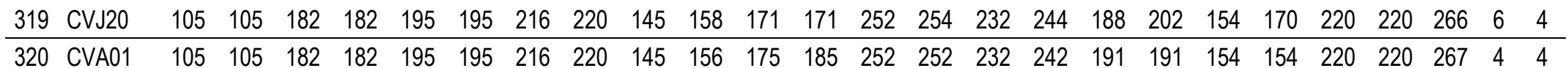
$\begin{array}{lllllllllllllllllllllllllllll}321 & \text { CVA02 } & 105 & 105 & 182 & 182 & 195 & 195 & 216 & 216 & 156 & 156 & 167 & 175 & 252 & 252 & 242 & 244 & 191 & 191 & 154 & 154 & 220 & 220 & 268 & 2 & 4\end{array}$ $\begin{array}{lllllllllllllllllllllllllllll}322 & \text { CVA03 } & 105 & 105 & 167 & 182 & 195 & 195 & 216 & 224 & 156 & 158 & 169 & 185 & 252 & 252 & 232 & 232 & 188 & 191 & 154 & 170 & 220 & 220 & 269 & 6 & 3\end{array}$ $\begin{array}{lllllllllllllllllllllllllllll}323 & \text { CVA04 } & 105 & 105 & 182 & 182 & 195 & 195 & 220 & 224 & 145 & 158 & 183 & 199 & 252 & 252 & 232 & 242 & 188 & 191 & 170 & 170 & 220 & 220 & 270 & 5 & 4\end{array}$

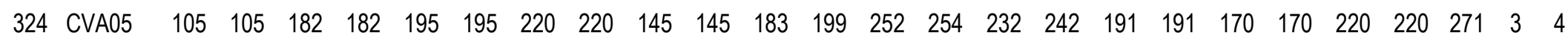
$\begin{array}{lllllllllllllllllllllllllll}325 & \text { CVA06 } & 105 & 105 & 182 & 182 & 195 & 195 & 216 & 220 & 145 & 156 & 167 & 169 & 252 & 254 & 242 & 244 & 188 & 191 & 170 & 170 & 220 & 220 & 272 & 6 & 4\end{array}$ $\begin{array}{lllllllllllllllllllllllllllll}326 & \text { CVA07 } & 105 & 105 & 167 & 182 & 195 & 195 & 220 & 224 & 145 & 158 & 183 & 199 & 252 & 252 & 232 & 242 & 188 & 191 & 154 & 170 & 218 & 220 & 273 & 8 & 3\end{array}$ $\begin{array}{llllllllllllllllllllllllllll}327 & \text { CVA08 } & 105 & 105 & 182 & 182 & 195 & 195 & 216 & 216 & 156 & 156 & 167 & 175 & 252 & 252 & 232 & 244 & 188 & 188 & 154 & 170 & 216 & 220 & 274 & 4 & 4\end{array}$

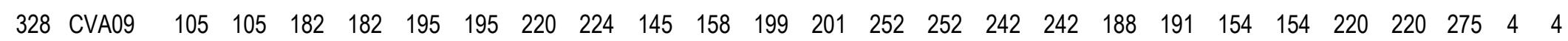




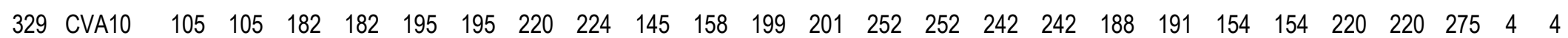

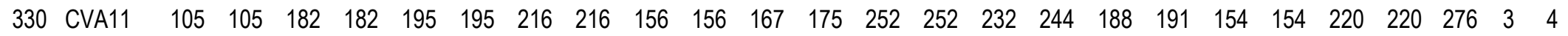

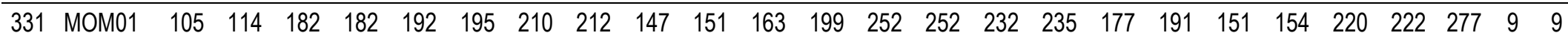

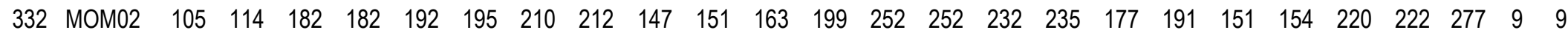
$\begin{array}{llllllllllllllllllllllllllll}333 & \text { МОM03 } & 105 & 114 & 182 & 182 & 192 & 195 & 210 & 212 & 147 & 151 & 163 & 199 & 252 & 252 & 232 & 235 & 177 & 191 & 151 & 154 & 220 & 222 & 277 & 9 & 9\end{array}$ $\begin{array}{llllllllllllllllllllllllllll}334 & \text { MOM04 } & 105 & 114 & 182 & 182 & 192 & 195 & 210 & 212 & 147 & 151 & 163 & 199 & 252 & 252 & 232 & 235 & 177 & 191 & 151 & 154 & 220 & 222 & 277 & 9 & 9\end{array}$

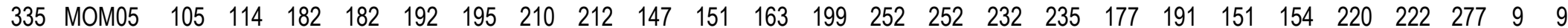
$\begin{array}{lllllllllllllllllllllllllll}336 & \text { MOM06 } & 105 & 114 & 182 & 182 & 192 & 195 & 210 & 212 & 147 & 151 & 163 & 199 & 252 & 252 & 232 & 235 & 177 & 191 & 151 & 154 & 220 & 222 & 277 & 9 & 9\end{array}$ $\begin{array}{lllllllllllllllllllllllllll}337 & \text { MOM07 } & 105 & 105 & 182 & 182 & 195 & 195 & 210 & 218 & 145 & 158 & 199 & 205 & 252 & 252 & 232 & 242 & 191 & 191 & 154 & 170 & 220 & 220 & 278 & 5 & 4\end{array}$

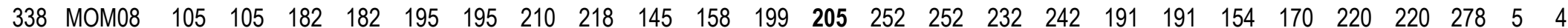
$\begin{array}{llllllllllllllllllllllllllll}339 & \text { MOM09 } & 105 & 105 & 182 & 182 & 195 & 195 & 210 & 218 & 145 & 158 & 199 & 205 & 252 & 252 & 232 & 242 & 191 & 191 & 154 & 170 & 220 & 220 & 278 & 5 & 4\end{array}$ \begin{tabular}{lllllllllllllllllllllllllll}
340 & MOM10 & 105 & 114 & 182 & 182 & 192 & 195 & 210 & 212 & 147 & 151 & 163 & 199 & 252 & 252 & 232 & 235 & 177 & 191 & 151 & 154 & 220 & 222 & 277 & 9 & 9 \\
\hline 341 & CAN01 & 105 & 105 & 182 & 182 & 195 & 195 & 214 & 214 & 154 & 154 & 165 & 165 & 252 & 252 & 236 & 242 & 188 & 191 & 154 & 156 & 220 & 220 & 279 & 3 & 4
\end{tabular}

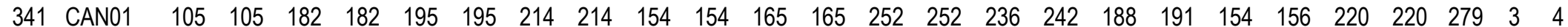
$\begin{array}{lllllllllllllllllllllllllll}342 & \text { CAN02 } & 105 & 108 & 182 & 182 & 195 & 195 & 208 & 208 & 151 & 154 & 163 & 189 & 252 & 252 & 236 & 244 & 188 & 191 & 154 & 170 & 220 & 220 & 280 & 6 & 9\end{array}$ $\begin{array}{lllllllllllllllllllllllllllll}343 & \text { CAN03 } & 105 & 105 & 182 & 182 & 195 & 195 & 216 & 216 & 154 & 158 & 157 & 185 & 252 & 254 & 236 & 242 & 188 & 188 & 154 & 156 & 220 & 220 & 281 & 5 & 5\end{array}$

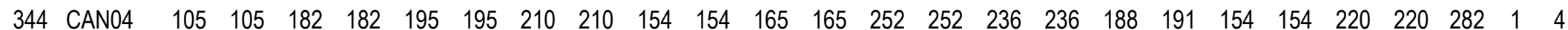
$\begin{array}{lllllllllllllllllllllllllllll}345 & \text { CAN05 } & 105 & 105 & 182 & 182 & 195 & 195 & 208 & 214 & 154 & 158 & 183 & 189 & 252 & 252 & 232 & 236 & 188 & 188 & 154 & 156 & 220 & 220 & 283 & 5 & 5\end{array}$

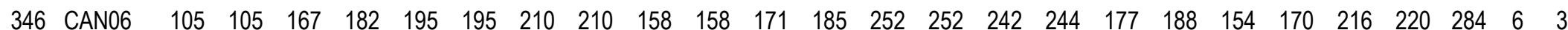
$\begin{array}{lllllllllllllllllllllllllll}347 & \text { CAN07 } & 105 & 105 & 182 & 182 & 195 & 195 & 218 & 218 & 158 & 158 & 169 & 185 & 252 & 252 & 232 & 244 & 177 & 188 & 154 & 172 & 216 & 236 & 285 & 5 & 4\end{array}$ \begin{tabular}{lllllllllllllllllllllllllll}
348 & CAN08 & 105 & 105 & 182 & 182 & 195 & 195 & 218 & 218 & 158 & 158 & 169 & 185 & 252 & 252 & 232 & 244 & 177 & 188 & 154 & 172 & 216 & 236 & 285 & 5 & 4 \\
\hline 349 & ALD01 & 105 & 105 & 182 & 182 & 195 & 195 & 208 & 208 & 158 & 166 & 169 & 171 & 252 & 252 & 232 & 232 & 188 & 202 & 154 & 170 & 216 & 233 & 286 & 5 & 6
\end{tabular} $\begin{array}{llllllllllllllllllllllllllll}349 & \text { ALD01 } & 105 & 105 & 182 & 182 & 195 & 195 & 208 & 208 & 158 & 166 & 169 & 171 & 252 & 252 & 232 & 232 & 188 & 202 & 154 & 170 & 216 & 233 & 286 & 5 & 6\end{array}$ $\begin{array}{llllllllllllllllllllllllllll}350 & \text { ALD02 } & 105 & 105 & 182 & 182 & 195 & 195 & 200 & 200 & 156 & 158 & 169 & 171 & 252 & 252 & 232 & 232 & 188 & 202 & 154 & 154 & 216 & 233 & 287 & 4 & 4\end{array}$ $\begin{array}{llllllllllllllllllllllllllll}351 & \text { ALD03 } & 105 & 105 & 182 & 182 & 195 & 195 & 208 & 208 & 158 & 166 & 175 & 185 & 252 & 252 & 232 & 244 & 188 & 202 & 154 & 170 & 216 & 233 & 288 & 6 & 6\end{array}$

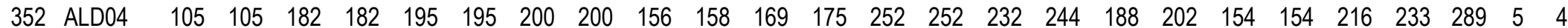
$\begin{array}{llllllllllllllllllllllllllll}353 & \text { ALD05 } & 105 & 105 & 182 & 182 & 195 & 195 & 208 & 208 & 158 & 166 & 175 & 185 & 252 & 252 & 242 & 244 & 188 & 202 & 154 & 170 & 216 & 233 & 290 & 6 & 6\end{array}$ $\begin{array}{lllllllllllllllllllllllllll}354 & \text { ALD06 } & 105 & 105 & 182 & 182 & 195 & 195 & 200 & 200 & 156 & 158 & 185 & 185 & 252 & 252 & 232 & 242 & 188 & 202 & 154 & 154 & 216 & 220 & 291 & 4 & 4\end{array}$

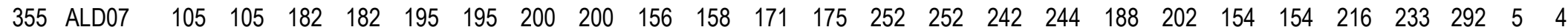
$\begin{array}{llllllllllllllllllllllllllllll}356 & \text { ALD08 } & 105 & 105 & 182 & 182 & 195 & 201 & 208 & 208 & 158 & 166 & 175 & 185 & 252 & 252 & 220 & 242 & 188 & 191 & 156 & 170 & 220 & 233 & 293 & 7 & 6\end{array}$ $\begin{array}{llllllllllllllllllllllllllll}357 & \text { ALD09 } & 105 & 105 & 182 & 182 & 195 & 195 & 200 & 208 & 156 & 166 & 175 & 175 & 252 & 252 & 232 & 242 & 188 & 202 & 154 & 170 & 216 & 216 & 294 & 5 & 5\end{array}$

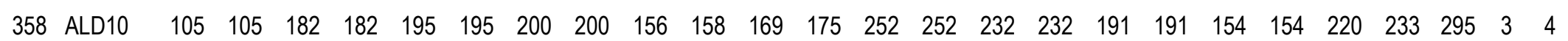




\begin{tabular}{|c|c|c|c|c|c|c|c|c|c|c|c|c|c|c|c|c|c|c|c|c|c|c|c|c|c|}
\hline \multirow[b]{2}{*}{0} & VIL01 & 105 & 55 & 167 & 182 & 195 & 195 & 210 & 210 & 47 & 154 & 157 & 157 & 252 & 252 & 232 & 244 & 188 & 188 & 154 & 154 & 216 & 216 & 296 & \\
\hline & IL02 & 105 & 05 & 167 & 182 & 195 & 195 & 210 & 0 & 17 & 56 & 57 & 157 & 252 & 252 & 242 & 244 & 188 & 191 & 154 & 54 & 216 & 16 & 97 & \\
\hline 1 & 03 & & 55 & 79 & 182 & 195 & 195 & 208 & & 66 & 8 & & 79 & 252 & 252 & 232 & 36 & 188 & 202 & 54 & & 16 & 16 & & \\
\hline 2 & 04 & & & 32 & 82 & & 195 & 8 & & & & & 7 & 2 & 2 & 236 & & & & & & & & & \\
\hline 63 & .05 & & 5 & 32 & 182 & 35 & 195 & 0 & 0 & & & & 157 & 2 & 2 & 32 & 6 & 91 & 02 & & & 10 & 10 & & \\
\hline 364 & 06 & 5 & 55 & 182 & 182 & 195 & 195 & 210 & 210 & 64 & 54 & 57 & 171 & 252 & 252 & 236 & 244 & 191 & 202 & 54 & 81 & 216 & 216 & 301 & \\
\hline b & .07 & 15 & 5 & 182 & 182 & 195 & 195 & 210 & 210 & 47 & 154 & 157 & 157 & 252 & 252 & 232 & 36 & 191 & 202 & 4 & & 216 & 216 & 0 & \\
\hline 6 & 108 & 5 & 05 & 182 & 182 & 195 & 195 & 210 & 10 & 44 & 56 & 57 & 171 & 252 & 252 & 242 & 244 & 188 & 191 & 154 & 154 & 216 & 216 & 302 & \\
\hline 7 & 09 & & 5 & 82 & 182 & 195 & 195 & 208 & 0 & 4 & 56 & & 171 & 252 & 252 & 236 & 244 & 202 & 202 & 54 & 0 & 276 & 210 & & \\
\hline & -10 & & 5 & 182 & 182 & 195 & 195 & 208 & 210 & 54 & 56 & & 171 & 252 & 252 & 236 & 244 & 202 & 202 & 104 & 10 & 216 & 210 & & \\
\hline 9 & L11 & 5 & 05 & 182 & 182 & 195 & 195 & 210 & 210 & 54 & 54 & 57 & 195 & 252 & 252 & 232 & 236 & 191 & 202 & 54 & 81 & 216 & 216 & 04 & \\
\hline 0 & 12 & 5 & 55 & 167 & 182 & 195 & 195 & 210 & 210 & 17 & 54 & 57 & 157 & 252 & 252 & 236 & 44 & 188 & 202 & 54 & 54 & 216 & 216 & 305 & \\
\hline 1 & 13 & 5 & 55 & 182 & 182 & 195 & 195 & 208 & 10 & 154 & 156 & 157 & 171 & 252 & 252 & 244 & 244 & 188 & 202 & 154 & 154 & 216 & 216 & 306 & \\
\hline 2 & L14 & 5 & 05 & 167 & 179 & 195 & 195 & 212 & 212 & 58 & 158 & 157 & 157 & 252 & 252 & 236 & 242 & 188 & 202 & 154 & 158 & 216 & 220 & $30 /$ & \\
\hline 373 & L15 & 10 & 105 & 167 & 179 & 195 & 195 & 212 & 212 & 58 & 158 & 57 & 157 & 252 & 252 & 236 & 242 & 188 & 202 & 154 & 158 & 216 & 220 & 30, & \\
\hline 374 & R01 & 5 & 105 & 182 & 182 & 195 & 195 & 220 & 220 & 158 & 158 & 157 & 167 & 252 & 252 & 236 & 244 & 202 & 202 & 54 & & 216 & 216 & $30 \varepsilon$ & \\
\hline 5 & R02 & 5 & 105 & 182 & 182 & 195 & 195 & 208 & 20 & 158 & 58 & 157 & 175 & 252 & 252 & 232 & 244 & 191 & 202 & 54 & 54 & 216 & 220 & 309 & \\
\hline 376 & R03 & 105 & 105 & 182 & 182 & 195 & 195 & 208 & 210 & 158 & 58 & 75 & 201 & 252 & 252 & 236 & 244 & 191 & 202 & 154 & 170 & 216 & 216 & & \\
\hline 377 & R04 & 10 & 105 & 182 & 185 & 195 & 201 & 210 & 220 & 154 & 158 & 157 & 169 & 252 & 252 & 242 & 244 & 188 & 202 & 154 & 154 & 220 & 220 & & \\
\hline 378 & R05 & & 105 & 167 & 182 & 195 & 195 & 208 & 210 & 4 & 158 & 179 & 201 & 252 & 252 & 242 & 244 & 194 & 202 & 154 & 156 & 216 & 216 & 31 & \\
\hline 379 & R06 & 1( & 105 & 182 & 182 & 195 & 195 & 216 & 220 & 154 & 58 & 57 & 179 & 252 & 252 & 236 & 242 & 188 & 202 & 56 & 181 & 216 & 220 & 313 & \\
\hline 0 & R07 & 1 & 5 & 167 & 182 & 195 & 201 & 208 & 210 & 154 & 158 & 57 & 171 & 252 & 252 & 232 & 236 & 194 & 202 & 54 & 56 & 216 & 216 & 14 & \\
\hline 381 & R08 & 1 & 55 & 182 & 182 & 195 & 201 & 208 & 208 & 158 & 164 & 5 & 201 & 252 & 252 & 236 & 244 & 202 & 202 & 154 & $1 / 0$ & 216 & 216 & 315 & \\
\hline 382 & R09 & & 105 & 182 & 182 & 195 & 195 & 208 & 216 & 15 & 158 & 15 & 175 & 252 & 252 & 232 & 236 & 191 & 202 & 154 & 156 & 216 & 216 & 316 & \\
\hline 383 & R10 & & 105 & 182 & 182 & 195 & 201 & 216 & 220 & 158 & 158 & 15 & 157 & 252 & 252 & 236 & 242 & 188 & 194 & 154 & 154 & 216 & 216 & 317 & \\
\hline 384 & R11 & 105 & 105 & 182 & 182 & 195 & 195 & 210 & 220 & 15 & 158 & & 175 & 252 & 252 & 236 & 236 & 188 & 202 & 154 & 154 & 216 & 220 & 10 & \\
\hline 385 & $\mathrm{R} 12$ & 105 & 55 & 182 & 182 & 195 & 195 & 216 & 220 & 158 & 158 & & 175 & 252 & 252 & 232 & 236 & 191 & 202 & 54 & 56 & 216 & 218 & $y$ & \\
\hline 386 & R13 & 105 & 105 & 167 & 182 & 195 & 201 & 208 & 208 & 158 & 158 & 157 & 157 & 252 & 252 & 236 & 242 & 202 & 202 & 154 & 154 & 216 & 216 & 20 & \\
\hline $3 \varepsilon$ & & & & 167 & 182 & 19 & 201 & 208 & 210 & 15 & & & 179 & 25 & 252 & 236 & 244 & 194 & 202 & 154 & 156 & 216 & 218 & 321 & \\
\hline 388 & R15 & 105 & 105 & 182 & 182 & 195 & 201 & 216 & 216 & 145 & 156 & 157 & 157 & 252 & 252 & 236 & 236 & 188 & 202 & 154 & 151 & 216 & 220 & 322 & \\
\hline
\end{tabular}




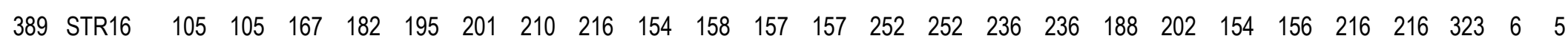
$\begin{array}{llllllllllllllllllllllllllll}390 & \text { STR17 } & 105 & 105 & 182 & 182 & 201 & 201 & 208 & 216 & 156 & 158 & 157 & 171 & 252 & 252 & 236 & 236 & 202 & 202 & 154 & 156 & 216 & 220 & 324 & 5 & 6\end{array}$ $\begin{array}{lllllllllllllllllllllllllll}391 & \text { STR18 } & 105 & 105 & 182 & 182 & 195 & 195 & 208 & 216 & 154 & 156 & 175 & 175 & 252 & 252 & 236 & 236 & 191 & 202 & 154 & 154 & 216 & 220 & 325 & 4 & 5\end{array}$

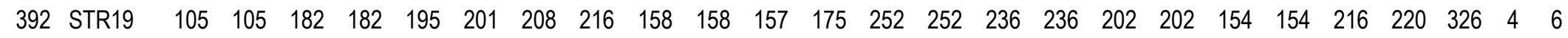

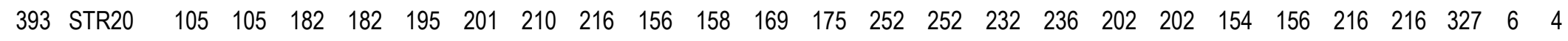
$\begin{array}{lllllllllllllllllllllllllllll}394 & \text { STR21 } & 105 & 105 & 182 & 182 & 195 & 195 & 210 & 216 & 154 & 158 & 157 & 175 & 252 & 252 & 236 & 236 & 191 & 191 & 154 & 154 & 216 & 218 & 328 & 4 & 5\end{array}$ $\begin{array}{llllllllllllllllllllllllllll}395 & \text { STR22 } & 105 & 105 & 182 & 182 & 195 & 195 & 210 & 216 & 154 & 158 & 157 & 175 & 252 & 252 & 236 & 236 & 191 & 191 & 154 & 154 & 216 & 218 & 328 & 4 & 5\end{array}$

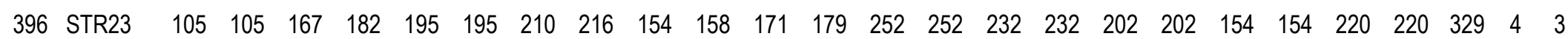
$\begin{array}{llllllllllllllllllllllllllllll}397 & \text { STR24 } & 105 & 105 & 182 & 182 & 195 & 195 & 210 & 220 & 158 & 158 & 157 & 201 & 252 & 252 & 236 & 244 & 188 & 202 & 154 & 154 & 216 & 216 & 330 & 4 & 5\end{array}$ $\begin{array}{lllllllllllllllllllllllllll}398 & \text { STR25 } & 105 & 105 & 182 & 182 & 201 & 201 & 208 & 208 & 158 & 158 & 167 & 175 & 252 & 252 & 236 & 236 & 188 & 202 & 154 & 154 & 216 & 220 & 331 & 3 & 6\end{array}$ $\begin{array}{llllllllllllllllllllllllllll}399 & \text { STR26 } & 105 & 105 & 182 & 182 & 195 & 201 & 210 & 220 & 158 & 158 & 175 & 175 & 252 & 252 & 236 & 236 & 191 & 202 & 154 & 154 & 216 & 216 & 332 & 3 & 4\end{array}$ $\begin{array}{lllllllllllllllllllllllllll}400 & \text { STR27 } & 105 & 105 & 182 & 182 & 195 & 201 & 210 & 220 & 156 & 158 & 175 & 179 & 252 & 252 & 236 & 244 & 191 & 202 & 154 & 154 & 216 & 216 & 333 & 6 & 4\end{array}$ $\begin{array}{lllllllllllllllllllllllllll}401 & \text { STR28 } & 105 & 105 & 167 & 182 & 195 & 201 & 208 & 216 & 158 & 158 & 179 & 179 & 252 & 252 & 232 & 236 & 188 & 191 & 170 & 170 & 216 & 220 & 334 & 6 & 4\end{array}$ \begin{tabular}{llllllllllllllllllllllllllll}
402 & STR29 & 105 & 105 & 167 & 182 & 195 & 195 & 216 & 220 & 154 & 158 & 175 & 171 & 252 & 252 & 232 & 232 & 188 & 202 & 154 & 156 & 216 & 216 & 335 & 5 & 3 \\
\hline 403 & BEN01 & 105 & 105 & 107 & 182 & 195 & 201 & 216 & 216 & 154 & 158 & 171 & 171 & 252 & 254 & 232 & 232 & 188 & 191 & 156 & 170 & 216 & 218 & 336 & 7 & 3
\end{tabular} $\begin{array}{llllllllllllllllllllllllllllllllllll}404 & \text { BEN02 } & 105 & 105 & 182 & 182 & 195 & 195 & 210 & 210 & 154 & 154 & 157 & 171 & 252 & 254 & 220 & 232 & 188 & 191 & 154 & 170 & 216 & 220 & 337 & 6 & 5\end{array}$ $\begin{array}{lllllllllllllllllllllllllllll}405 & \text { BEN03 } & 105 & 105 & 182 & 182 & 195 & 195 & 212 & 212 & 158 & 158 & 157 & 159 & 252 & 254 & 220 & 242 & 188 & 191 & 170 & 170 & 216 & 216 & 338 & 4 & 5\end{array}$ $\begin{array}{llllllllllllllllllllllllllll}406 & \text { BEN04 } & 105 & 105 & 182 & 182 & 195 & 201 & 220 & 220 & 158 & 158 & 175 & 197 & 252 & 254 & 220 & 232 & 188 & 191 & 170 & 170 & 216 & 220 & 339 & 6 & 4\end{array}$ $\begin{array}{lllllllllllllllllllllllllllll}407 & \text { BEN05 } & 105 & 105 & 182 & 182 & 195 & 201 & 212 & 212 & 154 & 158 & 157 & 175 & 252 & 254 & 220 & 232 & 191 & 191 & 154 & 156 & 216 & 216 & 340 & 6 & 5\end{array}$ $\begin{array}{lllllllllllllllllllllllllllllll}408 & \text { BEN06 } & 105 & 105 & 182 & 182 & 201 & 201 & 212 & 212 & 154 & 158 & 157 & 175 & 252 & 254 & 232 & 242 & 188 & 191 & 154 & 156 & 216 & 216 & 341 & 6 & 5\end{array}$ $\begin{array}{llllllllllllllllllllllllllll}409 & \text { BEN07 } & 105 & 105 & 182 & 182 & 195 & 201 & 210 & 220 & 158 & 158 & 157 & 157 & 252 & 252 & 220 & 232 & 191 & 191 & 170 & 170 & 216 & 218 & 342 & 4 & 6\end{array}$ $\begin{array}{lllllllllllllllllllllllllllll}410 & \text { BEN08 } & 105 & 105 & 182 & 182 & 195 & 201 & 216 & 216 & 154 & 154 & 171 & 173 & 254 & 254 & 232 & 232 & 191 & 191 & 156 & 170 & 216 & 216 & 343 & 3 & 4\end{array}$ $\begin{array}{lllllllllllllllllllllllllll}411 & \text { BEN09 } & 105 & 105 & 182 & 182 & 195 & 201 & 216 & 216 & 154 & 158 & 171 & 171 & 252 & 252 & 232 & 232 & 191 & 191 & 154 & 170 & 216 & 218 & 344 & 4 & 4\end{array}$

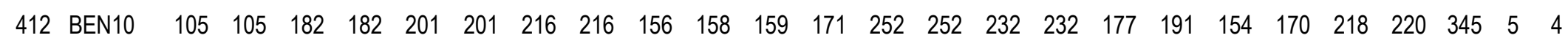
$\begin{array}{lllllllllllllllllllllllllllll}413 & \text { BEN11 } & 105 & 105 & 167 & 182 & 195 & 201 & 216 & 216 & 154 & 154 & 171 & 175 & 252 & 254 & 220 & 232 & 188 & 191 & 154 & 170 & 216 & 216 & 346 & 7 & 3\end{array}$ $\begin{array}{lllllllllllllllllllllllllllll}414 & \text { BEN12 } & 105 & 105 & 167 & 182 & 195 & 195 & 210 & 210 & 154 & 158 & 157 & 171 & 252 & 252 & 232 & 232 & 188 & 188 & 154 & 170 & 216 & 218 & 347 & 5 & 4\end{array}$ $\begin{array}{lllllllllllllllllllllllllllll}415 & \text { BEN13 } & 105 & 105 & 182 & 182 & 195 & 195 & 210 & 210 & 154 & 154 & 177 & 183 & 252 & 252 & 220 & 232 & 188 & 191 & 154 & 170 & 216 & 218 & 348 & 5 & 4\end{array}$ $\begin{array}{lllllllllllllllllllllllllllll}416 & \text { BEN14 } & 105 & 105 & 182 & 182 & 195 & 195 & 210 & 212 & 154 & 154 & 157 & 177 & 252 & 252 & 232 & 232 & 188 & 188 & 156 & 170 & 216 & 218 & 349 & 4 & 5\end{array}$ $\begin{array}{lllllllllllllllllllllllllll}417 & \text { BEN15 } & 105 & 105 & 182 & 182 & 195 & 201 & 210 & 216 & 154 & 156 & 171 & 171 & 252 & 254 & 232 & 242 & 188 & 191 & 170 & 170 & 216 & 220 & 350 & 7 & 4\end{array}$ $\begin{array}{llllllllllllllllllllllllllll}418 & \text { BEN16 } & 105 & 105 & 182 & 182 & 195 & 195 & 216 & 216 & 154 & 158 & 159 & 171 & 252 & 252 & 232 & 242 & 188 & 188 & 170 & 170 & 216 & 220 & 351 & 4 & 4\end{array}$ 


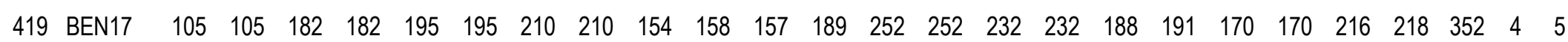
$\begin{array}{lllllllllllllllllllllllllll}420 & \text { BEN18 } & 105 & 105 & 167 & 182 & 195 & 201 & 200 & 210 & 154 & 158 & 157 & 175 & 252 & 252 & 232 & 232 & 188 & 191 & 154 & 156 & 216 & 218 & 353 & 8 & 4\end{array}$ $\begin{array}{lllllllllllllllllllllllllllll}421 & \text { BEN19 } & 105 & 105 & 182 & 182 & 195 & 201 & 210 & 210 & 154 & 156 & 157 & 189 & 252 & 254 & 220 & 232 & 188 & 188 & 154 & 170 & 216 & 220 & 354 & 7 & 5\end{array}$ $\begin{array}{llllllllllllllllllllllllllll}422 & \text { BEN20 } & 105 & 105 & 182 & 182 & 195 & 195 & 212 & 212 & 154 & 158 & 157 & 171 & 252 & 254 & 220 & 232 & 188 & 191 & 154 & 156 & 216 & 216 & 355 & 6 & 5\end{array}$ $\begin{array}{lllllllllllllllllllllllllll}423 & \text { BEN21 } & 105 & 105 & 182 & 182 & 195 & 201 & 210 & 212 & 154 & 154 & 177 & 197 & 252 & 252 & 242 & 242 & 188 & 202 & 154 & 170 & 216 & 218 & 356 & 6 & 4\end{array}$ $\begin{array}{llllllllllllllllllllllllllllllllll}424 & \text { BEN22 } & 105 & 105 & 182 & 182 & 195 & 201 & 210 & 210 & 154 & 158 & 157 & 157 & 252 & 254 & 232 & 242 & 188 & 188 & 154 & 156 & 216 & 216 & 357 & 5 & 6\end{array}$ $\begin{array}{lllllllllllllllllllllllllllll}425 & \text { BEN23 } & 105 & 105 & 182 & 182 & 195 & 201 & 216 & 216 & 154 & 158 & 157 & 175 & 252 & 254 & 220 & 232 & 188 & 188 & 154 & 170 & 216 & 218 & 358 & 7 & 5\end{array}$ $\begin{array}{llllllllllllllllllllllllllll}426 & \text { BEN24 } & 105 & 105 & 182 & 182 & 201 & 201 & 210 & 216 & 154 & 154 & 157 & 171 & 252 & 252 & 232 & 242 & 191 & 191 & 170 & 170 & 216 & 216 & 359 & 3 & 5\end{array}$

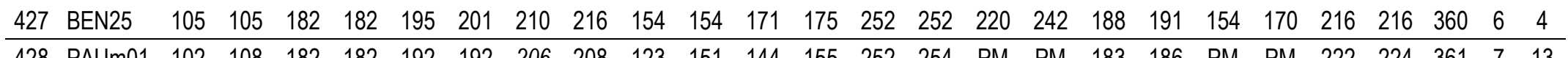
$\begin{array}{lllllllllllllllllllllllllllll}429 & \text { PAUm02 } & 102 & 108 & 182 & 182 & 192 & 192 & 206 & 208 & 123 & 151 & 144 & 155 & 252 & 254 & \text { PM } & \text { PM } & 183 & 186 & \text { PM } & \text { PM } & 222 & 224 & 361 & 7 & 13\end{array}$ $\begin{array}{lllllllllllllllllllllllllllll}430 & \text { PAUm03 } & 102 & 108 & 182 & 182 & 192 & 192 & 206 & 208 & 123 & 151 & 144 & 155 & 252 & 254 & \text { PM } & \text { PM } & 183 & 186 & \text { PM } & \text { PM } & 222 & 224 & 361 & 7 & 13\end{array}$ $\begin{array}{llllllllllllllllllllllllllllll}431 & \text { PAUm04 } & 102 & 108 & 182 & 182 & 192 & 192 & 206 & 208 & 123 & 151 & 144 & 155 & 252 & 254 & \text { PM } & \text { PM } & 183 & 186 & \text { PM } & \text { PM } & 222 & 224 & 361 & 7 & 13\end{array}$ \begin{tabular}{llllllllllllllllllllllllllll}
432 & PAUm05 & 102 & 108 & 182 & 182 & 192 & 192 & 206 & 208 & 123 & 151 & 144 & 155 & 252 & 254 & PM & PM & 183 & 186 & PM & PM & 222 & 224 & 361 & 7 & 13 \\
\hline
\end{tabular}

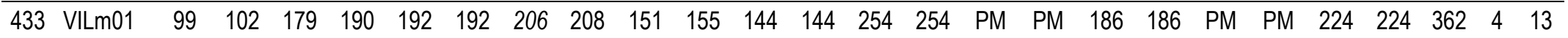
$\begin{array}{lllllllllllllllllllllllllllll}434 & \text { VILm02 } & 99 & 102 & 182 & 182 & 189 & 192 & 208 & 208 & 151 & 151 & 161 & 163 & 252 & 254 & \text { PM } & \text { PM } & 186 & 186 & \text { PM } & \text { PM } & 224 & 224 & 363 & 4 & 16\end{array}$ $\begin{array}{llllllllllllllllllllllllllllll}435 & \text { VILm03 } & 99 & 114 & 182 & 182 & 192 & 192 & 208 & 208 & 151 & 151 & 161 & 163 & 252 & 256 & \text { PM } & \text { PM } & 186 & 186 & \text { PM } & \text { PM } & 222 & 222 & 364 & 3 & 17\end{array}$ $\begin{array}{lllllllllllllllllllllllllllll}436 & \text { VILm04 } & 99 & 114 & 182 & 182 & 189 & 192 & 208 & 208 & 151 & 151 & 152 & 157 & 250 & 252 & \text { PM } & \text { PM } & 186 & 186 & \text { PM } & \text { PM } & 222 & 222 & 365 & 4 & 15\end{array}$ \begin{tabular}{llllllllllllllllllllllllllll}
437 & VILm05 & 99 & 102 & 182 & 182 & 192 & 192 & 208 & 208 & 151 & 151 & 157 & 163 & 252 & 252 & PM & PM & 186 & 186 & PM & PM & 222 & 222 & 366 & 2 & 17 \\
\hline
\end{tabular} \begin{tabular}{llllllllllllllllllllllllllll}
\hline 438 & ESBm01 & 102 & 108 & 182 & 182 & 192 & 192 & 206 & 208 & 123 & 151 & 144 & 155 & 252 & 254 & PM & PM & 183 & 186 & PM & PM & 222 & 224 & 361 & 7 & 13
\end{tabular} $\begin{array}{lllllllllllllllllllllllllllll}439 & \text { ESBm02 } & 102 & 108 & 182 & 182 & 192 & 192 & 206 & 208 & 123 & 151 & 144 & 155 & 252 & 254 & \text { PM } & \text { PM } & 183 & 186 & \text { PM } & \text { PM } & 222 & 224 & 361 & 7 & 13\end{array}$ $\begin{array}{llllllllllllllllllllllllllll}440 & \text { ESBm03 } & 102 & 108 & 182 & 182 & 192 & 192 & 206 & 208 & 123 & 151 & 144 & 155 & 252 & 254 & \text { PM } & \text { PM } & 183 & 186 & \text { PM } & \text { PM } & 222 & 224 & 361 & 7 & 13\end{array}$ $\begin{array}{llllllllllllllllllllllllllll}441 & \text { ESBm04 } & 102 & 108 & 182 & 182 & 192 & 192 & 206 & 208 & 123 & 151 & 144 & 155 & 252 & 254 & \text { PM } & \text { PM } & 183 & 186 & \text { PM } & \text { PM } & 222 & 224 & 361 & 7 & 13\end{array}$

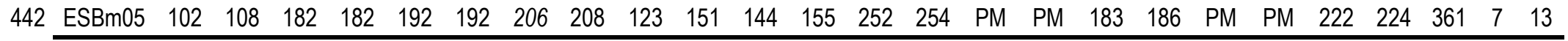




\section{Anexo II}

\section{ANÁLISIS DE STRUCTURE Y DE NEWHYBRIDS}

Resultados obtenidos con los análisis de STRUCTURE 2.3 y NewHybrids 1.1 en los 442 individuos de olmos estudiados ( 427 de U. glabra y 15 de U. minor). COD: Códigos de individuos, constituidos por el código de la población (ver Tabla 1.1) más el número asignado a cada individuo dentro de la misma.

Análisis de STRUCTURE: coeficientes de asignación posterior $q \geq 0,9$ se muestran en negrita e indican asignación al clúster correspondiente (A o B).

Análisis de NewHybrids: probabilidades de asignación posterior $p \geq 0,9$ se muestran en negrita e indican asignación a la clase correspondiente (U. glabra, U. minor, $F_{1}, F_{2} O$ los dos retrocruzamientos de la $F_{1}$ ). 


\begin{tabular}{|c|c|c|c|c|c|c|c|c|}
\hline \multirow[b]{2}{*}{ CÓD } & \multicolumn{2}{|c|}{ STRUCTURE } & \multicolumn{6}{|c|}{ NewHybrids } \\
\hline & $\begin{array}{c}\text { Clúster } \\
\text { A }\end{array}$ & $\begin{array}{c}\text { Clúster } \\
\text { B }\end{array}$ & U. glabra & U. minor & $F_{1}$ & $F_{2}$ & $\begin{array}{l}F_{1} \times U . \\
\text { glabra }\end{array}$ & $\begin{array}{l}F_{1} \times U . \\
\text { minor }\end{array}$ \\
\hline CNT01 & 0,997 & 0,003 & 0,99982 & 0,00000 & 0,00000 & 0,00000 & 0,00017 & 0,00000 \\
\hline CNJ01 & 0,995 & 0,005 & 0,99969 & 0,00000 & 0,00000 & 0,00001 & 0,00029 & 0,00000 \\
\hline CNJO2 & 0,992 & 0,008 & 0,99946 & 0,00000 & 0,00000 & 0,00006 & 0,00048 & 0,00000 \\
\hline CNJO3 & 0,994 & 0,006 & 0,99963 & 0,00000 & 0,00000 & 0,00001 & 0,00036 & 0,00000 \\
\hline CNJO4 & 0,986 & 0,014 & 0,99837 & 0,00000 & 0,00003 & 0,00027 & 0,00134 & 0,00000 \\
\hline CNJ05 & 0,994 & 0,006 & 0,99962 & 0,00000 & 0,00000 & 0,00002 & 0,00035 & 0,00000 \\
\hline CNJ06 & 0,989 & 0,011 & 0,99889 & 0,00000 & 0,00002 & 0,00012 & 0,00098 & 0,00000 \\
\hline CNJ07 & 0,996 & 0,004 & 0,99975 & 0,00000 & 0,00000 & 0,00001 & 0,00024 & 0,00000 \\
\hline CNJ08 & 0,995 & 0,005 & 0,99987 & 0,00000 & 0,00000 & 0,00000 & 0,00013 & 0,00000 \\
\hline CNJ09 & 0,993 & 0,007 & 0,99931 & 0,00000 & 0,00001 & 0,00009 & 0,00060 & 0,00000 \\
\hline CNJ10 & 0,994 & 0,006 & 0,99949 & 0,00000 & 0,00001 & 0,00004 & 0,00046 & 0,00000 \\
\hline CNJ11 & 0,995 & 0,005 & 0,99974 & 0,00000 & 0,00000 & 0,00001 & 0,00025 & 0,00000 \\
\hline CNJ12 & 0,993 & 0,007 & 0,99931 & 0,00000 & 0,00001 & 0,00003 & 0,00064 & 0,00000 \\
\hline CNJ13 & 0,992 & 0,008 & 0,99899 & 0,00000 & 0,00002 & 0,00009 & 0,00091 & 0,00000 \\
\hline CNJ14 & 0,996 & 0,004 & 0,99965 & 0,00000 & 0,00000 & 0,00001 & 0,00033 & 0,00000 \\
\hline CNJ15 & 0,997 & 0,003 & 0,99987 & 0,00000 & 0,00000 & 0,00000 & 0,00013 & 0,00000 \\
\hline CNJ16 & 0,993 & 0,007 & 0,99915 & 0,00000 & 0,00001 & 0,00005 & 0,00079 & 0,00000 \\
\hline CNJ17 & 0,981 & 0,019 & 0,99835 & 0,00000 & 0,00003 & 0,00027 & 0,00135 & 0,00000 \\
\hline CNJ18 & 0,993 & 0,007 & 0,99939 & 0,00000 & 0,00000 & 0,00007 & 0,00054 & 0,00000 \\
\hline CNJ19 & 0,993 & 0,007 & 0,99907 & 0,00000 & 0,00002 & 0,00006 & 0,00085 & 0,00000 \\
\hline CNJ2O & 0,996 & 0,004 & 0,99968 & 0,00000 & 0,00000 & 0,00001 & 0,00030 & 0,00000 \\
\hline CNJ21 & 0,995 & 0,005 & 0,99965 & 0,00000 & 0,00001 & 0,00001 & 0,00032 & 0,00000 \\
\hline CNJ22 & 0,996 & 0,004 & 0,99968 & 0,00000 & 0,00000 & 0,00001 & 0,00030 & 0,00000 \\
\hline CNJ23 & 0,996 & 0,004 & 0,99986 & 0,00000 & 0,00000 & 0,00000 & 0,00014 & 0,00000 \\
\hline CNJ24 & 0,995 & 0,005 & 0,99966 & 0,00000 & 0,00000 & 0,00002 & 0,00032 & 0,00000 \\
\hline CNJ25 & 0,997 & 0,003 & 0,99983 & 0,00000 & 0,00000 & 0,00001 & 0,00016 & 0,00000 \\
\hline CNJ26 & 0,996 & 0,004 & & 0,00000 & 0,00000 & 0,00000 & 0,00019 & 0,00000 \\
\hline CNJ27 & 0,994 & 0,006 & 0,99960 & 0,00000 & 0,00000 & 0,00003 & 0,00037 & 0,00000 \\
\hline CNJ28 & 0,996 & 0,004 & 0,99977 & 0,00000 & 0,00000 & & 0,00023 & 0,00000 \\
\hline CNJ29 & 0,831 & 0,169 & 0,97479 & 0,00000 & 0,00301 & 0,00245 & & 0,00001 \\
\hline CNJ30 & 0,996 & 0,004 & 0,99977 & 0,00000 & 0,00000 & 0,00001 & 0,00022 & 0,00000 \\
\hline CNJ31 & 0,996 & 0,004 & 0,99978 & 0,00000 & 0,00000 & 0,00001 & 0,00021 & 0,00000 \\
\hline CNJ32 & 0,995 & 0,005 & 0,99958 & 0,00000 & 0,00001 & 0,00001 & 0,00039 & 0,00000 \\
\hline CNJ33 & 0,994 & 0,006 & 0,99973 & 0,00000 & 0,00000 & 0,00001 & 0,00026 & 0,00000 \\
\hline CNJ34 & 0,997 & 0,003 & 0,99976 & 0,00000 & 0,00001 & 0,00001 & 0,00023 & 0,00000 \\
\hline CNJ35 & 0,997 & 0,003 & 0,99992 & 0,00000 & 0,00000 & 0,00000 & 0,00007 & 0,00000 \\
\hline CNJ36 & 0,996 & 0,004 & 0,99980 & 0,00000 & 0,00000 & 0,00001 & 0,00019 & 0,00000 \\
\hline CNJ37 & 0,995 & 0,005 & 0,99967 & 0,00000 & 0,00001 & 0,00001 & 0,00031 & 0,00000 \\
\hline CNJ38 & 0,943 & 0,057 & 0,99811 & 0,00000 & 0,00007 & 0,00030 & 0,00152 & 0,00000 \\
\hline
\end{tabular}




\begin{tabular}{|c|c|c|c|c|c|c|c|c|}
\hline В0С01 & 0,997 & 0,003 & 0,99990 & 0,00000 & 0,00000 & 0,00000 & 0,00010 & 0,00000 \\
\hline $\mathrm{BOCO2}$ & 0,997 & 0,003 & 0,99990 & 0,00000 & 0,00000 & 0,00000 & 0,00010 &, 00000 \\
\hline OC03 & 0,997 & 0,003 & 0,99990 & 0,00000 & 0,00000 & 0,00000 & 0,00010 &, 00000 \\
\hline OCO4 & 0,997 & 0,003 & 0,99988 & 0,00000 & 0,00000 & 0,00000 &, 00011 &, 00000 \\
\hline RZA01 & 0,995 & 0,005 & 0,99916 & 0,00000 & 0,00016 & 0,00005 &, 00063 &, 00000 \\
\hline RZA02 & 0,996 & 0,004 & 0,99975 & 0,00000 & 0,00000 & 0,00001 & 0,00024 &, 00000 \\
\hline RZA03 & 0,996 & 0,004 & 0,99976 & 0,00000 & 0,00000 & 0,00001 & 0,00023 &, 000 \\
\hline RZA04 & 0,997 & 0,003 & 0,99985 & 0,00000 & 0,00000 & 0,00000 & 0,00015 & 0,00000 \\
\hline RZA05 & 0,995 & 0,005 & 0,99934 & 0,00000 & 0,00006 & 0,00005 & 0,00056 & 0,00000 \\
\hline RZA06 & 0,997 & 0,003 & 0,99996 & 0,00000 & 0,00000 & 0,00000 & 0,00004 & 0,00000 \\
\hline RZA07 & 0,997 & 0,003 & 0,99984 & 0,00000 & 0,00000 & 0,00000 & 0,00015 & 0,00000 \\
\hline RZA08 & 0,997 & 0,003 & 0,99968 & 0,00000 & 0,00000 & 0,00001 & 0,00031 &, 00000 \\
\hline RZA09 & 0,996 & 0,004 & 0,99960 & 0,00000 & 0,00000 & 0,00002 & 0,00037 & 0,00000 \\
\hline RZA10 & 0,997 & 0,003 & 0,99976 & 0,00000 & 0,00000 & 0,00001 & 0,00023 & 0,00000 \\
\hline RZA11 & 0,997 & 0,003 & 0,99984 & 0,00000 & 0,00000 & 0,00001 & 0,00015 & 0,00000 \\
\hline RZA12 & 0,997 & 0,003 & 0,99989 & 0,00000 & 0,00000 & 0,00000 & 0,00011 & חמחחתח \\
\hline RZA13 & 0,998 & 0,002 & 0,99996 & 0,00000 & 0,00000 & 0,00000 & 0,00004 & ח \\
\hline RZA14 & 0,997 & 0,003 & 0,99993 & 0,00000 & 0,00000 & 0,00000 & 0,00007 & 0,000 \\
\hline RZA15 & 0,995 & 0,005 & 0,99957 & 0,00000 & 0,00002 & 0,00002 & 0,00039 & 0,00000 \\
\hline RZA16 & 0,998 & 0,002 & 0,99995 & 0,00000 & 0,00000 & 0,00000 & 0,00004 & 0,00000 \\
\hline RZA17 & 0,997 & 0,003 & 0,99985 & 0,00000 & 0,00000 & 0,00000 & 0,00015 & 0,00000 \\
\hline RZA18 & 0,997 & 0,003 & 0,99995 & 0,00000 & 0,00000 & 0,00000 & 0,00005 & 0,00000 \\
\hline RZA19 & 0,997 & 0,003 & 0,99992 & 0,00000 & 0,00000 & 0,00000 & 0,00008 & 0,00000 \\
\hline RZA20 & 0,998 & 0,002 & 0,99997 & 0,00000 & 0,00000 & 0,00000 & 0,00003 & 0,00000 \\
\hline RZA21 & 0,998 & 0,002 & 0,99993 & 0,00000 & 0,00000 & 0,00000 & 0,00007 & 0,000 \\
\hline RZA22 & 0,997 & 0,003 & 0,99981 & 0,00000 & 0,00000 & 0,00001 & 0,00019 & 0,000 \\
\hline NAV01 & 0,996 & 0,004 & 0,99966 & 0,00000 & 0,00000 & 0,00001 & 0,00032 & 0,00000 \\
\hline NAV02 & 0,995 & 0,005 & 0,99943 & 0,00000 & 0,00000 & 0,00002 & 0,00054 & 0,000 \\
\hline NAV03 & 0,996 & 0,004 & 0,99961 & 0,00000 & 0,00000 & 0,00002 & 0,00037 & \\
\hline NAV04 & 0,997 & 0,003 & 0,99985 & 0,00000 & 0,00000 & 0,00000 & 0,00015 & 0,00000 \\
\hline NAV05 & 0,997 & 0,003 & 0,99987 & 0,00000 & 0,00000 & 0,00000 & 0,00012 & 0,000 \\
\hline NAV06 & 0,998 & 0,002 & 0,99997 & 0,00000 & 0,00000 & 0,00000 & 0,00003 & 0,00000 \\
\hline NAV07 & 0,996 & 0,004 & 0,99971 & 0,00000 & 0,00000 & 0,00001 & 0,00028 & 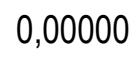 \\
\hline NAV08 & 0,997 & 0,003 & 0,99983 & 0,00000 & 0,00000 & 0,00000 & 0,00017 & 0,000 \\
\hline NAV09 & 0,996 & 0,004 & 0,99974 & 0,00000 & 0,00000 & 0,00001 & 0,00025 & 0,00000 \\
\hline NAV10 & 0,993 & 0,007 & 0,99877 & 0,00000 & 0,00001 & 0,00012 & 0,00110 & 0,00000 \\
\hline NAV11 & 0,997 & 0,003 & 0,99984 & 0,00000 & 0,00000 & 0,00000 & 0,00016 & 0,00000 \\
\hline NAV12 & 0,996 & 0,004 & 0,99984 & 0,00000 & 0,00000 & 0,00000 & 0,00016 & 0,00000 \\
\hline NAV13 & 0,997 & 0,003 & 0,99988 & 0,00000 & 0,00000 & 0,00000 & 0,00011 & 0,00000 \\
\hline NAV14 & 0,997 & 0,003 & 0,99986 & 0,00000 & 0,00000 & 0,00000 & 0,00013 & 0,00000 \\
\hline MON01 & 0,997 & 0,003 & 0,99986 & 0,00000 & 0,00000 & 0,00000 & 0,00014 & 0,00000 \\
\hline MON02 & 0,998 & 0,002 & 0,99994 & 0,00000 & 0,00000 & 0,00000 & 0,00006 & 0,000 \\
\hline
\end{tabular}




\begin{tabular}{|c|c|c|c|c|c|c|c|c|}
\hline MON03 & 0,998 & 0,002 & 0,99993 & 0,00000 & 0,00000 & 0,00000 & 0,00007 & 0,00000 \\
\hline MON04 & 0,997 & 0,003 & 0,99983 & 0,00000 & 0,00000 & 0,00000 & 0,00017 & 0,00000 \\
\hline MON05 & 0,997 & 0,003 & 0,99991 & 0,00000 & 0,00000 & 0,00000 & 0,00009 &, 00000 \\
\hline MON06 & 0,997 & 0,003 & ,99982 & 0,00000 & 0,00000 & 0,00001 & 0,00018 &, 00000 \\
\hline MON07 & 0,997 & 0,003 & 0,99987 & 0,00000 & 0,00000 & 0,00000 & 0,00012 & 0,00000 \\
\hline RAS01 & 0,997 & 0,003 & 0,99989 & 0,00000 & 0,00000 & 0,00000 & 0,00011 &, 00000 \\
\hline RAS02 & 0,996 & 0,004 & 0,99971 & 0,00000 & 0,00000 & 0,00001 & 0,00028 & 0,00000 \\
\hline RAS03 & 0,997 & 0,003 & 0,99979 & 0,00000 & 0,00000 & 0,00001 & 0,00020 & 0,00000 \\
\hline RAS04 & 0,996 & 0,004 & 0,99966 & 0,00000 & 0,00000 & 0,00002 & 0,00031 & 0,00000 \\
\hline RAS05 & 0,995 & 0,005 & 0,99964 & 0,00000 & 0,00000 & 0,00003 & 0,00033 & 0,00000 \\
\hline RAS06 & 0,995 & 0,005 & 0,99964 & 0,00000 & 0,00000 & 0,00003 & 0,00033 & 0,00000 \\
\hline RAS07 & 0,997 & 0,003 & 0,99990 & 0,00000 & 0,00000 & 0,00000 & 0,00010 & 0,00000 \\
\hline RAS08 & 0,996 & 0,004 & 0,99966 & 0,00000 & 0,00000 & 0,00002 & 0,00031 & 0,00000 \\
\hline RAS09 & 0,997 & 0,003 & 0,99983 & 0,00000 & 0,00000 & 0,00000 & 0,00016 & 0,00000 \\
\hline RAS10 & 0,996 & 0,004 & 0,99966 & 0,00000 & 0,00000 & 0,00002 & 0,00031 & 0,00000 \\
\hline RAS11 & 0,996 & 0,004 & 0,99966 & 0,00000 & 0,00000 & 0,00002 & 0,00031 & 0,00000 \\
\hline RAS12 & 0,996 & 0,004 & 0,99988 & 0,00000 & 0,00000 & 0,00000 & 0,00012 & 0,00000 \\
\hline RAS13 & 0,997 & 0,003 & 0,99990 & 0,00000 & 0,00000 & 0,00000 & 0,00010 & 0,00000 \\
\hline RAS14 & 0,996 & 0,004 & 0,99966 & 0,00000 & 0,00000 & 0,00002 & 0,00031 & 0,00000 \\
\hline RAS15 & 0,997 & 0,003 & 0,99989 & 0,00000 & 0,00000 & 0,00000 & 0,00011 & 0,00000 \\
\hline RAS16 & 0,996 & 0,004 & 0,99966 & 0,00000 & 0,00000 & 0,00002 & 0,00031 & 0,00000 \\
\hline RAS17 & 0,995 & 0,005 & 0,99964 & 0,00000 & 0,00000 & 0,00003 & 0,00033 & 0,00000 \\
\hline RAS18 & 997 & 0,003 & 0,99979 & 0,00000 & 0,00000 & 0,00001 & 0,00020 & 0,00000 \\
\hline RAS19 & 0,995 & 0,005 & 0,99966 & 0,00000 & 0,00000 & 0,00002 & 0,00031 & 0,00000 \\
\hline RAS20 & 0,994 & 0,006 & 0,99963 & 0,00000 & 0,00000 & 0,00003 & 0,00034 & 0,00000 \\
\hline RAS21 & 0,996 & 0,004 & 0,99966 & 0,00000 & 0,00000 & 0,00002 & 0,00031 & 0,00000 \\
\hline RAS22 & 0,996 & 0,004 & 0,99966 & 0,00000 & 0,00000 & 0,00002 & 0,00031 & 0,00000 \\
\hline RAS23 & 0,996 & 0,004 & 0,99968 & 0,00000 & 0,00000 & 0,00002 & 0,00030 & 0,00000 \\
\hline RAS24 & 0,996 & 0,004 & 0,99966 & 0,00000 & 0,00000 & 0,00002 & 0,00031 & 0,00000 \\
\hline RAS25 & 0,997 & 0,003 & 0,99980 & 0,00000 & 0,00000 & 0,00001 & 0,00019 & 0,00000 \\
\hline RAS26 & 0,996 & 0,004 & 0,99966 & 0,00000 & 0,00000 & 0,00002 & & 0,00000 \\
\hline RAS27 & 0,995 & 0,005 & 0,99964 & 0,00000 & 0,00000 & 0,00003 & 0,00033 & 0,00000 \\
\hline RAS28 & 0,997 & 0,003 & 0,99992 & 0,00000 & 0,00000 & 0,00000 & 0,00008 & 0,00000 \\
\hline RAS29 & 0,997 & 0,003 & 0,99991 & 0,00000 & 0,00000 & 0,00000 & 0,00009 & 0,00000 \\
\hline RAS30 & 0,997 & 0,003 & 0,99993 & 0,00000 & 0,00000 & 0,00000 & 0,00007 & 0,00000 \\
\hline RAS31 & 0,997 & 0,003 & 0,99990 & 0,00000 & 0,00000 & 0,00000 & 0,00010 & 0,00000 \\
\hline RAS32 & 0,996 & 0,004 & 0,99977 & 0,00000 & 0,00000 & 0,00001 & 0,00022 & 0,00000 \\
\hline RAS33 & 0,996 & 0,004 & 0,99973 & 0,00000 & 0,00000 & 0,00001 & 0,00026 & 0,00000 \\
\hline PAU01 & 0,996 & 0,004 & 0,99958 & 0,00000 & 0,00001 & 0,00002 & 0,00039 & 0,00000 \\
\hline CER01 & 0,996 & 0,004 & 0,99971 & 0,00000 & 0,00000 & 0,00001 & 0,00028 & 0,00000 \\
\hline CER02 & 0,996 & 0,004 & 0,99971 & 0,00000 & 0,00000 & 0,00001 & 0,00028 & 0,00000 \\
\hline CER03 & 0,996 & 0,004 & 0,99971 & 0,00000 & 0,00000 & 0,00001 & 0,00028 & 0,00000 \\
\hline
\end{tabular}




\begin{tabular}{|c|c|c|c|c|c|c|c|c|}
\hline CERO4 & 0,996 & 0,004 & 0,99971 & 0,00000 & 0,00000 & 0,00001 & 0,00028 & 0,00000 \\
\hline CER05 & 0,996 & 0,004 & 0,99971 & 0,00000 & 0,00000 & 0,00001 & 0,00028 & 0,00000 \\
\hline CER06 & 0,996 & 0,004 & 0,99971 & 0,00000 & 0,00000 & 0,00001 & 0,00028 & 0,00000 \\
\hline ROZO1 & 0,395 & 0,605 & 0,00014 & 0,00001 & 0,98050 & 0,00681 & 0,01040 & 0,00214 \\
\hline ROZO2 & 0,011 & 0,989 & 0,00000 & 0,00870 & 0,94046 & 0,01155 & 0,00088 & 0,03841 \\
\hline ROZO3 & 0,012 & 0,988 & 0,00000 & 0,00870 & 0,94046 & 0,01155 & 0,00088 & 0,03841 \\
\hline ROZO4 & 0,012 & 0,988 & 0,00000 & 0,00870 & 0,94046 & 0,01155 & 0,00088 & 0,03841 \\
\hline ROZO5 & 0,661 & 0,339 & 0,91040 & 0,00000 & 0,00341 & 0,00991 & 0,07628 & 0,00001 \\
\hline ROZO6 & 0,010 & 0,990 & 0,00000 & 0,00186 & 0,98143 & 0,00385 & 0,00074 & 0,01213 \\
\hline OZOZ & 0,010 & 0,990 & 0,00000 & 0,00186 & 0,98143 & 0,00385 & 0,00074 & 0,01213 \\
\hline ROZO8 & 0,010 & 0,990 & 0,00000 & 0,00186 & 0,98143 & 0,00385 & 0,00074 & 0,01213 \\
\hline ROZO9 & 0,011 & 0,989 & 0,00000 & 0,00186 & 0,98143 & 0,00385 & 0,00074 & 0,01213 \\
\hline ROZ10 & 0,009 & 0,991 & 0,00000 & 0,00186 & 0,98143 & 0,00385 & 0,00074 & 0,01213 \\
\hline ROZ11 & 0,350 & 0,650 & 0,00427 & 0,00002 & 0,85264 & 0,04449 & 0,09611 & 0,00249 \\
\hline ROZ12 & 0,021 & 0,979 & 0,00850 & 0,00776 & 0,84981 & 0,07188 & 0,04580 & 0,01626 \\
\hline ROZ13 & 0,010 & 0,990 & 0,00000 & 0,00186 & 0,98143 & 0,00385 & 0,00074 & 0,01213 \\
\hline ROZ14 & 0,987 & 0,013 & 0,99947 & 0,00000 & 0,00003 & 0,00003 & 0,00047 & 0,00000 \\
\hline ROZ15 & 0,678 & 0,322 & 0,70345 & 0,00000 & 0,15993 & 0,02442 & 0,11181 & 0,00040 \\
\hline ROZ16 & 0,535 & 0,465 & 0,65422 & 0,00000 & 0,11055 & 0,03201 & 0,20311 & 0,00013 \\
\hline ROZ17 & 0,141 & 0,859 & 0,01306 & 0,00835 & 0,50581 & 0,34138 & 0,09228 & 0,03913 \\
\hline ROZ18 & 0,010 & 0,990 & 0,00000 & 0,00186 & 0,98143 & 0,00385 & 0,00074 & 0,01213 \\
\hline ROZ19 & 0,010 & 0,990 & 0,00000 & 0,00186 & 0,98143 & 0,00385 & 0,00074 & 0,01213 \\
\hline ROZ20 & 0,010 & 0,990 & 0,00000 & 0,00186 & 0,98143 & 0,00385 & 0,00074 & 0,01213 \\
\hline ROZ21 & 0,009 & 0,991 & 0,00000 & 0,00186 & 0,98143 & 0,00385 & 0,00074 & 0,01213 \\
\hline ROZ22 & 0,010 & 0,990 & 0,00000 & 0,00186 & 0,98143 & 0,00385 & 0,00074 & 0,01213 \\
\hline ROZ23 & 0,010 & 0,990 & 0,00000 & 0,00186 & 0,98143 & 0,00385 & 0,00074 & 0,01213 \\
\hline ROZ24 & 0,848 & 0,152 & 0,99764 & 0,00000 & 0,00003 & 0,00012 & 0,00222 & 0,00000 \\
\hline ROZ25 & 0,004 & 0,996 & 0,00000 & 0,98677 & 0,00071 & 0,00062 & 0,00000 & 0,01190 \\
\hline ROZ26 & 0,004 & 0,996 & 0,00000 & 0,98677 & 0,00071 & 0,00062 & 0,00000 & 0,01190 \\
\hline ROZ27 & 0,004 & 0,996 & 0,00000 & 0,98677 & 0,00071 & 0,00062 & 0,00000 & 0,01190 \\
\hline ROZ28 & 0,004 & 0,996 & 0,00000 & 0,98677 & 0,00071 & 0,00062 & 0,00000 & 0,01190 \\
\hline ROZ29 & 0,004 & 0,996 & 0,00000 & 0,98677 & 0,00071 & 0,00062 & 0,00000 & 0,01190 \\
\hline ROZ30 & 0,004 & 0,996 & 0,00000 & 0,98677 & 0,00071 & 0,00062 & 0,00000 & 0,01190 \\
\hline ROZ31 & 0,004 & 0,996 & 0,00000 & 0,98677 & 0,00071 & 0,00062 & 0,00000 & 0,01190 \\
\hline ROZ32 & 0,004 & 0,996 & 0,00000 & 0,98677 & 0,00071 & 0,00062 & 0,00000 & 0,01190 \\
\hline ROZ33 & 0,004 & 0,996 & 0,00000 & 0,98677 & 0,00071 & 0,00062 & 0,00000 & 0,01190 \\
\hline ROZ34 & 0,004 & 0,996 & 0,00000 & 0,98677 & 0,00071 & 0,00062 & 0,00000 & 0,01190 \\
\hline ROZ35 & 0,004 & 0,996 & 0,00000 & 0,98677 & 0,00071 & 0,00062 & 0,00000 & 0,01190 \\
\hline ROZ36 & 0,004 & 0,996 & 0,00000 & 0,98677 & 0,00071 & 0,00062 & 0,00000 & 0,01190 \\
\hline ROZ37 & 0,004 & 0,996 & 0,00000 & 0,98677 & 0,00071 & 0,00062 & 0,00000 & 0,01190 \\
\hline ROZ38 & 0,004 & 0,996 & 0,00000 & 0,98677 & 0,00071 & 0,00062 & 0,00000 & 0,01190 \\
\hline ROZ39 & 0,004 & 0,996 & 0,00000 & 0,98677 & 0,00071 & 0,00062 & 0,00000 & 0,01190 \\
\hline
\end{tabular}




\begin{tabular}{|c|c|c|c|c|c|c|c|c|}
\hline ROZ40 & 0,005 & 0,995 & 0,00000 & 0,98677 & 0,00071 & 0,00062 & 0,00000 & 0,01190 \\
\hline ROZ41 & 0,004 & 0,996 & 0,00000 & 0,98677 & 0,00071 & 0,00062 & 0,00000 & 0,01190 \\
\hline ROZ42 & 0,004 & 0,996 & 0,00000 & 0,98677 & 0,00071 & 0,00062 & 0,00000 & 0,01190 \\
\hline ROZ43 & 0,004 & 0,996 & 0,00000 & 0,98677 & 0,00071 & 0,00062 & 0,00000 & 0,01190 \\
\hline ROZ44 & 0,005 & 0,995 & 0,00000 & 0,98677 & 0,00071 & 0,00062 & 0,00000 & 0,01190 \\
\hline ROZ45 & 0,004 & 0,996 & 0,00000 & 0,98677 & 0,00071 & 0,00062 & 0,00000 & 0,01190 \\
\hline ROZ46 & 0,004 & 0,996 & 0,00000 & 0,98677 & 0,00071 & 0,00062 & 0,00000 & 0,01190 \\
\hline TIE01 & 0,997 & 0,003 & 0,99991 & 0,00000 & 0,00000 & 0,00000 & 0,00009 & 0,00000 \\
\hline TIE02 & 0,992 & 0,008 & 0,99922 & 0,00000 & 0,00001 & 0,00009 & 0,00068 & 0,00000 \\
\hline TIE03 & 0,995 & 0,005 & 0,99942 & 0,00000 & 0,00001 & 0,00004 & 0,00054 & 0,00000 \\
\hline TIE04 & 0,990 & 0,010 & 0,99888 & 0,00000 & 0,00002 & 0,00020 & 0,00091 & 0,00000 \\
\hline TIE05 & 0,996 & 0,004 & 0,99966 & 0,00000 & 0,00000 & 0,00001 & 0,00032 & 0,00000 \\
\hline TIE06 & 0,996 & 0,004 & 0,99966 & 0,00000 & 0,00000 & 0,00001 & 0,00032 & 0,00000 \\
\hline TIE07 & 0,997 & 0,003 & 0,99978 & 0,00000 & 0,00000 & 0,00001 & 0,00022 & 0,00000 \\
\hline TIE08 & 0,996 & 0,004 & 0,99956 & 0,00000 & 0,00001 & 0,00002 & 0,00042 & 0,00000 \\
\hline TIE09 & 0,996 & 0,004 & 0,99967 & 0,00000 & 0,00000 & 0,00002 & 0,00030 & 0,00000 \\
\hline TIE10 & 0,995 & 0,005 & 0,99955 & 0,00000 & 0,00000 & 0,00002 & 0,00042 & 0,00000 \\
\hline TIE11 & 0,990 & 0,010 & 0,99888 & 0,00000 & 0,00002 & 0,00020 & 0,00091 & 0,00000 \\
\hline TIE12 & 0,993 & 0,007 & 0,99919 & 0,00000 & 0,00001 & 0,00010 & 0,00069 & 0,00000 \\
\hline TIE13 & 0,997 & 0,003 & 0,99991 & 0,00000 & 0,00000 & 0,00000 & 0,00009 & 0,00000 \\
\hline TIE14 & 0,993 & 0,007 & 0,99916 & 0,00000 & 0,00001 & 0,00011 & 0,00071 & 0,00000 \\
\hline TIE15 & 0,996 & 0,004 & 0,99979 & 0,00000 & 0,00000 & 0,00001 & 0,00021 & 0,00000 \\
\hline TIE16 & 0,996 & 0,004 & 0,99967 & 0,00000 & 0,00000 & 0,00001 & 0,00031 & 0,00000 \\
\hline TIE17 & 0,994 & 0,006 & 0,99951 & 0,00000 & 0,00000 & 0,00005 & 0,00044 & 0,00000 \\
\hline TIE18 & 0,997 & 0,003 & 0,99993 & 0,00000 & 0,00000 & 0,00000 & 0,00007 & 0,00000 \\
\hline TIE19 & 0,993 & 0,007 & 0,99916 & 0,00000 & 0,00001 & 0,00011 & 0,00071 & 0,00000 \\
\hline TIE20 & 0,998 & 0,002 & 0,99993 & 0,00000 & 0,00000 & 0,00000 & 0,00007 & 0,00000 \\
\hline TIE21 & 0,997 & 0,003 & 0,99994 & 0,00000 & 0,00000 & 0,00000 & 0,00006 & 0,00000 \\
\hline TIE22 & 0,997 & 0,003 & 0,99993 & 0,00000 & 0,00000 & 0,00000 & 0,00007 & 0,00000 \\
\hline TIE23 & 0,996 & 0,004 & 0,99983 & 0,00000 & 0,00000 & 0,00000 & 0,00016 & 0,00000 \\
\hline TIE24 & 0,997 & 0,003 & 0,99993 & 0,00000 & 0,00000 & 0,00000 & 0,00007 & 0,00000 \\
\hline TIE25 & 0,997 & 0,003 & 0,99994 & 0,00000 & 0,00000 & 0,00000 & 0,00006 & 0,00000 \\
\hline TIE26 & 0,998 & 0,002 & 0,99996 & 0,00000 & 0,00000 & 0,00000 & 0,00004 & 0,00000 \\
\hline TIE27 & 0,997 & 0,003 & 0,99995 & 0,00000 & 0,00000 & 0,00000 & 0,00005 & 0,00000 \\
\hline TIE28 & 0,997 & 0,003 & 0,99997 & 0,00000 & 0,00000 & 0,00000 & 0,00003 & 0,00000 \\
\hline TIE29 & 0,997 & 0,003 & 0,99989 & 0,00000 & 0,00000 & 0,00000 & 0,00011 & 0,00000 \\
\hline TIE30 & 0,997 & 0,003 & 0,99996 & 0,00000 & 0,00000 & 0,00000 & 0,00004 & 0,00000 \\
\hline TIE31 & 0,997 & 0,003 & 0,99985 & 0,00000 & 0,00000 & 0,00000 & 0,00015 & 0,00000 \\
\hline TIE32 & 0,997 & 0,003 & 0,99992 & 0,00000 & 0,00000 & 0,00000 & 0,00008 & 0,00000 \\
\hline TIE33 & 0,997 & 0,003 & 0,99995 & 0,00000 & 0,00000 & 0,00000 & 0,00005 & 0,00000 \\
\hline TIE34 & 0,998 & 0,002 & 0,99995 & 0,00000 & 0,00000 & 0,00000 & 0,00005 & 0,00000 \\
\hline TIE35 & 0,997 & 0,003 & 0,99994 & 0,00000 & 0,00000 & 0,00000 & 0,00006 & 0,00000 \\
\hline
\end{tabular}




\begin{tabular}{|c|c|c|c|c|c|c|c|c|}
\hline TIE36 & 0,997 & 0,003 & 0,99993 & 0,00000 & 0,00000 & 0,00000 & 0,00007 & 0,00000 \\
\hline TIE37 & 0,997 & 0,003 & 0,99994 & 0,00000 & 0,00000 & 0,00000 & 0,00006 & 0,00000 \\
\hline TIE38 & 0,997 & 0,003 & 0,99994 & 0,00000 & 0,00000 & 0,00000 & 0,00006 & 0,00000 \\
\hline TIE39 & 0,997 & 0,003 & 0,99978 & 0,00000 & 0,00001 & 0,00001 & 0,00021 & 0,00000 \\
\hline TIE40 & 0,998 & 0,002 & 0,99994 & 0,00000 & 0,00000 & 0,00000 & 0,00006 & 0,00000 \\
\hline TIE41 & 0,998 & 0,002 & 0,99997 & 0,00000 & 0,00000 & 0,00000 & 0,00003 & 0,00000 \\
\hline TIE42 & 0,998 & 0,002 & 0,99997 & 0,00000 & 0,00000 & 0,00000 & 0,00003 & 0,00000 \\
\hline RU01 & 0,997 & 0,003 & 0,99994 & 0,00000 & 0,00000 & 0,00000 & 0,00006 & 0,00000 \\
\hline RU02 & 0,997 & 0,003 & 0,99994 & 0,00000 & 0,00000 & 0,00000 & 0,00006 & 0,00000 \\
\hline QU03 & 0,997 & 0,003 & 0,99986 & 0,00000 & 0,00000 & 0,00000 & 0,00013 & 0,00000 \\
\hline RU04 & 0,997 & 0,003 & 0,99993 & 0,00000 & 0,00000 & 0,00000 & 0,00007 & 0,00000 \\
\hline RU05 & 0,994 & 0,006 & 0,99970 & 0,00000 & 0,00000 & 0,00001 & 0,00028 & 0,00000 \\
\hline RU06 & 0,997 & 0,003 & 0,99992 & 0,00000 & 0,00000 & 0,00000 & 0,00008 & 0,00000 \\
\hline IRU07 & 0,997 & 0,003 & 0,99991 & 0,00000 & 0,00000 & 0,00000 & 0,00009 & 0,00000 \\
\hline IRU08 & 0,997 & 0,003 & 0,99991 & 0,00000 & 0,00000 & 0,00000 & 0,00009 & 0,00000 \\
\hline IRU09 & 0,997 & 0,003 & 0,99993 & 0,00000 & 0,00000 & 0,00000 & 0,00007 & 0,00000 \\
\hline IRU10 & 0,996 & 0,004 & 0,99989 & 0,00000 & 0,00000 & 0,00000 & 0,00011 & 0,00000 \\
\hline IRU11 & 0,997 & 0,003 & 0,99993 & 0,00000 & 0,00000 & 0,00000 & 0,00007 & 0,00000 \\
\hline IRU12 & 0,995 & 0,005 & 0,99985 & 0,00000 & 0,00000 & 0,00000 & 0,00015 & 0,00000 \\
\hline IRU13 & 0,996 & 0,004 & 0,99969 & 0,00000 & 0,00000 & 0,00001 & 0,00029 & 0,00000 \\
\hline IRU14 & 0,997 & 0,003 & 0,99993 & 0,00000 & 0,00000 & 0,00000 & 0,00007 & 0,00000 \\
\hline IRU15 & 0,456 & 0,544 & 0,00004 & 0,00003 & 0,98317 & 0,00669 & 0,00729 & 0,00279 \\
\hline IRU16 & 0,996 & 0,004 & 0,99988 & 0,00000 & 0,00000 & 0,00000 & 0,00012 & 0,00000 \\
\hline IRU17 & 0,997 & 0,003 & 0,99993 & 0,00000 & 0,00000 & 0,00000 & 0,00006 & 0,00000 \\
\hline IRU18 & 0,997 & 0,003 & 0,99988 & 0,00000 & 0,00000 & 0,00000 & 0,00012 & 0,00000 \\
\hline IRU19 & 0,997 & 0,003 & 0,99992 & 0,00000 & 0,00000 & 0,00000 & 0,00008 & 0,00000 \\
\hline IRU20 & 0,994 & 0,006 & 0,99977 & 0,00000 & 0,00000 & 0,00001 & 0,00022 & 0,00000 \\
\hline IRU21 & 0,996 & 0,004 & 0,99979 & 0,00000 & 0,00000 & 0,00001 & 0,00020 & 0,00000 \\
\hline IRU22 & 0,997 & 0,003 & 0,99990 & 0,00000 & 0,00000 & 0,00000 & 0,00010 & 0,00000 \\
\hline IRU23 & 0,994 & 0,006 & 0,99978 & 0,00000 & 0,00000 & 0,00001 & 0,00021 & 0,00000 \\
\hline IRU24 & 0,997 & 0,003 & 0,99991 & 0,00000 & 0,00000 & 0,00000 & 0,00009 & 0,00000 \\
\hline IRU25 & 0,997 & 0,003 & 0,99991 & 0,00000 & 0,00000 & 0,00000 & 0,00009 & 0,00000 \\
\hline IRU26 & 0,997 & 0,003 & 0,99986 & 0,00000 & 0,00000 & 0,00000 & 0,00014 & 0,00000 \\
\hline IRU27 & 0,997 & 0,003 & 0,99991 & 0,00000 & 0,00000 & 0,00000 & 0,00009 & 0,00000 \\
\hline IRU28 & 0,996 & 0,004 & 0,99990 & 0,00000 & 0,00000 & 0,00000 & 0,00010 & 0,00000 \\
\hline IRU29 & 0,995 & 0,005 & 0,99986 & 0,00000 & 0,00000 & 0,00000 & 0,00014 & 0,00000 \\
\hline IRU30 & 0,997 & 0,003 & 0,99993 & 0,00000 & 0,00000 & 0,00000 & 0,00007 & 0,00000 \\
\hline IRU31 & 0,997 & 0,003 & 0,99993 & 0,00000 & 0,00000 & 0,00000 & 0,00007 & 0,00000 \\
\hline IRU32 & 0,997 & 0,003 & 0,99990 & 0,00000 & 0,00000 & 0,00000 & 0,00009 & 0,00000 \\
\hline IRU33 & 0,997 & 0,003 & 0,99991 & 0,00000 & 0,00000 & 0,00000 & 0,00009 & 0,00000 \\
\hline IRU34 & 0,996 & 0,004 & 0,99986 & 0,00000 & 0,00000 & 0,00000 & 0,00014 & 0,00000 \\
\hline IRU35 & 0,994 & 0,006 & 0,99973 & 0,00000 & 0,00000 & 0,00001 & 0,00025 & 0,00000 \\
\hline
\end{tabular}




\begin{tabular}{|c|c|c|c|c|c|c|c|c|}
\hline IRU36 & 0,994 & 0,006 & 0,99977 & 0,00000 & 0,00000 & 0,00001 & 0,00022 & 0,00000 \\
\hline IRU37 & 0,997 & 0,003 & 0,99988 & 0,00000 & 0,00000 & 0,00000 & 0,00011 & 0,00000 \\
\hline IRU38 & 0,997 & 0,003 & 0,99983 & 0,00000 & 0,00000 & 0,00001 & 0,00016 & 0,00000 \\
\hline IRU39 & 0,579 & 0,421 & 0,00026 & 0,00000 & 0,79275 & 0,06814 & 0,13763 & 0,00124 \\
\hline IRU40 & 0,995 & 0,005 & 0,99986 & 0,00000 & 0,00000 & 0,00000 & 0,00014 & 0,00000 \\
\hline IRU41 & 0,996 & 0,004 & 0,99983 & 0,00000 & 0,00000 & 0,00000 & 0,00017 & 0,00000 \\
\hline IRU42 & 0,995 & 0,005 & 0,99985 & 0,00000 & 0,00000 & 0,00000 & 0,00015 & 0,00000 \\
\hline IRU43 & 0,988 & 0,012 & 0,99962 & 0,00000 & 0,00000 & 0,00003 & 0,00035 & 0,00000 \\
\hline IRU44 & 0,997 & 0,003 & 0,99992 & 0,00000 & 0,00000 & 0,00000 & 0,00007 & 0,00000 \\
\hline IRU45 & 0,995 & 0,005 & 0,99981 & 0,00000 & 0,00000 & 0,00000 & 0,00019 & 0,00000 \\
\hline IRU46 & 0,997 & 0,003 & 0,99993 & 0,00000 & 0,00000 & 0,00000 & 0,00007 & 0,00000 \\
\hline IRU47 & 0,996 & 0,004 & 0,99977 & 0,00000 & 0,00000 & 0,00001 & 0,00023 & 0,00000 \\
\hline IRU48 & 0,995 & 0,005 & 0,99976 & 0,00000 & 0,00000 & 0,00000 & 0,00024 & 0,00000 \\
\hline IRU49 & 0,996 & 0,004 & 0,99976 & 0,00000 & 0,00000 & 0,00001 & 0,00023 & 0,00000 \\
\hline IRU50 & 0,995 & 0,005 & 0,99964 & 0,00000 & 0,00000 & 0,00002 & 0,00033 & 0,00000 \\
\hline IRU51 & 0,996 & 0,004 & 0,99985 & 0,00000 & 0,00000 & 0,00000 & 0,00015 & 0,00000 \\
\hline IRU52 & 0,996 & 0,004 & 0,99988 & 0,00000 & 0,00000 & 0,00000 & 0,00012 & 0,00000 \\
\hline IRU53 & 0,997 & 0,003 & 0,99988 & 0,00000 & 0,00000 & 0,00000 & 0,00012 & 0,00000 \\
\hline IRU54 & 0,997 & 0,003 & 0,99988 & 0,00000 & 0,00000 & 0,00000 & 0,00012 & 0,00000 \\
\hline IRU55 & 0,996 & 0,004 & 0,99972 & 0,00000 & 0,00000 & 0,00001 & 0,00027 & 0,00000 \\
\hline IRU56 & 0,997 & 0,003 & 0,99994 & 0,00000 & 0,00000 & 0,00000 & 0,00006 & 0,00000 \\
\hline IRU57 & 0,997 & 0,003 & 0,99991 & 0,00000 & 0,00000 & 0,00000 & 0,00009 & 0,00000 \\
\hline CAS01 & 0,996 & 0,004 & 0,99975 & 0,00000 & 0,00000 & 0,00001 & 0,00024 & 0,00000 \\
\hline CASO2 & 0,995 & 0,005 & 0,99977 & 0,00000 & 0,00000 & 0,00001 & 0,00021 & 0,00000 \\
\hline CASO3 & 0,996 & 0,004 & 0,99978 & 0,00000 & 0,00000 & 0,00001 & 0,00021 & 0,00000 \\
\hline CASO4 & 0,996 & 0,004 & 0,99973 & 0,00000 & 0,00000 & 0,00001 & 0,00025 & 0,00000 \\
\hline CAS05 & 0,996 & 0,004 & 0,99970 & 0,00000 & 0,00001 & 0,00001 & 0,00029 & 0,00000 \\
\hline CASO6 & 0,980 & 0,020 & 0,99955 & 0,00000 & 0,00000 & 0,00002 & 0,00043 & 0,00000 \\
\hline CAS07 & 0,996 & 0,004 & 0,99990 & 0,00000 & 0,00000 & 0,00000 & 0,00010 & 0,00000 \\
\hline CAS08 & 0,997 & 0,003 & 0,99974 & 0,00000 & 0,00000 & 0,00001 & 0,00025 & 0,00000 \\
\hline CAS09 & 0,997 & 0,003 & 0,99990 & 0,00000 & 0,00000 & 0,00000 & 0,00010 & 0,00000 \\
\hline CAS10 & 0,997 & 0,003 & 0,99986 & 0,00000 & 0,00000 & 0,00000 & 0,00014 & 0,00000 \\
\hline CAS11 & 0,996 & 0,004 & 0,99986 & 0,00000 & 0,00000 & 0,00000 & 0,00013 & 0,00000 \\
\hline CAS12 & 0,997 & 0,003 & 0,99973 & 0,00000 & 0,00000 & 0,00001 & 0,00026 & 0,00000 \\
\hline CAS13 & 0,997 & 0,003 & 0,99983 & 0,00000 & 0,00000 & 0,00001 & 0,00017 & 0,00000 \\
\hline CAS14 & 0,997 & 0,003 & 0,99978 & 0,00000 & 0,00000 & 0,00001 & 0,00021 & 0,00000 \\
\hline CAS15 & 0,997 & 0,003 & 0,99984 & 0,00000 & 0,00000 & 0,00000 & 0,00015 & 0,00000 \\
\hline CAS16 & 0,997 & 0,003 & 0,99979 & 0,00000 & 0,00000 & 0,00001 & 0,00020 & 0,00000 \\
\hline CAS17 & 0,996 & 0,004 & 0,99977 & 0,00000 & 0,00000 & 0,00001 & 0,00022 & 0,00000 \\
\hline CAS18 & 0,996 & 0,004 & 0,99983 & 0,00000 & 0,00000 & 0,00001 & 0,00017 & 0,00000 \\
\hline CAS19 & 0,994 & 0,006 & 0,99971 & 0,00000 & 0,00000 & 0,00002 & 0,00027 & 0,00000 \\
\hline CAS20 & 0,997 & 0,003 & 0,99986 & 0,00000 & 0,00000 & 0,00000 & 0,00013 & 0,00000 \\
\hline
\end{tabular}




\begin{tabular}{|c|c|c|c|c|c|c|c|c|}
\hline CAS21 & 0,997 & 0,003 & 0,99987 & 0,00000 & 0,00000 & 0,00000 & 0,00012 & 0,00000 \\
\hline PIE01 & 0,997 & 0,003 & 0,99988 & 0,00000 & 0,00000 & 0,00000 & 0,00011 & 0,00000 \\
\hline PIE02 & 0,982 & 0,018 & 0,99960 & 0,00000 & 0,00001 & 0,00002 & 0,00037 & 0,00000 \\
\hline ગ|E03 & 0,998 & 0,002 & ,99992 & 0,00000 & 0,00000 & 0,00000 &, 00007 & 0,00000 \\
\hline PIE04 & 0,982 & 0,018 & 0,99960 & 0,00000 & 0,00001 & 0,00002 &, 00037 & 0,00000 \\
\hline PIE05 & 0,997 & 0,003 & 0,99992 & 0,00000 & 0,00000 & 0,00000 & 0,00007 & 0,00000 \\
\hline PIE06 & 0,995 & 0,005 & 0,99985 & 0,00000 & 0,00000 & 0,00001 & 0,00015 & 0,00000 \\
\hline PIE07 & 0,997 & 0,003 & 0,99993 & 0,00000 & 0,00000 & 0,00000 & 0,00007 & 0,00000 \\
\hline CVJ01 & 0,997 & 0,003 & 0,99985 & 0,00000 & 0,00000 & 0,00000 & 0,00015 & 0,00000 \\
\hline CVJO2 & 0,997 & 0,003 & 0,99985 & 0,00000 & 0,00000 & 0,00000 & 0,00015 & 0,00000 \\
\hline CVJ03 & 0,997 & 0,003 & 0,99990 & 0,00000 & 0,00000 & 0,00000 & 0,00009 & 0,00000 \\
\hline CVJO4 & 0,997 & 0,003 & 0,99987 & 0,00000 & 0,00000 & 0,00000 & 0,00013 & 0,00000 \\
\hline CVJ05 & 0,997 & 0,003 & 0,99986 & 0,00000 & 0,00000 & 0,00000 & 0,00013 & 0,00000 \\
\hline CVJ06 & 0,997 & 0,003 & 0,99984 & 0,00000 & 0,00000 & 0,00001 & 0,00015 & 0,00000 \\
\hline CVJO7 & 0,017 & 0,983 & 0,00000 & 0,04005 & 0,90289 & 0,02264 & 0,00376 & 0,03067 \\
\hline CVJ08 & 0,018 & 0,982 & 0,00000 & 0,04005 & 0,90289 & 0,02264 & 0,00376 & 0,03067 \\
\hline CVJo9 & 0,997 & 0,003 & & 0,00000 & 0,00000 & 0,00000 & 0,00011 & 0,00000 \\
\hline CVJ10 & 0,997 & 0,003 & 0,99991 & 0,00000 & 0,00000 & 0,00000 & 0,00009 & 0,00000 \\
\hline CVJ11 & 0,997 & 0,003 & 0,99989 & 0,00000 & 0,00000 & 0,00000 & 0,00011 & 0,00000 \\
\hline CVJ12 & 0,997 & 0,003 & 0,99991 & 0,00000 & 0,00000 & 0,00000 & 0,00009 & 0,00000 \\
\hline CVJ13 & 0,997 & 0,003 & 0,99989 & 0,00000 & 0,00000 & 0,00000 & 0,00011 & 0,00000 \\
\hline CVJ14 & 0,997 & 0,003 & 0,99989 & 0,00000 & 0,00000 & 0,00000 & 0,00011 & 0,00000 \\
\hline CVJ15 & 0,997 & 0,003 & 0,99990 & 0,00000 & 0,00000 & 0,00000 & 0,00009 & 0,00000 \\
\hline CVJ16 & 0,996 & 0,004 & 0,99967 & 0,00000 & 0,00000 & 0,00001 & 0,00031 & 0,00000 \\
\hline CVJ17 & 0,996 & 0,004 & 0,99982 & 0,00000 & 0,00000 & 0,00000 & 0,00018 & 0,00000 \\
\hline CVJ18 & 0,997 & 0,003 & 0,99979 & 0,00000 & 0,00001 & 0,00001 & 0,00020 & 0,00000 \\
\hline CVJ19 & 0,996 & 0,004 & 0,99976 & 0,00000 & 0,00000 & 0,00001 & 0,00023 & 0,00000 \\
\hline CVJ20 & 0,996 & 0,004 & 0,99976 & 0,00000 & 0,00000 & 0,00001 & 0,00023 & 0,00000 \\
\hline CVA01 & 0,997 & 0,003 & 0,99994 & 0,00000 & 0,00000 & 0,00000 & 0,00005 & 0,00000 \\
\hline CVA02 & 0,997 & 0,003 & 0,99994 & 0,00000 & 0,00000 & 0,00000 & 0,00005 & 0,00000 \\
\hline CVA03 & 0,997 & 0,003 & 0,99987 & 0,00000 & 0,00000 & 0,00000 & 0,00013 & 0,00000 \\
\hline CVA04 & 0,995 & 0,005 & 0,99972 & 0,00000 & 0,00000 & 0,00001 & 0,00027 & 0,00000 \\
\hline CVA05 & 0,995 & 0,005 & 0,99975 & 0,00000 & 0,00000 & 0,00001 & 0,00024 & 0,00000 \\
\hline CVA06 & 0,996 & 0,004 & 0,99975 & 0,00000 & 0,00000 & 0,00001 & 0,00024 & 0,00000 \\
\hline CVA07 & 0,996 & 0,004 & 0,99962 & 0,00000 & 0,00005 & 0,00001 & 0,00033 & 0,00000 \\
\hline CVA08 & 0,997 & 0,003 & 0,99991 & 0,00000 & 0,00000 & 0,00000 & 0,00008 & 0,00000 \\
\hline CVA09 & 0,996 & 0,004 & 0,99976 & 0,00000 & 0,00000 & 0,00001 & 0,00023 & 0,00000 \\
\hline CVA10 & 0,995 & 0,005 & 0,99976 & 0,00000 & 0,00000 & 0,00001 & 0,00023 & 0,00000 \\
\hline CVA11 & 0,997 & 0,003 & 0,99993 & 0,00000 & 0,00000 & 0,00000 & 0,00007 & 0,00000 \\
\hline MOM01 & 0,032 & 0,968 & 0,00000 & 0,00005 & 0,98876 & 0,00474 & 0,00298 & 0,00348 \\
\hline MOM02 & 0,031 & 0,969 & 0,00000 & 0,00005 & 0,98876 & 0,00474 & 0,00298 & 0,00348 \\
\hline MOM03 & 0,030 & 0,970 & 0,00000 & 0,00005 & 0,98876 & 0,00474 & 0,00298 & 0,00348 \\
\hline
\end{tabular}




\begin{tabular}{|c|c|c|c|c|c|c|c|c|}
\hline MOM04 & 0,030 & 0,970 & 0,00000 & 0,00005 & 0,98876 & 0,00474 & 0,00298 & 0,00348 \\
\hline MOM05 & 0,031 & 0,969 & 0,00000 & 0,00005 & 0,98876 & 0,00474 & 0,00298 & 0,00348 \\
\hline MOM06 & 0,030 & 0,970 & 0,00000 & 0,00005 & 0,98876 & 0,00474 & 0,00298 & 0,00348 \\
\hline MOM07 & 0,996 & 0,004 & 0,99985 & 0,00000 & 0,00000 & 0,00000 & 0,00015 & 0,00000 \\
\hline MOM08 & 0,996 & 0,004 & 0,99985 & 0,00000 & 0,00000 & 0,00000 & 0,00015 & 0,00000 \\
\hline MOM09 & 0,996 & 0,004 & 0,99985 & 0,00000 & 0,00000 & 0,00000 & 0,00015 & 0,00000 \\
\hline MOM10 & 0,030 & 0,970 & 0,00000 & 0,00005 & 0,98876 & 0,00474 & 0,00298 & 0,00348 \\
\hline CAN01 & 0,997 & 0,003 & 0,99989 & 0,00000 & 0,00000 & 0,00000 & 0,00011 & 0,00000 \\
\hline CAN02 & 0,657 & 0,343 & 0,28195 & 0,00000 & 0,21610 & 0,12663 & 0,37462 & 0,00071 \\
\hline CAN03 & 0,995 & 0,005 & 0,99976 & 0,00000 & 0,00000 & 0,00001 & 0,00023 & 0,00000 \\
\hline CAN04 & 0,997 & 0,003 & 0,99990 & 0,00000 & 0,00000 & 0,00000 & 0,00009 & 0,00000 \\
\hline CAN05 & 0,997 & 0,003 & 0,99976 & 0,00000 & & 0,00001 & 0,00023 & 0,00000 \\
\hline CAN06 & 0,996 & 0,004 & 0,99982 & 0,00000 & 0,00000 & 0,00000 & 0,00018 & 0,00000 \\
\hline CAN07 & 0,996 & 0,004 & 0,99943 & 0,00000 & 0,00004 & 0,00003 & 0,00050 & 0,00000 \\
\hline CAN08 & 0,996 & 0,004 & 0,99943 & 0,00000 & 0,00004 & 0,00003 & 0,00050 & 0,00000 \\
\hline ALD01 & 0,994 & 0,006 & 0,99940 & 0,00000 & 0,00005 & 0,00004 & 0,00051 & 0,00000 \\
\hline ALD02 & 0,996 & 0,004 & 0,99979 & 0,00000 & 0,00000 & 0,00001 & 0,00020 & 0,00000 \\
\hline ALD03 & 0,994 & 0,006 & 0,99946 & 0,00000 & 0,00003 & 0,00003 & 0,00048 & 0,00000 \\
\hline ALD04 & 0,996 & 0,004 & 0,99979 & 0,00000 & 0,00000 & 0,00001 & 0,00020 & 0,00000 \\
\hline ALD05 & 0,994 & 0,006 & 0,99946 & 0,00000 & 0,00003 & 0,00003 & 0,00048 & 0,00000 \\
\hline ALD06 & 0,997 & 0,003 & 0,99992 & 0,00000 & 0,00000 & 0,00000 & 0,00008 & 0,00000 \\
\hline ALD07 & 0,996 & 0,004 & 0,99980 & 0,00000 & 0,00000 & 0,00000 & 0,00019 & 0,00000 \\
\hline ALD08 & 0,994 & 0,006 & 0,99950 & 0,00000 & 0,00002 & 0,00003 & 0,00046 & 0,00000 \\
\hline ALD09 & 0,997 & 0,003 & 0,99989 & 0,00000 & 0,00000 & 0,00000 & 0,00010 & 0,00000 \\
\hline ALD10 & 0,996 & 0,004 & 0,99984 & 0,00000 & 0,00000 & 0,00000 & 0,00016 & 0,00000 \\
\hline VIL01 & 0,996 & 0,004 & 0,99993 & 0,00000 & 0,00000 & 0,00000 & 0,00007 & 0,00000 \\
\hline VIL02 & 0,996 & 0,004 & 0,99994 & 0,00000 & 0,00000 & 0,00000 & 0,00006 & 0,00000 \\
\hline VIL03 & 0,986 & 0,014 & 0,99908 & 0,00000 & 0,00001 & 0,00007 & 0,00085 & 0,00000 \\
\hline VIL04 & 0,997 & 0,003 & 0,99992 & 0,00000 & 0,00000 & 0,00000 & 0,00008 & 0,00000 \\
\hline VIL05 & 0,995 & 0,005 & 0,99994 & 0,00000 & 0,00000 & 0,00000 & 0,00006 & 0,00000 \\
\hline VIL06 & 0,997 & 0,003 & 0,99995 & 0,00000 & 0,00000 & 0,00000 & 0,00005 & 0,00000 \\
\hline VIL07 & 0,995 & 0,005 & 0,99994 & 0,00000 & 0,00000 & 0,00000 & 0,00006 & 0,00000 \\
\hline VIL08 & 0,997 & 0,003 & 0,99994 & 0,00000 & 0,00000 & 0,00000 & 0,00006 & 0,00000 \\
\hline VIL09 & 0,997 & 0,003 & 0,99992 & 0,00000 & 0,00000 & 0,00000 & 0,00008 & 0,00000 \\
\hline VIL10 & 0,997 & 0,003 & 0,99992 & 0,00000 & 0,00000 & 0,00000 & 0,00008 & 0,00000 \\
\hline VIL11 & 0,997 & 0,003 & 0,99994 & 0,00000 & 0,00000 & 0,00000 & 0,00006 & 0,00000 \\
\hline VIL12 & 0,996 & 0,004 & 0,99994 & 0,00000 & 0,00000 & 0,00000 & 0,00006 & 0,00000 \\
\hline VIL13 & 0,997 & 0,003 & 0,99990 & 0,00000 & 0,00000 & 0,00000 & 0,00010 & 0,00000 \\
\hline VIL14 & 0,947 & 0,053 & 0,99822 & 0,00000 & 0,00001 & 0,00037 & 0,00140 & 0,00000 \\
\hline VIL15 & 0,947 & 0,053 & 0,99822 & 0,00000 & 0,00001 & 0,00037 & 0,00140 & 0,00000 \\
\hline STR01 & 0,997 & 0,003 & 0,99990 & 0,00000 & 0,00000 & 0,00000 & 0,00010 & 0,00000 \\
\hline STR02 & 0,997 & 0,003 & 0,99987 & 0,00000 & 0,00000 & 0,00000 & 0,00013 & 0,00000 \\
\hline
\end{tabular}




\begin{tabular}{|c|c|c|c|c|c|c|c|c|}
\hline STR03 & 0,997 & 0,003 & 0,99986 & 0,00000 & 0,00000 & 0,00000 & 0,00014 & 0,00000 \\
\hline STR04 & 0,997 & 0,003 & 0,99990 & 0,00000 & 0,00000 & 0,00000 & 0,00009 & 000 \\
\hline STR05 & 0,998 & 0,002 & 0,99987 & 0,00000 & 0,00000 & 0,00000 & 0,00013 &, 00000 \\
\hline STR06 & 0,997 & 0,003 & ,99992 & 0,00000 & 0,00000 & 0,00000 & 0,00008 & 0,00000 \\
\hline STR07 & 0,997 & 0,003 & 0,99989 & 0,00000 & 0,00000 & 0,00000 & 0,00011 &, 0000 \\
\hline STR08 & 0,997 & 0,003 & 0,99978 & 0,00000 & 0,00000 & 0,00001 & 0,00021 & 0,00000 \\
\hline STR09 & 0,997 & 0,003 & 0,99990 & 0,00000 & 0,00000 & 0,00000 & 0,00010 & 0,000 \\
\hline STR10 & 0,997 & 0,003 & 0,99987 & 0,00000 & 0,00000 & 0,00000 & 0,00012 & 0,000 \\
\hline STR11 & 0,997 & 0,003 & 0,99990 & 0,00000 & 0,00000 & 0,00000 & 0,00010 & 0,0000 \\
\hline STR12 & 0,997 & 0,003 & 0,99985 & 0,00000 & 0,00000 & 0,00000 & 0,00015 & 0,000 \\
\hline STR13 & 0,997 & 0,003 & 0,99986 & 0,00000 & 0,00000 & 0,00000 & 0,00014 & 0,000 \\
\hline STR14 & 0,997 & 0,003 & 0,99980 & 0,00000 & 0,00001 & 0,00000 & 0,00018 & 0,000 \\
\hline STR15 & 0,997 & 0,003 & 0,99993 & 0,00000 & 0,00000 & 0,00000 & 0,00007 & 0,000 \\
\hline STR16 & 0,997 & 0,003 & 0,99994 & 0,00000 & 0,00000 & 0,00000 & 0,00006 & 0,00000 \\
\hline STR17 & 0,997 & 0,003 & 0,99990 & 0,00000 & 0,00000 & 0,00000 & 0,00009 & 0,000 \\
\hline STR18 & 0,997 & 0,003 & 0,99992 & 0,00000 & 0,00000 & 0,00000 & 0,00008 & 0,00000 \\
\hline STR19 & 0,997 & 0,003 & 0,99988 & 0,00000 & 0,00000 & 0,00000 & 0,00012 & 0,000 \\
\hline STR20 & 0,997 & 0,003 & 0,99994 & 0,00000 & 0,00000 & 0,00000 & 0,00006 & 0,000 \\
\hline STR21 & 0,997 & 0,003 & 0,99990 & 0,00000 & 0,00000 & 0,00000 & 0,00009 & 0,000 \\
\hline STR22 & 0,997 & 0,003 & 0,99990 & 0,00000 & 0,00000 & 0,00000 & 0,00009 & 0,00000 \\
\hline STR23 & 0,998 & 0,002 & 0,99995 & 0,00000 & 0,00000 & 0,00000 & 0,00005 & 0,00000 \\
\hline STR24 & 0,997 & 0,003 & 0,99989 & 0,00000 & 0,00000 & 0,00000 & 0,00011 & 0,00000 \\
\hline STR25 & 0,997 & 0,003 & 0,99973 & 0,00000 & 0,00000 & 0,00001 & 0,00026 & 0,000 \\
\hline STR26 & 0,997 & 0,003 & 0,99993 & 0,00000 & 0,00000 & 0,00000 & 0,00007 & 0,000 \\
\hline STR27 & 0,997 & 0,003 & 0,99994 & 0,00000 & 0,00000 & 0,00000 & 0,00006 & 0,000 \\
\hline STR28 & 0,997 & 0,003 & 0,99987 & 0,00000 & 0,00000 & 0,00000 & 0,00012 & 0,000 \\
\hline STR29 & 0,998 & 0,002 & 0,99994 & 0,00000 & 0,00000 & 0,00000 & 0,00006 & 0,000 \\
\hline BEN01 & 0,996 & 0,004 & 0,99978 & 0,00000 & 0,00000 & 0,00000 & 0,00022 & 0,000 \\
\hline BEN02 & 0,996 & 0,004 & 0,99984 & 0,00000 & 0,00000 & 0,00000 & 0,00016 & 0,000 \\
\hline BEN03 & 0,832 & 0,168 & 0,99045 & 0,00000 & 0,00047 & 0,00376 & 0,00531 & 0,000 \\
\hline BEN04 & 0,997 & 0,003 & 0,99976 & 0,00000 & 0,00000 & 0,00001 & 0,00023 & 0,000 \\
\hline BEN05 & 0,932 & 0,068 & 0,99703 & 0,00000 & 0,00000 & 0,00072 & 0,00225 & 0,000 \\
\hline BEN06 & 0,932 & 0,068 & 0,99623 & 0,00000 & 0,00002 & 0,00102 & 0,00273 & 0,000 \\
\hline BEN07 & 0,997 & 0,003 & 0,99988 & 0,00000 & 0,00000 & 0,00000 & 0,00012 & 0,000 \\
\hline BEN08 & 0,995 & 0,005 & 0,99954 & 0,00000 & 0,00000 & 0,00003 & 0,00044 & 0,00000 \\
\hline BEN09 & 0,997 & 0,003 & 0,99991 & 0,00000 & 0,00000 & 0,00000 & 0,00009 & 0,00000 \\
\hline BEN10 & 0,994 & 0,006 & 0,99963 & 0,00000 & 0,00001 & 0,00001 & 0,00035 & 0,00000 \\
\hline BEN11 & 0,997 & 0,003 & 0,99989 & 0,00000 & 0,00000 & 0,00000 & 0,00010 & 0,00000 \\
\hline BEN12 & 0,997 & 0,003 & 0,99988 & 0,00000 & 0,00000 & 0,00000 & 0,00012 & 0,000 \\
\hline BEN13 & 0,997 & 0,003 & 0,99987 & 0,00000 & 0,00000 & 0,00000 & 0,00013 & 0,00000 \\
\hline BEN14 & 0,983 & 0,017 & 0,99897 & 0,00000 & 0,00002 & 0,00004 & 0,00097 & 0,000 \\
\hline BEN15 & 0,996 & 0,004 & 0,99986 & 0,00000 & 0,00000 & 0,00000 & 0,00014 & 0,000 \\
\hline
\end{tabular}




\begin{tabular}{|c|c|c|c|c|c|c|c|c|}
\hline BEN16 & 0,996 & 0,004 & 0,99987 & 0,00000 & 0,00000 & 0,00000 & 0,00013 & 0,00000 \\
\hline BEN17 & 0,997 & 0,003 & 0,99986 & 0,00000 & 0,00000 & 0,00000 & 0,00014 & 0,00000 \\
\hline BEN18 & 0,997 & 0,003 & 0,99991 & 0,00000 & 0,00000 & 0,00000 & 0,00009 & 0,00000 \\
\hline BEN19 & 0,996 & 0,004 & 0,99979 & 0,00000 & 0,00000 & 0,00001 & 0,00020 & 0,00000 \\
\hline BEN20 & 0,917 & 0,083 & 0,99572 & 0,00000 & 0,00005 & 0,00123 & 0,00301 & 0,00000 \\
\hline BEN21 & 0,988 & 0,012 & 0,99922 & 0,00000 & 0,00001 & 0,00002 & 0,00075 & 0,00000 \\
\hline BEN22 & 0,996 & 0,004 & 0,99975 & 0,00000 & 0,00000 & 0,00001 & 0,00024 & 0,00000 \\
\hline BEN23 & 0,995 & 0,005 & 0,99963 & 0,00000 & 0,00000 & 0,00001 & 0,00035 & 0,00000 \\
\hline BEN24 & 0,997 & 0,003 & 0,99996 & 0,00000 & 0,00000 & 0,00000 & 0,00004 & 0,00000 \\
\hline BEN25 & 0,997 & 0,003 & 0,99995 & 0,00000 & 0,00000 & 0,00000 & 0,00005 & 0,00000 \\
\hline PAUm01 & 0,002 & 0,998 & 0,00000 & 0,99919 & 0,00000 & 0,00001 & 0,00000 & 0,00080 \\
\hline PAUm02 & 0,002 & 0,998 & 0,00000 & 0,99919 & 0,00000 & 0,00001 & 0,00000 & 0,00080 \\
\hline PAUm03 & 0,002 & 0,998 & 0,00000 & 0,99919 & 0,00000 & 0,00001 & 0,00000 & 0,00080 \\
\hline PAUm04 & 0,002 & 0,998 & 0,00000 & 0,99919 & 0,00000 & 0,00001 & 0,00000 & 0,00080 \\
\hline PAUm05 & 0,002 & 0,998 & 0,00000 & 0,99919 & 0,00000 & 0,00001 & 0,00000 & 0,00080 \\
\hline VILm01 & 0,008 & 0,992 & 0,00000 & 0,99911 & 0,00000 & 0,00001 & 0,00000 & 0,00089 \\
\hline VILm02 & 0,003 & 0,997 & 0,00000 & 0,99869 & 0,00000 & 0,00002 & 0,00000 & 0,00129 \\
\hline VILm03 & 0,003 & 0,997 & 0,00000 & 0,99877 & 0,00000 & 0,00002 & 0,00000 & 0,00122 \\
\hline VILm04 & 0,003 & 0,997 & 0,00000 & 0,99372 & 0,00000 & 0,00016 & 0,00000 & 0,00612 \\
\hline VILm05 & 0,004 & 0,996 & 0,00000 & 0,98964 & 0,00000 & 0,00070 & 0,00000 & 0,00967 \\
\hline ESBm01 & 0,002 & 0,998 & 0,00000 & 0,99919 & 0,00000 & 0,00001 & 0,00000 & 0,00080 \\
\hline ESBm02 & 0,002 & 0,998 & 0,00000 & 0,99919 & 0,00000 & 0,00001 & 0,00000 & 0,00080 \\
\hline ESBm03 & 0,002 & 0,998 & 0,00000 & 0,99919 & 0,00000 & 0,00001 & 0,00000 & 0,00080 \\
\hline ESBm04 & 0,002 & 0,998 & 0,00000 & 0,99919 & 0,00000 & 0,00001 & 0,00000 & 0,00080 \\
\hline ESBm05 & 0,002 & 0,998 & 0,00000 & 0,99919 & 0,00000 & 0,00001 & 0,00000 & 0,00080 \\
\hline
\end{tabular}




\section{Anexo III}

\section{Artículo Científico Publicado}

"Genetic Diversity in Relict and Fragmented Populations of Ulmus glabra Hudson in the Central System of the Iberian Peninsula"

Forests 2017, 8(5), 143; doi:10.3390/f8050143

Factor de Impacto: 1,951 (Q1) en Forestry (13/64) 
Article

\title{
Genetic Diversity in Relict and Fragmented Populations of Ulmus glabra Hudson in the Central System of the Iberian Peninsula
}

\author{
María Martín del Puerto ${ }^{1}$, Felipe Martínez García ${ }^{2}$, Aparajita Mohanty ${ }^{3}$ and \\ Juan Pedro Martín 1,* \\ 1 Departamento de Biotecnología-Biología Vegetal, Escuela Técnica Superior de Ingeniería Agronómica, \\ Alimentaria y de Biosistemas, Universidad Politécnica de Madrid, Avda. Puerta de Hierro 2-4, \\ 28040 Madrid, Spain; maria.martin.delpuerto@upm.es \\ 2 Departamento de Sistemas y Recursos Naturales, Escuela Técnica Superior de Ingeniería de Montes, \\ Forestal y del Medio Natural, Universidad Politécnica de Madrid, Paseo de las Moreras s/n, \\ 28040 Madrid, Spain; felipe.martinez@upm.es \\ 3 Department of Botany, Gargi College, University of Delhi, Sirifort Road, New Delhi 110049, India; \\ aparajita.gargi@gmail.com \\ * Correspondence: juanpedro.martin@upm.es; Tel.: +34-913-365-662
}

Academic Editor: Timothy A. Martin

Received: 16 February 2017; Accepted: 20 April 2017; Published: 27 April 2017

\begin{abstract}
Ulmus glabra Hudson, or Wych elm, occurs as fragmented and relict natural populations in the Central System, which acts as a refugium in the Iberian Peninsula. Considering the importance of the Central System populations of U. glabra, the main objective was to assess their genetic diversity using nuclear microsatellite markers. A total of 360 different genotypes were detected in the $427 U$. glabra individuals analyzed. Wych elm populations showed a highly significant genetic differentiation $(24 \% ; p=0.0001)$. Of the 22 populations studied, population of Rozas de Puerto Real (ROZ) showed the highest values of effective number of alleles (2.803), mean Shannon's diversity (1.047) and expected heterozygosity (0.590). Populations of ROZ and Mombeltrán (MOM) showed the highest values of observed heterozygosity ( 0.838 and 0.709 , respectively), and highly negative values for inbreeding coefficient $(-0.412$ and -0.575 , respectively). Also, most of putative hybrids (50 of 55) were observed in these two populations. Demographic analysis revealed signals for recent (four populations) and ancestral (fifteen populations) bottlenecks. Fragmented populations with diminishing number of individuals, along with anthropogenic intervention and Dutch elm disease (DED), are the main threats to $U$. glabra populations. From a future perspective, the information generated can be considered in the formulation of conservation strategies for U. glabra populations in the Central System.
\end{abstract}

Keywords: fragmented populations; genetic diversity; introgression; microsatellite markers; population bottleneck; Ulmus glabra; Wych elm

\section{Introduction}

Wych elm (Ulmus glabra Hudson) is a deciduous tree distributed mainly in the Eurosiberian region. U. glabra is spread over central and northern Europe, reaching up to the Ural Mountains and further extending towards eastern and southern Europe (i.e., Mediterranean region) [1]. The Iberian Peninsula is the southwestern limit for Wych elm [2]. The continuity and abundance of $U$. glabra populations in the peninsula is greater in the northern strip and Pyrenean-Cantabric axis. The most meridional populations are separated by hundreds of kilometers [2]. Some of these populations belong to the Central System (Figure 1). Due to its location, orientation and altitude, this Central System is 
important in modulating the general climate and acting as an island. These climatic and geographical characteristics have enabled the persistence of some areas with Eurosiberian conditions surrounded by zones with Mediterranean climate [3]. The persistence of these areas acting as refugia with a favorable climate, has enabled the survival of the Eurosiberian species till the present $[4,5]$.

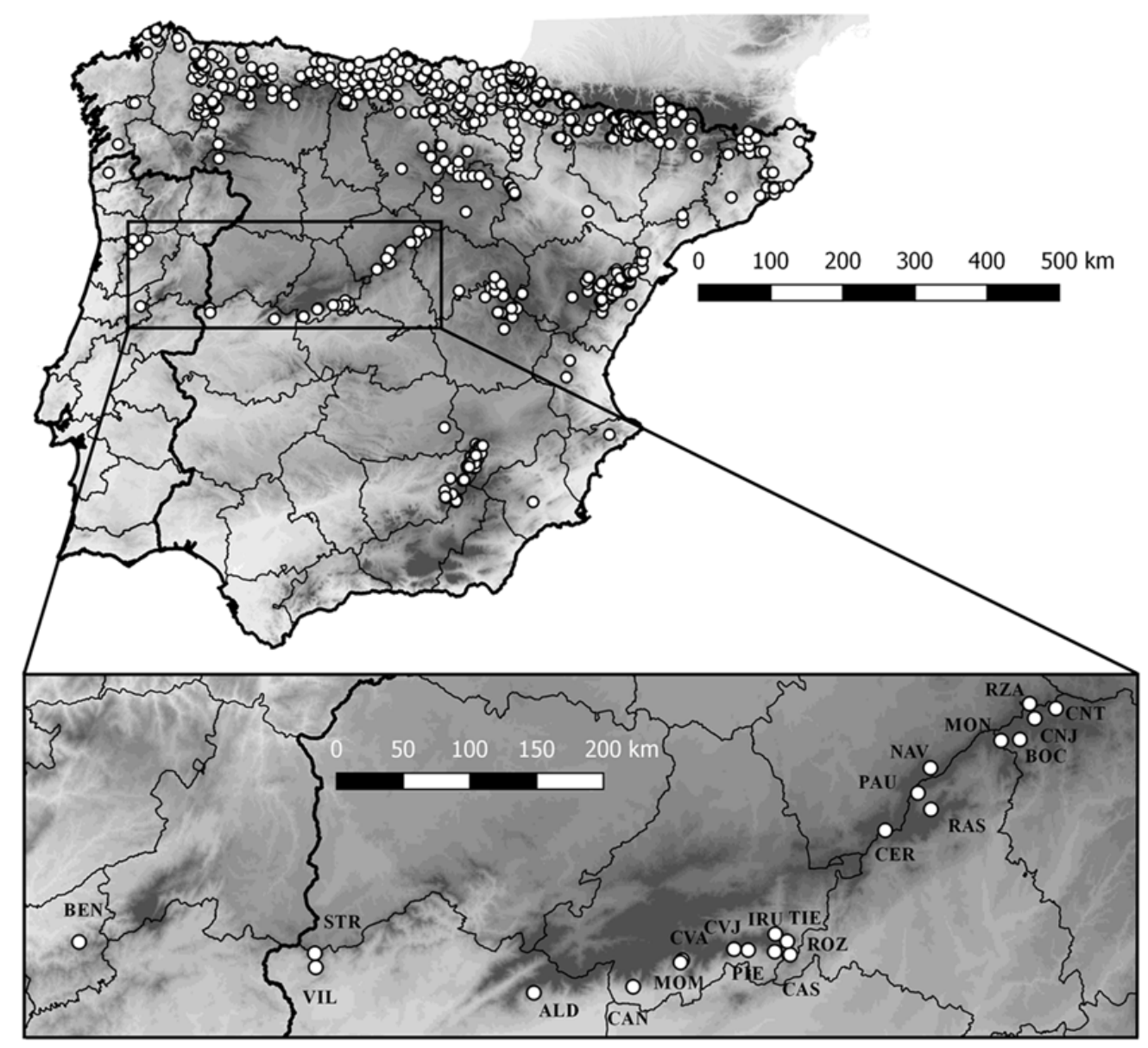

Figure 1. Map depicts the locations of Ulmus glabra populations in the Iberian Peninsula. The details of distribution of the studied populations along the Central System are shown in the rectangle (see Table 1 for codes).

The presence of the genus Ulmus in the Iberian Peninsula dates back to the Miocene and also has been reported throughout the Pleistocene and Holocene [6]. Paleobotanic and paleoclimatic studies confirm a temperature increase over the Late Glacial and, also, in the Holocene [7]. Therefore, the Mediterranean climate has gradually expanded to the Iberian Peninsula. Consequently, Eurosiberian vegetation has been reduced both latitudinally and altitudinally [4,8,9]. In addition to the climatic factors, the development of human-related activities has drastically reduced the woody vegetation in these mountains [10,11], thus affecting the genus Ulmus [12].

Besides landscape, climatic and anthropogenic factors, natural interspecific hybridization and introgression among relatives of the genus Ulmus have had significant consequences on the genetic diversity, genetic structure and conservation of their natural populations [13-15]. In the Iberian Peninsula, three Ulmus species are considered natives: U. glabra, U. minor Mill. and U. laevis Pall. [16,17]. $U$. minor and $U$. glabra are genetically most close [18], so hybridization and introgression between the two species have been described in natural populations where Field elms and Wych elms coexist [15,19]. Both these Ulmus species are monoecious, self incompatible, wind pollinated and their seed dispersal is also by wind [1]. 
Table 1. Location, number of sampled individuals $(\mathrm{Ns})$ and estimated total number of individuals (Nt) of Ulmus glabra and $U$. minor populations studied along the Central System of the Iberian Peninsula.

\begin{tabular}{|c|c|c|c|c|c|c|c|c|c|}
\hline & & Populations & & & & & & & \\
\hline No & Code & Locality & Province & Species & Latitude & Longitude & Altitude (m) & Ns & $N t^{1}$ \\
\hline 1 & CNT & Cantalojas & Guadalajara & U. glabra & 41.24913 & -3.23853 & 1393 & 1 & 1 \\
\hline 2 & CNJ & Cantalojas (Arroyo de la Zarza) & Guadalajara & U. glabra & 41.20193 & -3.34225 & 1557 & 38 & 194 \\
\hline 3 & $\mathrm{BOC}$ & El Cardoso de la Sierra-Bocígano & Guadalajara & U. glabra & 41.13182 & -3.41177 & 1314 & 4 & 8 \\
\hline 4 & RZA & Riaza-Becerril & Segovia & U. glabra & 41.26585 & -3.36955 & 1556 & 22 & 27 \\
\hline 5 & NAV & Navafría & Segovia & U. glabra & 41.01932 & -3.84353 & 1512 & 14 & 14 \\
\hline 6 & MON & Montejo de la Sierra-El Cardoso de la Sierra & Madrid & U. glabra & 41.13687 & -3.51304 & 1463 & 7 & 9 \\
\hline 7 & RAS & Rascafría-Morcuera & Madrid & U. glabra & 40.86605 & -3.83780 & 1451 & 33 & 37 \\
\hline 8 & PAU & El Paular (Pista de las Poyatas) & Madrid & U. glabra & 40.92471 & -3.90225 & 1670 & 1 & 1 \\
\hline 9 & CER & Cercedilla & Madrid & U. glabra & 40.78363 & -4.05626 & 1260 & 6 & 6 \\
\hline 10 & $\mathrm{ROZ}$ & Rozas de Puerto Real & Madrid & U. glabra & 40.31348 & -4.49671 & 801 & 46 & 46 \\
\hline 11 & TIE & El Tiemblo & Ávila & U. glabra & 40.35743 & -4.51245 & 1163 & 42 & 91 \\
\hline 12 & IRU & El Barraco (Valle de Iruelas) & Ávila & U. glabra & 40.38169 & -4.56854 & 1260 & 57 & $>6500$ \\
\hline 13 & CAS & Casillas & Ávila & U. glabra & 40.32280 & -4.57195 & 955 & 21 & 78 \\
\hline 14 & PIE & Piedralaves & Ávila & U. glabra & 40.33955 & -4.70401 & 1042 & 7 & 14 \\
\hline 15 & CVJ & Casavieja & Ávila & U. glabra & 40.32676 & -4.76926 & 1170 & 20 & 60 \\
\hline 16 & CVA & Cuevas del Valle & Ávila & U. glabra & 40.27778 & -5.01679 & 797 & 11 & 17 \\
\hline 17 & MOM & Mombeltrán & Ávila & U. glabra & 40.26935 & -5.02413 & 757 & 10 & 18 \\
\hline 18 & CAN & Candeleda & Ávila & U. glabra & 40.17660 & -5.24816 & 654 & 8 & 11 \\
\hline 19 & ALD & Aldeanueva de la Vera & Cáceres & U. glabra & 40.13357 & -5.72310 & 696 & 10 & 11 \\
\hline 20 & VIL & Villamiel & Cáceres & U. glabra & 40.18574 & -6.77448 & 680 & 15 & 22 \\
\hline 21 & STR & San Martín de Trevejo-Eljas & Cáceres & U. glabra & 40.23256 & -6.78812 & 820 & 29 & $>5000$ \\
\hline 22 & BEN & Benfeita & Arganil (Portugal) & U. glabra & 40.21813 & -7.91848 & 546 & 25 & 195 \\
\hline 23 & PAUm & El Paular & Madrid & U. minor & 40.88794 & -3.88643 & 1164 & 5 & NA \\
\hline 24 & VILm & Villamiel & Cáceres & U. minor & 40.16955 & -6.79228 & 573 & 5 & NA \\
\hline 25 & $\mathrm{ESBm}$ & Escalos de Baixo & Castelo Branco (Portugal) & U. minor & 39.87995 & -7.38771 & 374 & 5 & NA \\
\hline
\end{tabular}

${ }^{1} \mathrm{NA}=$ not available. 
Thus, the available data about vegetation evolution together with the current distribution of U. glabra in the Iberian Peninsula emphasize the relict and peripheral distribution of Wych elm populations in the Central System. According to Rossignoli and Génova [2], these populations are not only relict but also have fragmented distribution. Collin et al. [20] have emphasized the need for special attention to marginal populations of $U$. glabra because of their rarity and adaptability to unique geographical conditions. These populations are also important for the natural heritage preservation, particularly in view of the fact that major threats to their survival were found [2]. The scattered distribution, small population size and impact of human activities, can increase the fragmentation of populations along with genetic erosion, mainly towards the southern limits of the species distribution, causing them to be more susceptible to stochastic, genetic, and demographic events [21].

Moreover, in the last decades, Dutch elm disease (DED) has reduced the number of trees in Wych elm populations [2,16]. Fifteen populations of $U$. glabra from the Central System have been previously described [2] as having low numbers of individuals in general and with a high contribution of young individuals combined with re-sprouting stumps. For the present study, these 15 populations and an additional seven populations have been included. Hence, 22 populations of $U$. glabra, located along a 600-kilometer stretch of the large mountainous region, which includes the Spanish provinces of Guadalajara, Segovia, Madrid, Ávila and Cáceres, and one population found in the Serra da Estrela in Portugal (Figure 1), have been analyzed in the present investigation.

For understanding and establishing adequate conservation management strategies in the natural populations of $U$. glabra in the Central System of Iberian Peninsula, characterization of genetic diversity is the first necessary step. To study genetic variability in populations of elm species, molecular markers such as Random Amplified Polymorphic DNAs (RAPDs) [22-24], Inter Simple Sequence Repeats (ISSRs) [23], and Amplified Fragment Length Polymorphisms (AFLPs) [15,16,25] have been used. AFLP markers have also been used to investigate interspecific hybridization between $U$. minor and U. glabra in Flanders [15].

In addition, numerous microsatellite markers have been developed for different Ulmus species, such as $U$. laevis [26], U. minor [27] and U. rubra Muhl. [28], and used for testing of cross-amplification in other elm species, including $U$. glabra. Many $U$. laevis populations located along Europe have been studied using these markers $[17,29,30]$. Genetic diversity of a few localized natural populations of U. minor (e.g., in Balearic Islands, [31]; in the Netherlands, [32]; in Croatia, [33]) and U. glabra (e.g., in Denmark, [34]) have also been studied using microsatellite markers. The most extensive analysis of European populations of these two species together, using restriction fragment-length polymorphisms in chloroplast DNA, AFLPs and nuclear microsatellites [16], included only five populations of Wych elm from Spain, of which one was from the Central System. Moreover, there are some studies using microsatellite markers focused on detecting hybridization and introgression between elm species, e.g., between invasive $U$. pumila $L$. and native $U$. rubra in USA $[13,35]$ or native U. minor in Italy $[14,36]$.

Keeping in view the importance of Central System populations of $U$. glabra in the Iberian Peninsula and simultaneous lack of studies on genetic diversity, interspecific hybridization and introgression, the major objectives of the present investigation were (i) to assess the level of the genetic diversity of $U$. glabra populations in the Central System; (ii) to analyze possible demographic processes (e.g., evidence of bottleneck events) they have undergone; and (iii) to detect possible introgression between $U$. glabra and $U$. minor, which can significantly influence the genetic diversity and genetic structure in Wych elm populations.

\section{Materials and Methods}

\subsection{Sampling of Plant Material}

Leaf material of 427 individuals from 22 populations of $U$. glabra in the Central System was sampled for the present study (Table 1, Figure 1). Whenever possible, leaf material was collected from 
clearly-separated individuals to reduce the risk of sampling ramets. In addition, fifteen individuals of $U$. minor were sampled in three different Central System locations (Table 1). Also, since U. glabra populations have a fragmented distribution in the Central System and the number of estimated individuals/population ( $N t$ ) was extremely varied (see Table 1), sampling was done so as to reflect the distribution of the species in the Central System. Hence, a representative number of individuals (approximately between 20 and 60) which were mostly at a uniform separation within the population, were collected. For populations that had less than 20 estimated individuals/population (see Table 1), collection of all possible individuals was done, after taking care to avoid the collection of ramets. In such cases the number of individuals per population was less (less than 20). Leaf material of all individuals was stored at $-80^{\circ} \mathrm{C}$ until DNA extraction.

\subsection{DNA Extraction and Microsatellite Genotyping}

Total genomic DNA was extracted from frozen leaf material following the protocol supplied in the "NucleoSpin ${ }^{\circledR}$ Plant II Kit" (Macherey-Nagel GmbH \& Co. KG, Düren, Germany). Extracted DNA was quantified by visual comparison with known concentrations of lambda DNA on $1.2 \%$ agarose gels, and a working solution of DNA (approx. $10 \mathrm{ng} / \mu \mathrm{L}$ ) was made.

Twenty two microsatellite loci comprising of seven developed in $U$. laevis (Ulm2, Ulm3, Ulm6, Ulm8, Ulm9, Ulm12 and Ulm19; [26]), four in U. minor (Ulmi1-21, Ulmi1-98, Ulmi1-165 and Ulmi2-16; [27]), and eleven in U. rubra (UR101, UR123, UR138, UR141, UR153, UR158, UR159, UR173a, UR173b, UR175 and UR188a; [28]) were screened using 32 samples of $U$. glabra (one from each population with $\leq 20$ samples and two from populations with $>20$ samples). One sample of each of the three locations of $U$. minor was also used for this preliminary screening. Eleven of 22 microsatellite markers (Ulm2, Ulm3, Ulm8, Ulmi1-21, Ulmi1-98, Ulmi1-165, UR123, UR138, UR153, UR173a and UR175), were shortlisted for use in the present study based on interpretable polymorphisms in both elm species. However, UR138 and UR173a showed multiband patterns in U. minor, and therefore, they were not used for analysis in this species.

One primer of each pair was labeled with a fluorescent dye $\left(6-\mathrm{FAM}^{\mathrm{TM}}, \mathrm{VIC}{ }^{\circledR}, \mathrm{NED}^{\mathrm{TM}}\right.$ or $\mathrm{PET}^{\mathrm{TM}}$; Applied Biosystems ${ }^{\mathrm{TM}}$, Foster City, CA, USA) at the $5^{\prime}$ end. Polymerase chain reactions were performed in $20 \mu \mathrm{L}$ of final volume containing $2 \mu \mathrm{L}$ of genomic DNA (about $20 \mathrm{ng}$ ), $0.5 \mu \mathrm{M}$ of each of the forward and reverse primers, $0.15 \mathrm{mM}$ of each deoxynucleotide triphosphate (dNTP), $2 \mathrm{mM}$ of $\mathrm{MgCl}_{2}$ and $0.8 \mathrm{U}$ of Tth DNA polymerase in $1 \mathrm{X}$ of the manufacturer's reaction buffer (BIOTOOLS, B\&M Labs, Madrid, Spain). DNA amplifications were carried out in a PTC-100 thermalcycler (MJ Research, Inc., Waltham, MA, USA) with heated lid, using the same protocol for all microsatellite loci: an initial denaturalization step of $4 \mathrm{~min}$ at $94{ }^{\circ} \mathrm{C}$, followed by 35 cycles of $45 \mathrm{~s}$ at $94{ }^{\circ} \mathrm{C}, 1 \mathrm{~min}$ at $50{ }^{\circ} \mathrm{C}$ and $1 \mathrm{~min}$ $30 \mathrm{~s}$ at $72{ }^{\circ} \mathrm{C}$, with a final extension step of $72{ }^{\circ} \mathrm{C}$ for $10 \mathrm{~min}$. Amplified products were separated by capillary electrophoresis using an ABI PRISM ${ }^{\circledR} 3730$ DNA analyzer (Applied Biosystems, Foster City, CA, USA). GeneScan-500LIZ (Applied Biosystems, Foster City, CA, USA) was used as an internal size standard. Alleles were scored using Peak Scanner ${ }^{\mathrm{TM}}$ software version 1.0 (Applied Biosystems, Foster City, CA, USA).

\subsection{Data Analysis}

\subsubsection{Genetic Diversity}

Genetic diversity parameters were calculated based on data from eleven microsatellite loci analyzed in 427 Wych elm samples from 22 populations. For each locus: allele frequencies, total number of alleles $\left(N_{A}\right)$ and effective number of alleles $\left(N_{E}\right)$, number of different genotypes observed $\left(G_{O}\right)$, observed heterozygosity $\left(H_{O}\right)$ and expected heterozygosity $\left(H_{E}\right)$, and Shannon's information index $(I)$ were calculated, using GenAlEx software version 6.5 [37,38]. Polymorphic information content per locus (PIC) was also calculated according to Bostein et al. [39]. 
Furthermore, the discrimination power $(D ;[40,41])$ of microsatellite markers was estimated. This parameter is an estimate of the probability that two randomly-sampled trees could be distinguished by their microsatellite profiles, and was calculated for each locus as $D=1-C$, where $C$ is the probability of coincidence, i.e., two samples match by chance at one locus $\left(C=\Sigma P_{i}{ }^{2}\right.$, and $P_{i}$ is the frequency of different genotypes observed at that locus). The discrimination power for all loci combined $(\mathrm{m}=11)$ was calculated as $D_{T}=1-C_{T}$, where $C_{T}=\Pi C_{m}$, and represents the probability of coincidence cumulative for all loci.

Considering the overall microsatellite loci analyzed, for each population the percentage of polymorphic loci $(P)$ and $G_{O}$ were calculated. Also, other parameters, such as the mean over all loci of $N_{E}, I, H_{O}, H_{E}$ and inbreeding coefficient $(F)$, were also calculated using the GenAlEx 6.5 software [37,38].

Relationships among $19 \mathrm{U}$. glabra populations (with at least six sampled individuals) were obtained using the UPGMA (unweighted pair group with arithmetic mean) method with NTSYS-pc software version 2.2 [42], based on Nei's standard genetic distances [43]. A co-phenetic matrix was derived from the genetic distance matrix to test the goodness-of-fit of the clusters by comparing the two matrices using the Mantel matrix correspondence test in the MxComp program of the NTSYS-pc package, using 10,000 random permutations. The robustness of the dendrogram was also tested using 10,000 bootstraps implemented with the Phylip software version 3.6 [44].

Additionally, in order to determine the significance of partitioning of genetic diversity among and within populations, an analysis of molecular variance (AMOVA; [45]) was conducted using the GenAlEx 6.5 software. Levels of significance of variance component estimates were computed by non-parametric permutational procedures using 10,000 random permutations. Genetic differentiation $\left(F_{S T}\right)$ was also calculated over all populations in a group and then among all pairs of populations, and their significance was tested by a permutation procedure using 10,000 permutations.

\subsubsection{Demographic Analysis}

The effective population size $\left(N_{e}\right)$ is a critical parameter to study the evolution and conservation in natural populations. As estimates of $N_{e}$ can be affected by recent population size changes, the test for evidence of recent bottlenecks in $U$. glabra populations was performed using the $T_{2}$ statistic implemented in the program BOTTLENECK version 1.2 [46,47]. This statistic represents an average over loci of the deviation of the actual $H_{E}$ from the $H_{E}$ expected from the number of alleles in the population assuming mutation-drif equilibrium in a constant size population. The program tests for excess of heterozygosity using several mutation models including the stepwise mutation model (SMM), infinite allele model (IAM), and a two-phase model (TPM). For microsatellite data, the TPM is suggested to be the most appropriate mutation model [47-49]. Thus, the TPM model was applied assuming 95\% single-step mutations and 5\% multiple-step mutations [47], and a variance among multiple steps of 26. Positive values of $T_{2}$ indicate bottleneck, whereas negative values are consistent with recent population expansions. Also, considering the number of polymorphic loci used in the present study, the Wilcoxon's signed rank test was chosen to determine the $T_{2}$ significance as recommended by Piry et al. [47]. The test was run with 10,000 iterations.

Additionally, the $M$-ratio values (calculated as a ratio of the number of alleles to the range in allele size at a microsatellite locus [50]) were calculated using Arlequin software version 3.5 [51]. M-ratio value was used to detect reductions in effective population size. In comparison to the BOTTLENECK methods that are tailored to detect recent bottlenecks, $M$-ratio reflects a population size decline over a longer timescale and may be more powerful for detecting ancestral bottlenecks [48,50]. Based on empirical evidence, Garza and Williamson [50] indicated that in any population study where seven or more loci are analyzed and if the population shows $M$-ratio below 0.68 , then it may be assumed that they have undergone a genetic bottleneck [17]. Both $T_{2}$ bottleneck statistic and $M$-ratio method used to detect bottleneck events were carried out in only 15 U. glabra populations that were comprised of at least 10 sampled individuals. 
Finally, the effective population size for each of the $10 \mathrm{U}$. glabra populations with at least 20 sampled individuals, was calculated using two different single-sample estimation methods: the linkage-disequilibrium information and approximate Bayesian computation. LDNe software version 1.31 [52] was used, which employs linkage-disequilibrium information among alleles at different loci caused by genetic drift in finite populations. This method corrects for biases associated with small sample sizes $[52,53]$. $N_{e}$ was estimated assuming random mating and excluding alleles with frequencies less than 0.05 . This critical value has been shown to produce little bias from rare alleles while maintaining moderate precision [54]. The $95 \%$ confidence intervals for $N_{e}$ were obtained using a Jackknife method as recommended in Waples and Do [52].

Approximate Bayesian computations to estimate variance $N_{e}$ from summary statistics that are related to $N_{e}$ were performed using ONeSAMP software version 1.1 [55]. The user defines prior estimates of $N_{e}$ (lower and upper bounds) and ONeSAMP generates 50,000 simulated populations drawn randomly from the distribution of $N_{e}$ priors. Summary statistics are calculated and compared to the actual data and similar summary statistics are retained for use in generating an estimate of $N_{e}$ using weighted local regression [55]. Several lower and upper bounds were tested on the prior estimates for $N_{e}$ per population. Finally, 2-7000 for two populations (STR and IRU; see Table 1 for population codes) and 2-200 for the other eight populations tested, were used to estimate their $N_{e}$ along with $95 \%$ confidence intervals.

\subsubsection{Introgression between $U$. glabra and $U$. minor}

To identify genetic groups within $U$. glabra populations and the relationships with $U$. minor genotypes, STRUCTURE software version 2.3.4 [56] was used. This Bayesian approach uses no a priori classification and assigns samples to $K$ genetic clusters based on the allele frequencies at each locus. A first analysis was carried out on $427 \mathrm{U}$. glabra individuals using data from the eleven microsatellite markers, and the range of possible groups $(K)$ tested was from 1 to 25 , i.e., the total number of sampled populations plus three [57]. Then, to know the relationships between $U$. glabra and $U$. minor genotypes, a second analysis was performed by adding the $15 \mathrm{U}$. minor samples, using only data from the nine microsatellite loci that were amplified in both species, and wherein the number of groups tested ranged from 1 to 10 considering the results of previous analysis.

The estimate of the most likely number of genetic groups was performed following the procedure of Evanno et al. [57], which proposed the ad hoc statistic $\Delta K$. Program settings used were the admixture ancestry and correlated allele frequencies models. The degree of admixture alpha was inferred from the data, and lambda, the parameter of the distribution of allelic frequencies, was set to $1[57,58]$. The program was run 20 independent times for each $K$ value. In each run, a burn-in period of 10,000 iterations, and 100,000 post-burning MCMC (Markov chain Monte Carlo) simulations, were carried out. Finally, among the 20 runs performed for the optimal $K$ value estimated, the run with the least negative log-likelihood value [59] was used to obtain the membership coefficients $(q)$ for each individual in each of the $K$ inferred groups.

In the second STRUCTURE analysis, admixed individuals could represent putative hybrids between $U$. glabra and $U$. minor, so an analytical tool more focused on hybrid detection was also applied. Bayesian statistical methods provided in the program NewHybrids version 1.1 beta [60] were used to estimate posterior probabilities of whether each analyzed individual belonged to parental classes (U. glabra and $U$. minor) or hybrid categories (i.e., $\mathrm{F}_{1}, \mathrm{~F}_{2}$ and backcrosses $\mathrm{F}_{1}$ ). This was performed using prior information about individual assignments corresponding to genetic clusters previously detected by STRUCTURE analysis. The program was carried out using the default parameters for the six genotype class frequencies and ten independent runs with a burn-in period of 100,000 iterations followed by 600,000 MCMC simulations. 


\section{Results}

\subsection{Genetic Diversity}

An analysis of 11 microsatellite loci in 442 elm individuals (427 U. glabra and 15 U. minor) revealed a total of 101 alleles. Of the 101 alleles, 92 were detected in U. glabra (see Tables S1 and S2). Frequencies of 50 out of 92 alleles were below 0.05, whereas five alleles showed frequencies above 0.5 (Table S2).

Results of the genetic diversity analysis in $U$. glabra per locus are presented in Table 2 . The number of alleles per locus ranged from 3 in UR123 to 23 in Ulmi1-165, with an average of 8.4 alleles per locus. The average effective number of alleles per locus was 3.6, and the range varied between 10.4 for Ulmi1-165 and 1.2 for Ulm2. The average number of observed genotypes was 23.6, with a maximum (95) in Ulmi1-165 and a minimum (5) in UR123. The means of observed and expected heterozygosity were 0.477 and 0.566 , respectively. The maximum values of $H_{E}$ and $H_{O}$ were obtained in Ulmi1-165 and minimum values were observed in Ulm2. The mean of Shannon's diversity index over all loci was 1.272 and varied between 2.639 (Ulmi1-165) and 0.356 (Ulm2). Similar trends were observed for polymorphic information content and discrimination power. For PIC, the maximum (0.899) and minimum (0.141) values were for Ulmi1-165 and Ulm2 respectively, and the mean value was 0.539 (Table 2). The maximum and minimum values obtained for $D$ were also for Ulmi1-165 (0.974) and Ulm2 (0.269) respectively, with a cumulative probability for all loci close to 1 (Table 2). In general, microsatellite loci developed in U. minor (Ulmi1-SSR series) showed the highest values for $N_{A}, N_{E}, G_{O}$, heterozygosity, PIC and D, and the lowest values in Ulm-SSR series, developed in U. laevis.

Table 2. Genetic diversity parameters at eleven microsatellite loci analyzed in 427 Ulmus glabra individuals from the Central System of the Iberian Peninsula.

\begin{tabular}{cccccccccc}
\hline Loci & $N_{\boldsymbol{A}}$ & $N_{\boldsymbol{E}}$ & $G_{\boldsymbol{O}}$ & $\boldsymbol{H}_{\boldsymbol{O}}$ & $\boldsymbol{H}_{\boldsymbol{E}}$ & $\boldsymbol{I}$ & $\boldsymbol{P I C}$ & $\boldsymbol{D}$ \\
\hline Ulm2 & 5 & 1.169 & 6 & 0.148 & 0.144 & 0.356 & 0.141 & 0.731 & 0.269 \\
Ulm3 & 9 & 1.420 & 13 & 0.260 & 0.296 & 0.687 & 0.283 & 0.525 & 0.475 \\
Ulm8 & 4 & 1.325 & 6 & 0.246 & 0.245 & 0.523 & 0.234 & 0.577 & 0.423 \\
Ulmi1-21 & 9 & 5.757 & 34 & 0.520 & 0.826 & 1.979 & 0.809 & 0.068 & 0.932 \\
Ulmi1-98 & 10 & 4.444 & 32 & 0.670 & 0.775 & 1.736 & 0.743 & 0.091 & 0.909 \\
Ulmi1-165 & 23 & 10.365 & 95 & 0.806 & 0.904 & 2.639 & 0.899 & 0.026 & 0.974 \\
UR123 & 3 & 1.373 & 5 & 0.234 & 0.272 & 0.527 & 0.252 & 0.599 & 0.401 \\
UR138 & 7 & 3.928 & 18 & 0.712 & 0.745 & 1.570 & 0.706 & 0.109 & 0.891 \\
UR153 & 6 & 3.287 & 15 & 0.604 & 0.696 & 1.327 & 0.646 & 0.137 & 0.863 \\
UR173a & 9 & 2.514 & 20 & 0.539 & 0.602 & 1.254 & 0.552 & 0.196 & 0.804 \\
UR175 & 7 & 3.512 & 16 & 0.513 & 0.715 & 1.393 & 0.665 & 0.135 & 0.865 \\
Mean & 8.4 & 3.554 & 23.6 & 0.477 & 0.566 & 1.272 & 0.539 & --- \\
Cumulative & 92 & --- & 260 & --- & --- & --- & --- & $8.4 \times 10^{-9}$ & 0.999999992
\end{tabular}

$N_{A}$-number of alleles, $N_{E}$-effective number of alleles, $G_{O}$-number of observed genotypes, $H_{O}$-observed heterozygosity, $H_{E}$ - expected heterozygosity, I-Shannon's information index, PIC - polymorphic information content, $C$ - probability of coincidence, and $D$-discrimination power.

Microsatellite-based genotyping for the 11 combined SSR loci in 427 individuals of U. glabra revealed a high number (360) of distinct genotypes (Table S1). Only 25 of 360 genotypes were common to two or more individuals. The three Ulmi1-SSR loci alone showed a discrimination power of 0.99984 . They could distinguish 301 different genotypes, which is about $84 \%$ of the total genotypes detected using the 11 SSR loci.

The results of genetic diversity analysis in populations of $U$. glabra are presented in Table 3. Percentages of polymorphic loci varied between 100\% (ROZ, IRU and CVJ populations) and $46 \%$ (CNT). Three populations (BOC, PAU and CER) with a low number of individuals showed relatively low values of $P(64 \%)$. The number of different genotypes observed across all loci in each population was similar to the number of sampled individuals, except in CER, ROZ and MOM populations where number of genotypes was $<30 \%$ of the sampled individuals (Table 3 ). The highest values of effective number of alleles $\left(N_{E}=2.803\right)$, mean Shannon's diversity $(I=1.047)$ and expected heterozygosity $\left(H_{E}=0.590\right)$ were observed in ROZ population while the lowest values $\left(N_{E}=1.711, \mathrm{I}=0.547\right.$ and 
$H_{E}=0.310$ ) were detected in RAS population (Table 3), when populations with sample size below 5 (CNT, BOC, and PAU) and population with one unique genotype (i.e., CER) were excluded from the analyses. Populations of ROZ and MOM showed the highest values of observed heterozygosity ( $H_{O}=0.838$ and 0.709 , respectively), which corresponded to highly negative values for inbreeding coefficient $(F=-0.412$ and -0.575 , respectively; Table 3$)$.

Table 3. Genetic diversity parameters calculated for Ulmus glabra populations from the Central System of the Iberian Peninsula using data from eleven microsatellite loci. See Table 1 for population codes.

\begin{tabular}{cccccccc}
\hline Population & $\boldsymbol{P}(\boldsymbol{\%})$ & $G_{\boldsymbol{O}}(\mathbf{N s})$ & $\boldsymbol{N}_{\boldsymbol{E}}$ & $\boldsymbol{I}$ & $\boldsymbol{H}_{\boldsymbol{O}}$ & $\boldsymbol{H}_{\boldsymbol{E}}$ & $\boldsymbol{F}$ \\
\hline CNT & 46 & $1(1)$ & --- & --- & 0.455 & --- & --- \\
CNJ & 82 & $38(38)$ & 1.959 & 0.678 & 0.428 & 0.393 & -0.086 \\
BOC & 64 & $2(4)$ & --- & --- & 0.568 & --- & --- \\
RZA & 82 & $22(22)$ & 2.090 & 0.751 & 0.397 & 0.413 & 0.038 \\
NAV & 82 & $14(14)$ & 1.897 & 0.640 & 0.429 & 0.399 & -0.090 \\
MON & 73 & $7(7)$ & 2.045 & 0.728 & 0.416 & 0.404 & -0.028 \\
RAS & 82 & $29(33)$ & 1.711 & 0.547 & 0.309 & 0.310 & 0.017 \\
PAU & 64 & $1(1)$ & --- & --- & 0.636 & --- & --- \\
CER & 64 & $1(6)$ & --- & --- & 0.636 & --- & -- \\
ROZ & 100 & $13(46)$ & 2.803 & 1.047 & 0.838 & 0.590 & -0.412 \\
TIE & 73 & $39(42)$ & 2.213 & 0.769 & 0.394 & 0.443 & 0.089 \\
IRU & 100 & $56(57)$ & 2.222 & 0.867 & 0.445 & 0.435 & 0.006 \\
CAS & 82 & $21(21)$ & 2.136 & 0.695 & 0.398 & 0.376 & -0.024 \\
PIE & 73 & $5(7)$ & 2.048 & 0.666 & 0.442 & 0.371 & -0.185 \\
CVJ & 100 & $17(20)$ & 2.078 & 0.848 & 0.482 & 0.435 & -0.089 \\
CVA & 82 & $10(11)$ & 2.187 & 0.672 & 0.405 & 0.385 & -0.052 \\
MOM & 82 & $2(10)$ & 2.083 & 0.717 & 0.709 & 0.450 & -0.575 \\
CAN & 91 & $7(8)$ & 2.505 & 0.847 & 0.409 & 0.444 & 0.026 \\
ALD & 73 & $10(10)$ & 2.020 & 0.655 & 0.455 & 0.388 & -0.132 \\
VIL & 73 & $12(15)$ & 1.890 & 0.637 & 0.394 & 0.355 & -0.097 \\
STR & 82 & $28(29)$ & 2.161 & 0.807 & 0.464 & 0.434 & -0.074 \\
BEN & 91 & $25(25)$ & 2.233 & 0.828 & 0.491 & 0.475 & -0.061 \\
\hline
\end{tabular}

$P$-percentage of polymorphic loci, $G_{O}$-number of observed genotypes across all loci. Mean values of $N_{E}, I, H_{O}$, $H_{E}$ and inbreeding coefficient $(F)$ calculated over all loci per population. $N_{E}, I, H_{E}$ and $F$ parameters were not calculated for populations with a sample size less than 5 (CNT, BOC and PAU) or population with one unique genotype observed (CER).

In the present investigation, ten unique or private alleles were detected in seven of the 22 populations (NAV, MON, RAS, IRU, CAS, CVJ and MOM; see Table S1). The abundance of three of the unique alleles (Ulm2-111, Ulm3-164, UR173a-185 found in CAS, MON and RAS, respectively) was $>50 \%$ (Table S1).

\subsection{Population Relationships}

The UPGMA dendrogram shows the relationships among $19 \mathrm{U}$. glabra populations with more than five sampled individuals (Figure 2). The Mantel test revealed a good and significant co-phenetic correlation $(r=0.87 ; p=0.0001)$, which indicates a good fit to the cluster analysis [42]. The dendrogram shows the populations grouped in two main clusters, separated at a genetic distance level of 0.48 . Populations of ROZ and MOM group together in a cluster with a support of $66.5 \%$, and in the other cluster are the remaining 17 populations with a support of 54.3\% (Figure 2). Within the second cluster, CER, RAS and MON populations are distanced from the remaining 14 populations (Figure 2). On the other hand, the western populations (VIL, STR and BEN) group together, and especially VIL and STR are located in the same subgroup and are separated from the rest with a support of $72.4 \%$ (Figure 2). 


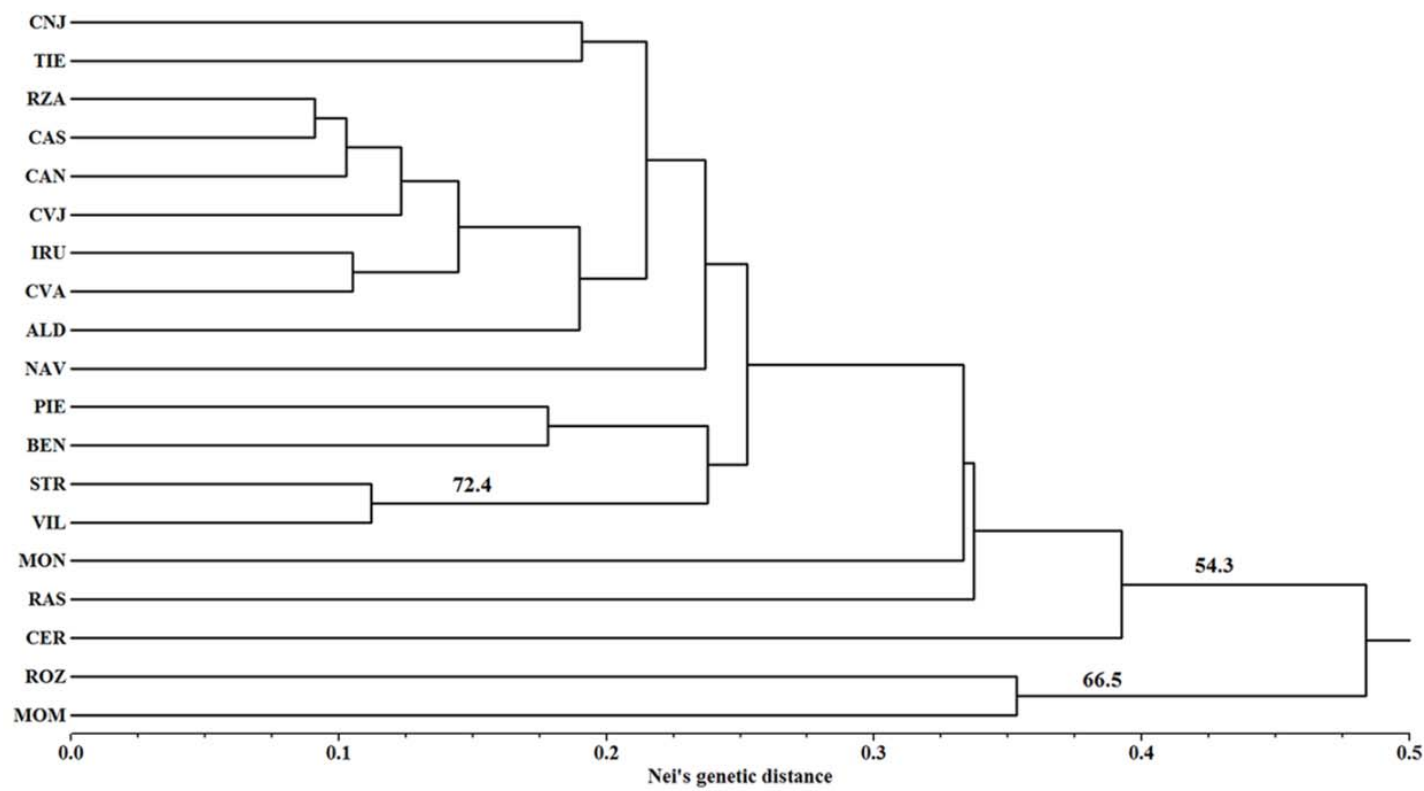

Figure 2. Unweighted pair group with arithmetic mean (UPGMA) clustering showing the relationships among the 19 Ulmus glabra populations from the Central System of the Iberian Peninsula with at least six sampled individuals (see Table 1 for codes), based on 11 microsatellite loci data using Nei's genetic distance. The numbers at nodes are support ( $>50 \%)$ by bootstrap analysis (10,000 replicates).

Results of AMOVA analysis revealed a highly significant genetic differentiation among the 19 U. glabra populations $(24 \% ; p=0.0001)$. A major portion of variation was harbored within populations $(76 \%)$. Genetic differentiation values among all population pairs were also calculated (Table S3), and all of them were highly significant $(p<0.0005)$. The highest $F_{S T}$ value was observed between RAS and MOM populations (43.6\%) and the lowest value was between CAS-CAN and RZA-CAN population pairs ( $8.5 \%$ in both cases).

\subsection{Demographic Analysis}

The results of demographic analysis are shown in Tables 4 and 5. $T_{2}$ statistic using the TPM model implemented in BOTTLENECK program showed a significant $(p<0.05)$ excess of heterozygosity (positive values of $T_{2}$ ) in four (NAV, ROZ, TIE and MOM) of the 15 populations studied (Table 4), suggesting that these populations could have suffered a recent bottleneck. On the other hand, values of $M$-ratio (a recommended statistical parameter to detect a bottleneck lasting several generations followed by a demographic recovery) revealed bottleneck marks (based on $M$-ratio < 0.68; [50]) in all the analyzed populations (Table 4).

The effective population size values for the ten Wych elm populations that were analyzed are shown in Table 5. The $N_{e}$ was less than 20 in eight and seven of the ten analyzed populations using ONeSAMP and LDNe programs, respectively. The lowest $N_{e}$ values were observed in ROZ population using both programs (Table 5). 
Table 4. Detection of genetic bottlenecks in the 15 Ulmus glabra populations (see Table 1 for codes) with at least 10 sampled individuals, using the $T_{2}$ statistic and $p$-values of the Wilcoxon's signed rank test under the two-phase model (TPM) as implemented in Bottleneck v. 1.2, and mean values over loci for the $M$-ratio as calculated in Arlequin v. 3.5.

\begin{tabular}{cccc}
\hline Population & $\boldsymbol{T}_{\mathbf{2}}$ Statistic & Wilcoxon's Test $(\boldsymbol{p} \text { values })^{\mathbf{1}}$ & $\boldsymbol{M}$-ratio \\
\hline CNJ & 0.2056 & 0.2480 & 0.2950 \\
RZA & 0.0192 & 0.5000 & 0.2725 \\
NAV & 0.6597 & 0.0068 & 0.3559 \\
RAS & -0.1479 & 0.7148 & 0.2892 \\
ROZ & 0.6865 & 0.0061 & 0.3702 \\
TIE & 0.6194 & 0.0195 & 0.2643 \\
IRU & -1.6151 & 0.9976 & 0.2780 \\
CAS & 0.0206 & 0.3672 & 0.2867 \\
CVJ & -0.9445 & 0.9976 & 0.3193 \\
CVA & 0.3550 & 0.1250 & 0.3320 \\
MOM & 0.9936 & 0.0010 & 0.2902 \\
ALD & 0.5103 & 0.1563 & 0.2149 \\
VIL & -0.0650 & 0.4727 & 0.2798 \\
STR & -0.1423 & 0.5898 & 0.2749 \\
BEN & 0.3321 & 0.1377 & 0.3196 \\
\hline
\end{tabular}

${ }^{1}$ Significant $p$ values $(<0.05)$ are in italics.

Table 5. Estimates for the effective population size $\left(N_{e}\right)$ in the 10 Ulmus glabra populations (see Table 1 for codes) with at least 20 sampled individuals, using approximate Bayesian computation (ONeSAMP v. 1.1) and linkage-disequilibrium information (LDNe v. 1.31). In parentheses are the lower and upper values at $95 \%$ confidence intervals (CI).

\begin{tabular}{ccc}
\hline & \multicolumn{2}{c}{$N_{e}(\mathbf{9 5} \%$ CI) } \\
\hline Population & ONeSAMP & LDNe \\
\hline CNJ & $18.3(14.7-24.6)$ & $11.4(4.7-23.1)$ \\
RZA & $17.9(14.0-26.2)$ & $12.8(7.3-25)$ \\
RAS & $16.6(12.4-24.5)$ & $2.2(1.4-3.3)$ \\
ROZ & $9.3(7.3-12.1)$ & $0.9(0.8-1.1)$ \\
TIE & $15.9(12.8-23.1)$ & $3(1.8-6.8)$ \\
IRU & $668.0(253.4-5277.2)$ & $16.6(10.9-25.2)$ \\
CAS & $18.5(15.3-24.2)$ & $29.1(11.6-1550.5)$ \\
CVJ & $10.0(8.1-12.8)$ & $1.2(1-1.4)$ \\
STR & $36.7(21.4-96.4)$ & $51.3(18.8-\infty)$ \\
BEN & $18.8(15.6-26.9)$ & $48.4(19.3-\infty)$ \\
\hline
\end{tabular}

\subsection{Introgression between U. glabra and U. minor}

In order to analyze the existence of a possible introgression between U. glabra and U. minor, genetic data from nine microsatellite loci that amplified in both species were used. Seventy six alleles in 427 U. glabra individuals from 22 populations, and 28 alleles in $15 U$. minor individuals from three locations in the Central System, were detected (see Table S2). Nineteen of the 28 alleles detected in U. minor were common to U. glabra also. Two of these alleles (Ulm3-182 and UR123-252) showed high frequency $(\geq 0.5)$ in both species (Table S2). All U. glabra samples shared at least two alleles with individuals of $U$. minor (see Table S1).

STRUCTURE analysis carried out on 427 U. glabra individuals using data from the 11 microsatellite markers, showed the modal value of the distribution of $\Delta K$, i.e., the optimal number of groups estimated, for $K=2$. Similar results were obtained when a second analysis was performed using data only from the nine microsatellite loci in 442 samples, 427 U. glabra and 15 U. minor (Figure S1). 
With respect to $427 U$. glabra individuals, STRUCTURE analysis revealed the existence of two clearly-defined genetic clusters (A and B), based on coefficients $q \geq 0.9$ for one of the two groups [61]. Thus, 368 individuals were assigned to genetic group A, 47 to group B, and 12 were considered as admixture samples, because they showed admixture values below 0.9 (Table 6 and Table S4). The 15 U. minor individuals were clustered with the 47 U. glabra from group B (Table S4).

Table 6. Number and percentage of individuals assigned to clusters (A and B) or considered as admixture samples as defined by STRUCTURE analysis in each Ulmus glabra population studied. See Table 1 for population codes.

\begin{tabular}{|c|c|c|c|c|}
\hline Population & Ns & Cluster A (\%) & Cluster B (\%) & Admixture Samples \\
\hline CNT & 1 & $1(100)$ & --- & - - - \\
\hline $\mathrm{CNJ}$ & 38 & $37(97.4)$ & $-{ }_{-}$ & $1(2.6 \%)$ \\
\hline $\mathrm{BOC}$ & 4 & $4(100)$ & --- & - - \\
\hline RZA & 22 & $22(100)$ & - - $_{-}$ & - - $_{-}$ \\
\hline NAV & 14 & $14(100)$ & -- & --- \\
\hline MON & 7 & $7(100)$ & $-\ldots$ & $-\ldots$ \\
\hline RAS & 33 & $33(100)$ & --- & -- \\
\hline PAU & 1 & $1(100)$ & -- & -- \\
\hline CER & 6 & $6(100)$ & - - - & - - - \\
\hline ROZ & 46 & $1(2.2)$ & $38(82.6)$ & $7(15.2)$ \\
\hline TIE & 42 & $42(100)$ & -- & --- \\
\hline IRU & 57 & $55(96.5)$ & --- & $2(3.5)$ \\
\hline CAS & 21 & $21(100)$ & --- & -- \\
\hline PIE & 7 & $7(100)$ & - - - & -- \\
\hline CVJ & 20 & $18(90.0)$ & $2(10.0)$ & -- \\
\hline CVA & 11 & $11(100)$ & - - & -- \\
\hline MOM & 10 & $3(30.0)$ & $7(70.0)$ & --- \\
\hline CAN & 8 & $7(87.5)$ & - - & $1(12.5)$ \\
\hline ALD & 10 & $10(100)$ & -- &.- \\
\hline VIL & 15 & 15 (100) & - - - & -- \\
\hline STR & 29 & 29 (100) &.- & -- \\
\hline BEN & 25 & $24(96.0)$ & - - - & $1(4.0)$ \\
\hline
\end{tabular}

For performing NewHybrids analysis, the 368 U. glabra individuals which had clustered into group A (by STRUCTURE analysis) and the $15 \mathrm{U}$. minor individuals which had clustered into group $\mathrm{B}$ (by STRUCTURE analysis), were treated as reference samples for $U$. glabra and $U$. minor respectively. Similar to STRUCTURE analysis, all individuals with a posterior assignment probability $p \geq 0.9$ [61], were placed in one of the six predefined genotypic classes (Table S4). Based on NewHybrids analysis, 372 individuals were assigned to parental class of $U$. glabra, 22 (all from ROZ population and with the same genotype; see Table S1) together with $15 U$. minor samples were assigned to $U$. minor class, and 26 to $F_{1}$ hybrid class (16 from ROZ population, 7 from MOM, 2 from CVJ and 1 from IRU). The remaining seven samples ( 5 from ROZ population, 1 from IRU and 1 from CAN) showed values of posterior assignment probability lower than 0.9 and were not assigned to any parental or hybrid class (Table S4). The 55 individuals ( 22 of $\mathrm{ROZ}+26$ of $\mathrm{F}_{1}$ hybrid class +7 unassigned) which were not classified into $U$. glabra parental class following NewHybrids analysis, showed the highest number of heterozygotic loci ( 7 to 10 ; see Table S1) and these individuals also shared 5 to 10 alleles with $U$. minor (see Table S1).

\section{Discussion}

\subsection{Genetic Diversity and Population Relationship}

An analysis of microsatellite diversity values $\left(N s=427, H_{O}=0.477\right.$ and $H_{E}=0.566$; see Table 2) of populations of $U$. glabra from the Central System yielded lower values than a similar study in the 
Suserup Forest of Denmark ( $N s=29, H_{O}=0.759$ and $H_{E}=0.774 ;$ [34]). However, as each study analyses a different number of samples, one should exercise caution while comparing the results. In the present analysis as well as in the study by Nielsen and Kjær [34], Ulmi1-165 was the most polymorphic and informative locus, suggesting that Ulmi1-165 is an appropriate locus to study genetic diversity of U. glabra.

Populations with the highest number of individuals (IRU, Nt $>6500$; STR, $N t>5000$ ) showed high diversity indexes (Table 3). However, this trend cannot be generalized (e.g., populations MOM and CAN which have small population size also show high diversity values). The location of IRU and STR in protected areas (Natural Reserve of Valley of Iruelas and ZEPA-Zona de Especial Protección para las Aves - of Sierra de Gata, respectively) has probably helped to maintain the high number of individuals. Also, most of the IRU and STR individuals are young with very limited rates of sexual reproduction [2]. According to Rossignoli and Génova [2], in the last few decades, DED has affected the populations of Wych elm from the Central System. As a consequence of this, many ramets are formed by sprouting from the stumps of the old trees, resulting in an increase of young individuals in a population. Thus, DED may be the reason behind the high number of young individuals, as the older elms are preferred by bark beetles and therefore perish due to disease [62].

Population CER had only six young individuals in nature, located in an area of approximately $20 \mathrm{~m}^{2}$, which showed the same genotype. This probably indicates that they may be sprouts of one adult tree, which does not exist anymore. In general, the presence of sprouting was detected in all Ulmus populations analyzed in this study. Wych elm does not show root sprouts but sprouts on trunks of young trees have been described by Cox et al. [15]. Vegetative reproduction by sprouting helps to diminish the effects of fragmentation and genetic drift, thus avoiding allelic loss [63] and contributing to clonal restoration of $U$. glabra populations on disturbed sites [34].

In general, signs of population isolation and low gene flow were detected throughout the Central System $\left(F_{S T}=0.239\right)$ compared to that reported for some other wind-pollinated temperate forest species: $F_{S T}=0.049$ in Quercus garryana Douglas ex Hook [64], $F_{S T}=0.052$ in Populus euphratica Olivier [65], $\Phi_{S T}=0.013$ in Fraxinus excelsior L. [66], and $F_{S T}=0.074$ in Castanea sativa Mill. [67]. In the present study, high and significant $F_{S T}$ values among population pairs indicated both high genetic differentiation and low average diversity within populations, probably due to small population size in most of them. Pollen flow up to $1000 \mathrm{~m}$ was estimated in U. glabra [34], so geographic distances between elm populations appear to have favored population differentiation observed in the Central System.

The UPGMA tree showed a main cluster of 17 populations and another of two populations. Populations MOM and ROZ group together and form a separate cluster, probably because both these populations are similar in that they contain a high number of putative hybrids (38/46 in ROZ and 7/10 in MOM) with $U$. minor and also low $\mathrm{F}_{\mathrm{ST}}$ amongst them. Within the majority cluster, MON and RAS populations are separated from the rest, probably because they are geographically isolated populations. Also, these populations showed high frequency of private alleles. The presence of private alleles has been associated with low gene flow and, therefore, population isolation [68]. The clustering results are related to geographic isolation and suggest a decrease in gene flow because of larger geographical distances [69]. In addition, the presence of BEN in the majority cluster suggests its genetic relatedness with other Iberian population in the Central System. This indicates U. glabra in Portugal (BEN) is a part of natural populations, as proposed by Monteiro-Henriquez et al. [70].

\subsection{Demographic Analysis}

Demographic analyses using Wilcoxon's test indicated bottlenecks in fewer populations (4 of 15; NAV, ROZ, TIE and MOM) compared to $M$-ratio values, where the 15 analyzed populations revealed bottlenecks. A similar trend of detection of bottlenecks by the two statistical methods was observed in $U$. laevis populations by Fuentes-Utrilla et al. [17]. Low $M$-values in the 15 populations indicated an ancestral and extended bottleneck [50]. Bottlenecks described in Spanish populations of $U$. laevis were attributed to Holocene expansion of more xeric habitats in the Iberian Peninsula [17] or glacial 
periods in Pleistocene [30]. It is probable that the same factors have affected the Wych elm, contributing to an ancestral and progressive loss of trees in the Central System, reducing the interpopulation gene flow (shown by high genetic differentiation) and leading to fragmented populations.

Four of the studied populations (NAV, ROZ, TIE and MOM) showed recent bottleneck signals as detected by $T_{2}$ statistic and Wilcoxon's test. In contrast to the $M$-value, $T_{2}$ bottleneck statistic is more effective in detecting bottlenecks in populations that have experienced a recent and severe reduction in the number of individuals [47].

In most populations of $U$. glabra from the Central System, clear signs of anthropogenic activity were observed, which can be attributed to different forestry land-uses (i.e., wood removals, grazing, etc.). In the case of NAV (now a managed pinewood forest), there is a history of successive and high wood removals [71]. Thus, it is possible that the Ulmus stands from NAV population also have been affected. According to the National Plan of Aerial Orthophotography (PNOA, (C) Instituto Geográfico Nacional; http:/ / pnoa.ign.es/), in TIE population also a similar process of wood removal was observed in the 1970's. Therefore, it is possible that forest land-uses could be the reason for the existence of a recent bottleneck in TIE and NAV populations. In such cases, bottlenecks can further increase the interpopulation differentiation that existed prior to the anthropogenic intervention [72].

In the MOM and ROZ populations, only two genotypes in 10 samples and 13 genotypes in 46 samples, respectively, were observed (i.e., $<30 \%$ of the sampled individuals). This may be a consequence of high rates of sprouting in these populations. The recent bottlenecks observed in these populations may be due to samples being the ramets of the same clone which the software recognized as a bottleneck. Also, repeated genotypes due to vegetative reproduction cause a reduction in $N_{e}$ of populations. Another effect of asexual reproduction is the absence of segregation, leading to maintenance of some of the allelic combinations in heterozygotes, which resulted in negative $F$ values [73].

Furthermore, a very low $N_{e}$ (except in IRU), was observed in populations of the Central System. A reduction of $N_{e}$ of population is caused by factors leading to genetic drift, and such populations with low $N_{e}$ have a greater probability of extinction [74]. Wych elm is a self-incompatible species [34], and therefore even more susceptible to habitat fragmentation and reduction in population sizes. Thus, population fragmentation in Wych elm in the Central System is evident, with a scarce number of populations and a limited number of trees.

\subsection{Introgression between $U$. glabra and U. minor}

In the present study of populations of the Central System, introgression between U. glabra and U. minor was detected. Such introgression has also been observed in other European populations of Wych elm [15,75]. The genetic proximity between $U$. glabra and $U$. minor [18], and the lack of reproductive barriers between them [15], have favored natural hybridization. These two factors (i.e., genetic relatedness and absence of reproductive barriers) are probably responsible for the large number of alleles shared between both species, some of them in high frequency.

Putative hybrids constituted 13\% (55 of 427 individuals) and were detected in five of 22 populations of the Central System (ROZ, IRU, CVJ, MOM and CAN). Although significant introgression was observed, it was less compared to other studies, e.g., in natural populations of Wych elm in northern Belgium (46\%; [15]). The attributed reason is that in Belgium, U. glabra is more abundant and coexists with $U$. minor at the same altitude [15]. However, in the Central System the presence of $U$. glabra is limited and its populations can be found at an average altitude of $1150 \mathrm{~m}$ reaching <1800 $\mathrm{m}$ [76], while $U$. minor does not usually surpass $1200 \mathrm{~m}$ [77], thus introgression in the Central System is more restricted.

Besides co-existence of the two species at the same altitudes, introgression is influenced by anthropogenic activities as well [78-80]. Traditionally, U. minor is the more cultivated species and is frequently naturalized [76]. Populations of ROZ and MOM are located close to individuals of $U$. minor and are exposed to anthropogenic activities. These factors have probably resulted in 
maximum hybridization (38/46 individuals in $\mathrm{ROZ}$ and 7/10 individuals in $\mathrm{MOM}$ ). The presence of large numbers of putative hybrids in $\mathrm{ROZ}$ and $\mathrm{MOM}$ is responsible for its high observed heterozygosity and estimated diversity values. Also, the inbreeding coefficient of the MOM and ROZ populations was highly negative, indicating excess of heterozygosity. Similar results were obtained by Zalapa et al. [13], where the extent of hybridization in naturalized populations of $U$. pumila influenced the genetic diversity.

Throughout the study area, 26 individuals were identified as possible $\mathrm{F}_{1}$ hybrids by NewHybrids analysis. These samples were heterozygous for the majority of loci (9 or 10 of 11) analyzed, as expected in hybrid individuals. Zalapa et al. [13] have shown a similar increase of genetic diversity due to hybridization between $U$. pumila and $U$. rubra. In addition, the putative hybrid individuals detected in the present study shared numerous alleles with $U$. minor, some of which were present in high frequency in $U$. minor and uncommon in Wych elm, which indicated asymmetric introgression of $U$. minor into $U$. glabra. This could happen because at $<1200 \mathrm{~m}$ of altitude in the Central System, U. minor is in abundance compared to $U$. glabra, thus facilitating asymmetric gene flow. Due to large differences in abundance of parental species, asymmetric gene flow has been observed in other studies [81,82].

The NewHybrids program also classified 22 individuals of $U$. glabra from ROZ population, which presented the same genotype, into $U$. minor parental class. The lack of sufficient numbers of species-specific exclusive alleles can complicate the classification of individuals when using the NewHybrids software [60]. In the present investigation, the 15 samples of $U$. minor analyzed (which presented six different genotypes and eight exclusive alleles) could be insufficient to assign correctly some hybrid individuals. Morphologically, the 22 samples did not differ much from the rest of $U$. glabra samples collected. The morphological characteristics have been shown to be questionable in the classification of the genus Ulmus, especially in hybrid individuals $[13,14,23,32,36]$. These samples showed a high number of alleles shared with $U$. minor ( 9 of 18 possible alleles), and were heterozygous for most loci (10 of 11) analyzed. Consequently, these 22 individuals probably have undergone a high level of introgression with $U$. minor.

As in $U$. minor, root suckering was also observed in introgressed individuals from ROZ and MOM populations, which increases the number of introgressed samples with the same genotype in these populations. Similar observations were made by [15].

In the present study, despite extensive sampling, no $\mathrm{F}_{2}$ individuals were detected using the NewHybrids program. Cox et al. [15] also did not find $F_{2}$ offspring of $F_{1}$ hybrids among elms sampled in northern Belgium. One possible explanation for failing to detect $F_{2}$ hybrids could be that an increase of homozygous incompatibility in $\mathrm{F}_{2}$ individuals would lead to loss of fitness [83]. The other possibilities are the existence of pollen-stigma incompatibilities in $\mathrm{F}_{1}$ hybrid, which would contain S-alleles from the two parental sources [35], or because of outbreeding depression [84].

\section{Conclusions and Future Prospects}

Populations of ROZ and MOM showed lowest numbers of genotypes, high heterozygosity, lowest genetic differentiation between the two populations, and highly negative values of inbreeding coefficient. This points towards the existence of introgression and propagation through vegetative means (as indicated by high $H_{O}$, low $G_{O}$ and highly negative $F$ ) and that the populations are genetically not very different $\left(\right.$ low $\left.F_{S T}\right)$. The estimated population size is much lower $(\mathrm{ROZ}=46, \mathrm{MOM}=18)$ compared to IRU (>6500) and STR ( $>5000)$. This could probably be due to the location of the IRU and STR populations in protected and undisturbed areas. Populations IRU and STR not only maintained a high number of individuals but also represented a very high number of genotypes $(>95 \%$ of the sampled individuals), indicating low frequency of clonal propagation. A distinct feature of $\mathrm{ROZ}$ and MOM populations was that maximum numbers of putative hybrids (with $U$. minor) were detected, which enhanced their genetic diversity indexes. Population of RAS on the other hand did not show any putative hybrids and revealed lowest diversity indexes. However, a high number of genotypes with private alleles was detected ( $>87 \%$ of the analyzed individuals) in RAS population compared to ROZ 
and MOM ( $<30 \%$ of the sampled individuals), and high genetic differentiation between RAS-ROZ and RAS-MOM population pairs was observed. Thus, the RAS population appears to be more isolated with respect to interpopulation gene flow. Such information can play an important role in the formulation of appropriate conservation strategies for Ulmus populations of the Central System.

In general, populations of U. glabra analyzed in the Central System showed recent and/or ancestral bottlenecks and low effective population size. As U. glabra is a self-incompatible species, has bottlenecks and reduced $N_{e}$, the chances of population fragmentation and decrease in number of individuals, and probability of extinction increases. At this point, it is also important to note that existence of clonal propagation in U. glabra populations possibly contributes to reducing the effects of fragmentation and genetic drift and hence allelic loss. Also, existence of natural hybridization with $U$. minor influences genetic diversity and may elevate the number of alleles and effective alleles in U. glabra populations.

To summarize, the fragmented and relict natural populations of U. glabra of the Central System of the Iberian Peninsula are marked by moderate genetic diversity, high genetic differentiation and ancestral as well as extended bottlenecks. The small number of fragmented populations with diminishing number of individuals in most populations, along with anthropogenic intervention and the biotic stress of DED are the main threats to Wych elm in the Central System. Further, there is no continuity of $U$. glabra populations of the Central System with the populations of the rest of the peninsula and no strategies for conservation of these relict populations. This is especially true in the province of Avila, where most of the populations have aggregated. Therefore, the present information generated from this study (i.e., high genetic differentiation and lack of continuity of Central System populations with the rest of the peninsula) emphasizes the need for formulating regional conservation strategies to secure the future of the Central System populations.

Supplementary Materials: The following are available online at www.mdpi.com/1999-4907/8/5/143/s1, Figure S1: Estimation of the optimal number of genetic groups $(K)$ based on the rate of change in the statistic $\Delta K$ between successive $K$ values [57], for $K=1$ to 25 (using data from 11 microsatellite markers analyzed in 427 U. glabra individuals; a) and $K=1$ to 10 (using data from the nine microsatellite loci that were amplified in both species, 427 U. glabra individuals and 15 U. minor samples; b)); Table S1: Allele sizes in base pairs at each of eleven microsatellite loci analyzed in $427 \mathrm{U}$. glabra individuals from 22 populations and $15 \mathrm{U}$. minor individuals from three locations sampled in the Central System; Table S2: Allele sizes (in base pairs) and frequencies at each of eleven microsatellite loci analyzed in $427 \mathrm{U}$. glabra and $15 \mathrm{U}$. minor individuals sampled from the Central System; Table S3: Pairwise $\mathrm{F}_{\mathrm{ST}}$ (below the diagonal) and $p$ (above the diagonal) values among $19 \mathrm{U}$. glabra populations (see Table 1 for codes) based on eleven microsatellite loci data using the AMOVA method. Significance was obtained on 10,000 random permutations; Table S4: Results of Structure and NewHybrids analysis obtained in $442 \mathrm{elm}$ individuals (427 U. glabra and $15 U$. minor) studied.

Acknowledgments: We would like to thank Fernando Gómez Manzaneque, Mar Génova Fuster and the personnel associated with national forests of the Central System, who provided assistance in locating sites to obtain sample collections. We would also like to thank Universidad Politécnica de Madrid and Comunidad de Madrid for their financial support through projects CCG07-UPM/AMB-1467 and CCG10-UPM/AMB-5728.

Author Contributions: J.P.M. and F.M.G. conceived and designed the experiments; M.M.P., J.P.M. and F.M.G. contributed to sample collection; M.M.P. performed the experiments; M.M.P., A.M. and J.P.M. analyzed the data; J.P.M. and F.M.G. contributed reagents/materials/analysis tools; M.M.P., F.M.G., A.M. and J.P.M. contributed in writing the paper.

Conflicts of Interest: The authors declare no conflict of interest.

\section{References}

1. Caudullo, G.; de Rigo, D. Ulmus-elms in Europe: Distribution, habitat, usage and threats. In European Atlas of Forest Tree Species; San-Miguel-Ayanz, J., de Rigo, D., Caudullo, G., Houston Durrant, T., Mauri, A., Eds.; Publication Office of the European Union: Luxembourg, 2016; pp. 137-139.

2. Rossignoli, A.; Génova, M. Corología y hábitat de Ulmus glabra Huds, en la Península Ibérica. Ecología 2003, 17, 99-121. 
3. Ruiz-Labourdette, D.; Martínez García, F.; Martín-López, B.; Montes, C.; Pineda, F.D. Equilibrium of vegetation and climate at the European rear edge. A reference for climate change planning in mountainous Mediterranean regions. Int. J. Biometeorol. 2011, 55, 285-301. [CrossRef] [PubMed]

4. Costa Tenorio, M.; García Antón, M.; Morla, C.; Sainz Ollero, H. La evolución de los bosques en la Península Ibérica: Una interpretación basada en datos paleobiográficos. Ecología 1990, 1, 31-58.

5. Abel Schaad, D.; Pulido, F.; López Sáez, J.A.; Alba Sánchez, F.; Nieto Lugilde, D.; Franco Múgica, F.; Pérez Díaz, S.; Ruiz Zapata, M.B.; Gil García, M.J.; Dorado Valiño, M. Persistence of tree relicts in the Spanish Central System through the Holocene. Lazaroa 2014, 35, 107-131. [CrossRef]

6. López, R.A. Paleobotánica de los olmos. In Los Olmos Ibéricos. Conservación y Mejora frente a la Grafiosis; Gil, L., Solla, A., Iglesias, S., Eds.; Organismo Autónomo Parques Nacionales: Madrid, Spain, 2000; pp. 49-68.

7. Carrión, J.S.; Fernández, S.; González Sampériz, P.; Gil Romera, G.; Badal, E.; Carrión Marco, Y.; López Merino, L.; López Sáez, J.A.; Fierro, E.; Burjachs, F. Expected trends and surprises in the Lateglacial and Holocene vegetation history of the Iberian Peninsula and Balearic Islands. Rev. Palaeobot. Palynol. 2010, 162, 458-475. [CrossRef]

8. Carrión, J.S.; Fernández, S.; González Sampériz, P.; López Merino, L.; Peña, L.; Burjachs, F.; López Sáez, J.A.; García Antón, M.; Carrión Marco, Y.; Uzquiano, P.; et al. Paleoflora y Paleovegetación de la Península Ibérica e Islas Baleares: Plioceno-Cuaternario; Ministerio Economía y Competitividad y la Universidad de Murcia: Murcia, Spain, 2012; p. 972.

9. Blanco Castro, E.; Casado González, M.A.; Costa Tenorio, M.; Escribano Bombín, R.; García Antón, M.; Génova, M.; Gómez Manzaneque, Á.; Moreno Saiz, J.C.; Morla Juaristi, C.; Regato Pajares, P.; et al. Los Bosques Ibéricos. Una Interpretación Geobotánica; Editorial Planeta: Barcelona, Spain, 1997; p. 572.

10. Franco Múgica, F.; García Antón, M.; Sainz Ollero, H. Vegetation dynamics and human impact in the Sierra de Guadarrama, Central System, Spain. Holocene 1998, 8, 69-82. [CrossRef]

11. López Sáez, J.A.; Abel Schaad, D.; Pérez Díaz, S.; Blanco-González, A.; Alba Sánchez, F.; Dorado Valiño, M.; Ruiz Zapata, M.B.; Gil-García, M.J.; Gómez-González, C.; Franco Múgica, F. Vegetation history, climate and human impact in the Spanish Central System over the last 9000 years. Quat. Int. 2014, 353, 98-122. [CrossRef]

12. Venturas, M.; Nanos, N.; Gil, L. The reproductive ecology of Ulmus laevis Pallas in a transformed habitat. For. Ecol. Manag. 2014, 312, 170-178. [CrossRef]

13. Zalapa, J.E.; Brunet, J.; Guries, R.P. The extent of hybridization and its impact on the genetic diversity and population structure of an invasive tree, Ulmus pumila (Ulmaceae). Evol. Appl. 2010, 3, 157-168. [CrossRef] [PubMed]

14. Brunet, J.; Zalapa, J.E.; Pecori, F.; Santini, A. Hybridization and introgression between the exotic Siberian elm, Ulmus pumila, and the native Field elm, U. minor, in Italy. Biol. Invasions 2013, 15, 2717-2730. [CrossRef]

15. Cox, K.; Broeck, A.V.; Vander Mijnsbrugge, K.; Buiteveld, J.; Collin, E.; Heybroek, H.M.; Mergeay, J. Interspecific hybridisation and interaction with cultivars affect the genetic variation of Ulmus minor and Ulmus glabra in Flanders. Tree Genet. Genomes 2014, 10, 813-826. [CrossRef]

16. Gil, L.; Fuentes-Utrilla, P.; Soto, Á.; Cervera, M.T.; Collada, C. English elm is a 2000-year-old Roman clone. Nature 2004, 431, 1053. [CrossRef] [PubMed]

17. Fuentes-Utrilla, P.; Venturas, M.; Hollingsworth, P.M.; Squirrell, J.; Collada, C.; Stone, G.N.; Gil, L. Extending glacial refugia for a European tree: Genetic markers show that Iberian populations of white elm are native relicts and not introductions. Heredity 2014, 112, 105-113. [CrossRef] [PubMed]

18. Wiegrefe, S.J.; Sytsma, K.J.; Guries, R.P. Phylogeny of elms (Ulmus, Ulmaceae): Molecular evidence for a sectional classification. Syst. Bot. 1994, 19, 590-612. [CrossRef]

19. Richens, R.H.; Jeffers, J.N.R. Numerical taxonomy and ethnobotany of the elms of northern Spain. An. Jard. Bot. Madr. 1986, 42, 325-341.

20. Collin, E.; Bilger, I.; Eriksson, G.; Turok, J. The conservation of elms genetics resources in Europe. In The Elms: Breeding, Conservation, and Disease Management; Dunn, C.P., Ed.; Kluwer Academic Publisher: Boston, MA, USA, 2000; pp. 281-293.

21. Ganopoulos, I.; Aravanopoulos, F.A.; Argiriou, A.; Kalivas, A.; Tsaftaris, A. Is the genetic diversity of small scattered forest tree populations at the southern limits of their range more prone to stochastic events? A wild cherry case study by microsatellite-based markers. Tree Genet. Genomes 2011, 7, 1299-1313. [CrossRef]

22. Coleman, M.; Hollingsworth, M.L.; Hollingsworth, P.M. Application of RAPDs to the critical taxonomy of the English endemic elm Ulmus plotii Druce. Bot. J. Linn. Soc. 2000, 133, 241-262. [CrossRef] 
23. Goodall-Copestake, W.P.; Hollingsworth, M.L.; Hollingsworth, P.M.; Jenkins, G.I.; Collin, E. Molecular markers and ex situ conservation of the European elms (Ulmus spp.). Biol. Conserv. 2005, 122, 537-546. [CrossRef]

24. Wesche, K.; Walther, D.; Von Wehrden, H.; Hensen, I. Trees in the desert: Reproduction and genetic structure of fragmented Ulmus pumila forests in Mongolian drylands. Flora 2011, 206, 91-99. [CrossRef]

25. Pooler, M.R.; Townsend, A.M. DNA fingerprinting of clones and hybrids of American elm and other elm species with AFLP markers. J. Environ. Hortic. 2005, 23, 113-117.

26. Whiteley, R.E.; Black-Samuelsson, S.; Clapham, D. Development of microsatellite markers for the European white elm (Ulmus laevis Pall.) and cross-species amplification within the genus Ulmus. Mol. Ecol. Notes 2003, 3, 598-600. [CrossRef]

27. Collada, C.; Fuentes-Utrilla, P.; Gil, L.; Cervera, M.T. Characterization of microsatellite loci in Ulmus minor Miller and cross-amplification in U. glabra Hudson and U. laevis Pall. Mol. Ecol. Notes 2004, 4, 731-732. [CrossRef]

28. Zalapa, J.E.; Brunet, J.; Guries, R.P. Isolation and characterization of microsatellite markers for red elm (Ulmus rubra Muhl.) and cross-species amplification with Siberian elm (Ulmus pumila L.). Mol. Ecol. Resour. 2008, 8, 109-112. [CrossRef] [PubMed]

29. Nielsen, L.R.; Kjær, E.D. Fine-scale gene flow and genetic structure in a relic Ulmus laevis population at its northern range. Tree Genet. Genomes 2010, 6, 643-649. [CrossRef]

30. Venturas, M.; Fuentes-Utrilla, P.; Ennos, R.; Collada, C.; Gil, L. Human-induced changes on fine-scale genetic structure in Ulmus laevis Pallas wetland forests at its SW distribution limit. Plant Ecol. 2013, 214, 317-327. [CrossRef]

31. Fuentes-Utrilla, P.; Valbuena-Carabaña, M.; Ennos, R.; Gil, L. Population clustering and clonal structure evidence the relict state of Ulmus minor Mill. in the Balearic Islands. Heredity 2014, 113, 21-31. [CrossRef] [PubMed]

32. Buiteveld, J.; Vanden Broeck, A.; Cox, K.; Collin, E. Human impact on the genetic diversity of Dutch field elm (Ulmus minor) populations in the Netherlands: Implications for conservation. Plant Ecol. Evol. 2016, 149, 165-176. [CrossRef]

33. Zebec, M.; Idžojtić, M.; Šatović, Z.; Poljak, I.; Liber, Z. Alive and kicking, or, living on borrowed time?-Microsatellite diversity in natural populations of the endangered Ulmus minor Mill. sensu latissimo from Croatia. Acta Bot. Croat. 2016, 75, 53-59. [CrossRef]

34. Nielsen, L.R.; Kjær, E.D. Gene flow and mating patterns in individuals of Wych elm (Ulmus glabra) in forest and open land after the influence of Dutch elm disease. Conserv. Genet. 2010, 11, 257-268. [CrossRef]

35. Zalapa, J.E.; Brunet, J.; Guries, R.P. Patterns of hybridization and introgression between invasive Ulmus pumila (Ulmaceae) and native U. rubra. Am. J. Bot. 2009, 96, 1116-1128. [CrossRef] [PubMed]

36. Bertolasi, B.; Leonarduzzi, C.; Piotti, A.; Leonardi, S.; Zago, L.; Gui, L.; Gorian, F.; Vanetti, I.; Binelli, G. A last stand in the Po valley: Genetic structure and gene flow patterns in Ulmus minor and U. pumila. Ann. Bot. 2015, 115, 683-692. [CrossRef] [PubMed]

37. Peakall, R.; Smouse, P.E. GenAlEx 6: Genetic analysis in Excel. Population genetic software for teaching and research. Mol. Ecol. Notes 2006, 6, 288-295. [CrossRef]

38. Peakall, R.; Smouse, P.E. GenAlEx 6.5: Genetic analysis in Excel. Population genetic software for teaching and research-An update. Bioinformatics 2012, 28, 2537-2539. [CrossRef] [PubMed]

39. Bostein, D.; White, R.L.; Skolnik, M.; Davis, R.W. Construction of a genetic linkage map in man using restriction fragment length polymorphisms. Am. J. Hum. Genet. 1980, 32, 314-331.

40. Lamboy, W.F; Alpha, C.G. Using simple sequence repeats (SSRs) for DNA fingerprinting germplasm accessions of grape (Vitis L.) species. J. Am. Soc. Hortic. Sci. 1998, 123, 182-188.

41. Jones, D.A. Blood samples: Probability of discrimination. J. Forensic. Sci. Soc. 1972, 12, 355-359. [CrossRef]

42. Rohlf, F.J. NTSYSpc: Numerical Taxonomy System; Version 2.20; Exeter Publishing, Ltd.: Exeter, UK, 2008.

43. Nei, M. Genetic distance between populations. Am. Nat. 1972, 106, 283-292. [CrossRef]

44. Felsenstein, J. PHYLIP (Phylogeny Inference Package) Version 3.6; Department of Genome Sciences, University of Washington: Washington, DC, USA, 1993.

45. Excoffier, L.; Smouse, P.E.; Quattro, J.M. Analysis of molecular variance inferred from metric distances among DNA haplotypes: Application to human mitochondrial DNA restriction data. Genetics 1992, 131, 479-491. [PubMed] 
46. Cornuet, J.M.; Luikart, G. Description and power analysis of two tests for detecting recent population bottlenecks from allele frequency data. Genetics 1996, 144, 2001-2014. [PubMed]

47. Piry, S.; Luikart, G.; Cornuet, J.M. BOTTLENECK: A computer program for detecting recent reductions in the effective population size suing allele frequency data. J. Hered. 1999, 90, 502-503. [CrossRef]

48. Williamson-Natesan, E.G. Comparison of methods for detecting bottlenecks from microsatellite loci. Conserv. Genet. 2005, 6, 551-562. [CrossRef]

49. Di Rienzo, A.; Peterson, A.C.; Garza, J.C.; Valdes, A.M.; Slatkin, M.; Freimer, N.B. Mutational processes of simple-sequence repeat loci in human populations. Proc. Natl. Acad. Sci. USA 1994, 91, 3166-3170. [CrossRef] [PubMed]

50. Garza, J.C.; Williamson, E.G. Detection of reduction in population size using data from microsatellite loci. Mol. Ecol. 2001, 10, 305-318. [CrossRef] [PubMed]

51. Excoffier, L.; Lischer, H.E.L. Arlequin suite Version 3.5: A new series of programs to perform population genetics analyses under Linux and Windows. Mol. Ecol. Resour. 2010, 10, 564-567. [CrossRef] [PubMed]

52. Waples, R.S.; Do, C. LDNE: A program for estimating effective population size from data on linkage disequilibrium. Mol. Ecol. Resour. 2008, 8, 753-756. [CrossRef] [PubMed]

53. England, P.R.; Cornuet, J.M.; Berthier, P.; Tallmon, D.A.; Luikart, G. Estimating effective population size from linkage disequilibrium: Severe bias in small samples. Conserv. Genet. 2006, 7, 303-308. [CrossRef]

54. Waples, R.S.; Do, C. Linkage disequilibrium estimates of contemporary Ne using highly variable genetic markers: A largely untapped resource for applied conservation and evolution. Evol. Appl. 2010, 3, 244-262. [CrossRef] [PubMed]

55. Tallmon, D.A.; Koyuk, A.; Luikart, G.; Beaumont, M.A. COMPUTER PROGRAMS: ONeSAMP: A program to estimate effective population size using approximate Bayesian computation. Mol. Ecol. Resour. 2008, 8, 299-301. [CrossRef] [PubMed]

56. Pritchard, J.K.; Stephens, M.; Donnelly, P. Inference of population structure using multilocus genotype data. Genetics 2000, 155, 945-959. [PubMed]

57. Evanno, G.; Regnaut, S.; Goudet, J. Detecting the number of clusters of individuals using the software STRUCTURE: A simulation study. Mol. Ecol. 2005, 14, 2611-2620. [CrossRef] [PubMed]

58. Falush, D.; Stephens, M.; Pritchard, J.K. Inference of population structure using multilocus genotype data: Linked loci and correlated allele frequencies. Genetics 2003, 164, 1567-1587. [PubMed]

59. Worthington, M.; Soleri, D.; Aragón-Cuevas, F.; Gepts, P. Genetic composition and spatial distribution of farmer-managed Phaseolus bean plantings: An example from a village in Oaxaca, Mexico. Crop Sci. 2012, 52, 1721-1735. [CrossRef]

60. Anderson, E.C.; Thompson, E.A. A model-based method for identifying species hybrids using multilocus genetic data. Genetics 2002, 160, 1217-1229. [PubMed]

61. Vähä, J.P.; Primmer, C.R. Efficiency of model-based Bayesian methods for detecting hybrid individuals under different hybridization scenarios and with different numbers of loci. Mol. Ecol. 2006, 15, 63-72. [CrossRef] [PubMed]

62. Webber, J.F. Experimental studies on factors influencing the transmission of Dutch elm disease. Investig. Agrar. Sist. Recur. For. 2004, 13, 197-205.

63. Wei, X.; Jiang, M. Limited genetic impacts of habitat fragmentation in an "old rare" relict tree, Euptelea pleiospermum (Eupteleaceae). Plant Ecol. 2012, 213, 909-917. [CrossRef]

64. Marsico, T.D.; Hellmann, J.J.; Romero-Severson, J. Patterns of seed dispersal and pollen flow in Quercus garryana (Fagaceae) following post-glacial climatic changes. J. Biogeogr. 2009, 36, 929-941. [CrossRef]

65. Wang, J.; Li, Z.; Guo, Q.; Ren, G.; Wu, Y. Genetic variation within and between populations of a desert poplar (Populus euphratica) revealed by SSR markers. Ann. For. Sci. 2011, 68, 1143-1149. [CrossRef]

66. Beatty, G.E.; Brown, J.A.; Cassidy, E.M.; Finlay, C.M.; McKendrick, L.; Montgomery, W.I.; Reid, N.; Tosh, D.G.; Provan, J. Lack of genetic structure and evidence for long-distance dispersal in ash (Fraxinus excelsior) populations under threat from an emergent fungal pathogen: Implications for restorative planting. Tree Genet. Genomes 2015, 11. [CrossRef]

67. Lusini, I.; Velichkov, I.; Pollegioni, P.; Chiocchini, F.; Hinkov, G.; Zlatanov, T.; Cherubini, M.; Mattioni, C. Estimating the genetic diversity and spatial structure of Bulgarian Castanea sativa populations by SSRs: Implications for conservation. Conserv. Genet. 2014, 15, 283-293. [CrossRef] 
68. Tero, N.; Aspi, J.; Siikamäki, P.; Jäkäläniemi, A.; Tuomi, J. Genetic structure and gene flow in a metapopulation of an endangered plant species, Silene tatarica. Mol. Ecol. 2003, 12, 2073-2085. [CrossRef] [PubMed]

69. Sexton, J.P.; Hangartner, S.B.; Hoffmann, A.A. Genetic isolation by environment or distance: Which pattern of gene flow is most common? Evolution 2014, 68, 1-15. [CrossRef] [PubMed]

70. Monteiro-Henriques, T.; Costa, J.C.; Bellu, A.; Aguiar, C. Fraxino Angustifoliae-Ulmetum Glabrae: An original endemic and extremely localized forest from mainland Portugal. Braun Blanquetia 2010, 46, 323-327.

71. Huertas Migueláñez, D.A.; Martín Muñoz, J.C. Análisis de la ordenación del monte pinar de Navafría en el período 1895-2000. Cuad. Soc. Esp. Ciencias For. 2001, 11, 103-110.

72. Torres-Díaz, C.; Ruiz, E.; González, F.; Fuentes, G.; Cavieres, L.A. Genetic diversity in Nothofagus alessandrii (Fagaceae), an endangered endemic tree species of the coastal maulino forest of Central Chile. Ann. Bot. 2007, 100, 75-82. [CrossRef] [PubMed]

73. Valero, M.; Engel, C.; Billot, C.; Kloareg, B.; Destombe, C. Concept and issues of population genetics in seaweeds. Cah. Biol. Mar. 2001, 42, 53-62.

74. Newman, D.; Pilson, D. Increased probability of extinction due to decreased genetic effective population size: Experimental populations of Clarkia pulchella. Evolution 1997, 51, 354-362. [CrossRef]

75. Petrokas, R.; Baliuckas, V. Natural Hybridisation within Elms (Ulmus L.) in Lithuania. Balt. For. 2012, 18, 237-246.

76. Navarro, C.; Castroviejo, S. Ulmus L. In Flora Ibérica III; Castroviejo, S., Aedo, C., Laínz, M., Muñoz Garmendia, F., Nieto Feliner, G., Paiva, J., Benedí, C., Eds.; Real Jardín Botánico-CSIC: Madrid, Spain, 1993; pp. $244-248$.

77. Venturas, M.; Iglesias, S.; Nicolás Perangón, J.L.; Martín García, J.A.; Gil, L. Ulmus minor Mill. In Producción y Manejo de Semillas y Plantas Forestales. Tomo II; Pemán, J., Navarro, R.M., Nicolás, J.L., Prada, M.A., Serrada, R., Eds.; Organismo Autónomo de Parques Nacionales-Ministerio de Agricultura, Alimentación y Medio Ambiente: Madrid, Spain, 2013; pp. 575-597.

78. Ellstrand, N.C.; Schierenbeck, K.A. Hybridization as a stimulus for the evolution of invasiveness in plants? Proc. Natl. Acad. Sci. USA 2000, 97, 7043-7050. [CrossRef] [PubMed]

79. Rhymer, J.M.; Simberloff, D. Extinction by hybridization and introgression. Annu. Rev. Ecol. Syst. 1996, 27, 83-109. [CrossRef]

80. Hoban, S.M.; McCleary, T.S.; Schlarbaum, S.E.; Anagnostakis, S.L.; Romero-Severson, J. Human-impacted landscapes facilitate hybridization between a native and an introduced tree. Evol. Appl. 2012, 5, 720-731. [CrossRef] [PubMed]

81. Burgess, K.S.; Morgan, M.; Deverno, L.; Husband, B.C. Asymmetrical introgression between two Morus species (M. alba, M. rubra) that differ in abundance. Mol. Ecol. 2005, 14, 3471-3483. [CrossRef] [PubMed]

82. Lepais, O.; Petit, R.J.; Guichoux, E.; Lavabre, J.; Alberto, F.; Kremer, A.; Gerber, S. Species relative abundance and direction of introgression in oaks. Mol. Ecol. 2009, 18, 2228-2242. [CrossRef] [PubMed]

83. Turelli, M.; Orr, H.A. Dominance, epistasis and the genetics of postzygotic isolation. Genetics 2000, 154, 1663-1679. [PubMed]

84. Edmands, S. Between a rock and a hard place: Evaluating the relative risks of inbreeding and outbreeding for conservation and management. Mol. Ecol. 2007, 16, 463-475. [CrossRef] [PubMed]

(C) 2017 by the authors. Licensee MDPI, Basel, Switzerland. This article is an open access article distributed under the terms and conditions of the Creative Commons Attribution (CC BY) license (http:/ / creativecommons.org/licenses/by/4.0/). 


\section{Supplementary Material (Figure S1):}

\section{Genetic Diversity in Relict and Fragmented \\ Populations of Ulmus glabra Hudson in the Central System of the Iberian Peninsula}

María Martín del Puerto, Felipe Martínez García, Aparajita Mohanty and Juan Pedro Martín
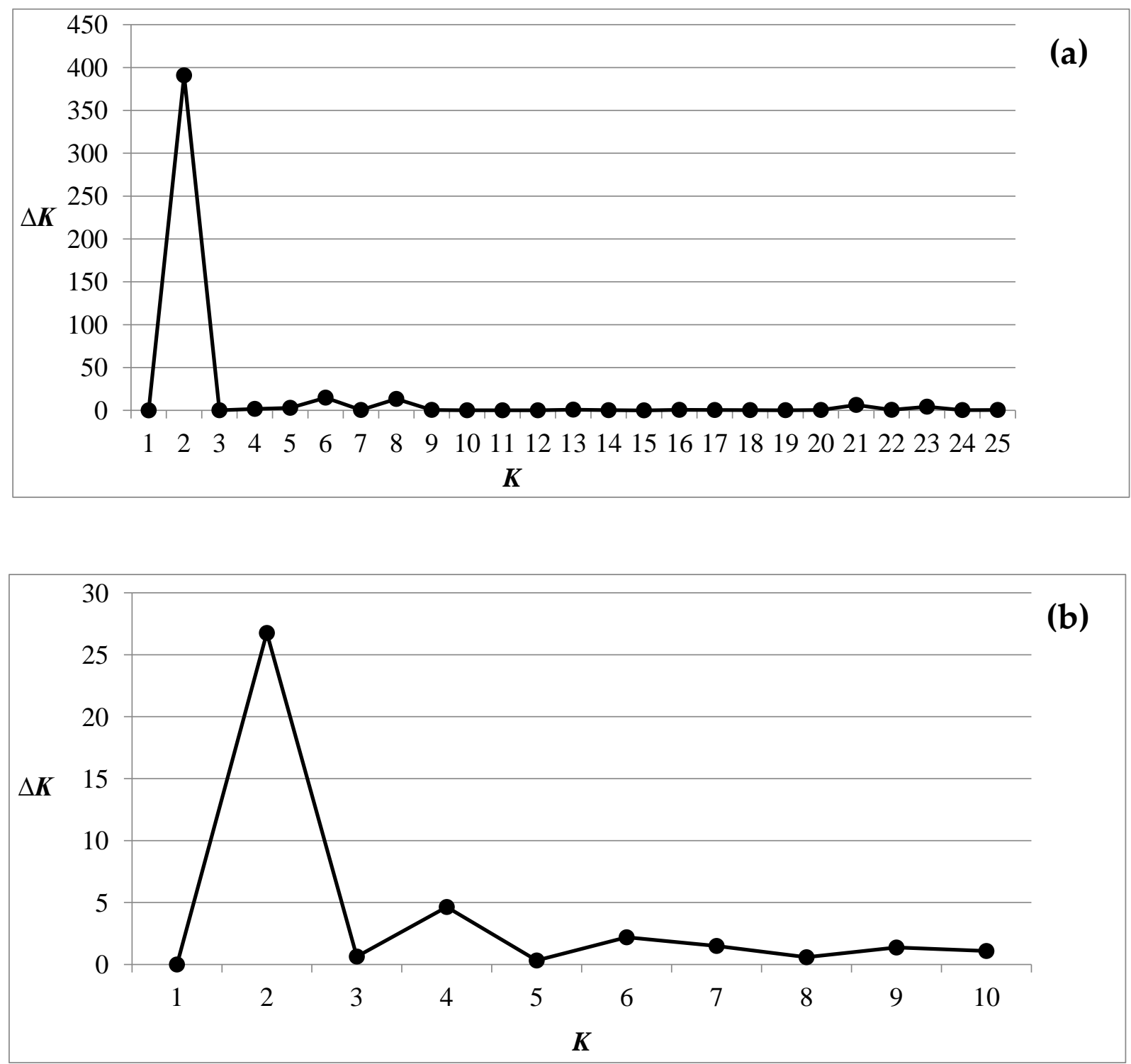

Figure S1. Estimation of the optimal number of genetic groups $(K)$ based on the rate of change in the statistic $\Delta K$ between successive $K$ values [57], for $K=1$ to 25 (using data from 11 microsatellite markers analyzed in $427 \mathrm{U}$. glabra individuals; a) and $K=1$ to 10 (using data from the nine microsatellite loci that were amplified in both species, $427 \mathrm{U}$. glabra individuals and $15 \mathrm{U}$. minor samples; $\mathbf{b})$. 
Supplementary Material (Table S1):

Genetic Diversity in Relict and Fragmented Populations of Ulmus glabra Hudson in the Central System of the Iberian Peninsula

María Martín del Puerto, Felipe Martínez García, Aparajita Mohanty and Juan Pedro Martín

Table S1. Allele sizes in base pairs at each of eleven microsatellite loci analyzed in 427 U. glabra individuals from 22 populations and 15 U. minor individuals from three locations sampled in Central System. Unique or private alleles in $U$. glabra populations are indicated in bold and those which are shared with $U$. minor are also in italics

G - different individual genotypes (allelic combinations over all loci), 1 to 366; HL - number of heterozygotic loci at each individual; AS - number of alleles shared by each $U$. glabra individual with any

U. minor individual and viceversa

${ }^{\text {a }}$ Population code (see Table 1) along with an individual number; ${ }^{\mathrm{b}}$ Microsatellite not analized in U. minor individuals because showed multiband patterns (MP)

\begin{tabular}{|c|c|c|c|c|c|c|c|c|c|c|c|c|c|c|c|c|c|c|c|c|c|c|c|c|c|c|}
\hline \multirow{2}{*}{$\frac{\text { No }}{1}$} & \multirow{2}{*}{$\begin{array}{l}\text { Individual Code }^{\mathbf{a}} \\
\text { CNT01 }\end{array}$} & \multicolumn{2}{|c|}{ Ulm2 } & \multicolumn{2}{|c|}{ Ulm3 } & \multicolumn{2}{|c|}{ Ulm8 } & \multicolumn{2}{|c|}{ Ulmi1-21 } & \multicolumn{2}{|c|}{ Ulmi1-98 } & \multicolumn{2}{|c|}{ Ulmi1-165 } & \multicolumn{2}{|c|}{ UR123 } & \multicolumn{2}{|c|}{ UR138 $^{\mathrm{b}}$} & \multicolumn{2}{|c|}{ UR153 } & \multicolumn{2}{|c|}{ UR173a $^{b}$} & \multicolumn{2}{|c|}{ UR175 } & \multirow{2}{*}{$\frac{\mathbf{G}}{1}$} & \multirow{2}{*}{$\frac{\text { HL }}{5}$} & \multirow{2}{*}{$\frac{\text { AS }}{4}$} \\
\hline & & 105 & 105 & 182 & 182 & 195 & 195 & 216 & 216 & 156 & 160 & 165 & 185 & 252 & 252 & 242 & 242 & 191 & 202 & 154 & 156 & 218 & 220 & & & \\
\hline 2 & CNJ01 & 105 & 105 & 182 & 182 & 195 & 195 & 200 & 216 & 154 & 156 & 157 & 197 & 252 & 252 & 232 & 242 & 177 & 202 & 154 & 170 & 218 & 218 & 2 & 6 & 5 \\
\hline 3 & CNJ02 & 105 & 105 & 182 & 182 & 195 & 195 & 200 & 216 & 154 & 154 & 157 & 197 & 252 & 252 & 232 & 242 & 177 & 177 & 154 & 170 & 218 & 218 & 3 & 4 & 5 \\
\hline 4 & CNJ03 & 105 & 105 & 182 & 182 & 195 & 195 & 210 & 216 & 154 & 154 & 157 & 157 & 252 & 254 & 232 & 242 & 177 & 202 & 154 & 170 & 220 & 220 & 4 & 5 & 6 \\
\hline 5 & CNJ04 & 105 & 105 & 182 & 182 & 195 & 195 & 200 & 200 & 154 & 156 & 157 & 157 & 252 & 254 & 232 & 242 & 177 & 177 & 170 & 170 & 218 & 218 & 5 & 3 & 6 \\
\hline 6 & CNJ05 & 105 & 105 & 182 & 182 & 195 & 195 & 200 & 216 & 154 & 154 & 157 & 197 & 252 & 252 & 242 & 242 & 177 & 177 & 170 & 170 & 218 & 220 & 6 & 3 & 5 \\
\hline 7 & CNJ06 & 105 & 105 & 182 & 182 & 195 & 195 & 200 & 200 & 156 & 156 & 177 & 197 & 252 & 254 & 232 & 242 & 177 & 177 & 154 & 170 & 218 & 220 & 7 & 5 & 4 \\
\hline 8 & CNJ07 & 105 & 105 & 182 & 182 & 195 & 195 & 200 & 216 & 154 & 156 & 157 & 197 & 252 & 254 & 242 & 242 & 188 & 191 & 170 & 170 & 218 & 220 & 8 & 6 & 5 \\
\hline 9 & CNJ08 & 105 & 105 & 182 & 182 & 195 & 195 & 210 & 216 & 154 & 154 & 157 & 199 & 252 & 254 & 242 & 242 & 191 & 202 & 170 & 170 & 220 & 220 & 9 & 4 & 5 \\
\hline 10 & CNJ09 & 105 & 105 & 182 & 182 & 195 & 195 & 200 & 200 & 156 & 156 & 189 & 201 & 252 & 252 & 232 & 242 & 177 & 177 & 154 & 170 & 218 & 218 & 10 & 3 & 4 \\
\hline 11 & CNJ10 & 105 & 105 & 182 & 182 & 195 & 195 & 200 & 220 & 156 & 158 & 197 & 197 & 252 & 252 & 242 & 242 & 177 & 177 & 154 & 170 & 218 & 220 & 11 & 4 & 4 \\
\hline 12 & CNJ11 & 105 & 105 & 182 & 182 & 195 & 195 & 216 & 216 & 154 & 156 & 157 & 201 & 252 & 252 & 242 & 242 & 177 & 188 & 154 & 154 & 218 & 220 & 12 & 4 & 5 \\
\hline 13 & CNJ12 & 105 & 105 & 182 & 182 & 195 & 195 & 200 & 200 & 156 & 156 & 157 & 201 & 252 & 254 & 242 & 242 & 177 & 202 & 154 & 170 & 218 & 220 & 13 & 5 & 5 \\
\hline 14 & CNJ13 & 105 & 105 & 182 & 182 & 195 & 195 & 200 & 216 & 154 & 156 & 197 & 201 & 252 & 254 & 232 & 242 & 177 & 188 & 154 & 170 & 218 & 218 & 14 & 7 & 4 \\
\hline 15 & CNJ14 & 105 & 105 & 182 & 182 & 195 & 195 & 200 & 200 & 156 & 156 & 197 & 201 & 252 & 252 & 232 & 242 & 177 & 202 & 154 & 154 & 218 & 218 & 15 & 3 & 4 \\
\hline 16 & CNJ15 & 105 & 105 & 182 & 182 & 195 & 195 & 200 & 200 & 154 & 158 & 157 & 157 & 252 & 252 & 232 & 242 & 188 & 202 & 154 & 170 & 218 & 220 & 16 & 5 & 6 \\
\hline 17 & CNJ16 & 105 & 105 & 182 & 182 & 195 & 195 & 200 & 200 & 154 & 156 & 157 & 197 & 252 & 254 & 232 & 242 & 177 & 202 & 154 & 170 & 218 & 218 & 17 & 6 & 5 \\
\hline 18 & CNJ17 & 105 & 105 & 182 & 182 & 195 & 195 & 200 & 200 & 156 & 156 & 157 & 157 & 252 & 254 & 232 & 242 & 177 & 177 & 170 & 170 & 218 & 218 & 18 & 2 & 6 \\
\hline 19 & CNJ18 & 105 & 105 & 182 & 182 & 195 & 195 & 200 & 216 & 154 & 154 & 157 & 201 & 252 & 252 & 242 & 242 & 177 & 177 & 154 & 170 & 218 & 218 & 19 & 3 & 5 \\
\hline 20 & CNJ19 & 105 & 105 & 182 & 182 & 195 & 195 & 200 & 216 & 154 & 154 & 157 & 201 & 252 & 254 & 242 & 242 & 177 & 202 & 154 & 170 & 218 & 218 & 20 & 5 & 5 \\
\hline 21 & CNJ20 & 105 & 105 & 182 & 182 & 195 & 195 & 200 & 220 & 154 & 158 & 197 & 197 & 252 & 252 & 232 & 242 & 177 & 188 & 154 & 170 & 218 & 220 & 21 & 6 & 4 \\
\hline 22 & CNJ21 & 105 & 105 & 182 & 182 & 195 & 195 & 200 & 220 & 156 & 158 & 157 & 157 & 252 & 252 & 242 & 242 & 177 & 188 & 154 & 154 & 218 & 220 & 22 & 4 & 6 \\
\hline 23 & CNJ22 & 105 & 105 & 182 & 182 & 195 & 195 & 200 & 216 & 154 & 156 & 169 & 197 & 252 & 252 & 232 & 232 & 177 & 202 & 154 & 170 & 218 & 218 & 23 & 5 & 4 \\
\hline 24 & CNJ23 & 105 & 105 & 182 & 182 & 195 & 195 & 216 & 216 & 154 & 154 & 157 & 197 & 252 & 252 & 242 & 242 & 177 & 188 & 154 & 170 & 220 & 220 & 24 & 3 & 5 \\
\hline 25 & CNJ24 & 105 & 105 & 182 & 182 & 195 & 195 & 200 & 216 & 154 & 156 & 157 & 197 & 252 & 252 & 242 & 242 & 177 & 188 & 154 & 170 & 218 & 218 & 25 & 5 & 5 \\
\hline 26 & CNJ25 & 105 & 105 & 182 & 182 & 195 & 195 & 200 & 200 & 156 & 158 & 197 & 197 & 252 & 252 & 232 & 242 & 188 & 202 & 154 & 154 & 218 & 218 & 26 & 3 & 4 \\
\hline 27 & CNJ26 & 105 & 105 & 182 & 182 & 195 & 195 & 200 & 210 & 154 & 154 & 197 & 197 & 252 & 254 & 232 & 242 & 191 & 202 & 170 & 170 & 218 & 220 & 27 & 5 & 4 \\
\hline 28 & CNJ27 & 105 & 105 & 182 & 182 & 195 & 195 & 200 & 220 & 154 & 156 & 157 & 197 & 252 & 252 & 242 & 242 & 177 & 177 & 154 & 170 & 218 & 220 & 28 & 5 & 5 \\
\hline 29 & CNJ28 & 105 & 105 & 182 & 182 & 195 & 195 & 216 & 216 & 154 & 154 & 157 & 197 & 252 & 252 & 242 & 242 & 177 & 188 & 170 & 170 & 218 & 220 & 29 & 3 & 5 \\
\hline 30 & CNJ29 & 105 & 105 & 182 & 182 & 195 & 195 & 200 & 210 & 154 & 156 & 191 & 197 & 252 & 254 & 232 & 242 & 177 & 191 & 154 & 154 & 218 & 218 & 30 & 6 & 4 \\
\hline & & & & & & & & & & & & & & & & & & & & & & & & & & \\
\hline
\end{tabular}




\begin{tabular}{|c|c|c|c|c|c|c|c|c|c|c|c|c|c|c|c|c|c|c|c|c|c|c|c|c|c|c|}
\hline 32 & CNJ31 & 105 & 105 & 182 & 182 & 195 & 195 & 200 & 216 & 154 & 156 & 157 & 197 & 252 & 252 & 232 & 242 & 177 & 202 & 154 & 170 & 218 & 220 & 32 & & 5 \\
\hline 33 & CNJ32 & 105 & 105 & 182 & 182 & 195 & 204 & 216 & 216 & 154 & 164 & 157 & 177 & 252 & 252 & 242 & 242 & 177 & 191 & 154 & 170 & 218 & 220 & 33 & & 5 \\
\hline 34 & CNJ33 & 105 & 105 & 182 & 182 & 195 & 195 & 210 & 216 & 154 & 154 & 157 & 199 & 252 & 254 & 242 & 242 & 188 & 191 & 154 & 170 & 218 & 220 & 34 & & 5 \\
\hline 35 & CNJ34 & 105 & 105 & 182 & 182 & 195 & 204 & 210 & 216 & 158 & 164 & 157 & 201 & 252 & 252 & 232 & 242 & 188 & 202 & 154 & 170 & 218 & 220 & 35 & & 5 \\
\hline 36 & CNJ35 & 105 & 105 & 182 & 182 & 195 & 195 & 200 & 216 & 154 & 158 & 157 & 197 & 252 & 252 & 242 & 242 & 188 & 202 & 154 & 170 & 220 & 220 & 36 & & 5 \\
\hline 37 & CNJ36 & 105 & 105 & 182 & 182 & 195 & 195 & 200 & 210 & 156 & 158 & 197 & 201 & 252 & 252 & 232 & 242 & 188 & 202 & 154 & 154 & 218 & 218 & 37 & & 4 \\
\hline 38 & CNJ37 & 105 & 105 & 182 & 182 & 195 & 195 & 210 & 216 & 154 & 158 & 157 & 201 & 252 & 252 & 242 & 242 & 177 & 191 & 154 & 170 & 218 & 220 & 38 & & 5 \\
\hline 39 & CNJ38 & 105 & 105 & 182 & 182 & 195 & 195 & 216 & 216 & 147 & 156 & 157 & 175 & 254 & 254 & 242 & 242 & 177 & 191 & 154 & 154 & 218 & 218 & 39 & 3 & 5 \\
\hline 40 & BOC01 & 105 & 105 & 179 & 182 & 195 & 204 & 210 & 216 & 156 & 158 & 189 & 199 & 252 & 252 & 242 & 242 & 191 & 202 & 154 & 181 & 220 & 220 & 40 & . & 4 \\
\hline 41 & BOC02 & 105 & 105 & 179 & 182 & 195 & 204 & 210 & 216 & 156 & 158 & 189 & 199 & 252 & 252 & 242 & 242 & 191 & 202 & 154 & 181 & 220 & 220 & 40 & t & 4 \\
\hline 42 & ВОС03 & 105 & 105 & 179 & 182 & 195 & 204 & 210 & 216 & 156 & 158 & 189 & 199 & 252 & 252 & 242 & 242 & 191 & 202 & 154 & 181 & 220 & 220 & 40 & . & 4 \\
\hline 43 & BOC04 & 105 & 105 & 179 & 182 & 195 & 204 & 210 & 210 & 158 & 158 & 197 & 199 & 252 & 252 & 242 & 242 & 191 & 202 & 154 & 154 & 220 & 220 & 41 & s & 4 \\
\hline 44 & RZA01 & 105 & 105 & 182 & 182 & 195 & 195 & 218 & 218 & 158 & 158 & 167 & 175 & 252 & 254 & 242 & 242 & 188 & 188 & 154 & 154 & 218 & 220 & 42 & 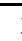 & 4 \\
\hline 45 & RZA02 & 105 & 105 & 182 & 182 & 195 & 195 & 200 & 218 & 154 & 158 & 175 & 185 & 252 & 254 & 242 & 244 & 188 & 188 & 154 & 154 & 220 & 220 & 43 & 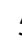 & 4 \\
\hline 46 & RZA03 & 105 & 105 & 182 & 182 & 195 & 195 & 200 & 216 & 154 & 158 & 167 & 197 & 252 & 252 & 242 & 242 & 177 & 188 & 154 & 154 & 220 & 220 & 44 & s & 4 \\
\hline 47 & RZA04 & 105 & 105 & 167 & 182 & 195 & 195 & 200 & 218 & 154 & 158 & 185 & 197 & 252 & 252 & 232 & 244 & 177 & 188 & 154 & 154 & 220 & 220 & 45 & 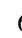 & 3 \\
\hline 48 & RZA05 & 105 & 105 & 182 & 182 & 195 & 195 & 200 & 218 & 154 & 158 & 165 & 197 & 252 & 252 & 232 & 242 & 177 & 188 & 154 & 154 & 218 & 218 & 46 & s & 4 \\
\hline 49 & RZA06 & 105 & 105 & 167 & 182 & 195 & 195 & 216 & 216 & 156 & 156 & 157 & 197 & 252 & 252 & 244 & 244 & 188 & 191 & 154 & 156 & 220 & 220 & 47 & r & 4 \\
\hline 50 & RZA07 & 105 & 105 & 167 & 167 & 195 & 195 & 216 & 224 & 154 & 156 & 175 & 197 & 252 & 252 & 244 & 244 & 188 & 188 & 154 & 154 & 220 & 236 & 48 & $2+2$ & 2 \\
\hline 51 & RZA08 & 105 & 105 & 182 & 182 & 195 & 195 & 216 & 224 & 154 & 154 & 175 & 175 & 252 & 252 & 242 & 244 & 188 & 191 & 154 & 154 & 218 & 236 & 49 & 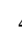 & 4 \\
\hline 52 & RZA09 & 105 & 105 & 182 & 182 & 195 & 195 & 216 & 218 & 158 & 158 & 167 & 185 & 252 & 254 & 242 & 242 & 188 & 188 & 154 & 154 & 220 & 220 & 50 & & 4 \\
\hline 53 & RZA10 & 105 & 105 & 167 & 182 & 195 & 195 & 218 & 218 & 154 & 156 & 173 & 175 & 252 & 252 & 242 & 244 & 188 & 188 & 154 & 154 & 218 & 220 & 51 & & 3 \\
\hline 54 & RZA11 & 105 & 105 & 182 & 182 & 195 & 195 & 218 & 218 & 158 & 158 & 165 & 175 & 252 & 252 & 242 & 242 & 188 & 188 & 154 & 154 & 220 & 220 & 52 & & 4 \\
\hline 55 & RZA12 & 105 & 105 & 182 & 182 & 195 & 195 & 200 & 216 & 154 & 160 & 157 & 185 & 252 & 252 & 232 & 244 & 188 & 191 & 154 & 154 & 220 & 220 & 53 & 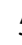 & 5 \\
\hline 56 & RZA13 & 105 & 105 & 167 & 167 & 195 & 195 & 210 & 210 & 154 & 154 & 175 & 175 & 252 & 252 & 242 & 244 & 188 & 188 & 154 & 170 & 220 & 220 & 54 & 2 & 2 \\
\hline 57 & RZA14 & 105 & 105 & 167 & 182 & 195 & 195 & 216 & 218 & 156 & 158 & 185 & 197 & 252 & 252 & 242 & 244 & 188 & 188 & 154 & 154 & 220 & 220 & 55 & 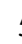 & 3 \\
\hline 58 & RZA15 & 105 & 105 & 182 & 182 & 195 & 195 & 216 & 218 & 156 & 158 & 157 & 175 & 252 & 254 & 242 & 244 & 188 & 188 & 154 & 156 & 218 & 220 & 56 & , & 5 \\
\hline 59 & RZA16 & 105 & 105 & 167 & 182 & 195 & 195 & 200 & 200 & 154 & 158 & 175 & 197 & 252 & 252 & 244 & 244 & 191 & 202 & 154 & 154 & 220 & 220 & 57 & 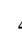 & 3 \\
\hline 60 & RZA17 & 105 & 105 & 167 & 182 & 195 & 195 & 216 & 216 & 154 & 160 & 175 & 197 & 252 & 252 & 242 & 244 & 188 & 188 & 154 & 170 & 218 & 220 & 58 & 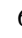 & 3 \\
\hline 61 & RZA18 & 105 & 105 & 167 & 182 & 195 & 195 & 216 & 216 & 154 & 156 & 175 & 197 & 252 & 252 & 242 & 244 & 188 & 188 & 154 & 170 & 220 & 220 & 59 & 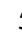 & 3 \\
\hline 62 & RZA19 & 105 & 105 & 167 & 182 & 195 & 195 & 216 & 216 & 154 & 156 & 175 & 175 & 252 & 252 & 242 & 244 & 188 & 188 & 170 & 170 & 218 & 220 & 60 & 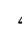 & 3 \\
\hline 63 & RZA20 & 105 & 105 & 167 & 182 & 195 & 195 & 216 & 216 & 154 & 156 & 157 & 197 & 252 & 252 & 242 & 242 & 191 & 202 & 170 & 170 & 220 & 220 & 61 & . & 4 \\
\hline 64 & RZA21 & 105 & 105 & 167 & 182 & 195 & 195 & 200 & 200 & 154 & 158 & 185 & 197 & 252 & 252 & 242 & 244 & 202 & 202 & 154 & 170 & 218 & 220 & 62 & 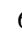 & 3 \\
\hline 65 & RZA22 & 105 & 105 & 167 & 182 & 195 & 195 & 216 & 218 & 158 & 160 & 175 & 175 & 252 & 252 & 244 & 244 & 188 & 188 & 154 & 154 & 218 & 220 & 63 & s & 3 \\
\hline 66 & NAV01 & 105 & 105 & 167 & 182 & 195 & 201 & 208 & 224 & 156 & 156 & 185 & 185 & 252 & 254 & 232 & 242 & 188 & 191 & 154 & 154 & 216 & 220 & 64 & 7 & 4 \\
\hline 67 & NAV02 & 105 & 105 & 167 & 182 & 195 & 195 & 208 & 216 & 154 & 156 & 161 & 183 & 252 & 254 & 232 & 242 & 188 & 191 & 154 & 154 & 216 & 220 & 65 & 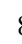 & 5 \\
\hline 68 & NAV03 & 105 & 105 & 182 & 182 & 195 & 195 & 214 & 224 & 154 & 156 & 161 & 183 & 252 & 252 & 232 & 242 & 188 & 191 & 154 & 154 & 216 & 216 & 66 & 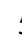 & 5 \\
\hline 69 & NAV04 & 105 & 105 & 167 & 182 & 195 & 201 & 224 & 224 & 156 & 158 & 185 & 185 & 252 & 252 & 232 & 242 & 191 & 191 & 154 & 154 & 220 & 220 & 67 & r & 3 \\
\hline 70 & NAV05 & 105 & 105 & 167 & 182 & 195 & 195 & 208 & 214 & 154 & 156 & 183 & 185 & 252 & 252 & 232 & 242 & 188 & 188 & 154 & 154 & 216 & 220 & 68 & 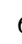 & 4 \\
\hline 71 & NAV06 & 105 & 105 & 167 & 167 & 195 & 201 & 214 & 214 & 154 & 154 & 171 & 185 & 252 & 252 & 232 & 232 & 188 & 191 & 154 & 154 & 216 & 216 & 69 & 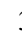 & 2 \\
\hline 72 & NAV07 & 105 & 105 & 167 & 182 & 195 & 201 & 216 & 224 & 156 & 156 & 161 & 185 & 252 & 252 & 232 & 232 & 188 & 188 & 154 & 154 & 216 & 220 & 70 & 5 & 4 \\
\hline 73 & NAV08 & 105 & 105 & 182 & 182 & 195 & 195 & 214 & 214 & 154 & 154 & 161 & 171 & 252 & 252 & 232 & 232 & 188 & 191 & 154 & 154 & 216 & 216 & 71 & & 5 \\
\hline & (1) & 105 & 105 & 167 & 182 & 195 & 195 & 214 & 224 & 154 & 156 & 161 & 185 & 252 & 252 & 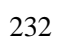 & 232 & 188 & 191 & 154 & 154 & 216 & 220 & 72 & & \\
\hline
\end{tabular}




\begin{tabular}{|c|c|c|c|c|c|c|c|c|c|c|c|c|c|c|c|c|c|c|c|c|c|c|c|c|c|c|}
\hline 75 & NAV10 & 105 & 105 & 167 & 182 & 195 & 201 & 208 & 224 & 156 & 156 & 161 & 183 & 252 & 254 & 242 & 244 & 188 & 188 & 154 & 154 & 216 & 220 & 73 & 7 & 5 \\
\hline 76 & NAV11 & 105 & 105 & 167 & 182 & 195 & 195 & 208 & 224 & 156 & 156 & 185 & 185 & 252 & 252 & 242 & 242 & 188 & 188 & 154 & 154 & 216 & 220 & 74 & 3 & 4 \\
\hline 77 & NAV12 & 105 & 105 & 167 & 182 & 195 & 195 & 208 & 224 & 156 & 156 & 171 & 185 & 252 & 252 & 232 & 242 & 188 & 188 & 154 & 154 & 216 & 216 & 75 & 4 & 4 \\
\hline 78 & NAV13 & 105 & 105 & 167 & 182 & 195 & 201 & 224 & 224 & 156 & 156 & 185 & 185 & 252 & 252 & 232 & 242 & 191 & 191 & 154 & 154 & 220 & 220 & 76 & 3 & 3 \\
\hline 79 & NAV14 & 105 & 105 & 167 & 167 & 195 & 195 & 224 & 224 & 154 & 158 & 171 & 185 & 252 & 252 & 242 & 242 & 188 & 191 & 154 & 154 & 220 & 220 & 77 & 3 & 2 \\
\hline 80 & MON01 & 105 & 105 & 182 & 182 & 195 & 195 & 208 & 214 & 154 & 158 & 157 & 197 & 252 & 252 & 220 & 244 & 188 & 202 & 154 & 154 & 216 & 220 & 78 & 6 & 6 \\
\hline 81 & MON02 & 105 & 105 & 164 & 164 & 195 & 195 & 210 & 216 & 154 & 156 & 169 & 185 & 252 & 252 & 220 & 220 & 188 & 188 & 154 & 170 & 216 & 216 & 79 & 4 & 2 \\
\hline 82 & MON03 & 105 & 105 & 164 & 164 & 195 & 195 & 210 & 210 & 156 & 156 & 165 & 169 & 252 & 252 & 220 & 220 & 188 & 191 & 158 & 170 & 216 & 216 & 80 & 3 & 2 \\
\hline 83 & MON04 & 105 & 105 & 164 & 170 & 195 & 195 & 210 & 216 & 156 & 156 & 169 & 201 & 252 & 252 & 220 & 220 & 188 & 191 & 158 & 170 & 216 & 216 & 81 & 5 & 2 \\
\hline 84 & MON05 & 105 & 105 & 164 & 164 & 195 & 195 & 210 & 216 & 154 & 156 & 185 & 201 & 252 & 252 & 220 & 242 & 188 & 191 & 154 & 158 & 216 & 218 & 82 & 7 & 2 \\
\hline 85 & MON06 & 105 & 105 & 182 & 182 & 195 & 195 & 208 & 210 & 156 & 164 & 185 & 185 & 252 & 252 & 242 & 244 & 188 & 188 & 158 & 158 & 216 & 216 & 83 & 3 & 5 \\
\hline 86 & MON07 & 105 & 105 & 164 & 164 & 195 & 195 & 208 & 208 & 154 & 156 & 185 & 185 & 252 & 252 & 220 & 220 & 188 & 191 & 154 & 158 & 216 & 220 & 84 & 4 & 4 \\
\hline 87 & RAS01 & 105 & 105 & 167 & 182 & 195 & 195 & 208 & 216 & 155 & 156 & 177 & 197 & 252 & 252 & 232 & 232 & 188 & 188 & 185 & 185 & 216 & 216 & 85 & 4 & 5 \\
\hline 88 & RAS02 & 105 & 105 & 167 & 182 & 195 & 195 & 208 & 224 & 156 & 166 & 171 & 185 & 252 & 254 & 232 & 232 & 191 & 191 & 154 & 185 & 216 & 220 & 86 & 7 & 4 \\
\hline 89 & RAS03 & 105 & 105 & 182 & 182 & 195 & 195 & 216 & 224 & 155 & 166 & 171 & 177 & 252 & 252 & 232 & 244 & 188 & 188 & 170 & 170 & 216 & 216 & 87 & 4 & 5 \\
\hline 90 & RAS04 & 105 & 105 & 182 & 182 & 195 & 195 & 224 & 224 & 155 & 166 & 177 & 197 & 252 & 252 & 232 & 244 & 188 & 188 & 170 & 185 & 216 & 216 & 88 & 4 & 5 \\
\hline 91 & RAS05 & 105 & 105 & 182 & 182 & 195 & 195 & 224 & 224 & 155 & 166 & 177 & 177 & 252 & 252 & 232 & 244 & 188 & 188 & 170 & 185 & 216 & 216 & 89 & 3 & 5 \\
\hline 92 & RAS06 & 105 & 105 & 182 & 182 & 195 & 195 & 224 & 224 & 155 & 166 & 177 & 177 & 252 & 252 & 244 & 244 & 188 & 188 & 170 & 170 & 216 & 216 & 90 & 1 & 5 \\
\hline 93 & RAS07 & 105 & 105 & 182 & 182 & 195 & 195 & 210 & 210 & 155 & 166 & 177 & 177 & 252 & 252 & 232 & 244 & 188 & 188 & 170 & 185 & 216 & 216 & 91 & 3 & 5 \\
\hline 94 & RAS08 & 105 & 105 & 182 & 182 & 195 & 195 & 224 & 224 & 155 & 166 & 171 & 177 & 252 & 252 & 244 & 244 & 188 & 188 & 170 & 185 & 216 & 216 & 92 & 3 & 5 \\
\hline 95 & RAS09 & 105 & 105 & 182 & 182 & 195 & 195 & 216 & 224 & 155 & 166 & 177 & 197 & 252 & 252 & 232 & 232 & 188 & 191 & 170 & 170 & 216 & 216 & 93 & 4 & 5 \\
\hline 96 & RAS10 & 105 & 105 & 182 & 182 & 195 & 195 & 224 & 224 & 155 & 166 & 171 & 177 & 252 & 252 & 242 & 244 & 188 & 188 & 170 & 185 & 216 & 216 & 94 & 4 & 5 \\
\hline 97 & RAS11 & 105 & 105 & 182 & 182 & 195 & 195 & 224 & 224 & 155 & 166 & 171 & 177 & 252 & 252 & 232 & 242 & 188 & 188 & 170 & 185 & 216 & 216 & 95 & 4 & 5 \\
\hline 98 & RAS12 & 105 & 105 & 167 & 182 & 195 & 195 & 208 & 208 & 156 & 156 & 177 & 177 & 252 & 252 & 232 & 242 & 188 & 191 & 185 & 185 & 216 & 216 & 96 & 3 & 5 \\
\hline 99 & RAS13 & 105 & 105 & 182 & 182 & 195 & 195 & 216 & 216 & 155 & 155 & 171 & 177 & 252 & 252 & 232 & 244 & 188 & 188 & 170 & 170 & 216 & 216 & 97 & 2 & 6 \\
\hline 100 & RAS14 & 105 & 105 & 182 & 182 & 195 & 195 & 224 & 224 & 155 & 166 & 177 & 197 & 252 & 252 & 232 & 244 & 188 & 188 & 170 & 185 & 216 & 216 & 88 & 4 & 5 \\
\hline 101 & RAS15 & 105 & 105 & 182 & 182 & 195 & 195 & 210 & 210 & 155 & 155 & 177 & 177 & 252 & 252 & 232 & 242 & 188 & 188 & 185 & 185 & 216 & 216 & 98 & 1 & 6 \\
\hline 102 & RAS16 & 105 & 105 & 182 & 182 & 195 & 195 & 224 & 224 & 155 & 166 & 171 & 177 & 252 & 252 & 242 & 242 & 188 & 188 & 170 & 170 & 216 & 216 & 99 & 2 & 5 \\
\hline 103 & RAS17 & 105 & 105 & 182 & 182 & 195 & 195 & 224 & 224 & 155 & 166 & 177 & 177 & 252 & 252 & 242 & 244 & 188 & 188 & 170 & 170 & 216 & 216 & 100 & 2 & 5 \\
\hline 104 & RAS18 & 105 & 105 & 182 & 182 & 195 & 195 & 216 & 224 & 155 & 166 & 177 & 197 & 252 & 252 & 242 & 242 & 188 & 188 & 170 & 170 & 216 & 216 & 101 & 3 & 5 \\
\hline 105 & RAS19 & 105 & 105 & 182 & 182 & 195 & 195 & 224 & 224 & 155 & 166 & 171 & 177 & 252 & 252 & 232 & 244 & 188 & 188 & 170 & 185 & 216 & 216 & 102 & 4 & 5 \\
\hline 106 & RAS20 & 105 & 105 & 182 & 182 & 195 & 195 & 224 & 224 & 155 & 166 & 177 & 199 & 252 & 252 & 232 & 244 & 188 & 188 & 170 & 170 & 216 & 216 & 103 & 3 & 5 \\
\hline 107 & RAS21 & 105 & 105 & 182 & 182 & 195 & 195 & 224 & 224 & 155 & 166 & 171 & 177 & 252 & 252 & 242 & 244 & 188 & 188 & 170 & 185 & 216 & 216 & 94 & 4 & 5 \\
\hline 108 & RAS22 & 105 & 105 & 182 & 182 & 195 & 195 & 224 & 224 & 155 & 166 & 171 & 177 & 252 & 252 & 242 & 244 & 188 & 188 & 170 & 185 & 216 & 216 & 94 & 4 & 5 \\
\hline 109 & RAS23 & 105 & 105 & 182 & 182 & 195 & 195 & 224 & 224 & 166 & 166 & 177 & 177 & 252 & 252 & 232 & 244 & 188 & 188 & 170 & 170 & 216 & 216 & 104 & 1 & 4 \\
\hline 110 & RAS24 & 105 & 105 & 182 & 182 & 195 & 195 & 224 & 224 & 155 & 166 & 177 & 197 & 252 & 252 & 242 & 242 & 188 & 188 & 170 & 185 & 216 & 216 & 105 & 3 & 5 \\
\hline 111 & RAS25 & 105 & 105 & 182 & 182 & 195 & 195 & 216 & 216 & 155 & 155 & 197 & 197 & 252 & 254 & 242 & 244 & 188 & 191 & 154 & 154 & 216 & 216 & 106 & 3 & 6 \\
\hline 112 & RAS26 & 105 & 105 & 182 & 182 & 195 & 195 & 224 & 224 & 155 & 166 & 171 & 177 & 252 & 252 & 232 & 244 & 188 & 188 & 170 & 185 & 216 & 216 & 102 & 4 & 5 \\
\hline 113 & RAS27 & 105 & 105 & 182 & 182 & 195 & 195 & 224 & 224 & 155 & 166 & 177 & 177 & 252 & 252 & 232 & 242 & 188 & 188 & 170 & 185 & 216 & 216 & 107 & 3 & 5 \\
\hline 114 & RAS28 & 105 & 105 & 182 & 182 & 195 & 195 & 216 & 216 & 155 & 155 & 177 & 197 & 252 & 252 & 220 & 232 & 188 & 191 & 154 & 185 & 216 & 220 & 108 & 5 & 6 \\
\hline 115 & RAS29 & 105 & 105 & 182 & 182 & 195 & 195 & 216 & 216 & 155 & 155 & 171 & 197 & 252 & 252 & 232 & 244 & 188 & 188 & 170 & 185 & 216 & 216 & 109 & 3 & 6 \\
\hline 116 & RAS30 & 105 & 105 & 167 & 182 & 195 & 195 & 208 & 216 & 155 & 156 & 177 & 185 & 252 & 252 & 220 & 232 & 191 & 191 & 154 & 185 & 216 & 216 & 110 & 6 & 5 \\
\hline 117 & RAS31 & 105 & 105 & 182 & 182 & 195 & 195 & 216 & 216 & 155 & 155 & 171 & 177 & 252 & 252 & 232 & 244 & 188 & 188 & 170 & 185 & 216 & 216 & 111 & 3 & 6 \\
\hline
\end{tabular}


118 RAS32

$\begin{array}{lllllllllllllllllllllllll}105 & 105 & 182 & 182 & 195 & 195 & 224 & 224 & 166 & 166 & 171 & 197 & 252 & 252 & 232 & 244 & 188 & 191 & 170 & 170 & 216 & 216 & 112 & 3 & 4\end{array}$

\begin{tabular}{|c|c|c|c|c|c|c|c|c|c|c|c|c|c|c|c|c|c|c|c|c|c|c|c|c|c|c|}
\hline 119 & RAS33 & 105 & 105 & 182 & 182 & 195 & 195 & 224 & 224 & 155 & 166 & 177 & 197 & 252 & 252 & 232 & 244 & 188 & 191 & 170 & 185 & 216 & 216 & 113 & 5 & 5 \\
\hline 120 & PAU01 & 105 & 105 & 182 & 182 & 195 & 204 & 216 & 218 & 154 & 158 & 165 & 187 & 252 & 254 & 244 & 244 & 188 & 191 & 154 & 170 & 216 & 216 & 114 & 7 & 4 \\
\hline 121 & CER01 & 105 & 105 & 182 & 182 & 195 & 195 & 200 & 218 & 154 & 154 & 169 & 177 & 252 & 254 & 220 & 232 & 188 & 191 & 154 & 174 & 216 & 218 & 115 & 7 & 4 \\
\hline 122 & CER02 & 105 & 105 & 182 & 182 & 195 & 195 & 200 & 218 & 154 & 154 & 169 & 177 & 252 & 254 & 220 & 232 & 188 & 191 & 154 & 174 & 216 & 218 & 115 & 7 & 4 \\
\hline 123 & CER03 & 105 & 105 & 182 & 182 & 195 & 195 & 200 & 218 & 154 & 154 & 169 & 177 & 252 & 254 & 220 & 232 & 188 & 191 & 154 & 174 & 216 & 218 & 115 & 7 & 4 \\
\hline 124 & CER04 & 105 & 105 & 182 & 182 & 195 & 195 & 200 & 218 & 154 & 154 & 169 & 177 & 252 & 254 & 220 & 232 & 188 & 191 & 154 & 174 & 216 & 218 & 115 & 7 & 4 \\
\hline 125 & CER05 & 105 & 105 & 182 & 182 & 195 & 195 & 200 & 218 & 154 & 154 & 169 & 177 & 252 & 254 & 220 & 232 & 188 & 191 & 154 & 174 & 216 & 218 & 115 & 7 & 4 \\
\hline 126 & CER06 & 105 & 105 & 182 & 182 & 195 & 195 & 200 & 218 & 154 & 154 & 169 & 177 & 252 & 254 & 220 & 232 & 188 & 191 & 154 & 174 & 216 & 218 & 115 & 7 & 4 \\
\hline 127 & ROZ01 & 105 & 108 & 182 & 182 & 192 & 195 & 216 & 224 & 158 & 158 & 152 & 175 & 252 & 256 & 233 & 235 & 188 & 191 & 151 & 170 & 220 & 233 & 116 & 9 & 7 \\
\hline 128 & ROZ02 & 105 & 108 & 182 & 182 & 192 & 195 & 212 & 216 & 151 & 158 & 152 & 177 & 254 & 256 & 232 & 233 & 177 & 188 & 151 & 170 & 220 & 233 & 117 & 10 & 8 \\
\hline 129 & ROZ03 & 105 & 108 & 182 & 182 & 192 & 195 & 212 & 216 & 151 & 158 & 152 & 177 & 254 & 256 & 232 & 233 & 177 & 188 & 151 & 170 & 220 & 233 & 117 & 10 & 8 \\
\hline 130 & ROZ04 & 105 & 108 & 182 & 182 & 192 & 195 & 212 & 216 & 151 & 158 & 152 & 177 & 254 & 256 & 232 & 233 & 177 & 188 & 151 & 170 & 220 & 233 & 117 & 10 & 8 \\
\hline 131 & ROZ05 & 105 & 105 & 176 & 182 & 195 & 195 & 210 & 216 & 147 & 158 & 152 & 171 & 252 & 256 & 232 & 233 & 188 & 191 & 170 & 170 & 220 & 220 & 118 & 7 & 4 \\
\hline 132 & ROZ06 & 105 & 108 & 182 & 182 & 192 & 195 & 212 & 216 & 151 & 156 & 152 & 157 & 252 & 256 & 232 & 233 & 177 & 188 & 151 & 170 & 233 & 233 & 119 & 9 & 9 \\
\hline 133 & ROZ07 & 105 & 108 & 182 & 182 & 192 & 195 & 212 & 216 & 151 & 156 & 152 & 157 & 252 & 256 & 232 & 233 & 177 & 188 & 151 & 154 & 233 & 233 & 120 & 9 & 9 \\
\hline 134 & ROZ08 & 105 & 108 & 182 & 182 & 192 & 195 & 212 & 216 & 151 & 156 & 152 & 157 & 252 & 256 & 232 & 233 & 177 & 188 & 151 & 154 & 233 & 233 & 120 & 9 & 9 \\
\hline 135 & ROZ09 & 105 & 108 & 182 & 182 & 192 & 195 & 212 & 216 & 151 & 156 & 152 & 157 & 252 & 256 & 232 & 233 & 177 & 188 & 151 & 154 & 233 & 233 & 120 & 9 & 9 \\
\hline 136 & ROZ10 & 105 & 108 & 182 & 182 & 192 & 195 & 212 & 216 & 151 & 156 & 152 & 157 & 252 & 256 & 232 & 233 & 177 & 188 & 151 & 154 & 233 & 233 & 120 & 9 & 9 \\
\hline 137 & ROZ11 & 105 & 108 & 182 & 182 & 192 & 195 & 210 & 216 & 147 & 158 & 152 & 171 & 252 & 256 & 232 & 233 & 188 & 188 & 170 & 170 & 218 & 220 & 121 & 8 & 7 \\
\hline 138 & ROZ12 & 105 & 108 & 176 & 182 & 195 & 195 & 210 & 212 & 147 & 151 & 157 & 177 & 252 & 254 & 232 & 233 & 188 & 188 & 151 & 170 & 233 & 233 & 122 & 8 & 6 \\
\hline 139 & ROZ13 & 105 & 108 & 182 & 182 & 192 & 195 & 212 & 216 & 151 & 156 & 152 & 157 & 252 & 256 & 232 & 233 & 177 & 188 & 151 & 154 & 233 & 233 & 120 & 9 & 9 \\
\hline 140 & ROZ14 & 105 & 105 & 182 & 182 & 195 & 195 & 210 & 216 & 147 & 158 & 171 & 177 & 252 & 254 & 232 & 233 & 188 & 188 & 170 & 170 & 218 & 220 & 123 & 6 & 4 \\
\hline 141 & ROZ15 & 105 & 114 & 182 & 182 & 195 & 195 & 216 & 218 & 145 & 156 & 171 & 191 & 252 & 254 & 232 & 232 & 188 & 191 & 156 & 170 & 218 & 218 & 124 & 7 & 5 \\
\hline 142 & ROZ16 & 105 & 108 & 182 & 182 & 192 & 195 & 216 & 216 & 156 & 158 & 157 & 177 & 252 & 252 & 232 & 232 & 177 & 191 & 154 & 170 & 220 & 233 & 125 & 7 & 7 \\
\hline 143 & ROZ17 & 105 & 105 & 176 & 182 & 192 & 195 & 216 & 218 & 145 & 156 & 152 & 177 & 254 & 256 & 232 & 233 & 177 & 188 & 154 & 156 & 233 & 233 & 126 & 9 & 5 \\
\hline 144 & ROZ18 & 105 & 108 & 182 & 182 & 192 & 195 & 212 & 216 & 151 & 156 & 152 & 157 & 252 & 256 & 232 & 233 & 177 & 188 & 151 & 154 & 233 & 233 & 120 & 9 & 9 \\
\hline 145 & ROZ19 & 105 & 108 & 182 & 182 & 192 & 195 & 212 & 216 & 151 & 156 & 152 & 157 & 252 & 256 & 232 & 233 & 177 & 188 & 151 & 154 & 233 & 233 & 120 & 9 & 9 \\
\hline 146 & ROZ20 & 105 & 108 & 182 & 182 & 192 & 195 & 212 & 216 & 151 & 156 & 152 & 157 & 252 & 256 & 232 & 233 & 177 & 188 & 151 & 154 & 233 & 233 & 120 & 9 & 9 \\
\hline 147 & ROZ21 & 105 & 108 & 182 & 182 & 192 & 195 & 212 & 216 & 151 & 156 & 152 & 157 & 252 & 256 & 232 & 233 & 177 & 188 & 151 & 154 & 233 & 233 & 120 & 9 & 9 \\
\hline 148 & ROZ22 & 105 & 108 & 182 & 182 & 192 & 195 & 212 & 216 & 151 & 156 & 152 & 157 & 252 & 256 & 232 & 233 & 177 & 188 & 151 & 154 & 233 & 233 & 120 & 9 & 9 \\
\hline 149 & ROZ23 & 105 & 108 & 182 & 182 & 192 & 195 & 212 & 216 & 151 & 156 & 152 & 157 & 252 & 256 & 232 & 233 & 177 & 188 & 151 & 154 & 233 & 233 & 120 & 9 & 9 \\
\hline 150 & ROZ24 & 105 & 105 & 182 & 182 & 195 & 195 & 216 & 216 & 154 & 156 & 152 & 177 & 252 & 252 & 232 & 233 & 188 & 188 & 154 & 158 & 220 & 233 & 127 & 5 & 5 \\
\hline 151 & ROZ25 & 105 & 114 & 182 & 182 & 192 & 195 & 212 & 224 & 151 & 158 & 163 & 191 & 254 & 256 & 232 & 235 & 177 & 188 & 151 & 154 & 218 & 222 & 128 & 10 & 9 \\
\hline 152 & ROZ26 & 105 & 114 & 182 & 182 & 192 & 195 & 212 & 224 & 151 & 158 & 163 & 191 & 254 & 256 & 232 & 235 & 177 & 188 & 151 & 154 & 218 & 222 & 128 & 10 & 9 \\
\hline 153 & ROZ27 & 105 & 114 & 182 & 182 & 192 & 195 & 212 & 224 & 151 & 158 & 163 & 191 & 254 & 256 & 232 & 235 & 177 & 188 & 151 & 154 & 218 & 222 & 128 & 10 & 9 \\
\hline 154 & ROZ28 & 105 & 114 & 182 & 182 & 192 & 195 & 212 & 224 & 151 & 158 & 163 & 191 & 254 & 256 & 232 & 235 & 177 & 188 & 151 & 154 & 218 & 222 & 128 & 10 & 9 \\
\hline 155 & ROZ29 & 105 & 114 & 182 & 182 & 192 & 195 & 212 & 224 & 151 & 158 & 163 & 191 & 254 & 256 & 232 & 235 & 177 & 188 & 151 & 154 & 218 & 222 & 128 & 10 & 9 \\
\hline 156 & ROZ30 & 105 & 114 & 182 & 182 & 192 & 195 & 212 & 224 & 151 & 158 & 163 & 191 & 254 & 256 & 232 & 235 & 177 & 188 & 151 & 154 & 218 & 222 & 128 & 10 & 9 \\
\hline 157 & ROZ31 & 105 & 114 & 182 & 182 & 192 & 195 & 212 & 224 & 151 & 158 & 163 & 191 & 254 & 256 & 232 & 235 & 177 & 188 & 151 & 154 & 218 & 222 & 128 & 10 & 9 \\
\hline 158 & ROZ32 & 105 & 114 & 182 & 182 & 192 & 195 & 212 & 224 & 151 & 158 & 163 & 191 & 254 & 256 & 232 & 235 & 177 & 188 & 151 & 154 & 218 & 222 & 128 & 10 & 9 \\
\hline 159 & ROZ33 & 105 & 114 & 182 & 182 & 192 & 195 & 212 & 224 & 151 & 158 & 163 & 191 & 254 & 256 & 232 & 235 & 177 & 188 & 151 & 154 & 218 & 222 & 128 & 10 & 9 \\
\hline & & 105 & 114 & 182 & 182 & 192 & 195 & 212 & 224 & 151 & 158 & 163 & 191 & 254 & 256 & 232 & 235 & I/7 & 188 & 151 & 154 & 218 & 222 & 128 & & \\
\hline
\end{tabular}




\begin{tabular}{|c|c|c|c|c|c|c|c|c|c|c|c|c|c|c|c|c|c|c|c|c|c|c|c|c|c|c|}
\hline 161 & ROZ35 & 105 & 114 & 182 & 182 & 192 & 195 & 212 & 224 & 151 & 158 & 163 & 191 & 254 & 256 & 232 & 235 & 177 & 188 & 151 & 154 & 218 & 222 & 128 & 10 & 9 \\
\hline 162 & ROZ36 & 105 & 114 & 182 & 182 & 192 & 195 & 212 & 224 & 151 & 158 & 163 & 191 & 254 & 256 & 232 & 235 & 177 & 188 & 151 & 154 & 218 & 222 & 128 & 10 & 9 \\
\hline 163 & ROZ37 & 105 & 114 & 182 & 182 & 192 & 195 & 212 & 224 & 151 & 158 & 163 & 191 & 254 & 256 & 232 & 235 & 177 & 188 & 151 & 154 & 218 & 222 & 128 & 10 & 9 \\
\hline 164 & ROZ38 & 105 & 114 & 182 & 182 & 192 & 195 & 212 & 224 & 151 & 158 & 163 & 191 & 254 & 256 & 232 & 235 & 177 & 188 & 151 & 154 & 218 & 222 & 128 & 10 & 9 \\
\hline 165 & ROZ39 & 105 & 114 & 182 & 182 & 192 & 195 & 212 & 224 & 151 & 158 & 163 & 191 & 254 & 256 & 232 & 235 & 177 & 188 & 151 & 154 & 218 & 222 & 128 & 10 & 9 \\
\hline 166 & ROZ40 & 105 & 114 & 182 & 182 & 192 & 195 & 212 & 224 & 151 & 158 & 163 & 191 & 254 & 256 & 232 & 235 & 177 & 188 & 151 & 154 & 218 & 222 & 128 & 10 & 9 \\
\hline 167 & ROZ41 & 105 & 114 & 182 & 182 & 192 & 195 & 212 & 224 & 151 & 158 & 163 & 191 & 254 & 256 & 232 & 235 & 177 & 188 & 151 & 154 & 218 & 222 & 128 & 10 & 9 \\
\hline 168 & ROZ42 & 105 & 114 & 182 & 182 & 192 & 195 & 212 & 224 & 151 & 158 & 163 & 191 & 254 & 256 & 232 & 235 & 177 & 188 & 151 & 154 & 218 & 222 & 128 & 10 & 9 \\
\hline 169 & ROZ43 & 105 & 114 & 182 & 182 & 192 & 195 & 212 & 224 & 151 & 158 & 163 & 191 & 254 & 256 & 232 & 235 & 177 & 188 & 151 & 154 & 218 & 222 & 128 & 10 & 9 \\
\hline 170 & ROZ44 & 105 & 114 & 182 & 182 & 192 & 195 & 212 & 224 & 151 & 158 & 163 & 191 & 254 & 256 & 232 & 235 & 177 & 188 & 151 & 154 & 218 & 222 & 128 & 10 & 9 \\
\hline 171 & ROZ45 & 105 & 114 & 182 & 182 & 192 & 195 & 212 & 224 & 151 & 158 & 163 & 191 & 254 & 256 & 232 & 235 & 177 & 188 & 151 & 154 & 218 & 222 & 128 & 10 & 9 \\
\hline 172 & ROZ46 & 105 & 114 & 182 & 182 & 192 & 195 & 212 & 224 & 151 & 158 & 163 & 191 & 254 & 256 & 232 & 235 & 177 & 188 & 151 & 154 & 218 & 222 & 128 & 10 & 9 \\
\hline 173 & TIE01 & 105 & 105 & 182 & 182 & 195 & 195 & 214 & 214 & 158 & 158 & 157 & 179 & 252 & 252 & 232 & 242 & 191 & 202 & 170 & 170 & 216 & 220 & 129 & 4 & 5 \\
\hline 174 & TIE02 & 105 & 105 & 182 & 182 & 195 & 195 & 208 & 214 & 158 & 158 & 157 & 179 & 252 & 252 & 232 & 242 & 177 & 177 & 170 & 170 & 216 & 220 & 130 & 4 & 6 \\
\hline 175 & TIE03 & 105 & 105 & 182 & 182 & 195 & 195 & 208 & 208 & 158 & 158 & 157 & 157 & 252 & 252 & 232 & 242 & 177 & 202 & 170 & 170 & 216 & 216 & 131 & 2 & 8 \\
\hline 176 & TIE04 & 105 & 105 & 182 & 182 & 195 & 195 & 208 & 208 & 158 & 158 & 157 & 179 & 252 & 252 & 232 & 242 & 177 & 177 & 170 & 170 & 216 & 220 & 132 & 3 & 7 \\
\hline 177 & TIE05 & 105 & 105 & 173 & 182 & 195 & 195 & 208 & 214 & 158 & 158 & 157 & 179 & 252 & 252 & 242 & 242 & 177 & 202 & 154 & 170 & 216 & 220 & 133 & 6 & 5 \\
\hline 178 & TIE06 & 105 & 105 & 173 & 182 & 195 & 195 & 208 & 214 & 158 & 158 & 157 & 179 & 252 & 252 & 242 & 242 & 177 & 202 & 154 & 170 & 216 & 220 & 133 & 6 & 5 \\
\hline 179 & TIE07 & 105 & 105 & 173 & 182 & 195 & 195 & 214 & 214 & 158 & 158 & 179 & 179 & 252 & 252 & 232 & 242 & 177 & 202 & 170 & 170 & 216 & 220 & 134 & 4 & 3 \\
\hline 180 & TIE08 & 105 & 105 & 182 & 182 & 195 & 195 & 208 & 214 & 158 & 158 & 179 & 179 & 252 & 252 & 232 & 242 & 177 & 191 & 154 & 154 & 216 & 216 & 135 & 3 & 5 \\
\hline 181 & TIE09 & 105 & 105 & 182 & 185 & 195 & 195 & 208 & 208 & 158 & 158 & 179 & 189 & 252 & 252 & 232 & 244 & 188 & 202 & 154 & 154 & 216 & 220 & 136 & 5 & 5 \\
\hline 182 & TIE10 & 105 & 105 & 173 & 182 & 195 & 195 & 208 & 208 & 158 & 158 & 157 & 157 & 252 & 252 & 232 & 242 & 177 & 202 & 154 & 170 & 216 & 220 & 137 & 5 & 7 \\
\hline 183 & TIE11 & 105 & 105 & 182 & 182 & 195 & 195 & 208 & 208 & 158 & 158 & 157 & 179 & 252 & 252 & 232 & 242 & 177 & 177 & 170 & 170 & 216 & 220 & 132 & 3 & 7 \\
\hline 184 & TIE12 & 105 & 105 & 182 & 182 & 195 & 195 & 208 & 214 & 158 & 158 & 179 & 179 & 252 & 252 & 232 & 242 & 177 & 177 & 154 & 154 & 216 & 220 & 138 & 3 & 5 \\
\hline 185 & TIE13 & 105 & 105 & 182 & 182 & 195 & 195 & 214 & 216 & 154 & 158 & 157 & 179 & 252 & 252 & 232 & 232 & 188 & 202 & 170 & 170 & 216 & 220 & 139 & 5 & 5 \\
\hline 186 & TIE14 & 105 & 105 & 173 & 182 & 195 & 195 & 208 & 208 & 158 & 158 & 157 & 179 & 252 & 252 & 232 & 242 & 177 & 177 & 154 & 170 & 216 & 216 & 140 & 4 & 6 \\
\hline 187 & TIE15 & 105 & 105 & 173 & 182 & 195 & 195 & 214 & 214 & 158 & 158 & 157 & 157 & 252 & 252 & 232 & 242 & 177 & 202 & 170 & 170 & 216 & 220 & 141 & 4 & 5 \\
\hline 188 & TIE16 & 105 & 105 & 173 & 182 & 195 & 195 & 208 & 214 & 158 & 158 & 157 & 157 & 252 & 252 & 232 & 242 & 177 & 202 & 154 & 170 & 216 & 216 & 142 & 5 & 6 \\
\hline 189 & TIE17 & 105 & 105 & 182 & 182 & 195 & 195 & 214 & 214 & 158 & 158 & 157 & 179 & 252 & 252 & 232 & 242 & 177 & 177 & 170 & 170 & 216 & 220 & 143 & 3 & 5 \\
\hline 190 & TIE18 & 105 & 105 & 173 & 182 & 195 & 195 & 216 & 220 & 145 & 154 & 179 & 185 & 252 & 252 & 242 & 244 & 191 & 191 & 154 & 154 & 218 & 220 & 144 & 6 & 3 \\
\hline 191 & TIE19 & 105 & 105 & 173 & 182 & 195 & 195 & 208 & 208 & 158 & 158 & 157 & 179 & 252 & 252 & 232 & 242 & 177 & 177 & 154 & 170 & 216 & 216 & 140 & 4 & 6 \\
\hline 192 & TIE20 & 105 & 105 & 173 & 182 & 195 & 195 & 218 & 218 & 154 & 158 & 171 & 177 & 252 & 252 & 242 & 242 & 188 & 191 & 154 & 154 & 216 & 220 & 145 & 5 & 3 \\
\hline 193 & TIE21 & 105 & 105 & 173 & 182 & 195 & 195 & 218 & 218 & 156 & 156 & 157 & 171 & 252 & 252 & 242 & 242 & 191 & 191 & 170 & 170 & 218 & 220 & 146 & 3 & 4 \\
\hline 194 & TIE22 & 105 & 105 & 173 & 182 & 195 & 195 & 218 & 218 & 158 & 158 & 157 & 179 & 252 & 252 & 242 & 242 & 191 & 191 & 154 & 170 & 220 & 220 & 147 & 3 & 4 \\
\hline 195 & TIE23 & 105 & 105 & 173 & 182 & 195 & 195 & 220 & 220 & 145 & 145 & 157 & 157 & 252 & 252 & 232 & 244 & 177 & 191 & 154 & 154 & 216 & 216 & 148 & 3 & 5 \\
\hline 196 & TIE24 & 105 & 105 & 173 & 182 & 195 & 195 & 218 & 218 & 156 & 156 & 179 & 185 & 252 & 252 & 232 & 232 & 191 & 202 & 154 & 170 & 218 & 220 & 149 & 5 & 3 \\
\hline 197 & TIE25 & 105 & 105 & 173 & 182 & 195 & 195 & 216 & 218 & 154 & 156 & 157 & 171 & 252 & 252 & 232 & 242 & 191 & 191 & 154 & 170 & 218 & 220 & 150 & 7 & 4 \\
\hline 198 & TIE26 & 105 & 105 & 173 & 182 & 195 & 195 & 218 & 218 & 156 & 156 & 157 & 179 & 252 & 252 & 232 & 232 & 191 & 191 & 154 & 170 & 216 & 220 & 151 & 4 & 4 \\
\hline 199 & TIE27 & 105 & 105 & 173 & 173 & 195 & 195 & 216 & 218 & 145 & 154 & 157 & 157 & 252 & 252 & 232 & 232 & 191 & 191 & 154 & 170 & 218 & 220 & 152 & 4 & 4 \\
\hline 200 & TIE28 & 105 & 105 & 173 & 173 & 195 & 195 & 216 & 218 & 156 & 156 & 157 & 157 & 252 & 252 & 232 & 242 & 191 & 191 & 154 & 170 & 220 & 220 & 153 & 3 & 4 \\
\hline 201 & TIE29 & 105 & 105 & 173 & 182 & 195 & 195 & 218 & 218 & 145 & 156 & 157 & 179 & 252 & 252 & 232 & 244 & 191 & 191 & 154 & 154 & 218 & 218 & 154 & 4 & 4 \\
\hline 202 & TIE30 & 105 & 105 & 173 & 182 & 195 & 195 & 216 & 218 & 156 & 156 & 157 & 157 & 252 & 252 & 232 & 242 & 191 & 191 & 154 & 170 & 220 & 220 & 155 & 4 & \\
\hline
\end{tabular}




\begin{tabular}{|c|c|c|c|c|c|c|c|c|c|c|c|c|c|c|c|c|c|c|c|c|c|c|c|c|c|c|}
\hline 204 & TIE32 & 105 & 105 & 173 & 182 & 195 & 195 & 218 & 218 & 145 & 156 & 157 & 179 & 252 & 252 & 232 & 232 & 191 & 191 & 154 & 154 & 218 & 220 & 157 & 4 & 4 \\
\hline 205 & TIE33 & 105 & 105 & 182 & 182 & 195 & 195 & 216 & 218 & 154 & 156 & 157 & 157 & 252 & 252 & 242 & 244 & 191 & 191 & 154 & 170 & 220 & 220 & 158 & 4 & 6 \\
\hline 206 & TIE34 & 105 & 105 & 173 & 173 & 195 & 195 & 216 & 218 & 154 & 156 & 157 & 179 & 252 & 252 & 232 & 232 & 191 & 191 & 170 & 170 & 218 & 220 & 159 & 4 & 3 \\
\hline 207 & TIE35 & 105 & 105 & 182 & 182 & 195 & 195 & 218 & 220 & 145 & 156 & 157 & 179 & 252 & 252 & 242 & 244 & 191 & 191 & 154 & 170 & 216 & 220 & 160 & 6 & 5 \\
\hline 208 & TIE36 & 105 & 105 & 173 & 182 & 195 & 195 & 218 & 218 & 156 & 156 & 157 & 157 & 252 & 252 & 232 & 242 & 191 & 191 & 154 & 170 & 218 & 220 & 161 & 4 & 5 \\
\hline 209 & TIE37 & 105 & 105 & 173 & 182 & 195 & 195 & 218 & 218 & 156 & 156 & 171 & 171 & 252 & 252 & 232 & 242 & 191 & 191 & 154 & 170 & 218 & 220 & 162 & 4 & 3 \\
\hline 210 & TIE38 & 105 & 105 & 173 & 173 & 195 & 195 & 218 & 218 & 145 & 156 & 157 & 179 & 252 & 252 & 232 & 242 & 191 & 191 & 154 & 154 & 218 & 220 & 163 & 4 & 3 \\
\hline 211 & TIE39 & 105 & 105 & 173 & 182 & 195 & 195 & 208 & 218 & 158 & 158 & 157 & 185 & 252 & 252 & 220 & 242 & 188 & 191 & 154 & 170 & 216 & 218 & 164 & 7 & 5 \\
\hline 212 & TIE40 & 105 & 105 & 173 & 182 & 195 & 195 & 216 & 218 & 154 & 156 & 171 & 185 & 252 & 252 & 232 & 242 & 191 & 191 & 154 & 154 & 216 & 218 & 165 & 6 & 3 \\
\hline 213 & TIE41 & 105 & 105 & 173 & 173 & 195 & 195 & 216 & 218 & 154 & 156 & 157 & 171 & 252 & 252 & 242 & 242 & 191 & 191 & 154 & 170 & 220 & 220 & 166 & 4 & 3 \\
\hline 214 & TIE42 & 105 & 105 & 173 & 182 & 195 & 195 & 216 & 216 & 154 & 154 & 157 & 171 & 252 & 252 & 242 & 244 & 191 & 191 & 154 & 154 & 220 & 220 & 167 & 3 & 4 \\
\hline 215 & IRU01 & 105 & 105 & 167 & 182 & 195 & 195 & 200 & 200 & 154 & 156 & 169 & 175 & 252 & 252 & 232 & 242 & 191 & 202 & 154 & 154 & 218 & 220 & 168 & 6 & 3 \\
\hline 216 & IRU02 & 105 & 105 & 182 & 182 & 195 & 195 & 216 & 220 & 156 & 158 & 171 & 175 & 252 & 252 & 232 & 242 & 191 & 191 & 154 & 170 & 220 & 220 & 169 & 5 & 4 \\
\hline 217 & IRU03 & 105 & 105 & 182 & 182 & 195 & 195 & 216 & 216 & 154 & 158 & 157 & 197 & 252 & 252 & 220 & 242 & 191 & 194 & 154 & 181 & 218 & 220 & 170 & 6 & 5 \\
\hline 218 & IRU04 & 105 & 105 & 182 & 182 & 195 & 195 & 216 & 216 & 154 & 158 & 175 & 185 & 252 & 252 & 220 & 242 & 188 & 191 & 154 & 154 & 220 & 220 & 171 & 4 & 4 \\
\hline 219 & IRU05 & 105 & 105 & 167 & 182 & 195 & 195 & 216 & 216 & 158 & 158 & 175 & 185 & 252 & 252 & 242 & 242 & 188 & 194 & 154 & 170 & 218 & 233 & 172 & & 3 \\
\hline 220 & IRU06 & 105 & 105 & 182 & 182 & 195 & 201 & 216 & 216 & 158 & 158 & 175 & 185 & 252 & 252 & 232 & 242 & 188 & 191 & 154 & 170 & 220 & 220 & 173 & & 4 \\
\hline 221 & IRU07 & 105 & 105 & 182 & 182 & 195 & 195 & 216 & 216 & 158 & 158 & 169 & 185 & 252 & 252 & 242 & 242 & 188 & 191 & 154 & 154 & 220 & 220 & 174 & 2 & 4 \\
\hline 222 & IRU08 & 105 & 105 & 182 & 182 & 195 & 195 & 216 & 216 & 154 & 158 & 175 & 185 & 252 & 252 & 242 & 242 & 191 & 202 & 154 & 154 & 218 & 220 & 175 & 4 & 4 \\
\hline 223 & IRU09 & 105 & 105 & 182 & 182 & 195 & 201 & 200 & 216 & 154 & 156 & 169 & 175 & 252 & 252 & 220 & 242 & 191 & 191 & 154 & 181 & 218 & 220 & 176 & 7 & 4 \\
\hline 224 & IRU10 & 105 & 105 & 167 & 182 & 195 & 195 & 200 & 216 & 156 & 158 & 175 & 175 & 252 & 252 & 242 & 242 & 191 & 191 & 154 & 154 & 216 & 233 & 177 & 4 & 3 \\
\hline 225 & IRU11 & 105 & 105 & 182 & 182 & 195 & 195 & 216 & 216 & 154 & 156 & 175 & 175 & 252 & 252 & 242 & 242 & 191 & 202 & 154 & 154 & 218 & 220 & 178 & 3 & 4 \\
\hline 226 & IRU12 & 105 & 105 & 182 & 182 & 195 & 195 & 216 & 216 & 158 & 158 & 175 & 199 & 252 & 252 & 232 & 242 & 188 & 191 & 154 & 154 & 218 & 220 & 179 & 4 & 4 \\
\hline 227 & IRU13 & 105 & 105 & 182 & 182 & 195 & 195 & 216 & 216 & 154 & 158 & 175 & 197 & 252 & 254 & 242 & 244 & 188 & 191 & 154 & 170 & 218 & 220 & 180 & 7 & 4 \\
\hline 228 & IRU14 & 105 & 105 & 182 & 182 & 195 & 201 & 216 & 216 & 158 & 158 & 169 & 175 & 252 & 252 & 232 & 242 & 191 & 191 & 154 & 154 & 220 & 220 & 181 & 3 & 4 \\
\hline 229 & IRU15 & 105 & 114 & 167 & 182 & 192 & 195 & 212 & 216 & 151 & 154 & 152 & 185 & 252 & 252 & 235 & 242 & 177 & 188 & 151 & 170 & 218 & 218 & 182 & 9 & 7 \\
\hline 230 & IRU16 & 105 & 105 & 182 & 182 & 195 & 195 & 216 & 216 & 154 & 156 & 175 & 185 & 252 & 252 & 232 & 242 & 188 & 191 & 154 & 181 & 218 & 218 & 183 & 5 & 4 \\
\hline 231 & IRU17 & 105 & 105 & 182 & 182 & 195 & 195 & 200 & 216 & 156 & 158 & 169 & 169 & 252 & 252 & 220 & 242 & 191 & 202 & 154 & 154 & 220 & 220 & 184 & 4 & 4 \\
\hline 232 & IRU18 & 105 & 105 & 182 & 182 & 195 & 195 & 200 & 216 & 156 & 158 & 175 & 197 & 252 & 252 & 242 & 244 & 188 & 202 & 154 & 170 & 218 & 220 & 185 & 7 & 4 \\
\hline 233 & IRU19 & 105 & 105 & 182 & 182 & 195 & 195 & 200 & 216 & 156 & 158 & 185 & 201 & 252 & 252 & 232 & 242 & 188 & 202 & 154 & 154 & 220 & 220 & 186 & 5 & 4 \\
\hline 234 & IRU20 & 105 & 105 & 182 & 182 & 195 & 195 & 216 & 216 & 156 & 158 & 175 & 185 & 252 & 252 & 242 & 244 & 188 & 191 & 154 & 154 & 218 & 233 & 187 & 5 & 4 \\
\hline 235 & IRU21 & 105 & 105 & 167 & 182 & 195 & 195 & 200 & 200 & 154 & 158 & 169 & 189 & 252 & 252 & 242 & 244 & 188 & 188 & 154 & 154 & 220 & 233 & 188 & 5 & 3 \\
\hline 236 & IRU22 & 105 & 105 & 182 & 182 & 195 & 201 & 216 & 216 & 154 & 156 & 185 & 197 & 252 & 252 & 220 & 242 & 191 & 194 & 154 & 181 & 218 & 220 & 189 & 7 & 4 \\
\hline 237 & IRU23 & 105 & 105 & 167 & 182 & 195 & 195 & 216 & 216 & 154 & 158 & 157 & 185 & 252 & 252 & 232 & 242 & 188 & 188 & 154 & 154 & 218 & 233 & 190 & 5 & 4 \\
\hline 238 & IRU24 & 105 & 105 & 182 & 182 & 195 & 201 & 216 & 216 & 154 & 158 & 169 & 175 & 252 & 252 & 220 & 242 & 191 & 202 & 154 & 170 & 218 & 220 & 191 & 7 & 4 \\
\hline 239 & IRU25 & 105 & 105 & 182 & 182 & 195 & 195 & 216 & 216 & 154 & 158 & 197 & 197 & 252 & 252 & 220 & 232 & 191 & 202 & 154 & 170 & 218 & 220 & 192 & 5 & 4 \\
\hline 240 & IRU26 & 105 & 105 & 182 & 182 & 195 & 195 & 216 & 216 & 158 & 158 & 185 & 197 & 252 & 252 & 232 & 244 & 188 & 202 & 154 & 154 & 218 & 220 & 193 & 4 & 4 \\
\hline 241 & IRU27 & 105 & 105 & 182 & 182 & 195 & 195 & 216 & 216 & 154 & 158 & 185 & 197 & 252 & 252 & 232 & 242 & 188 & 188 & 154 & 154 & 220 & 220 & 194 & 3 & 4 \\
\hline 242 & IRU28 & 105 & 105 & 167 & 182 & 195 & 195 & 210 & 210 & 154 & 156 & 157 & 189 & 252 & 252 & 232 & 242 & 191 & 202 & 154 & 154 & 220 & 233 & 195 & 6 & 4 \\
\hline 243 & IRU29 & 105 & 105 & 167 & 182 & 195 & 195 & 210 & 210 & 154 & 156 & 175 & 197 & 252 & 252 & 232 & 242 & 188 & 191 & 154 & 154 & 218 & 233 & 196 & 6 & 3 \\
\hline 244 & IRU30 & 105 & 105 & 182 & 182 & 195 & 195 & 216 & 216 & 154 & 158 & 175 & 197 & 252 & 252 & 220 & 242 & 188 & 191 & 154 & 154 & 220 & 220 & 197 & 4 & 4 \\
\hline 245 & IRU31 & 105 & 105 & 182 & 182 & 195 & 195 & 216 & 216 & 154 & 156 & 157 & 197 & 252 & 252 & 232 & 232 & 191 & 202 & 154 & 154 & 216 & 218 & 198 & 4 & \\
\hline
\end{tabular}




\begin{tabular}{|c|c|c|c|c|c|c|c|c|c|c|c|c|c|c|c|c|c|c|c|c|c|c|c|c|c|c|}
\hline 247 & IRU33 & 105 & 105 & 167 & 182 & 195 & 195 & 216 & 216 & 156 & 158 & 169 & 197 & 252 & 252 & 242 & 242 & 188 & 202 & 154 & 154 & 218 & 220 & 200 & 5 & 3 \\
\hline 248 & IRU34 & 105 & 105 & 182 & 182 & 195 & 195 & 210 & 210 & 156 & 156 & 169 & 197 & 252 & 252 & 242 & 242 & 188 & 202 & 154 & 154 & 218 & 218 & 201 & & 4 \\
\hline 249 & IRU35 & 105 & 105 & 182 & 182 & 195 & 195 & 216 & 216 & 156 & 158 & 197 & 201 & 252 & 252 & 232 & 244 & 188 & 202 & 154 & 181 & 218 & 233 & 202 & 6 & 4 \\
\hline 250 & IRU36 & 105 & 105 & 182 & 182 & 195 & 195 & 216 & 216 & 156 & 158 & 197 & 197 & 252 & 252 & 232 & 232 & 188 & 202 & 154 & 154 & 218 & 233 & 203 & 3 & 4 \\
\hline 251 & IRU37 & 105 & 105 & 182 & 182 & 195 & 195 & 216 & 216 & 154 & 158 & 185 & 197 & 252 & 252 & 232 & 242 & 188 & 202 & 154 & 154 & 218 & 220 & 204 & 5 & 4 \\
\hline 252 & IRU38 & 105 & 105 & 182 & 182 & 195 & 195 & 216 & 216 & 154 & 156 & 175 & 197 & 252 & 252 & 220 & 242 & 188 & 194 & 154 & 154 & 218 & 218 & 205 & 4 & 4 \\
\hline 253 & IRU39 & 105 & 105 & 167 & 182 & 192 & 195 & 208 & 220 & 151 & 158 & 175 & 175 & 252 & 256 & 220 & 232 & 186 & 191 & 170 & 174 & 220 & 224 & 206 & 9 & 8 \\
\hline 254 & IRU40 & 105 & 105 & 167 & 182 & 195 & 195 & 210 & 210 & 154 & 156 & 175 & 197 & 252 & 252 & 232 & 242 & 188 & 202 & 154 & 154 & 218 & 233 & 207 & 6 & 3 \\
\hline 255 & IRU41 & 105 & 105 & 182 & 182 & 195 & 195 & 220 & 220 & 156 & 158 & 175 & 189 & 252 & 252 & 232 & 232 & 191 & 191 & 170 & 170 & 220 & 233 & 208 & 3 & 4 \\
\hline 256 & IRU42 & 105 & 105 & 182 & 182 & 195 & 195 & 216 & 220 & 156 & 158 & 157 & 175 & 252 & 252 & 220 & 232 & 191 & 191 & 170 & 170 & 220 & 233 & 209 & 5 & 5 \\
\hline 257 & IRU43 & 105 & 105 & 182 & 182 & 195 & 195 & 216 & 216 & 158 & 158 & 175 & 197 & 252 & 252 & 232 & 242 & 188 & 191 & 154 & 154 & 233 & 233 & 210 & 3 & 4 \\
\hline 258 & IRU44 & 105 & 105 & 182 & 182 & 195 & 195 & 216 & 216 & 158 & 166 & 185 & 197 & 252 & 252 & 220 & 242 & 188 & 191 & 154 & 154 & 216 & 220 & 211 & 5 & 4 \\
\hline 259 & IRU45 & 105 & 105 & 182 & 182 & 195 & 195 & 216 & 216 & 158 & 166 & 175 & 197 & 252 & 252 & 232 & 242 & 188 & 191 & 154 & 154 & 220 & 233 & 212 & 5 & 4 \\
\hline 260 & IRU46 & 105 & 105 & 182 & 182 & 195 & 195 & 216 & 216 & 158 & 158 & 171 & 197 & 252 & 252 & 232 & 242 & 191 & 202 & 154 & 170 & 220 & 220 & 213 & 4 & 4 \\
\hline 261 & IRU47 & 105 & 105 & 182 & 182 & 195 & 195 & 216 & 216 & 158 & 158 & 175 & 197 & 252 & 254 & 232 & 242 & 188 & 191 & 154 & 170 & 216 & 220 & 214 & & 4 \\
\hline 262 & IRU48 & 105 & 105 & 173 & 182 & 195 & 195 & 216 & 216 & 154 & 166 & 175 & 185 & 252 & 254 & 232 & 242 & 191 & 191 & 154 & 154 & 216 & 233 & 215 & & 3 \\
\hline 263 & IRU49 & 105 & 105 & 182 & 182 & 195 & 195 & 216 & 216 & 158 & 158 & 185 & 185 & 252 & 254 & 232 & 242 & 188 & 191 & 154 & 154 & 216 & 220 & 216 & & 4 \\
\hline 264 & IRU50 & 105 & 105 & 182 & 182 & 195 & 195 & 216 & 216 & 158 & 166 & 169 & 175 & 254 & 254 & 220 & 232 & 188 & 191 & 154 & 154 & 216 & 216 & 217 & & 4 \\
\hline 265 & IRU51 & 105 & 105 & 182 & 182 & 195 & 195 & 216 & 216 & 156 & 158 & 175 & 185 & 252 & 254 & 232 & 242 & 191 & 191 & 154 & 170 & 216 & 220 & 218 & & 4 \\
\hline 266 & IRU52 & 105 & 105 & 173 & 182 & 195 & 195 & 216 & 216 & 158 & 166 & 175 & 185 & 252 & 252 & 232 & 242 & 191 & 191 & 154 & 154 & 216 & 233 & 219 & 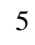 & 3 \\
\hline 267 & IRU53 & 105 & 105 & 173 & 182 & 195 & 195 & 216 & 216 & 158 & 166 & 175 & 175 & 252 & 254 & 242 & 242 & 191 & 191 & 154 & 170 & 216 & 220 & 220 & 5 & 3 \\
\hline 268 & IRU54 & 105 & 105 & 173 & 182 & 195 & 195 & 216 & 216 & 158 & 166 & 175 & 175 & 252 & 254 & 242 & 242 & 191 & 191 & 154 & 170 & 216 & 220 & 220 & 5 & 3 \\
\hline 269 & IRU55 & 105 & 105 & 179 & 182 & 195 & 195 & 216 & 216 & 158 & 158 & 175 & 175 & 252 & 254 & 242 & 242 & 188 & 191 & 154 & 154 & 216 & 216 & 221 & 3 & 4 \\
\hline 270 & IRU56 & 105 & 105 & 182 & 182 & 195 & 195 & 216 & 216 & 156 & 158 & 171 & 175 & 252 & 252 & 232 & 242 & 191 & 202 & 154 & 170 & 216 & 216 & 222 & 5 & 4 \\
\hline 271 & IRU57 & 105 & 105 & 182 & 182 & 195 & 204 & 216 & 216 & 158 & 166 & 185 & 185 & 252 & 252 & 220 & 242 & 188 & 191 & 170 & 172 & 220 & 220 & 223 & 5 & 4 \\
\hline 272 & CAS01 & 105 & 105 & 182 & 185 & 195 & 195 & 208 & 216 & 154 & 158 & 195 & 197 & 252 & 252 & 242 & 244 & 188 & 188 & 154 & 154 & 220 & 220 & 224 & 5 & 4 \\
\hline 273 & CAS02 & 105 & 111 & 182 & 182 & 195 & 195 & 208 & 208 & 154 & 154 & 157 & 199 & 252 & 252 & 232 & 244 & 188 & 188 & 154 & 154 & 220 & 220 & 225 & 3 & 7 \\
\hline 274 & CAS03 & 105 & 111 & 182 & 182 & 195 & 195 & 208 & 208 & 154 & 154 & 197 & 199 & 252 & 252 & 232 & 242 & 188 & 188 & 154 & 154 & 220 & 220 & 226 & 3 & 6 \\
\hline 275 & CAS04 & 105 & 111 & 182 & 182 & 195 & 195 & 208 & 208 & 154 & 158 & 197 & 197 & 252 & 252 & 242 & 244 & 188 & 188 & 154 & 154 & 216 & 220 & 227 & 4 & 6 \\
\hline 276 & CAS05 & 105 & 111 & 182 & 185 & 195 & 195 & 208 & 216 & 154 & 158 & 157 & 195 & 252 & 252 & 232 & 244 & 188 & 188 & 154 & 154 & 220 & 220 & 228 & 6 & 5 \\
\hline 277 & CAS06 & 105 & 105 & 176 & 182 & 195 & 195 & 216 & 216 & 158 & 158 & 175 & 195 & 252 & 252 & 232 & 244 & 188 & 188 & 154 & 154 & 220 & 220 & 229 & 3 & 3 \\
\hline 278 & CAS07 & 105 & 105 & 182 & 182 & 195 & 195 & 216 & 216 & 156 & 158 & 157 & 189 & 252 & 252 & 232 & 244 & 188 & 188 & 154 & 154 & 216 & 220 & 230 & 4 & 5 \\
\hline 279 & CAS08 & 105 & 111 & 182 & 182 & 195 & 195 & 208 & 218 & 154 & 158 & 195 & 197 & 252 & 252 & 242 & 244 & 188 & 188 & 154 & 170 & 220 & 220 & 231 & 6 & 5 \\
\hline 280 & CAS09 & 111 & 111 & 182 & 182 & 195 & 195 & 216 & 216 & 156 & 156 & 189 & 197 & 252 & 252 & 242 & 244 & 188 & 188 & 154 & 170 & 216 & 220 & 232 & 4 & 4 \\
\hline 281 & CAS10 & 105 & 111 & 182 & 182 & 195 & 195 & 208 & 216 & 154 & 156 & 185 & 197 & 252 & 252 & 242 & 244 & 188 & 188 & 170 & 170 & 220 & 220 & 233 & 5 & 5 \\
\hline 282 & CAS11 & 105 & 105 & 182 & 182 & 195 & 195 & 208 & 216 & 154 & 156 & 169 & 199 & 252 & 252 & 242 & 242 & 188 & 188 & 154 & 170 & 216 & 220 & 234 & 5 & 5 \\
\hline 283 & CAS12 & 105 & 111 & 182 & 182 & 195 & 195 & 208 & 218 & 158 & 158 & 157 & 187 & 252 & 252 & 232 & 242 & 188 & 202 & 170 & 170 & 220 & 220 & 235 & 5 & 6 \\
\hline 284 & CAS13 & 105 & 111 & 182 & 182 & 195 & 195 & 208 & 208 & 154 & 156 & 157 & 197 & 252 & 252 & 232 & 244 & 188 & 191 & 154 & 154 & 220 & 220 & 236 & 5 & 7 \\
\hline 285 & CAS14 & 105 & 105 & 182 & 182 & 195 & 195 & 208 & 220 & 154 & 158 & 175 & 195 & 252 & 252 & 244 & 244 & 188 & 188 & 154 & 154 & 216 & 220 & 237 & 4 & 5 \\
\hline 286 & CAS15 & 105 & 105 & 182 & 182 & 195 & 195 & 216 & 218 & 158 & 158 & 195 & 197 & 252 & 252 & 232 & 242 & 188 & 188 & 154 & 154 & 216 & 220 & 238 & 4 & 4 \\
\hline 287 & CAS16 & 105 & 111 & 182 & 182 & 195 & 195 & 208 & 216 & 154 & 158 & 195 & 197 & 252 & 252 & 220 & 244 & 188 & 202 & 154 & 154 & 220 & 220 & 239 & 6 & 5 \\
\hline 288 & CAS17 & 105 & 105 & 182 & 182 & 195 & 195 & 208 & 208 & 154 & 158 & 157 & 197 & 252 & 252 & 244 & 244 & 188 & 188 & 154 & 154 & 220 & 220 & 240 & 2 & \\
\hline
\end{tabular}




\begin{tabular}{|c|c|c|c|c|c|c|c|c|c|c|c|c|c|c|c|c|c|c|c|c|c|c|c|c|c|c|}
\hline 290 & CAS19 & 105 & 105 & 182 & 185 & 195 & 195 & 208 & 208 & 154 & 158 & 185 & 199 & 252 & 252 & 232 & 244 & 188 & 188 & 154 & 170 & 220 & 220 & 242 & 5 & 5 \\
\hline 291 & CAS20 & 105 & 105 & 182 & 182 & 195 & 195 & 208 & 208 & 154 & 156 & 189 & 189 & 252 & 252 & 220 & 244 & 191 & 191 & 154 & 154 & 220 & 220 & 243 & 2 & 6 \\
\hline 292 & CAS21 & 105 & 111 & 182 & 182 & 195 & 195 & 208 & 216 & 154 & 156 & 175 & 189 & 252 & 252 & 232 & 244 & 188 & 191 & 154 & 154 & 220 & 220 & 244 & 6 & 5 \\
\hline 293 & PIE01 & 105 & 105 & 167 & 182 & 195 & 195 & 216 & 216 & 154 & 154 & 157 & 185 & 252 & 252 & 242 & 244 & 188 & 188 & 154 & 170 & 218 & 218 & 245 & 4 & 4 \\
\hline 294 & PIE02 & 105 & 105 & 182 & 182 & 195 & 201 & 216 & 216 & 147 & 158 & 159 & 185 & 252 & 252 & 232 & 242 & 188 & 188 & 154 & 154 & 216 & 233 & 246 & 5 & 4 \\
\hline 295 & PIE03 & 105 & 105 & 167 & 182 & 195 & 201 & 216 & 218 & 154 & 158 & 171 & 189 & 252 & 252 & 232 & 232 & 188 & 188 & 154 & 154 & 216 & 220 & 247 & 6 & 3 \\
\hline 296 & PIE04 & 105 & 105 & 182 & 182 & 195 & 201 & 216 & 216 & 147 & 158 & 159 & 185 & 252 & 252 & 232 & 242 & 188 & 188 & 154 & 154 & 216 & 233 & 246 & 5 & 4 \\
\hline 297 & PIE05 & 105 & 105 & 167 & 182 & 195 & 201 & 216 & 218 & 154 & 158 & 171 & 189 & 252 & 252 & 232 & 232 & 188 & 188 & 154 & 154 & 216 & 220 & 247 & 6 & 3 \\
\hline 298 & PIE06 & 105 & 105 & 182 & 182 & 195 & 204 & 210 & 216 & 147 & 158 & 169 & 189 & 252 & 252 & 232 & 232 & 188 & 188 & 154 & 154 & 216 & 216 & 248 & 4 & 4 \\
\hline 299 & PIE07 & 105 & 105 & 167 & 182 & 201 & 204 & 216 & 216 & 154 & 154 & 157 & 189 & 252 & 252 & 232 & 244 & 188 & 188 & 154 & 154 & 216 & 216 & 249 & 4 & 4 \\
\hline 300 & CVJ01 & 105 & 105 & 182 & 182 & 195 & 195 & 216 & 220 & 158 & 158 & 185 & 187 & 252 & 252 & 244 & 244 & 188 & 188 & 154 & 158 & 216 & 220 & 250 & 4 & 4 \\
\hline 301 & CVJ02 & 105 & 105 & 182 & 182 & 195 & 195 & 216 & 220 & 158 & 158 & 185 & 187 & 252 & 252 & 244 & 244 & 188 & 188 & 154 & 158 & 216 & 220 & 250 & 4 & 4 \\
\hline 302 & CVJ03 & 105 & 105 & 182 & 182 & 195 & 195 & 216 & 220 & 158 & 158 & 157 & 171 & 252 & 252 & 244 & 244 & 188 & 202 & 154 & 154 & 216 & 220 & 251 & 4 & 5 \\
\hline 303 & CVJ04 & 105 & 105 & 182 & 182 & 195 & 195 & 216 & 220 & 158 & 158 & 157 & 187 & 252 & 252 & 232 & 244 & 188 & 202 & 154 & 154 & 216 & 220 & 252 & 5 & 5 \\
\hline 304 & CVJ05 & 105 & 105 & 182 & 182 & 195 & 195 & 216 & 216 & 158 & 164 & 185 & 187 & 252 & 252 & 232 & 242 & 188 & 202 & 170 & 170 & 216 & 220 & 253 & 5 & 4 \\
\hline 305 & CVJ06 & 105 & 105 & 200 & 200 & 195 & 195 & 216 & 216 & 158 & 158 & 157 & 185 & 252 & 252 & 244 & 244 & 188 & 188 & 154 & 154 & 216 & 220 & 254 & 2 & 3 \\
\hline 306 & CVJ07 & 102 & 105 & 182 & 185 & 192 & 195 & 208 & 216 & 145 & 151 & 152 & 159 & 252 & 252 & 232 & 233 & 186 & 188 & 151 & 156 & 218 & 222 & 255 & 10 & 10 \\
\hline 307 & CVJ08 & 102 & 105 & 182 & 185 & 192 & 195 & 208 & 216 & 145 & 151 & 152 & 159 & 252 & 252 & 232 & 233 & 186 & 188 & 151 & 156 & 218 & 222 & 255 & 10 & 10 \\
\hline 308 & CVJ09 & 105 & 105 & 182 & 200 & 195 & 195 & 216 & 220 & 158 & 158 & 157 & 171 & 252 & 252 & 232 & 244 & 188 & 202 & 154 & 154 & 220 & 220 & 256 & 5 & 4 \\
\hline 309 & CVJ10 & 105 & 105 & 182 & 182 & 195 & 195 & 216 & 216 & 154 & 158 & 157 & 171 & 252 & 252 & 244 & 244 & 188 & 188 & 154 & 158 & 216 & 220 & 257 & 4 & 5 \\
\hline 310 & CVJ11 & 105 & 105 & 182 & 182 & 195 & 195 & 216 & 220 & 158 & 158 & 171 & 185 & 252 & 252 & 232 & 244 & 188 & 188 & 154 & 154 & 220 & 220 & 258 & 3 & 4 \\
\hline 311 & CVJ12 & 105 & 105 & 182 & 182 & 195 & 195 & 200 & 216 & 154 & 156 & 185 & 187 & 252 & 252 & 232 & 244 & 188 & 188 & 154 & 158 & 216 & 220 & 259 & 6 & 4 \\
\hline 312 & CVJ13 & 105 & 105 & 182 & 182 & 195 & 195 & 216 & 220 & 158 & 164 & 157 & 171 & 252 & 252 & 242 & 244 & 188 & 202 & 154 & 170 & 216 & 220 & 260 & 7 & 5 \\
\hline 313 & CVJ14 & 105 & 105 & 182 & 200 & 195 & 195 & 216 & 220 & 158 & 158 & 157 & 171 & 252 & 252 & 244 & 244 & 188 & 191 & 154 & 154 & 216 & 216 & 261 & 4 & 4 \\
\hline 314 & CVJ15 & 105 & 105 & 182 & 182 & 195 & 195 & 200 & 220 & 156 & 158 & 157 & 171 & 252 & 252 & 232 & 244 & 188 & 188 & 154 & 154 & 220 & 220 & 262 & 4 & 5 \\
\hline 315 & CVJ16 & 105 & 105 & 182 & 182 & 195 & 195 & 216 & 220 & 145 & 164 & 171 & 171 & 252 & 254 & 232 & 232 & 188 & 188 & 154 & 170 & 216 & 220 & 263 & 5 & 4 \\
\hline 316 & CVJ17 & 105 & 105 & 167 & 182 & 195 & 195 & 216 & 220 & 158 & 158 & 171 & 171 & 252 & 252 & 232 & 242 & 188 & 191 & 154 & 170 & 216 & 233 & 264 & 6 & 3 \\
\hline 317 & CVJ18 & 105 & 105 & 182 & 182 & 195 & 195 & 200 & 220 & 156 & 158 & 171 & 187 & 252 & 252 & 232 & 244 & 188 & 188 & 154 & 170 & 218 & 220 & 265 & 6 & 4 \\
\hline 318 & CVJ19 & 105 & 105 & 182 & 182 & 195 & 195 & 216 & 220 & 145 & 158 & 171 & 171 & 252 & 254 & 232 & 244 & 188 & 202 & 154 & 170 & 220 & 220 & 266 & 6 & 4 \\
\hline 319 & CVJ20 & 105 & 105 & 182 & 182 & 195 & 195 & 216 & 220 & 145 & 158 & 171 & 171 & 252 & 254 & 232 & 244 & 188 & 202 & 154 & 170 & 220 & 220 & 266 & 6 & 4 \\
\hline 320 & CVA01 & 105 & 105 & 182 & 182 & 195 & 195 & 216 & 220 & 145 & 156 & 175 & 185 & 252 & 252 & 232 & 242 & 191 & 191 & 154 & 154 & 220 & 220 & 267 & 4 & 4 \\
\hline 321 & CVA02 & 105 & 105 & 182 & 182 & 195 & 195 & 216 & 216 & 156 & 156 & 167 & 175 & 252 & 252 & 242 & 244 & 191 & 191 & 154 & 154 & 220 & 220 & 268 & 2 & 4 \\
\hline 322 & CVA03 & 105 & 105 & 167 & 182 & 195 & 195 & 216 & 224 & 156 & 158 & 169 & 185 & 252 & 252 & 232 & 232 & 188 & 191 & 154 & 170 & 220 & 220 & 269 & 6 & 3 \\
\hline 323 & CVA04 & 105 & 105 & 182 & 182 & 195 & 195 & 220 & 224 & 145 & 158 & 183 & 199 & 252 & 252 & 232 & 242 & 188 & 191 & 170 & 170 & 220 & 220 & 270 & 5 & 4 \\
\hline 324 & CVA05 & 105 & 105 & 182 & 182 & 195 & 195 & 220 & 220 & 145 & 145 & 183 & 199 & 252 & 254 & 232 & 242 & 191 & 191 & 170 & 170 & 220 & 220 & 271 & 3 & 4 \\
\hline 325 & CVA06 & 105 & 105 & 182 & 182 & 195 & 195 & 216 & 220 & 145 & 156 & 167 & 169 & 252 & 254 & 242 & 244 & 188 & 191 & 170 & 170 & 220 & 220 & 272 & 6 & 4 \\
\hline 326 & CVA07 & 105 & 105 & 167 & 182 & 195 & 195 & 220 & 224 & 145 & 158 & 183 & 199 & 252 & 252 & 232 & 242 & 188 & 191 & 154 & 170 & 218 & 220 & 273 & 8 & 3 \\
\hline 327 & CVA08 & 105 & 105 & 182 & 182 & 195 & 195 & 216 & 216 & 156 & 156 & 167 & 175 & 252 & 252 & 232 & 244 & 188 & 188 & 154 & 170 & 216 & 220 & 274 & 4 & 4 \\
\hline 328 & CVA09 & 105 & 105 & 182 & 182 & 195 & 195 & 220 & 224 & 145 & 158 & 199 & 201 & 252 & 252 & 242 & 242 & 188 & 191 & 154 & 154 & 220 & 220 & 275 & 4 & 4 \\
\hline 329 & CVA10 & 105 & 105 & 182 & 182 & 195 & 195 & 220 & 224 & 145 & 158 & 199 & 201 & 252 & 252 & 242 & 242 & 188 & 191 & 154 & 154 & 220 & 220 & 275 & 4 & 4 \\
\hline 330 & CVA11 & 105 & 105 & 182 & 182 & 195 & 195 & 216 & 216 & 156 & 156 & 167 & 175 & 252 & 252 & 232 & 244 & 188 & 191 & 154 & 154 & 220 & 220 & 276 & 3 & 4 \\
\hline 331 & MOM01 & 105 & 114 & 182 & 182 & 192 & 195 & 210 & 212 & 147 & 151 & 163 & 199 & 252 & 252 & 232 & 235 & 177 & 191 & 151 & 154 & 220 & 222 & 277 & 9 & 9 \\
\hline
\end{tabular}




\begin{tabular}{|c|c|c|c|c|c|c|c|c|c|c|c|c|c|c|c|c|c|c|c|c|c|c|c|c|c|c|}
\hline 333 & MOM03 & 105 & 114 & 182 & 182 & 192 & 195 & 210 & 212 & 147 & 151 & 163 & 199 & 252 & 252 & 232 & 235 & 177 & 191 & 151 & 154 & 220 & 222 & 277 & 9 & 9 \\
\hline 334 & MOM04 & 105 & 114 & 182 & 182 & 192 & 195 & 210 & 212 & 147 & 151 & 163 & 199 & 252 & 252 & 232 & 235 & 177 & 191 & 151 & 154 & 220 & 222 & 277 & 9 & 9 \\
\hline 335 & MOM05 & 105 & 114 & 182 & 182 & 192 & 195 & 210 & 212 & 147 & 151 & 163 & 199 & 252 & 252 & 232 & 235 & 177 & 191 & 151 & 154 & 220 & 222 & 277 & 9 & 9 \\
\hline 336 & MOM06 & 105 & 114 & 182 & 182 & 192 & 195 & 210 & 212 & 147 & 151 & 163 & 199 & 252 & 252 & 232 & 235 & 177 & 191 & 151 & 154 & 220 & 222 & 277 & 9 & 9 \\
\hline 337 & MOM07 & 105 & 105 & 182 & 182 & 195 & 195 & 210 & 218 & 145 & 158 & 199 & 205 & 252 & 252 & 232 & 242 & 191 & 191 & 154 & 170 & 220 & 220 & 278 & 5 & 4 \\
\hline 338 & MOM08 & 105 & 105 & 182 & 182 & 195 & 195 & 210 & 218 & 145 & 158 & 199 & 205 & 252 & 252 & 232 & 242 & 191 & 191 & 154 & 170 & 220 & 220 & 278 & 5 & 4 \\
\hline 339 & MOM09 & 105 & 105 & 182 & 182 & 195 & 195 & 210 & 218 & 145 & 158 & 199 & 205 & 252 & 252 & 232 & 242 & 191 & 191 & 154 & 170 & 220 & 220 & 278 & 5 & 4 \\
\hline 340 & MOM10 & 105 & 114 & 182 & 182 & 192 & 195 & 210 & 212 & 147 & 151 & 163 & 199 & 252 & 252 & 232 & 235 & 177 & 191 & 151 & 154 & 220 & 222 & 277 & 9 & 9 \\
\hline 341 & CAN01 & 105 & 105 & 182 & 182 & 195 & 195 & 214 & 214 & 154 & 154 & 165 & 165 & 252 & 252 & 236 & 242 & 188 & 191 & 154 & 156 & 220 & 220 & 279 & 3 & 4 \\
\hline 342 & CAN02 & 105 & 108 & 182 & 182 & 195 & 195 & 208 & 208 & 151 & 154 & 163 & 189 & 252 & 252 & 236 & 244 & 188 & 191 & 154 & 170 & 220 & 220 & 280 & 6 & 9 \\
\hline 343 & CAN03 & 105 & 105 & 182 & 182 & 195 & 195 & 216 & 216 & 154 & 158 & 157 & 185 & 252 & 254 & 236 & 242 & 188 & 188 & 154 & 156 & 220 & 220 & 281 & 5 & 5 \\
\hline 344 & CAN04 & 105 & 105 & 182 & 182 & 195 & 195 & 210 & 210 & 154 & 154 & 165 & 165 & 252 & 252 & 236 & 236 & 188 & 191 & 154 & 154 & 220 & 220 & 282 & 1 & 4 \\
\hline 345 & CAN05 & 105 & 105 & 182 & 182 & 195 & 195 & 208 & 214 & 154 & 158 & 183 & 189 & 252 & 252 & 232 & 236 & 188 & 188 & 154 & 156 & 220 & 220 & 283 & 5 & 5 \\
\hline 346 & CAN06 & 105 & 105 & 167 & 182 & 195 & 195 & 210 & 210 & 158 & 158 & 171 & 185 & 252 & 252 & 242 & 244 & 177 & 188 & 154 & 170 & 216 & 220 & 284 & 6 & 3 \\
\hline 347 & CAN07 & 105 & 105 & 182 & 182 & 195 & 195 & 218 & 218 & 158 & 158 & 169 & 185 & 252 & 252 & 232 & 244 & 177 & 188 & 154 & 172 & 216 & 236 & 285 & 5 & 4 \\
\hline 348 & CAN08 & 105 & 105 & 182 & 182 & 195 & 195 & 218 & 218 & 158 & 158 & 169 & 185 & 252 & 252 & 232 & 244 & 177 & 188 & 154 & 172 & 216 & 236 & 285 & 5 & 4 \\
\hline 349 & ALD01 & 105 & 105 & 182 & 182 & 195 & 195 & 208 & 208 & 158 & 166 & 169 & 171 & 252 & 252 & 232 & 232 & 188 & 202 & 154 & 170 & 216 & 233 & 286 & 5 & 6 \\
\hline 350 & ALD02 & 105 & 105 & 182 & 182 & 195 & 195 & 200 & 200 & 156 & 158 & 169 & 171 & 252 & 252 & 232 & 232 & 188 & 202 & 154 & 154 & 216 & 233 & 287 & 4 & 4 \\
\hline 351 & ALD03 & 105 & 105 & 182 & 182 & 195 & 195 & 208 & 208 & 158 & 166 & 175 & 185 & 252 & 252 & 232 & 244 & 188 & 202 & 154 & 170 & 216 & 233 & 288 & 6 & 6 \\
\hline 352 & ALD04 & 105 & 105 & 182 & 182 & 195 & 195 & 200 & 200 & 156 & 158 & 169 & 175 & 252 & 252 & 232 & 244 & 188 & 202 & 154 & 154 & 216 & 233 & 289 & 5 & 4 \\
\hline 353 & ALD05 & 105 & 105 & 182 & 182 & 195 & 195 & 208 & 208 & 158 & 166 & 175 & 185 & 252 & 252 & 242 & 244 & 188 & 202 & 154 & 170 & 216 & 233 & 290 & 6 & 6 \\
\hline 354 & ALD06 & 105 & 105 & 182 & 182 & 195 & 195 & 200 & 200 & 156 & 158 & 185 & 185 & 252 & 252 & 232 & 242 & 188 & 202 & 154 & 154 & 216 & 220 & 291 & 4 & 4 \\
\hline 355 & ALD07 & 105 & 105 & 182 & 182 & 195 & 195 & 200 & 200 & 156 & 158 & 171 & 175 & 252 & 252 & 242 & 244 & 188 & 202 & 154 & 154 & 216 & 233 & 292 & 5 & 4 \\
\hline 356 & ALD08 & 105 & 105 & 182 & 182 & 195 & 201 & 208 & 208 & 158 & 166 & 175 & 185 & 252 & 252 & 220 & 242 & 188 & 191 & 156 & 170 & 220 & 233 & 293 & 7 & 6 \\
\hline 357 & ALD09 & 105 & 105 & 182 & 182 & 195 & 195 & 200 & 208 & 156 & 166 & 175 & 175 & 252 & 252 & 232 & 242 & 188 & 202 & 154 & 170 & 216 & 216 & 294 & 5 & 5 \\
\hline 358 & ALD10 & 105 & 105 & 182 & 182 & 195 & 195 & 200 & 200 & 156 & 158 & 169 & 175 & 252 & 252 & 232 & 232 & 191 & 191 & 154 & 154 & 220 & 233 & 295 & 3 & 4 \\
\hline 359 & VIL01 & 105 & 105 & 167 & 182 & 195 & 195 & 210 & 210 & 147 & 154 & 157 & 157 & 252 & 252 & 232 & 244 & 188 & 188 & 154 & 154 & 216 & 216 & 296 & 3 & 5 \\
\hline 360 & VIL02 & 105 & 105 & 167 & 182 & 195 & 195 & 210 & 210 & 147 & 156 & 157 & 157 & 252 & 252 & 242 & 244 & 188 & 191 & 154 & 154 & 216 & 216 & 297 & 4 & 5 \\
\hline 361 & VIL03 & 105 & 105 & 179 & 182 & 195 & 195 & 208 & 212 & 156 & 158 & 157 & 179 & 252 & 252 & 232 & 236 & 188 & 202 & 154 & 158 & 216 & 216 & 298 & 7 & 6 \\
\hline 362 & VIL04 & 105 & 105 & 182 & 182 & 195 & 195 & 208 & 210 & 154 & 156 & 157 & 157 & 252 & 252 & 236 & 244 & 191 & 202 & 154 & 181 & 216 & 216 & 299 & 5 & 7 \\
\hline 363 & VIL05 & 105 & 105 & 182 & 182 & 195 & 195 & 210 & 210 & 147 & 154 & 157 & 157 & 252 & 252 & 232 & 236 & 191 & 202 & 154 & 154 & 216 & 216 & 300 & 3 & 6 \\
\hline 364 & VIL06 & 105 & 105 & 182 & 182 & 195 & 195 & 210 & 210 & 154 & 154 & 157 & 171 & 252 & 252 & 236 & 244 & 191 & 202 & 154 & 181 & 216 & 216 & 301 & 4 & 5 \\
\hline 365 & VIL07 & 105 & 105 & 182 & 182 & 195 & 195 & 210 & 210 & 147 & 154 & 157 & 157 & 252 & 252 & 232 & 236 & 191 & 202 & 154 & 154 & 216 & 216 & 300 & 3 & 6 \\
\hline 366 & VIL08 & 105 & 105 & 182 & 182 & 195 & 195 & 210 & 210 & 154 & 156 & 157 & 171 & 252 & 252 & 242 & 244 & 188 & 191 & 154 & 154 & 216 & 216 & 302 & 4 & 5 \\
\hline 367 & VIL09 & 105 & 105 & 182 & 182 & 195 & 195 & 208 & 210 & 154 & 156 & 157 & 171 & 252 & 252 & 236 & 244 & 202 & 202 & 154 & 181 & 216 & 216 & 303 & 5 & 6 \\
\hline 368 & VIL10 & 105 & 105 & 182 & 182 & 195 & 195 & 208 & 210 & 154 & 156 & 157 & 171 & 252 & 252 & 236 & 244 & 202 & 202 & 154 & 181 & 216 & 216 & 303 & 5 & 6 \\
\hline 369 & VIL11 & 105 & 105 & 182 & 182 & 195 & 195 & 210 & 210 & 154 & 154 & 157 & 195 & 252 & 252 & 232 & 236 & 191 & 202 & 154 & 181 & 216 & 216 & 304 & 4 & 5 \\
\hline 370 & VIL12 & 105 & 105 & 167 & 182 & 195 & 195 & 210 & 210 & 147 & 154 & 157 & 157 & 252 & 252 & 236 & 244 & 188 & 202 & 154 & 154 & 216 & 216 & 305 & 4 & 5 \\
\hline 371 & VIL13 & 105 & 105 & 182 & 182 & 195 & 195 & 208 & 210 & 154 & 156 & 157 & 171 & 252 & 252 & 244 & 244 & 188 & 202 & 154 & 154 & 216 & 216 & 306 & 4 & 6 \\
\hline 372 & VIL14 & 105 & 105 & 167 & 179 & 195 & 195 & 212 & 212 & 158 & 158 & 157 & 157 & 252 & 252 & 236 & 242 & 188 & 202 & 154 & 158 & 216 & 220 & 307 & 5 & 5 \\
\hline 373 & VIL15 & 105 & 105 & 167 & 179 & 195 & 195 & 212 & 212 & 158 & 158 & 157 & 157 & 252 & 252 & 236 & 242 & 188 & 202 & 154 & 158 & 216 & 220 & 307 & 5 & 5 \\
\hline 374 & & 105 & 105 & 182 & 182 & 195 & 195 & 220 & 220 & 158 & 158 & 157 & 167 & 252 & 252 & 236 & 244 & 202 & 202 & 154 & 156 & 216 & 216 & 308 & 3 & 5 \\
\hline
\end{tabular}




\begin{tabular}{|c|c|c|c|c|c|c|c|c|c|c|c|c|c|c|c|c|c|c|c|c|c|c|c|c|c|c|}
\hline 376 & STR03 & 105 & 105 & 182 & 182 & 195 & 195 & 208 & 210 & 158 & 158 & 175 & 201 & 252 & 252 & 236 & 244 & 191 & 202 & 154 & 170 & 216 & 216 & 310 & 5 & 5 \\
\hline 377 & STR04 & 105 & 105 & 182 & 185 & 195 & 201 & 210 & 220 & 154 & 158 & 157 & 169 & 252 & 252 & 242 & 244 & 188 & 202 & 154 & 154 & 220 & 220 & 311 & & 4 \\
\hline 378 & STR05 & 105 & 105 & 167 & 182 & 195 & 195 & 208 & 210 & 154 & 158 & 179 & 201 & 252 & 252 & 242 & 244 & 194 & 202 & 154 & 156 & 216 & 216 & 312 & ? & 4 \\
\hline 379 & STR06 & 105 & 105 & 182 & 182 & 195 & 195 & 216 & 220 & 154 & 158 & 157 & 179 & 252 & 252 & 236 & 242 & 188 & 202 & 156 & 181 & 216 & 220 & 313 & 7 & 5 \\
\hline 380 & STR07 & 105 & 105 & 167 & 182 & 195 & 201 & 208 & 210 & 154 & 158 & 157 & 171 & 252 & 252 & 232 & 236 & 194 & 202 & 154 & 156 & 216 & 216 & 314 & 8 & 5 \\
\hline 381 & STR08 & 105 & 105 & 182 & 182 & 195 & 201 & 208 & 208 & 158 & 164 & 175 & 201 & 252 & 252 & 236 & 244 & 202 & 202 & 154 & 170 & 216 & 216 & 315 & 5 & 6 \\
\hline 382 & STR09 & 105 & 105 & 182 & 182 & 195 & 195 & 208 & 216 & 156 & 158 & 157 & 175 & 252 & 252 & 232 & 236 & 191 & 202 & 154 & 156 & 216 & 216 & 316 & 6 & 6 \\
\hline 383 & STR10 & 105 & 105 & 182 & 182 & 195 & 201 & 216 & 220 & 158 & 158 & 157 & 157 & 252 & 252 & 236 & 242 & 188 & 194 & 154 & 154 & 216 & 216 & 317 & 4 & 6 \\
\hline 384 & STR11 & 105 & 105 & 182 & 182 & 195 & 195 & 210 & 220 & 158 & 158 & 157 & 175 & 252 & 252 & 236 & 236 & 188 & 202 & 154 & 154 & 216 & 220 & 318 & 4 & 5 \\
\hline 385 & STR12 & 105 & 105 & 182 & 182 & 195 & 195 & 216 & 220 & 158 & 158 & 167 & 175 & 252 & 252 & 232 & 236 & 191 & 202 & 154 & 156 & 216 & 218 & 319 & 6 & 4 \\
\hline 386 & STR13 & 105 & 105 & 167 & 182 & 195 & 201 & 208 & 208 & 158 & 158 & 157 & 157 & 252 & 252 & 236 & 242 & 202 & 202 & 154 & 154 & 216 & 216 & 320 & 3 & 7 \\
\hline 387 & STR14 & 105 & 105 & 167 & 182 & 195 & 201 & 208 & 210 & 154 & 158 & 157 & 179 & 252 & 252 & 236 & 244 & 194 & 202 & 154 & 156 & 216 & 218 & 321 & 9 & 5 \\
\hline 388 & STR15 & 105 & 105 & 182 & 182 & 195 & 201 & 216 & 216 & 145 & 156 & 157 & 157 & 252 & 252 & 236 & 236 & 188 & 202 & 154 & 154 & 216 & 220 & 322 & 4 & 6 \\
\hline 389 & STR16 & 105 & 105 & 167 & 182 & 195 & 201 & 210 & 216 & 154 & 158 & 157 & 157 & 252 & 252 & 236 & 236 & 188 & 202 & 154 & 156 & 216 & 216 & 323 & 6 & 5 \\
\hline 390 & STR17 & 105 & 105 & 182 & 182 & 201 & 201 & 208 & 216 & 156 & 158 & 157 & 171 & 252 & 252 & 236 & 236 & 202 & 202 & 154 & 156 & 216 & 220 & 324 & 5 & 6 \\
\hline 391 & STR18 & 105 & 105 & 182 & 182 & 195 & 195 & 208 & 216 & 154 & 156 & 175 & 175 & 252 & 252 & 236 & 236 & 191 & 202 & 154 & 154 & 216 & 220 & 325 & 4 & 5 \\
\hline 392 & STR19 & 105 & 105 & 182 & 182 & 195 & 201 & 208 & 216 & 158 & 158 & 157 & 175 & 252 & 252 & 236 & 236 & 202 & 202 & 154 & 154 & 216 & 220 & 326 & 4 & 6 \\
\hline 393 & STR20 & 105 & 105 & 182 & 182 & 195 & 201 & 210 & 216 & 156 & 158 & 169 & 175 & 252 & 252 & 232 & 236 & 202 & 202 & 154 & 156 & 216 & 216 & 327 & o & 4 \\
\hline 394 & STR21 & 105 & 105 & 182 & 182 & 195 & 195 & 210 & 216 & 154 & 158 & 157 & 175 & 252 & 252 & 236 & 236 & 191 & 191 & 154 & 154 & 216 & 218 & 328 & 4 & 5 \\
\hline 395 & STR22 & 105 & 105 & 182 & 182 & 195 & 195 & 210 & 216 & 154 & 158 & 157 & 175 & 252 & 252 & 236 & 236 & 191 & 191 & 154 & 154 & 216 & 218 & 328 & 4 & 5 \\
\hline 396 & STR23 & 105 & 105 & 167 & 182 & 195 & 195 & 210 & 216 & 154 & 158 & 171 & 179 & 252 & 252 & 232 & 232 & 202 & 202 & 154 & 154 & 220 & 220 & 329 & 4 & 3 \\
\hline 397 & STR24 & 105 & 105 & 182 & 182 & 195 & 195 & 210 & 220 & 158 & 158 & 157 & 201 & 252 & 252 & 236 & 244 & 188 & 202 & 154 & 154 & 216 & 216 & 330 & 4 & 5 \\
\hline 398 & STR25 & 105 & 105 & 182 & 182 & 201 & 201 & 208 & 208 & 158 & 158 & 167 & 175 & 252 & 252 & 236 & 236 & 188 & 202 & 154 & 154 & 216 & 220 & 331 & 3 & 6 \\
\hline 399 & STR26 & 105 & 105 & 182 & 182 & 195 & 201 & 210 & 220 & 158 & 158 & 175 & 175 & 252 & 252 & 236 & 236 & 191 & 202 & 154 & 154 & 216 & 216 & 332 & 3 & 4 \\
\hline 400 & STR27 & 105 & 105 & 182 & 182 & 195 & 201 & 210 & 220 & 156 & 158 & 175 & 179 & 252 & 252 & 236 & 244 & 191 & 202 & 154 & 154 & 216 & 216 & 333 & 6 & 4 \\
\hline 401 & STR28 & 105 & 105 & 167 & 182 & 195 & 201 & 208 & 216 & 158 & 158 & 179 & 179 & 252 & 252 & 232 & 236 & 188 & 191 & 170 & 170 & 216 & 220 & 334 & 6 & 4 \\
\hline 402 & STR29 & 105 & 105 & 167 & 182 & 195 & 195 & 216 & 220 & 154 & 158 & 175 & 171 & 252 & 252 & 232 & 232 & 188 & 202 & 154 & 156 & 216 & 216 & 335 & 5 & 3 \\
\hline 403 & BEN01 & 105 & 105 & 167 & 182 & 195 & 201 & 216 & 216 & 154 & 158 & 171 & 171 & 252 & 254 & 232 & 232 & 188 & 191 & 156 & 170 & 216 & 218 & 336 & 7 & 3 \\
\hline 404 & BEN02 & 105 & 105 & 182 & 182 & 195 & 195 & 210 & 210 & 154 & 154 & 157 & 171 & 252 & 254 & 220 & 232 & 188 & 191 & 154 & 170 & 216 & 220 & 337 & 6 & 5 \\
\hline 405 & BEN03 & 105 & 105 & 182 & 182 & 195 & 195 & 212 & 212 & 158 & 158 & 157 & 159 & 252 & 254 & 220 & 242 & 188 & 191 & 170 & 170 & 216 & 216 & 338 & 4 & 5 \\
\hline 406 & BEN04 & 105 & 105 & 182 & 182 & 195 & 201 & 220 & 220 & 158 & 158 & 175 & 197 & 252 & 254 & 220 & 232 & 188 & 191 & 170 & 170 & 216 & 220 & 339 & 6 & 4 \\
\hline 407 & BEN05 & 105 & 105 & 182 & 182 & 195 & 201 & 212 & 212 & 154 & 158 & 157 & 175 & 252 & 254 & 220 & 232 & 191 & 191 & 154 & 156 & 216 & 216 & 340 & 6 & 5 \\
\hline 408 & BEN06 & 105 & 105 & 182 & 182 & 201 & 201 & 212 & 212 & 154 & 158 & 157 & 175 & 252 & 254 & 232 & 242 & 188 & 191 & 154 & 156 & 216 & 216 & 341 & 6 & 5 \\
\hline 409 & BEN07 & 105 & 105 & 182 & 182 & 195 & 201 & 210 & 220 & 158 & 158 & 157 & 157 & 252 & 252 & 220 & 232 & 191 & 191 & 170 & 170 & 216 & 218 & 342 & 4 & 6 \\
\hline 410 & BEN08 & 105 & 105 & 182 & 182 & 195 & 201 & 216 & 216 & 154 & 154 & 171 & 173 & 254 & 254 & 232 & 232 & 191 & 191 & 156 & 170 & 216 & 216 & 343 & 3 & 4 \\
\hline 411 & BEN09 & 105 & 105 & 182 & 182 & 195 & 201 & 216 & 216 & 154 & 158 & 171 & 171 & 252 & 252 & 232 & 232 & 191 & 191 & 154 & 170 & 216 & 218 & 344 & 4 & 4 \\
\hline 412 & BEN10 & 105 & 105 & 182 & 182 & 201 & 201 & 216 & 216 & 156 & 158 & 159 & 171 & 252 & 252 & 232 & 232 & 177 & 191 & 154 & 170 & 218 & 220 & 345 & 5 & 4 \\
\hline 413 & BEN11 & 105 & 105 & 167 & 182 & 195 & 201 & 216 & 216 & 154 & 154 & 171 & 175 & 252 & 254 & 220 & 232 & 188 & 191 & 154 & 170 & 216 & 216 & 346 & 7 & 3 \\
\hline 414 & BEN12 & 105 & 105 & 167 & 182 & 195 & 195 & 210 & 210 & 154 & 158 & 157 & 171 & 252 & 252 & 232 & 232 & 188 & 188 & 154 & 170 & 216 & 218 & 347 & 5 & 4 \\
\hline 415 & BEN13 & 105 & 105 & 182 & 182 & 195 & 195 & 210 & 210 & 154 & 154 & 177 & 183 & 252 & 252 & 220 & 232 & 188 & 191 & 154 & 170 & 216 & 218 & 348 & 5 & 4 \\
\hline 416 & BEN14 & 105 & 105 & 182 & 182 & 195 & 195 & 210 & 212 & 154 & 154 & 157 & 177 & 252 & 252 & 232 & 232 & 188 & 188 & 156 & 170 & 216 & 218 & 349 & 4 & 5 \\
\hline 417 & BEN15 & 105 & 105 & 182 & 182 & 195 & 201 & 210 & 216 & 154 & 156 & 171 & 171 & 252 & 254 & 232 & 242 & 188 & 191 & 170 & 170 & 216 & 220 & 350 & 7 & 4 \\
\hline
\end{tabular}




\begin{tabular}{|c|c|c|c|c|c|c|c|c|c|c|c|c|c|c|c|c|c|c|c|c|c|c|c|c|c|c|}
\hline 419 & BEN17 & 105 & 105 & 182 & 182 & 195 & 195 & 210 & 210 & 154 & 158 & 157 & 189 & 252 & 252 & 232 & 232 & 188 & 191 & 170 & 170 & 216 & 218 & 352 & 4 & 5 \\
\hline 420 & BEN18 & 105 & 105 & 167 & 182 & 195 & 201 & 200 & 210 & 154 & 158 & 157 & 175 & 252 & 252 & 232 & 232 & 188 & 191 & 154 & 156 & 216 & 218 & 353 & 8 & 4 \\
\hline 421 & BEN19 & 105 & 105 & 182 & 182 & 195 & 201 & 210 & 210 & 154 & 156 & 157 & 189 & 252 & 254 & 220 & 232 & 188 & 188 & 154 & 170 & 216 & 220 & 354 & 7 & 5 \\
\hline 422 & BEN20 & 105 & 105 & 182 & 182 & 195 & 195 & 212 & 212 & 154 & 158 & 157 & 171 & 252 & 254 & 220 & 232 & 188 & 191 & 154 & 156 & 216 & 216 & 355 & 6 & 5 \\
\hline 423 & BEN21 & 105 & 105 & 182 & 182 & 195 & 201 & 210 & 212 & 154 & 154 & 177 & 197 & 252 & 252 & 242 & 242 & 188 & 202 & 154 & 170 & 216 & 218 & 356 & 6 & 4 \\
\hline 424 & BEN22 & 105 & 105 & 182 & 182 & 195 & 201 & 210 & 210 & 154 & 158 & 157 & 157 & 252 & 254 & 232 & 242 & 188 & 188 & 154 & 156 & 216 & 216 & 357 & 5 & 6 \\
\hline 425 & BEN23 & 105 & 105 & 182 & 182 & 195 & 201 & 216 & 216 & 154 & 158 & 157 & 175 & 252 & 254 & 220 & 232 & 188 & 188 & 154 & 170 & 216 & 218 & 358 & 7 & 5 \\
\hline 426 & BEN24 & 105 & 105 & 182 & 182 & 201 & 201 & 210 & 216 & 154 & 154 & 157 & 171 & 252 & 252 & 232 & 242 & 191 & 191 & 170 & 170 & 216 & 216 & 359 & 3 & 5 \\
\hline 427 & BEN25 & 105 & 105 & 182 & 182 & 195 & 201 & 210 & 216 & 154 & 154 & 171 & 175 & 252 & 252 & 220 & 242 & 188 & 191 & 154 & 170 & 216 & 216 & 360 & 6 & 4 \\
\hline 428 & PAUm01 & 102 & 108 & 182 & 182 & 192 & 192 & 206 & 208 & 123 & 151 & 144 & 155 & 252 & 254 & MP & MP & 183 & 186 & MP & MP & 222 & 224 & 361 & 7 & 13 \\
\hline 429 & PAUm02 & 102 & 108 & 182 & 182 & 192 & 192 & 206 & 208 & 123 & 151 & 144 & 155 & 252 & 254 & MP & MP & 183 & 186 & MP & MP & 222 & 224 & 361 & 7 & 13 \\
\hline 430 & PAUm03 & 102 & 108 & 182 & 182 & 192 & 192 & 206 & 208 & 123 & 151 & 144 & 155 & 252 & 254 & MP & MP & 183 & 186 & MP & MP & 222 & 224 & 361 & 7 & 13 \\
\hline 431 & PAUm04 & 102 & 108 & 182 & 182 & 192 & 192 & 206 & 208 & 123 & 151 & 144 & 155 & 252 & 254 & MP & MP & 183 & 186 & MP & MP & 222 & 224 & 361 & 7 & 13 \\
\hline 432 & PAUm05 & 102 & 108 & 182 & 182 & 192 & 192 & 206 & 208 & 123 & 151 & 144 & 155 & 252 & 254 & MP & MP & 183 & 186 & MP & MP & 222 & 224 & 361 & 7 & 13 \\
\hline 433 & VILm01 & 99 & 102 & 179 & 190 & 192 & 192 & 206 & 208 & 151 & 155 & 144 & 144 & 254 & 254 & MP & MP & 186 & 186 & MP & MP & 224 & 224 & 362 & 4 & 13 \\
\hline 434 & VILm02 & 99 & 102 & 182 & 182 & 189 & 192 & 208 & 208 & 151 & 151 & 161 & 163 & 252 & 254 & MP & MP & 186 & 186 & MP & MP & 224 & 224 & 363 & 4 & 16 \\
\hline 435 & VILm03 & 99 & 114 & 182 & 182 & 192 & 192 & 208 & 208 & 151 & 151 & 161 & 163 & 252 & 256 & MP & MP & 186 & 186 & MP & MP & 222 & 222 & 364 & 3 & 17 \\
\hline 436 & VILm04 & 99 & 114 & 182 & 182 & 189 & 192 & 208 & 208 & 151 & 151 & 152 & 157 & 250 & 252 & MP & MP & 186 & 186 & MP & MP & 222 & 222 & 365 & 4 & 15 \\
\hline 437 & VILm05 & 99 & 102 & 182 & 182 & 192 & 192 & 208 & 208 & 151 & 151 & 157 & 163 & 252 & 252 & MP & MP & 186 & 186 & MP & MP & 222 & 222 & 366 & 2 & 17 \\
\hline 438 & ESBm01 & 102 & 108 & 182 & 182 & 192 & 192 & 206 & 208 & 123 & 151 & 144 & 155 & 252 & 254 & MP & MP & 183 & 186 & MP & MP & 222 & 224 & 361 & 7 & 13 \\
\hline 439 & ESBm02 & 102 & 108 & 182 & 182 & 192 & 192 & 206 & 208 & 123 & 151 & 144 & 155 & 252 & 254 & MP & MP & 183 & 186 & MP & MP & 222 & 224 & 361 & 7 & 13 \\
\hline 440 & ESBm03 & 102 & 108 & 182 & 182 & 192 & 192 & 206 & 208 & 123 & 151 & 144 & 155 & 252 & 254 & MP & MP & 183 & 186 & MP & MP & 222 & 224 & 361 & 7 & 13 \\
\hline 441 & ESBm04 & 102 & 108 & 182 & 182 & 192 & 192 & 206 & 208 & 123 & 151 & 144 & 155 & 252 & 254 & MP & MP & 183 & 186 & MP & MP & 222 & 224 & 361 & 7 & 13 \\
\hline 442 & ESBm05 & 102 & 108 & 182 & 182 & 192 & 192 & 206 & 208 & 123 & 151 & 144 & 155 & 252 & 254 & MP & MP & 183 & 186 & MP & MP & 222 & 224 & 361 & 7 & 13 \\
\hline
\end{tabular}


Supplementary Material (Table S2):

Genetic Diversity in Relict and Fragmented Populations of Ulmus glabra Hudson in the Central System of the Iberian Peninsula

María Martín del Puerto, Felipe Martínez García, Aparajita Mohanty and Juan Pedro Martín

Table S2. Allele sizes (in base pairs) and frequencies at each of eleven microsatellite loci analyzed in 427 U. glabra and 15 U. minor individuals sampled from Central System. ${ }^{\mathrm{a}}$ Microsatellite loci with multiband patterns (MP) in U. minor samples were not analyzed in this species

\begin{tabular}{|c|c|c|c|}
\hline Loci $^{a}$ & Allele size & $\begin{array}{l}\text { Ulmus glabra } \\
(\mathrm{Ns}=427)\end{array}$ & $\begin{array}{l}\text { Ulmus minor } \\
(\mathrm{Ns}=15)\end{array}$ \\
\hline \multirow[t]{6}{*}{ Ulm2 } & 99 & --- & 0.167 \\
\hline & 102 & 0.002 & 0.433 \\
\hline & 105 & 0.924 & --- \\
\hline & 108 & 0.023 & 0.333 \\
\hline & 111 & 0.014 & --- \\
\hline & 114 & 0.036 & 0.067 \\
\hline \multirow[t]{10}{*}{ Ulm3 } & 164 & 0.011 & --- \\
\hline & 167 & 0.082 & --- \\
\hline & 170 & 0.001 & --- \\
\hline & 173 & 0.046 & --- \\
\hline & 176 & 0.005 & --- \\
\hline & 179 & 0.009 & 0.033 \\
\hline & 182 & 0.834 & 0.933 \\
\hline & 185 & 0.008 & --- \\
\hline & 190 & --- & 0.033 \\
\hline & 200 & 0.005 & --- \\
\hline \multirow[t]{5}{*}{ Ulm8 } & 189 & --- & 0.067 \\
\hline & 192 & 0.061 & 0.933 \\
\hline & 195 & 0.864 & --- \\
\hline & 201 & 0.063 & --- \\
\hline & 204 & 0.012 & --- \\
\hline \multirow[t]{7}{*}{ Ulmi1-21 } & 200 & 0.090 & --- \\
\hline & 206 & --- & 0.367 \\
\hline & 208 & 0.114 & 0.633 \\
\hline & 210 & 0.123 & --- \\
\hline & 212 & 0.071 & --- \\
\hline & 214 & 0.030 & --- \\
\hline & 216 & 0.335 & --- \\
\hline
\end{tabular}




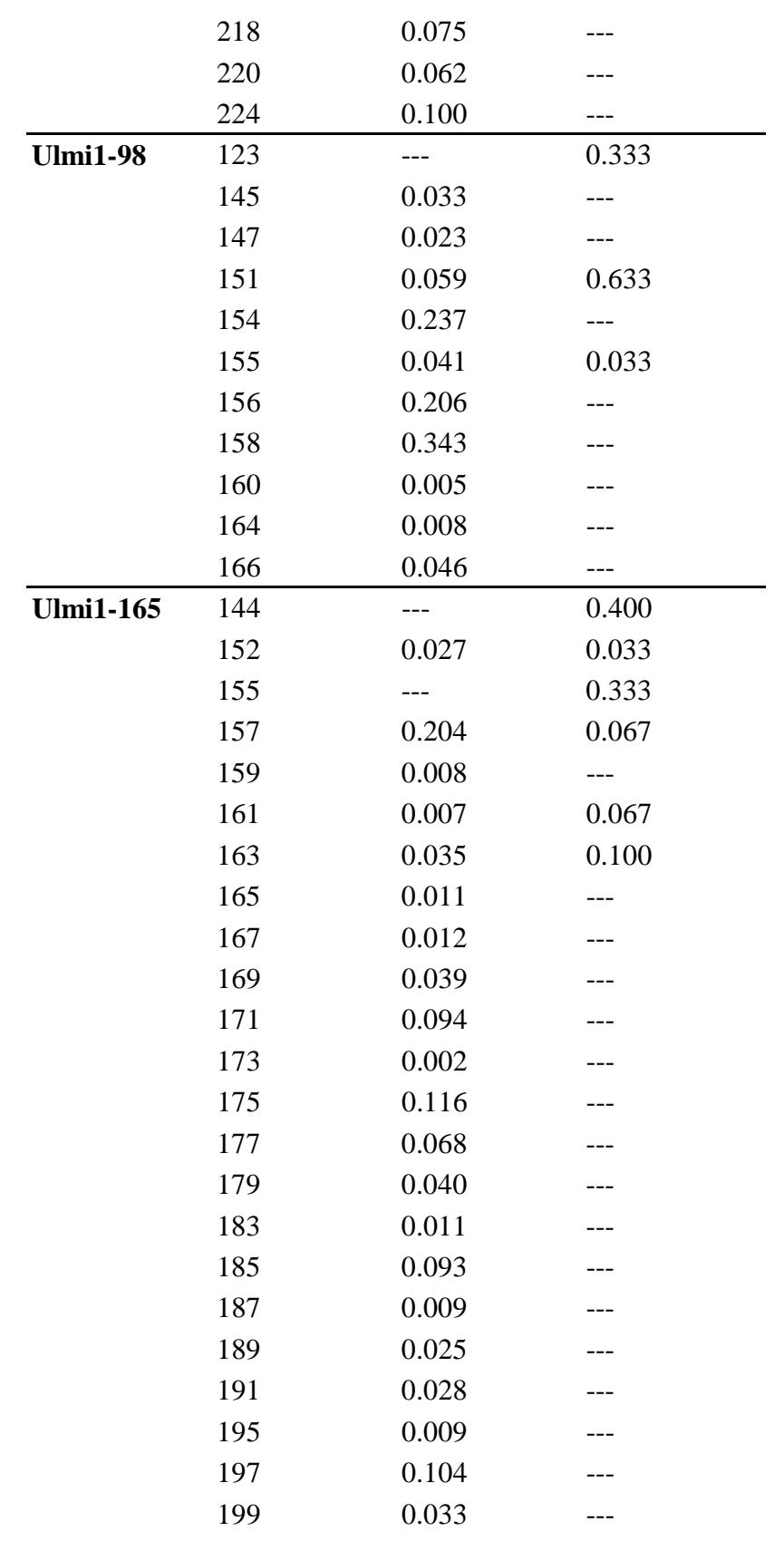




\begin{tabular}{|c|c|c|c|}
\hline & 201 & 0.023 & --- \\
\hline & 205 & 0.004 & --- \\
\hline \multirow[t]{4}{*}{ UR123 } & 250 & --- & 0.033 \\
\hline & 252 & 0.845 & 0.500 \\
\hline & 254 & 0.105 & 0.433 \\
\hline & 256 & 0.049 & 0.033 \\
\hline \multirow[t]{7}{*}{ UR138 } & 220 & 0.055 & MP \\
\hline & 232 & 0.352 & MP \\
\hline & 233 & 0.028 & MP \\
\hline & 235 & 0.036 & MP \\
\hline & 236 & 0.060 & MP \\
\hline & 242 & 0.311 & MP \\
\hline & 244 & 0.157 & MP \\
\hline \multirow[t]{7}{*}{ UR153 } & 177 & 0.135 & --- \\
\hline & 183 & --- & 0.333 \\
\hline & 186 & 0.004 & 0.667 \\
\hline & 188 & 0.438 & --- \\
\hline & 191 & 0.272 & --- \\
\hline & 194 & 0.009 & --- \\
\hline & 202 & 0.143 & --- \\
\hline \multirow[t]{9}{*}{ UR173a } & 151 & 0.057 & MP \\
\hline & 154 & 0.566 & MP \\
\hline & 156 & 0.035 & MP \\
\hline & 158 & 0.016 & MP \\
\hline & 170 & 0.268 & MP \\
\hline & 172 & 0.004 & MP \\
\hline & 174 & 0.008 & MP \\
\hline & 181 & 0.016 & MP \\
\hline & 185 & 0.029 & MP \\
\hline \multirow[t]{7}{*}{ UR175 } & 216 & 0.337 & --- \\
\hline & 218 & 0.190 & --- \\
\hline & 220 & 0.358 & --- \\
\hline & 222 & 0.036 & 0.533 \\
\hline & 224 & 0.001 & 0.467 \\
\hline & 233 & 0.073 & --- \\
\hline & 236 & 0.005 & ---- \\
\hline
\end{tabular}


Supplementary Material (Table S3):

Genetic Diversity in Relict and Fragmented Populations of Ulmus glabra Hudson in the Central System of the Iberian Peninsula

María Martín del Puerto, Felipe Martínez García, Aparajita Mohanty and Juan Pedro Martín

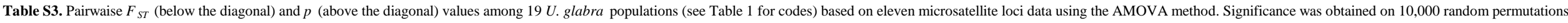
Populations with a sample size less than 5 (CNT, BOC and PAU) were not included in the analysis

The greatest $F_{S T}$ value is in bold and the lowest $F_{S T}$ values are in italics

\begin{tabular}{|c|c|c|c|c|c|c|c|c|c|c|c|c|c|c|c|c|c|c|c|}
\hline & CNJ & RZA & NAV & MON & RAS & CER & ROZ & TIE & IRU & CAS & $\begin{array}{l}\text { PIE } \\
\end{array}$ & CVJ & CVA & MOM & CAN & ALD & VIL & $\begin{array}{l}\text { STR } \\
\end{array}$ & BEN \\
\hline CNJ & & 0.0001 & 0.0001 & 0.0001 & 0.0001 & 0.0001 & 0.0001 & 0.0001 & 0.0001 & 0.0001 & 0.0001 & 0.0001 & 0.0001 & 0.0001 & 0.0001 & 0.0001 & 0.0001 & 0.0001 & 0.0001 \\
\hline RZA & 0.1812 & & 0.0001 & 0.0001 & 0.0001 & 0.0001 & 0.0001 & 0.0001 & 0.0001 & 0.0001 & 0.0001 & 0.0001 & 0.0001 & 0.0001 & 0.0001 & 0.0001 & 0.0001 & 0.0001 & 0.0001 \\
\hline NAV & 0.2952 & 0.1847 & & 0.0001 & 0.0001 & 0.0001 & 0.0001 & 0.0001 & 0.0001 & 0.0001 & 0.0001 & 0.0001 & 0.0001 & 0.0001 & 0.0001 & 0.0001 & 0.0001 & 0.0001 & 0.0001 \\
\hline MON & 0.3279 & 0.2621 & 0.2253 & & 0.0001 & 0.0001 & 0.0001 & 0.0001 & 0.0001 & 0.0001 & 0.0001 & 0.0001 & 0.0001 & 0.0001 & 0.0001 & 0.0001 & 0.0001 & 0.0001 & 0.0001 \\
\hline RAS & 0.3788 & 0.3505 & 0.3373 & 0.3407 & & 0.0001 & 0.0001 & 0.0001 & 0.0001 & 0.0001 & 0.0001 & 0.0001 & 0.0001 & 0.0001 & 0.0001 & 0.0001 & 0.0001 & 0.0001 & 0.0001 \\
\hline CER & 0.2913 & 0.3073 & 0.3319 & 0.3239 & 0.4075 & & 0.0001 & 0.0001 & 0.0001 & 0.0001 & 0.0001 & 0.0001 & 0.0001 & 0.0001 & 0.0001 & 0.0001 & 0.0001 & 0.0001 & 0.0001 \\
\hline ROZ & 0.2629 & 0.2671 & 0.2806 & 0.3121 & 0.3358 & 0.2789 & & 0.0001 & 0.0001 & 0.0001 & 0.0001 & 0.0001 & 0.0001 & 0.0001 & 0.0001 & 0.0001 & 0.0001 & 0.0001 & 0.0001 \\
\hline TIE & 0.1846 & 0.1945 & 0.2128 & 0.2493 & 0.3266 & 0.3101 & 0.2810 & & 0.0001 & 0.0001 & 0.0001 & 0.0001 & 0.0001 & 0.0001 & 0.0001 & 0.0001 & 0.0001 & 0.0001 & 0.0001 \\
\hline IRU & 0.1553 & 0.0936 & 0.1876 & 0.2447 & 0.3234 & 0.2834 & 0.2503 & 0.1547 & & 0.0001 & 0.0001 & 0.0001 & 0.0001 & 0.0001 & 0.0001 & 0.0001 & 0.0001 & 0.0001 & 0.0001 \\
\hline CAS & 0.2557 & 0.0969 & 0.2175 & 0.2781 & 0.3506 & 0.3521 & 0.2768 & 0.2146 & 0.1613 & & 0.0001 & 0.0001 & 0.0001 & 0.0001 & 0.0003 & 0.0001 & 0.0001 & 0.0001 & 0.0001 \\
\hline PIE & 0.2959 & 0.1774 & 0.1767 & 0.2722 & 0.3385 & 0.3258 & 0.2394 & 0.2563 & 0.1529 & 0.2009 & & 0.0002 & 0.0001 & 0.0001 & 0.0001 & 0.0001 & 0.0001 & 0.0001 & 0.0001 \\
\hline CVJ & 0.2470 & 0.1208 & 0.2160 & 0.2424 & 0.2832 & 0.3234 & 0.2221 & 0.1811 & 0.1280 & 0.1182 & 0.1311 & & 0.0001 & 0.0001 & 0.0003 & 0.0001 & 0.0001 & 0.0001 & 0.0001 \\
\hline CVA & 0.2147 & 0.1266 & 0.1852 & 0.2853 & 0.3465 & 0.3610 & 0.2527 & 0.1535 & 0.0989 & 0.1639 & 0.2616 & 0.1345 & & 0.0001 & 0.0001 & 0.0001 & 0.0001 & 0.0001 & 0.0001 \\
\hline МOM & 0.3054 & 0.2930 & 0.3104 & 0.3466 & 0.4356 & 0.3701 & 0.1830 & 0.2394 & 0.2505 & 0.2997 & 0.3289 & 0.2738 & 0.2102 & & 0.0002 & 0.0001 & 0.0001 & 0.0001 & 0.0001 \\
\hline CAN & 0.2159 & 0.0845 & 0.1761 & 0.2117 & 0.3242 & 0.2568 & 0.2149 & 0.1513 & 0.1322 & 0.0845 & 0.1629 & 0.0921 & 0.1351 & 0.2020 & & 0.0001 & 0.0001 & 0.0001 & 0.0001 \\
\hline ALD & 0.2358 & 0.1881 & 0.2019 & 0.2457 & 0.3054 & 0.3042 & 0.2403 & 0.1830 & 0.1436 & 0.1903 & 0.2177 & 0.1461 & 0.2052 & 0.2859 & 0.1521 & & 0.0001 & 0.0001 & 0.0001 \\
\hline VIL & 0.3031 & 0.2785 & 0.2629 & 0.2368 & 0.3562 & 0.3577 & 0.3157 & 0.2193 & 0.2599 & 0.2836 & 0.2718 & 0.2326 & 0.3292 & 0.3294 & 0.2058 & 0.2390 & & 0.0001 & 0.0001 \\
\hline STR & 0.2751 & 0.2197 & 0.2397 & 0.2559 & 0.3416 & 0.3329 & 0.2863 & 0.1811 & 0.1672 & 0.2253 & 0.1997 & 0.1566 & 0.2366 & 0.2919 & 0.1398 & 0.1497 & 0.1162 & & 0.0001 \\
\hline BEN & 0.2120 & 0.2254 & 0.2184 & 0.2166 & 0.2580 & 0.1991 & 0.2216 & 0.1814 & 0.1664 & 0.2411 & 0.1380 & 0.1713 & 0.2122 & 0.2527 & 0.1577 & 0.1939 & 0.1924 & 0.1667 & \\
\hline
\end{tabular}


Supplementary Material (Table S4):

Genetic Diversity in Relict and Fragmented Populations of Ulmus glabra Hudson in the Central System of the Iberian Peninsula

María Martín del Puerto, Felipe Martínez García, Aparajita Mohanty and Juan Pedro Martín

Table S4. Results of Structure and NewHybrids analysis obtained in 442 elm individuals (427 U. glabra and 15 U. minor ) studied.

Structure analysis: admixture coefficients $q \geq 0.9$ are in bold and indicate assignment to the corresponding cluster (A or B)

NewHybrids analysis: posterior assignment probabilities $p \geq 0.9$ are in bold and indicate assignment to the corresponding class $\left(U\right.$. glabra , U. minor, $\mathrm{F}_{1}, \mathrm{~F}_{2}$ or both backcrosses $\left.\mathrm{F}_{1}\right)$

${ }^{\text {a }}$ The individual code is the population code (see Table 1 ) along with an individual number

\begin{tabular}{|c|c|c|c|c|c|c|c|c|}
\hline \multirow{2}{*}{$\begin{array}{l}\text { Individual } \\
\text { Code }^{\text {a }}\end{array}$} & \multicolumn{2}{|c|}{ Structure analysis } & \multicolumn{6}{|c|}{ NewHybrids analysis } \\
\hline & Cluster A & Cluster B & U. glabra & U. minor & $F_{1}$ & $F_{2}$ & $\mathrm{~F}_{1} \times$ U. glabra & $F_{1} \times U$. minor \\
\hline CNT01 & 0.997 & 0.003 & 0.99982 & 0.00000 & 0.00000 & 0.00000 & 0.00017 & 0.00000 \\
\hline CNJ01 & 0.995 & 0.005 & 0.99969 & 0.00000 & 0.00000 & 0.00001 & 0.00029 & 0.00000 \\
\hline CNJ02 & 0.992 & 0.008 & 0.99946 & 0.00000 & 0.00000 & 0.00006 & 0.00048 & 0.00000 \\
\hline CNJ03 & 0.994 & 0.006 & 0.99963 & 0.00000 & 0.00000 & 0.00001 & 0.00036 & 0.00000 \\
\hline CNJ04 & 0.986 & 0.014 & 0.99837 & 0.00000 & 0.00003 & 0.00027 & 0.00134 & 0.00000 \\
\hline CNJ05 & 0.994 & 0.006 & 0.99962 & 0.00000 & 0.00000 & 0.00002 & 0.00035 & 0.00000 \\
\hline CNJ06 & 0.989 & 0.011 & 0.99889 & 0.00000 & 0.00002 & 0.00012 & 0.00098 & 0.00000 \\
\hline CNJ07 & 0.996 & 0.004 & 0.99975 & 0.00000 & 0.00000 & 0.00001 & 0.00024 & 0.00000 \\
\hline CNJ08 & 0.995 & 0.005 & 0.99987 & 0.00000 & 0.00000 & 0.00000 & 0.00013 & 0.00000 \\
\hline CNJ09 & 0.993 & 0.007 & 0.99931 & 0.00000 & 0.00001 & 0.00009 & 0.00060 & 0.00000 \\
\hline CNJ10 & 0.994 & 0.006 & 0.99949 & 0.00000 & 0.00001 & 0.00004 & 0.00046 & 0.00000 \\
\hline CNJ11 & 0.995 & 0.005 & 0.99974 & 0.00000 & 0.00000 & 0.00001 & 0.00025 & 0.00000 \\
\hline CNJ12 & 0.993 & 0.007 & 0.99931 & 0.00000 & 0.00001 & 0.00003 & 0.00064 & 0.00000 \\
\hline CNJ13 & 0.992 & 0.008 & 0.99899 & 0.00000 & 0.00002 & 0.00009 & 0.00091 & 0.00000 \\
\hline CNJ14 & 0.996 & 0.004 & 0.99965 & 0.00000 & 0.00000 & 0.00001 & 0.00033 & 0.00000 \\
\hline CNJ15 & 0.997 & 0.003 & 0.99987 & 0.00000 & 0.00000 & 0.00000 & 0.00013 & 0.00000 \\
\hline CNJ16 & 0.993 & 0.007 & 0.99915 & 0.00000 & 0.00001 & 0.00005 & 0.00079 & 0.00000 \\
\hline CNJ17 & 0.981 & 0.019 & 0.99835 & 0.00000 & 0.00003 & 0.00027 & 0.00135 & 0.00000 \\
\hline CNJ18 & 0.993 & 0.007 & 0.99939 & 0.00000 & 0.00000 & 0.00007 & 0.00054 & 0.00000 \\
\hline CNJ19 & 0.993 & 0.007 & 0.99907 & 0.00000 & 0.00002 & 0.00006 & 0.00085 & 0.00000 \\
\hline CNJ20 & 0.996 & 0.004 & 0.99968 & 0.00000 & 0.00000 & 0.00001 & 0.00030 & 0.00000 \\
\hline CNJ21 & 0.995 & 0.005 & 0.99965 & 0.00000 & 0.00001 & 0.00001 & 0.00032 & 0.00000 \\
\hline CNJ22 & 0.996 & 0.004 & 0.99968 & 0.00000 & 0.00000 & 0.00001 & 0.00030 & 0.00000 \\
\hline CNJ23 & 0.996 & 0.004 & 0.99986 & 0.00000 & 0.00000 & 0.00000 & 0.00014 & 0.00000 \\
\hline CNJ24 & 0.995 & 0.005 & 0.99966 & 0.00000 & 0.00000 & 0.00002 & 0.00032 & 0.00000 \\
\hline CNJ25 & 0.997 & 0.003 & 0.99983 & 0.00000 & 0.00000 & 0.00001 & 0.00016 & 0.00000 \\
\hline CNJ26 & 0.996 & 0.004 & 0.99980 & 0.00000 & 0.00000 & 0.00000 & 0.00019 & 0.00000 \\
\hline CNJ27 & 0.994 & 0.006 & 0.99960 & 0.00000 & 0.00000 & 0.00003 & 0.00037 & 0.00000 \\
\hline CNJ28 & 0.996 & 0.004 & 0.99977 & 0.00000 & 0.00000 & 0.00001 & 0.00023 & 0.00000 \\
\hline CNJ29 & 0.831 & 0.169 & 0.97479 & 0.00000 & 0.00301 & 0.00245 & 0.01975 & 0.00001 \\
\hline CNJ30 & 0.996 & 0.004 & 0.99977 & 0.00000 & 0.00000 & 0.00001 & 0.00022 & 0.00000 \\
\hline CNJ31 & 0.996 & 0.004 & 0.99978 & 0.00000 & 0.00000 & 0.00001 & 0.00021 & 0.00000 \\
\hline CNJ32 & 0.995 & 0.005 & 0.99958 & 0.00000 & 0.00001 & 0.00001 & 0.00039 & 0.00000 \\
\hline CNJ33 & 0.994 & 0.006 & 0.99973 & 0.00000 & 0.00000 & 0.00001 & 0.00026 & 0.00000 \\
\hline CNJ34 & 0.997 & 0.003 & 0.99976 & 0.00000 & 0.00001 & 0.00001 & 0.00023 & 0.00000 \\
\hline CNJ35 & 0.997 & 0.003 & 0.99992 & 0.00000 & 0.00000 & 0.00000 & 0.00007 & 0.00000 \\
\hline CNJ36 & 0.996 & 0.004 & 0.99980 & 0.00000 & 0.00000 & 0.00001 & 0.00019 & 0.00000 \\
\hline CNJ37 & 0.995 & 0.005 & 0.99967 & 0.00000 & 0.00001 & 0.00001 & 0.00031 & 0.00000 \\
\hline CNJ38 & 0.943 & 0.057 & 0.99811 & 0.00000 & 0.00007 & 0.00030 & 0.00152 & 0.00000 \\
\hline BOC01 & 0.997 & 0.003 & 0.99990 & 0.00000 & 0.00000 & 0.00000 & 0.00010 & 0.00000 \\
\hline ВОС02 & 0.997 & 0.003 & 0.99990 & 0.00000 & 0.00000 & 0.00000 & 0.00010 & 0.00000 \\
\hline ВОС03 & 0.997 & 0.003 & 0.99990 & 0.00000 & 0.00000 & 0.00000 & 0.00010 & 0.00000 \\
\hline BOC04 & 0.997 & 0.003 & 0.99988 & 0.00000 & 0.00000 & 0.00000 & 0.00011 & 0.00000 \\
\hline RZA01 & 0.995 & 0.005 & 0.99916 & 0.00000 & 0.00016 & 0.00005 & 0.00063 & 0.00000 \\
\hline RZA02 & 0.996 & 0.004 & 0.99975 & 0.00000 & 0.00000 & 0.00001 & 0.00024 & 0.00000 \\
\hline RZA03 & 0.996 & 0.004 & 0.99976 & 0.00000 & 0.00000 & 0.00001 & 0.00023 & 0.00000 \\
\hline RZA04 & 0.997 & 0.003 & 0.99985 & 0.00000 & 0.00000 & 0.00000 & 0.00015 & 0.00000 \\
\hline RZA05 & 0.995 & 0.005 & 0.99934 & 0.00000 & 0.00006 & 0.00005 & 0.00056 & 0.00000 \\
\hline RZA06 & 0.997 & 0.003 & 0.99996 & 0.00000 & 0.00000 & 0.00000 & 0.00004 & 0.00000 \\
\hline RZA07 & 0.997 & 0.003 & 0.99984 & 0.00000 & 0.00000 & 0.00000 & 0.00015 & 0.00000 \\
\hline RZA08 & 0.997 & 0.003 & 0.99968 & 0.00000 & 0.00000 & 0.00001 & 0.00031 & 0.00000 \\
\hline RZA09 & 0.996 & 0.004 & 0.99960 & 0.00000 & 0.00000 & 0.00002 & 0.00037 & 0.00000 \\
\hline RZA10 & 0.997 & 0.003 & 0.99976 & 0.00000 & 0.00000 & 0.00001 & 0.00023 & 0.00000 \\
\hline RZA11 & 0.997 & 0.003 & 0.99984 & 0.00000 & 0.00000 & 0.00001 & 0.00015 & 0.00000 \\
\hline RZA12 & 0.997 & 0.003 & 0.99989 & 0.00000 & 0.00000 & 0.00000 & 0.00011 & 0.00000 \\
\hline RZA13 & 0.998 & 0.002 & 0.99996 & 0.00000 & 0.00000 & 0.00000 & 0.00004 & 0.00000 \\
\hline RZA14 & 0.997 & 0.003 & 0.99993 & 0.00000 & 0.00000 & 0.00000 & 0.00007 & 0.00000 \\
\hline RZA15 & 0.995 & 0.005 & 0.99957 & 0.00000 & 0.00002 & 0.00002 & 0.00039 & 0.00000 \\
\hline RZA16 & 0.998 & 0.002 & 0.99995 & 0.00000 & 0.00000 & 0.00000 & 0.00004 & 0.00000 \\
\hline RZA17 & 0.997 & 0.003 & 0.99985 & 0.00000 & 0.00000 & 0.00000 & 0.00015 & 0.00000 \\
\hline RZA18 & 0.997 & 0.003 & 0.99995 & 0.00000 & 0.00000 & 0.00000 & 0.00005 & 0.00000 \\
\hline RZA19 & 0.997 & 0.003 & 0.99992 & 0.00000 & 0.00000 & 0.00000 & 0.00008 & 0.00000 \\
\hline RZA20 & 0.998 & 0.002 & 0.99997 & 0.00000 & 0.00000 & 0.00000 & 0.00003 & 0.00000 \\
\hline RZA21 & 0.998 & 0.002 & 0.99993 & 0.00000 & 0.00000 & 0.00000 & 0.00007 & 0.00000 \\
\hline RZA22 & 0.997 & 0.003 & 0.99981 & 0.00000 & 0.00000 & 0.00001 & 0.00019 & 0.00000 \\
\hline NAV01 & 0.996 & 0.004 & 0.99966 & 0.00000 & 0.00000 & 0.00001 & 0.00032 & 0.00000 \\
\hline NAV02 & 0.995 & 0.005 & 0.99943 & 0.00000 & 0.00000 & 0.00002 & 0.00054 & 0.00000 \\
\hline NAV03 & 0.996 & 0.004 & 0.99961 & 0.00000 & 0.00000 & 0.00002 & 0.00037 & 0.00000 \\
\hline NAV04 & 0.997 & 0.003 & 0.99985 & 0.00000 & 0.00000 & 0.00000 & 0.00015 & 0.00000 \\
\hline NAV05 & 0.997 & 0.003 & 0.99987 & 0.00000 & 0.00000 & 0.00000 & 0.00012 & 0.00000 \\
\hline NAV06 & 0.998 & 0.002 & 0.99997 & 0.00000 & 0.00000 & 0.00000 & 0.00003 & 0.00000 \\
\hline NAV07 & 0.996 & 0.004 & 0.99971 & 0.00000 & 0.00000 & 0.00001 & 0.00028 & 0.00000 \\
\hline NAV08 & 0.997 & 0.003 & 0.99983 & 0.00000 & 0.00000 & 0.00000 & 0.00017 & 0.00000 \\
\hline NAV09 & 0.996 & 0.004 & 0.99974 & 0.00000 & 0.00000 & 0.00001 & 0.00025 & 0.00000 \\
\hline NAV10 & 0.993 & 0.007 & 0.99877 & 0.00000 & 0.00001 & 0.00012 & 0.00110 & 0.00000 \\
\hline
\end{tabular}




\begin{tabular}{|c|c|c|c|c|c|c|c|c|}
\hline NAV11 & 0.997 & 0.003 & 0.99984 & 0.00000 & 0.00000 & 0.00000 & 0.00016 & 0.00000 \\
\hline NAV12 & 0.996 & 0.004 & 0.99984 & 0.00000 & 0.00000 & 0.00000 & 0.00016 & 0.00000 \\
\hline NAV13 & 0.997 & 0.003 & 0.99988 & 0.00000 & 0.00000 & 0.00000 & 0.00011 & 0.00000 \\
\hline NAV14 & 0.997 & 0.003 & 0.99986 & 0.00000 & 0.00000 & 0.00000 & 0.00013 & 0.00000 \\
\hline MON01 & 0.997 & 0.003 & 0.99986 & 0.00000 & 0.00000 & 0.00000 & 0.00014 & 0.00000 \\
\hline MON02 & 0.998 & 0.002 & 0.99994 & 0.00000 & 0.00000 & 0.00000 & 0.00006 & 0.00000 \\
\hline MON03 & 0.998 & 0.002 & 0.99993 & 0.00000 & 0.00000 & 0.00000 & 0.00007 & 0.00000 \\
\hline MON04 & 0.997 & 0.003 & 0.99983 & 0.00000 & 0.00000 & 0.00000 & 0.00017 & 0.00000 \\
\hline MON05 & 0.997 & 0.003 & 0.99991 & 0.00000 & 0.00000 & 0.00000 & 0.00009 & 0.00000 \\
\hline MON06 & 0.997 & 0.003 & 0.99982 & 0.00000 & 0.00000 & 0.00001 & 0.00018 & 0.00000 \\
\hline MON07 & 0.997 & 0.003 & 0.99987 & 0.00000 & 0.00000 & 0.00000 & 0.00012 & 0.00000 \\
\hline RAS01 & 0.997 & 0.003 & 0.99989 & 0.00000 & 0.00000 & 0.00000 & 0.00011 & 0.00000 \\
\hline RAS02 & 0.996 & 0.004 & 0.99971 & 0.00000 & 0.00000 & 0.00001 & 0.00028 & 0.00000 \\
\hline RAS03 & 0.997 & 0.003 & 0.99979 & 0.00000 & 0.00000 & 0.00001 & 0.00020 & 0.00000 \\
\hline RAS04 & 0.996 & 0.004 & 0.99966 & 0.00000 & 0.00000 & 0.00002 & 0.00031 & 0.00000 \\
\hline RAS05 & 0.995 & 0.005 & 0.99964 & 0.00000 & 0.00000 & 0.00003 & 0.00033 & 0.00000 \\
\hline RAS06 & 0.995 & 0.005 & 0.99964 & 0.00000 & 0.00000 & 0.00003 & 0.00033 & 0.00000 \\
\hline RAS07 & 0.997 & 0.003 & 0.99990 & 0.00000 & 0.00000 & 0.00000 & 0.00010 & 0.00000 \\
\hline RAS08 & 0.996 & 0.004 & 0.99966 & 0.00000 & 0.00000 & 0.00002 & 0.00031 & 0.00000 \\
\hline RAS09 & 0.997 & 0.003 & 0.99983 & 0.00000 & 0.00000 & 0.00000 & 0.00016 & 0.00000 \\
\hline RAS10 & 0.996 & 0.004 & 0.99966 & 0.00000 & 0.00000 & 0.00002 & 0.00031 & 0.00000 \\
\hline RAS11 & 0.996 & 0.004 & 0.99966 & 0.00000 & 0.00000 & 0.00002 & 0.00031 & 0.00000 \\
\hline RAS12 & 0.996 & 0.004 & 0.99988 & 0.00000 & 0.00000 & 0.00000 & 0.00012 & 0.00000 \\
\hline RAS13 & 0.997 & 0.003 & 0.99990 & 0.00000 & 0.00000 & 0.00000 & 0.00010 & 0.00000 \\
\hline RAS14 & 0.996 & 0.004 & 0.99966 & 0.00000 & 0.00000 & 0.00002 & 0.00031 & 0.00000 \\
\hline RAS15 & 0.997 & 0.003 & 0.99989 & 0.00000 & 0.00000 & 0.00000 & 0.00011 & 0.00000 \\
\hline RAS16 & 0.996 & 0.004 & 0.99966 & 0.00000 & 0.00000 & 0.00002 & 0.00031 & 0.00000 \\
\hline RAS17 & 0.995 & 0.005 & 0.99964 & 0.00000 & 0.00000 & 0.00003 & 0.00033 & 0.00000 \\
\hline RAS18 & 0.997 & 0.003 & 0.99979 & 0.00000 & 0.00000 & 0.00001 & 0.00020 & 0.00000 \\
\hline RAS19 & 0.995 & 0.005 & 0.99966 & 0.00000 & 0.00000 & 0.00002 & 0.00031 & 0.00000 \\
\hline RAS20 & 0.994 & 0.006 & 0.99963 & 0.00000 & 0.00000 & 0.00003 & 0.00034 & 0.00000 \\
\hline RAS21 & 0.996 & 0.004 & 0.99966 & 0.00000 & 0.00000 & 0.00002 & 0.00031 & 0.00000 \\
\hline RAS22 & 0.996 & 0.004 & 0.99966 & 0.00000 & 0.00000 & 0.00002 & 0.00031 & 0.00000 \\
\hline RAS23 & 0.996 & 0.004 & 0.99968 & 0.00000 & 0.00000 & 0.00002 & 0.00030 & 0.00000 \\
\hline RAS24 & 0.996 & 0.004 & 0.99966 & 0.00000 & 0.00000 & 0.00002 & 0.00031 & 0.00000 \\
\hline RAS25 & 0.997 & 0.003 & 0.99980 & 0.00000 & 0.00000 & 0.00001 & 0.00019 & 0.00000 \\
\hline RAS26 & 0.996 & 0.004 & 0.99966 & 0.00000 & 0.00000 & 0.00002 & 0.00031 & 0.00000 \\
\hline RAS27 & 0.995 & 0.005 & 0.99964 & 0.00000 & 0.00000 & 0.00003 & 0.00033 & 0.00000 \\
\hline RAS28 & 0.997 & 0.003 & 0.99992 & 0.00000 & 0.00000 & 0.00000 & 0.00008 & 0.00000 \\
\hline RAS29 & 0.997 & 0.003 & 0.99991 & 0.00000 & 0.00000 & 0.00000 & 0.00009 & 0.00000 \\
\hline RAS30 & 0.997 & 0.003 & 0.99993 & 0.00000 & 0.00000 & 0.00000 & 0.00007 & 0.00000 \\
\hline RAS31 & 0.997 & 0.003 & 0.99990 & 0.00000 & 0.00000 & 0.00000 & 0.00010 & 0.00000 \\
\hline RAS32 & 0.996 & 0.004 & 0.99977 & 0.00000 & 0.00000 & 0.00001 & 0.00022 & 0.00000 \\
\hline RAS33 & 0.996 & 0.004 & 0.99973 & 0.00000 & 0.00000 & 0.00001 & 0.00026 & 0.00000 \\
\hline PAU01 & 0.996 & 0.004 & 0.99958 & 0.00000 & 0.00001 & 0.00002 & 0.00039 & 0.00000 \\
\hline CER01 & 0.996 & 0.004 & 0.99971 & 0.00000 & 0.00000 & 0.00001 & 0.00028 & 0.00000 \\
\hline CER02 & 0.996 & 0.004 & 0.99971 & 0.00000 & 0.00000 & 0.00001 & 0.00028 & 0.00000 \\
\hline CER03 & 0.996 & 0.004 & 0.99971 & 0.00000 & 0.00000 & 0.00001 & 0.00028 & 0.00000 \\
\hline CER04 & 0.996 & 0.004 & 0.99971 & 0.00000 & 0.00000 & 0.00001 & 0.00028 & 0.00000 \\
\hline CER05 & 0.996 & 0.004 & 0.99971 & 0.00000 & 0.00000 & 0.00001 & 0.00028 & 0.00000 \\
\hline CER06 & 0.996 & 0.004 & 0.99971 & 0.00000 & 0.00000 & 0.00001 & 0.00028 & 0.00000 \\
\hline ROZ01 & 0.395 & 0.605 & 0.00014 & 0.00001 & 0.98050 & 0.00681 & 0.01040 & 0.00214 \\
\hline ROZ02 & 0.011 & 0.989 & 0.00000 & 0.00870 & 0.94046 & 0.01155 & 0.00088 & 0.03841 \\
\hline ROZ03 & 0.012 & 0.988 & 0.00000 & 0.00870 & 0.94046 & 0.01155 & 0.00088 & 0.03841 \\
\hline ROZ04 & 0.012 & 0.988 & 0.00000 & 0.00870 & 0.94046 & 0.01155 & 0.00088 & 0.03841 \\
\hline ROZ05 & 0.661 & 0.339 & 0.91040 & 0.00000 & 0.00341 & 0.00991 & 0.07628 & 0.00001 \\
\hline ROZ06 & 0.010 & 0.990 & 0.00000 & 0.00186 & 0.98143 & 0.00385 & 0.00074 & 0.01213 \\
\hline ROZ07 & 0.010 & 0.990 & 0.00000 & 0.00186 & 0.98143 & 0.00385 & 0.00074 & 0.01213 \\
\hline ROZ08 & 0.010 & 0.990 & 0.00000 & 0.00186 & 0.98143 & 0.00385 & 0.00074 & 0.01213 \\
\hline ROZ09 & 0.011 & 0.989 & 0.00000 & 0.00186 & 0.98143 & 0.00385 & 0.00074 & 0.01213 \\
\hline ROZ10 & 0.009 & 0.991 & 0.00000 & 0.00186 & 0.98143 & 0.00385 & 0.00074 & 0.01213 \\
\hline ROZ11 & 0.350 & 0.650 & 0.00427 & 0.00002 & 0.85264 & 0.04449 & 0.09611 & 0.00249 \\
\hline ROZ12 & 0.021 & 0.979 & 0.00850 & 0.00776 & 0.84981 & 0.07188 & 0.04580 & 0.01626 \\
\hline ROZ13 & 0.010 & 0.990 & 0.00000 & 0.00186 & 0.98143 & 0.00385 & 0.00074 & 0.01213 \\
\hline ROZ14 & 0.987 & 0.013 & 0.99947 & 0.00000 & 0.00003 & 0.00003 & 0.00047 & 0.00000 \\
\hline ROZ15 & 0.678 & 0.322 & 0.70345 & 0.00000 & 0.15993 & 0.02442 & 0.11181 & 0.00040 \\
\hline ROZ16 & 0.535 & 0.465 & 0.65422 & 0.00000 & 0.11055 & 0.03201 & 0.20311 & 0.00013 \\
\hline ROZ17 & 0.141 & 0.859 & 0.01306 & 0.00835 & 0.50581 & 0.34138 & 0.09228 & 0.03913 \\
\hline ROZ18 & 0.010 & 0.990 & 0.00000 & 0.00186 & 0.98143 & 0.00385 & 0.00074 & 0.01213 \\
\hline ROZ19 & 0.010 & 0.990 & 0.00000 & 0.00186 & 0.98143 & 0.00385 & 0.00074 & 0.01213 \\
\hline ROZ20 & 0.010 & 0.990 & 0.00000 & 0.00186 & 0.98143 & 0.00385 & 0.00074 & 0.01213 \\
\hline ROZ21 & 0.009 & 0.991 & 0.00000 & 0.00186 & 0.98143 & 0.00385 & 0.00074 & 0.01213 \\
\hline ROZ22 & 0.010 & 0.990 & 0.00000 & 0.00186 & 0.98143 & 0.00385 & 0.00074 & 0.01213 \\
\hline ROZ23 & 0.010 & 0.990 & 0.00000 & 0.00186 & 0.98143 & 0.00385 & 0.00074 & 0.01213 \\
\hline ROZ24 & 0.848 & 0.152 & 0.99764 & 0.00000 & 0.00003 & 0.00012 & 0.00222 & 0.00000 \\
\hline ROZ25 & 0.004 & 0.996 & 0.00000 & 0.98677 & 0.00071 & 0.00062 & 0.00000 & 0.01190 \\
\hline ROZ26 & 0.004 & 0.996 & 0.00000 & 0.98677 & 0.00071 & 0.00062 & 0.00000 & 0.01190 \\
\hline ROZ27 & 0.004 & 0.996 & 0.00000 & 0.98677 & 0.00071 & 0.00062 & 0.00000 & 0.01190 \\
\hline ROZ28 & 0.004 & 0.996 & 0.00000 & 0.98677 & 0.00071 & 0.00062 & 0.00000 & 0.01190 \\
\hline ROZ29 & 0.004 & 0.996 & 0.00000 & 0.98677 & 0.00071 & 0.00062 & 0.00000 & 0.01190 \\
\hline ROZ30 & 0.004 & 0.996 & 0.00000 & 0.98677 & 0.00071 & 0.00062 & 0.00000 & 0.01190 \\
\hline ROZ31 & 0.004 & 0.996 & 0.00000 & 0.98677 & 0.00071 & 0.00062 & 0.00000 & 0.01190 \\
\hline ROZ32 & 0.004 & 0.996 & 0.00000 & 0.98677 & 0.00071 & 0.00062 & 0.00000 & 0.01190 \\
\hline ROZ33 & 0.004 & 0.996 & 0.00000 & 0.98677 & 0.00071 & 0.00062 & 0.00000 & 0.01190 \\
\hline ROZ34 & 0.004 & 0.996 & 0.00000 & 0.98677 & 0.00071 & 0.00062 & 0.00000 & 0.01190 \\
\hline ROZ35 & 0.004 & 0.996 & 0.00000 & 0.98677 & 0.00071 & 0.00062 & 0.00000 & 0.01190 \\
\hline ROZ36 & 0.004 & 0.996 & 0.00000 & 0.98677 & 0.00071 & 0.00062 & 0.00000 & 0.01190 \\
\hline
\end{tabular}




\begin{tabular}{|c|c|c|c|c|c|c|c|c|}
\hline ROZ37 & 0.004 & 0.996 & 0.00000 & $\mathbf{0 . 9 8 6 7 7}$ & 0.00071 & 0.00062 & 0.00000 & 0.01190 \\
\hline ROZ38 & 0.004 & 0.996 & 0.00000 & 0.98677 & 0.00071 & 0.00062 & 0.00000 & 0.01190 \\
\hline ROZ39 & 0.004 & 0.996 & 0.00000 & 0.98677 & 0.00071 & 0.00062 & 0.00000 & 0.01190 \\
\hline ROZ40 & 0.005 & 0.995 & 0.00000 & 0.98677 & 0.00071 & 0.00062 & 0.00000 & 0.01190 \\
\hline ROZ41 & 0.004 & 0.996 & 0.00000 & 0.98677 & 0.00071 & 0.00062 & 0.00000 & 0.01190 \\
\hline ROZ42 & 0.004 & 0.996 & 0.00000 & 0.98677 & 0.00071 & 0.00062 & 0.00000 & 0.01190 \\
\hline ROZ43 & 0.004 & 0.996 & 0.00000 & 0.98677 & 0.00071 & 0.00062 & 0.00000 & 0.01190 \\
\hline ROZ44 & 0.005 & 0.995 & 0.00000 & 0.98677 & 0.00071 & 0.00062 & 0.00000 & 0.01190 \\
\hline ROZ45 & 0.004 & 0.996 & 0.00000 & 0.98677 & 0.00071 & 0.00062 & 0.00000 & 0.01190 \\
\hline ROZ46 & 0.004 & 0.996 & 0.00000 & $\mathbf{0 . 9 8 6 7 7}$ & 0.00071 & 0.00062 & 0.00000 & 0.01190 \\
\hline TIE01 & 0.997 & 0.003 & 0.99991 & 0.00000 & 0.00000 & 0.00000 & 0.00009 & 0.00000 \\
\hline TIE02 & 0.992 & 0.008 & 0.99922 & 0.00000 & 0.00001 & 0.00009 & 0.00068 & 0.00000 \\
\hline TIE03 & 0.995 & 0.005 & 0.99942 & 0.00000 & 0.00001 & 0.00004 & 0.00054 & 0.00000 \\
\hline TIE04 & 0.990 & 0.010 & 0.99888 & 0.00000 & 0.00002 & 0.00020 & 0.00091 & 0.00000 \\
\hline TIE05 & 0.996 & 0.004 & 0.99966 & 0.00000 & 0.00000 & 0.00001 & 0.00032 & 0.00000 \\
\hline TIE06 & 0.996 & 0.004 & 0.99966 & 0.00000 & 0.00000 & 0.00001 & 0.00032 & 0.00000 \\
\hline TIE07 & 0.997 & 0.003 & 0.99978 & 0.00000 & 0.00000 & 0.00001 & 0.00022 & 0.00000 \\
\hline TIE08 & 0.996 & 0.004 & 0.99956 & 0.00000 & 0.00001 & 0.00002 & 0.00042 & 0.00000 \\
\hline TIE09 & 0.996 & 0.004 & 0.99967 & 0.00000 & 0.00000 & 0.00002 & 0.00030 & 0.00000 \\
\hline TIE10 & 0.995 & 0.005 & 0.99955 & 0.00000 & 0.00000 & 0.00002 & 0.00042 & 0.00000 \\
\hline TIE11 & 0.990 & 0.010 & 0.99888 & 0.00000 & 0.00002 & 0.00020 & 0.00091 & 0.00000 \\
\hline TIE12 & 0.993 & 0.007 & 0.99919 & 0.00000 & 0.00001 & 0.00010 & 0.00069 & 0.00000 \\
\hline TIE13 & 0.997 & 0.003 & 0.99991 & 0.00000 & 0.00000 & 0.00000 & 0.00009 & 0.00000 \\
\hline TIE14 & 0.993 & 0.007 & 0.99916 & 0.00000 & 0.00001 & 0.00011 & 0.00071 & 0.00000 \\
\hline TIE15 & 0.996 & 0.004 & 0.99979 & 0.00000 & 0.00000 & 0.00001 & 0.00021 & 0.00000 \\
\hline TIE16 & 0.996 & 0.004 & 0.99967 & 0.00000 & 0.00000 & 0.00001 & 0.00031 & 0.00000 \\
\hline TIE17 & 0.994 & 0.006 & 0.99951 & 0.00000 & 0.00000 & 0.00005 & 0.00044 & 0.00000 \\
\hline TIE18 & 0.997 & 0.003 & 0.99993 & 0.00000 & 0.00000 & 0.00000 & 0.00007 & 0.00000 \\
\hline TIE19 & 0.993 & 0.007 & 0.99916 & 0.00000 & 0.00001 & 0.00011 & 0.00071 & 0.00000 \\
\hline TIE20 & 0.998 & 0.002 & 0.99993 & 0.00000 & 0.00000 & 0.00000 & 0.00007 & 0.00000 \\
\hline TIE21 & 0.997 & 0.003 & 0.99994 & 0.00000 & 0.00000 & 0.00000 & 0.00006 & 0.00000 \\
\hline TIE22 & 0.997 & 0.003 & 0.99993 & 0.00000 & 0.00000 & 0.00000 & 0.00007 & 0.00000 \\
\hline TIE23 & 0.996 & 0.004 & 0.99983 & 0.00000 & 0.00000 & 0.00000 & 0.00016 & 0.00000 \\
\hline TIE24 & 0.997 & 0.003 & 0.99993 & 0.00000 & 0.00000 & 0.00000 & 0.00007 & 0.00000 \\
\hline TIE25 & 0.997 & 0.003 & 0.99994 & 0.00000 & 0.00000 & 0.00000 & 0.00006 & 0.00000 \\
\hline TIE26 & 0.998 & 0.002 & 0.99996 & 0.00000 & 0.00000 & 0.00000 & 0.00004 & 0.00000 \\
\hline TIE27 & 0.997 & 0.003 & 0.99995 & 0.00000 & 0.00000 & 0.00000 & 0.00005 & 0.00000 \\
\hline TIE28 & 0.997 & 0.003 & 0.99997 & 0.00000 & 0.00000 & 0.00000 & 0.00003 & 0.00000 \\
\hline TIE29 & 0.997 & 0.003 & 0.99989 & 0.00000 & 0.00000 & 0.00000 & 0.00011 & 0.00000 \\
\hline TIE30 & 0.997 & 0.003 & 0.99996 & 0.00000 & 0.00000 & 0.00000 & 0.00004 & 0.00000 \\
\hline TIE31 & 0.997 & 0.003 & 0.99985 & 0.00000 & 0.00000 & 0.00000 & 0.00015 & 0.00000 \\
\hline TIE32 & 0.997 & 0.003 & 0.99992 & 0.00000 & 0.00000 & 0.00000 & 0.00008 & 0.00000 \\
\hline TIE33 & 0.997 & 0.003 & 0.99995 & 0.00000 & 0.00000 & 0.00000 & 0.00005 & 0.00000 \\
\hline TIE34 & 0.998 & 0.002 & 0.99995 & 0.00000 & 0.00000 & 0.00000 & 0.00005 & 0.00000 \\
\hline TIE35 & 0.997 & 0.003 & 0.99994 & 0.00000 & 0.00000 & 0.00000 & 0.00006 & 0.00000 \\
\hline TIE36 & 0.997 & 0.003 & 0.99993 & 0.00000 & 0.00000 & 0.00000 & 0.00007 & 0.00000 \\
\hline TIE37 & 0.997 & 0.003 & 0.99994 & 0.00000 & 0.00000 & 0.00000 & 0.00006 & 0.00000 \\
\hline TIE38 & 0.997 & 0.003 & 0.99994 & 0.00000 & 0.00000 & 0.00000 & 0.00006 & 0.00000 \\
\hline TIE39 & 0.997 & 0.003 & 0.99978 & 0.00000 & 0.00001 & 0.00001 & 0.00021 & 0.00000 \\
\hline TIE40 & 0.998 & 0.002 & 0.99994 & 0.00000 & 0.00000 & 0.00000 & 0.00006 & 0.00000 \\
\hline TIE41 & 0.998 & 0.002 & 0.99997 & 0.00000 & 0.00000 & 0.00000 & 0.00003 & 0.00000 \\
\hline TIE42 & 0.998 & 0.002 & 0.99997 & 0.00000 & 0.00000 & 0.00000 & 0.00003 & 0.00000 \\
\hline IRU01 & 0.997 & 0.003 & 0.99994 & 0.00000 & 0.00000 & 0.00000 & 0.00006 & 0.00000 \\
\hline IRU02 & 0.997 & 0.003 & 0.99994 & 0.00000 & 0.00000 & 0.00000 & 0.00006 & 0.00000 \\
\hline IRU03 & 0.997 & 0.003 & 0.99986 & 0.00000 & 0.00000 & 0.00000 & 0.00013 & 0.00000 \\
\hline IRU04 & 0.997 & 0.003 & 0.99993 & 0.00000 & 0.00000 & 0.00000 & 0.00007 & 0.00000 \\
\hline IRU05 & 0.994 & 0.006 & 0.99970 & 0.00000 & 0.00000 & 0.00001 & 0.00028 & 0.00000 \\
\hline IRU06 & 0.997 & 0.003 & 0.99992 & 0.00000 & 0.00000 & 0.00000 & 0.00008 & 0.00000 \\
\hline IRU07 & 0.997 & 0.003 & 0.99991 & 0.00000 & 0.00000 & 0.00000 & 0.00009 & 0.00000 \\
\hline IRU08 & 0.997 & 0.003 & 0.99991 & 0.00000 & 0.00000 & 0.00000 & 0.00009 & 0.00000 \\
\hline IRU09 & 0.997 & 0.003 & 0.99993 & 0.00000 & 0.00000 & 0.00000 & 0.00007 & 0.00000 \\
\hline IRU10 & 0.996 & 0.004 & 0.99989 & 0.00000 & 0.00000 & 0.00000 & 0.00011 & 0.00000 \\
\hline IRU11 & 0.997 & 0.003 & 0.99993 & 0.00000 & 0.00000 & 0.00000 & 0.00007 & 0.00000 \\
\hline IRU12 & 0.995 & 0.005 & 0.99985 & 0.00000 & 0.00000 & 0.00000 & 0.00015 & 0.00000 \\
\hline IRU13 & 0.996 & 0.004 & 0.99969 & 0.00000 & 0.00000 & 0.00001 & 0.00029 & 0.00000 \\
\hline IRU14 & 0.997 & 0.003 & 0.99993 & 0.00000 & 0.00000 & 0.00000 & 0.00007 & 0.00000 \\
\hline IRU15 & 0.456 & 0.544 & 0.00004 & 0.00003 & 0.98317 & 0.00669 & 0.00729 & 0.00279 \\
\hline IRU16 & 0.996 & 0.004 & 0.99988 & 0.00000 & 0.00000 & 0.00000 & 0.00012 & 0.00000 \\
\hline IRU17 & 0.997 & 0.003 & 0.99993 & 0.00000 & 0.00000 & 0.00000 & 0.00006 & 0.00000 \\
\hline IRU18 & 0.997 & 0.003 & 0.99988 & 0.00000 & 0.00000 & 0.00000 & 0.00012 & 0.00000 \\
\hline IRU19 & 0.997 & 0.003 & 0.99992 & 0.00000 & 0.00000 & 0.00000 & 0.00008 & 0.00000 \\
\hline IRU20 & 0.994 & 0.006 & 0.99977 & 0.00000 & 0.00000 & 0.00001 & 0.00022 & 0.00000 \\
\hline IRU21 & 0.996 & 0.004 & 0.99979 & 0.00000 & 0.00000 & 0.00001 & 0.00020 & 0.00000 \\
\hline IRU22 & 0.997 & 0.003 & 0.99990 & 0.00000 & 0.00000 & 0.00000 & 0.00010 & 0.00000 \\
\hline IRU23 & 0.994 & 0.006 & 0.99978 & 0.00000 & 0.00000 & 0.00001 & 0.00021 & 0.00000 \\
\hline IRU24 & 0.997 & 0.003 & 0.99991 & 0.00000 & 0.00000 & 0.00000 & 0.00009 & 0.00000 \\
\hline IRU25 & 0.997 & 0.003 & 0.99991 & 0.00000 & 0.00000 & 0.00000 & 0.00009 & 0.00000 \\
\hline IRU26 & 0.997 & 0.003 & 0.99986 & 0.00000 & 0.00000 & 0.00000 & 0.00014 & 0.00000 \\
\hline IRU27 & 0.997 & 0.003 & 0.99991 & 0.00000 & 0.00000 & 0.00000 & 0.00009 & 0.00000 \\
\hline IRU28 & 0.996 & 0.004 & 0.99990 & 0.00000 & 0.00000 & 0.00000 & 0.00010 & 0.00000 \\
\hline IRU29 & 0.995 & 0.005 & 0.99986 & 0.00000 & 0.00000 & 0.00000 & 0.00014 & 0.00000 \\
\hline IRU30 & 0.997 & 0.003 & 0.99993 & 0.00000 & 0.00000 & 0.00000 & 0.00007 & 0.00000 \\
\hline IRU31 & 0.997 & 0.003 & 0.99993 & 0.00000 & 0.00000 & 0.00000 & 0.00007 & 0.00000 \\
\hline IRU32 & 0.997 & 0.003 & 0.99990 & 0.00000 & 0.00000 & 0.00000 & 0.00009 & 0.00000 \\
\hline IRU33 & 0.997 & 0.003 & 0.99991 & 0.00000 & 0.00000 & 0.00000 & 0.00009 & 0.00000 \\
\hline IRU34 & 0.996 & 0.004 & 0.99986 & 0.00000 & 0.00000 & 0.00000 & 0.00014 & 0.00000 \\
\hline IRU35 & 0.994 & 0.006 & 0.99973 & 0.00000 & 0.00000 & 0.00001 & 0.00025 & 0.00000 \\
\hline
\end{tabular}




\begin{tabular}{|c|c|c|c|c|c|c|c|c|}
\hline IRU36 & 0.994 & 0.006 & 0.99977 & 0.00000 & 0.00000 & 0.00001 & 0.00022 & 0.00000 \\
\hline IRU37 & 0.997 & 0.003 & 0.99988 & 0.00000 & 0.00000 & 0.00000 & 0.00011 & 0.00000 \\
\hline IRU38 & 0.997 & 0.003 & 0.99983 & 0.00000 & 0.00000 & 0.00001 & 0.00016 & 0.00000 \\
\hline IRU39 & 0.579 & 0.421 & 0.00026 & 0.00000 & 0.79275 & 0.06814 & 0.13763 & 0.00124 \\
\hline IRU40 & 0.995 & 0.005 & 0.99986 & 0.00000 & 0.00000 & 0.00000 & 0.00014 & 0.00000 \\
\hline IRU41 & 0.996 & 0.004 & 0.99983 & 0.00000 & 0.00000 & 0.00000 & 0.00017 & 0.00000 \\
\hline IRU42 & 0.995 & 0.005 & 0.99985 & 0.00000 & 0.00000 & 0.00000 & 0.00015 & 0.00000 \\
\hline IRU43 & 0.988 & 0.012 & 0.99962 & 0.00000 & 0.00000 & 0.00003 & 0.00035 & 0.00000 \\
\hline IRU44 & 0.997 & 0.003 & 0.99992 & 0.00000 & 0.00000 & 0.00000 & 0.00007 & 0.00000 \\
\hline IRU45 & 0.995 & 0.005 & 0.99981 & 0.00000 & 0.00000 & 0.00000 & 0.00019 & 0.00000 \\
\hline IRU46 & 0.997 & 0.003 & 0.99993 & 0.00000 & 0.00000 & 0.00000 & 0.00007 & 0.00000 \\
\hline IRU47 & 0.996 & 0.004 & 0.99977 & 0.00000 & 0.00000 & 0.00001 & 0.00023 & 0.00000 \\
\hline IRU48 & 0.995 & 0.005 & 0.99976 & 0.00000 & 0.00000 & 0.00000 & 0.00024 & 0.00000 \\
\hline IRU49 & 0.996 & 0.004 & 0.99976 & 0.00000 & 0.00000 & 0.00001 & 0.00023 & 0.00000 \\
\hline IRU50 & 0.995 & 0.005 & 0.99964 & 0.00000 & 0.00000 & 0.00002 & 0.00033 & 0.00000 \\
\hline IRU51 & 0.996 & 0.004 & 0.99985 & 0.00000 & 0.00000 & 0.00000 & 0.00015 & 0.00000 \\
\hline IRU52 & 0.996 & 0.004 & 0.99988 & 0.00000 & 0.00000 & 0.00000 & 0.00012 & 0.00000 \\
\hline IRU53 & 0.997 & 0.003 & 0.99988 & 0.00000 & 0.00000 & 0.00000 & 0.00012 & 0.00000 \\
\hline IRU54 & 0.997 & 0.003 & 0.99988 & 0.00000 & 0.00000 & 0.00000 & 0.00012 & 0.00000 \\
\hline IRU55 & 0.996 & 0.004 & 0.99972 & 0.00000 & 0.00000 & 0.00001 & 0.00027 & 0.00000 \\
\hline IRU56 & 0.997 & 0.003 & 0.99994 & 0.00000 & 0.00000 & 0.00000 & 0.00006 & 0.00000 \\
\hline IRU57 & 0.997 & 0.003 & 0.99991 & 0.00000 & 0.00000 & 0.00000 & 0.00009 & 0.00000 \\
\hline$\overline{\text { CAS01 }}$ & 0.996 & 0.004 & 0.99975 & 0.00000 & 0.00000 & 0.00001 & 0.00024 & 0.00000 \\
\hline CAS02 & 0.995 & 0.005 & 0.99977 & 0.00000 & 0.00000 & 0.00001 & 0.00021 & 0.00000 \\
\hline CAS03 & 0.996 & 0.004 & 0.99978 & 0.00000 & 0.00000 & 0.00001 & 0.00021 & 0.00000 \\
\hline CAS04 & 0.996 & 0.004 & 0.99973 & 0.00000 & 0.00000 & 0.00001 & 0.00025 & 0.00000 \\
\hline CAS05 & 0.996 & 0.004 & 0.99970 & 0.00000 & 0.00001 & 0.00001 & 0.00029 & 0.00000 \\
\hline CAS06 & 0.980 & 0.020 & 0.99955 & 0.00000 & 0.00000 & 0.00002 & 0.00043 & 0.00000 \\
\hline CAS07 & 0.996 & 0.004 & 0.99990 & 0.00000 & 0.00000 & 0.00000 & 0.00010 & 0.00000 \\
\hline CAS08 & 0.997 & 0.003 & 0.99974 & 0.00000 & 0.00000 & 0.00001 & 0.00025 & 0.00000 \\
\hline CAS09 & 0.997 & 0.003 & 0.99990 & 0.00000 & 0.00000 & 0.00000 & 0.00010 & 0.00000 \\
\hline CAS10 & 0.997 & 0.003 & 0.99986 & 0.00000 & 0.00000 & 0.00000 & 0.00014 & 0.00000 \\
\hline CAS11 & 0.996 & 0.004 & 0.99986 & 0.00000 & 0.00000 & 0.00000 & 0.00013 & 0.00000 \\
\hline CAS12 & 0.997 & 0.003 & 0.99973 & 0.00000 & 0.00000 & 0.00001 & 0.00026 & 0.00000 \\
\hline CAS13 & 0.997 & 0.003 & 0.99983 & 0.00000 & 0.00000 & 0.00001 & 0.00017 & 0.00000 \\
\hline CAS14 & 0.997 & 0.003 & 0.99978 & 0.00000 & 0.00000 & 0.00001 & 0.00021 & 0.00000 \\
\hline CAS15 & 0.997 & 0.003 & 0.99984 & 0.00000 & 0.00000 & 0.00000 & 0.00015 & 0.00000 \\
\hline CAS16 & 0.997 & 0.003 & 0.99979 & 0.00000 & 0.00000 & 0.00001 & 0.00020 & 0.00000 \\
\hline CAS17 & 0.996 & 0.004 & 0.99977 & 0.00000 & 0.00000 & 0.00001 & 0.00022 & 0.00000 \\
\hline CAS18 & 0.996 & 0.004 & 0.99983 & 0.00000 & 0.00000 & 0.00001 & 0.00017 & 0.00000 \\
\hline CAS19 & 0.994 & 0.006 & 0.99971 & 0.00000 & 0.00000 & 0.00002 & 0.00027 & 0.00000 \\
\hline CAS20 & 0.997 & 0.003 & 0.99986 & 0.00000 & 0.00000 & 0.00000 & 0.00013 & 0.00000 \\
\hline CAS 21 & 0.997 & 0.003 & 0.99987 & 0.00000 & 0.00000 & 0.00000 & 0.00012 & 0.00000 \\
\hline PIE01 & 0.997 & 0.003 & 0.99988 & 0.00000 & 0.00000 & 0.00000 & 0.00011 & 0.00000 \\
\hline PIE02 & 0.982 & 0.018 & 0.99960 & 0.00000 & 0.00001 & 0.00002 & 0.00037 & 0.00000 \\
\hline PIE03 & 0.998 & 0.002 & 0.99992 & 0.00000 & 0.00000 & 0.00000 & 0.00007 & 0.00000 \\
\hline PIE04 & 0.982 & 0.018 & 0.99960 & 0.00000 & 0.00001 & 0.00002 & 0.00037 & 0.00000 \\
\hline PIE05 & 0.997 & 0.003 & 0.99992 & 0.00000 & 0.00000 & 0.00000 & 0.00007 & 0.00000 \\
\hline PIE06 & 0.995 & 0.005 & 0.99985 & 0.00000 & 0.00000 & 0.00001 & 0.00015 & 0.00000 \\
\hline PIE07 & 0.997 & 0.003 & 0.99993 & 0.00000 & 0.00000 & 0.00000 & 0.00007 & 0.00000 \\
\hline$\overline{\text { CVJ01 }}$ & 0.997 & 0.003 & 0.99985 & 0.00000 & 0.00000 & 0.00000 & 0.00015 & 0.00000 \\
\hline CVJ02 & 0.997 & 0.003 & 0.99985 & 0.00000 & 0.00000 & 0.00000 & 0.00015 & 0.00000 \\
\hline CVJ03 & 0.997 & 0.003 & 0.99990 & 0.00000 & 0.00000 & 0.00000 & 0.00009 & 0.00000 \\
\hline CVJ04 & 0.997 & 0.003 & 0.99987 & 0.00000 & 0.00000 & 0.00000 & 0.00013 & 0.00000 \\
\hline CVJ05 & 0.997 & 0.003 & 0.99986 & 0.00000 & 0.00000 & 0.00000 & 0.00013 & 0.00000 \\
\hline CVJ06 & 0.997 & 0.003 & 0.99984 & 0.00000 & 0.00000 & 0.00001 & 0.00015 & 0.00000 \\
\hline CVJ07 & 0.017 & 0.983 & 0.00000 & 0.04005 & 0.90289 & 0.02264 & 0.00376 & 0.03067 \\
\hline CVJ08 & 0.018 & 0.982 & 0.00000 & 0.04005 & 0.90289 & 0.02264 & 0.00376 & 0.03067 \\
\hline CVJ09 & 0.997 & 0.003 & 0.99989 & 0.00000 & 0.00000 & 0.00000 & 0.00011 & 0.00000 \\
\hline CVJ10 & 0.997 & 0.003 & 0.99991 & 0.00000 & 0.00000 & 0.00000 & 0.00009 & 0.00000 \\
\hline CVJ11 & 0.997 & 0.003 & 0.99989 & 0.00000 & 0.00000 & 0.00000 & 0.00011 & 0.00000 \\
\hline CVJ12 & 0.997 & 0.003 & 0.99991 & 0.00000 & 0.00000 & 0.00000 & 0.00009 & 0.00000 \\
\hline CVJ13 & 0.997 & 0.003 & 0.99989 & 0.00000 & 0.00000 & 0.00000 & 0.00011 & 0.00000 \\
\hline CVJ14 & 0.997 & 0.003 & 0.99989 & 0.00000 & 0.00000 & 0.00000 & 0.00011 & 0.00000 \\
\hline CVJ15 & 0.997 & 0.003 & 0.99990 & 0.00000 & 0.00000 & 0.00000 & 0.00009 & 0.00000 \\
\hline CVJ16 & 0.996 & 0.004 & 0.99967 & 0.00000 & 0.00000 & 0.00001 & 0.00031 & 0.00000 \\
\hline CVJ17 & 0.996 & 0.004 & 0.99982 & 0.00000 & 0.00000 & 0.00000 & 0.00018 & 0.00000 \\
\hline CVJ18 & 0.997 & 0.003 & 0.99979 & 0.00000 & 0.00001 & 0.00001 & 0.00020 & 0.00000 \\
\hline CVJ19 & 0.996 & 0.004 & 0.99976 & 0.00000 & 0.00000 & 0.00001 & 0.00023 & 0.00000 \\
\hline CVJ20 & 0.996 & 0.004 & 0.99976 & 0.00000 & 0.00000 & 0.00001 & 0.00023 & 0.00000 \\
\hline$\overline{\text { CVA01 }}$ & 0.997 & 0.003 & 0.99994 & 0.00000 & 0.00000 & 0.00000 & 0.00005 & 0.00000 \\
\hline CVA02 & 0.997 & 0.003 & 0.99994 & 0.00000 & 0.00000 & 0.00000 & 0.00005 & 0.00000 \\
\hline CVA03 & 0.997 & 0.003 & 0.99987 & 0.00000 & 0.00000 & 0.00000 & 0.00013 & 0.00000 \\
\hline CVA04 & 0.995 & 0.005 & 0.99972 & 0.00000 & 0.00000 & 0.00001 & 0.00027 & 0.00000 \\
\hline CVA05 & 0.995 & 0.005 & 0.99975 & 0.00000 & 0.00000 & 0.00001 & 0.00024 & 0.00000 \\
\hline CVA06 & 0.996 & 0.004 & 0.99975 & 0.00000 & 0.00000 & 0.00001 & 0.00024 & 0.00000 \\
\hline CVA07 & 0.996 & 0.004 & 0.99962 & 0.00000 & 0.00005 & 0.00001 & 0.00033 & 0.00000 \\
\hline CVA08 & 0.997 & 0.003 & 0.99991 & 0.00000 & 0.00000 & 0.00000 & 0.00008 & 0.00000 \\
\hline CVA09 & 0.996 & 0.004 & 0.99976 & 0.00000 & 0.00000 & 0.00001 & 0.00023 & 0.00000 \\
\hline CVA10 & 0.995 & 0.005 & 0.99976 & 0.00000 & 0.00000 & 0.00001 & 0.00023 & 0.00000 \\
\hline CVA11 & 0.997 & 0.003 & 0.99993 & 0.00000 & 0.00000 & 0.00000 & 0.00007 & 0.00000 \\
\hline MOM01 & 0.032 & 0.968 & 0.00000 & 0.00005 & 0.98876 & 0.00474 & 0.00298 & 0.00348 \\
\hline MOM02 & 0.031 & 0.969 & 0.00000 & 0.00005 & 0.98876 & 0.00474 & 0.00298 & 0.00348 \\
\hline MOM03 & 0.030 & 0.970 & 0.00000 & 0.00005 & 0.98876 & 0.00474 & 0.00298 & 0.00348 \\
\hline MOM04 & 0.030 & 0.970 & 0.00000 & 0.00005 & 0.98876 & 0.00474 & 0.00298 & 0.00348 \\
\hline MOM05 & 0.031 & 0.969 & 0.00000 & 0.00005 & 0.98876 & 0.00474 & 0.00298 & 0.00348 \\
\hline MOM06 & 0.030 & 0.970 & 0.00000 & 0.00005 & 0.98876 & 0.00474 & 0.00298 & 0.00348 \\
\hline
\end{tabular}




\begin{tabular}{|c|c|c|c|c|c|c|c|c|}
\hline MOM07 & 0.996 & 0.004 & 0.99985 & 0.00000 & 0.00000 & 0.00000 & 0.00015 & 0.00000 \\
\hline MOM08 & 0.996 & 0.004 & 0.99985 & 0.00000 & 0.00000 & 0.00000 & 0.00015 & 0.00000 \\
\hline MOM09 & 0.996 & 0.004 & 0.99985 & 0.00000 & 0.00000 & 0.00000 & 0.00015 & 0.00000 \\
\hline MOM10 & 0.030 & 0.970 & 0.00000 & 0.00005 & 0.98876 & 0.00474 & 0.00298 & 0.00348 \\
\hline $\begin{array}{l}\text { CAN01 } \\
\end{array}$ & 0.997 & 0.003 & 0.99989 & 0.00000 & 0.00000 & 0.00000 & 0.00011 & 0.00000 \\
\hline CANO2 & 0.657 & 0.343 & 0.28195 & 0.00000 & 0.21610 & 0.12663 & 0.37462 & 0.00071 \\
\hline CAN03 & 0.995 & 0.005 & 0.99976 & 0.00000 & 0.00000 & 0.00001 & 0.00023 & 0.00000 \\
\hline CANO4 & 0.997 & 0.003 & 0.99990 & 0.00000 & 0.00000 & 0.00000 & 0.00009 & 0.00000 \\
\hline CAN05 & 0.997 & 0.003 & 0.99976 & 0.00000 & 0.00000 & 0.00001 & 0.00023 & 0.00000 \\
\hline CAN06 & 0.996 & 0.004 & 0.99982 & 0.00000 & 0.00000 & 0.00000 & 0.00018 & 0.00000 \\
\hline CAN07 & 0.996 & 0.004 & 0.99943 & 0.00000 & 0.00004 & 0.00003 & 0.00050 & 0.00000 \\
\hline CAN08 & 0.996 & 0.004 & 0.99943 & 0.00000 & 0.00004 & 0.00003 & 0.00050 & 0.00000 \\
\hline ALD01 & 0.994 & 0.006 & 0.99940 & 0.00000 & 0.00005 & 0.00004 & 0.00051 & 0.00000 \\
\hline ALD02 & 0.996 & 0.004 & 0.99979 & 0.00000 & 0.00000 & 0.00001 & 0.00020 & 0.00000 \\
\hline ALD03 & 0.994 & 0.006 & 0.99946 & 0.00000 & 0.00003 & 0.00003 & 0.00048 & 0.00000 \\
\hline ALD04 & 0.996 & 0.004 & 0.99979 & 0.00000 & 0.00000 & 0.00001 & 0.00020 & 0.00000 \\
\hline ALD05 & 0.994 & 0.006 & 0.99946 & 0.00000 & 0.00003 & 0.00003 & 0.00048 & 0.00000 \\
\hline ALD06 & 0.997 & 0.003 & 0.99992 & 0.00000 & 0.00000 & 0.00000 & 0.00008 & 0.00000 \\
\hline ALD07 & 0.996 & 0.004 & 0.99980 & 0.00000 & 0.00000 & 0.00000 & 0.00019 & 0.00000 \\
\hline ALD08 & 0.994 & 0.006 & 0.99950 & 0.00000 & 0.00002 & 0.00003 & 0.00046 & 0.00000 \\
\hline ALD09 & 0.997 & 0.003 & 0.99989 & 0.00000 & 0.00000 & 0.00000 & 0.00010 & 0.00000 \\
\hline ALD10 & 0.996 & 0.004 & 0.99984 & 0.00000 & 0.00000 & 0.00000 & 0.00016 & 0.00000 \\
\hline $\begin{array}{l}\text { VIL01 } \\
\end{array}$ & 0.996 & 0.004 & 0.99993 & 0.00000 & 0.00000 & 0.00000 & 0.00007 & 0.00000 \\
\hline VIL02 & 0.996 & 0.004 & 0.99994 & 0.00000 & 0.00000 & 0.00000 & 0.00006 & 0.00000 \\
\hline VIL03 & 0.986 & 0.014 & 0.99908 & 0.00000 & 0.00001 & 0.00007 & 0.00085 & 0.00000 \\
\hline VIL04 & 0.997 & 0.003 & 0.99992 & 0.00000 & 0.00000 & 0.00000 & 0.00008 & 0.00000 \\
\hline VIL05 & 0.995 & 0.005 & 0.99994 & 0.00000 & 0.00000 & 0.00000 & 0.00006 & 0.00000 \\
\hline VIL06 & 0.997 & 0.003 & 0.99995 & 0.00000 & 0.00000 & 0.00000 & 0.00005 & 0.00000 \\
\hline VIL07 & 0.995 & 0.005 & 0.99994 & 0.00000 & 0.00000 & 0.00000 & 0.00006 & 0.00000 \\
\hline VIL08 & 0.997 & 0.003 & 0.99994 & 0.00000 & 0.00000 & 0.00000 & 0.00006 & 0.00000 \\
\hline VIL09 & 0.997 & 0.003 & 0.99992 & 0.00000 & 0.00000 & 0.00000 & 0.00008 & 0.00000 \\
\hline VIL10 & 0.997 & 0.003 & 0.99992 & 0.00000 & 0.00000 & 0.00000 & 0.00008 & 0.00000 \\
\hline VIL11 & 0.997 & 0.003 & 0.99994 & 0.00000 & 0.00000 & 0.00000 & 0.00006 & 0.00000 \\
\hline VIL12 & 0.996 & 0.004 & 0.99994 & 0.00000 & 0.00000 & 0.00000 & 0.00006 & 0.00000 \\
\hline VIL13 & 0.997 & 0.003 & 0.99990 & 0.00000 & 0.00000 & 0.00000 & 0.00010 & 0.00000 \\
\hline VIL14 & 0.947 & 0.053 & 0.99822 & 0.00000 & 0.00001 & 0.00037 & 0.00140 & 0.00000 \\
\hline VIL15 & 0.947 & 0.053 & 0.99822 & 0.00000 & 0.00001 & 0.00037 & 0.00140 & 0.00000 \\
\hline$\overline{\text { STR01 }}$ & 0.997 & $\begin{array}{ll}0.003 \\
\end{array}$ & 0.99990 & 0.00000 & 0.00000 & 0.00000 & 0.00010 & 0.00000 \\
\hline STR02 & 0.997 & 0.003 & 0.99987 & 0.00000 & 0.00000 & 0.00000 & 0.00013 & 0.00000 \\
\hline STR03 & 0.997 & 0.003 & 0.99986 & 0.00000 & 0.00000 & 0.00000 & 0.00014 & 0.00000 \\
\hline STR04 & 0.997 & 0.003 & 0.99990 & 0.00000 & 0.00000 & 0.00000 & 0.00009 & 0.00000 \\
\hline STR05 & 0.998 & 0.002 & 0.99987 & 0.00000 & 0.00000 & 0.00000 & 0.00013 & 0.00000 \\
\hline STR06 & 0.997 & 0.003 & 0.99992 & 0.00000 & 0.00000 & 0.00000 & 0.00008 & 0.00000 \\
\hline STR07 & 0.997 & 0.003 & 0.99989 & 0.00000 & 0.00000 & 0.00000 & 0.00011 & 0.00000 \\
\hline STR08 & 0.997 & 0.003 & 0.99978 & 0.00000 & 0.00000 & 0.00001 & 0.00021 & 0.00000 \\
\hline STR09 & 0.997 & 0.003 & 0.99990 & 0.00000 & 0.00000 & 0.00000 & 0.00010 & 0.00000 \\
\hline STR10 & 0.997 & 0.003 & 0.99987 & 0.00000 & 0.00000 & 0.00000 & 0.00012 & 0.00000 \\
\hline STR11 & 0.997 & 0.003 & 0.99990 & 0.00000 & 0.00000 & 0.00000 & 0.00010 & 0.00000 \\
\hline STR12 & 0.997 & 0.003 & 0.99985 & 0.00000 & 0.00000 & 0.00000 & 0.00015 & 0.00000 \\
\hline STR13 & 0.997 & 0.003 & 0.99986 & 0.00000 & 0.00000 & 0.00000 & 0.00014 & 0.00000 \\
\hline STR14 & 0.997 & 0.003 & 0.99980 & 0.00000 & 0.00001 & 0.00000 & 0.00018 & 0.00000 \\
\hline STR15 & 0.997 & 0.003 & 0.99993 & 0.00000 & 0.00000 & 0.00000 & 0.00007 & 0.00000 \\
\hline STR16 & 0.997 & 0.003 & 0.99994 & 0.00000 & 0.00000 & 0.00000 & 0.00006 & 0.00000 \\
\hline STR17 & 0.997 & 0.003 & 0.99990 & 0.00000 & 0.00000 & 0.00000 & 0.00009 & 0.00000 \\
\hline STR18 & 0.997 & 0.003 & 0.99992 & 0.00000 & 0.00000 & 0.00000 & 0.00008 & 0.00000 \\
\hline STR19 & 0.997 & 0.003 & 0.99988 & 0.00000 & 0.00000 & 0.00000 & 0.00012 & 0.00000 \\
\hline STR20 & 0.997 & 0.003 & 0.99994 & 0.00000 & 0.00000 & 0.00000 & 0.00006 & 0.00000 \\
\hline STR21 & 0.997 & 0.003 & 0.99990 & 0.00000 & 0.00000 & 0.00000 & 0.00009 & 0.00000 \\
\hline STR22 & 0.997 & 0.003 & 0.99990 & 0.00000 & 0.00000 & 0.00000 & 0.00009 & 0.00000 \\
\hline STR23 & 0.998 & 0.002 & 0.99995 & 0.00000 & 0.00000 & 0.00000 & 0.00005 & 0.00000 \\
\hline STR24 & 0.997 & 0.003 & 0.99989 & 0.00000 & 0.00000 & 0.00000 & 0.00011 & 0.00000 \\
\hline STR25 & 0.997 & 0.003 & 0.99973 & 0.00000 & 0.00000 & 0.00001 & 0.00026 & 0.00000 \\
\hline STR26 & 0.997 & 0.003 & 0.99993 & 0.00000 & 0.00000 & 0.00000 & 0.00007 & 0.00000 \\
\hline STR27 & 0.997 & 0.003 & 0.99994 & 0.00000 & 0.00000 & 0.00000 & 0.00006 & 0.00000 \\
\hline STR28 & 0.997 & 0.003 & 0.99987 & 0.00000 & 0.00000 & 0.00000 & 0.00012 & 0.00000 \\
\hline STR29 & 0.998 & 0.002 & 0.99994 & 0.00000 & 0.00000 & 0.00000 & 0.00006 & 0.00000 \\
\hline BEN01 & 0.996 & 0.004 & 0.99978 & 0.00000 & 0.00000 & 0.00000 & 0.00022 & 0.00000 \\
\hline BEN02 & 0.996 & 0.004 & 0.99984 & 0.00000 & 0.00000 & 0.00000 & 0.00016 & 0.00000 \\
\hline BEN03 & 0.832 & 0.168 & 0.99045 & 0.00000 & 0.00047 & 0.00376 & 0.00531 & 0.00001 \\
\hline BEN04 & 0.997 & 0.003 & 0.99976 & 0.00000 & 0.00000 & 0.00001 & 0.00023 & 0.00000 \\
\hline BEN05 & 0.932 & 0.068 & 0.99703 & 0.00000 & 0.00000 & 0.00072 & 0.00225 & 0.00000 \\
\hline BEN06 & 0.932 & 0.068 & 0.99623 & 0.00000 & 0.00002 & 0.00102 & 0.00273 & 0.00000 \\
\hline BEN07 & 0.997 & 0.003 & 0.99988 & 0.00000 & 0.00000 & 0.00000 & 0.00012 & 0.00000 \\
\hline BEN08 & 0.995 & 0.005 & 0.99954 & 0.00000 & 0.00000 & 0.00003 & 0.00044 & 0.00000 \\
\hline BEN09 & 0.997 & 0.003 & 0.99991 & 0.00000 & 0.00000 & 0.00000 & 0.00009 & 0.00000 \\
\hline BEN10 & 0.994 & 0.006 & 0.99963 & 0.00000 & 0.00001 & 0.00001 & 0.00035 & 0.00000 \\
\hline BEN11 & 0.997 & 0.003 & 0.99989 & 0.00000 & 0.00000 & 0.00000 & 0.00010 & 0.00000 \\
\hline BEN12 & 0.997 & 0.003 & 0.99988 & 0.00000 & 0.00000 & 0.00000 & 0.00012 & 0.00000 \\
\hline BEN13 & 0.997 & 0.003 & 0.99987 & 0.00000 & 0.00000 & 0.00000 & 0.00013 & 0.00000 \\
\hline BEN14 & 0.983 & 0.017 & 0.99897 & 0.00000 & 0.00002 & 0.00004 & 0.00097 & 0.00000 \\
\hline BEN15 & 0.996 & 0.004 & 0.99986 & 0.00000 & 0.00000 & 0.00000 & 0.00014 & 0.00000 \\
\hline BEN16 & 0.996 & 0.004 & 0.99987 & 0.00000 & 0.00000 & 0.00000 & 0.00013 & 0.00000 \\
\hline BEN17 & 0.997 & 0.003 & 0.99986 & 0.00000 & 0.00000 & 0.00000 & 0.00014 & 0.00000 \\
\hline BEN18 & 0.997 & 0.003 & 0.99991 & 0.00000 & 0.00000 & 0.00000 & 0.00009 & 0.00000 \\
\hline BEN19 & 0.996 & 0.004 & 0.99979 & 0.00000 & 0.00000 & 0.00001 & 0.00020 & 0.00000 \\
\hline BEN20 & 0.917 & 0.083 & 0.99572 & 0.00000 & 0.00005 & 0.00123 & 0.00301 & 0.00000 \\
\hline BEN21 & 0.988 & 0.012 & 0.99922 & 0.00000 & 0.00001 & 0.00002 & 0.00075 & 0.00000 \\
\hline
\end{tabular}




\begin{tabular}{lll|llllll} 
BEN22 & $\mathbf{0 . 9 9 6}$ & 0.004 & $\mathbf{0 . 9 9 9 7 5}$ & 0.00000 & 0.00000 & 0.00001 & 0.00024 & 0.00000 \\
BEN23 & $\mathbf{0 . 9 9 5}$ & 0.005 & $\mathbf{0 . 9 9 9 3}$ & 0.00000 & 0.00000 & 0.00001 & 0.00035 & 0.00000 \\
BEN24 & $\mathbf{0 . 9 9 7}$ & 0.003 & $\mathbf{0 . 9 9 9 9 6}$ & 0.00000 & 0.00000 & 0.00000 & 0.00004 & 0.00000 \\
BEN25 & $\mathbf{0 . 9 9 7}$ & 0.003 & $\mathbf{0 . 9 9 9 9 5}$ & 0.00000 & 0.00000 & 0.00000 & 0.00005 & 0.00000 \\
\hline PAUm01 & 0.002 & $\mathbf{0 . 9 9 8}$ & 0.00000 & $\mathbf{0 . 9 9 9 1 9}$ & 0.00000 & 0.00001 & 0.00000 & 0.00080 \\
PAUm02 & 0.002 & $\mathbf{0 . 9 9 8}$ & 0.00000 & $\mathbf{0 . 9 9 9 1 9}$ & 0.00000 & 0.00001 & 0.00000 & 0.00080 \\
PAUm03 & 0.002 & $\mathbf{0 . 9 9 8}$ & 0.00000 & $\mathbf{0 . 9 9 9 1 9}$ & 0.00000 & 0.00001 & 0.00000 & 0.00080 \\
PAUm04 & 0.002 & $\mathbf{0 . 9 9 8}$ & 0.00000 & $\mathbf{0 . 9 9 9 1 9}$ & 0.00000 & 0.00001 & 0.00000 & 0.00080 \\
PAUm05 & 0.002 & $\mathbf{0 . 9 9 8}$ & 0.00000 & $\mathbf{0 . 9 9 9 1 9}$ & 0.00000 & 0.00001 & 0.00000 & 0.00080 \\
\hline VILm01 & 0.008 & $\mathbf{0 . 9 9 2}$ & 0.00000 & $\mathbf{0 . 9 9 9 1 1}$ & 0.00000 & 0.00001 & 0.00000 & 0.00089 \\
VILm02 & 0.003 & $\mathbf{0 . 9 9 7}$ & 0.00000 & $\mathbf{0 . 9 9 8 6 9}$ & 0.00000 & 0.00002 & 0.00000 & 0.00129 \\
VILm03 & 0.003 & $\mathbf{0 . 9 9 7}$ & 0.00000 & $\mathbf{0 . 9 9 8 7 7}$ & 0.00000 & 0.00002 & 0.00000 & 0.00122 \\
VILm04 & 0.003 & $\mathbf{0 . 9 9 7}$ & 0.00000 & $\mathbf{0 . 9 9 3 7 2}$ & 0.00000 & 0.00016 & 0.00000 & 0.00612 \\
VILm05 & 0.004 & $\mathbf{0 . 9 9 6}$ & 0.00000 & $\mathbf{0 . 9 8 9 6 4}$ & 0.00000 & 0.00070 & 0.00000 & 0.00967 \\
\hline ESBm01 & 0.002 & $\mathbf{0 . 9 9 8}$ & 0.00000 & $\mathbf{0 . 9 9 9 1 9}$ & 0.00000 & 0.00001 & 0.00000 & 0.00080 \\
ESBm02 & 0.002 & $\mathbf{0 . 9 9 8}$ & 0.00000 & $\mathbf{0 . 9 9 9 1 9}$ & 0.00000 & 0.00001 & 0.00000 & 0.00080 \\
ESBm03 & 0.002 & $\mathbf{0 . 9 9 8}$ & 0.00000 & $\mathbf{0 . 9 9 9 1 9}$ & 0.00000 & 0.00001 & 0.00000 & 0.00080 \\
ESBm04 & 0.002 & $\mathbf{0 . 9 9 8}$ & 0.00000 & $\mathbf{0 . 9 9 9 1 9}$ & 0.00000 & 0.00001 & 0.00000 & 0.00080 \\
ESBm05 & 0.002 & $\mathbf{0 . 9 9 8}$ & 0.00000 & $\mathbf{0 . 9 9 9 1 9}$ & 0.00000 & 0.00001 & 0.00000 & 0.00080 \\
\hline
\end{tabular}

